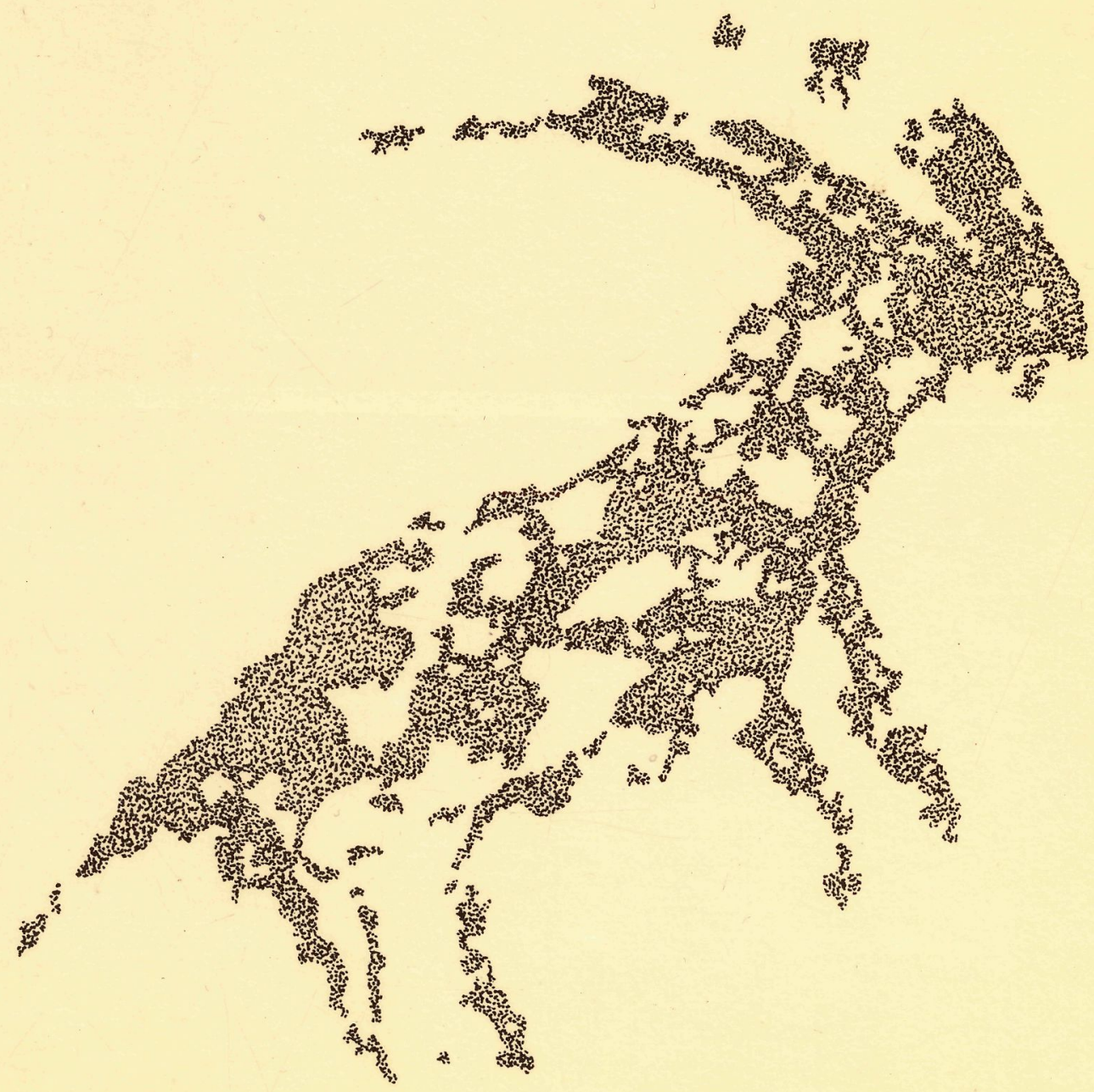

Anales de la Universidad de Alicante Prehistoria, Arqueología e Historia Antigua 




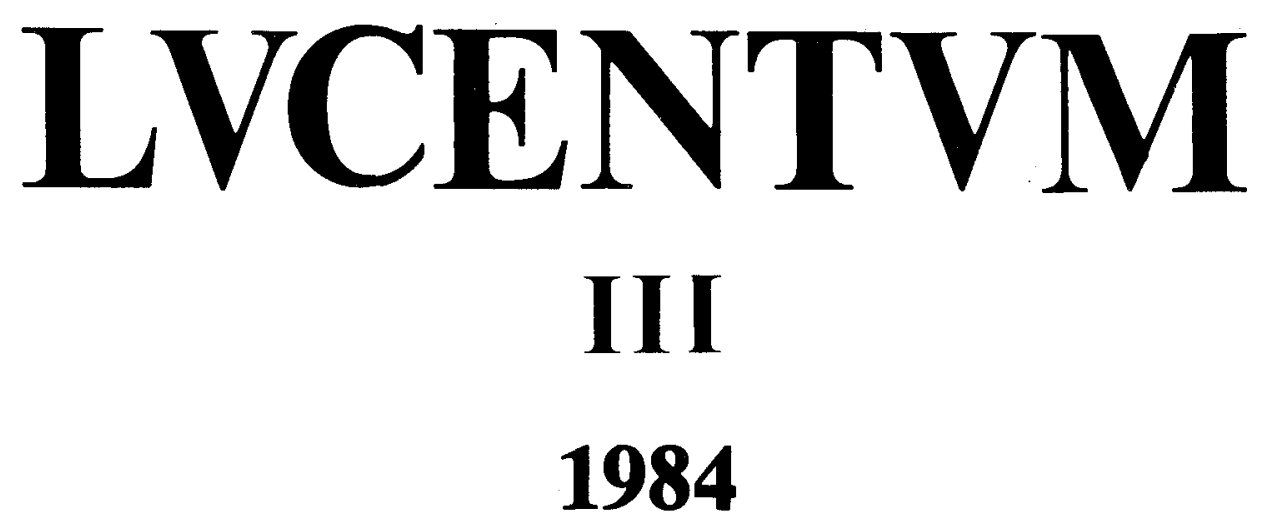

Anales de la Universidad de Alicante Prehistoria, Arqueología e Historia Antigua 


\section{CONSEJO DE REDACCION}

Lorenzo Abad Casal, director

Manuel A. Rabanal Alonso, subdirector

Mauro S. Hernández Pérez

José Uroz Sáez

Alfredo González Prats

Juan Manuel Abascal Palazón

María Francia Galiana Botella, secretaria

Este número de la revista «Lvcentvm» se publica en el marco del Convenio suscrito entre la Universidad y la Excma. Diputación Provincial de Alicante, y ha sido financiado por este organismo.

Los artículos de M. S. Hernández, J. Trelis, A. González, M. D. Sánchez, L. Abad y M. J. Sánchez han sido realizados en el Departamento de Prehistoria y Arqueología de la Universidad de Alicante, dentro del proyecto «Poblamiento prehistórico y antiguo en la provincia de Alicante», financiado por la Comisión Asesora de Investigación Científica y Técnica.

PORTADA

Pintura rupestre del Barranc del Bosquet (Moixent, Valencia). Dibujo de Mauro S. Hernández Pérez y Centre d'Estudis Contestans.

Edita: Servicio de Publicaciones de la Universidad de Alicante.

Dep. Legal A-968-1985 - Imprime: Estilo. Gral. Elizaicin, 11 - Alicante. 


\section{INDICE}

PINTURAS RUPESTRES EN EL BARRANC DEL BOSQUET (MOIXENT, VALENCIA) ......

PAG.

Mauro S. Hernández Pérez y Centre d'Estudis Contestans

EL POBLADO DE LA EDAD DEL BRONCE DE LA MOLA ALTA DE SERELLES (ALCOY, ALICANTE)

Julio Trelis Martí

LA COLECCION DE CERAMICA CAMPANIENSE DE IBIZA EN EL MUSEO ARQUEO-

LOGICO NACIONAL

Lourdes Prados Torreira y Juan A. Santos Velasco

EL VIDRIO ROMANO EN LA PROVINCIA DE ALICANTE

María Dolores Sánchez de Prado

APORTACIONES AL CONOCIMIENTO DEL PORTUS ILLICITANUS. RESEÑA DE LOS TRABAJOS DE URGENCIA DE 1976: LA TERRA SIGILLATA

Alfredo González Prats

ESTUDIO PRELIMINAR SOBRE LAS ANFORAS ROMANAS DEL PORTंUS ILLICITANUS María José Sánchez Fernández y María Teresa Lobregad Collado

LOS DIOSES LARES EN LA HISPANIA ROMANA

María Isabel Portela Filgueiras

LA TUMBA DEL EMPERADOR JULIANO

Javier Arce Martínez

ARCOS ROMANOS EN EL PAIS VALENCIANO: LOS TESTIMONIOS EPIGRAFICOS....... Lorenzo Abad Casal

REFLEXIONES ACERCA DE LA SOCIEDAD HISPANA REFLEJADA EN LA «GEOGRAFIA» DE ESTRABON

Adolfo J. Domínguez Monedero

LOS COGNOMINA DE PARENTESCO EN LA PENINSULA IBERICA. A PROPOSITO DEL INFLU JO ROMANIZADOR EN LA ONOMASTICA Juan M. Abascal Palazón

OBSERVACIONES SOBRE UN EMPERADOR CRISTIANO: Fl. JUl. CONSTANTE Elisa Garrido González

IDEOLOGIA Y POLITICA EN EL EMPERADOR MARCO AURELIO Jesús Daza Martínez

EL PRESTAMO Y LA USURA EN EL MEDITERRANEO ANTIGUO 



\title{
PINTURAS RUPESTRES EN EL BARRANC DEL BOSQUET (MOIXENT, VALENCIA)
}

\author{
MAURO S. HERNANDEZ PEREZ \\ y CENTRE D'ESTUDIS CONTESTANS
}

Universidad de Alicante

\begin{abstract}
Se da cuenta del hallazgo de dos abrigos con pinturas rupestres esquemáticas en el Barranc del Bosquet (Moixent, Valencia). Se analizan los temas representados, entre los que destacan por su abundancia y variedad tipológica las figuras humanas, y se realizan una serie de consideraciones sobre la cronología y significado de esta manifestación artística prehistórica en el País Valenciano.

Account is given of the finding of two caves containing schematic paintings in the Barranc del Bosquet (Moixent, Valencia). The subjects there pictured are analysed; among these, human figures outstand by their abundance and typological variety. Some considerations are brought up about chronology and meaning of this prehistoric artistic manifestation in the Valencian country.
\end{abstract}

Fruto de las prospecciones sistemáticas que desde 1980 venimos realizando en las comarcas centro-meridionales del País Valenciano ha sido el descubrimiento de más de un centenar de yacimientos con arte rupestre prehistórico. Si bien aquéllas han sido más intensas en la provincia de Alicante, también han abarcado las comarcas valencianas próximas de La Vall d'Albaida y La Costera, donde se han localizado varias estaciones con pinturas y grabados que con los del Barranc de Carbonera o Beniatjar, citada por H. Breuil $(1935,88-89)$ y reestudiada recientemente (HERNANDEZ PEREZ-SEGURA MARTI, 1985) junto a las de Coveta del Mig y Salem, esta última descubierta por uno de nosotros (Pere Ferrer Marset), constituyen un grupo de singular importancia para el estudio de la secuencia artística post-paleolítica del País Valenciano.

En 1982 descubrimos en Moixent dos abrigos con pinturas rupestres, ubicados en las márgenes izquierda - Abric II-y derecha - Abric I- del Barranc del Bosquet, por el que discurre la carretera C-3316 de Ontinyent a Moixent (figuras 1 y 2). Coordenadas: 38 52' 30' lat. N. - $0^{\circ} 44^{\prime} 15^{\prime}$ ' long. W. del meridiano de Greenwich.

Mientras el que hemos denominado Abric II sólo conserva dos barras pintadas en color rojo de 6 y $11,3 \mathrm{~cm}$. de largo y de grosor y bordes irregulares, el Abric I, a unos $300 \mathrm{~m}$. aguas abajo, conserva diversas representaciones de variada tipología e irregular estado de conservación, ya que algunas se ven afectadas por desconchados, varios de ellos recientes, y otras se encuentran cubiertas por capas de concreciones calizas de grosor y coloración diversos. 


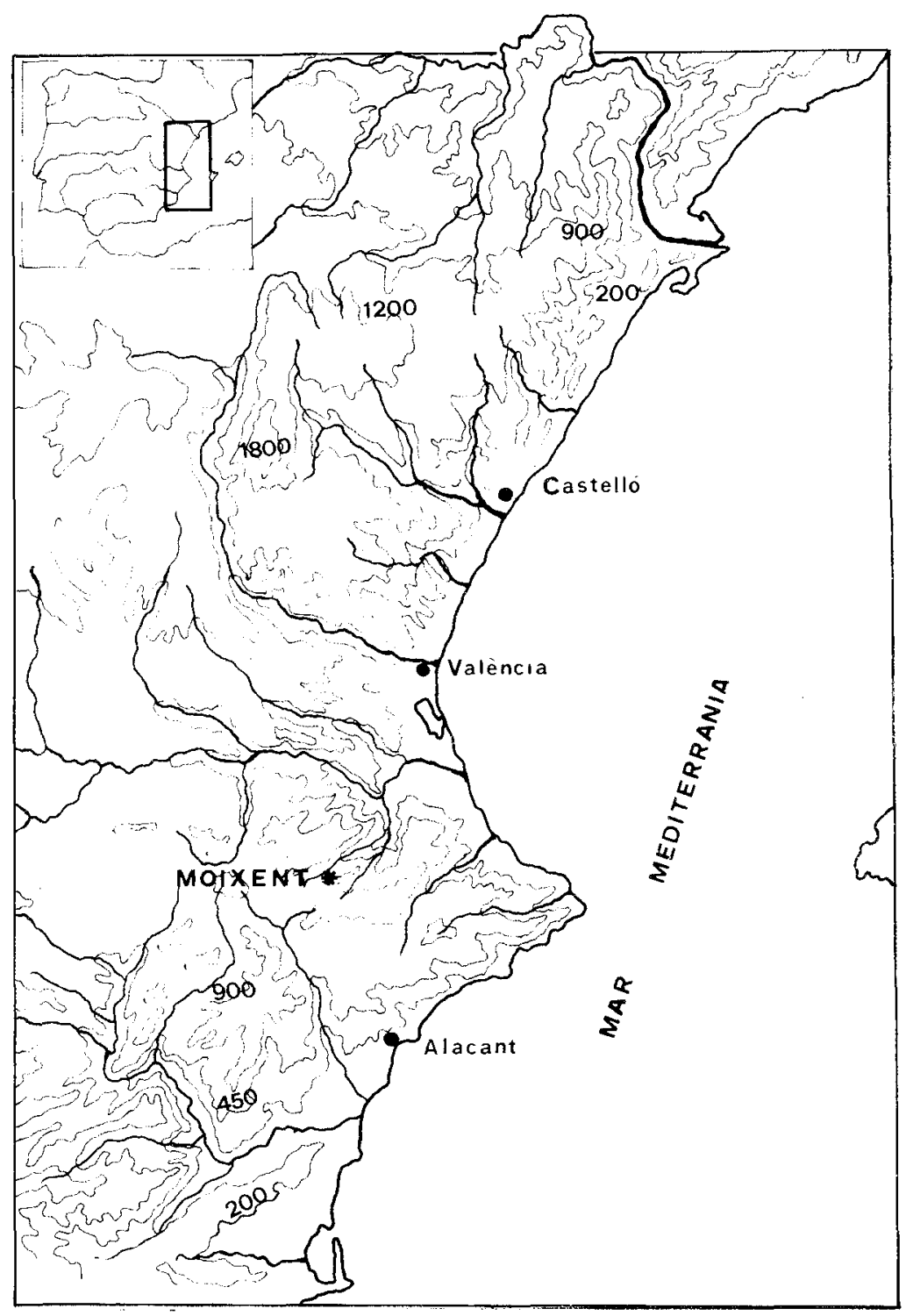

Figura 1.-Situación general del yacimiento.

\section{ABRIC I}

Situado en la margen derecha de la aludida carretera, a unos $40 \mathrm{~m}$. sobre ella, a la que se desciende por una acusada pendiente rocosa cubierta por una escasa vegetación.

Se trata de un abrigo de relativas dimensiones $-21 \mathrm{~m}$. de boca, $3,50 \mathrm{~m}$. de profundidad máxima y $5 \mathrm{~m}$. de altura de la cornisa-, carente de relleno y suelo irregular, con un acusado buzamiento hacia el exterior en la zona de mayor concentración de pinturas - paneles 4 a 9-(figura 3). La superficie de la pared presenta abundantes concreciones de grosor y coloración muy diversos. 


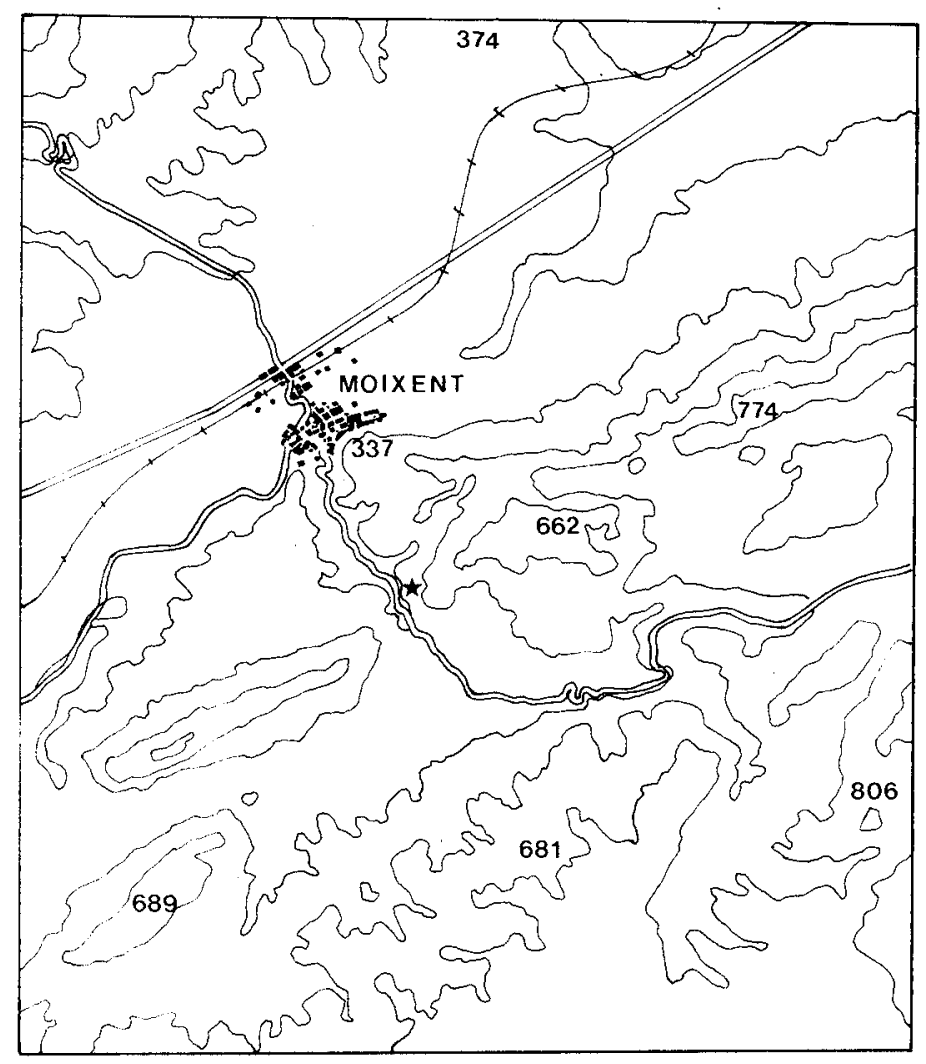

Figura 2.-Localización del yacimiento.
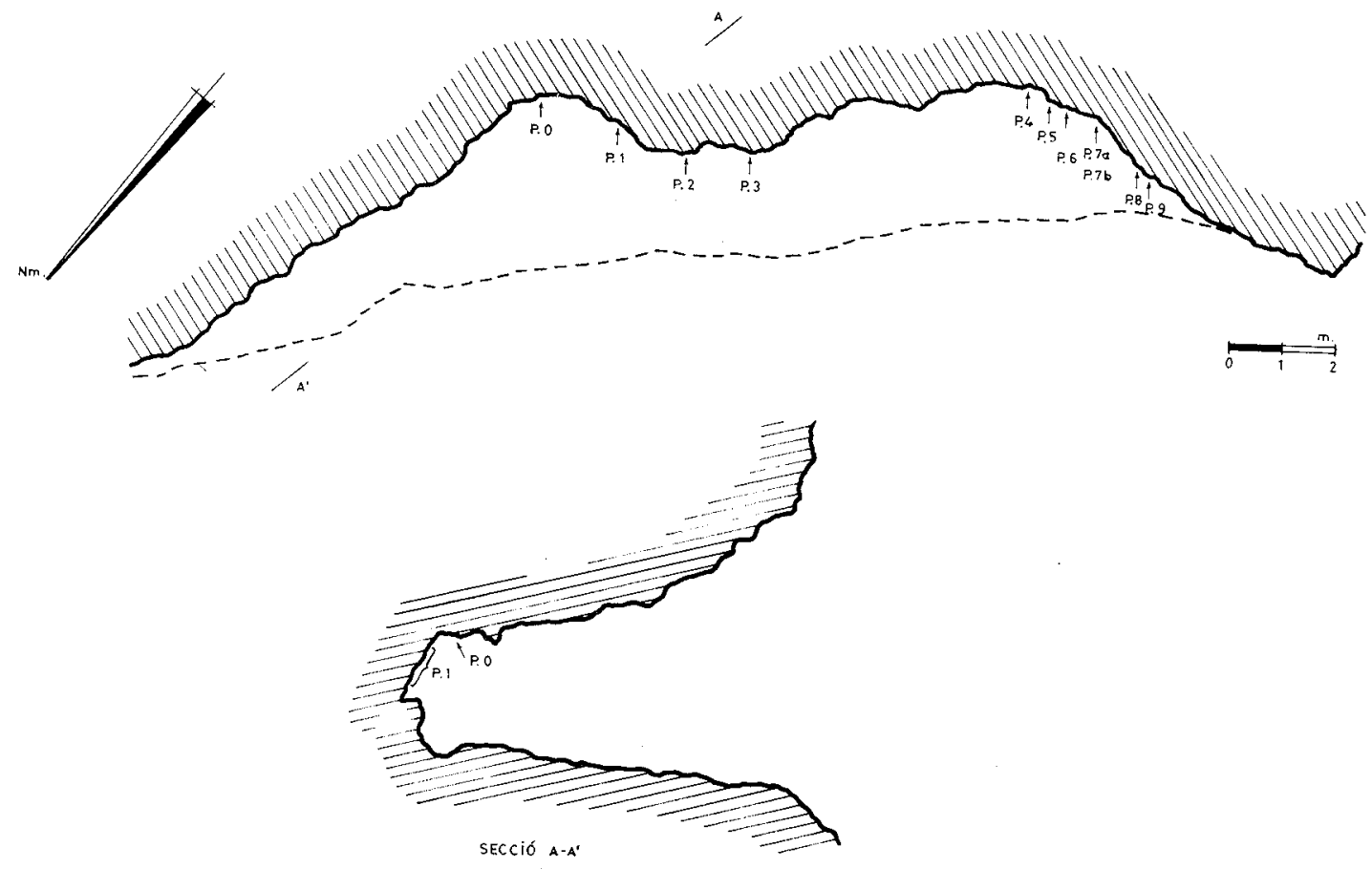

Figura 3.-Planimetría. 
Las pinturas las hemos agrupado en 11 paneles, que se numeran de izquierda a derecha del observador. Fueron calcadas y fotografiadas en varias jornadas para aprovechar al máximo las posibilidades de la luz y su coloración descrita mediante las tablas de colores Munsell.
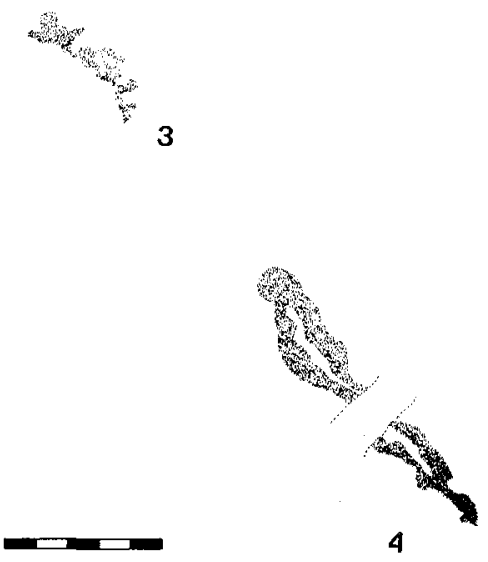

Figura 4.-Barranc del Bosquet. Abric I, panel 0. 


\section{Panel 0}

Situado en el techo de la pared más profunda del abrigo. Altura sobre el nivel del suelo: $2 \mathrm{~m}$. Las pinturas se encuentran cubiertas por concreciones oscuras (figura 4).

0.1.-Mancha. Color: M. 10 R 3/3 - M. 10 R 3/4.

0.2.-Mancha. Color: M. 10 R 3/2.

0.3. - Barra de estructura curvilínea de bordes irregulares. Largo: $4,3 \mathrm{~cm}$. Color: M. $10 \mathrm{R} 3 / 6$.

0.4. - Dos serpentiformes unidos por sus extremos para formar una figura oval con una pequeña prolongación por un extremo y un ensanchamiento por el otro. Largo: $10,5 \mathrm{~cm}$. Color: M. $10 \mathrm{R} \mathrm{3/6.}$

\section{Panel 1}

Conjunto de pinturas en el interior de una hornacina, a $1,52 \mathrm{~m}$. sobre el nivel del suelo. Su estado es muy deficiente al estar afectadas por desconchados y cubiertas por concreciones, por lo que en muchas ocasiones no se pueden identificar los motivos (figura 5).

1.1.-Restos de pinturas a modo de manchas, barras de diversos tamaños y en varias posiciones y un posible antropomorfo esquemático de tipo ancoriforme de $\mathrm{P}$. Acosta. Color: M. 10 R 3/2 - M. 10 R 3/4.

1.2.-Zoomorfo, posiblemente un cáprido, en el que se indican sus cuatro patas, tronco a modo de barra horizontal de $8 \mathrm{~cm}$. de largo, corta cola y dos cuernos curvados hacia atrás, el superior algo más desarrollado. Color: M. 10 R 4/6.

En la parte inferior se conservan restos de otro posible zoomorfo, del que se pueden identificar parte del tronco y de las dos patas traseras y unos extraños cuernos que parecen representados en posición frontal. Color: M. $10 \mathrm{R} \mathrm{3/2}-\mathrm{M} .10 \mathrm{R} \mathrm{3/4}$.

1.3.-Tectiforme vertical de estructura rectangular constituido por siete barras verticales de grosor y bordes irregulares, parcialmente afectadas por desconchados, unidas en sus extremos por trazos curvilíneos. Las dos barras laterales se incurvan hacia el exterior para adoptar la forma de doble cayado. Por su tamaño, estructura y posición parece dominar todo el panel, recordando en cierta medida los tipos de ídolos placas o estelas de P. Acosta, sin que por su deficiente estado de conservación nos podamos inclinar por una posible representación de una estructura, un ídolo o, incluso, de varios antropomorfos. Color: M. 10 R 3/2 - M. 10 R 3/4.

1.4.-Posible representación zoomorfa de tosco tronco con indicación de tres cortas y desiguales patas, cabeza e inicio de cuerno. Color: M. 10 R 3/2 - M. 10 R 3/3.

1.5.-Representación zoomorfa de tronco corto y grueso, patas traseras cortas y gruesas en actitud de marcha y las delanteras más finas y paralelas y dos cuernos cortos de implantación vertical. Sobre esta figura, a $1 \mathrm{~cm}$. de sus cuernos, existen restos de otro posible zoomorfo de tronco alargado e incurvado, del que se conservan las dos patas delanteras y restos de una de las traseras. Color: M. 10 R 3/2 - M. 10 R 3/4.

1.6.-Representación antropomorfa de tipo ramiforme simple, constituida por una barra vertical de $7,7 \mathrm{~cm}$. de largo, más gruesa en su extremo superior, cortada por tres barras incurvadas. La posición de estas últimas presenta problemas en cuanto a su identificación, como analizaremos más adelante. Color: M. 10 R 3/2 - M. 10 R 3/4.

1.7. - Restos de un zoomorfo, posiblemente un cáprido, muy afectado por los desconchados de la roca, del que se pueden identificar sus extremidades, en número de cuatro, parte del tronco, cuello y cabeza y sus dos cuernos inclinados hacia atrás. Color: M. 10 R 3/2 - M. 10 R 3/4. 


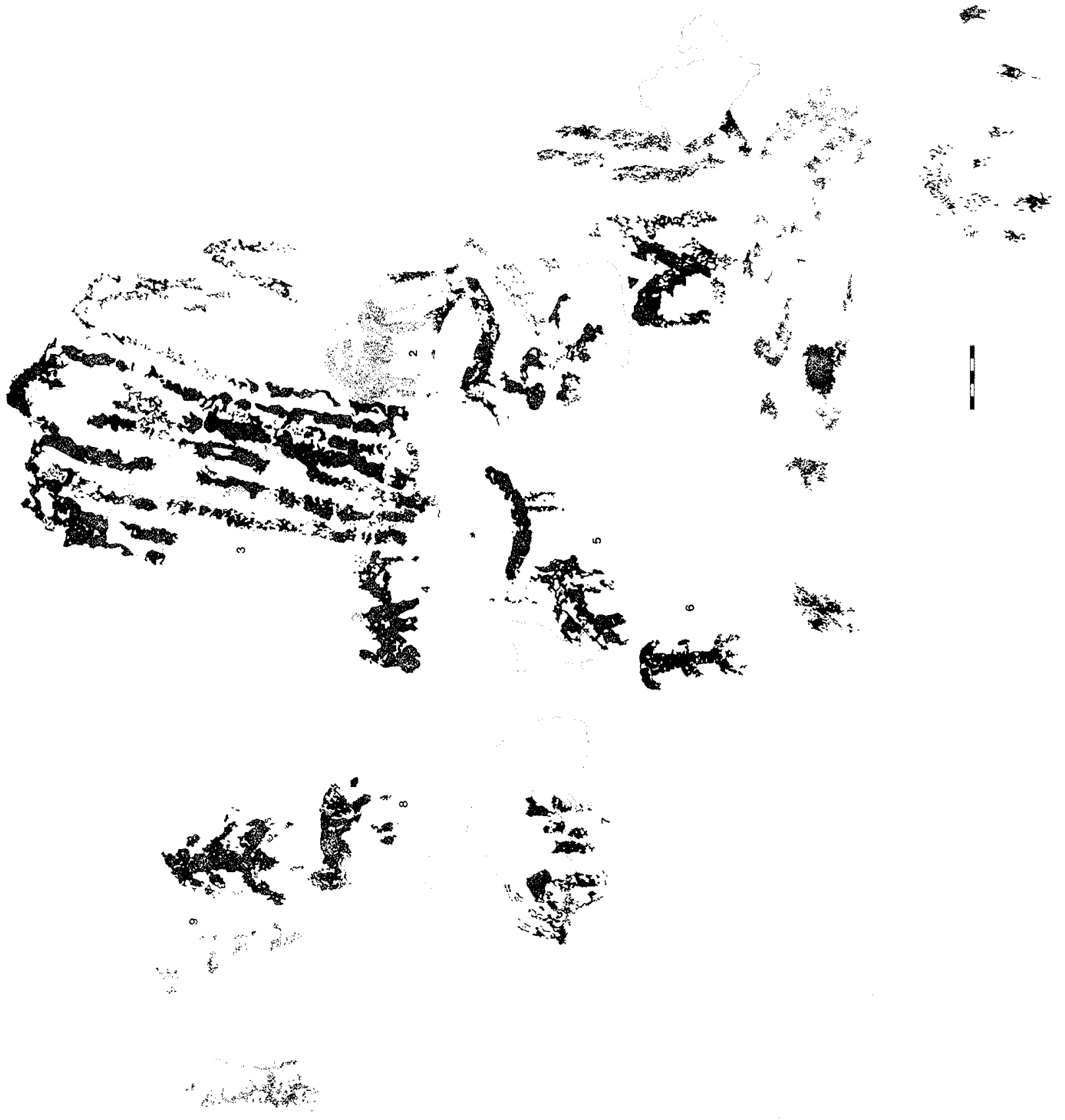

Figura 5.-Barrane del Bosquet. Abric I, panel 1. 
1.8.-Restos de un posible zoomorfo de grueso tronco, en el que se señala una gruesa cabeza carente de cuernos, conservando parte de sus extremidades, cortadas por un desconchado y algo desproporcionadas en relación con el tamaño del cuerpo. Color: M. 10 R 3/2 - M. 10 R 3/4.

1.9.-Representación antropomorfa de tipo ramiforme simple, constituida por barra vertical de $9,4 \mathrm{~cm}$. de largo y bordes irregulares, cortada perpendicularmente por otras tres de diverso tamaño e incurvadas hacia abajo. Al igual que el motivo 6 de este mismo panel, plantea problemas en cuanto a su identificación. A su derecha se conservan restos de pinturas. Color: M. $10 \mathrm{R} 3 / 2$ - M. $10 \mathrm{R}$ 3/4.

\section{Panel 2}

Cáprido semiesquemático (figura 6) con dos largos cuernos paralelos e incurvados hacia atrás, tronco en el que se señalan las curvas del vientre, grupa y dorso, este último cortado en parte por un desconchado, extremidades sin detalles anatómicos y larga cola. Entre las patas traseras y delanteras existe una delgada barra de $2 \mathrm{~cm}$. de largo. Altura sobre el nivel del suelo: $1,32 \mathrm{~cm}$. Color: M. $10 \mathrm{R} \mathrm{3/1} \mathrm{-} \mathrm{M.} 10 \mathrm{R} \mathrm{3/2.}$

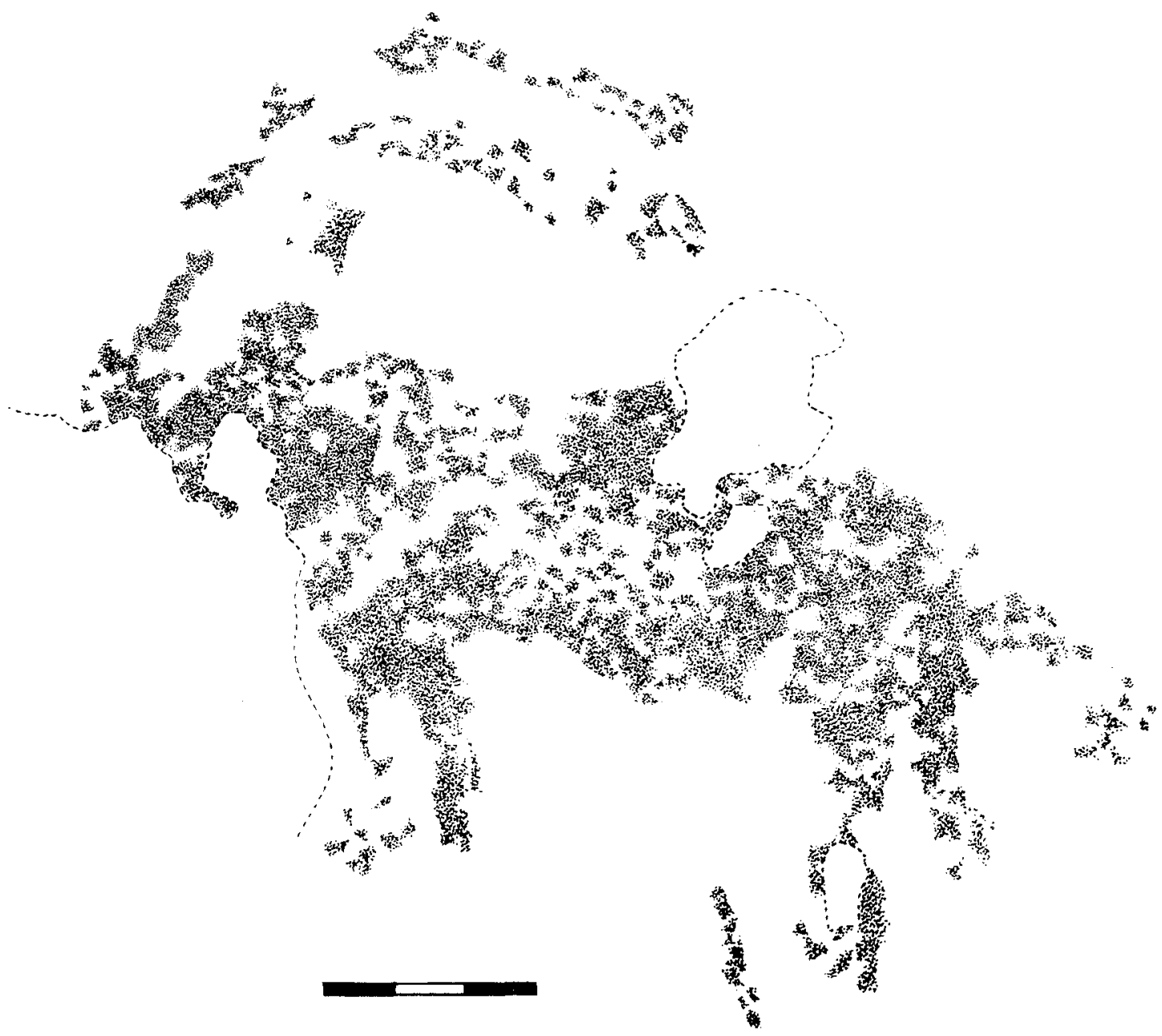

Figura 6.-Barranc del Bosquet. Abric I, panel 2. 

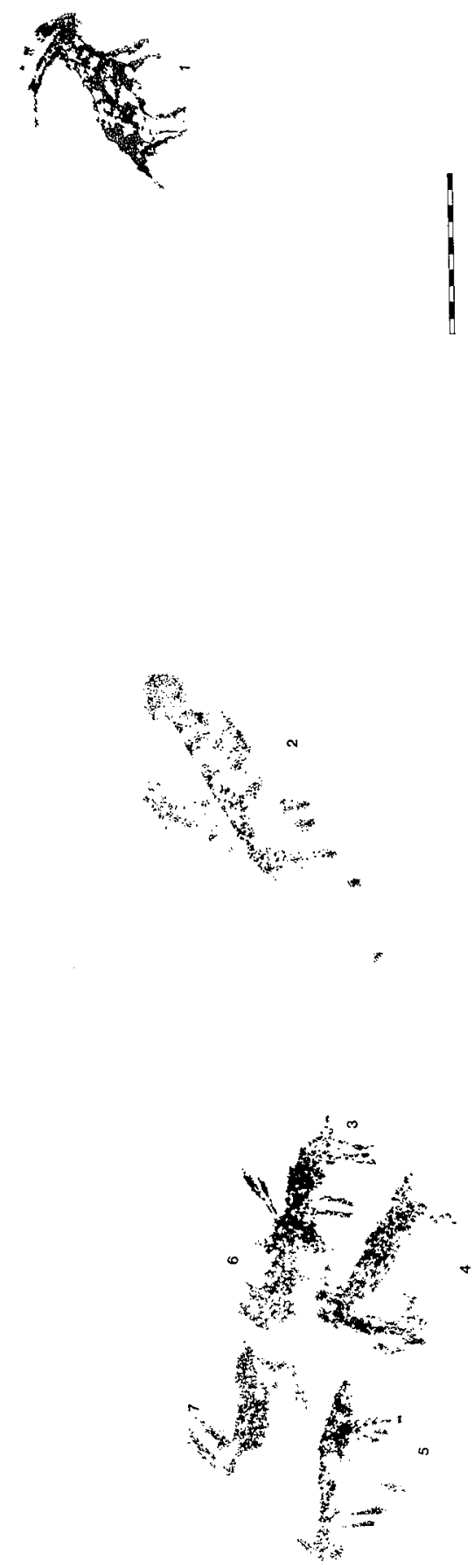

Figura 7.-Barranc del Bosquet. Abric I, panel 3. 


\section{Panel 3}

Panel de estructura horizontal, situado en una cornisa dentro del abrigo. Superficie rugosa y muy concrecionada que dificulta la identificación y calco de algunos de los motivos (figura 7).

3.1.-Cáprido semiesquemático de tronco corto, cuello grueso y desproporcionado, cabeza apenas insinuada, largos cuernos paralelos e incurvados hacia atrás, conservando mejor el inferior, patas carentes de detalles anatómicos y delgada cola. Cubierto por concreciones. Color: M. 10 R 3/2 - M. 10 R 3/3.

3.2.-Bajo una superficie muy concrecionada se conserva, apenas perceptible, un posible cuadrúpedo, del que se pueden identificar parte del tronco, cabeza y patas traseras, junto a otros restos de pinturas sobre el cuerpo que no sabemos interpretar. Color: M. $10 \mathrm{R} 5 / 8$.

3.3.-Cáprido esquemático de tronco fusiforme, pequeña cola, gruesa y desproporcionada cabeza y cuernos paralelos e inclinados, poco naturalistas al tener sus bases delgadas y puntas engrosadas. Color: 10 R 3/3 - M. 10 R 3/4.

3.4.- Restos de un zoomorfo, del que sólo se conserva su tronco, a modo de barra engrosada en un extremo para representar posiblemente la cabeza con el inicio de cuerno $u$ oreja, cola y restos de una de sus patas traseras, más corta que la delantera, en cuyo extremo inferior existen restos de pintura. Color: M. 10 R 3/3 - M. 10 R 3/4.

3.5.-Cuadrúpedo de tronco fusiforme, en el que se señalan cuello, cabeza, cuerno $\mathrm{u}$ oreja, extremidades delanteras y traseras, desproporcionalmente colocadas, y posible sexo. Entre ambas extremidades y a la altura de sus hipotéticas pezuñas existen restos de una barra de $1,5 \mathrm{~cm}$. de largo que, como ocurre con la figura del panel 2 , no nos atrevemos a interpretar. Color: M. 10 R 3/3 - M. 10 R 3/2.

3.6. - Posible zoomorfo, infrapuesto parcialmente a la cabeza del cáprido número 3 , del que sólo se puede identificar una ancha barra a modo de tronco con cuernos en un extremo. Color: M. 10 R 3/6.

3.7.-Cáprido del que se conserva el tronco, de tipo seminaturalista, parte de la cabeza, una de sus patas traseras, cola y cuernos paralelos e incurvados hacia atrás. Color: M. 10 R 3/6.

3.8. - Ancha barra, cortada por una colada, posible cuerpo de un animal y tres pequeñas manchas o puntos. Color: M. 10 R 3/1 - M. 10 R 3/2.

\section{Panel 4}

En una superficie rugosa y a una altura de $0,75 \mathrm{~m}$. sobre el suelo se realizó un complejo motivo a base de barras verticales cruzadas por una horizontal, todas de grosor y bordes irregulares, que hemos interpretado con reservas como un ramiforme horizontal (figura 8). Color: M. 10 R 3/2 - M. 10 R 3/3.

\section{Panel 5}

Panel de estructura vertical que ocupa una superficie algo concrecionada, bajo la cual, apenas visibles, se conservan las pinturas (figura 9).

5.1.-Restos de un zoomorfo, del que destacan parte de tronco a modo de barra que se prolonga para indicar la cola, las dos patas traseras y parte de los cuernos paralelos y ligeramente incurvados hacia atrás. Color: M. 10 R 4/1 - M. 10 R 3/1.

5.2. - Restos de un posible zoomorfo, del que sólo se conservan parte del tronco y dos de sus patas. Color: M. 10 R 3/1. 


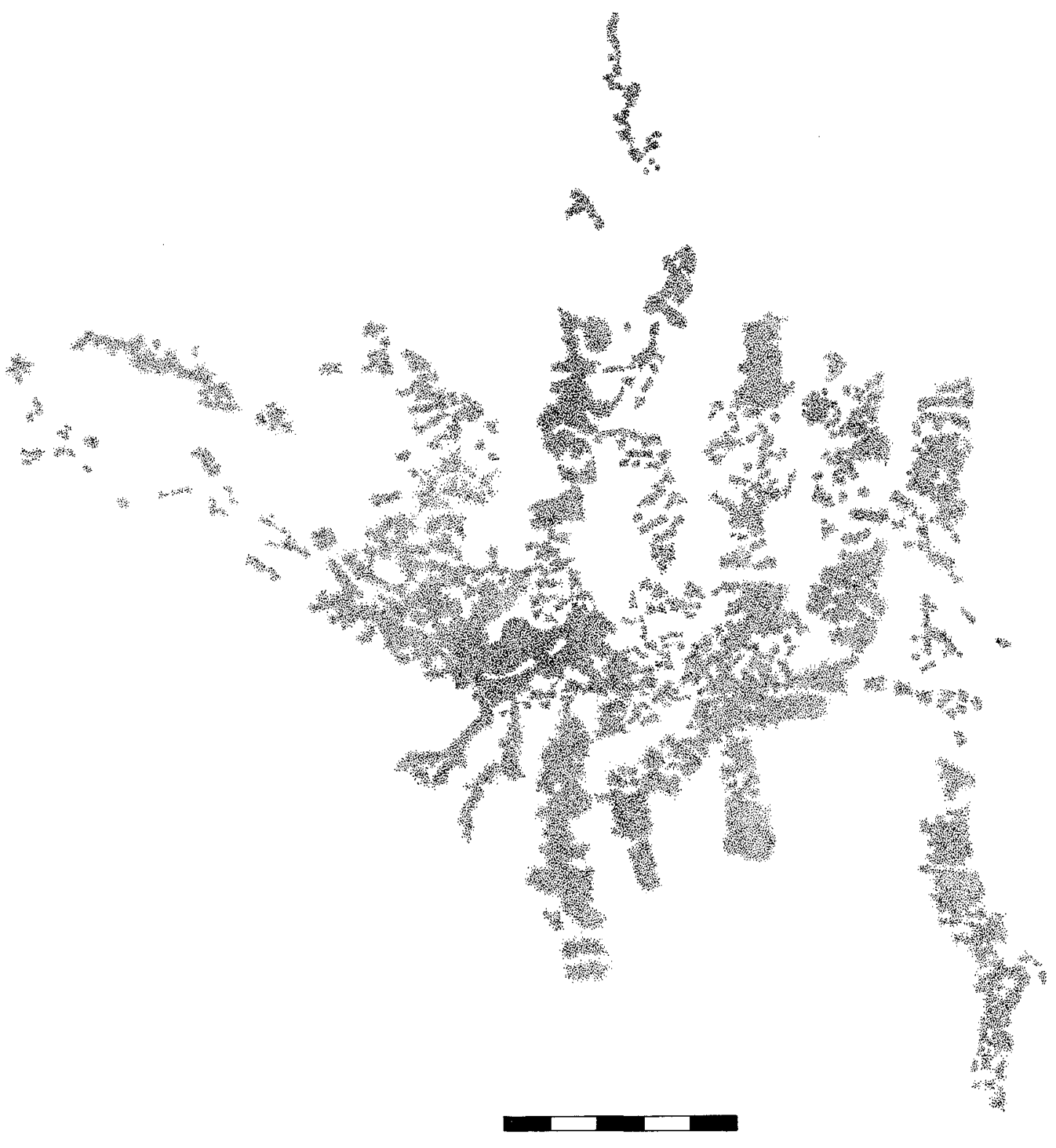

Figura 8.-Barranc del Bosquet. Abric I, panel 4.

5.3.-Cáprido esquemático de corto y grueso tronco, en el que se indican sus cuatro patas a modo de cortas y anchas barras perpendiculares a aquél, cabeza y dos cuernos incurvados hacia atrás de desigual desarrollo. Color: M. 10 R 3/2 - M. 10 R 3/3.

5.4.-Cabeza, cuello y cuerno, fuertemente incurvado hacia atrás, y restos de las extremidades delanteras de un cáprido seminaturalista. Altura sobre el nivel del suelo: $0,49 \mathrm{~m}$. Entre este motivo y el cáprido número 3 se conservan restos de otras pinturas no identificables. Color: M. 10 R 3/2 - M. 10 R 3/1. 


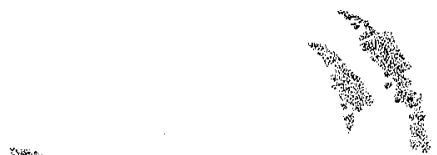

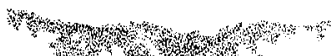
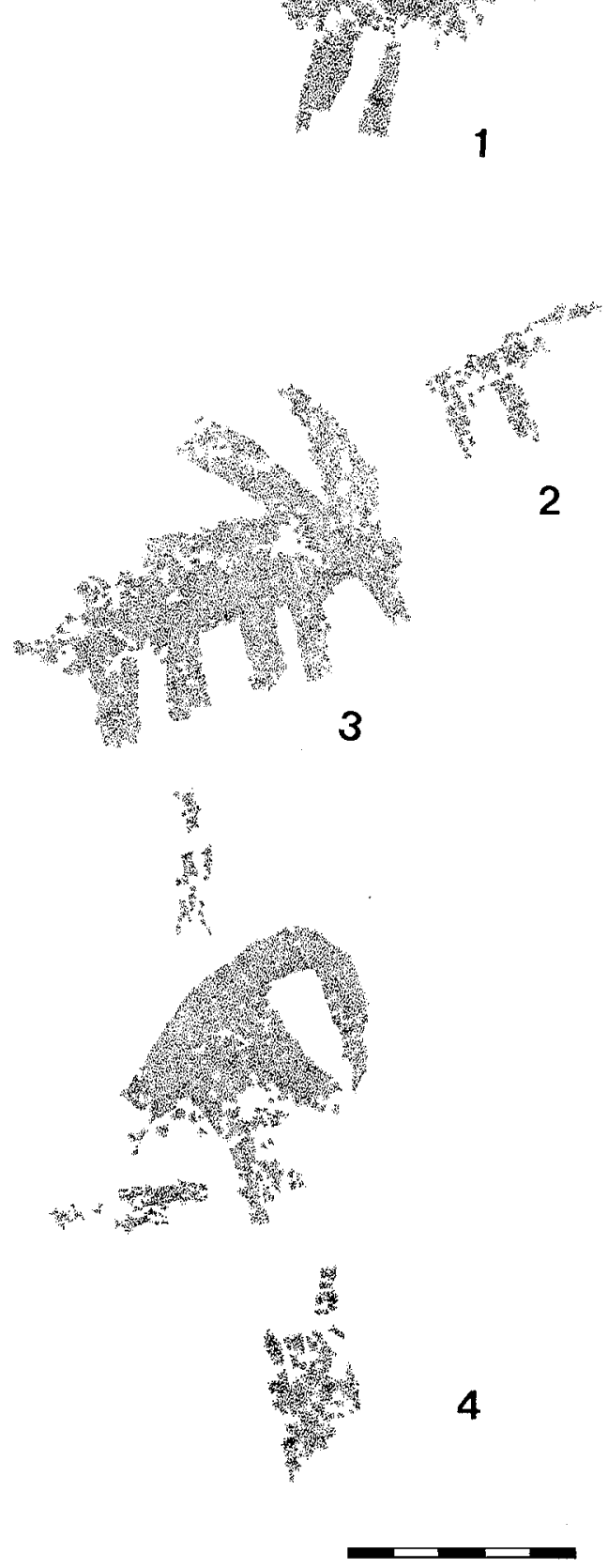

Figura 9.-Barranc del Bosquet. Abric I, panel 5. 


\section{Panel 6}

En una superficie no muy concrecionada existe una barra vertical de $6,6 \mathrm{~cm}$. de largo y de grosor y bordes irregulares (figura 10). Altura sobre el nivel del suelo: $0,48 \mathrm{~m}$. Color: M. 10 R 4/8 - M. 10 R 4/6.

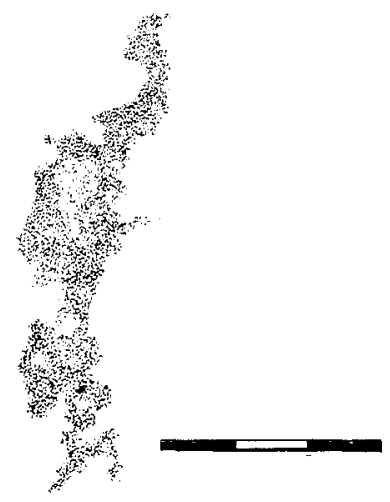

Figura 10.-Barranc del Bosquet. Abric I, panel 6.

\section{Panel 7 a}

Panel situado en la parte inferior de la pared del abrigo. Superficie concrecionada. El estado de las pinturas es muy deficiente (figura 11 ).

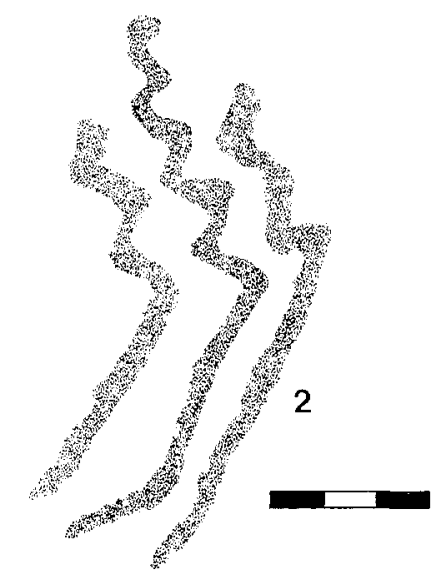

Figura 11.-Barranc del Bosquet. Abric I, panel 7 a. 
7 a.1.- Restos de un posible zoomorfo, del que se conservan el tronco a modo de larga e irregular barra, sus dos patas traseras perpendiculares a aquél, parte de la cabeza y uno de los cuernos. Color: M. $104 / 1$.

7 a.2.-Tres líneas quebradas de estructura vertical. Altura sobre el nivel del suelo: $0,15 \mathrm{~cm}$. Color: M. $10 \mathrm{R} \mathrm{3/3}$ - M. $10 \mathrm{R} \mathrm{3/4.}$

\section{Panel 7 b}

Antropomorfo esquemático de $12,3 \mathrm{~cm}$. de largo con piernas arqueadas y brazos a modo de serpentiformes. Presenta una pequeña cabeza como prolongación del tronco y una protuberancia entre las piernas que, con reservas, podría interpretarse como falo. A su izquierda se observan restos de pintura (figura 12). Altura sobre el nivel del suelo: $1,30 \mathrm{~m}$. Color: M. $10 \mathrm{R} 3 / 6$.

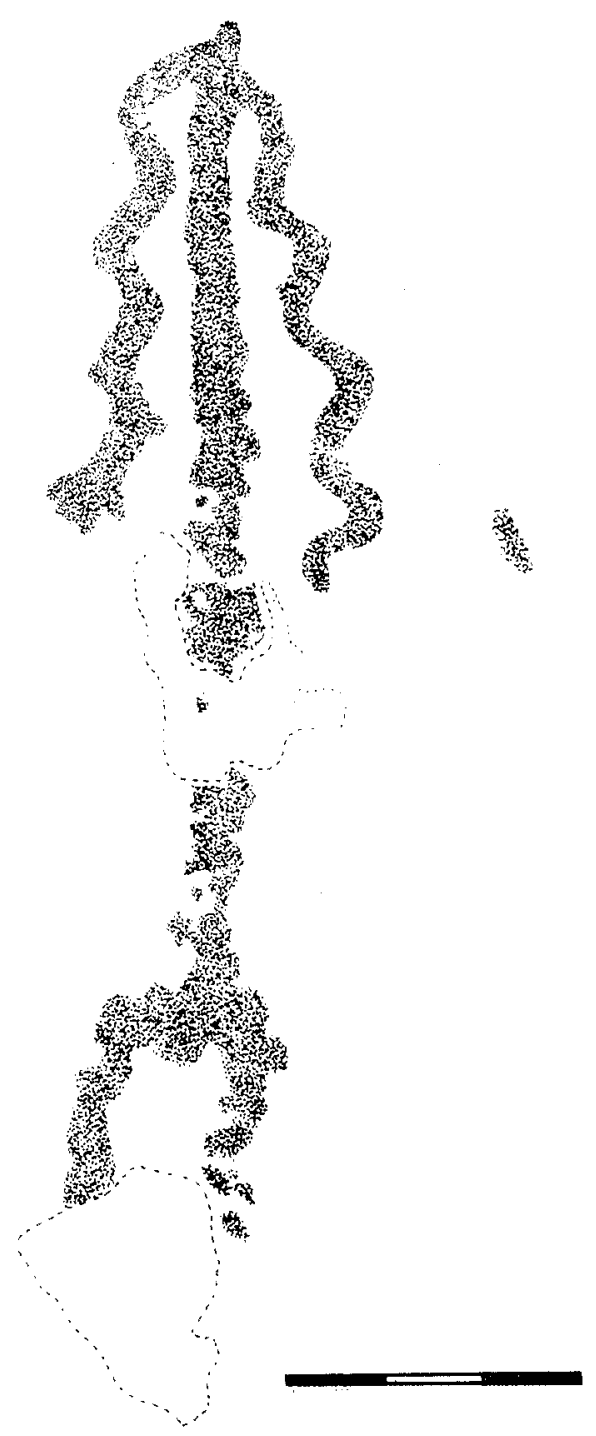

Figura 12.-Barranc del Bosquet. Abric I, panel $7 \mathrm{~b}$. 


\section{Panel 8}

Superficie muy concrecionada de color blanquecino con pinturas muy desvaídas (figura 13).

8.1.-Restos de un posible zoomorfo del que se conserva parte del tronco, patas delanteras gruesas y cortas, largo cuello, parte de la cabeza y un cuerno, también grueso. Altura sobre el nivel del suelo: 0,73 m. Color: M. $10 \mathrm{R} \mathrm{5/1} \mathrm{-} \mathrm{M.} 10 \mathrm{R} \mathrm{6/1}$.

8.2. - Restos de una barra vertical de $6,6 \mathrm{~cm}$. de largo. Color: M. $10 \mathrm{R} 3 / 4$ -M. 10 R 4/6.

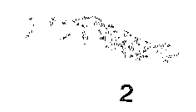

2

Figura 13.-Barranc del Bosquet. Abric I, panel 8.

\section{Panel 9}

Situado en el interior de una pequeña hornacina, sobre el zoomorfo del panel 8 (figura 14).
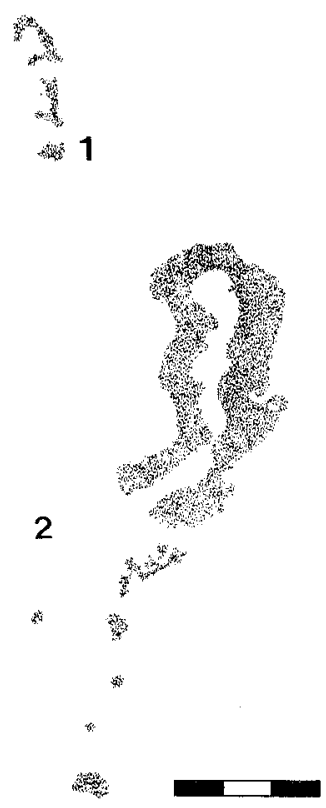

Figura 14.--Barranc del Bosquet. Abric I, panel 9. 
9.1.-Restos de una barra horizontal de $3 \mathrm{~cm}$. de largo, cubierta por concreciones. Color: M. 10 R $3 / 3$.

9.2. - Dos serpentiformes unidos por sus extremos superiores a modo de herradura, prolongándose uno de ellos por una serie de manchas. Color: M. 10 R 4/6.
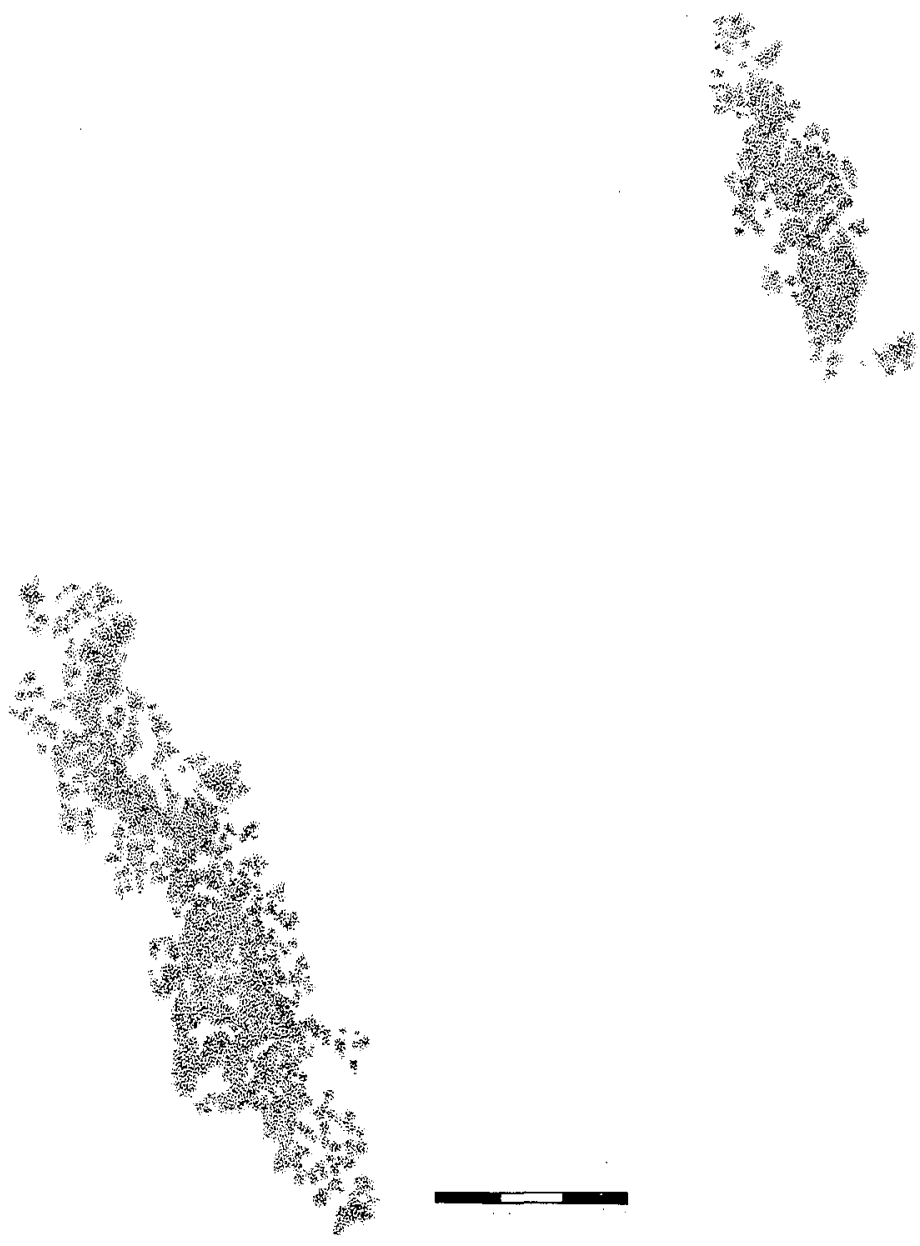

Figura 15.-Barranc del Bosquet. Abric II.

\section{CONSIDERACIONES FINALES}

En nuestra ponencia presentada al Coloquio Internacional sobre Arte Esquemático de la Península Ibérica afirmábamos que esta manifestación cultural era posiblemente «el elemento cultural más olvidado de la Prehistoria del País Valenciano, hasta el punto que en algunas obras generales no se señala su existencia y en otras apenas se le dedican algunas líneas. Este escaso interés parece venir condicionado por el atractivo que ofrece al investigador la abundancia y riqueza temática del arte levantino y por los escasos yacimientos citados en la monumental obra de $\mathrm{H}$. Breuil, base de todos los estudios posteriores sobre el arte esquemático peninsular» (HERNANDEZ PEREZ y CENTRE D'ESTUDIS CONTESTANS, 1983 b,, 63). 
En los últimos años el panorama ha comenzado a cambiar tras el descubrimiento de yacimientos con pinturas y grabados esquemáticos en las tres provincias valencianas, si bien, al menos por el momento, se observa una mayor concentración en la de Alicante como consecuencia, creemos, de una mayor intensidad en las prospecciones. El interés de estos recientes hallazgos, además de rellenar un cierto vacío en la distribución del arte esquemático en la Península Ibérica, aumenta si tenemos presente que son varios los abrigos que poseen pinturas levantinas y esquemáticas, incluso en algunas ocasiones infrapuestas las primeras a las segundas, y que suelen estar próximos los abrigos con uno y otro arte, con lo que se aporta nueva información en torno a la relación existente entre el arte levantino y el arte esquemático, objeto de controvertidas discusiones. No pretendemos tratar aquí este tema, por cuanto es necesario previamente conocer estos conjuntos, en su mayoría inéditos. Nos limitaremos, en cambio, a destacar algunos aspectos de las representaciones de estos abrigos de Moixent que consideramos de cierto interés en el marco de esa nueva «provincia» de arte esquemático que hemos establecido para el centro-sur del País Valenciano (HERNANDEZ PEREZ y CENTRE D'ESTUDIS CONTESTANS, 1983 a y 1983 b).

En primer lugar, sorprende la extraordinaria abundancia de representaciones zoomorfas, el reducido número de antropomorfos y motivos geométricos y la ausencia, salvo una dudosa figura, de motivos de carácter religioso, lo que convierte a este yacimiento en algo excepcional, al menos por el momento, en el conjunto del arte esquemático del País Valenciano, donde barras, petroglifoides, ídolos y antropomorfos son los temas más representados.

En efecto, hemos inventariado entre seguras y dudosas 21 representaciones zoomorfas en diverso grado de esquematización, desde la de tipo naturalista, próximo, si no lo es, al arte levantino, hasta los simples esquemas de barra horizontal, que señala tronco, cabeza y, en ocasiones, cola, con otras perpendiculares, a modo de cuernos y patas, con los tipos intermedios definidos tradicionalmente como seminaturalista y semiesquemático. Si tenemos en cuenta los convencionalismos en este tipo de representaciones (BELTRAN, 1971/1972), podemos señalar que nos encontramos ante cápridos cuyos cuernos en la mayoría de los ejemplares se representan siempre incurvados hacia atrás, siendo excepcional el motivo 3 del panel 3 , con cuernos de base más delgada que los extremos, lo que podría explicarse como convencionalismo, deficiente grado de conservación o impericia del autor.

La existencia de zoomorfos en diverso grado de esquematización plantea indudablemente problemas de cronología. El cáprido número 4 del panel 5 (figura 9.4) está más próximo a las representaciones levantinas que a las esquemáticas, mientras los restantes zoomorfos son indudablemente esquemáticos, por lo que parece lógico incluir aquél entre estos últimos. No obstante, ya hemos señalado que en las comarcas centromeridionales valencianas no es de extrañar la existencia en un mismo abrigo de representaciones de ambos tipos de manifestaciones artísticas. Por otro lado, la coloración de estas pinturas aporta escasa información, ya que, por ejemplo, esta misma figura presenta la misma tonalidad de rojo -M. $10 \mathrm{R} 3 / 2$ - M. $10 \mathrm{R} 3 / 1$ - que otras esquemáticas y semiesquemáticas. La diversidad de coloración, siempre de la gama del rojo, de las pinturas de este abrigo puede explicarse por las concreciones que las cubren, ya que, como opina A. Beltrán $(1968,26)$, la diversidad de tonalidades dentro de un mismo color no siempre debe «ser atribuida a una auténtica diferencia en la materia básica, sino a la intensidad del color en el disolvente, a la distinta calidad del mineral empleado o a las modificaciones mecánicas o químicas que se produjeran después de aplicar la pintura. Influyen también la calidad de la roca y su color, la hidratación y el grosor de la capa que se deposite. Las diferentes pátinas de tipo reseco, esmaltado o calcitado cambian también de color». Juega, asimismo, un papel importante en nuestra observación de co- 
lor el tipo de luz ambiental del momento, tal como hemos comprobado nosotros mismos, ya que, a pesar de utilizar un método claramente objetivo - Tablas Munsell-, en ocasiones cada uno de nosotros observaba ligeros matices diferenciadores e, incluso, una misma persona a distintas horas del día o en períodos de tiempo más largos clasificaba una pintura con una tonalidad distinta.

Mayor interés ofrecen sus paralelos muebles, de los que tenemos ejemplos relativamente próximos en el espacio. B. Martí (1985) ha señalado la existencia de un cáprido próximo tipológicamente al arte levantino entre las cerámicas impresas de la Cova de l'Or, mientras que del mismo yacimiento procede un fragmento cerámico con decoración incisa de tres zoomorfos esquemáticos, posiblemente ceŕvidos, que por el tipo de pasta no parece ser anterior al IV milenio a. C. (HERNANDEZ PEREZ y CENTRE D'ESTUDIS CONTESTANS, 1983 b , 74). El estudio de estas cerámicas, actualmente en curso por B. Martí, aportará, sin duda, una valiosa información en torno a la aparición del arte levantino y esquemático en las tierras valencianas.

Las representaciones antropomorfas son escasas, pero no de menor interés. Entre éstas destaca el antropomorfo del panel $7 b$ (figura 12), con un convencionalismo en la ejecución de los brazos para el que se carece de paralelos. No ocurre así con los dos antropomorfos masculinos del panel 1 (figura 5: 6 y 9) que tipológicamente hemos clasificado dentro del tipo ramiforme simple de $\mathrm{P}$. Acosta. Las tres barras más o menos incurvadas hacia abajo que cortan la vertical plantean problemas de identificación con las partes de la anatomía humana. La inferior representa indudablemente las piernas, mientras la central y superior ofrecen dudas. La central difícilmente puede identificarse con los pechos de una mujer, como se propone para un motivo similar del Peñón de la Visera (GOMEZ-BARRERA, 1982, 98), por tratarse de figuras claramente masculinas, por lo que nos inclinamos por identificarlo como la representación de los brazos y considerar el superior como la cabeza, tal como se han interpretado algunas figuras tipológicamente próximas de Peña Escrita (BREUIL, 1933, 86; CABALLERO KLINK, 1983, 455) o como un tocado.

Las restantes representaciones - zig zag, petroglifoides, ramiforme, barras, puntos...- ofrecen un menor interés. No ocurre así con el motivo central del panel 1 (figura 5:3) que hemos descrito como pectiniforme, si bien no descartamos su posible identificación como ídolo o, incluso, figura humana. Cualquiera de estas interpretaciones puede ser válida por el tipo de figuras que conforman el panel, donde se pueden identificar claramente antropomorfos y zoomorfos, que si bien no forman escenas, no podemos descartar una posible relación entre ellas. Esta no parece tener carácter venatorio, pero sí podría explicarse como de pastoreo, considerando el pectiniforme como una estructura, o de tipo religioso, en este caso podría interpretarse como un ídolo, relacionándose la escena con ritos de fecundidad - abundancia de zoomorfos y dos antropomorfos sexuados-. Sea cual fuere el significado del motivo y del panel, es evidente que nos encontramos, incluso por su situación en una hornacina en el centro del abrigo, ante un conjunto de singular importancia para explicar determinados aspectos del arte esquemático del País Valenciano. 


\section{BIBLIOGRAFIA}

ACOSTA, P. 1968: La pintura rupestre esquemática en España. Salamanca.

- 1983: «Técnicas, estilo, temática y tipología en la pintura esquemática hispana», Zephyrus, XXXVI, $7-25$.

BELTRAN, A. 1968: Arte rupestre levantino. Zaragoza.

1971/1972: "Las pinturas esquemáticas de Lecina (Huesca)», Caesaraugusta, 35-36, 71-99.

BREUIL, H. 1933/1935: Les peintures rupestres schématiques de la Peninsula Ibérique. Lagny.

CABALLERO KLINK, A. 1983: La Pintura Rupestre Esquemática de la vertiente septentrional de Sierra Morena (provincia de Ciudad Real) y su contexto arqueológico. Ciudad Real.

GOMEZ BARRERA, J. A. 1982: La Pintura Rupestre Esquemática en la Altimeseta Soriana. Soria.

HERNANDEZ PEREZ, M. S., y CENTRE D'ESTUDIS CONTESTANS. 1983 a: «Vorbericht über erforschung der felsbildkunst in der provinz Alicante», Madrider Mitteilungen, 24, 32-45.

- 1983 b: «Arte esquemático en el País Valenciano. Recientes aportaciones». Zephyrus, XXXVI, 63-75.

HERNANDEZ PEREZ, M. S., y SEGURA MARTI, J. M. 1985: «Pinturas rupestres esquemáticas en las estribaciones de la Serra de Benicadell, Vall d'Albaida (Valencia)», Trabajos Varios del S. I. P., 82 .

MARTI OLIVER, B. 1985: «Los estudios sobre el Neolítico en el País Valenciano y áreas próximas», Arqueología del País Valenciano. Alicante, 53-84.

RIPOLL PERELLO, E. 1983: «Cronología y periodización del esquematismo prehistórico en la Península Ibérica». Zephyrus, XXXVI, 27-35. 


\title{
EL POBLADO DE LA EDAD DEL BRONCE DE LA MOLA ALTA DE SERELLES (ALCOY, ALICANTE) *
}

\author{
JULIO TRELIS MARTI \\ Universidad de Alicante
}

\begin{abstract}
El objeto de este artículo es la revisión y actualización de uno de los poblados más característicos de la Cultura del Bronce Valenciano, la Mola Alta de Serelles, al igual que publicamos algunos materiales del mismo aún inéditos. De entre todos, podemos destacar el análisis de los restos constructivos conservados hasta la actualidad, la tipología del material cerámico, y en general el estudio que hacemos de la metalurgia, la industria lítica, ósea, etc.

The aim of this article is the revision ad bringing up to date of one of the most characteristics settlements of Valencian Bronze Culture, La Mola Alta de Serelles. We write of several of its materials not previously published. Above all, we can underscore the analysis of constructing remnants preserved up to our days, the typology of the ceramics and, in general, the study of metallurgical, lithic and bone industry, etc.
\end{abstract}

\section{SITUACION}

Físicamente lo que se denomina «les Valls d'Alcoi» es una cubeta perteneciente al Sistema Prebético, la cual está rodeada por varios pliegues de unos $1000 \mathrm{~m}$. de altitud, fracturados mediante una serie de valles.

La Sierra de Mariola es uno de estos pliegues situados al O. de la mencionada cubeta. En sus estribaciones más orientales, formadas por un anticlinal de dirección N.-S. y cortado por pequeños valles, existe un espolón rocoso delimitado por dos de esos valles, y que se conoce con el nombre de la Mola Alta de Serelles.

El yacimiento, situado en la cumbre del mencionado espolón, se halla en el término municipal de Alcoy, lindando ya con el término vecino de Cocentaina. Desde sus 1053 $\mathrm{m}$. de altitud $\mathrm{s} / \mathrm{n} / \mathrm{m} /$. se domina claramente el Valle Alto y Medio del Río Alcoy y gran parte de la Sierra Mariola. Sus coordenadas son: $38^{\circ} 43^{\prime} 55^{\prime \prime}$ latitud Norte y $3^{\circ} 11$ ' $36^{\prime \prime}$ longitud Este (Fig. 1) (1).

* Este trabajo es un resumen de nuestra Memoria de Licenciatura que, bajo la dirección del doctor Mauro S. Hernández Pérez, fue presentada en la Facultad de Filosofía y Letras de la Universidad de Alicante, obteniendo la calificación de «sobresaliente por unanimidad».

(1) Servicio Geográfico del Ejército. Hoja 821 (Alcov, E. 1: 25000, Cuarto III, 1950). 


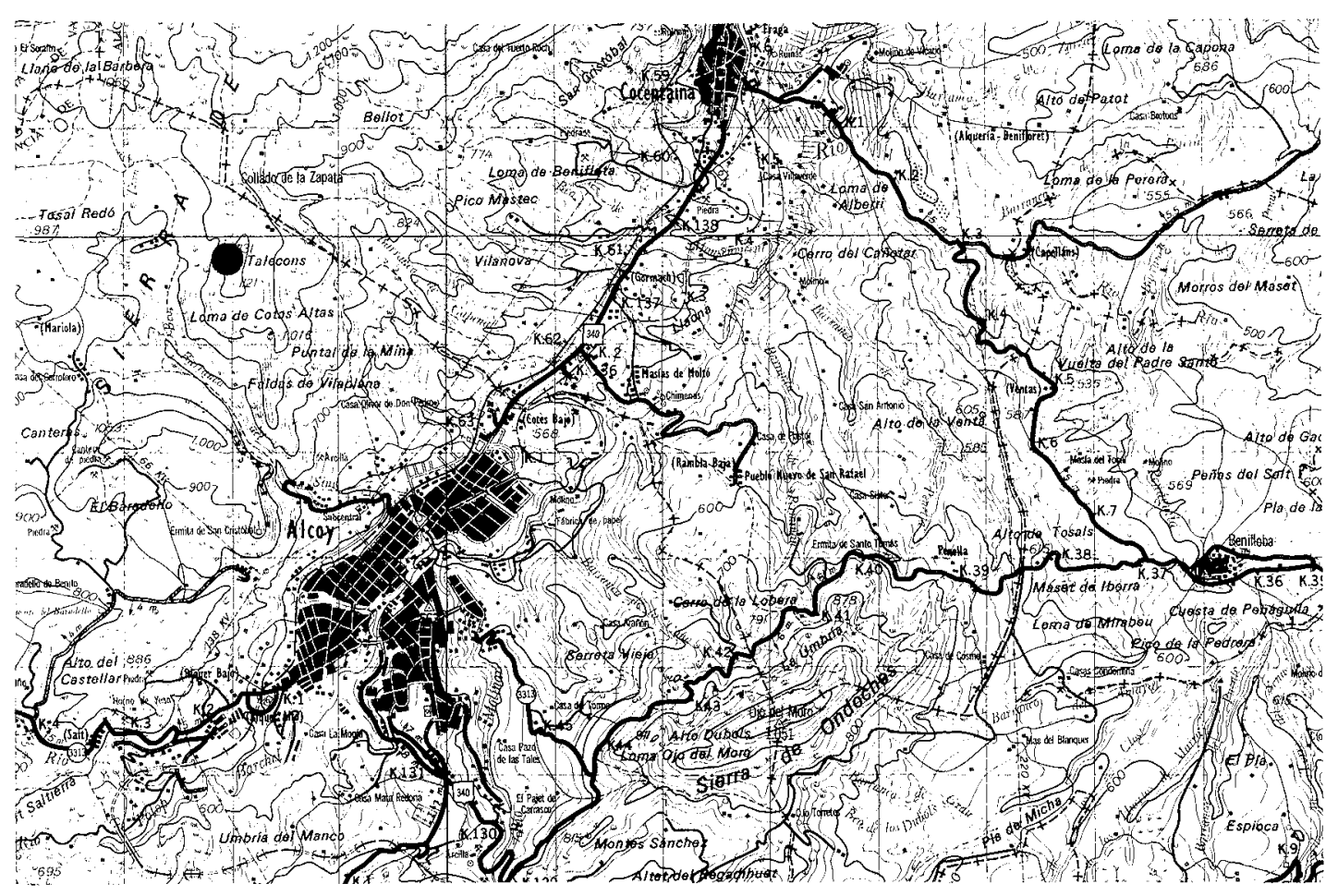

Figura 1.

Geológicamente se encuentra entre materiales miocénicos — pudingas, calcirruditas bioclásticas, calizas o areniscas en descomposición, etc.- - Es una zona profundamente fallada y karstificada, y de ahí que haya numerosas grietas y simas sobre todo en sus vertientes E. y O., muchas de las cuales ocupadas por el hombre desde época prehistórica.

El farallón tiene forma alargada, siendo sus laderas E. y O. muy escarpadas, mientras que la N. presenta una pendiente más suave. Su cima, en algunas partes amesetada, buza en dirección E.-O., hasta caer en la vertiente oriental, donde existe una pared casi vertical, que le sirve como defensa natural al poblado.

\section{HISTORIA DE LA INVESTIGACION}

Las primeras noticias sobre la existencia de restos prehistóricos en la Mola Alta de Serelles se deben a R. Vicedo $(1925,57-59)$, el cual, entre otras cosas, da a conocer la fecha de su descubrimiento -1924-, quiénes fueron sus descubridores - E. Botella, L. Gisbert y S. Reig-y adelanta un breve resumen de los primeros trabajos.

Sus excavaciones, en gran parte publicadas (BOTELLA, 1926 y 1928), se llevaron a cabo básicamente durante los años 1925-1928. Ellas se concentraron sobre todo en dos sitios: la grieta que se encuentra en el interior de una de las cuevas-abrigo de la vertiente E. del macizo, de donde extrajeron gran cantidad de cerámica, industria ósea, útiles de sílex con una punta de flecha y restos de fauna, y el poblado, en el cual hallaron cinco compartimientos paralelos entre sí y perpendiculares a una muralla, a los que se accedía por medio de un pasillo, y una torre de planta circuliforme, junto con una rica colección de material cerámico, óseo y lítico sobre todo, entre el cual cabe mencionar un vaso geminado, un posible «idolillo» de hueso, varios morillos y unas posibles «pesas de telar» de tierra cocida, objetos de metal y moldes de fundición. Al final se realizó un sondeo al 
exterior del poblado, en una construcción en forma de «L», de resultados poco notables.

Por último, sabemos, según información de J. M. Segura, que V. Pascual terminó de excavar restos de una vivienda y los materiales los depositó en el Museo Arqueológico Municipal de Alcoy «Camilo Visedo Moltó», desconociendo la fecha de ingreso y la referencia exacta de los mismos.

Los hallazgos, en la actualidad, se encuentran depositados en el Museo antes mencionado y en el Museo de Prehistoria de la Diputación Provincial de Valencia, ignorando si existen otros en alguna colección privada (2).

Sobre este yacimiento son numerosas las publicaciones en las que se hace referencia a ciertos aspectos del mismo en general, siendo su bibliografía muy extensa, y otras en las que también se estudian varios aspectos sobre éste en particular, entre las cuales cabría destacar, por aportar algún conocimiento nuevo, el análisis espectrográfico de un objeto metálico realizado por B. Blance (1959) y el inventario de los dientes de hoz y los molinos de R. Enguix (1975).

\section{EL POBLADO. DESCRIPCION DE LAS ESTRUCTURAS. LA CUEVA}

\section{III.1. El poblado}

El poblado, con una forma aproximadamente rectangular de unos $450 \mathrm{~m}^{2}$, ocupa una parte de la plataforma superior del espolón rocoso, cuyo terreno está bastante desnivelado.

En la actualidad las únicas estructuras que aún se conservan son las siguientes (Fig. 2):

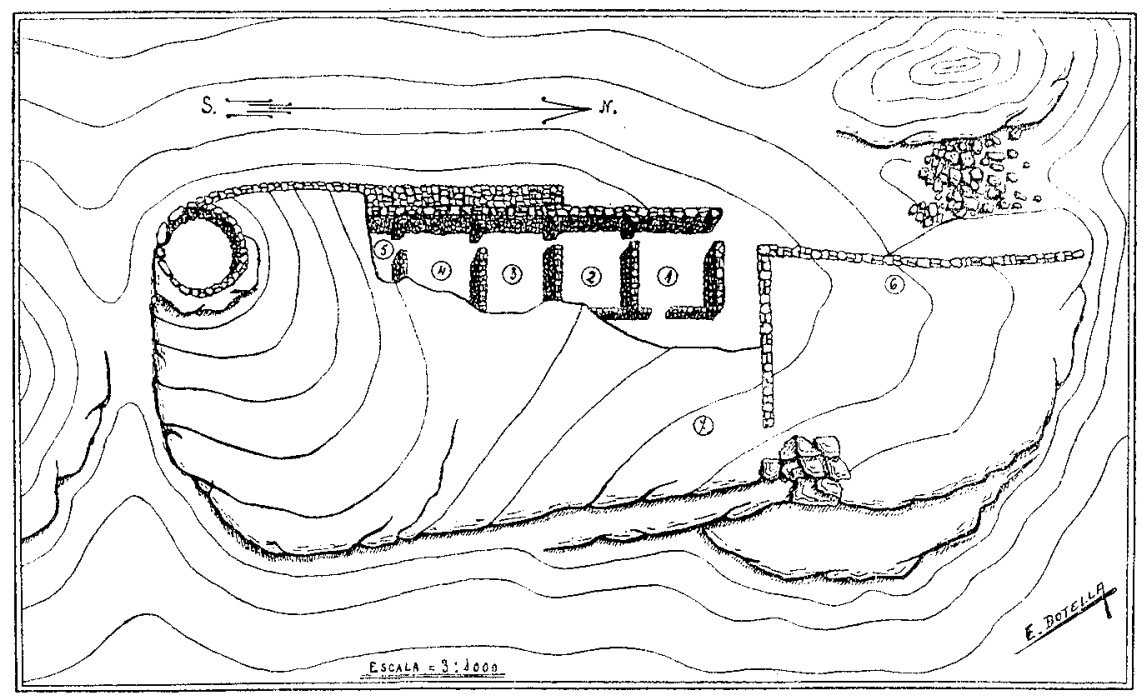

Figura 2.-Mola Alta de Serelles - Alcoy-. Poblado, planta. Equidistancia entre curvas de nivel: 1 metro.

(2) Agradecemos a D. F. Rubio Gomis y a D. E. Plá Ballester, directores de los respectivos Museos, el acceso a los materiales. También expresamos nuestro agradecimiento a M. S. Hernández Pérez, director de la Memoria, por su tarea desinteresada; a R. Enguix por prestarnos sus inventarios y algunos dibujos; y por último a J. M. Segura, E. Cortell y J. M. Vicéns por su ayuda en la realización de planimetrías, parle gráfica, etcétera. 
La muralla construida en la vertiente $O$., de acceso más fácil, pues en la E. el escarpe pronunciado supone una defensa natural. Está formada por dos muros unidos en ángulo recto de $28 \mathrm{~m}$. y $8 \mathrm{~m}$. de longitud, y 1'60-2 m. y 1'20 m. de grosor. Se adapta a las condiciones del terreno y tiene dos hiladas de piedra en seco de gran tamaño, asentadas directamente sobre la roca y careadas sólo por su parte interior, alcanzando en ocasiones una altura de 1 '50 $\mathrm{m}$.

La torre situada en la parte superior del poblado, flanqueándolo por su lado S. Tiene planta circuliforme de $7 \mathrm{~m}$. de diámetro máximo y sólo se conserva su hilada inferior con 1'40-2 m. de grosor. Su característica más importante es que no se trata de una torre propiamente dicha, adosada a la muralla, sino más bien es uno de los dos muros de ésta, el de mayor longitud, que en la zona más elevada se cierra sobre sí mismo, adoptando una forma circular.

Una construcción en forma de «L» que se encuentra fuera del poblado y en la parte opuesta de la torre. Es similar a la muralla, formada por dos muros de 2' 80 m. 3’20 m. de longitud, de una sola hilada de piedras en seco de mediano tamaño y sin carear, asentadas directamente sobre la roca. Entre esta construcción y la muralla antes descrita existe un pasillo de unos $4 \mathrm{~m}$. de amplitud, a través del cual se accedería posiblemente al poblado.

Por último, y en el interior del mismo, aún podemos apreciar dos lienzos de muros rectilíneos, paralelos y perpendiculares a la muralla, pero sin unirse a ella, y que son, casi con toda seguridad, restos de las paredes divisorias de los compartimientos. Tienen una hilada de piedras de mediano tamaño, asentadas directamente sobre la roca y unidas con una especie de tapial. Su longitud es de $3 \mathrm{~m}$. y 1'40 m.

Hoy en día, pues, ha desaparecido todo vestigio sobre un muro paralelo y pegado a la muralla, que junto con otros paralelos a los ya citados formarían cinco estancias de planta rectangular de unos $15 \mathrm{~m}^{2}$, menos una que tendría $3 \mathrm{~m}^{2}$. Tampoco queda nada de las estructuras que había dentro de las mismas: los bancos construidos con piedras planas colocadas encima de otras sueltas, que tapaban los huecos provocados por los salientes de la roca; los hogares situados en el interior de uno de esos huecos, el cual no se cubría adrede; el piso producto de nivelar el terreno con piedras y tierra apisonada; y un tronco de madera carbonizada colocado entre «piedras planas» para sustentar la techumbre (BOTELLA, 1928, 4-5 y lám. I) (Fig. 3).

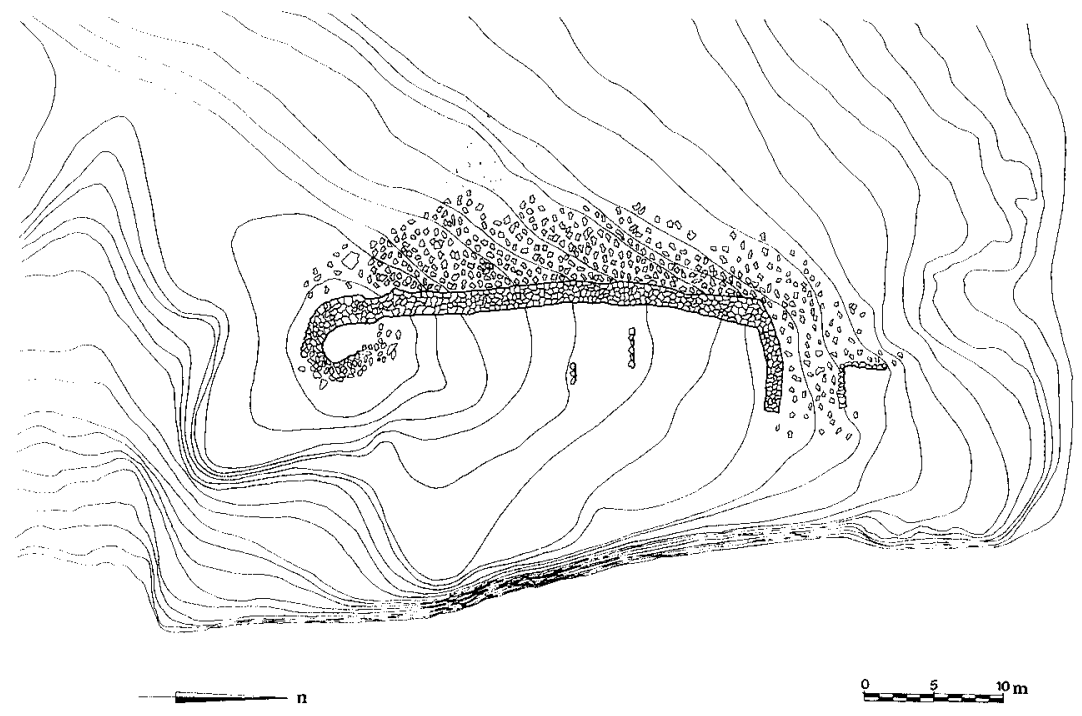

Figura 3.-Construcción fuera de la muralla. 
Del cotejo de lo publicado con lo que hoy se conserva observamos que en general la disposición y la orientación de las estructuras concuerdan, si bien las dimensiones en algunos casos varían tanto en los planos y en el texto de Botella como en el nuestro.

Tan sólo hay que hacer notar algunas salvedades: En primer lugar la muralla, según su planimetría, no era toda de dos hiladas de piedras grandes con otras pequeñas en el interior, sino sólo su parte central, hecho que tampoco hemos podido observar. En segundo lugar la planta de la torre no forma una circunferencia perfecta, tal y como la representa en su plano. Y por último destacamos que recientemente se ha publicado un croquis del poblado realizado por S. Reig (SEGURA-CORTELL, 1984, 45), en el cual la construcción en forma de «L» aparece orientada justo al revés de como es y por tanto no debe inducirnos a error, pues la disposición de la misma en este croquis no coincide con las planimetrías de Botella ni con las nuestras.

\section{III.2. La cueva}

En el centro de la cumbre existe una pequeña vaguada, que facilita el paso a la vertiente E. del espolón, donde Botella (1926, 4-5 y lám. II) prospectó seis cuevas-abrigo, de las que sólo en la $n .^{\circ} 4$ halló los restos prehistóricos publicados.

Se trata de una cueva de medianas dimensiones $-14 \mathrm{~m}$. de longitud hasta el fondo y $20 \mathrm{~m}$. de anchura máxima-. Su boca, de forma semicircular, está orientada al E. y mide $20 \mathrm{~m}$. de longitud y $6 \mathrm{~m}$. de altura. Su superficie presenta poca sedimentación y en ella la roca aflora sobre todo en la zona de contacto con las paredes laterales. La pared del fondo forma parte de una falla, la cual ha provocado la existencia de una grieta de $14 \mathrm{~m}$. de longitud, $1 \mathrm{~m}$. de anchura y $15 \mathrm{~m}$. de altura, con bastante sedimentación, y es donde se encuentra al área excavada, de la que desconocemos su situación y extensión (Fig. 4).

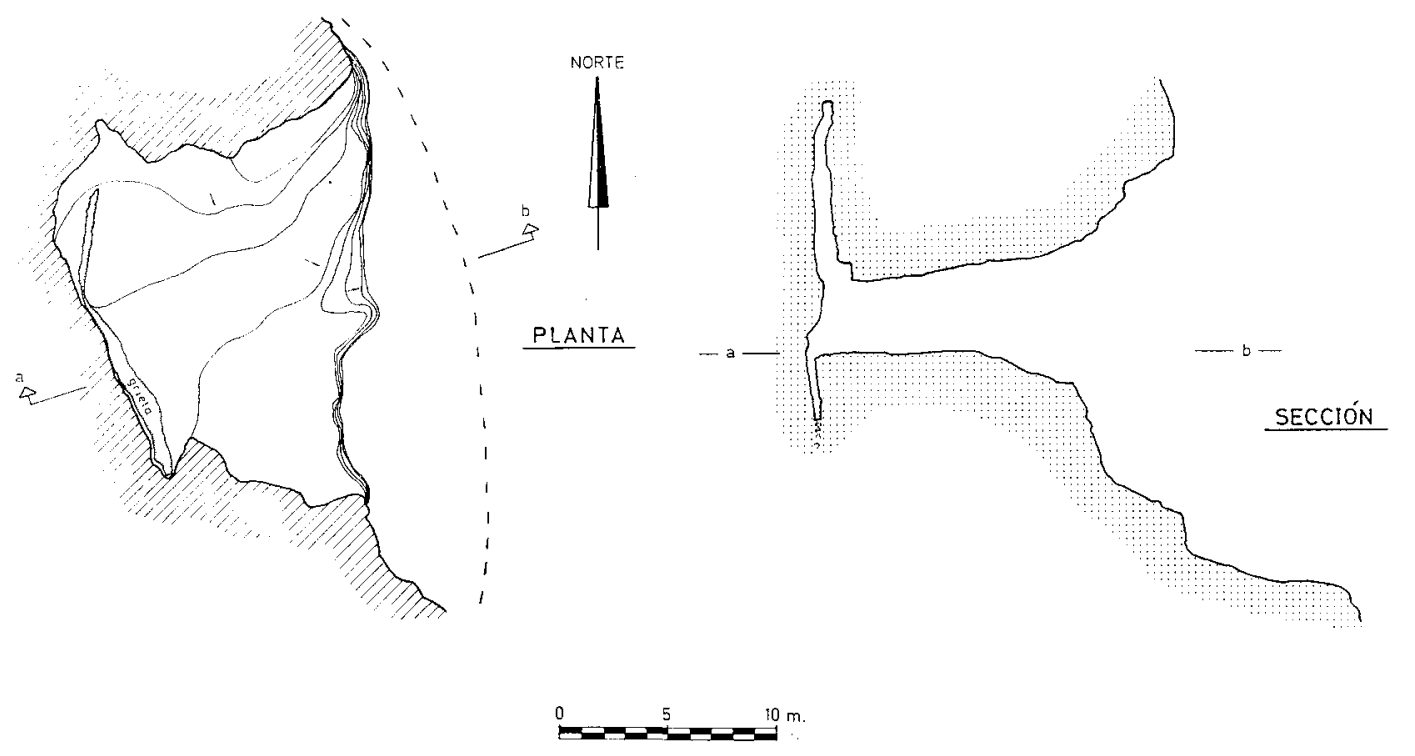

Figura 4.-Mola Alta de Serelles -Alcoy-. Cueva número 4. 
En líneas generales estas descripciones coinciden con las de Botella $(1926,4-6$ y lám. II), salvo la amplitud de la grieta, que según éste tenía $70 \mathrm{~cm}$. y se estrechaba conforme se profundizaba hasta unos $5 \mathrm{~m}$., donde ya era imposible su descenso (Fig. 5).

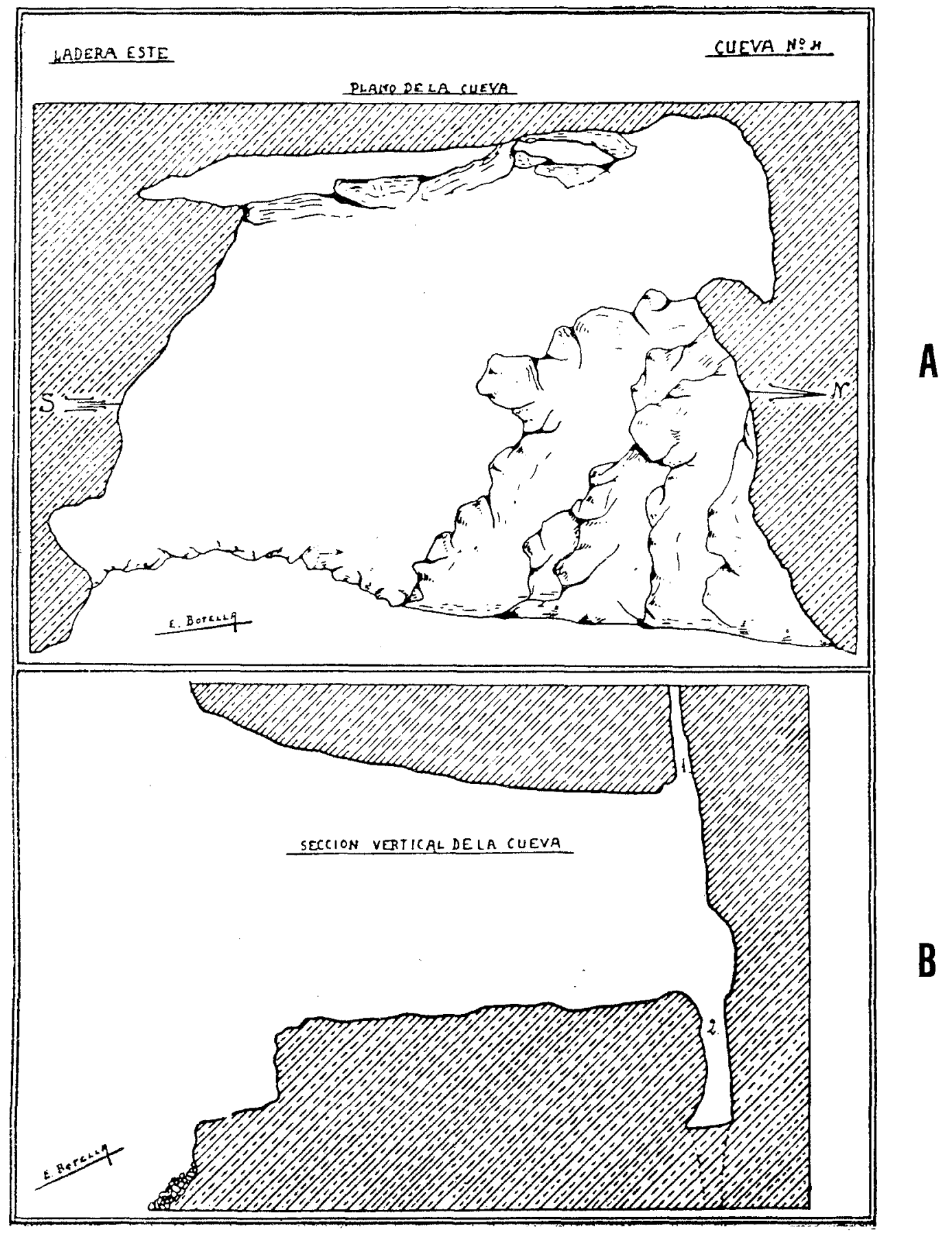

Figura 5.--Planta y sección de la cueva (según sus excavadores). (BOTELLA, 1926, lám. II.) 


\section{ESTUDIO DE LOS MATERIALES}

\section{IV.1. Cerámica}

El mayor conjunto de material es el cerámico, con un total de 5170 piezas inventariadas. La mayor parte tan sólo son fragmentos de borde o atípicos y de ellos 2854 no hemos podido estudiarlos por su tamaño muy reducido. Estas cifras no deben inducirnos a error, pues muchas de las piezas deben de pertenecer a una misma vasija, aunque su reconstrucción es prácticamente imposible.

\section{IV.1.1. Clasificación tipológica}

Se han contabilizado un total de 45 vasijas completas y 29 fragmentos de los que podemos conocer su forma y tamaño, lo cual supone el 1'4 \% del conjunto de piezas cerámicas. Hemos establecido los siguientes tipos:

- Tipo I.1. Vasijas de tendencia esférica.

Existen 6 ejemplares, que representan el $8 \%$ de las vasijas sobre las que se ha realizado esta clasificación tipológica. Miden entre $12 \mathrm{~cm}$. y $34 \mathrm{~cm}$. de diámetro máximo, y entre $9^{\prime} 5 \mathrm{~cm}$. y $21 \mathrm{~cm}$. de altura, aunque una sobrepasa los $30 \mathrm{~cm}$. La mayoría de ellas presentan elementos de aprehensión, habiendo una que posee un asa de lengüeta perforada (Fig. 10:1). Las superficies están alisadas y espatuladas, y su pasta es poco cuidada. Hay 4 variantes:

- Cuerpo de tendencia esférica con borde entrante y base convexa (Fig. 6, Tipo I.1. Variante D).

- Cuerpo de tendencia esférica con borde exvasado, cuello hiperbólico y base convexa (Fig. 6, Tipo I.1. Variante G).

- Cuerpo de tendencia esférica con borde exvasado, cuello troncónico y base convexa (Fig. 6, Tipo I.1. Variante H).

- Cuerpo de tendencia esférica con borde exvasado, cuello troncónico invertido y base convexa (Fig. 6, Tipo I.1. Variante I).

Los paralelos (3) más cercanos para este tipo de recipientes con o sin elementos de aprehensión o suspensión se encuentran en las estaciones vecinas de la Edad del Bronce de Mas de Menente (PERICOT-PONSELL, 1929, 107, fig. 8 y láms. III-IV), Barranc del Sint (VISEDO, 1937, 7, fig. 2), Ull del Moro, Cova la Boira, y en Cabeço Navarro (ENGUIX, 1970, 70, fig. 3: 83 y 68, fig. 2: 81), Muntanyeta de Cabrera (FLETCHERPLA, 1956, 18, fig. 7: 3-18 y lám. VII: 13), Mas d'Abad (GUSI-OLARIA, 1976, 104, fig. 1), Castillo de Frías (ATRIAN, 1974, 13, fig. 6: B), Serra Grossa (LLOBREGAT, 1969, 42, fig. 9, y 48, fig. 12: 25) y Terlinques (SOLER-FERNANDEZ, 1970, 30, fig. 4: $1)$, entre otras.

Este tipo de vasijas, a la vista de los paralelos expuestos, tiene gran amplitud geográfica a la vez que pocas precisiones cronológicas. Posiblemente la variante que presenta cuello troncocónico invertido se hubiese podido datar sólo en el Bronce Pleno, de no ser por su hallazgo en Muntanya Assolada (MARTI, 1983b, 52, fig. 5), donde existe también un nivel del Bronce Antiguo (MARTI, 1983b, 65), aunque desconocemos en qué nivel aparecieron estas vasijas.

(3) Los materiales de los yacimientos de Ull del Moro, Cova la Boira, Altet del Canalís, Mas del Corral, Cova Foradà, Sima del Pinaret del Mas Nou, Sima la «L», Pic del Baladre, Cau de les Raboses y Cova la Figuereta están por publicar o parcialmente publicados y se encuentran depositados en el Museo Arqueológico Municipal de Alcoy «Camilo Visedo Moltó» y en el Centre d'Estudis Contestans. 
- Tipo I.2. Vasijas semiesféricas.

Se han inventariado 16 ejemplares, lo cual supone el $22 \%$ de las vasijas sobre las que hemos realizado esta clasificación. Sus dimensiones varían entre $11 \mathrm{~cm}$. y $22 \mathrm{~cm}$. de diámetro máximo, aunque una sobrepasa los $32 \mathrm{~cm}$.; y entre $6^{\prime} 5 \mathrm{~cm}$. y $11 \mathrm{~cm}$. de altura, habiendo una que tiene $17 \mathrm{~cm}$. De ellas 4 poseen mamelones y algún asa de lengüeta como elementos de aprehensión. En cuanto al tratamiento de las superficies, dominan las alisadas y espatuladas, aunque también encontramos algunas superficies bruñidas, sin tratar y erosionadas con bastantes concreciones calizas. La pasta, en la mayoría de los casos, no está cuidada, con abundantes desgrasantes calizos, en ocasiones muy gruesos. Hemos distinguido 5 variantes:

- Cuerpo semiesférico con borde recto y base ligeramente plana (Fig. 6, Tipo I.2. Variante A).

- Cuerpo semiesférico con borde recto y base convexa (Fig. 6, Tipo I.2. Variante B).

- Cuerpo semiesférico con borde ligeramente entrante y base convexa (Fig. 6, Tipo I.2. Variante D).

- Cuerpo semiesférico con borde ligeramente exvasado y base plana (Fig. 6, Tipo I.2. Variante E).

- Cuerpo semiesférico con borde exvasado y base convexa (Fig. 6, Tipo I.2. Variante F).

- Tipo I.3. Vasijas de casquete esférico.

Hemos contabilizado un total de 15 piezas, lo cual representa el $20 \%$ de todas las completas o de las que conocemos su forma y tamaño. Junto con los cuencos semiesféricos es la forma más común de este yacimiento. Sus dimensiones varían entre $10^{\prime} 5 \mathrm{~cm}$. y $22 \mathrm{~cm}$. de diámetro en la boca, aunque una rebasa los $25 \mathrm{~cm}$.; y entre $4^{\prime} 5 \mathrm{~cm}$. y $6 \mathrm{~cm}$. de altura, habiendo una que tiene $10 \mathrm{~cm}$.. De todas únicamente tres poseen un mamelón colocado en el tercio superior del vaso. Predominan las superficies alisadas y espatuladas, aunque en algún caso se encuentran bruñidas o sin tratar. La pasta es generalmente de mala calidad. Sólo existe una variante:

- Cuerpo de casquete esférico con borde exvasado y base convexa (Fig. 6, Tipo I.3. Variante F).

Los cuencos semiesféricos y los de casquete esférico son una de las formas más sencillas de realizar. Durante la Edad del Bronce es frecuente encontrarlas en la mayoría de los yacimientos, por lo que no tienen una cronología precisa.

- Tipo II.1. Vasijas de tendencia elipsoide horizontal.

Existen 14 ejemplares, lo cual supone el $14 \%$ de todas las piezas sobre las que se ha realizado esta clasificación. Las de pequeño y mediano tamaño miden entre $8 \mathrm{~cm}$. y $16^{\prime} 5 \mathrm{~cm}$. de diámetro máximo y entre $5 \mathrm{~cm}$. y $15 \mathrm{~cm}$. de altura; las de gran tamaño llegan a los $34 \mathrm{~cm}$. de diámetro máximo y de altura. Cuatro de ellas presentan mamelones colocados generalmente en su tercio superior. Dominan las superficies alisadas o sin tratar, aunque muchas de ellas están espatuladas, bruñidas y erosionadas. La pasta suele ser de mala calidad, con abundantes desgrasantes minerales y una cocción defectuosa. Hay 6 variantes:

- Cuerpo de tendencia elipsoide horizontal con borde recto y base convexa (Fig. 7, Tipo II.1. Variante B).

- Cuerpo de tendencia elipsoide horizontal con borde entrante y base plana (Fig. 7, Tipo II.1. Variante C).

- Cuerpo de tendencia elipsoide horizontal con borde entrante y base convexa (Fig. 7, Tipo II.1. Variante D).

- Cuerpo de tendencia elipsoide horizontal con borde ligeramente exvasado y base plana (Fig. 7, Tipo II.1. Variante E). 


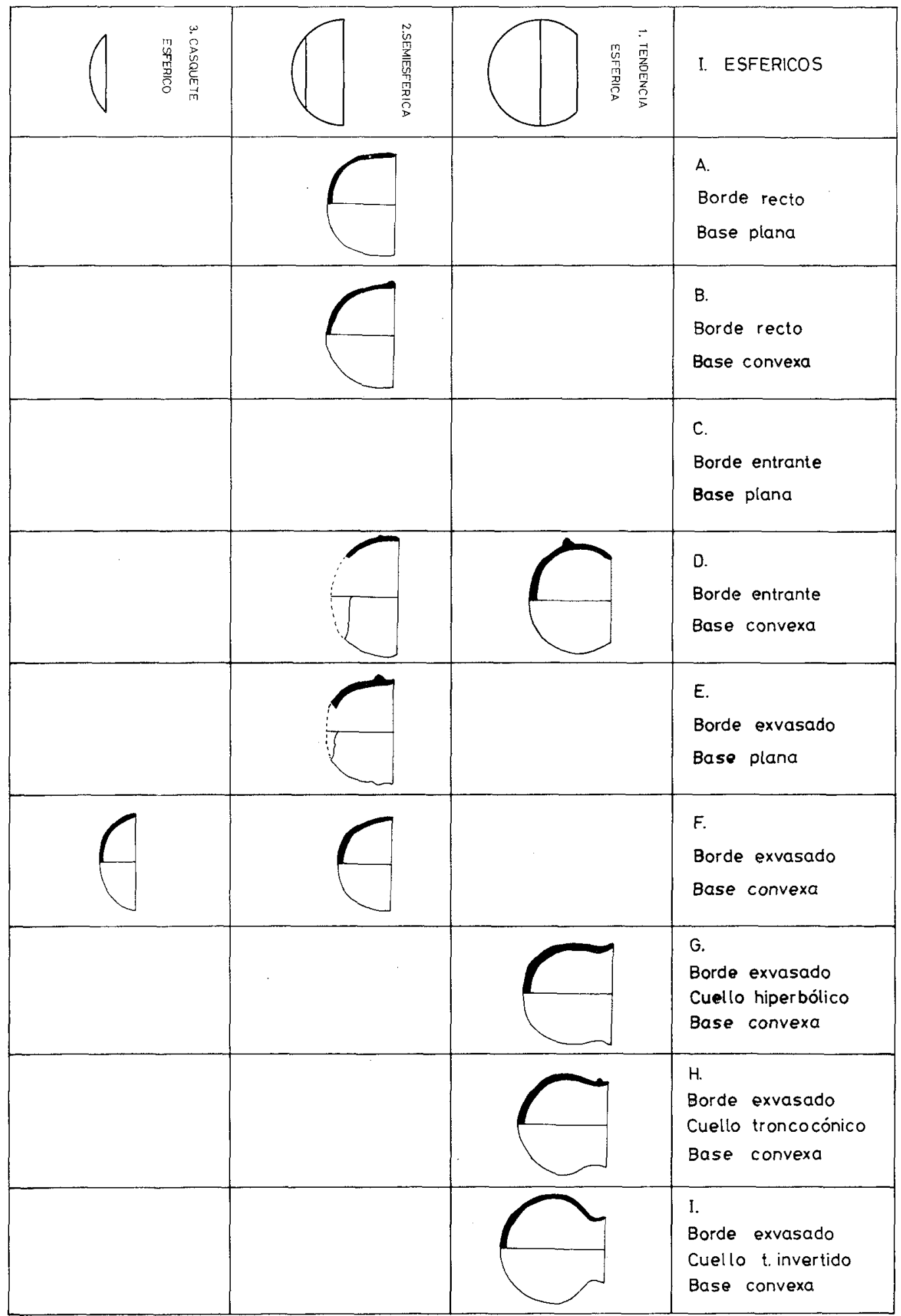

Figura 6.--Tabla tipológica. Tipo I. 


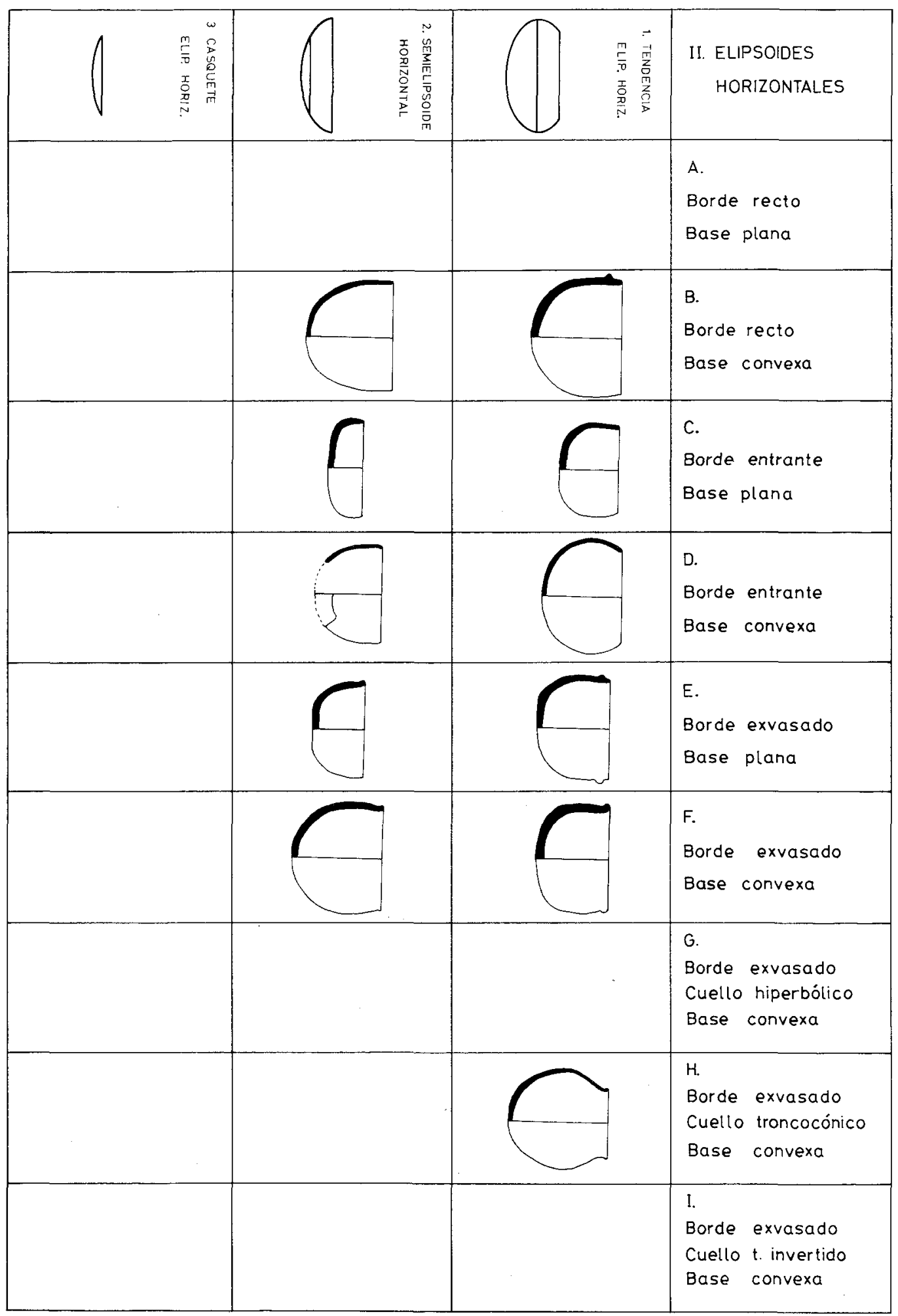

Figura 7.-Tabla tipológica. Tipo II. 
- Cuerpo de tendencia elipsoide horizontal con borde ligeramente exvasado y base convexa (Fig. 7, Tipo II.1. Variante F).

- Cuerpo de tendencia elipsoide horizontal con borde exvasado, cuello troncocónico y base convexa (Fig. 7, Tipo II.1. Variante H).

Paralelos para este tipo de vasijas, con o sin elementos de aprehensión, existen, entre otros yacimientos, en Cova la Boira, Ull del Moro, Mas de Menente (PERICOTPONSELL, 1929, 107, fig. 8 y láms. III-IV), Serra Grossa (LLOBREGAT, 1969, 38, fig. 4: 12, y 40, fig. 5: 14), El Tabaià (NAVARRO, 1982, 62, fig. 25: b), Tossal Redó (TARRADELL, 1958, lám. III: 3-6), Muntanya Assolada (MARTI, 1983b, 51, fig. 4: 1) y Mas d'Abad (GUSI-OLARIA, 1976, 104, fig. 1), por lo que tiene una gran difusión geográfica.

En cuanto a su cronología presenta pocas precisiones: La variante de borde recto aparece en el poblado del Bronce Pleno de Serra Grossa y en el Nivel Superficial/I de Mas d'Abad datado en el 1010 a. C. (GUSI-OLARIA, 1976, 103); las de borde entrante se han documentado en yacimientos con materiales adscribibles al Bronce Antiguo y Pleno como Ull del Moro y en otros poblados también del Bronce Pleno ya mencionados; las de borde exvasado se encuentran en poblados del Bronce Pleno como Serra Grossa y en El Tabaià con materiales del Bronce Pleno y Final, aunque se desconoce a cuál pertenece (NAVARRO, 1982, 64). Unicamente la variante con cuello troncónico, por sus paralelos (Mas de Menente, Serra Grossa y Tossal Redó, entre otros), datables, por regla general, en el Bronce Pleno, ofrece mayores precisiones cronológicas.

- Tipo II.2. Vasijas semielipsoides horizontales.

Hay 9 piezas, que suponen el $12 \%$ de todas las inventariadas en esta clasificación. Las de mediano tamaño miden entre 11'5 cm. y $18^{\prime} 7 \mathrm{~cm}$. de diámetro máximo, y entre $4 \mathrm{~cm}$. y $6^{\prime} 5 \mathrm{~cm}$. de altura; las de gran tamaño llegan hasta $26 \mathrm{~cm}$. de diámetro máximo y $20 \mathrm{~cm}$. de altura. Cinco de ellas tienen uno o varios mamelones colocados diametralmente en su mitad superior. Las superficies generalmente están sin tratar, alisadas o espatuladas. La pasta es de mala calidad, con muchos desgrasantes minerales, gruesos en ocasiones. Hemos distinguido 5 variantes:

- Cuerpo semielipsoide horizontal con borde recto y base convexa (Fig. 7, Tipo II.2. Variante B).

- Cuerpo semielipsoide horizontal con borde entrante y base plana (Fig. 7, Tipo II.2. Variante C).

- Cuerpo semielipsoide horizontal con borde ligeramente entrante y base convexa (Fig. 7, Tipo II.2. Variante D).

- Cuerpo semielipsoide horizontal con borde ligeramente exvasado y base plana (Fig. 7, Tipo II.2. Variante E).

- Cuerpo semielipsoide horizontal con borde ligeramente exvasado y base convexa (Fig. 7, Tipo II.2. Variante F).

Este tipo de vasijas es bastante frecuente dentro de la Edad del Bronce. Ejemplos de ellas son las de Mas de Menente (PERICOT-PONSELL, 1929, 107, fig. 8 y láms. IIIIV), Serra Grossa (LLOBREGAT, 1969, 41, fig. 6: 15), Muntanyeta de Cabrera (FLETCHER-PLA, 1956, fig. 7: 13-14), Sima la Higuera (LERMA, 1977, 65, fig. 1: 3), Ereta del Castellar (ARNAL-PRADES-FLETCHER, 1968, lám. XVI: 3), Nivel II del Castillo de Frías (ATRIAN, 1974, 15, fig. 11: a), Motilla de Azuer (NAJERA, 1979, 30, fig. 6: B), etc.

Este tipo aparece bien documentado en estos yacimientos que pertenecen al Bronce Pleno, si bien no se puede precisar mucho más sobre su cronología.

- Tipo III.1. Vasijas de tendencia elipsoide vertical.

Se han inventariado 12 ejemplares, que representan el $16 \%$ de las piezas sobre las que se ha realizado esta clasificación tipológica. Las de mediano tamaño miden entre $10^{\circ} 3 \mathrm{~cm}$. y $20 \mathrm{~cm}$. de diámetro máximo y hasta $16 \mathrm{~cm}$. de altura; las grandes tienen, co- 


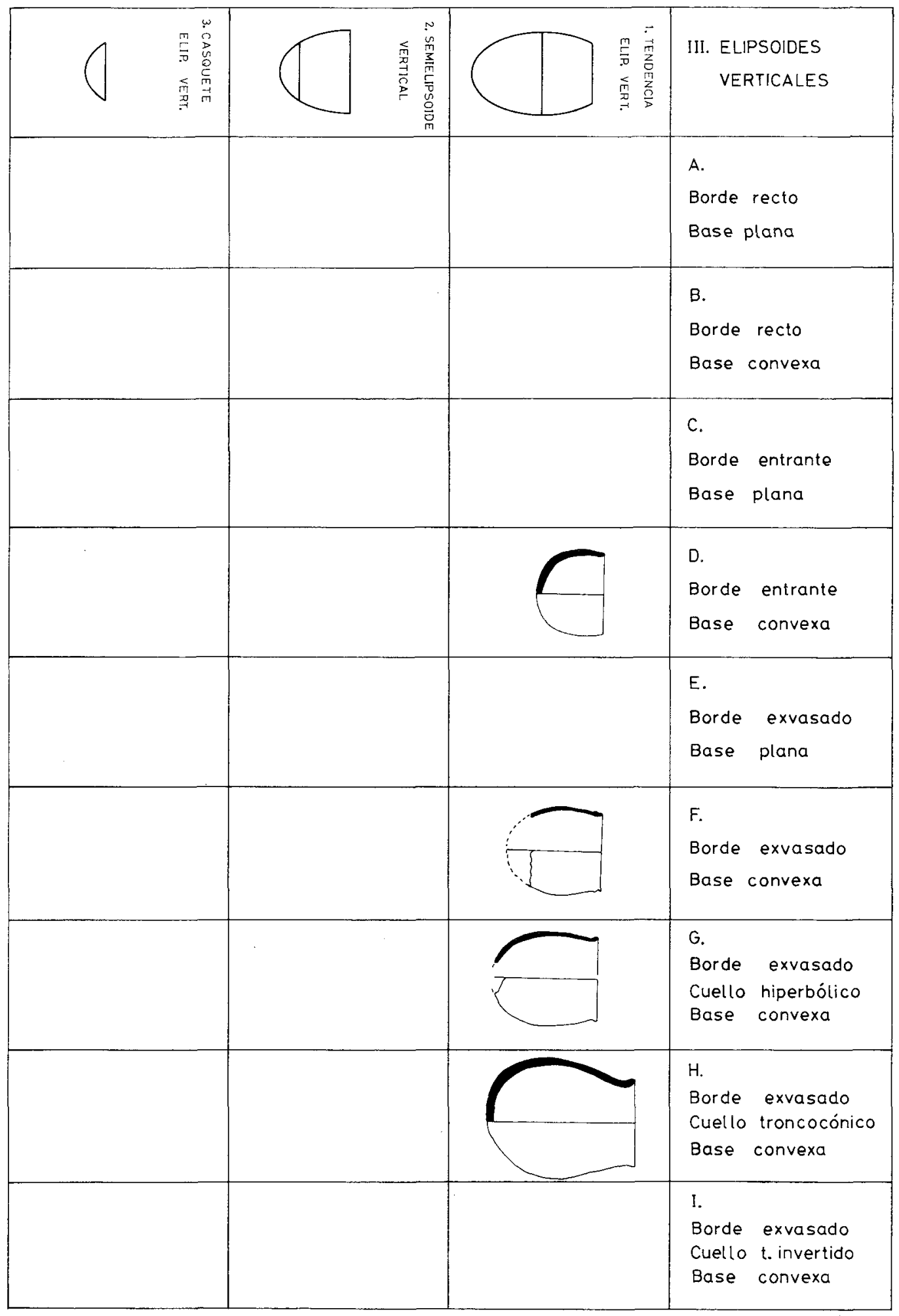

Figura 8.-Tabla tipológica. Tipo III. 
mo mucho, $30 \mathrm{~cm}$. de diámetro máximo y $39 \mathrm{~cm}$. de altura. De ellas cinco poseen mamelones colocados diametralmente en el tercio superior de la vasija. Sus superficies se encuentran sin tratar o alisadas, y la pasta es de mala calidad. Hay 4 variantes:

- Cuerpo de tendencia elipsoide vertical con borde entrante y base convexa (Fig. 8, Tipo III.1. Variante D).

- Cuerpo de tendencia elipsoide vertical con borde exvasado y base convexa (Fig. 8, Tipo III.1. Variante F).

- Cuerpo de tendencia elipsoide vertical con borde exvasado, cuello hiperbólico y base convexa (Fig. 8, Tipo III.1. Variante G).

- Cuerpo de tendencia elipsoide vertical con borde exvasado, cuello troncónico y base convexa (Fig. 8, Tipo III.1. Variante H).

Paralelos para este tipo de vasijas sin cuello los hallamos, entre otros yacimientos, en Mas de Menente (PERICOT-PONSELL, 1929, 107, fig. 8 y láms. III-IV), Cabeço dels Llorenços (APARICIO, 1981, 173, fig. 93: B), Serra Grossa (LLOBREGAT, 1969, 52, fig. 15: 31), Cabeço Navarro (ENGUIX, 1970, 70, fig. 3) y en el Nivel II-III del Castillo de Frías (ATRIAN, 1974, 16, fig. 11: b, y 18, fig. 18: f), todos ellos poblados pertenecientes al Bronce Pleno.

En lo que se refiere a las formas que presentan cuello hiperbólico o troncocónico, destacamos que se han hallado en algunos de los yacimientos mencionados anteriormente y en otros como Terlinques (SOLER-FERNANDEZ, 1970, 33, fig. 3), Alcudia de Veo (OLARIA DE GUSI, 1975, 156, fig. 2: 1) y Can Ballester (GUSI-OLARIA, 1979 , 89, fig. 32), por lo que presentan una cronología bastante amplia.

- Tipo IV. Vaso compuesto de hipérbole y casquete esférico con carena baja, borde exvasado y base convexa (Fig. 9).
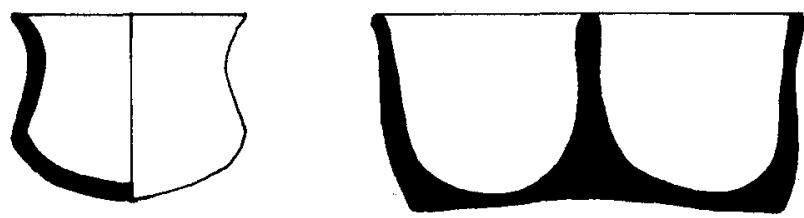

Figura 9.-Tipos 4 y 5.

Sólo existe un ejemplar de reducidas dimensiones ' $\left(6^{\prime} 8 \mathrm{~cm}\right.$. de diámetro máximo y 5 '2 cm. de altura). Representa el 1'5\% de todas las piezas estudiadas en esta clasificación tipológica. No posee elementos de aprehensión. El tratamiento de las superficies es el alisado y la pasta no está cuidada.

Sus paralelos más exactos se encuentran en Mas de Menente (PERICOTPONSELL, 1929, lám. III), Cabezo Redondo (SOLER, 1976, 45, fig. 3), Les Oliveretes (APARICIO, 1977, 80, fig. 34: 11), Puntal de Cambra (ALCACER, 1954, 81, fig. 11), Torrelló de Onda (GUSI, 1974, 34), Castillo de Frías (ATRIAN, 1974, 19, fig. 19: e), etcétera.

Este tipo de vasijas está bien documentado durante esta época. Según T. Nájera $(1979,32-33)$ se hallan ya en Fuente Bermeja, en los niveles preargáricos del Cerro de la Virgen de Orce y en diversos poblados del Bronce de la Meseta, al igual que perduran hasta los momentos finales del Bronce Pleno, como en Torrelló de Onda o Cabezo Redondo. En la Bastida de Totana (RUIZ-POSAC, 1956, 79) apareció en el interior de una cista y por tanto clasificable en el Argar A. O. Arteaga y H. Schubart $(1980,264)$ lo fechan en época del Argar. 
A la vista de los datos pensamos que esta forma presenta una gran amplitud geográfica-cronológica, llegando incluso hasta los momentos finales del Bronce Pleno.

- Tipo V. Vaso geminado compuesto por dos recipientes de forma semielipsoide, borde ligeramente exvasado y base cóncava (Fig. 9).

Poseemos un solo ejemplar, lo que supone el 1'5\% de las piezas de esta clasificación. Los dos vasos tienen $8^{\prime} 5 \mathrm{~cm}$. de diámetro máximo y $7^{\prime} 5 \mathrm{~cm}$. de altura. En la unión de los dos vasos existe un aditamento, que puede interpretarse como un elemento de aprehensión. El tratamiento de las superficies es el alisado y la pasta es de mala calidad. En la actualidad se encuentra muy restaurado.

Los vasos geminados durante la Edad del Bronce son también frecuentes, aunque no abundantes, presentando una difusión geográfica bastante amplia. Ejemplares de ellos completos o fragmentos de los mismos se han hallado en Cabezo Redondo (SOLER, 1976, 44, fig. 2), Tossal Redó (BALLESTER, 1949, 110), Muntanya Assolada (MARTI, 1983 b, 53, fig. 6: 5), Cardosilla (FLETCHER-PLA, 1954, 101), Atalayuela (BALLESTER, 1949, 130), Sima la Higuera (DE PEDRO, 1981, 113, fig. 4: 15), Oropesa la Vella (GUSI-OLARIA, 1977, fig. 3), Castillo de Frías (ATRIAN, 1974, 21, fig. 27: b y lám. XIV: 1), Ereta del Castellar (ARNAL-PRADES-FLETCHER, 1968, lám. XIV: 8), ete.

En cuanto a su cronología, no presentan muchas precisiones. Según M. J. de Pedro $(1981,116)$ no indican una fase concreta de la Edad del Bronce. Nosotros, y en base a los ejemplos antes citados, pensamos que esta forma puede datarse dentro de la Edad del Bronce desde su fase más antigua hasta los momentos finales del Bronce Pleno.

\section{IV.1.2. Fragmentos cerámicos que no se pueden incluir claramente en la clasificación tipológica.}

Se han inventariado 5096 fragmentos cerámicos que no hemos podido individualizar en alguno de los tipos anteriores. De ellos 4659 corresponden a fragmentos atípicos. Hay un solo fragmento de base convexa. Los 438 restantes son fragmentos de borde; fragmentos de borde y cuello; fragmentos de borde y cuerpo, y fragmentos de borde, cuello y cuerpo. Relación y porcentajes:

Bordes exvasados ................. $272\left(62^{\prime} 80 \%\right)$

Bordes rectos.

Bordes entrantes

Bordes engrosados

Bordes vueltos

Bordes erosionados

Cuellos troncocónicos

Cuellos hiperbólicos ....

Cuellos troncocónicos invertidos

Cuellos cilíndricos

$95\left(21^{\prime} 80 \%\right)$

$35(8,00 \%)$

$32(7,30 \%)$

$2\left(0^{\prime} 46 \%\right)$

$1\left(0^{\prime} 20 \%\right)$

$22(50,00 \%)$

$16\left(36^{\prime} 60 \%\right)$

$4\left(9^{\prime} 00 \%\right)$

$2\left(4^{\prime} 50 \%\right)$
Labios curvos

Labios apuntados

Labios planos

Labios biselados

Labios erosionados

Cuerpos casq. esf...................

Cuerpos semiesféricos.

Cuerpos esféricos

Cuerpos elip. hor.

Cuerpos elip. vert.

Cuerpos semielip.

Cuerpos tronc. inv.

Cuerpos carenados $284\left(65^{\prime} 00 \%\right)$

$63(14,40 \%)$

$50(11,40 \%)$

$23(5,20 \%)$

$17\left(3^{\prime} 90 \%\right)$

$7\left(36^{\prime} 80 \%\right)$

$4\left(21^{\prime} 00 \%\right)$

$1(5,30 \%)$

$1(5,30 \%)$

$2\left(10^{\prime} 50 \%\right)$

$1(5,30 \%)$

$1(5,30 \%)$

$2\left(10^{\prime} 50 \%\right)$

Vasijas con la carena en la mitad superior y cuello ligeramente troncocónico semejantes a la de la Figura 10: dos se encuentran en Mas de Menente (PERICOT-PONSELL, 1929, láms. III-IV), Nivel II de Mola d'Agres (GIL-MASCARELL, 1981b, 85, 
fig. 7, y 86, fig. 8: 7) con materiales del Bronce Pleno y Sima la Higuera (DE PEDRO, 1981, 108, fig. 1: 5-6), entre otros. Según M. J. de Pedro (1981, 114-115) también se ha hallado en el Nivel II del Torrelló de Onda (1350 a. C.), en la Fase B de Oropesa la Vella (1500-1260 a. C.), en el Nivel Superficial de Mas d'Abad (1010 a. C.), en San Miguel de Liria con materiales de fines del Bronce Pleno, en la Motilla de Azuer datado en el Bronce Pleno (1500-1300/1200 a. C.), etc.

Todo ello obliga a fechar esta forma en el Bronce Pleno.

El otro fragmento de vasija con carena en el tercio inferior y cuello troncocónico invertido (Fig. 10: 3) tiene paralelos parecidos en Muntanya Assolada (MARTI, 1983b, 56, fig. 10: 1), San Miguel de Liria (GIL-MASCARELL, 1981a, 365, fig. 2: 3, y 368, fig. 5) y Cuesta del Negro (MOLINA-PAREJA, 1975, fig. 21: 36).

Según M. Gil-Mascarell (1981a, 366) también se encuentran desde el Nivel III al II de Mas d'Abad (1350-1200 a. C.). En Cuesta del Negro se halló en el Estrato II-Norte datado en el Argar B (MOLINA-PAREJA, 1975).

Nosotros, y en base a los paralelos y dataciones antes mencionados, pensamos como B. Martí (1983b, 62) que estas vasijas corresponden a los momentos finales del Bronce Pleno, aunque no descartamos la posibilidad de que también puedan pertenecer al Bronce Tardío, si tenemos en cuenta la semejanza con algunos perfiles de la Isleta de Campello (GIL-MASCARELL, 1981c, 13, fig. 1: 1).

\section{IV.1.3. Elementos de aprehensión}

Los elementos de aprehensión hallados en Mola Alta de Serelles son los característicos de la Edad del Bronce: mamelones, asas de lengüeta y asas de cinta.

- Mamelones.

Se han inventariado 99 piezas que poseen mamelones, lo cual representa el $86^{\prime} 4 \%$ de todas las que tienen elementos de aprehensión, siendo éste el tipo más común del yacimiento. Son característicos los cuencos de casquete esférico con un solo mamelón colocado siempre en su tercio superior. Los podemos encontrar en varias posiciones:

- Mamelones situados bajo el borde o en el cuello.

Existen 45 ejemplares que suponen el $45^{\prime} 4 \%$ de todos los que tienen mamelones. Es la posición más común en la que se hallan éstos. De entre todos destacamos por su singularidad un fragmento de borde con dos mamelones juntos (Fig. 11: 1).

- Mamelones situados justo debajo del borde.

Hemos contabilizado un total de 29 piezas que representan el 29'2 \% de todas las que poseen mamelones, siendo por tanto también una posición bastante frecuente.

- Mamelones que nacen en el mismo borde.

De éstos sólo hemos hallado tres ejemplares, que forman el $3 \%$ de todos los que presentan mamelones.

- Asas de lengüeta.

Hay 13 piezas que poseen asas de lengüeta, lo cual supone el 11 ' $4 \%$ de todas las piezas que tienen elementos de aprehensión. Siempre se encuentran colocadas a mitad altura o en algún punto del tercio superior de la vasija, pero nunca nacen del mismo borde. Mención especial merece el hallazgo de una vasija de tendencia esférica que presenta un asa de lengüeta perforada a mitad altura, la cual debe interpretarse como un elemento de suspensión más que de aprehensión (Fig. 10: 1).

- Asas de cinta.

Hemos inventariado sólo dos que representan un porcentaje bajísimo (1'75\%) respecto a las piezas con elementos de aprehensión. En la actualidad se conservan sin estar unidas a la superficie de la vasija; por tanto,no conocemos su posición. 

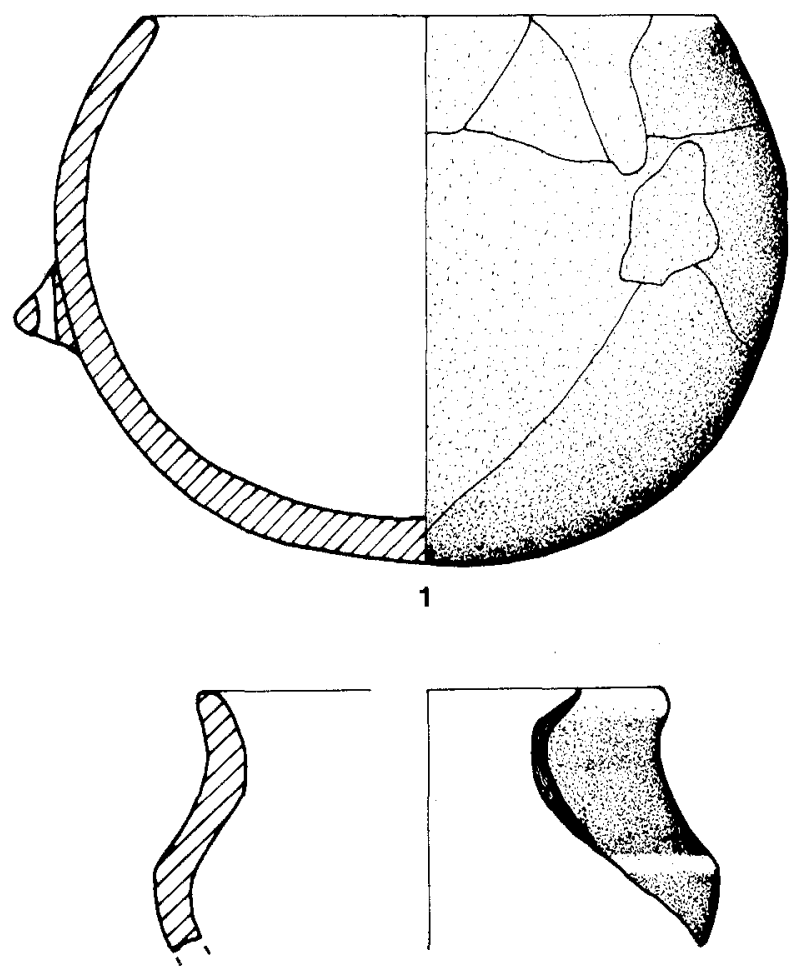

2
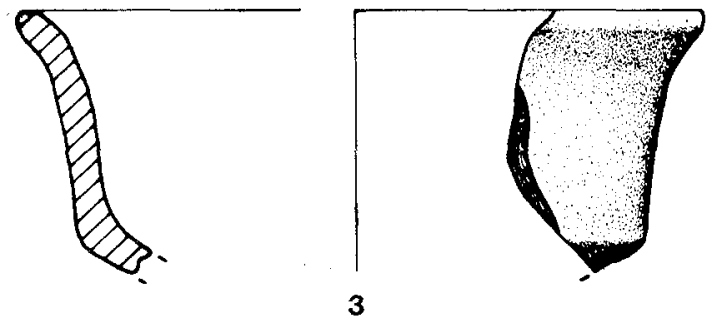

Figura 10.

\section{IV.1.4. Decoración}

Unicamente existen 10 fragmentos cerámicos, todos atípicos, con decoración, cifra muy pequeña comparada con la del total de cerámica inventariada (5170 piezas). Hemos distinguido dos tipos de decoración:

- Cordones.

Hay 9 fragmentos de cerámica con cordones aplicados (Fig. 11:2-6). De ellos sólo uno es liso y los restantes presentan ungulaciones realizadas mediante la técnica de la impresión. En algún caso hemos observado cómo éstos arrancan de un asa de lengüeta, formando un ángulo recto (Fig. 11: 5).

Cordones lisos y decorados con ungulaciones o digitaciones son corrientes en la mayoría de las estaciones de la Edad del Bronce, con una difusión cronológica muy amplia. Paralelos para este tipo de decoración los encontramos en los yacimientos de Cova 
la Boira, Serra Grossa, Castellar de Morera (LLOBREGAT, 1969, 62), Muntanyeta de Cabrera (FLETCHER-PLA, 1956, láms. X y XI: A), Torrelló de Onda (GUSI, 1974, 22), etc.

\section{- Puntillado.}

Existe un fragmento de cerámica atípico con una decoración puntillada realizado mediante la técnica de la impresión, formando una línea ligeramente recta (Fig. 11: 7).

Este tipo de decoración tiene una cronología poco precisa. Durante el Bronce Pleno hay pocos ejemplos, entre los cuales destacan los de Alt de Paella, Mola d'Agres,
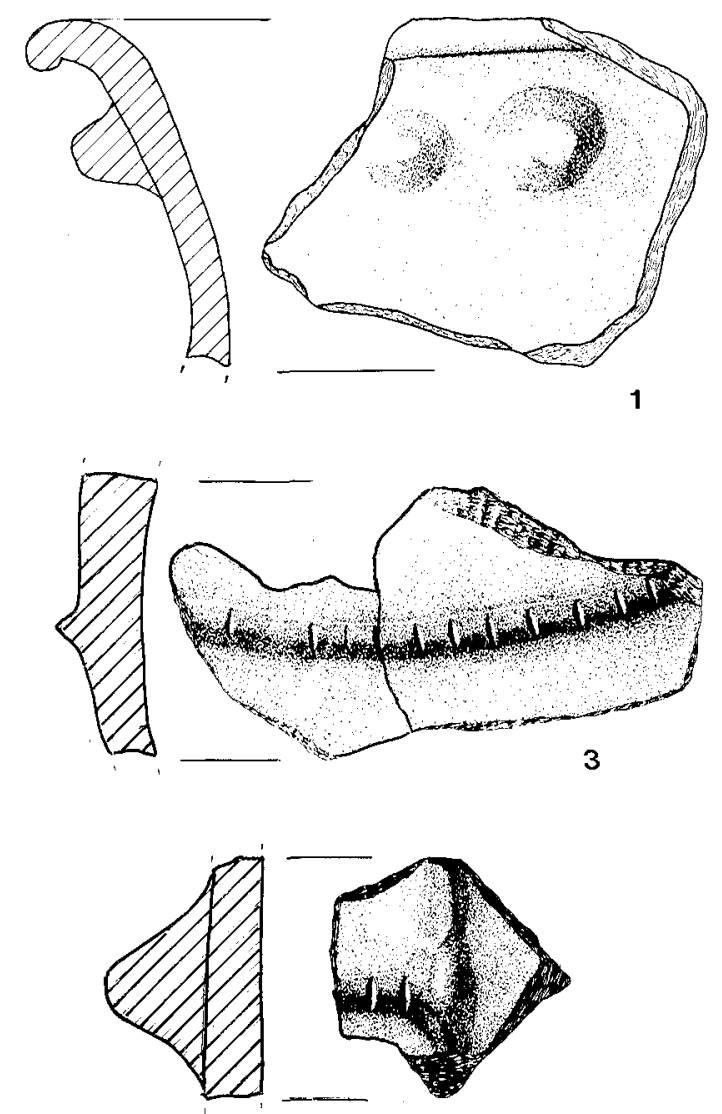

5

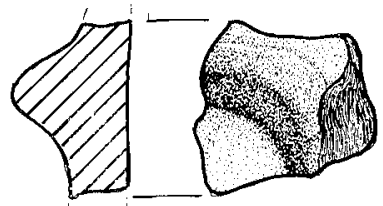

6
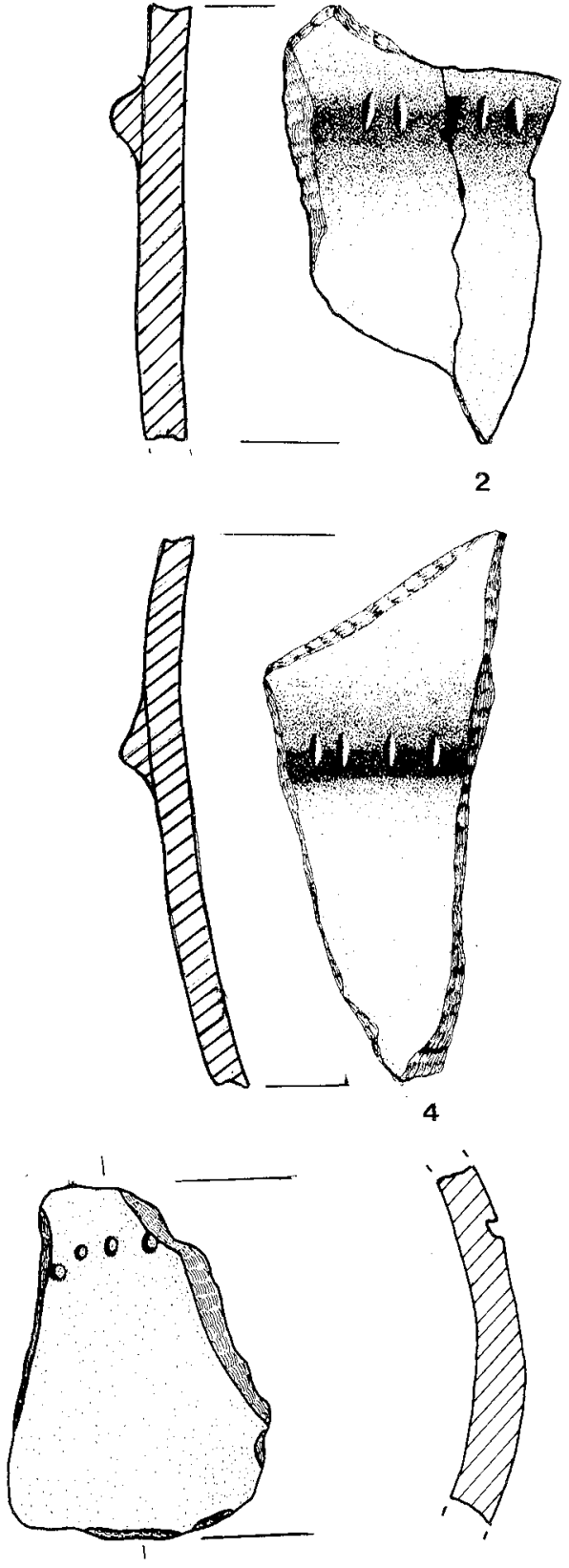

Figura 11.-Segura procedencia del poblado: 2-7. 
Cabezo Redondo (CERDA, 1983, 280-281), Muntanya Assolada (MARTI, 1983b, 55, fig. 8: 2-6) y Puntal de Cambra (ALCACER, 1954, 81, lám. IV: a), habiendo en estos poblados otro nivel más antiguo, en ocasiones poco diferenciado.

\section{IV.1.5. Tratamiento de las superficies, tipos de pasta y coloración}

Respecto al tratamiento de las superficies, domina el alisado y el espatulado, seguido de las superficies sin tratar y las erosionadas, las cuales presentan abundantes porosidades y concreciones calizas. Son muy pocas las piezas inventariadas que tienen las superficies bruñidas, siendo su pasta, por regla general, de buena calidad.

El tipo de pasta más frecuente es aquel en que ésta está poco levigada, con abundantes desgrasantes calizos, en ocasiones muy gruesos. Existe otra clase de textura compacta con desgrasantes apenas visibles.

En cuanto a la coloración, dominan los tonos rojizos, anaranjados, amarillentos, pardos y negruzcos. Hay muchas piezas de factura quebradiza con diferentes tonalidades, producto, entre otras causas, de una cocción deficiente.

Como E. Botella $(1926,8)$, hemos observado la existencia de dos tipos de cerámica: uno con superficies alisadas o bruñidas, pasta de buena calidad y excelente cochura; y otro de factura grosera, con abundantes desgrasantes calizos muy gruesos y mala cocción. Según Botella, el primer tipo es característico de la cueva y el segundo del poblado.

\section{IV.2. Industria lítica (4)}

Se han inventariado 178 objetos de piedra, de los cuales 166 están fabricados sobre sílex, 4 sobre arenisca y 8 sobre diversas piedras de origen volcánico y granítico.

\section{IV.2.1. Silex}

De los 166 objetos de sílex hemos podido distinguir: piezas retocadas, piezas con señales de uso y piezas sin retoque. Generalmente tienen unas tonalidades marrones, meladas, negruzcas, etc.

\section{IV.2.1.1. Clasificación tipológica}

Se ha realizado sobre el total de las piezas retocadas (111), las cuales representan el $67 \%$ de todos los objetos de sílex. Hemos establecido los siguientes tipos:

- Dientes de hoz.

Existen 107 dientes de hoz, que suponen el $96 \%$ de las piezas retocadas. De ellos 35 (36 \%) están fabricados sobre lascas o fragmentos de lascas, $26(24 \%)$ sobre láminas o fragmentos de láminas y $42(39 \%)$ sobre lascas o láminas. En cuanto a las características del retoque, desde el punto de vista de la dirección, $74(69 \%)$ lo presentan bifacial, 15 $(14 \%)$ directo y $18(17 \%)$ inverso; por lo que respecta al modo hay 96 que tienen el mismo retoque en las dos caras y de ellos $28(29 \%)$ lo poseen abrupto, $67(70 \%)$ oblicuo y 1 ( $1 \%$ ) plano; los restantes tienen un retoque diferente en las dos caras y de éstos $11(50 \%)$ son abruptos, $9(41 \%)$ oblicuos y $2(9 \%)$ planos; en lo que se refiere a su delineación, 97 $(91 \%)$ presentan retoque continuo y $10(9 \%)$ discontinuo.

Sólo $57(53 \%$ ) guardan la superficie del filo brillante por el lustre de los cereales y 36 $(34 \%)$ poseen un retoque abrupto en el dorso para poder ser ensartados con mayor facili-

(4) Los moldes de fundición los estudiamos en el capítulo referente a la metalurgia. 

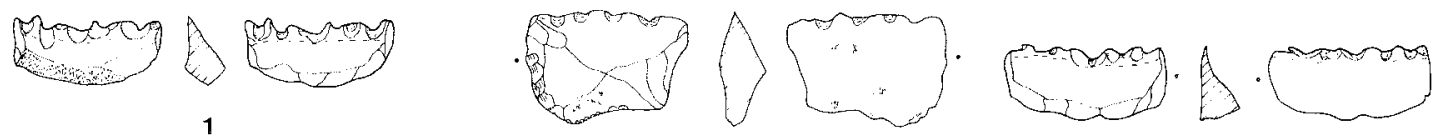

2

3

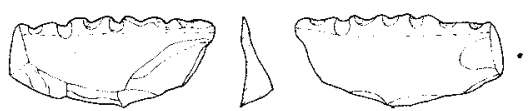

4
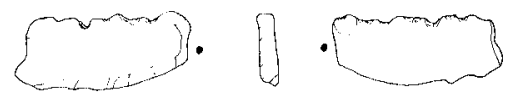

7
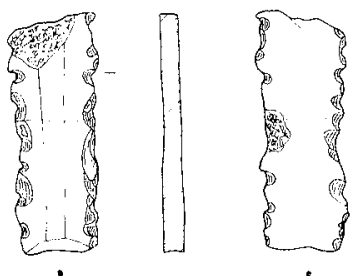

10

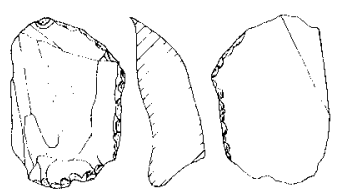

13
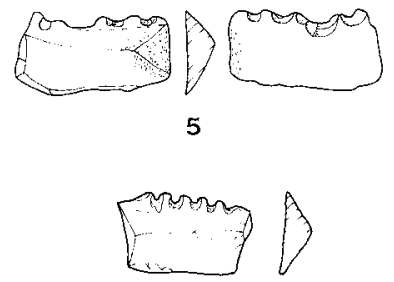

8

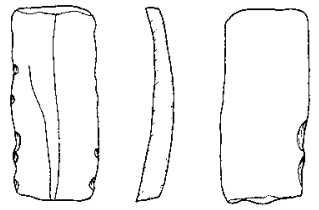

11

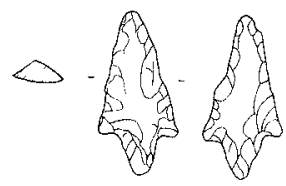

14

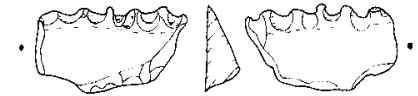

6

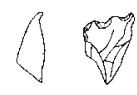

9
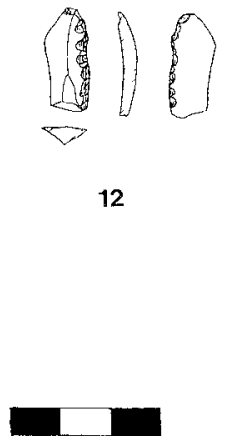

Figura 12.-Segura procedencia de la cueva: 14.

dad en un mango de madera. Algunos conservan huellas provocadas por la acción del fuego.

Generalmente su sección es trapezoidal o triangular y sus dimensiones varían entre 8 $\mathrm{mm}$. y $38 \mathrm{~mm}$. de longitud en el filo, aunque los más comunes tienen de $10 \mathrm{~mm}$. a $25 \mathrm{~mm}$.; entre $10 \mathrm{~mm}$. y $20 \mathrm{~mm}$. de amplitud, aunque alguno mide $38 \mathrm{~mm}$.; y entre $2 \mathrm{~mm}$. y $10 \mathrm{~mm}$. de grosor máximo, aunque hay un ejemplar de 1 '5 mm. y otro de $15 \mathrm{~mm}$.

Existen 2 variantes:

- Dientes de hoz con un solo filo (Fig. 12: 1-9).

- Diente de hoz con doble filo. Hay un ejemplar (Fig. 12: 10).

Dientes de hoz se encuentran prácticamente en la totalidad de los yacimientos de esta época y son el «fósil director de la Edad del Bronce Valenciano» (APARICIO, 1976, 154).

De todos resulta más interesante el que tiene doble filo por ser menos frecuente. Semejantes a éste se han hallado en los poblados vecinos del Altet del Canalís, Mas del Corral y Ull del Moro, y en otras estaciones de la Edad del Bronce como Terlinques (SOLER-FERNANDEZ, 1970, 50, fig. 19, y 52, fig. 21), Muntanyeta de Cabrera (FLETCHER-PLA, 1956, lám. XII: C) o Sima la Higuera (LERMA, 1977, 68, fig. 3: 1), entre otras. También son frecuentes en poblados típicamente argáricos como Lugarico Viejo o Ifre (SIRET, 1890, fig. 38 y láms. 16-183: o). 
Dientes de hoz aparecen ya en algunos yacimientos pertenecientes al «Horizonte de Transición», siendo corrientes durante toda la Edad del Bronce. R. Enguix (1980, 169170) observó una evolución de los fabricados sobre cuchillos característicos del Bronce Antiguo a los que tienen un perfil en «D» típicos del Bronce Pleno. La mayoría de los de Mola Alta de Serelles pertenecen a este segundo tipo.

- Láminas y pequeñas láminas retocadas.

Poseemos dos ejemplares que suponen el $2 \%$ del total de las piezas de sílex retocadas. Una tiene retoque abrupto y alternante (Fig. 12: 11); la otra presenta una truncadura con retoque directo y abrupto, y retoque bifacial y abrupto en el borde derecho (Fig. 12: 12).

- Lasca retocada.

Se conserva una sola pieza que representa un porcentaje bajísimo $(1 \%)$ respecto a las piezas de sílex retocadas. Presenta retoque bifacial y abrupto en el borde derecho y en los dos extremos, y dos posibles golpes de buril (Fig. 12: 13).

Los hallazgos tanto de láminas de reducido tamaño similares a las de Mola Alta de Serelles, como lascas retocadas, son característicos de la Edad del Bronce, si bien no se encuentran en grandes cantidades, presentando una gran difusión geográficocronológica.

- Punta de flecha.

Sólo existe una de forma triangular con pedúnculo y tiene retoque bifacial, plano y cubriente (Fig. 12: 14). Como la lasca retocada, supone un porcentaje bajísimo con respecto al total de las piezas de sílex retocadas.

Este útil no es típico de esta época, aunque nosotros hemos inventariado 19 yacimientos del Bronce Valenciano, donde existen puntas de flecha. Los ejemplares más parecidos al de Mola Alta de Serelles son el de La Torreta (BALLESTER, 1949, 136 y lám. XXXIV) y el de Muntanya Assolada (MARTI, 1983b, 58, fig. 11).

Las puntas de flecha de sílex son características del Eneolítico. También aparecen, pero en menor cantidad, en yacimientos del «Horizonte de Transición»: Sima la Pedrera (APARICIO, 1978, 80) o Casa Paus (NAVARRO, 1982, 80), y en otros de la Edad del Bronce, alguno de ellos como Terlinques con una fecha absoluta muy alta (1850 a. C.) (SOLER-FERNANDEZ, 1970, 59-61), siendo una pervivencia del período anterior.

\section{IV.2.1.2 Piezas con señales de uso y sin retoque}

En lo referente a las piezas de sílex con señales de uso, se han inventariado un total de 17, que forman el $10 \%$ de la industria de sílex. De ellas 15 son lascas o fragmentos de lascas y las dos restantes son una lámina y un fragmento de lámina.

En cuanto a las piezas de sílex sin retoque, se han contabilizado 38 , o sea el $23 \%$ de las piezas de sílex. Como las que tienen señales de uso, la mayor parte (30) son lascas o fragmentos de lascas y las restantes láminas o fragmentos de láminas.

\section{IV.2.2. Arenisca}

Sólo hay 4 objetos realizados sobre piedra arenisca de grano fino. De ellos 3 se conservan enteros y son brazaletes de arquero de forma paralelepípeda con las aristas romas, que tienen dos perforaciones bicónicas en el centro de sus dos extremos menores. Su color es marrón y miden entre $49 \mathrm{~mm}$. y $57 \mathrm{~mm}$. de longitud, entre $20 \mathrm{~mm}$. y $23 \mathrm{~mm}$. de amplitud y entre $6 \mathrm{~mm}$. y $8 \mathrm{~mm}$. de grosor. El diámetro de sus perforaciones va de $4 \mathrm{~mm}$. a 5'5 mm. Pertenecen al Tipo I de E. Sangmeister $(1964,102)$ (Fig. 13: 1-2).

También existe un fragmento de un posible brazalete de arquero o elemento de adorno de forma similar a los anteriores, aunque con una doble perforación bicónica en su extremo menor (Fig. 13: 3). 


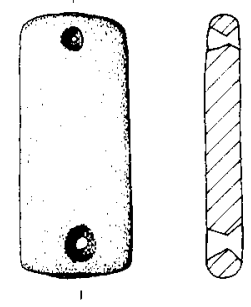

1
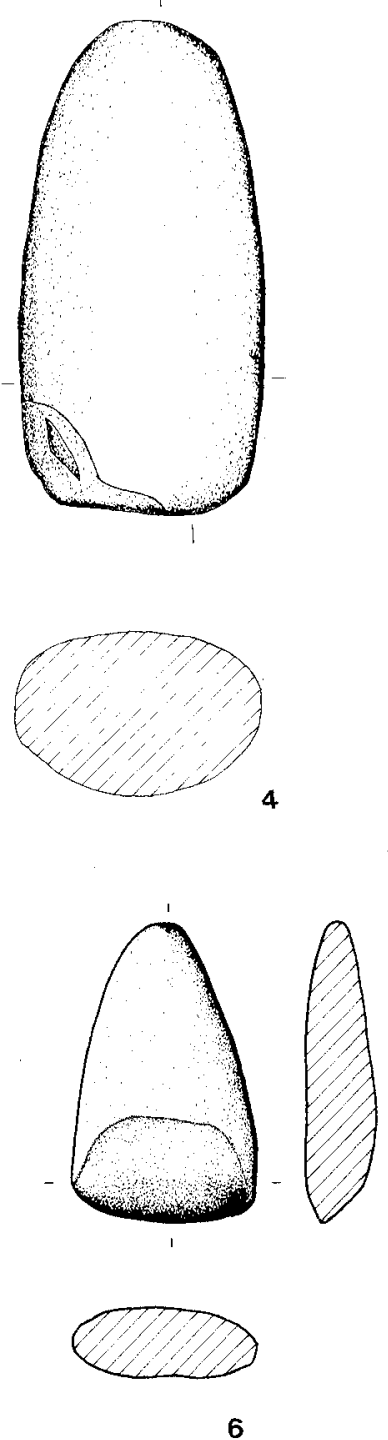
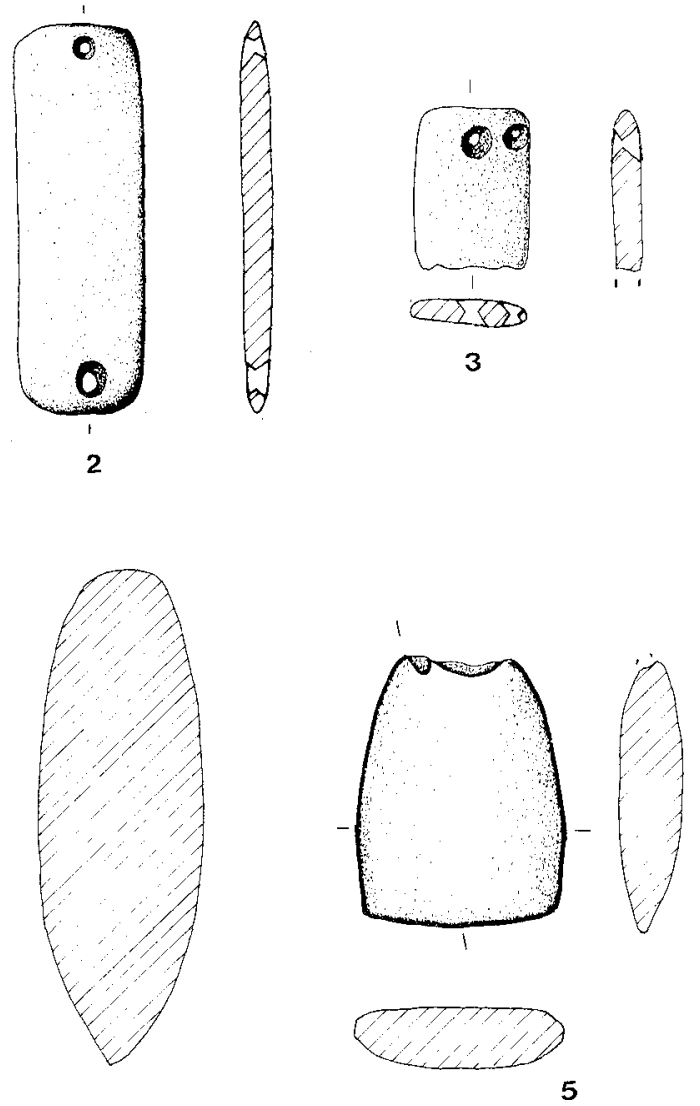

5
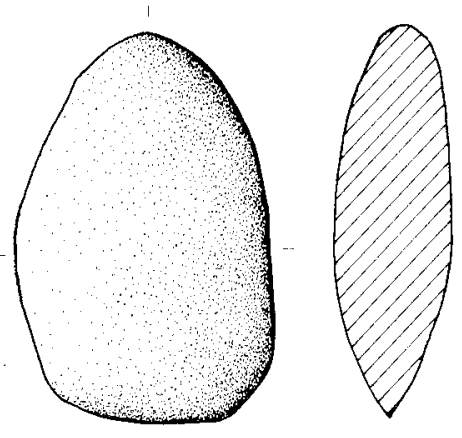

7

Figura 13.--Segura procedencia del poblado. 
Brazaletes de arquero con una perforación en cada extremo se han hallado en Mas de Menente (PERICOT-PONSELL, 1929, 104), Terlinques (SOLER-FERNANDEZ, 1970, 54, fig. 23), Cau de les Raboses (LLOBREGAT, 1971, 63, fig. 3: 6), Altico de Hoya (ALCACER, 1960, 105 y lám. II: 9) y otras estaciones también pertenecientes a la Edad del Bronce.

El fragmento de brazalete de arquero con dos perforaciones en un extremo menor tiene sus paralelos más similares en Altet del Canalís, Muntanyeta de Cabrera (FLETCHER-PLA, 1956, 46 y lám. XIII) y Castillo de Frías (ATRIAN, 1974, fig. 17: f y lám. XXIII).

Los brazaletes de arquero cronológicamente aparecen ya en el «Horizonte de Transición», aunque los ejemplares de forma rectangular con dos o cuatro perforaciones como los de Mola Alta de Serelles parecen ser característicos de la Edad del Bronce.

\section{IV.2.3. Piedra pulida}

Son una serie de útiles realizados mediante el pulimento de piedras de origen volcánico: biabasa, diorita, etc., y de origen granítico.

La mayor parte se conservan enteros, aunque muchos están bastante erosionados. Tienen generalmente una tonalidad verdosa, grisácea o amarillenta.

\section{IV.2.3.1. Clasificación tipológica}

Esta se ha realizado en base a los 6 objetos enteros, estableciendo 2 tipos:

- Hachas.

Hemos inventariado 5. Se caracterizan por tener el filo de tendencia simétrica. Miden de $49 \mathrm{~mm}$. a $91 \mathrm{~mm}$. de longitud, de $34 \mathrm{~mm}$. a $46 \mathrm{~mm}$. de amplitud y de $9 \mathrm{~mm}$. a 30 $\mathrm{mm}$. de grosor. Hemos distinguido 3 variantes:

- Hacha de forma trapezoidal con el filo rectilíneo (Fig. 13: 4).

- Hacha de forma triangular con el filo curvilíneo (Fig. 13: 5).

- Hacha de forma triangular con el filo rectilíneo (Fig. 13: 7).

Hachas de forma trapezoidal o triangular, aunque parecen ser más comunes las trapezoidales de sección oval, se encuentran en la mayoría de los yacimientos de la Edad del Bronce con una cronología poco precisa.

- Azuela.

Se caracteriza por tener el filo totalmente asimétrico. Existe un solo ejemplar de forma triangular y filo curvilíneo. Mide $55 \mathrm{~mm}$. de longitud, $34 \mathrm{~mm}$. de amplitud y 12'5 mm. de grosor (Fig. 13: 6).

Al igual que las hachas, es también un útil muy frecuente en esta época, por lo que presenta una gran amplitud geográfico-cronológica.

También se han inventariado dos fragmentos de útiles de piedra pulida que no hemos podido incluir en la clasificación tipológica: uno es un fragmento de hacha con forma de tendencia trapezoidal y filo de tendencia curvilínea y simétrica; el otro es un fragmento de hacha-azuela con forma de tendencia trapezoidal.

\section{IV.2.4. Objetos de piedra desaparecidos}

Por último, citamos varios útiles de piedra que no se conservan en ninguna de las dos colecciones estudiadas: "diversos objetos de sílex como flechas, uñas de trabajo, cuchillos y sierras-cuchillos» hallados en la capa inferior del castro (BOTELLA, 1926, lám. VII: B 1-15); cantos rodados, varios pulidores y un percutor procedentes de la cueva (BOTELLA, 1926, lám. XIII: B); molinos también aparecidos en la cueva (BOTELLA, 1926, lám. XIII: C); «una pieza con varias incisiones en su borde a modo de dibu- 
jo» (BOTELLA, 1926, lám. VI: B); varios molinos y posiblemente un mortero del poblado (BOTELLA, 1928, lám. IX: B); y varios percutores y un pulidor también procedentes del poblado (BOTELLA, 1928, lám. X).

De todos quizás la pieza más interesante es en primer lugar el posible mortero por ser un hallazgo menos frecuente durante la Edad del Bronce. De serlo tendría sus paralelos más próximos en Mas del Corral y en El Murón (NAVARRO, 1982, 36).

En segundo lugar, los cuchillos de sílex hallados en la capa inferior del castro, de los que ejemplares similares han aparecido en Ull del Moro, Mas de Menente (PERICOT-PONSELL, 1929, 106, fig. 6), Tossal Redó (TARRADELL, 1958, lám. IV: 8-11-12) y Puntal dels Moros (PITARCH, 1969, 82), entre otros. Estos son útiles característicos del Eneolítico, aunque también existen en yacimientos del Bronce Antiguo (ENGUIX, 1980, 169).

$Y$ en tercer lugar, la piedra con incisiones en su borde por su singularidad, ya que resulta difícil encontrar ejemplos semejantes a la misma. En los poblados argáricos de Fuente Alamo y El Oficio (SIRET, 1890, 242-246, 257-259 y figs. 87-88) se hallaron unas piedras con unas ranuras alargadas, que H. y L. Siret interpretaron como goznes de puertas. Estas son quizás las piezas más parecidas a la de Mola Alta de Serelles.

Por lo que respecta a los molinos, percutores, alisadores, cantos rodados, etc., son objetos que se dan en épocas anteriores, al igual que en la Edad del Bronce, con una gran amplitud cronológica-geográfica.

\section{IV.3. Metalurgia}

Bajo este epígrafe englobamos tanto los útiles de metal como los moldes de fundición con los que se realiza su fabricación.

\section{IV.3.1. Utiles de metal}

Sólo existen 4: una posible punta de Palmela con la hoja de tendencia ovalada, un fragmento de punzón de sección cuadrada, una lámina informe y una escoria de fundición (Fig. 14).
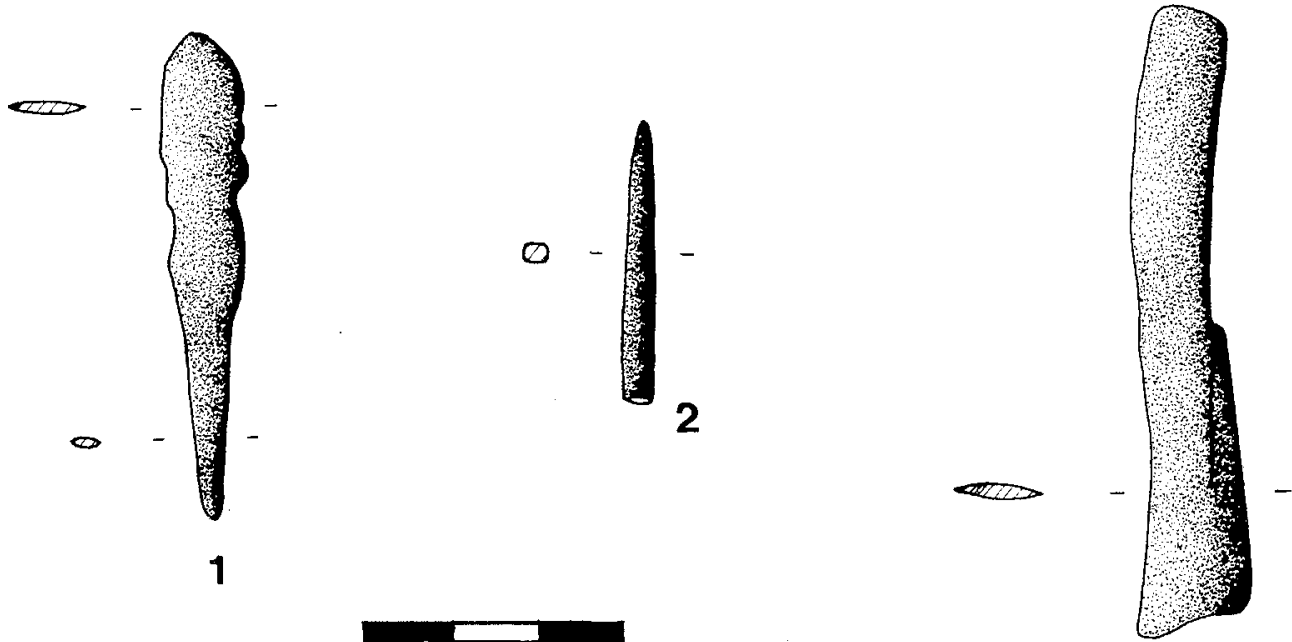

3

Figura 14.-Segura procedencia del poblado: 1 y 3 . En la ladera y en superficie: 2 . 
Según los análisis espectrográficos realizados por B. Blance $(1959,166-169$ y fig. 3: 10) sobre una muestra recogida de la lámina informe, la materia prima que se utilizó fue cobre $\left(98^{\prime} 92 \%\right.$ ) junto con arsénico $\left(0^{\prime} 56 \%\right)$, estaño $\left(0^{\prime} 16 \%\right)$, plata $\left(0^{\prime} 13 \%\right)$, plomo $\left(0^{\prime} 12 \%\right)$ y níquel $\left(0^{\prime} 11 \%\right)$.

De ellos los únicos que se pueden estudiar son la posible punta de Palmela y el fragmento de punzón, de los cuales el estado de conservación dificulta el conocimiento exacto de su tipología. De todas formas son útiles bastante frecuentes en la Edad del Bronce, como lo demuestran los inventarios de J. Aparicio (1976, fig. 11) referente a yacimientos de la Cultura del Bronce Valenciano y de M. S. Hernández (1983a, 36) sobre yacimientos del Valle Medio del Vinalopó en concreto, donde se han contabilizado alrededor de 15 puntas de Palmela y otros tantos punzones por lo menos, la mayoría de sección cuadrada.

En cuanto a su cronología, ninguno de estos útiles presenta gran precisión. Así pues, las puntas de Palmela aparecen en el «Horizonte de Transición» y perduran ocasionalmente incluso hasta en niveles ibéricos (HERNANDEZ, 1983a, 34). Por otro lado, los punzones están atestiguados ya desde el Eneolítico Pleno (LERMA, 1981, 123) y son comunes en todas las fases de la Edad del Bronce.

\section{IV.3.2. Moldes de fundición}

En este yacimiento se encontraron 9 moldes de fundición, siendo ésta la colección más numerosa de moldes hallada en la Cultura del Bronce Valenciano hasta la actualidad.

Están fabricados con piedra arenisca de grano fino y como características comunes podemos señalar: estar formados por dos piezas (bivalvos), su forma prismática o paralelepípeda y tener una de las caras completamente lisa.

\section{IV.3.2.1. Clasificación tipológica}

Se han inventariado seis ejemplares enteros. Hemos establecido dos tipos: - Moldes.

Sólo existen cuatro. En la totalidad de los casos la impronta arranca del mismo borde. La mayoría de ellos se utilizarían para fundir más de un útil. Miden entre $81 \mathrm{~mm}$. y $200 \mathrm{~mm}$. de longitud, entre $85 \mathrm{~mm}$. y $130 \mathrm{~mm}$. de amplitud y entre $31 \mathrm{~mm}$. y $77 \mathrm{~mm}$. de grosor. Hemos distinguido 3 variantes:

- Molde para la fusión de un solo objeto. Hemos inventariado un único ejemplar que se utilizaría para fundir varillas (Fig. 15: 1).

- Molde para la fusión de dos objetos. Existen 2, los cuales servirían para fabricar barras, barritas y hachas de los Tipos II y III de B. Blance (Fig. 15: 2 y Fig. 16).

- Molde para la fusión de tres objetos. Se ha contabilizado un solo ejemplar, con el que se fundirían por una cara barras y por la otra dos hachas del Tipo II de B. Blance (Fig. 18).

Desconocemos la existencia de moldes para fundir tres objetos. En cambio sí contamos con dos moldes para fundir dos piezas: uno el de El Gargao (APARICIO, 1976, 261, fig. 15: H) que serviría para fabricar dos puntas de Palmela; y el otro el de la Mina de Riner (SERRA, 1923, 535-536, figs. 202-206), muy parecido al de la Figura 16 de Mola Alta de Serelles, el cual también serviría para fundir un solo objeto.

En cuanto al tipo de útiles que se desea fundir, vemos cómo también cuentan con multitud de paralelos sobre todo en la Cultura del Bronce Valenciano y en la Cultura de $\mathrm{El}$ Argar. Ejemplos de moldes para fundir varillas se han hallado en Ull del Moro y El 

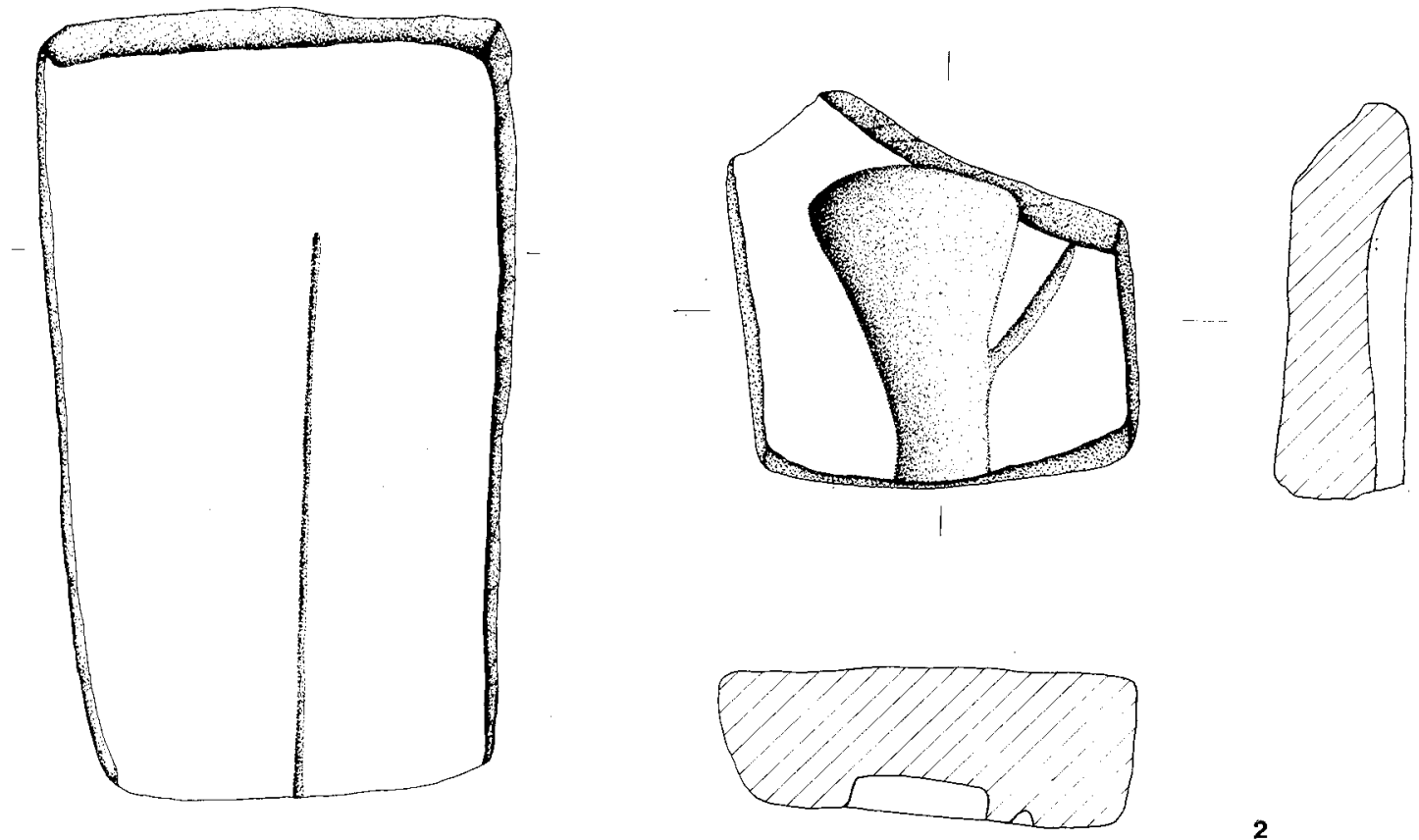

2

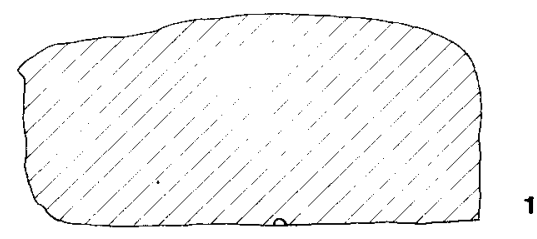

Figura 15.-Segura procedencia del poblado.

Murón (cita oral de M. S. Hernández); moldes para fundir barras y barritas existen, entre otros yacimientos, en la Mina de Riner, ya mencionada anteriormente, Mas del Corral, La Pedrera (NAVARRO, 1982, 39, fig. 10: e) y Fuente Alamo (ARTEAGASCHUBART, 1980, 266, fig. 12: 1); y por último se han encontrado moldes para fundir hachas, aparte de la Mina de Riner, en Castell d'Almanzor (APARICIO, 1976, 156), El Oficio (SIRET, 1890, 242-246), Cuesta del Negro (MOLINA-PAREJA, 1975, 53-56, figs. 48-51) y otros más.

En lo referente a su cronología, todos estos moldes al ser bivalvos, no son anteriores a la Edad del Bronce, aunque no ofrecen grandes precisiones cronológicas, salvo los de fundir hachas de los Tipos II y III de Blance datables en el Argar B (1600-1200 a. C.) (BLANCE, 1971, 153).

- Tapaderas.

Existen únicamente 2. De ninguna tenemos la certeza absoluta de que correspondan a algún molde antes mencionado.

Una tiene forma prismática, presenta una huella en forma de hacha provocada por la acción de la fusión del metal y mide 198'5 mm. de longitud, 113'5 mm. de amplitud y 

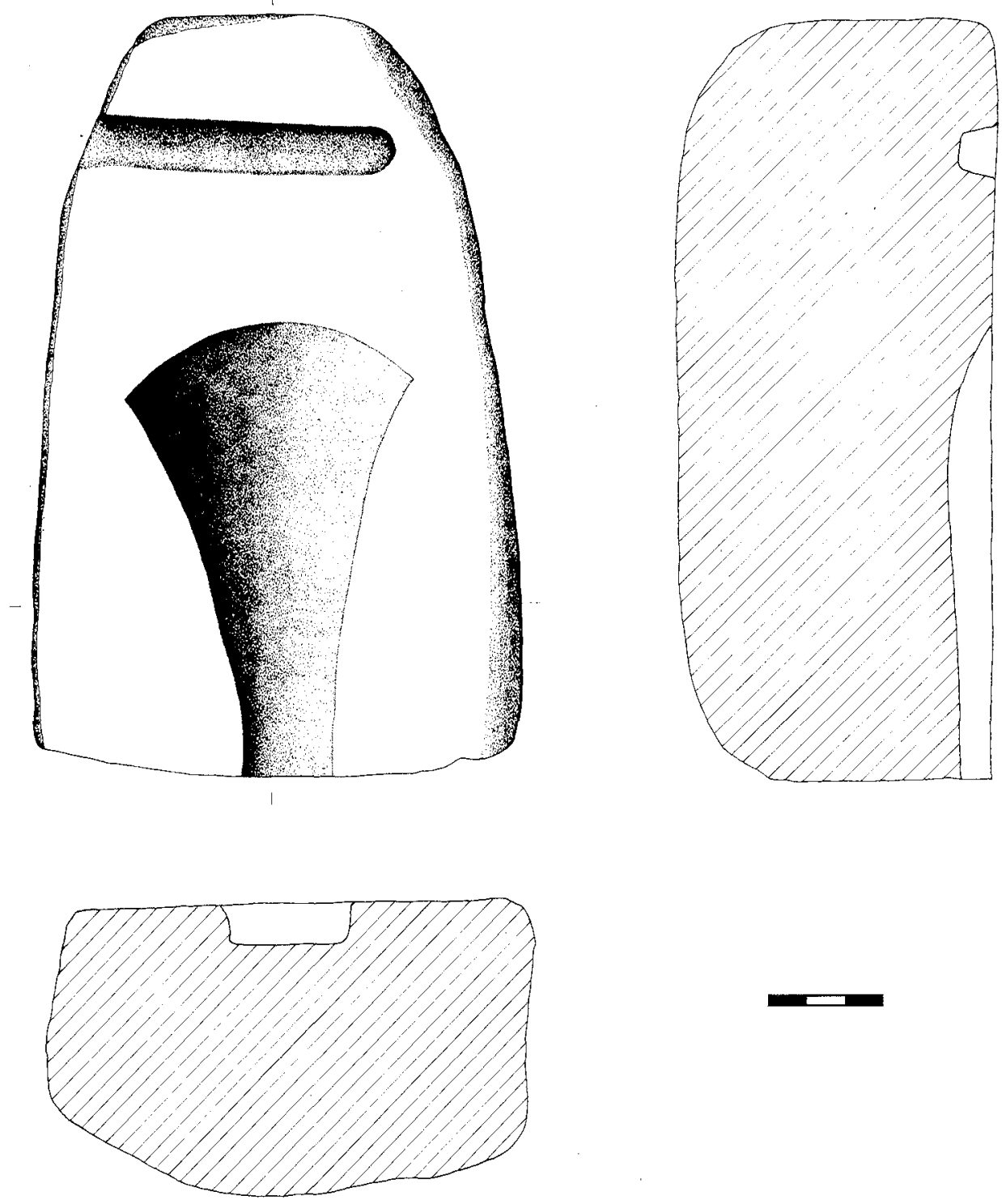

Figura 16.-Segura procedencia del poblado.

$62 \mathrm{~mm}$. de grosor (posiblemente pertenezca al molde de la Figura 16) (Fig. 17). La otra también tiene forma prismática y sus dimensiones son: $168 \mathrm{~mm}$. de longitud, $105 \mathrm{~mm}$. de amplitud y $52 \mathrm{~mm}$. de grosor (posiblemente sea la tapadera del molde para fabricar varillas).

Los hallazgos de tapaderas son menos frecuentes que el de los moldes propiamente dichos. Así podríamos citar, aparte de los de Mola Alta de Serelles, dos en la Mina de Riner (SERRA, 1923, 535-536, figs. 202-206), de las cuales una presenta dos escapes de fusión en forma de barras; dos en Cuesta del Negro (MOLINA-PAREJA, 1975, 53-56, figs. 48-51) y algunas más.

Por último, sólo destacar que presentan la misma cronología que su posible par. 

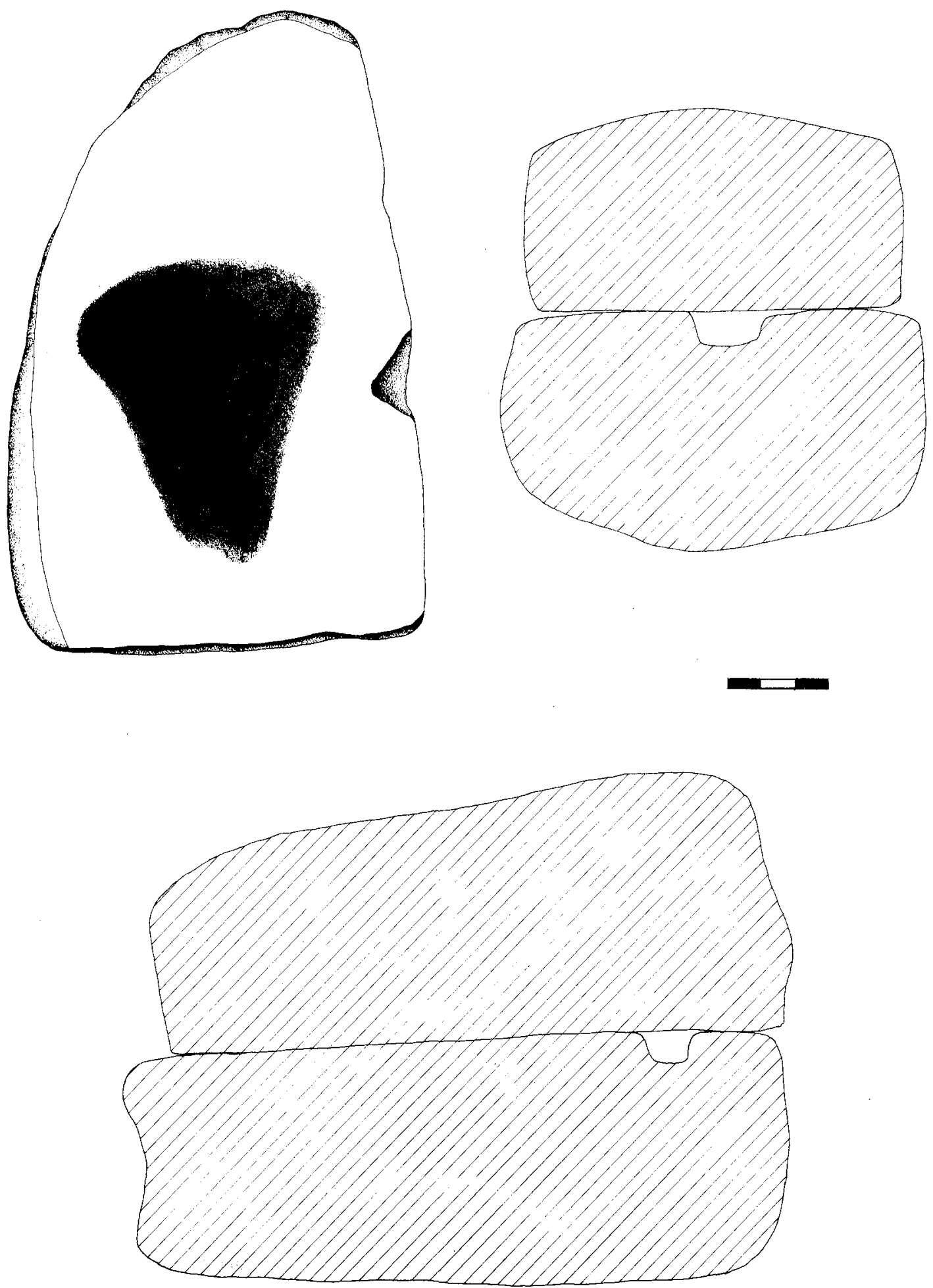

Figura 17.- Tapadera de un molde de fundición y dos vistas de la misma (frontal y lateral) con su posible molde. Segura procedencia del poblado. 

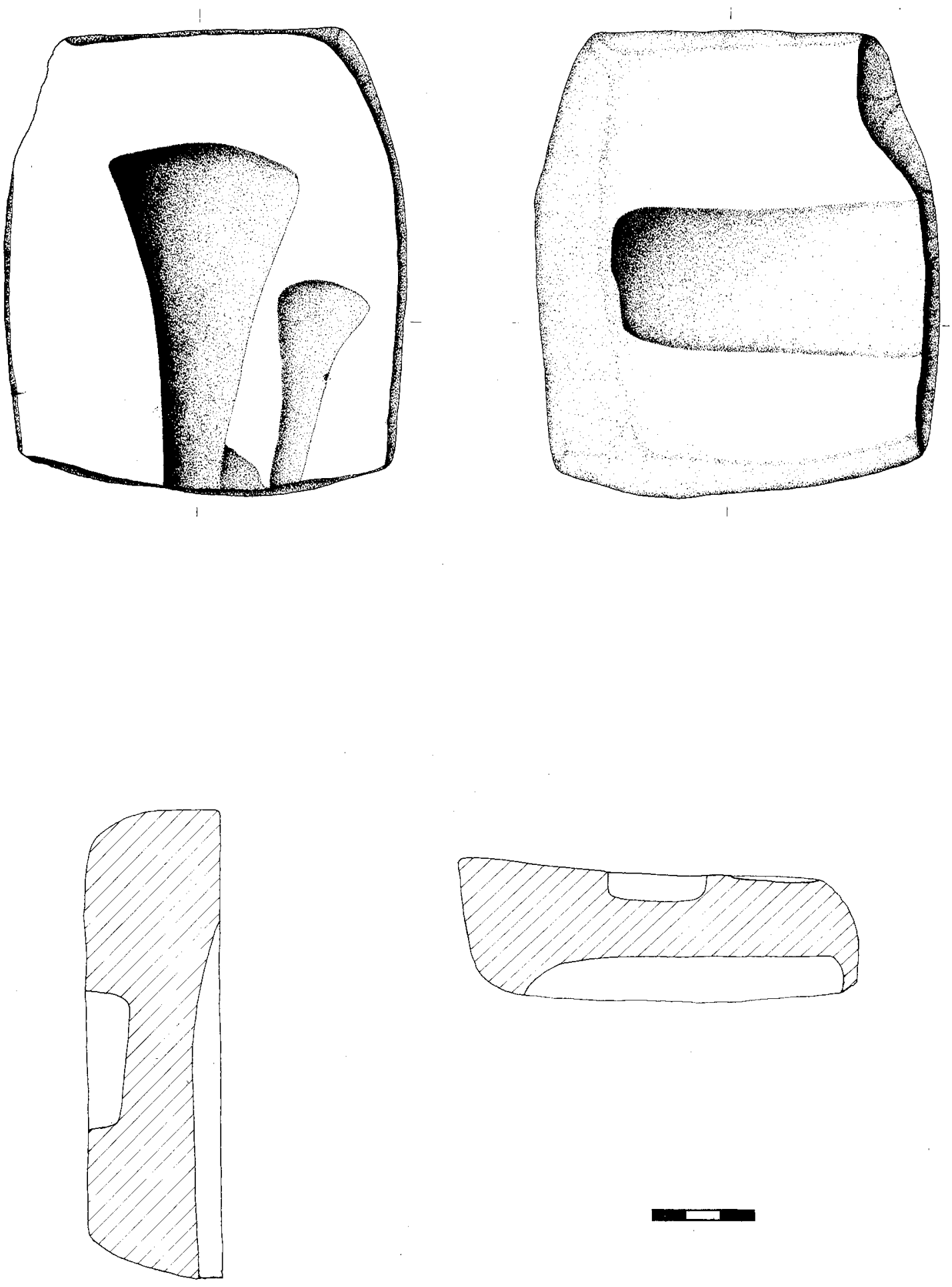

Figura 18.- Segura procedencia del poblado. 
IV.3.2.2. Fragmentos de moldes de fundición que no se pueden incluir claramente en la clasificación tipológica

En lo que concierne a las piezas fragmentadas, se han inventariado tres ejemplares. De ellos, dos son moldes de forma prismática, de los cuales uno serviría para fabricar hachas (Fig. 19: 1) y el otro posiblemente puñales o alabardas (Fig. 19: 2); el fragmento restante pertenece a una tapadera de forma paralelepípeda, que presenta la huella provocada por la acción de la fusión del metal, la cual tiene la forma de la parte proximal y medial de un hacha (Fig. 19: 3).
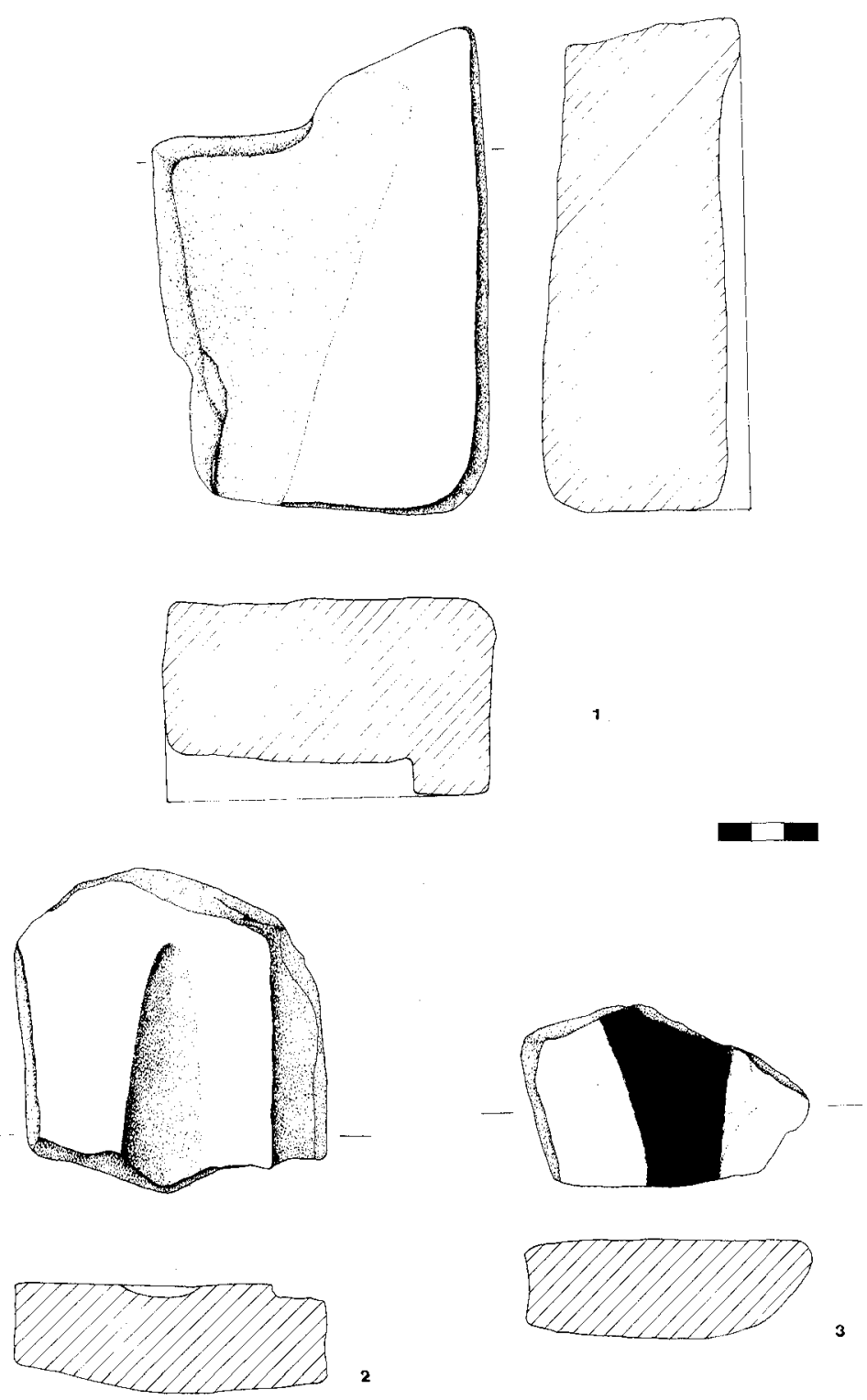

Figura 19.-Segura procedencia del poblado. 

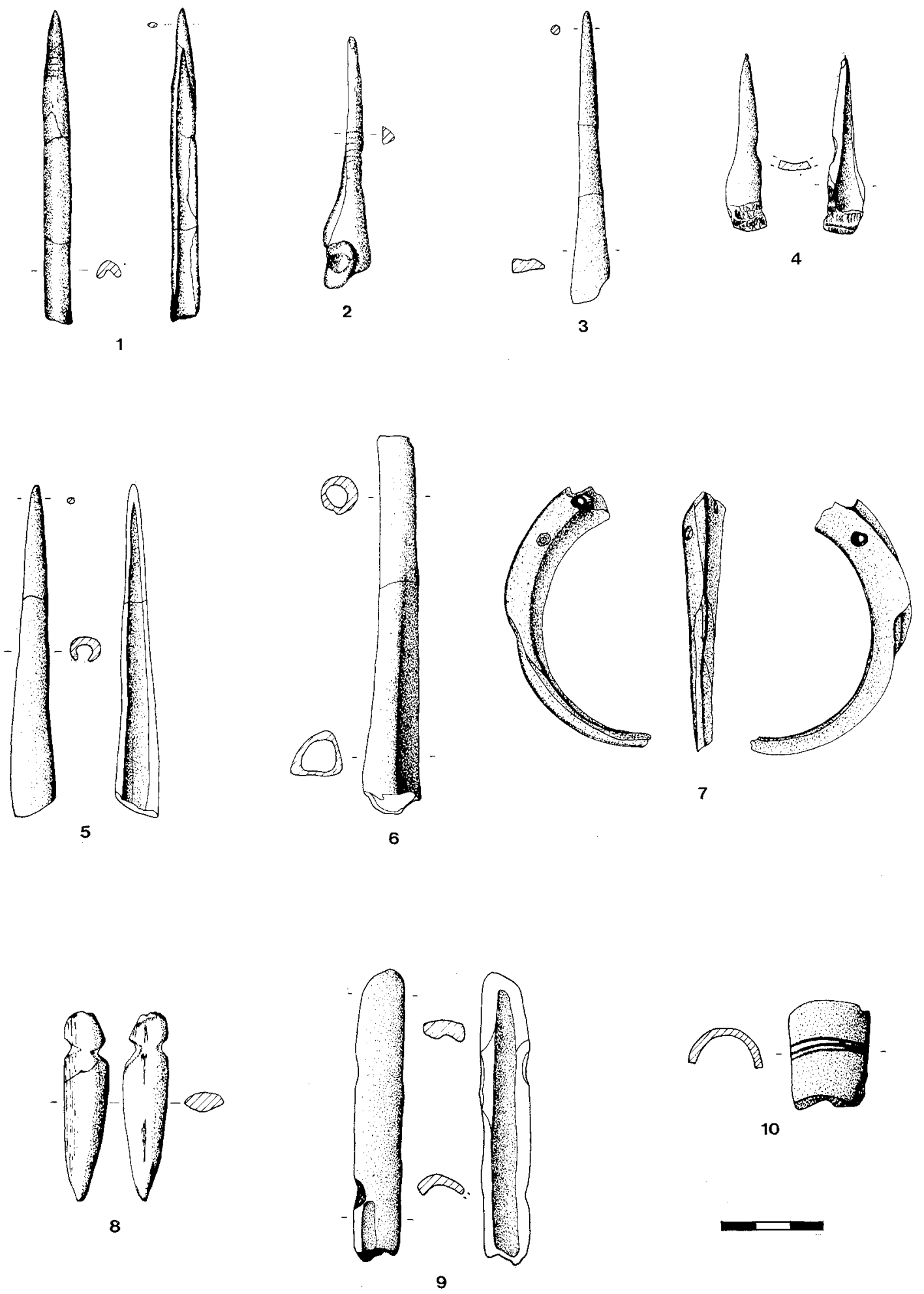

Figura 20.-Segura procedencia del poblado: 1 y 8 . Segura procedencia de la cueva: $2,4,9$ y 10 . 


\section{IV.4. Industria ósea}

Este yacimiento posee un abundante lote de objetos realizados sobre hueso con un total de 77 piezas inventariadas. La mayoría de ellas se encuentran fragmentadas debido, entre otras causas, a la naturaleza de la materia sobre la que están realizadas. En ocasiones conservan un fuerte pulimento, presentando una superficie brillante. Algunas poseen señales de haber estado sometidas a la acción del fuego y por ello tienen una tonalidad de color negruzco.

\section{IV.4.1. Clasificación tipológica}

Se han contabilizado sólo 17 objetos enteros, que representan el $22 \%$ de las piezas fabricadas en hueso. Hemos establecido los siguientes tipos:

- Punzones.

Existen 13 punzones que suponen el $76^{\prime} 4 \%$ de los objetos sobre los que se ha realizado esta clasificación. Es el útil de hueso más común de este yacimiento. Dos de ellos están decorados con acanaladuras paralelas y horizontales y presentan un fuerte pulimento (Fig. 20: 1-2). Unos miden entre $50 \mathrm{~mm}$. y $70 \mathrm{~mm}$. de longitud, otros entre $85 \mathrm{~mm}$. y $100 \mathrm{~mm}$., y hay uno que sobrepasa los $100 \mathrm{~mm}$. de longitud. En cuanto a su amplitud máxima, generalmente tienen entre $11 \mathrm{~mm}$. y $22 \mathrm{~mm}$. Existen 2 variantes:

- Punzones realizados sobre caña de hueso. Sólo hay 4 y representan el 30 '8 \% del total de los punzones (Fig. $20: 2-3$ ).

- Punzones realizados sobre media caña de hueso. Tenemos 9 y suponen el 69'2 \% de todos los punzones (Fig. 20: 1 y 4-5).

Punzones realizados tanto sobre caña como sobre media caña se hallan en la mayoría de los yacimientos de la Edad del Bronce y no presentan una cronología precisa.

Más interesantes son en cambio los decorados con acanaladuras. Aunque huesos decorados con incisiones han aparecido en varios poblados y cuevas de la Edad del Bronce como Ull del Moro, Muntanya Assolada (MARTI, 1983b, 60, fig. 13: 7), Cueva del Barranc de Palop (APARICIO-SAN VALERO, 1977, 64, fig. 22), Fuente Alamo (ARTEAGA-SCHUBART, 1980, 166, fig. 12: k), etc., los paralelos más cercanos a estos punzones decorados con acanaladuras de Mola Alta de Serelles se hallan en el Estrato I de la Ereta de Pedregal (FLETCHER-PLA-LLOBREGAT, 1964, fig. 6: 17) y en el Nivel V del Castillo de Frías (ATRIAN, 1974, 26, fig. 37: a y lám. XX: 1).

En lo que se refiere a su cronología, se encuentran ya documentados en el Eneolítico en la Ereta del Pedregal (FLETCHER-PLA-LLOBREGAT, 1964, 16, fig. 8: 17), aunque su paralelo más exacto, ya referido, está en los primeros niveles del Bronce (FLETCHER-PLA-LLOBREGAT, 1964, 20), no siendo esto un elemento suficiente para datarlos en el Bronce Antiguo.

- Posibles mangos para punzones metálicos.

Sólo existen dos ejemplares que suponen el 11'8\% de los objetos sobre los que se ha realizado esta clasificación. Los dos presentan huellas provocadas por la acción del fuego (Fig. 20: 6).

Este tipo de útiles son menos frecuentes que los punzones. Se han encontrado en Cabeço Navarro (ENGUIX, 1970, 73, fig. 5), Ereta del Pedregal (FLETCHERALCACER, 1958, 108), El Oficio (SIRET, 1890, fig. 77 y lám. 63) y Fuente Alamo (ARTEAGA-SCHUBART, 1980, 166, fig. 12: k), entre otros.

Punzones de metal (LERMA, 1981, 123), al igual que mangos (BERNABEU, 1978$79,117)$, existen desde el Eneolítico, si bien no tienen una cronología concreta.

- Colmillo de jabalí perforado.

También se halló un colmillo de jabalí con dos perforaciones en forma de «V» en su extremo proximal y el inicio de otra perforación (Fig. 20: 7). 
Colmillos de jabalí, con o sin perforaciones, similares al de Mola Alta de Serelles, utilizados como elemento de adorno, se han encontrado en Cova Foradà, Cueva del Barranc de Palop (APARICIO-SAN VALERO, 1977, 64-65, fig. 22), San Antón de Orihuela (FURGUS, 1937, fig. 5-6), El Argar (SIRET, 1890, 179), etc., no siendo muy frecuentes.

En cuanto a su cronología, no se puede precisar.

- «Idolillo».

Por último, reseñamos el hallazgo de un posible idolillo. Este tiene forma lanceolada y presenta dos escotaduras, una en cada lado, cerca de su extremo proximal (Fig. 20: 8).

Este posible idolillo es un hallazgo ocasional. Su paralelo más afín podría ser un idolillo realizado sobre un fragmento de colmillo de jabalí con dos escotaduras laterales, esquematizando la figura humana, como el de Mola Alta de Serelles, hallado en la Atalayuela (BALLESTER, 1949, 107, fig. 5).

Idolos fabricados en piedra, esquematizando igualmente la figura humana, muy parecidos al de Mola Alta de Serelles, se han encontrado en los poblados de la Edad del Bronce de Ull del Moro y Tossal de la Roca (ASQUERINO, 1978, 159, fig. 2: 221-326).

Por otra parte pensamos que también guarda semejanza con ciertos ídolos de época eneolítica (ALMAGRO, 1973, 121, fig. 20).

De todo ello concluimos que este posible idolillo responde a una tradición eneolítica, pero pertenece a la Edad del Bronce y dentro de la misma podemos datarlo en su fase más antigua por los ejemplos citados y por los materiales asociados a ellos. Así, por ejemplo, en el caso de Ull del Moro apareció junto con puntas de flecha de sílex, largas hojas-cuchillo, un botón de hueso piramidal con perforación en «V», etc.

\section{IV.4.2. Fragmentos de útiles de hueso que no se pueden incluir claramente en la clasificación tipológica}

En lo que se refiere a los objetos de hueso fragmentados, hemos inventariado un total de 60 piezas, que suponen el $78 \%$ del conjunto de objetos de hueso.

Hay 44 fragmentos de punzones y representan el 73' $3 \%$ del total de los objetos fragmentados. De ellos $11(25 \%)$ están fabricados sobre caña de hueso y los $33(75 \%)$ restantes sobre media caña de hueso.

Sólo se conservan dos fragmentos de espátulas que forman el 3‘3 \% de todos los objetos de hueso fragmentados. Se caracterizan por tener una sección aplanada (Fig. 20: 9).

Las espátulas son menos abundantes que los punzones en la Edad del Bronce, aunque también existen. Presentan una gran amplitud geográfico-cronológica. Sus paralelos más próximos se hallan en la Sima del Pinaret del Mas Nou, Mas de Menente (PONSELL, 1926, 6), y en Mola d'Agres (C. E. C., 1978, 110, fig. 8: 9), Muntanyeta de Cabrera (FLETCHER-PLA, 1956, lám. XIV: A), El Murón (NAVARRO, 1982, 35, fig. 9: a), etc.

También existen 5 fragmentos de espátulas o punzones y 9 fragmentos de mangos o punzones que suponen el 8’3\% y el $15 \%$ del total de la industria ósea fragmentada respectivamente.

Hay que hacer mención al hallazgo de una charnela posiblemente de época romana que presenta tres incisiones paralelas y horizontales, y que E. Botella $(1926,8)$ describió de la siguiente manera:

«al parecer un bastón de mando, con tres rayas grabadas circularmente, y en cuya fractura se aprecia la mitad de un agujero» (Fig. 20: 10). 


\section{IV.4.3. Objetos de hueso desaparecidos}

Por último, tenemos que destacar la aparición de una espátula-punzón en la cueva (BOTELLA, 1926, 7-8 y lám. VII-B), que no se conserva en ninguna de las dos colecciones estudiadas.

\section{IV.5. Tierra cocida}

Se han inventariado un total de 14 objetos de tierra cocida. Están fabricados con arcilla mezclada en ocasiones con un desgrasante mineral bastante grueso. Presentan formas cilíndricas, cilíndricas de tendencia discoidal, troncocónicas truncadas y paralelepípedas. La mayoría se encuentran muy deterioradas y casi la mitad de las mismas tan sólo son fragmentos, lo que demuestra la fragilidad de estas piezas debido a la baja temperatura en la que se ha efectuado su cocción.

\section{IV.5.1. Clasificación tipológica}

Se conservan únicamente 8 objetos enteros. Hemos distinguido los siguientes tipos:

- Pesa de telar.

Se posee un ejemplar. Tiene forma cilíndrica con una perforación en el centro y es de color negro (Fig. 21).
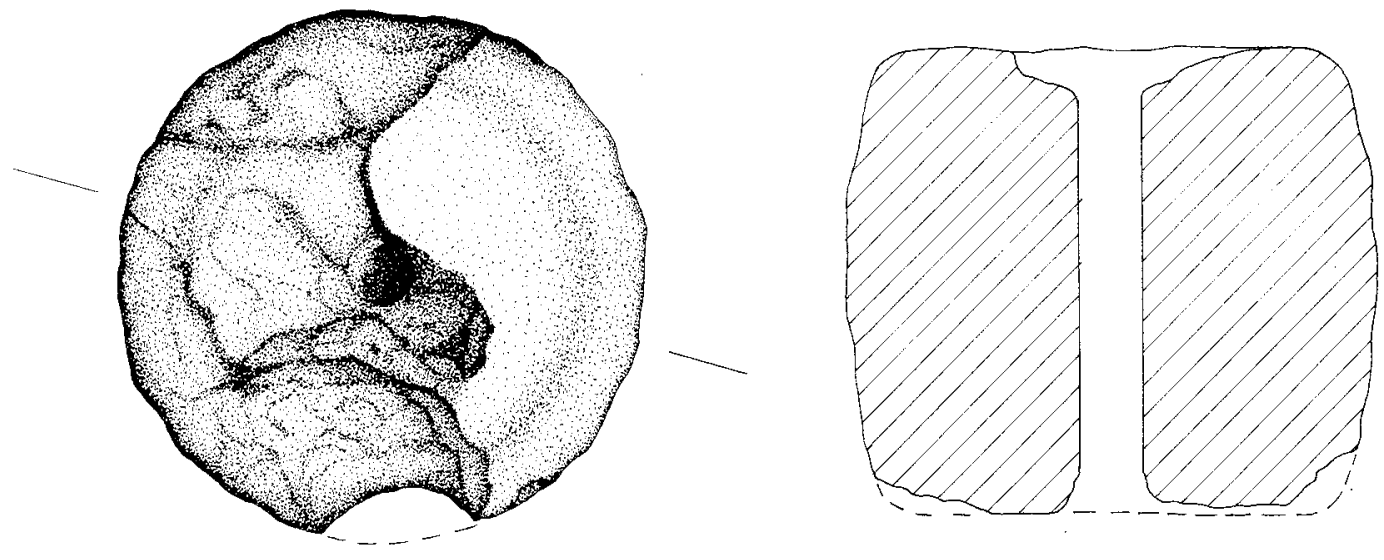

Figura 21.-Pesa de telar.

Pesas de telar parecidas existen en el poblado de la Edad del Bronce de El Murón, en uno de los dos poblados argáricos más conocidos de la Vega Baja del Segura: San Antón de Orihuela o la necrópolis de Callosa del Segura (cita oral de M. S. Hernández) y posiblemente en La Pedrera y Puntal de Bartolo (NAVARRO, 1982, 38-41), donde se hallaron unas «pesas de telar cilíndricas» con un orificio central, y Ull del Moro, en el cual apareció un objeto de tierra cocida de forma troncocónica truncada, fragmentado por su mitad y con un orificio central similar al de Mola Alta de Serelles.

Esta pieza, según los paralelos, se data en la Edad del Bronce, aunque resulta problemático precisar su cronología. 

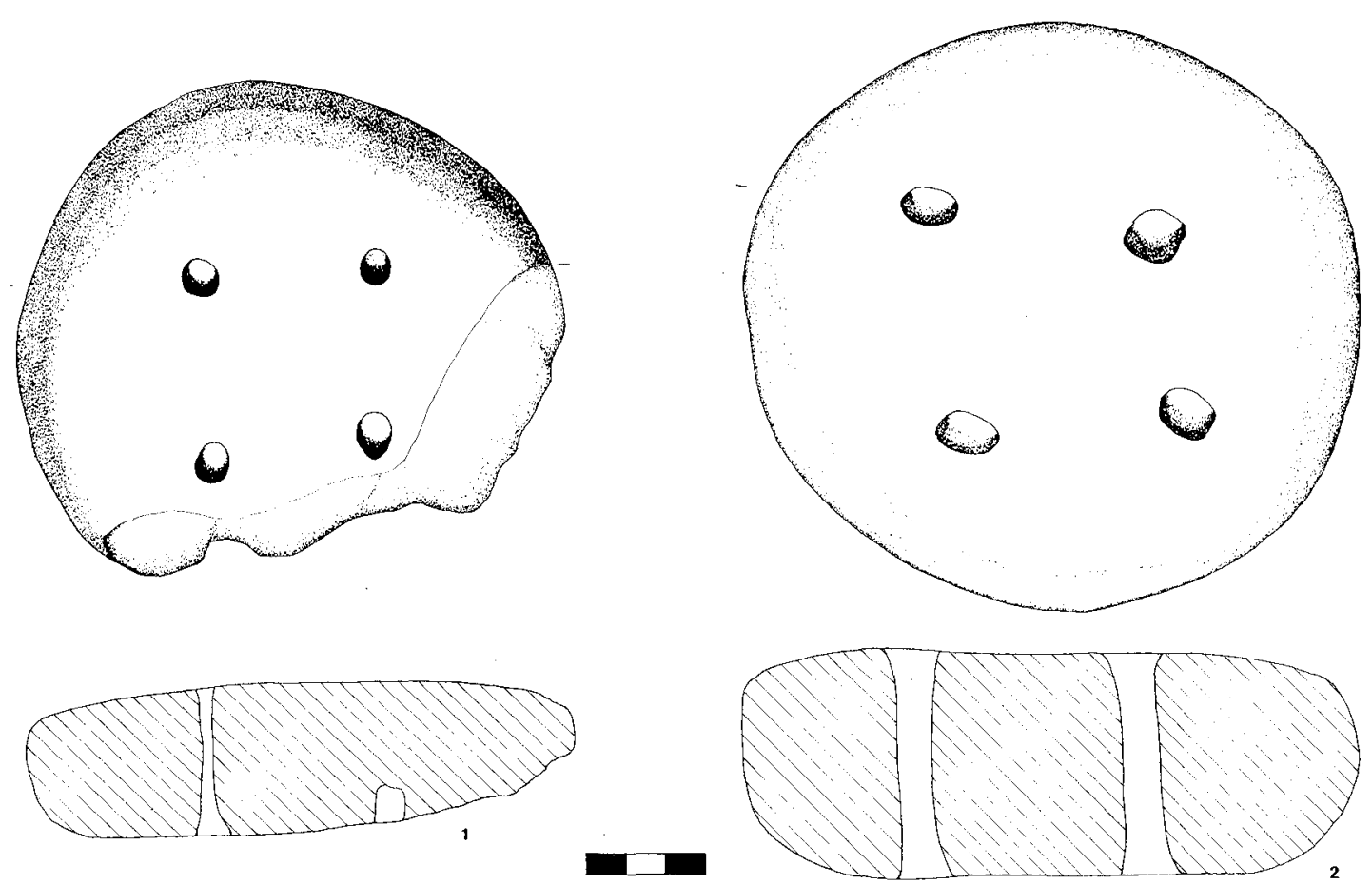

Figura 22.-Segura procedencia del poblado.

— «Pesas de telar» o «tortas refractarias».

Son piezas que tienen unas perforaciones (una, tres o cuatro), por regla general colocadas simétricamente, formando un cuadrado o un trapecio, si es de forma cilíndrica de tendencia discoidal, y un triángulo, si es de forma troncocónica truncada.

$\mathrm{El}$ hecho de que varias de estas perforaciones (Fig. 22:1) no atraviesen totalmente el objeto, hace que pongamos en tela de juicio su uso como pesas de telar, o como torcedores de fibras debido asimismo a su fragilidad ya mencionada. Por otra parte, el que algunas presenten síntomas de haber estado sometidas a la acción del fuego, apunta hacia la posibilidad de que puedan tratarse de tortas refractarias, cuya función sería la de mantener el calor.

Normalmente tienen una tonalidad blanquecina, aunque varias poseen una coloración irregular, producto de una cocción defectuosa. Las dimensiones de su diámetro oscilan entre $139 \mathrm{~mm}$. y $162 \mathrm{~mm}$. y su grosor entre $59 \mathrm{~mm}$. y $73 \mathrm{~mm}$., aunque una no llega a $40 \mathrm{~mm}$. y otra sobrepasa los $80 \mathrm{~mm}$. Sólo se han hallado 4 . Hemos establecido 2 variantes:

- «Pesas de telar» o «tortas refractarias» de forma cilíndrica de tendencia discoidal y cuatro perforaciones (Fig. 22: 2). Se han encontrado 3.

- «Pesa de telar»o «torta refractaria» de forma troncocónica truncada y tres perforaciones (Fig. 23: 1). Se conserva un solo ejemplar.

Estas piezas se hallan con frecuencia en los yacimientos de la Edad del Bronce. Las más semejantes a las de Mola Alta de Serelles con forma de tendencia discoidal o troncocónica truncada son las de Castellarejo de Moros (FLETCHER-ALCACER, 1958, 31, fig. 7: C), Ereta del Castellar (ARNAL-PRADES-FLETCHER, 1968, lám. XII), Cerro de la Virgen de Orce (SCHULE-PELLICER, 1966, figs. 27: 9, 38: 4 y 44: 7) y Motilla de Azuer (NAJERA, 1979, 31, fig. 7: c).

Estas «pesas de telar» o «tortas refractarias» típicas de la Edad del Bronce se encuentran ya documentadas en el Estrato Campaniforme B y C y en el Argárico A del 

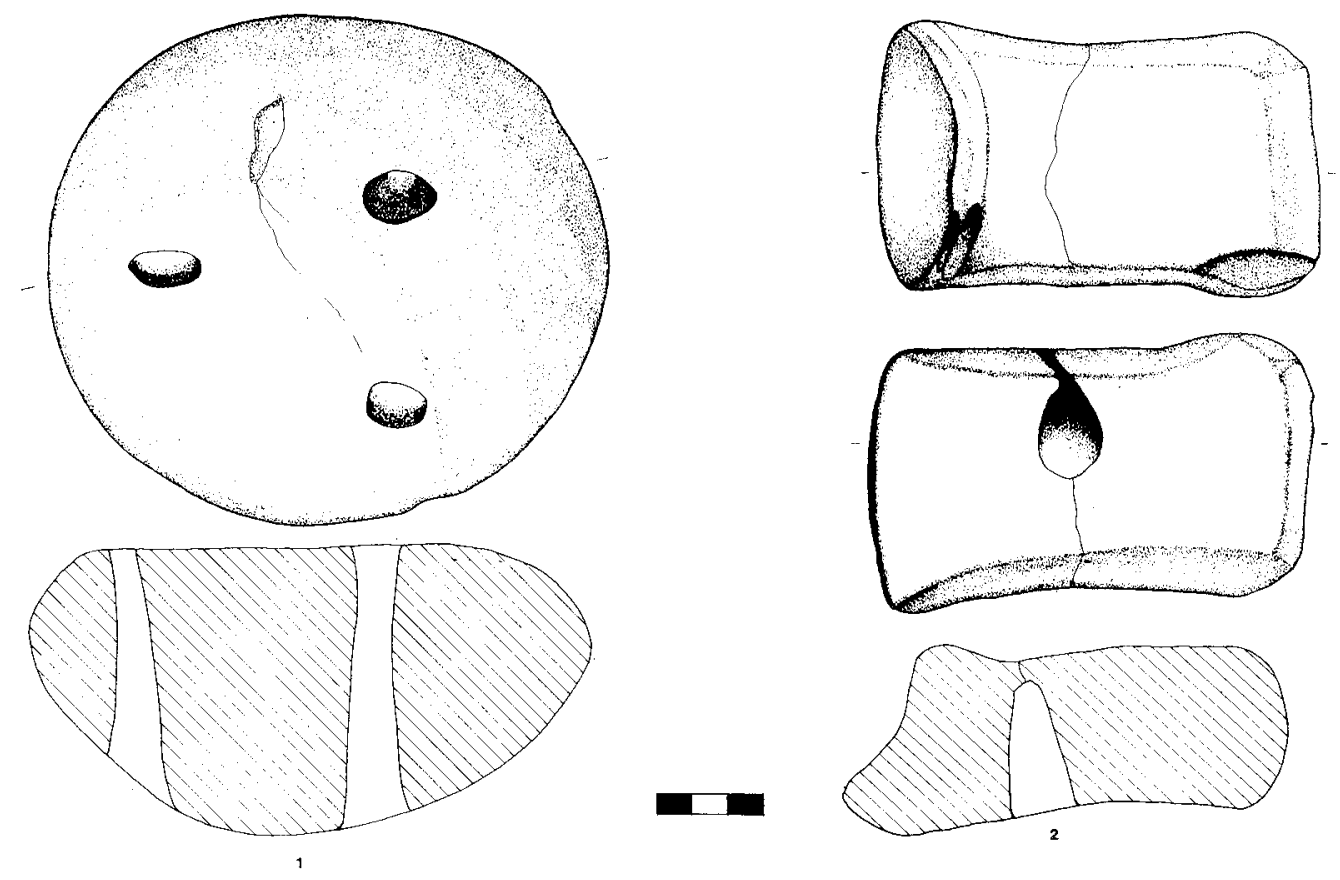

Figura 23.-Segura procedencia del poblado.

Cerro de la Virgen de Orce (SCHULE-PELLICER, 1966, 45), aunque perduran durante todo el Bronce Pleno.

- Morillos.

Existen únicamente tres. Todos tienen forma paralelepípeda y presentan una cara con una perforación circular y otra con su superficie cóncava. Son de color marrón rojizo y miden entre $128 \mathrm{~mm}$. y $173 \mathrm{~mm}$. de longitud, entre $78 \mathrm{~mm}$. y $102 \mathrm{~mm}$. de amplitud, y entre $50 \mathrm{~mm}$. y $72 \mathrm{~mm}$. de grosor (Fig. 23: 2).

Estas piezas no son frecuentes durante la Edad del Bronce. Ejempos similares, aunque con ligeras variantes, se han hallado en Mas de Menente (PERICOT-PONSELL, 1929, 108 y lám. V), Cabezo Redondo (SOLER, 1953, 43), Muñogalindo, Diego Alonso y Pico Agudo, estos tres últimos considerados también como objetos de culto (LOPEZ, 1975, 505), y posiblemente en El Oficio (SIRET, 1890, 242-246, fig. 74 y lám. 62).

Estos objetos pertenecen a la Edad del Bronce, aunque no tienen una cronología concreta.

\section{IV.5.2. Fragmentos de objetos de tierra cocida que no se pueden incluir claramente en la clasificación tipológica}

En lo referente a las piezas fragmentadas, se han inventariado seis ejemplares, de los que cinco son fragmentos de «pesas de telar» o «tortas refractarias».

De ellas dos tienen una sola perforación en el centro. Una presenta forma cilíndrica de tendencia discoidal y la otra troncocónica truncada y su perforación no atraviesa totalmente la pieza.

Las tres restantes poseen cuatro perforaciones. Dos son de forma cilíndrica de tendencia discoidal y una de ellas tiene una perforación que no atraviesa toda la pieza (Fig. 22: 1). La otra presenta forma troncocónica truncada.

El fragmento de morillo posee las mismas características que los referidos anteriormente. 


\section{IV.6. Fauna y malacofauna}

\section{IV.6.1. Fauna}

Hemos inventariado 109 restos óseos correspondientes a animales vertebrados.

Algunos presentan un avanzado estado de erosión y sólo cuatro conservan restos de haber sufrido la acción del fuego.

La mayoría son astas, mandíbulas, piezas dentarias y extremidades, aunque también hemos encontrado algún colmillo, costilla, vértebra y alguna falange.

Parece existir, al igual que en Cabezo Redondo, Muntanya Assolada, Les Planetes y Cueva de Soterraña (MARTI, 1983a, 104), un predominio de ovicápridos, seguido ya en menor cantidad por especies como cerdo, buey, conejo, jabalí, ciervo, etc.

\section{IV.6.2. Malacofauna}

Se han inventariado 18 ejemplares. Relación:

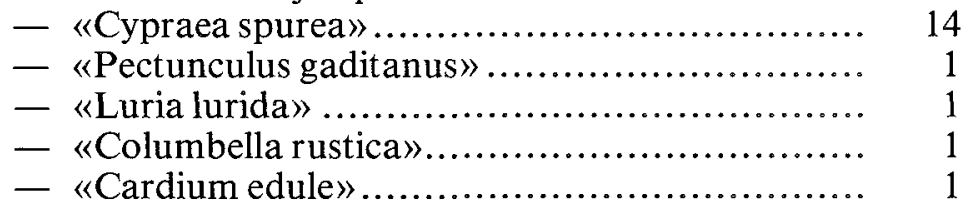

Todas las especies son marinas, lo cual demuestra las relaciones de esta zona situada al interior con la costa. Los ejemplares de «Luris lurida», "Columbella rustica» y «Cypraea spurea» pueden ser considerados como elementos de adorno (posible collar), pues todos presentan una perforación circular.

Conchas de moluscos marinos, perforados (como elementos de adorno) o sin perforar, existen en casi todos los yacimientos de la Edad del Bronce y no tienen una cronología precisa.

\section{SINTESIS Y CONCLUSIONES}

El análisis de su situación, restos constructivos y materiales, así como un examen detenido de su bibliografía, nos ha permitido realizar una síntesis y elaborar una serie de conclusiones sobre el yacimiento, que no ofrecen ninguna novedad destacable respecto al estado actual de los conocimientos de la Edad del Bronce en la comarca y en el País Valenciano.

Su emplazamiento sobre un cerro de fácil defensa, orientado a solana y dominando, entre otros, los pasos naturales hacia la costa a través del Río Alcoy y por el interior de la Sierra de Mariola a las comarcas centrales del País Valenciano y a la Meseta, responde a las características típicas del Bronce Valenciano. Ahora bien, presenta dos particularidades que debemos matizar:

En primer lugar, sus $1053 \mathrm{~m}$. de altura $\mathrm{s} / \mathrm{n} / \mathrm{m}$. a la que se suma un acceso muy dificultoso sobre todo por la parte Este. Sólo conocemos, además de Mola Alta de Serelles, cuatro yacimientos de la Cultura del Bronce Valenciano que se hallan a más de $1000 \mathrm{~m}$. de altura: Alt de Paella, Sima Simarro, Cova la Moneda (CERDA, 1983, 264) y Sima del Pinaret del Mas Nou (TRELIS, 1983, 90-91), tres en la Foia de Castalla y uno en L'Alcoià, aunque deben existir otros más, según comarcas, si bien este dato no siempre se encuentra reflejado en la bibliografía. Generalmente el habitat durante la Edad del Bronce, estudiado en estas dos comarcas, se sitúa entre los $700 \mathrm{~m}$. y $900 \mathrm{~m}$., habiendo una altitud media de las tierras de $600 \mathrm{~m}$. En el resto del País Valenciano, ésta también depende de su situación en zonas llanas o montañosas, siendo las cotas más frecuentes de $300 \mathrm{~m}$. a $900 \mathrm{~m}$. 
Habría que preguntarse, como mera hipótesis, si puede existir alguna relación entre las condiciones de su emplazamiento, ya reseñadas, y el hecho de hallarse la colección más numerosa de moldes de fundición aparecida en un poblado de la Cultura del Bronce Valenciano. La técnica metalúrgica y su producción, si estuviera en manos de un grupo reducido de gente o comunidad, éstos posiblemente ejercerían alguna clase de poder sobre el resto de una sociedad, cuya economía se basaba en la agricultura y la ganadría, sobre todo a base de privar a ésta de este tipo de conocimientos. De ahí que posiblemente se instalasen en zonas de acceso muy dificultoso.

La segunda particularidad a tener en cuenta es la del tándem cueva-poblado. Sólo queremos destacar que en ella no se han hallado restos humanos, aunque es posible que existan, pues no está totalmente excavada. Por tanto, es aventurado clasificarla como cueva de habitación o necrópolis.

Pensamos que esto es un hecho frecuente, si no generalizado, pues en las laderas y alrededores hay bastantes cuevas cercanas a poblados de la Edad del Bronce, algunas de difícil adscripción cultural, debido a sus materiales poco significativos o a las circustancias de su hallazgo, utilizadas como habitat o enterramiento. Entre ellas, cabe destacar la Sima la «L» en la vertiente O. de Mola Alta de Serelles; la covacha de la ladera S. del poblado del Piquet del Baladre; el Cau de les Raboses, muy próxima a Ull del Moro; la grieta de la cara N. de Mas del Corral; la Sima del Pinaret del Mas Nou, que no se encuentra lejos de un poblado recientemente descubierto en La Canal, etc.

En el resto de la Cultura del Bronce Valenciano también ocurre lo mismo. Algunos ejemplos de ello podrían ser la covacha excavada por M. Fusté y D. Fletcher (1953) en las inmediaciones de la Muntanyeta de Cabrera, la grieta de la ladera de El Murón (NAVARRO, 1982, 32) o la cueva situada en la falda de Muntanya Assolada (MARTI, 1983b, 54).

La existencia de un habitat en cueva paralelo al de los poblados en la Cultura del Bronce Valenciano ha sido ya planteada por varios autores como M. Tarradell (1969, 21-22), J. Aparicio (1976, 223), R. Enguix (1980, 162), B. Martí (1983a, 106-108) o M. S. Hernández (1983b, 7-8). Por nuestra parte pensamos que debe tratarse de un habitat secundario, dependiente de los poblados y seguramente relacionado con un tipo de economía agropecuario, pues en muchos de ellos encontramos molinos, dientes de hoz, encellas, etc.

La utilización de las cuevas cercanas a los poblados como lugar de enterramiento corrobora las ideas ya expuestas por M. Tarradell $(1963,67)$.

Por lo que respecta a su arquitectura, también responde a los arquetipos clásicos de la Cultura del Bronce Valenciano.

Son comunes en la mayoría de los poblados las murallas, protegiendo las zonas de acceso más fácil, construidas con piedras de mediano o gran tamaño en seco generalmente, de una o dos hiladas con un relleno de piedras en el interior, adaptándose a las condiciones del terreno.

Las torres, en cambio, son menos frecuentes, aunque también existen, flanqueando los puntos más estratégicos. Salvo en Mola Alta de Serelles, en nuestra comarca no tenemos ejemplos claros de las mismas, sino sólo indicios de una circular en un poblado de La Canal y otra posiblemente rectangular en Altet del Canalís, aunque ello puede deberse quizás a la falta de excavaciones. En el resto de la Cultura del Bronce Valenciano encontramos torres circulares en varios poblados como Tossal Redó y Tossal del Caldero (TARRADELL, 1958, 115-117 y 120), Castellet del Porquet (BALLESTER, 1937, 4), Puntal de Cambra (ALCACER, 1954, 70), Puntal dels Moros (PITARCH, 1969, 79), Torrelló de Onda (GUSI, 1975, 348), etc.

El interior del poblado de Mola Alta de Serelles tiene un tamaño aceptable $\left(450 \mathrm{~m}^{2}\right)$ y en él existe una ordenación lógica del espacio: pasillo de acceso, y a continuación los compartimientos con muros rectilíneos paralelos unos a otros y perpendicu- 
lares a la muralla por su parte trasera, con bancos y hogares en cada uno de ellos y restos de algún poste para sustentar la techumbre, que posiblemente sería de ramajes y barro.

Uno de los problemas que se nos plantea es el de encontrarle una explicación al muro paralelo y pegado a la muralla por su cara interior, el cual formaría el lienzo posterior de las viviendas (BOTELLA, 1928, 4 y lám. I). Nosotros pensamos que más bien se trataría de un añadido o refuerzo a la muralla, pues ésta puede realizar la misma función que dicho muro.

Por el momento poco podemos decir sobre el perímetro de los poblados de la comarca y del resto de la Cultura del Bronce Valenciano, pues es necesario realizar más prospecciones y confeccionar la mayor parte de sus planimetrías. En todos la magnitud y disposición de los elementos arquitectónicos están subordinados a las características del relieve, pues, como en Mola Alta de Serelles, predomina una idea defensiva en la elección del lugar de emplazamiento. Generalmente parecen ser de mediano tamaño, aunque hay excepciones.

En nuestra comarca no se ha practicado ninguna excavación en extensión que nos permita establecer comparaciones estrechas, salvo en Mas de Menente, donde también existe una ordenación lógica del terreno con varios compartimientos paralelos y alineados a la muralla, con bancos semicirculares y hogares. Tanto en Mola Alta de Serelles como en la mayoría de los poblados de la Cultura del Bronce Valenciano desconocemos si una casa estaba formada por uno o varios compartimientos. En Mas de Menente había dos estancias comunicadas entre sí (PERICOT-PONSELL, 1929, 102).

También ignoramos el sistema de acceso al interior de las viviendas, que en nuestro caso tendría que realizarse por su parte oriental, donde E. Botella (1928, 4-5) encontró el derrumbe de un muro, pues en el lado opuesto está la muralla. Umbrales de entrada son bastante frecuentes; ejemplos cercanos serían los de Mas de Menente (PERICOTPONSELL, 1929, 102) o Muntanya Assolada (MARTI, 1983b, 46).

Por último, el sistema de entrada al poblado por medio de un pasillo es único, pues sólo se constata aquí y posiblemente en Muntanya Assolada (MARTI, 1983b, 46). Esta ausencia pensamos que se debe a una falta, como hemos dicho antes, de excavaciones extensivas, pues son muchos los poblados en los que se ha practicado alguna cata y pocos los excavados.

De todo ello se desprende que en la Cultura del Bronce Valenciano existe una arquitectura bastante desarrollada, y en cierto modo podemos hablar de un «urbanismo incipiente», aunque no estamos en condiciones de demostrar que se trate de un hecho generalizado.

En lo que se refiere a la cerámica, lo primero que sorprende es el elevado número de piezas inventariadas (5170). Tiene su explicación en que, en realidad, son dos yacimientos excavados, y por lo menos el poblado totalmente con una potencia estratigráfica de cerca de $2 \mathrm{~m}$.

Son pocas las vasijas que se han conservado enteras (45), debido, entre otras cosas, a la calidad deficiente de muchas de ellas.

Todos los ejemplares son típicos de la Edad del Bronce. No tienen una gran precisión cronológica, pues la mayoría existen indistintamente en yacimientos clasificables en el Bronce Antiguo y Pleno. Unicamente los dos fragmentos de vasijas carenadas con cuello troncocónico y troncocónico invertido deben datarse sólo en el Bronce Pleno, aunque la última también puede pertenecer al Bronce Tardío.

Todas las formas, en líneas generales, pueden incluirse en la tipología realizada por R. Enguix (1981) para la cerámica de la Cultura del Bronce Valenciano, donde encuentra todos sus paralelos, aunque en algún caso existen ejemplos similares en yacimientos pertenecientes a la Cultura de El Argar y Las Motillas, hecho que se ha constatado también en varios yacimientos de esta cultura como Muntanya Assolada (MARTI, 1983b), Sima la Higuera (DE PEDRO, 1981) y otros. 
El bajísimo porcentaje de cerámica decorada (10 fragmentos atípicos) corrobora las ideas de M. Tarradell $(1969,24-27)$ en el sentido de que la cerámica decorada es menos característica en los yacimientos del Bronce Valenciano situados al S. del Turia.

De muy pocas vasijas conocemos la procedencia segura y, en líneas generales, coincidimos con E. Botella $(1962,8)$ respecto a sus diferencias. Así en la cueva parecen predominar los cuencos de pequeño o mediano tamaño de borde exvasado con las superficies mejor tratadas y coloraciones más oscuras, mientras que en el poblado son características las grandes vasijas elipsoidales o esféricas con cuello de superficies bastas y tonos claros. Estas podrían obedecer a dos momentos diferentes dentro de la Edad del Bronce, pero no tenemos elementos suficientes para demostrarlo.

En cuanto al material lítico, en primer lugar tenemos que destacar el gran número de piezas de sílex inventariadas. La mayoría de ellas son dientes de hoz, lascas y láminas sin retoque. Los primeros son el «fósil director» de la Cultura del Bronce Valenciano y no tienen una cronología precisa, al igual que las láminas y la lasca retocada.

Más interesante resulta el hallazgo en la cueva de dientes de hoz junto con hojascuchillo de mediano tamaño y una punta de flecha de sílex, los cuales deben pertenecer al mismo momento que el nivel inferior del poblado, donde también encontramos cuchillos de sílex, todos ellos elementos característicos del Bronce Antiguo con fuertes perduraciones del período anterior.

En la comarca existen varios yacimientos que se pueden clasificar dentro de esta fase de la Edad del Bronce, como Ull del Moro, con una industria de sílex muy semejante a la de Mola Alta de Serelles, junto con un botón prismático con doble perforación en «V» y un idolillo de piedra arenisca de difícil atribución cultural, y posiblemente Cova la Boira y Cova la Figuereta.

En el resto de la Cultura del Bronce Valenciano en los últimos años se han excavado una serie de estaciones adscribibles a esta fase como La Torreta, Sima la Pedrera, nivel inferior de Muntanya Assolada, etc., siendo por tanto una fase bien representada.

El material lítico restante: hachas, azuela, molinos, percutores, etc., no ofrece ninguna particularidad, pues es frecuente encontrarlo en la mayoría de los yacimientos de la Cultura del Bronce Valenciano con una amplia difusión cronológica y geográfica.

En lo que se refiere al material relacionado con la metalurgia, destacamos que todos se encontraron en el poblado. Menos la posible punta de Palmela descubierta a $300 \mathrm{~m}$. en las estribaciones y en superficie (BOTELLA, 1928, 8-9), los otros útiles de metal aparecieron en el nivel superior del mismo. Desconocemos, en cambio, la posición estratigráfica de los moldes de fundición, aunque todos estaban en el compartimiento n. ${ }^{\circ} 1$ (BOTELLA, 1928, 9).

El hecho de hallarse los moldes de fundición publicados por Botella en el interior de una sola estancia, así como la mayoría de las posibles «pesas de telar» o «tortas refractarias» (SEGURA-CORTELL, 1984, 45), revela que parece existir una cierta especialización y división del trabajo dentro de la vida socio-económica del poblado. Esta característica, en lo que respecta al segundo caso, también ha sido constatada en la Motilla de Azuer (MOLINA-NAJERA-AGUAYO, 1979, lám. XIII-b).

La cronología de los objetos de metal es muy amplia, pues ya aparecen en el Eneolítico Pleno (punzones) y «Horizonte de Transición» (puntas de Palmela), y perduran durante toda la Edad del Bronce. Los moldes de fundición bivalvos sólo se dan en esta última época y, en concreto, los de hachas de los Tipos II y III de B. Blance podemos datarlos en el Argar B (1600-1200 a. C.) (BLANCE, 1971, 153).

Los análisis espectrográficos de Mola Alta de Serelles (BLANCE, 1959), los de Muntanya Assolada y varios yacimientos del Valle Medio del Vinalopó (HERNANDEZ, 1983a, 38) confirman el uso de cobre y de éste aleado con estaño durante la Cultura del Bronce Valenciano. 
Por ello pensamos que el nivel superior del poblado pertenece al Bronce Pleno, mientras que el nivel inferior y la cueva pueden adscribirse al Bronce Antiguo, donde se encontraron cuchillos de sílex, una punta de flecha, etc.

El conjunto metalúrgico de Mola Alta de Serelles, sobre todo los moldes de fundición, es el más importante de los descubiertos hasta la actualidad no sólo en la comarca sino en toda la Cultura del Bronce Valenciano.

No obstante, en la primera existe una buena colección de útiles metálicos como los de Mas de Menente, Ull del Moro, Mas del Corral, Mas Felip, Sercat, etc., y moldes de fundición (Ull del Moro, Mas del Corral y Mola d'Agres).

Por ello estamos ante uno de los focos metalúrgicos más importantes de esta Cultura, como han señalado ya varios autores, entre los que cabe destacar a R. Enguix (1980, 167), B. Martí (1983a, 93-95) y M. S. Hernández (1983b, 39) y pensamos, como R. Enguix $(1980,167)$, que la única explicación posible, ante la ausencia de recursos metalíferos, sería su cercanía a la Cultura de El Argar, donde también tiene bastantes paralelos, la cual ejercería un potente influjo sobre estas comarcas.

En el resto de la Cultura del Bronce Valenciano los hallazgos metálicos también aparecen con frecuencia, aunque ésta disminuye conforme ascendemos hacia el Norte (LERMA, 1981, 139), lo cual confirma estas opiniones expresadas anteriormente.

Por lo que respecta a los objetos de hueso, este yacimiento posee una de las colecciones más importantes de la Cultura del Bronce Valenciano, tanto por su cantidad como por la belleza y fino acabado de alguno de ellos.

El posible «idolillo», los posibles mangos para punzones metálicos y los punzones sobre caña de hueso se descubrieron en el poblado; las espátulas y la posible charnela romana, en cambio, aparecieron sólo en la cueva; el resto se halló indistintamente en los dos sitios. Desconocemos la posición estratigráfica de todos.

El hallazgo en la cueva de fragmentos de espátulas poco frecuentes durante la Edad del Bronce y de punzones decorados con acanaladuras, cuyos paralelos más exactos se encuentran en los primeros niveles del Bronce de la Ereta del Pedregal, pueden ser quizás elementos suficientes para clasificarla en el Bronce Antiguo.

Por otra parte, el punzón con acanaladuras del poblado y el posible «idolillo» datable en el Bronce Antiguo confirman la hipótesis de dos momentos diferentes en el mismo, ya mencionados anteriormente al referirnos a la industria de sílex y a la metalurgia, uno de los cuales (el inferior) se correspondería con la cueva.

El resto de los objetos de hueso: punzones sobre caña o media caña, posibles mangos para punzones de metal, un colmillo de jabalí y una espátula-punzón no ofrecen una gran precisión cronológica.

La posible charnela romana es el único objeto fuera del contexto de la Edad del Bronce. De todas maneras, conocemos en el País Valenciano varias cuevas con hallazgos de época romana como las cercanas de Cova la Boira y Cova Figuereta, o Cova de la Torre del Mal Paso y Cova les Meravelles (ABAD, 1983, 22).

En cuanto a la industria ósea, por último, habría que reseñar dos cosas:

Primero que la cifra de objetos de hueso inventariados (77) contrasta con las exiguas cantidades halladas en los yacimientos de esta época tanto en nuestra comarca como en el resto de la Cultura del Bronce Valenciano. Por citar un ejemplo, en el inventario del material excavado en la primera campaña de Mas de Menente (PONSELL, 1926, 8) sólo se citan dos espátulas y dos punzones.

$\mathrm{Y}$ en segundo lugar, son objetos, más o menos, bien representados en la Cultura del Bronce Valenciano, aunque no es frecuente encontrar tanta variedad en un mismo yacimiento.

En lo que se refiere a las piezas de tierra cocida, todas se hallaron en el poblado o en una oquedad cerca de éste, menos la de la Figura 21, de la cual desconocemos su procedencia segura. Ignoramos también la posición estratigráfica de las mismas. 
No hay duda respecto a la funcionalidad de los morillos como tales, pues E. Botella $(1928,8)$ encontró uno, en el cual se apoyaba la base de una vasija por su parte cóncava.

En cambio, tenemos mayor incertidumbre sobre el uso de lo que llamamos posibles «pesas de telar» o «tortas refractarias», que quizás sirviesen para mantener el calor del fuego, aunque hay diferentes opiniones acerca de su empleo como pesas de telar, torcedores de fibras o «panes rituales».

Tanto la «pesa de telar» como éstas, en el caso de que se usaran como pesas de telar, son manifestaciones de una actividad textil, que junto con la metalúrgica y las agropecuarias serían los pilares básicos de su economía.

Cronológicamente todas se datan en la Edad del Bronce sin una cronología precisa.

Las más comunes, aunque no abundantes, son las «pesas de telar»o «tortas refractarias» con 3 ó 4 orificios tanto en nuestra comarca como en el resto de la Cultura del Bronce Valenciano, e incluso en Las Motillas y en yacimientos de la Cultura de El Argar. Pueden hallarse en poblados y en enterramientos, como es el caso del Barranc del Sint (VISEDO, 1937, 6).

En cuanto a los otros, sobre todo los morillos, son hallazgos poco frecuentes; tanto es así que no se mencionan en ninguna de las relaciones de materiales característicos del Bronce Valenciano.

Por último, los restos de fauna indican una importancia de la ganadería y la caza como actividades económicas. En cambio, la malacofauna de origen marino, hallada sólo en el poblado, es la única prueba de unas posibles relaciones comerciales de la costa con el interior.

En el resto de la Cultura del Bronce Valenciano éstas también tienen bastante significación dentro de la economía, como lo demuestran los hallazgos de Muntanya Assolada o Planetes de Benassal, junto con la agricultura, pues la abundancia de dientes de hoz, molinos y restos de semillas parecen confirmarlo. Ahora bien, en nuestra comarca parece existir, aparte de ello, un potente foco metalúrgico, como ya hemos manifestado anteriormente, el cual ejercería un papel relevante dentro de la misma.

De todo lo dicho se desprende que el yacimiento de Mola Alta de Serelles es uno de los más característicos de la Cultura del Bronce Valenciano. Sus materiales presentan una gran variedad tipológica, cuyos paralelos más estrechos se encuentran en los yacimientos de la misma cultura sobre todo de sus comarcas cercanas, y en algún caso se emparentan también con otros de las culturas vecinas de El Argar y Las Motillas.

Cronológicamente existen dos momentos: Uno datable en el Bronce Antiguo con hallazgos de objetos que hunden sus raíces en el Eneolítico como las hojas-cuchillo, la punta de flecha de sílex, los punzones decorados con acanaladuras y el posible «idolillo» de hueso, y otros típicos de la Edad del Bronce como dientes de hoz. El otro en el Bronce Pleno con útiles metálicos y otros relacionados con la metalurgia (moldes de fundición bivalvos), dientes de hoz con perfil de «D», grandes vasijas con cuello, etc. Al primero pertenecerían la cueva y el nivel inferior del poblado; al segundo su nivel, superior. 


\section{BIBLIOGRAFIA}

ABAD CASAL, L. 1983. «La Arqueología Romana en el País Valenciano: Panorama y Perspectivas». I Jornadas de Arqueología de la Universidad de Alicante (Ponencias repartidas para la celebración de las mismas).

ALCACER GRAU, J. 1954. «El Puntal de Cambra (Villar del Arzobispo, Valencia)». Archivo de Prehistoria Levantina, V, Valencia, pp. 65 y ss.

- 1960. «El Altico de Hoya (Navarrés, Valencia)». Archivo de Prehistoria Levantina, IX, Valencia, pp. 101-113.

ALMAGRO GORBEA, M. J. 1973. Los Idolos del Bronce I Hispano. «Biblioteca Prehistórica HispániCa», XII, Madrid.

APARICIO PEREZ, J. 1976. Estudio económico y social de la Edad del Bronce Valenciano. Valencia.

- $\quad$ 1977. Las raices de Mogente. Prehistoria y protohistoria. «Departamento de Historia Antigua de la Facultad de Filosofía y Letras», Serie Arqueológica 2, Valencia.

- 1978. «Sima de la Pedrera (Banicull, Polinà del Júcar, Valencia)». Archivo de Prehistoria Levantina, XV, Valencia, pp. 69-91.

APARICIO PEREZ, J., y SAN VALERO APARISI, J. 1977. Nuevas excavaciones y prospecciones arquológicas en la provincia de Valencia. «Departamento de Historia Antigua de la Facultad de Filosofía y Letras», Serie Arqueológica 5, Valencia.

APARICIO PEREZ, J. et alii. 1981. Las raíces de Bañeres. «Departamento de Historia Antigua de la Facultad de Filosofía y Letras», Serie Arqueológica 8, Valencia.

ARNAL, J.; PRADES, H. y FLETCHER, D. 1968. La Ereta del Castellar (Villafranca del Cid, Castellón). «Trabajos Varios del S.I.P.», 35, Valencia.

ARTEAGA, O. y SCHUBART, H. 1980. «Fuente Alamo. Excavaciones de 1977». Noticiario Arqueológico Hispánico, 9, Prehistoria, Madrid, pp. 245-289.

ASQUERINO FERNANDEZ, M. D. 1978. «Idolos inéditos del Museo de Alcoy». Instituto de Estudios Alicantinos, 23, Alicante, pp. 155-167.

ATRIAN JORDAN, P. 1974. «Un yacimiento de la Edad del Bronce en Frías de Albarracín». Teruel, 52, Teruel, pp. 7-32.

BALLESTER TORMO, I. 1937. El Castellet del Porquet. «Serie de Treballs Solts del S.I.P.», 1, Valencia.

- 1949. La labor del S.I.P. y su Museo en los 1940-48. Valencia.

BERNABEU AUBAN, J. 1978-79. Los elementos de adorno del Eneolitico Valenciano. Memoria de Licenciatura presentada en la Facultad de Filosofía y Letras de la Universidad de Valencia.

BLANCE, B. 1959. «Estudio espectrográfico de algunos objetos metálicos del Museo de Prehistoria de la Diputación de Valencia». Archivo de Prehistoria Levantina, VIII, Valencia, pp. 163 y ss.

- 1971. «Die Anfänge der Metallurgie auf der Iberischen Halbinsel». Studien zu den Anfängen der Metallurgie, 4, Berlín, pp. 121 y ss.

BOTELla CANDELA, E. 1926. Excavaciones en la «Mola Alta» de Serelles (Alcoy). «Memorias de la Junta Superior de Excavaciones y Antigüedades», 79, Madrid.

- 1928. Excavaciones en la «Mola Alta» de Serelles (Alcoy). «Memorias de la Junta Superior de Excavaciones y Antigüedades», 94, Madrid.

CENTRE D'ESTUDIS CONTEST ANS. 1978. «La Mola d'Agres». Archivo de Prehistoria Levantina, XV, Valencia, pp. 99-112.

CERDA BORDERA, F. 1983. Contribución a la Carta Arqueológica de la Foia de Castalla. Memoria de Licenciatura presentada en la Facultad de Filosofía y Letras de la Universidad de Alicante.

DE PEDRO MICHO, M. J. 1981. «Materiales procedentes del yacimiento del Bronce Valenciano de Sima La Higuera (Caudiel, Castelló)». Saguntum, 16, Valencia, pp. 107-117.

ENGUIX ALEMANY, R. 1970. «Cabeço de Navarro o Cabeço dels Alforins de Onteniente. Poblado de la Cultura del Bronce Valenciano». Papeles del Laboratorio de Arqueología de Valencia, 10, Valencia, pp. 62-79.

- 1975. «Notas sobre economía del Bronce Valenciano». Papeles del Laboratorio de Arqueología de Valencia, 11, Valencia, pp. 141-157.

- 1980. «La Edad del Bronce». Nuestra Historia, I, Valencia, pp. 151-170.

- 1981. «Tipología de la cerámicas de la Cultura del Bronce Valenciano». Saguntum, 16, Valencia, pp. 63-74.

FLETCHER VALLS, D. y PLA BALLESTER, E. 1954. El Museo del S.I.P. de la Diputación Provincial de Valencia. Madrid.

- 1956. El poblado del Bronce de la Muntanyeta de Cabrera (Vedat de Torrente). «Trabajos Varios del S.I.P.», 18, Valencia.

FLETCHER VALLS, D. y ALCACER GRAU, J. 1958. «El Castillarejo de Moros, Andilla (Valencia)». Archivo de Prehistoria Levantina, VII, Valencia, pp. 93-120. 
FLETCHER VALLS, D.; PLA BALLESTER, E. y LLOBREGAT CONESA, E. A. 1964. La Ereta del Pedregal (Navarrés, Valencia). «Excavaciones Arqueológicas en España», 42, Madrid.

FURGUS, J. 1937. «Edat prehistórica en Oriola (necrópolis de S. Antonio)». Serie de Trabajos Varios del S.I.P., 5, Valencia, pp. 7-45.

FUSTE ARA, M. y FLETCHER VALLS, D. 1953. «La covacha sepulcral del Vedat de Torrente». Archivo de Prehistoria Levantina, IV, Valencia, pp. 159 y ss.

GIL-MASCARELL BOSCA, M. 1981 a. «Algunos materiales prehistóricos del cerro de S. Miquel de Liria». Archivo de Prehistoria Levantina, XVI, Valencia, pp. 361-371.

- 1981 b. «El poblado de la Mola d’Agres. Dos cortes estratigráficos». Saguntum, 16, Valencia, pp. $75-89$.

- $\quad 1981$ c. «Bronce Tardío y Bronce Final en el País Valenciano». El Bronce Final y los comienzos de la Edad del Hierro en el País Valenciano, Valencia.

GUSI GENER, F. 1974. «Excavaciones del recinto fortificado del Torrelló d'Onda, Castellón». Cuadernos de Prehistoria y Arqueología Castellonense, 1, Castellón, pp. 19-61.

- 1975. «Un recin to fortificado del Bronce Valenciano (Onda, Castellón)». Congreso Nacional de Arqueología, XIII, Zaragoza, pp. 347-350.

GUSI GENER, E. y OLARIA DE GUSI, C. 1976. «La cerámica de la Edad del Bronce de la cueva del Mas d'Abad (Coves de Vinromà), Castellón (Campaña Arqueológica, 1975)». Cuadernos de Prehistoria y Arqueología Castellonense, 3, Castellón, pp. 103-115.

- 1977. «El poblado de la Edad del Bronce de Oropesa la Vella (Oropesa del Mar, Castellón)». Cuadernos de Prehistoria y Arqueología Castellonense, 4, Castellón, pp. 79-100.

- 1979. «El yacimiento prehistórico de Can Ballester (Vall d'Uxó, Castellón)». Cuadernos de Prehistoria y Arqueología Castellonense, 6, Castellón, pp. 39-95.

HERNANDEZ PEREZ, M. S. 1983 a. «La metalurgia prehistórica en el Valle Medio del Vinalopó (Alicante)). Lucentum, II, Alicante, pp. 17-42.

- 1983 b. «La Edad del Bronce en el País Valenciano: Panorama y Perspectivas». I Jornadas de Arqueología de la Universidad de Alicante (Ponencias repartidas para la celebración de las mismas).

LERMA ALEGRIA, J. V. 1977. «Sima de la Higuera, Caudiel (Castellón). Contribución al estudio del poblamiento del Valle del Palancia». Saitabi, XXVII, Valencia, pp. 63-69.

- 1981. «Los orígenes de la metalurgia en el País Valenciano». Archivo de Prehistoria Levantina, XVI, Valencia, pp. 129-140.

LLOBREGAT CONESA, E. A. 1969. «El poblado de la Cultura del Bronce Valenciano de la "Serra Grossa", Alicante». Papeles del Laboratorio de Arqueología de Valencia, 6, Valencia, páginas 31-70.

- 1971. «La colección de Andrés Monzó Nogués (Materiales para el estudio del poblamiento antiguo de la provincia de Valencia)». Archivo de Prehistoria Levantina, XIII, Valencia, páginas $55-80$.

LOPEZ PLAZA, S. 1975. «Morillos y objetos de culto de la Edad del Bronce hallados en Muñogalindo (Avila)». Congreso Nacional de Arqueología, XIII, Zaragoza, pp. 499-506.

MARTI OLIVER, B. 1983 a. El naiximent de l'agricultura en el País Valencià. Del Neolitic a l'Etat del Bronze. «Universitat de València, Cultura Universitaria Popular», 1, Valencia.

- 1983 b. «La Muntanya Assolada (Alzira, Valencia)». Lucentum, II, Alicante, pp. 43-67.

MOLINA, F. y PAREJA, E. 1975. El poblado de la Edad del Bronce de la Cuesta del Negro (Purullena). "Excavaciones Arqueológicas de España», 86, Madrid.

MOLINA, F.; NAJERA, T. y AGUAYO, P. 1979. «La Motilla de Azuer (Daimiel, Ciudad Real). Campaña de 1979». Cuadernos de Prehistoria de la Universidad de Granada, 4, Granada, páginas 265-294.

NAJERA, T. et alii. 1979. «La Motilla del Azuer (Daimiel, Ciudad Real). Campaña de 1976». Noticiario Arqueológico Hispánico, 6, Prehistoria, Madrid, pp. 21-50.

NAVARRO MEDEROS, J. F. 1982. «Materiales para el estudio de la Edad del Bronce en el Valle Medio del Vinalopó (Alicante)». Lucentum, I, Alicante, pp. 19-70.

OLARIA DE GUSI, C. 1975. «Cueva de enterramiento del Bronce Valenciano en Alcudia de Veo». Cuadernos de Prehistoria y Arqueología Castellonense, 2, Castellón, pp. 151-156.

PERICOT GARCIA, L. y PONSELL CORTES, F. 1929. "El poblado del Mas de Menente (Alcoy)», Archivo de Prehistoria Levantina, I, Valencia, pp. 101-112.

PITARCH, J. L. 1969. «El Puntal dels Moros (Náquera, Valencia)». Papeles del Laboratorio de Arqueología de Valencia, 6, Valencia, pp. 77-84.

PONSELL CORTES, F. 1926. Excavaciones en la finca «Mas de Menente», término de Alcoy (Alicante). «Memorias de la Junta Superior de Excavaciones y Antigüedades», 78, Madrid.

RUIZ ARGILES, V. y POSAC MON, C. F. 1956. «El Cabezo de la Bastida de Totana (Murcia)». Noticiario Arqueológico Hispánico, III-IV, Madrid, pp. 60-90. 
SANGMEISTER, E. 1964. «Die Schmalen "Armschuztplatten”». Studien ans Alteuropa, I, Kol-Graz, pp. 93 y ss.

SCHULE, W. y PELLICER, M. 1966. El Cerro de la Virgen de Orce (Granada), I. «Excavaciones Arqueológicas en España», 46, Madrid.

SEGURA MARTI, J. M. y CORTELL PEREZ, E. 1984. «Cien años de arqueología alcoyana (1884-1984)». Alcoy. Prehistoria y Arqueología. Cien años de investigación, Alcoy, pp. $31-131$.

SERRA VILARO, J. 1923. «Mina i fundició d'aram del primer periode de l'Etat del Bronze a Riner». Anuari del Institut d'Estudis Catalans, VI, Barcelona, pp. 535-538.

SIRET, H. y L. 1890. Las primeras edades del metal en el Sudeste de España, Barcelona.

SOLER GARCIA, J. M. 1953. «Poblado de Cabezo Redondo, Villena (Alicante)». Noticiario Arqueológico Hispánico, I, Madrid, pp. 38-43.

- 1976. Villena. Prehistoria, Historia y Monumentos. Alicante.

SOLER GARCIA, J. M. y FERNANDEZ MOSCOSO, E. 1970. «Terlinques. Poblado de la Edad del Bronce en Villena (Alicante)». Papeles del Laboratorio de Arqueología de Valencia, 10, Valencia, pp. 27-63.

TARRADELl MATEU, M. 1958. «El Tossal Redó y el Tossal del Caldero, dos poblados de la Edad del Bronce en el término de Bellús (Valencia)». Archivo de Prehistoria Levantina, VII, Valencia, pp. 111-126.

- 1963. «Ensayo de identificación de las necrópolis del Bronce Valenciano». Archivo de Prehistoria Levantina, X, Valencia, pp. 59-67.

- 1969. «La Cultura del Bronce Valenciano. Nuevo ensayo de aproximación». Papeles del Laboratorio de Arqueología de Valencia, 6, Valencia, pp. 7-30.

TRELIS MARTI, J. 1983. «Un fragmento de cerámica del Bronce Tardío de la Sima del Pinaret del Mas Nou. Alcoy (Alicante)». Alcoy. Revista de Fiestas de Moros y Cristianos, Alcoy, páginas 90-91.

VICEDO SANFELIPE, R. 1925. Guía de Alcoy. Alcoy.

VISEDO MOLTO, C. 1937. Un enterrament prehistóric al Barranc del Cinc (Alcoi). «Serie de Treballs Solts del S.I.P.», 4 Valencia. 


\title{
LA COLECCION DE CERAMICA CAMPANIENSE DE IBIZA EN EL MUSEO ARQUEOLOGICO NACIONAL
}

\author{
LOURDES PRADOS TORREIRA \\ y JUAN ANTONIO SANTOS VELASCO \\ Universidad Autónoma de Madrid
}

\begin{abstract}
El estudio de las cerámicas campanienses de Ibiza en el Museo Arqueológico Nacional de Madrid permite ampliar el número de formas conocidas de esta procedencia y establecer la relación de Ibiza con los centros productores del Mediterráneo.
\end{abstract}

The study of campanian ceramics from Ibiza in the Museo Arqueológico Nacional in Madrid allows us to increase the amount of forms previously known from this source and to establish the relationship between Ibiza and the producing centres of the Mediterranean.

Desde que M. del Amo publicara en 1970 su conocido artículo sobre las cerámicas de imitación de Ibiza en el que estudiaba igualmente las piezas campanienses depositadas en el Museo de dicha localidad (AMO, 1970), no se había vuelto a publicar ningún trabajo específico referido a este tema.

Con este artículo pretendemos dar a conocer los ejemplares campanienses conservados en el Museo Arqueológico Nacional. Estas cerámicas formaron parte de la antigua colección Vives Escudero y, sin embargo, en los inventarios de dicho museo no existen referencias a estas piezas, salvo la indicación de su antigua pertenencia a la citada colección, así como su procedencia. Somos conscientes de que estos vasos representan sólo una parte, y que lo idóneo hubiera sido poder estudiar el conjunto de cerámica campaniense de Ibiza, tanto de las del M. A. N. como las depositadas en el Museo Arqueológico de Barcelona, que, junto con las ya publicadas del Museo de Ibiza, permitirían un conocimiento global de las mismas. Dentro de esa «parcialidad» de nuestras piezas debe explicarse el hecho de que la mayoría se clasifiquen como campaniense B, lo que es mera consecuencia de la división de un lote en varias colecciones. Otra limitación a tener en cuenta a la hora de enfrentarnos a las mismas es el hecho, comúnmente admitido, de que todas proceden de necrópolis. Cabe esperar que con las futuras excavaciones de poblados en la isla se amplíe el horizonte que sobre ellas poseemos en la actualidad.

No obstante, consideramos que, gracias a los estudios particulares de este tipo de cerámica, quizá en unos años se esté en condiciones de ofrecer una visión de conjunto que permita ayudarnos a comprender cómo se desarrollaron los últimos siglos antes de Cristo en Ibiza, y en concreto sus relaciones comerciales con el exterior. 


\section{LOS MATERIALES}

\section{Forma 1}

$\mathrm{S} / \mathrm{n}$. Pasta rojiza y levemente micácea. Barniz negro brillante con irisaciones azuladas. Manchas de derrame sobre el fondo externo (fig. 1, 1).

285. Pasta rojiza y micácea. Barniz negro luciente con algunas irisaciones y manchas de derrame sobre el fondo externo (fig. 1,2).

$73 / 36 / 166$. Pasta rojiza y micácea. Barniz negro con irisaciones azuladas y manchas de derrame sobre el fondo externo (fig. 1,3).

Las características técnicas y tipológicas de estos tres vasos recuerdan algunas piezas procedentes del sur de Italia, con fechas alrededor de 100 a. C. (MOREL, 1981, $105)$.

18.510. Pasta beige bien depurada. Barniz negro mate con abundantes manchas marrones, fondo externo en reserva. Campaniense B (fig. 2, 1).

18.511. Pasta beige. Barniz negro mate, fondo reservado. Muy visibles las huellas de torno. Campaniense B (fig. 2, 3).

128/78. Pasta beige bien decantada. Barniz negro mate con abundantes manchas marrones. Campaniense B (fig. 2, 2).

73/36/154. Pasta beige. Barniz negro mate con manchas de derrame sobre el pie. Existe una pieza muy parecida en la colección del Museo de Ibiza (AMO, 1970, 234) (fig. 1, 4).

Esta forma de la campaniense B se conoce ya en el siglo II a. C.; se documenta básicamente en el siglo siguiente, perdurando en algunas zonas hasta la aparición de la cerámica aretina (MOREL, 1962-65, p. 114).

\section{Forma 3}

35.232. Pasta rojiza y algo micácea. Barniz negro mate y escamoso (fig. 2, 7).

36.226. Pasta beige bien depurada. Barniz negro con algunas irisaciones metálicas en el fondo externo. Campaniense B. Grafito sobre el fondo externo (fig. 2, 6).

36.227. Pasta rojiza, micácea y escamosa. Barniz negro brillante con irisaciones azuladas. Piezas de perfiles similares proceden de Ampurias, de los inicios del siglo I a. C. (SANMARTI, 1978, vol. I, núm. 26) (fig. 2, 4).
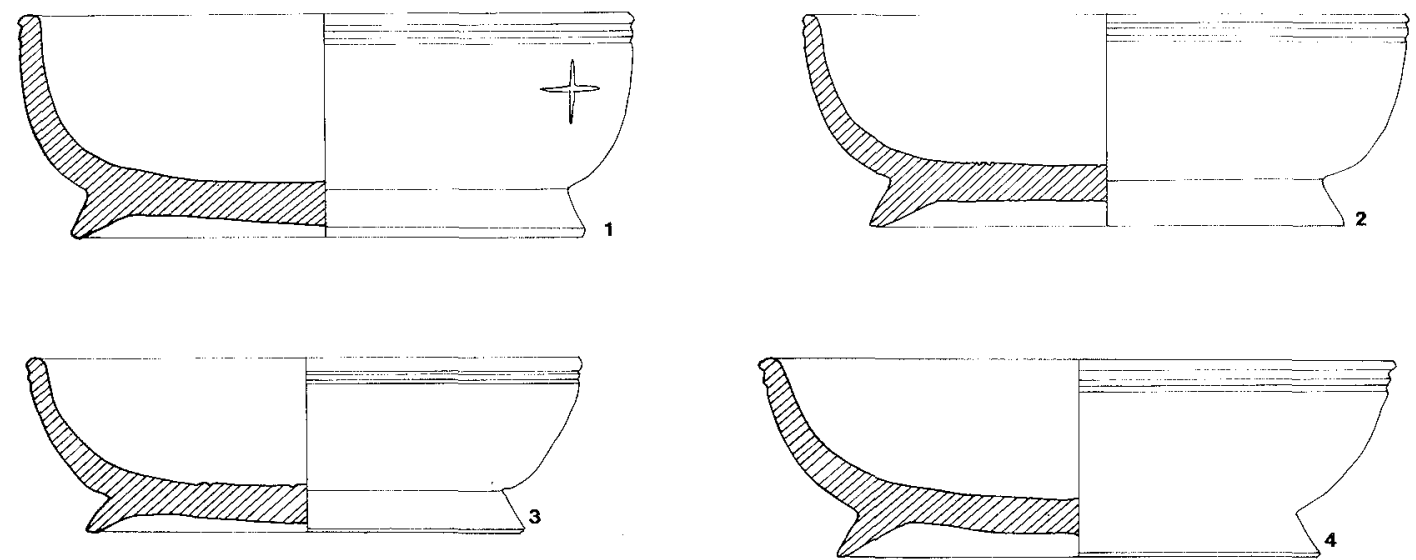

Figura 1: Forma 1: 1, s/n; 2, 285; 3, 73/36/116; 4, 73/36/154. 

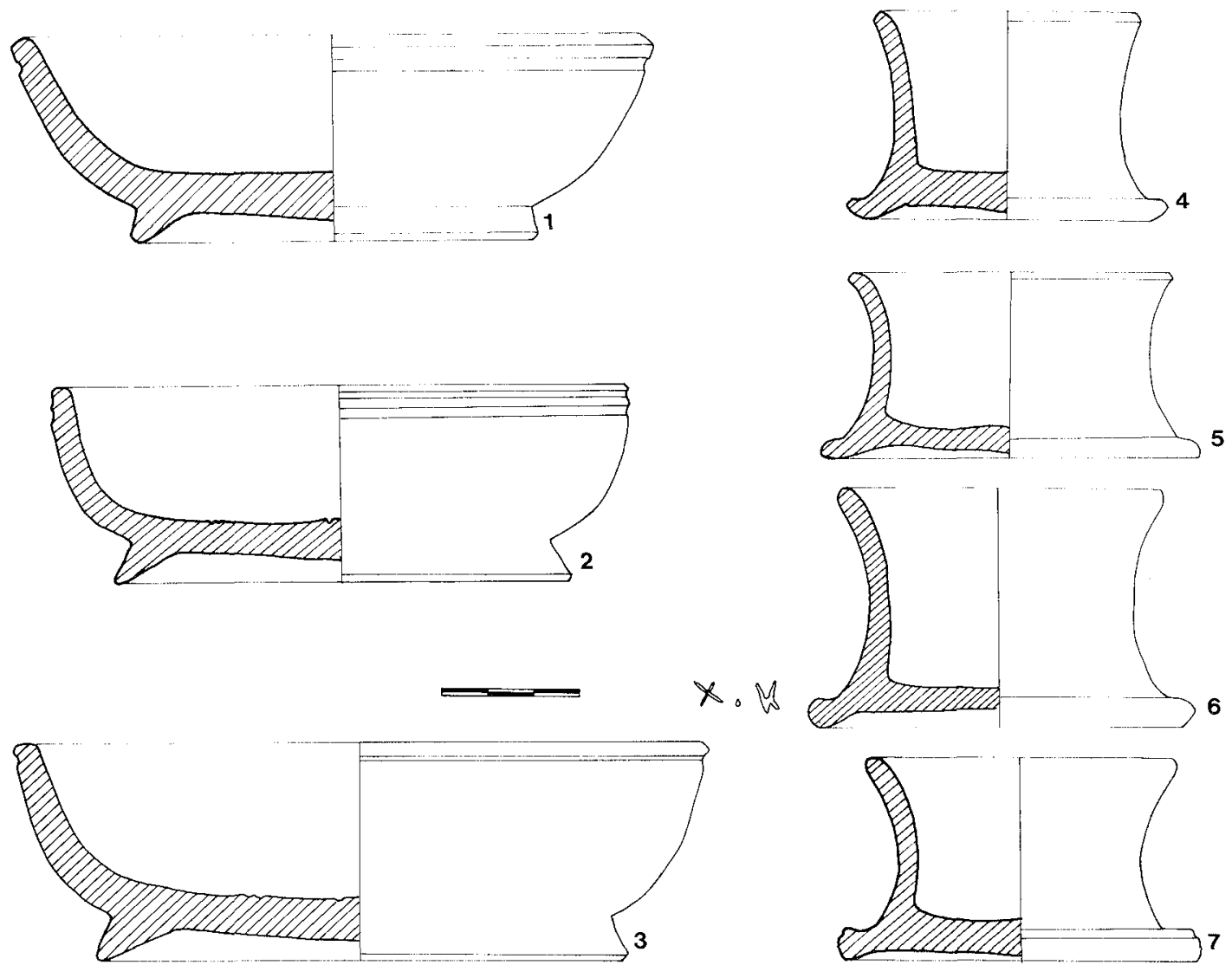

Figura 2: Forma $1: 1,18.510 ; 2,128 / 78 ; 3,18.511$. Forma $3: 4,36.227 ; 5,36.225 ; 6,36.226 ; 7,36.232$.

\section{Forma 14}

133. Pasta beige bien depurada. Barniz negro brillante de mala calidad con abundantes irisaciones metálicas. Morel clasifica estas piezas en la serie 9130 (MOREL, 1981). La forma del borde es igual a un fragmento de tapadera del depósito B de Cosa (B.52a) fechado entre 170-140 a. C. (TAYLOR, 1957, 163) (fig. 3, 4).

\section{Forma 20}

36.233. Pasta gris, levemente micácea y bien depurada. Barniz negro mate, fondo externo en reserva con manchas de inmersión. Se trata más bien de una variante que de propiamente la forma 20 de Lamboglia, aunque tiene ciertas similitudes formales con la pieza 2781.c.1. de Morel, procedente de Chiesti, asimismo de pasta gris y fechada en la primera mitad del s. III a. C. (MOREL, 1981, 232) (fig. 3, 5).

\section{Forma 27}

$\mathrm{S} / \mathrm{n}$. Pasta rojiza bien depurada. Barniz negro brillante con irisaciones azuladas, manchas de derrame sobre el fondo externo. Decorado con una roseta impresa sobre el fondo interno, en mal estado de conservación, tiene siete pétalos y punto central. Este tipo de roseta descuidada es propia de productos del s. II a. C. Se encuentra una del mismo tipo en Nages en el tercer cuarto del s. II a. C. (PY, 1978, núm. 48) (fig. 3, 2). 


\section{Forma 74}

$73 / 36 / 537$. Pasta rojiza bien depurada. Barniz negro mate con abundantes manchas marrones y rojizas alrededor del pie. Manchas de derrame sobre el fondo externo.

Un tipo igual procede de La Albufereta, clasificada como F 74, Kyathos. Se diferencia por estar decorada con una línea incisa y hojas de hiedra. Se data en la primera mitad del s. III a. C., y se clasifica como producto local (SALVA, 1967, 364). Esta pieza ha sido también estudiada en un trabajo anterior (RODERO, 1980, 26) (fig. 3, 7).

\section{Forma 99}

36.301. Pasta rojiza bien depurada. Barniz negro luciente, manchas de derrame en el fondo externo y en la base. Fondo reservado. Pertenece a la serie 5810 de Morel, quien apunta su origen en Italia central, desde Etruria a la zona septentrional de Campania (MOREL, 1981, 388). Sin embargo, no deja de hacer constar su frecuente aparición en yacimientos púnicos como Cartago (MOREL, 1980, 40) y Sicilia (TUSA CUTRONI, 1971). Estos ejemplares difieren tipológicamente de éste en algunos aspectos, pero uno igual se documenta en la necrópolis de Les Andalouses, tipo AN. 101, en cerámica gris, fechado entre los siglos III-II a. C. (VUILLEMOT, 1965, 339) (fig. 3, 6, lám. 1, 1).

\section{Forma 127}

36.216. Pasta beige bien depurada y micácea. Barniz negro luciente. Manchas rojizas sobre el pie y de derrame sobre el fondo externo (fig. 3,3 y lám. 1, 3).

$73 / 36 / 155$. Pasta marrón-rojiza porosa. Barniz negro luciente que cubre la parte interna y la mitad superior de la externa. Abundantes manchas de derrame y azuladas en el interior (fig. 3,1).

Forma propia del área etrusca que se documenta más bien en el s. II a. C. (MOREL, 1981, 248). El vaso 76/36/155 es muy similar al del pecio de La Pedrosa, L'Estartit (Gerona), datado entre 150-140 a. C. (BARBERA, 1975, 80). Sus características técnicas son muy semejantes a las del pecio de Sant Jordi (CERDA, 1980).

\section{LAS LUCERNAS DE BARNIZ NEGRO}

\section{a) Descripción}

$\mathrm{S} / \mathrm{n} / 1$. Lucerna sin asa, apéndice lateral con indicio de perforación. Pasta anaranjada. Barniz negro brillante de buena calidad, muy saltado. Completamente barnizada excepto la acanaladura del agujero de llenada. Pico quemado del uso.

Tipo 32 del Agora de Atenas desarrollo del 29B. Finales del segundo cuarto del s. III a. C. hasta fines del siglo y quizás más tarde (HOWLAND, 1958, p. 99, núm. 425432).

$\mathrm{S} / \mathrm{n} / 2$. Lucerna con apéndice sólido y arranque de asa vertical, completamente barnizada de negro, barniz brillante algo saltado. Pasta rojiza. Probablemente campaniense A.

Está entre los tipos II y III de Lattes. Del tipo II, la escasa altura, y del III, el cuerpo bitroncocónico, el asa y el apéndice sin perforar. Son contemporáneas a las primeras 

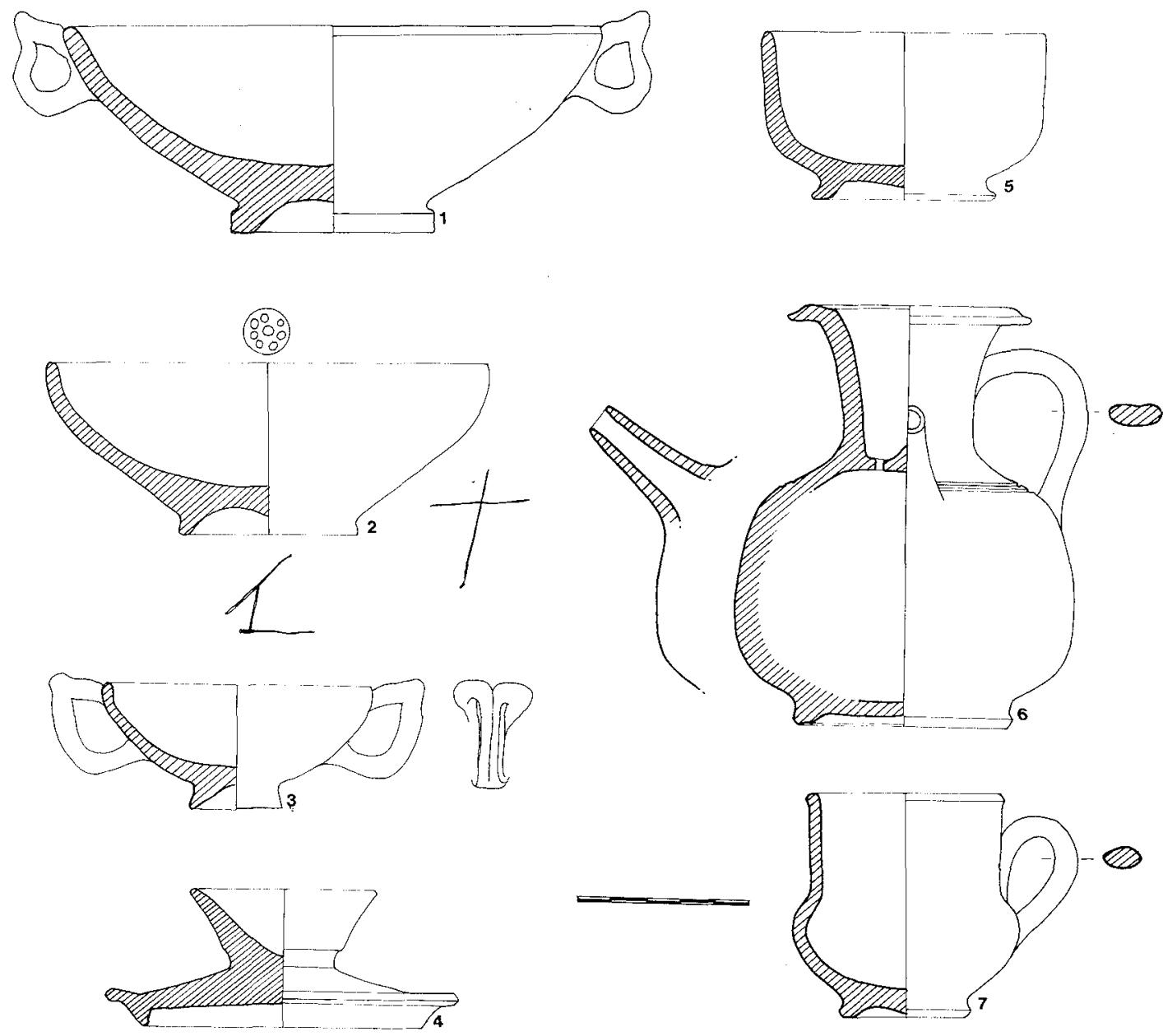

Figura 3: Forma 127: 1, 73/36/55; 3, 36.216. Forma 27:2, s/n. Forma 14: 4, 133. Forma 20: 5, 36.223. Forma 99: 6, 36.301. Forma 74: 7, 73/36/537.

exportaciones de campaniense A a fines del s. III a. C. (ESPEROU, 1978, 74). Probablemente ya del s. II a. C.

36.198. Lucerna plástica hecha con molde en dos partes. Pasta amarillenta con desgrasantes finos. Barniz negro en mal estado, mate, desgastado, en algunas zonas rojizo por defecto de cocción. Le falta parte del agujero de llenada.

Tipo $47 \mathrm{c}$ del Agora de Atenas, o al menos basada en modelos áticos de fines del s. III a fines del II a. C. (HOWLAND, 1958, núm. 615) (fig. 4, 3 y lám. 2, 3).

$73 / 36 / 21$. Lucerna con vertical y apéndice, completamente barnizada, incluso la acanaladura y el fondo externo. Pasta rojiza. Barniz negro brillante, bastante descascarillado. Tipo 29B del Agora de Atenas.

$73 / 36 / 25$. Lucerna con apéndice perforado y sin asa. Pasta amarillenta. Barniz negro mate con el fondo externo en reserva. La acanaladura superior de color rojo vinoso de pintura o barniz.

Tipo 29B del Agora de Atenas y con caracteres del 29A como la curvatura marcada de la pared y el fondo reservado. Primera mitad del s. III a. C. (HOWLAND, 1958, núm. 412-414). 

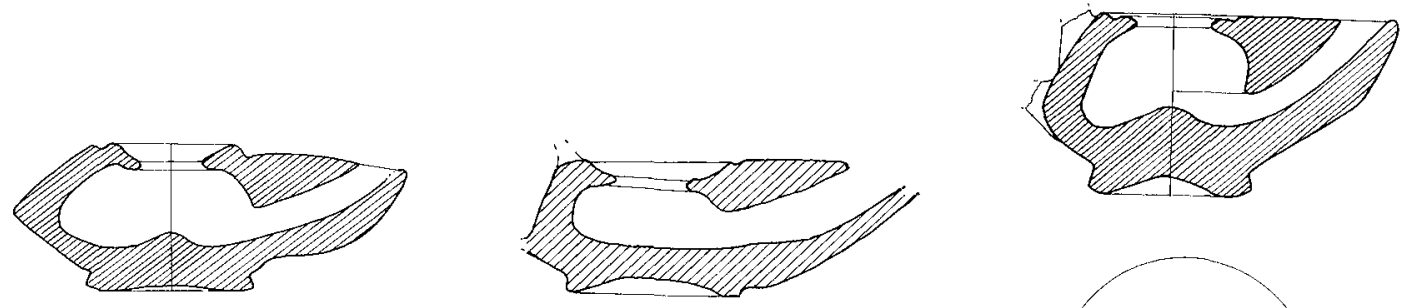

2
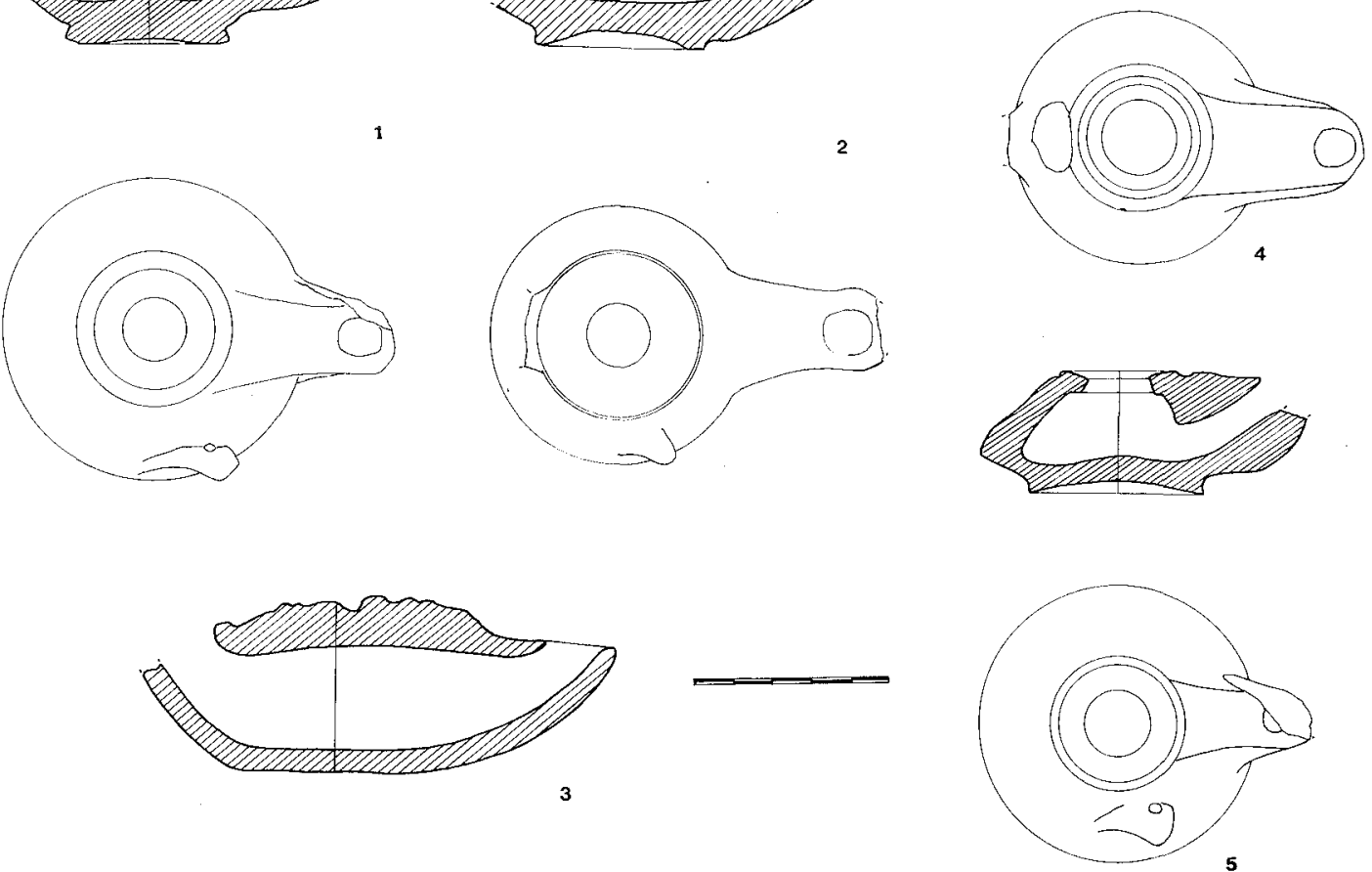

Figura 4: Lucernas: $1, \mathrm{~s} / \mathrm{nI} ; 2, \mathrm{~s} / \mathrm{n} 2 ; 3,36.198 ; 4,73 / 36 / 21$ 5,73/36/25.

\section{b) Análisis de los materiales}

Las lucernas, que tienen un especial significado funerario en el mundo púnico, son sin duda la forma más representada entre los vasos de importación e imitaciones en la necrópolis del Puig d'es Molins. El problema para el estudio de las lucernas helenísticas, que no son de procedencia ática, es que no existe una sistematización de los tipos, y que éstos perduran durante largos períodos de tiempo. Sólo se cuenta con determinadas consideraciones generales para su análisis, como el basarse fundamentalmente en prototipos áticos, y algunos aspectos sobre la evolución del pico y del cuerpo. Según la clasificación de Esperou en Lattes, los tipos corresponden más bien a piezas antiguas, por sus picos redondeados y la perforación del apéndice lateral (ESPEROU, 1978, 74). Se hace por lo tanto necesario recurrir a los prototipos griegos, lo que proporciona una cronología del s. III a. C. en la mayor parte de los casos. Sin embargo, el grueso de las importaciones de barniz negro se da a partir del s. II a. C. Tal vez se trate de una simple cuestión de depósito en los museos, puesto que las piezas del Puig se reparten entre varios de ellos, y a la falta de conocimiento que tenemos en esta materia de los fondos del Museo de Ibiza, pues no se incluyeron las lucernas en su estudio (AMO, 1970). Sólo las piezas $\mathrm{s} / \mathrm{n} / 2$ y 36.198 tendrían una datación en el s. II a. C.; las restantes deben ser importaciones de la primera mitad del s. III a. C., antes de comenzar las guerras púnicas y con ellas un período de inestabilidad que retrae el comercio en Occidente. 

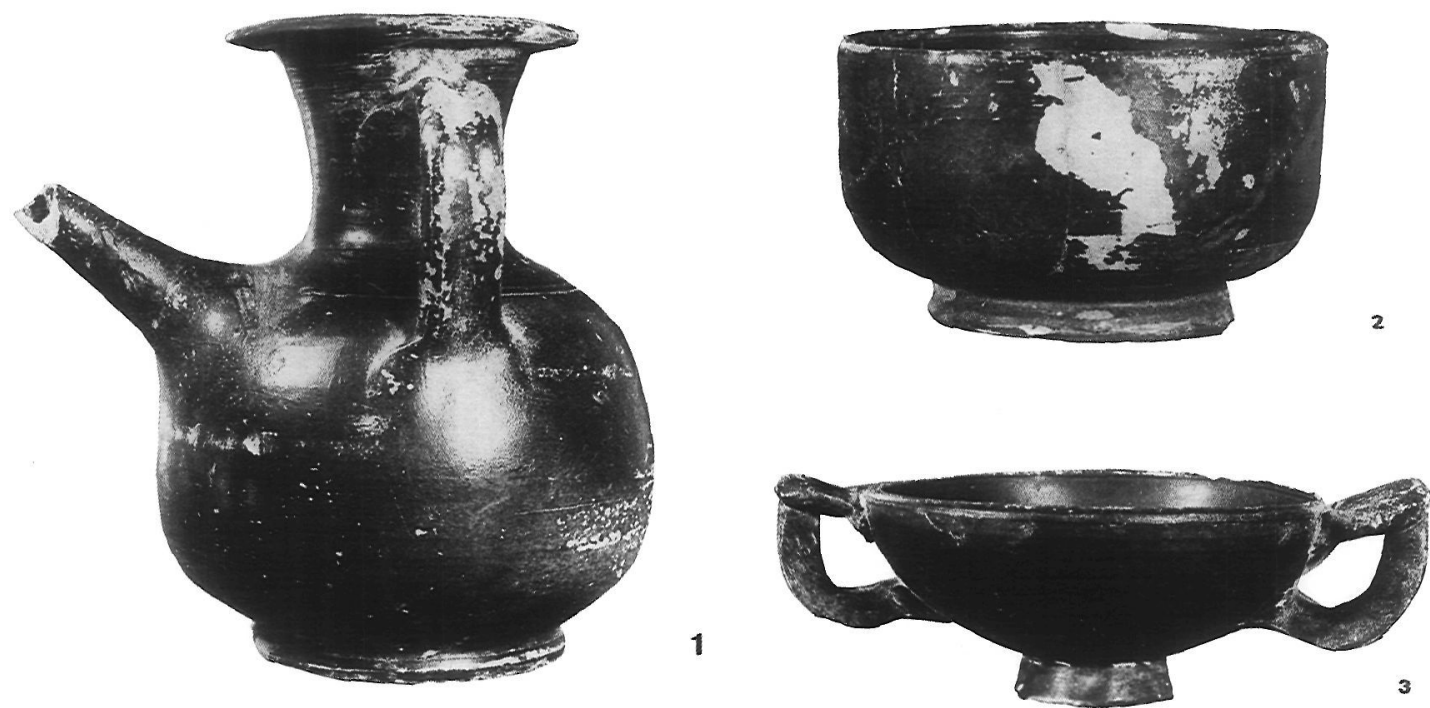

Lámina I: 1, F99; 2, F20; 3, F127.

\section{CONSIDERACIONES FINALES}

La difusión marítima e internacional de la cerámica campaniense en la cuenca del Mediterráneo ha sido objeto tanto de estudios generales como de análisis pormenorizados, que contribuyen a renovar, de una manera constante, el panorama que sobre este tipo de cerámica se tiene desde que fuera definida, de forma provisional, por Lamboglia (LAMBOGLIA, 1952).

Un yacimiento ya conocido por la bibliografía es Ibiza. No obstante, con la publicación de estas piezas, procedentes del Mủseo Arqueológico Nacional, se amplía notablemente la tipología del Puig d'es Molins. Así, entre las formas del s. III a. C., podemos citar la 99 y la 74 que, junto con la 44 y 12 del Museo de Ibiza, forman un conjunto bien diferenciado desde el punto de vista cronológico y cultural, ya que estas piezas son habituales en yacimientos púnicos e ibéricos, en lo que Morel ha dado en llamar «área punicizante» (MOREL, 1978, 149), que se extiende desde Cartago a nuestra península, con paralelos en la propia Cartago, Lilibeo, La Albufereta y Les Andalouses, entre otros. Sólo a partir del s. II a. C. podemos hablar de importación de cerámica campaniense, en una variedad de tipos bastante «standard», propia del alto grado de industrialización que alcanzan estos productos, que se encuentran con frecuencia en otros yacimientos del Mediterráneo. En este último período queda también ampliado el horizonte tipológico con las formas 14 y 127. La F127 tiene su origen en Etruria en el s. III a. C. (MONTAGNA PASQUINUCCI, 1972): Cabe destacar las similitudes técnicas y formales del vaso 73/36/155 (fig. 3, 1) con el procedente del pecio de L'Estartit, por lo que proponemos la misma cronología para nuestro ejemplar (150-140 a. C.). Otras piezas de esta misma forma, que nos interesan por sus implicaciones cronológicas y espaciales, son las de Cales Coves (BELEN y FERNANDEZ-MIRANDA, 1979, fig. 54), del pecio de Sant Jordi (CERDA, 1980), Ampurias (SANMARTI, 1978) y Valencia (MARTIN, 1964, 338). Su difusión es escasa y muy localizada, a pesar de lo cual fue objeto de imitación por los talleres ibicencos (GUERRERO, 1980), de los que estos vasos debieron ser sus prototipos. Por lo que respecta a otras formas, los vasos de la F1 s/n, 285 y 76/36/166 (fig. 1, 1, 2 y 3) son técnicamente iguales entre sí, y al mismo tiempo se dife- 


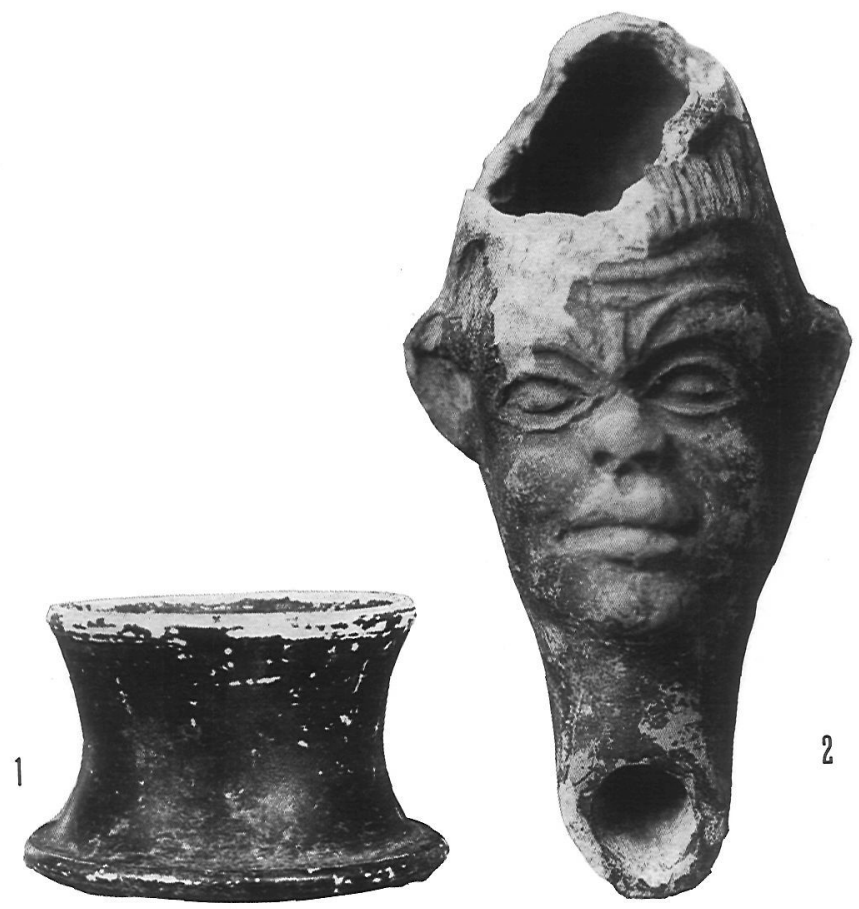

Lámina II: 1, F1; 2, F3,

rencian de los que se catalogan como campaniense $\mathrm{B}$, ya que recuerdan más, tanto por las particularidades del tipo como por sus características técnicas, piezas recogidas por Morel del sur de Italia y datadas alrededor de 100 a. C. (MOREL, 105).

Las producciones de campaniense no llegarían a la isla antes de 200 a. C. Las guerras púnicas influyeron en las relaciones comerciales del occidente mediterráneo y ese período de turbulencias empobreció las importaciones de la península y del norte de Africa (MOREL, 1968, 73). Esto viene apoyado por la cronología más propia de la primera mitad del s. III a. C. de las formas 99 y 74, así como por la escasez del lote, si se compara porcentualmente con las importaciones de cerámica ática, en siglos anteriores, y de campaniense más tarde.

La tipología de las piezas ibicencas se ha puesto en estrecha relación con el mundo púnico, resaltando su similitud con Cartago (AMO, 1970, 219). Esto resulta evidente en el barniz negro del s. III a. C., pero más difícil de sostener en contextos puramente campanienses, puesto que sus formas las encontramos dispersas por muchos puntos del Mediterráneo occidental, no únicamente en ambientes púnicos. Por otra parte, el horizonte tipológico cartaginés es muy amplio. En el cuadro comparativo (fig. 5) se observa que los tipos procedentes del Puig d'es Molins se pueden confrontar con los de yacimientos tan distantes y contextos tan diversos como L'Estartit, Hipona, la última fase de Cartago y los depósitos $\mathrm{B}$ y $\mathrm{D}$ de Cosa, debido a la representación de los mismos y a la frecuencia con que se documenta cada tipo (1). Comprobamos que del primer impacto de la exportación campaniense a fines del s. III a. C. faltan sus formas más características, que sí aparecen, por ejemplo, en Cataluña. Estas de Ibiza, por el contrario, forman un horizonte más propio de $200 \mathrm{a}$. C. en adelante (F 5, 6, 27c, 28, 31, 34, 55, 68).

(1) Clasificamos como F68 la que aparece como F48 en el trabajo de M. del Amo. 


\begin{tabular}{|c|c|c|c|c|c|c|c|c|c|c|c|c|c|c|}
\hline FORMAS & 1 & 2 & \begin{tabular}{l|l}
3 & 5 \\
\end{tabular} & 6 & 8 & $10+1$ & 1123 & \begin{tabular}{|l|l|}
3 & 27 \\
\end{tabular} & \begin{tabular}{l|l|}
28 & 31 \\
\end{tabular} & \begin{tabular}{l|l|}
3 & 33 \\
\end{tabular} & \begin{tabular}{|l|l|}
34 & 36 \\
\end{tabular} & 349 & \begin{tabular}{|l|l|}
55 & 65 \\
\end{tabular} & \begin{tabular}{l|l|l}
5 & 68 & 127
\end{tabular} \\
\hline IBIZA A & & & & & 0 & & & & & & O & & 0 & 0 \\
\hline IBIZA $\quad$ B;F127 & & & & & & 0 & & & & & & & & U \\
\hline GRAND CONGLO & & & & & & & & & & & & & & 2 \\
\hline CARTAGO & & & & & & & & & & & & & & 0 \\
\hline S. JORDI B:F1 & & & & & & & & & & & & & & 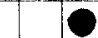 \\
\hline HIPONA & & & & & & & & & & & & & 0 & \\
\hline DEP. B $\operatorname{COSA}$ & & & & & & & & & & & & & 0 & \\
\hline DEP. D $\cos A$ & & & & & & & & & & & & & 0 & \\
\hline
\end{tabular}

Figura 5: Tipología comparada de Ibiza y otros yacimientos del Mediterráneo Occidental.

El conjunto ibicenco se puede comparar de un modo más directo con el pecio de L'Estartit (150-140 a. C.), con el segundo grupo que Morel asocia en Hipona (200180/120-100 a. C.), y de nuevo con los depósitos B y D de Cosa, datados entre 180160/140 el primero y entre 150-130/70-60 el segundo. De ahí que seamos partidarios de. pensar que las importaciones de campaniense de Ibiza obedecen más a un fenómeno internacional que a algo que atañe particularmente a áreas púnicas, y que se produce desde el s. II a. C. De hecho, con el fin de la II guerra púnica Ibiza se convierte en ciudad federada de Roma (201 a. C.). Con esta integración en la órbita romana la isla no parece sufrir ningún revés económico o comercial. Por el contrario, todas las evidencias parecen indicar que se adaptó sin problemas a la nueva situación. El auge de la moneda ebusitana se produce entre 200-100 a. C., las relaciones con la península ibérica y con Italia quedan atestiguadas, entre otras cosas, por la presencia de monedas procedentes de sus cecas en el área de Pompeya y en diversas zonas de Campania durante los siglos II-I a. C. (STAZIO, 1963, 20), así como en las costas hispanas (FERNANDEZ GOMEZ, 1976, 50). También es ahora cuando Ibiza quedaría abierta al tráfico de barniz negro procedente de Italia, y se realiza la apertura de la isla, por primera vez a gran escala, a productos itálicos, ya que con anterioridad no se encuentran más que escasos ejemplos de un posible contacto con Italia, como una copa (fig. 6), probablemente suritálica de la serie 4242 de Morel, puesto que las importaciones del s. IV a. C., que han sido objeto de un reciente estudio, son de origen ático (SANCHEZ FERNANDEZ, 1981). Respecto a las del s. III a. C. ya hemos hecho referencia a su carácter púnico y al escaso número de importaciones en ese período.

El conjunto de campaniense B unido a la forma 127, al igual que ocurre con el pecio de Sant Jordi, relaciona el centro-sur de Italia con Etruria y las Baleares, con pasos intermedios en Gerona (L'Estartit, Ampurias) y Valencia, que atestigua de nuevo los estrechos vínculos entre la zona ampuritana e Ibiza, cuestión que se hace también patente por ser una de las de mayor concentración de monedas ebusitanas en la península, y cuyas relaciones se documentan desde fechas anteriores, cuando dominaba el comercio de piezas áticas (SANCHEZ FERNANDEZ, 1981).

Queda asimismo patente la relación de Ibiza con las otras baleares por la aparición de productos típicos de esa isla en Mallorca y Menorca (cerámicas ibicencas, cuentas de pasta vítrea, terracotas, cerámicas seudo-campanienses de Ibiza, etc.) y también por las formas típicas de la cerámica campaniense, a las que hemos hecho referencia. Llama la atención la importancia de los cargamentos de barniz negro y la escasísima presencia de estas cerámicas en las fases finales de los poblados talayóticos, donde suelen estar representadas por un número muy reducido de piezas. Por ello cabe preguntarse si los grandes depósitos de campaniense procedentes de estas dos islas iban realmente destinados a Mallorca y Menorca, o se trataba de una simple escala en su viaje hacia otras costas (2).

Respecto al significado de la cerámica campaniense en Ibiza nos encontramos con un problema fundamental: la falta de excavaciones en poblados. Esto supone que la in- 


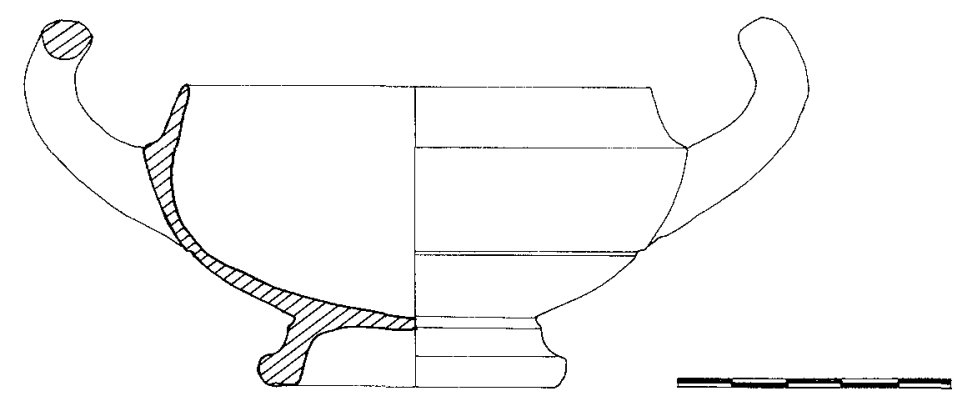

Figura 6: Copa 36.299 probablemente suritálica de la serie 4242 de Morel.

formación que nos proporcionan las piezas será siempre muy matizable, pues como señalamos al comienzo, se considera que todas ellas proceden de la necrópolis. Por ello, al menos en principio, cabe suponer un carácter más ritual que práctico para todas ellas, y por consiguiente no estrictamente coincidente con las formas procedentes de poblados. De hecho, a partir del s. III vemos cómo disminuyen las importaciones y aumenta la cerámica de imitación; sin embargo, a pesar de variar el tipo de cerámica, continuamos encontrando la misma clase de objetos en los ajuares: lucernas, platos, jarros, cuencos, etc. (GOMEZ BELLARD, 1984). También la aparición de un alto número de lucernas pudiera explicarse por este motivo, aunque puede deberse, asimismo, a la gran producción de aceite de la isla (TARRADELL-FONT, 1975, 259).

Para terminar, consideramos que del estudio de la cerámica campaniense de Ibiza - y con la carencia que supone no tener un contexto arqueológico ilustrativo- podemos deducir que a partir del final de la II guerra púnica la isla se integra plenamente en la órbita comercial romana, y no como mero intermediario, sino con un papel relevante. Sus relaciones comerciales no se redujeron a los territorios que en su día formaron el ámbito comercial púnico; sus contactos tanto con la península itálica como de manera especial con la ibérica y Baleares, están plenamente documentados (3). Esta integración comercial en el mundo romano no supuso que Ibiza renunciase a sus modos de vida tradicionales, creencias religiosas, costumbres funerarias, etc., pues, como sabemos, éstas se mantuvieron incluso con posterioridad al cambio de era.

(2) No es éste el lugar adecuado para extendernos sobre este punto por salirse del objetivo del artículo. Sin embargo, consideramos que resultaría de enorme interés realizar un estudio global sobre la campaniense en las islas Baleares.

(3) Estos contactos habian sido ya patentes durante los siglos anteriores a las guerras púnicas, en particular en la zona ampuritana, así como en el resto de Levante. 


\section{BIBLIOGRAFIA}

AMO DE LA HERA, M. 1970: «La cerámica campaniense de importación y las imitaciones campanienses de Ibiza», Trabajos de Prehistoria, 27. Madrid.

BARBERA, J. 1959: «Hallazgo submarino de un pecio con cargamento de cerámica campaniense», Zephyrus, X.

1975: «Un cargamento de cerámica barnizada de negro del pecio de la isla Pedrosa (L'Estartit, Gerona)», Inmersión y Ciencia, 89.

BELEN, M., y FERNANDEZ-MIRANDA, M. 1979: El fondeadero de Cales. Coves (Alayor, Menorca). E. A. E. 101. Madrid.

CAMPO, M. 1976: «Las monedas de Ebusus», A. N. E. Barcelona.

CERDA JUAN, D. 1980: La nave romana-republicana de Sant Jordi, Palma de Mallorca.

ESPEROU, J. L. 1978: «Les lampes à vernis noir de Lattes (Hérault)», Archéologie en Languedoc, 1.

FERNANDEZ GOMEZ, H. 1976: «La circulación monetaria ibérica en Ebusus», Numisma, n. 138-143, 49-57. Madrid.

- 1983: Guía del Museo Monográfico del Puig des Molins. Trabajos del Museo Arqueológico de Ibiza, 10. Madrid.

GOMEZ BELLARD, C. 1984: La necrópolis del Puig des Molins (Ibiza). Campaña de 1946. E. A. E. 132. Madrid.

GUERRERO, K. 1980: «Las cerámicas pseudocampanienses ebusitanas en Mallorca», Archéologie en Languedoc, 3.

HOWLAND, R. H. 1958: "Greek lamps and their survivals», The Athenian Agora, IV, 1958.

JEHASSE, J. y L. 1962: «La cerámique campanienne d'Aleria II», Rev. Etudes Cortes, 4. 1961-62.

- 1973: «La Nécropole prerromaine d'Aleria», XXV Suppl. a Gallia. París.

LAMBOGLIA, N. 1952: Per una classificazione preliminare della ceramica campana. Bordighera.

LLOBREGAT, E. 1974: «Las relaciones con Ibiza en la protohistoria valenciana», Prehistoria y Arqueología de las I. Baleares. VI Symposium de Prehist. Peninsular, 291-320.

MARTIN, G. 1974: «Cerámica campaniense de Valentia, Pollentia y Albintimilium», Prehist. y Arqueol. de las I. Baleares. VI Symposium de Prehist. Peninsular, 321-358.

MONTAGNA PASQUINUCCI, M. 1972: "La ceramica a vernice nera del Museo Guarnacci di Volterra», Mélanges de L'Ecole Française de Rome, Antiquité, 84-1.

MOREL, J. P. 1965: «Céramiques d'Hippone», Bulletin d'Archéologie Algérienne, I. 1962-65.

- 1968: "Céramique à vernis noir del Maroc», Antiquités Africaines, 2.

- 1978: «Observations sur les céramiques à vernis noir de France et d'Espagne», Archeologie en Languedoc, I.

- 1980: «Les vases à vernis noir et à figures rouges d'Afrique avant la deuxième guerre punique et les problemes des exportations de Grand-Grèce», Antiquités Africaines, XV.

- «Céramique campanienne. Les Formes», Ecole Française de Rome.

NICOLAS, J. C. de. 1979: La nave romana de Edad Republicana del Puerto de Mahón. C. I. S. M. Mahón.

PY, M. 1976: «Note sur l'évolution des céramiques à vernis noir des oppida languedociens de Roque de Vion et de Nages (Gard, France)», M.E.F. R. 88. 1976.

- 1978: «Apparition et développment des importations de céramique campanienne A sur l'oppidum des Castes (Nages, Gard) d'aprés les foulles du dépotoir I 1 », Archéologie en Languedoc, 1. 1970. Montpellier.

RODERO, A. 1980: Colección de cerámica púnica de Ibiza. Madrid.

SALVA, A. 1967: «Nuevas formas de cerámica precampaniense en la necrópolis ibérica de la Albufereta de Alicante», X.C. N. A. Mahón, 1967.

SANCHEZ FERNANDEZ, C. 1981: «La cerámica ática de Ibiza en el Museo Arqueológico Nacional», Trabajos de Prehistoria, 38.

SANMARTI GREGO, E. 1978: La cerámica campaniense de Emporion y Rhode. Barcelona.

STAZIO, A.: «Le piú antiche relazioni tra la Peninsola Iberica e la regione Campana», Numisma, n. ${ }^{\circ} 61$. Madrid. pp. 9-20.

TARRADELL, M., y FONT, M. 1975: Eivissa Cartaginessa. Barcelona.

TAYLOR, D. M. 1957: Cosa: Black glaze Pottery. Memoirs of the American Academy in Rome. XXV.

TUSA CUTRONI, A. 1971: «Lilibeo y Marsala. Nuovi scavi nella necropoli punica (1969-70)», Notizie degli scavi di antichità, XXV. 1971.

VENY, C., y CERDA, D. 1972: «Materiales arqueológicos de dos pecios de la isla de Cabrera (Baleares)», Trabajos de Prehistoria, 29, Madrid, 298-328.

VUILLEMONT, G. 1965: Reconnaissances aux échelles puniques en Oranie. 



\title{
EL VIDRIO ROMANO EN LA PROVINCIA DE ALICANTE *
}

\author{
M. DOLORES SANCHEZ DE PRADO \\ Universidad de Alicante
}

\begin{abstract}
Este trabajo pretende fundamentalmente dar a conocer un material muy postergado por la investigación arqueológica: el vidrio, que se ha encontrado con relativa frecuencia en las ciudades y necrópolis de la provincia de Alicante. En el vidrio recogido se pueden distinguir dos grupos:

- En las dos primeras centurias de nuestra Era se trata de un vidrio lujoso, de muy buena calidad, liso o decorado con motivos sencillos cuyo carácter es marcadamente oriental.

- A partir del siglo III d. C., la calidad de las piezas es menor, aunque las decoraciones más complicadas. Las fábricas occidentales se imponen progresivamente.

The aim of this study is to spread a sort of material quite ignored by the archaeologycal research: that's the glass, often obtained in the roman villages and necropolis of Alicante. With regard to its characteristics, we have found two different types:

- A top-quality glass, decorated with primitive motives, brought from oriental countries while 1 st and 2 nd centuries a. $C$.

- A medium-to-low quality glass, decorated with very complicated motives, brought european factories since 3rd century a. C. Quality in raw material was descending as production was getting higher.
\end{abstract}

El objetivo de este trabajo ha sido realizar un estudio preliminar sobre el vidrio antiguo, ciñéndonos al marco que ofrece la provincia de Alicante. Esta labor se nos reveló interesante y necesaria, ya que existía una falta total de estudios sobre el tema. El vidrio ha permanecido inédito en nuestros museos, salvo muy raras excepciones. Hasta ahora la atención del arqueólogo se ha dirigido hacia otros materiales que le ofrecerían resultados más brillantes. Pero últimamente esta tendencia está cambiando y paulatinamente se manifiesta un creciente interés por estos materiales de «segundo orden» que, en realidad, son importantes auxiliares cronológicos. Así, el vidrio se encuentra con frecuencia en poblados y necrópolis, pudiéndose citar a la Isleta de Campello, el Tossal de Manises, Lucentum, el Monastil y las Agualejas, Illici o el Portus como ciudades o importantes villas, necrópolis como L'Horta Major, Mas Blanc o el Montañar en Jávea. Por otra parte, el vidrio fue un artículo de lujo que nos sirve como indicador de unas relaciones comerciales en las que nuestra costa participó activamente.

El primer paso que dimos al inicio del trabajo fue la recogida de material por los museos municipales y provincial; también pudimos acceder a algunas de las colecciones particulares que poseían material de este tipo. Luego éste sería dibujado y descrito, siguiendo una tipología geométrica de las formas, manteniendo siempre su encuadre en el yacimiento del que procedía.

* Este trabajo es un resumen de nuestra Memoria de Licenciatura que, bajo la dirección del doctor Lorenzo Abad Casal, fue presentada en la Facultad de Filosofía y Letras de la Universidad de Alicante, obteniendo la calificación de «sobresaliente por unanimidad». 
El paso siguiente fue la bibliografía, tarea que resultó bastante problemática, ya que en España el tema ha sido tratado escasamente, lo cual nos llevó a la recogida de publicaciones extranjeras que habrían de ser básicas para nuestro estudio.

El trabajo original se estructura en dos grandes grupos: el vidrio prerromano y romano. Pero, para esta publicación, hemos considerado que la primera parte debía ser suprimida, pues los fragmentos hallados fueron muy escasos y mayormente son elementos de adorno, grupo que presenta una problemática distinta, ya que a través de los siglos tanto sus técnicas decorativas como formativas han permanecido invariables, lo cual dificulta extraordinariamente su adscripción cronológica. Así pues, nos hemos ceñido exclusivamente al vidrio romano, dando a conocer las piezas más significativas halladas en la provincia de Alicante. Estas se han catalogado según su forma en los siguientes grupos: Ungüentarios, Botellas, Cubiletes o Vasos, Cuencos, Copas, Platos y Jarros. El estudio tipológico se ha hecho siguiendo fundamentalmente la obra de C. Isings (1957); asimismo cuando ha sido posible hemos indicado los paralelos hallados en otras excavaciones de la Península.

\section{UNGÜENTARIOS}

El ungüentario o balsamario es un tipo de recipiente destinado principalmente a contener perfumes o ungüentos. Son las piezas más comunes y numerosas del mundo romano, distinguiéndose numerosas formas que hemos ido analizando según su cronología.

\section{I.1. Ungüentario globular (Isings 10)}

Este tipo de ungüentario aparece generalmente con el cuello roto, pues, dado que eran cerrados una vez llenos, era necesario rompérselo para poder utilizar su contenido. Los ejemplares más tempranos se datan en época de Tiberio a Claudio, no continuando, al parecer, en el siglo II d.C. El ejemplar (Fig. 1, 1) que hemos recogido ha sido fabricado en vidrio mosaico; se trata de una técnica tanto formativa como decorativa. Esta consistía en colocar barritas de vidrio de distintos colores uniéndolas por la parte interior del molde y cerrándolas con un segundo molde. El conjunto era calentado hasta su fundición y el recipiente resultante se pulía luego, a fin de eliminar las irregularidades superficiales. La escasez de este tipo de vidrio en nuestra provincia y su carácter de pieza lujosa, hace que nos planteemos la posibilidad de que este ungüentario haya sido importado desde Italia, donde estaban establecidos algunos talleres alejandrinos, que fueron maestros en esta técnica durante el siglo I d.C.

\subsection{Aríbalo (Isings 61)}

Se trata de un tipo cuya forma se deriva claramente del bronce y la cerámica. En nuestra provincia sólo hemos recogido tres fragmentos (Fig. 1, 2-4), procedentes del estrato romano de la ciudad del Tossal de Manises. La cronología general para estas piezas es desde fines del siglo I d.C. a principios de la centuria siguiente, momento en el que alcanzarán su máxima popularidad, siendo muy numerosos entre las ruinas de Pompeya (ISINGS, 1957, p. 78). El aríbalo continuará durante el siglo II, aunque introduce algunas variedades, como el borde triangular y el vidrio coloreado. En momentos posteriores, se impondrá el vidrio incoloro y, a veces, la pieza se decora con hilos en relieve. El siglo IV marcará la decadencia del tipo, que dejará de fabricarse tras la época de Constantino (HARDEN, 1936, p. 252). 

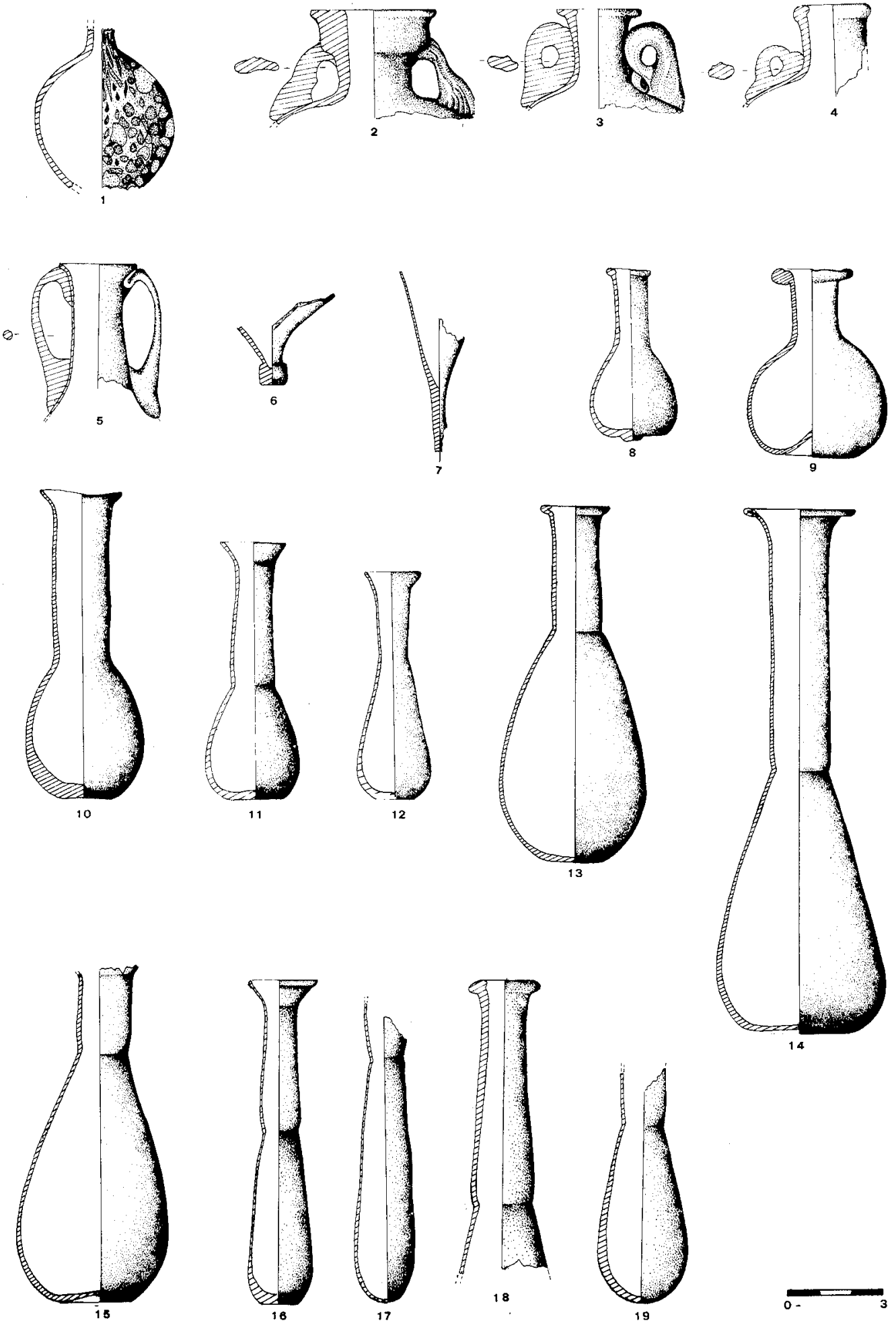

Figura 1.-Ungüentarios: 1, vidrio mosaico; 2-4, aríbalos; $3-7$, anforiscos; 8-15, piriformes; 16-17, tubulares. 


\section{I.3. Anforisco (Isings 15 y 60)}

Durante los dos primeros siglos de nuestra Era fue muy común el tipo de ánfora o botella con dos asas, que según su tamaño sería usada como ungüentario o botella. Calvi (1968, p. 21) distingue el ánfora de base plana, derivada claramente del metal, y el ánfora con cuerpo terminado en punta, que sería usada únicamente como ungüentario, dado su menor tamaño (Fig. 1, 5-7). Esta forma fue muy común tanto en la parte oriental como occidental del Imperio, datándose a partir de la segunda mitad de siglo I d.C., aunque se han hallado ejemplares más tardíos en Karanis (HARDEN, 1936, p. 258), que se fechan entre los siglos III-IV d.C., caracterizándose por su color verde-oliva, frente al verde-azulado de época imperial.

\section{I.4. Piriforme (Isings 6, 26 y 28)}

Se trata de una de las formas más comunes entre el vidrio romano, que sufrirá una continua evolución durante los dos primeros siglos de nuestra Era. El tipo más antiguo, de cuerpo piriforme y cuello cilíndrico, era hecho de vidrio coloreado, como nuestros ejemplares del Tossal (Fig. 1, 8) y Orihuela (Fig. 1, 9), que han de ser fechados hacia el 50 d.C. Paulatinamente el color verde-azulado se impondrá y la división entre el cuello y cuerpo, al principio muy marcada, se suaviza. Al mismo tiempo, el cuerpo del ungüentario se reduce hasta ocupar tan sólo $1 / 3$ ó 1/4 de su altura total (Fig. 1, 10-15).

Por otra parte, hay que añadir que dos pequeños ungüentarios (Fig. 1, 12), fueron hallados dentro de una urna cineraria de plomo, procedente de Elche, cuyo paralelo más próximo se encuentra en la Incineración Torres de Ampurias (ALMAGRO, 1955, Tabla Tipológica), datada en época de Tiberio-Claudio.

\section{I.5. Tubular (Isings 8 y 27)}

Este tipo se caracteriza por presentar un cuerpo cuyo ancho es casi igual al de su cuello. Fue muy numeroso durante el siglo I d.C., era hecho en vidrio verdoso o verdeazulado. El tipo más temprano se data en época julio-claudia, para hacerse muy popular en la segunda mitad del siglo. Su fecha final es más difícil de concretar, pues tanto entre el material de la Galia como en Karanis este ungüentario sigue apareciendo en contextos de los siglos III y IV d.C. (HARDEN, 1936, PL. XX, 834-835).

En nuestra provincia éste ha sido un hallazgo frecuente. Así en Alcoy (Fig. 1, 1617) y Elche (Fig. 2,1) se datan en el siglo I d.C. por su similitud con las piezas halladas en la Incineración Torres $n .^{\circ} 3$ y 5 de Ampurias (ALMAGRO, 1955) y con las halladas entre el ajuar de la sepultura XVI de la necrópolis del SE. de Baelo (REMESAL RODRIGUEZ, 1979, Fig. 20, 73/68), fechada en el período de Nerón y los Flavios. Entre las piezas de Tossal, hay que destacar una (Fig. 1,18), pues pertenece a un contexto más tardío, dada su fabricación en vidrio incoloro, que no se popularizaría hasta fines del siglo I d.C.; asimismo su borde es característico del siglo II. Finalmente, en Lucentum encontramos unos fragmentos en vidrio verde-amarillento, color típico del período tardorromano. Alguno conserva aún restos de un pequeño pie añadido, que nos llevó a compararlos a las piezas del Museo Real de Ontario (HAYES, 1975, n. ${ }^{\circ} 447-453$ ); éstas están decoradas con hilos en relieve y poseen dos asas, su cronología es de fines del siglo III y principios del IV d.C., al igual que un ejemplar de Barcelona (CARRERAS y VILLALBA, 1982, p. 20, n. ${ }^{\circ}$ 248). Así nuestras piezas (Fig. 2, 2-5), aunque fragmentadas, pueden adscribirse a esta cronología que encuadra con la general del yacimiento. 


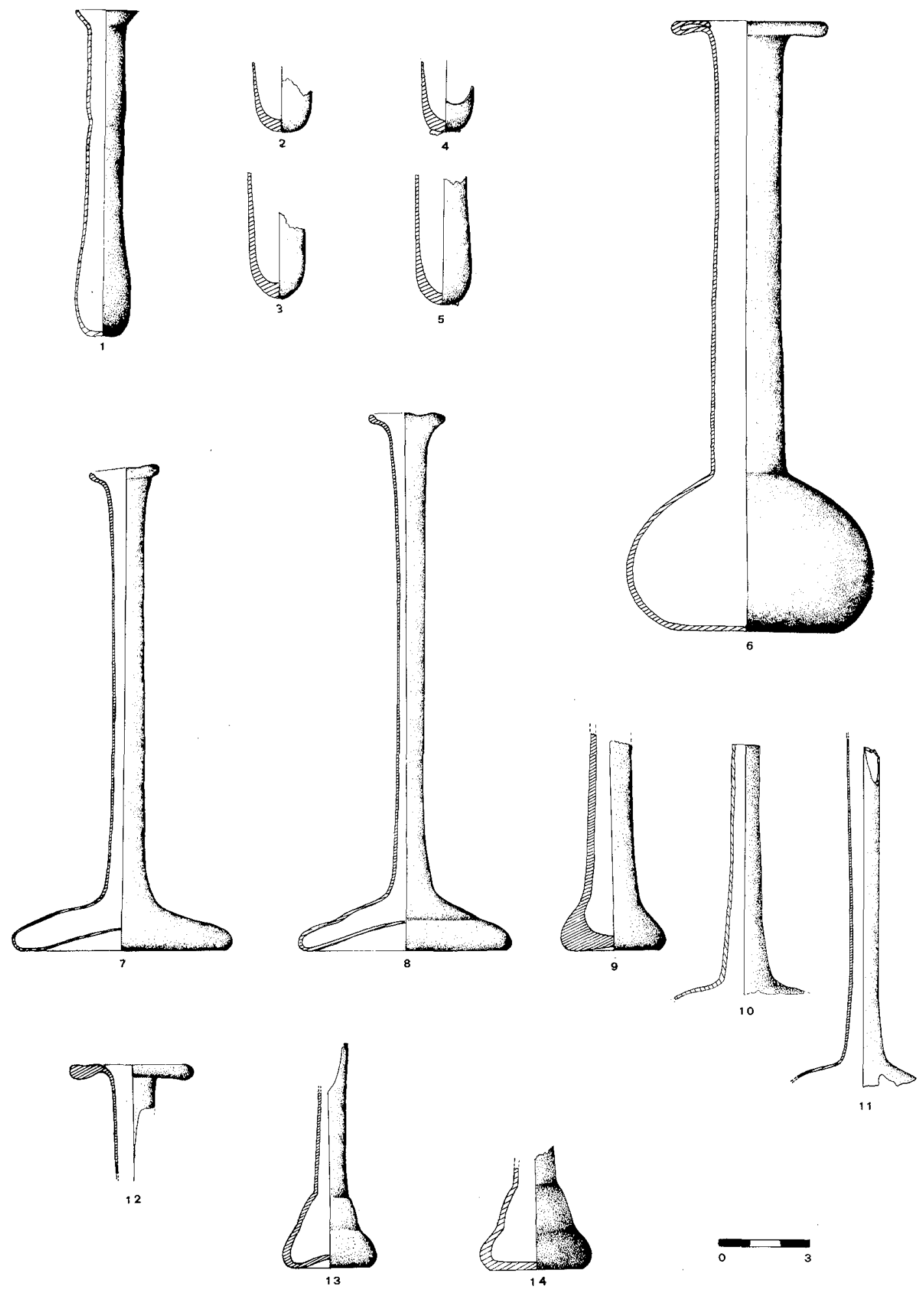

Figura 2.-Ungüentarios: 1-5, tubulares; 6-14, candelero. 


\subsection{Ungüentario de Candelero (Isings 82)}

Esta denominación agrupa varios tipos del característico frasco de largo cuello con cuerpo bajo y ancho. Según Vessberg $(1952$, p. 203) se trata de un recipiente con gran difusión por el Mediterráneo oriental y por el oeste, concretamente en el Valle del Ródano, donde debió fabricarse un subtipo, dado el gran número allí hallado con marca de fábrica.

La funcionalidad de estas piezas está clara por su parte más característica, el largo y estrecho cuello facilitaba el verter muy pequeñas dosis, al mismo tiempo que prevenía y evitaba la rápida evaporación del contenido.

Este ungüentario va a sufrir una continua evolución en sus formas. Según Calvi (1968, p. 134), los más antiguos son aquellos que presentan un cuerpo cónico y un estrangulamiento entre cuello y cuerpo (Fig. 2,6). Estos se fechan en la segunda mitad del siglo I d.C. en la región occidental, Renania y el Cantón Ticino, mientras que en Oriente, o sea Chipre, Egipto, Siria y Grecia aparecen en la segunda mitad de la centuria siguiente, continuando durante el siglo III d.C. Más tarde aparece un tipo más bulboso de perfil continuo y falto de división entre cuello y cuerpo (Fig. 2, 7-11), éste será muy popular entre los vidrios de Egipto, Chipre, Jerusalén y Colonia. En Chipre, aunque se originan en el siglo I d.C. se popularizan en el siglo siguiente; mientras que en Aquileia forman un grupo muy nutrido, llegando a pensar Calvi $(1968, p .139)$ que allí se hallaba un foco productor durante el siglo III d.C. El último tipo adopta una forma de campana (Fig. 2, 12-14; Fig. 3, 1-2). Este se encuentra entre el vidrio de la Galia y Chipre, donde se halló algún ejemplar en la tumba Limassol I, que se fecha en el 220 d.C.

Entre las piezas recogidas hay que destacar una (Fig. 3, 1), que fue hallada en una sepultura, junto al ungüentario se encontró una vasija decorada con los trabajos de Hércules, que recientemente se ha identificado como cerámica corintia, la cual era exportada a diversos lugares del Mediterráneo. Esta se fecha entre los siglos II-III d.C. (GRANADOS, 1977, p. 395).
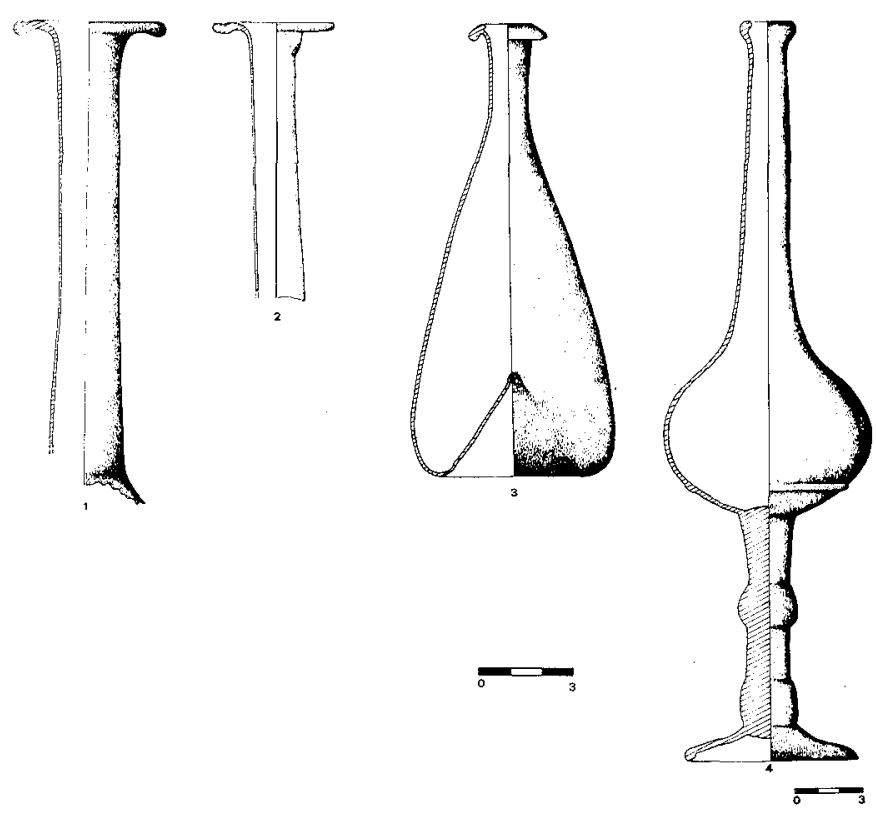

Figura 3.-Ungüentarios: 1-2, candelero; $3-4$, medievales. 


\section{I.7. Otros}

En nuestra provincia hemos recogido también algunas piezas que quedan adscritas al período intermedio entre la baja romanización y la época medieval. Así se destaca un ungüentario hallado en una sepultura del sector 6-F de la Alcudia (Elche). La necrópolis pertenece, según su excavador, a la ciudad del Bajo Imperio, datándola entre los siglos IV-V d.C. (RAMOS FERNANDEZ, 1974, p. 113). Sin embargo, una pieza procedente de Alcalá de los Gazules (CORZO SANCHEZ, 1981, p. 88, Fig. 6) es muy similar a la nuestra. Esta es fechada en torno al siglo VII d.C., dada la cerámica que salió acompañándola.

\section{BOTELLAS}

En el siglo I d.C. se originaron los tarros de cuerpo prismático con asas o sin ellas, de sección poligonal, generalmente cuadrada o rectangular. Algunos de ellos eran soplados al aire y otros dentro de un molde. Las botellas servían como envase para líquidos, ya que su forma las hacía muy estables y fácilmente transportables. Dentro de ellas hemos distinguido dos grupos:

1) Botellas con asas: siendo las más populares la cúbica y la cilíndrica.

2) Botellas sin asas: a este grupo lo denominamos frascos.

\section{II.1.1. Botella cúbica (Isings 50)}

Se trata de un recipiente muy común durante las dos primeras centurias de nuestra Era. El vidrio es generalmente grueso, de color verde-azulado y buena calidad. Charlesworth $(1966$, p . 28) distingue entre la botella soplada en molde o al aire, a la que luego se le aplanaban los lados y el fondo, dándole la forma cúbica. Las primeras suelen presentar su base decorada y su pared es bastante gruesa (Fig. 4, 6-7).

Cronológicamente, este tipo de botella no parece surgir antes del 70 d.C., popularizándose desde el período flavio en adelante, permaneciendo en uso durante los siglos II y III, pero ya en el siglo IV d.C. los hallazgos son muy escasos tanto en la parte occidental como oriental del Imperio (ISINGS, 1957, p. 65).

Entre las botellas recogidas, destacamos dos, que se conservan completas. Una (Fig. 4, 1) procede de la ciudad romana del Tossal de Manisses, la otra (Fig. 4. 5) de Illici. Esta última fue hallada en la boca número dos del alcantarillado romano de la ciudad. Junto a ella apareció cerámica sigillata clara, tipo 10 de Lamboglia, fechándose entre los siglos II y III d.C. Así este hallazgo nos marca la fecha tope para nuestro ejemplar, que encuentra un paralelo muy próximo en una botella hallada en la sepultura 22 de la necrópolis de Pollentia (Mallorca), y que se data entre los siglos I y II d.C. (ALMAGRO, 1953-4, p. 263).

\section{II.1.2. Botella cilíndrica (Isings 51)}

$\mathrm{Al}$ igual que el tipo anterior también es muy común durante las dos primeras centurias de nuestra Era en todo el territorio romano. El problema está al tratar el momento de su desaparición, ya que en Karanis (HARDEN, 1936, p. 234) aparece en contextos más tardíos, como los siglos II y III d.C., e incluso en hogares de niveles más altos. Nosotros tan sólo hemos recogido un fragmento de este tipo de botella (Fig. 5, 1). 

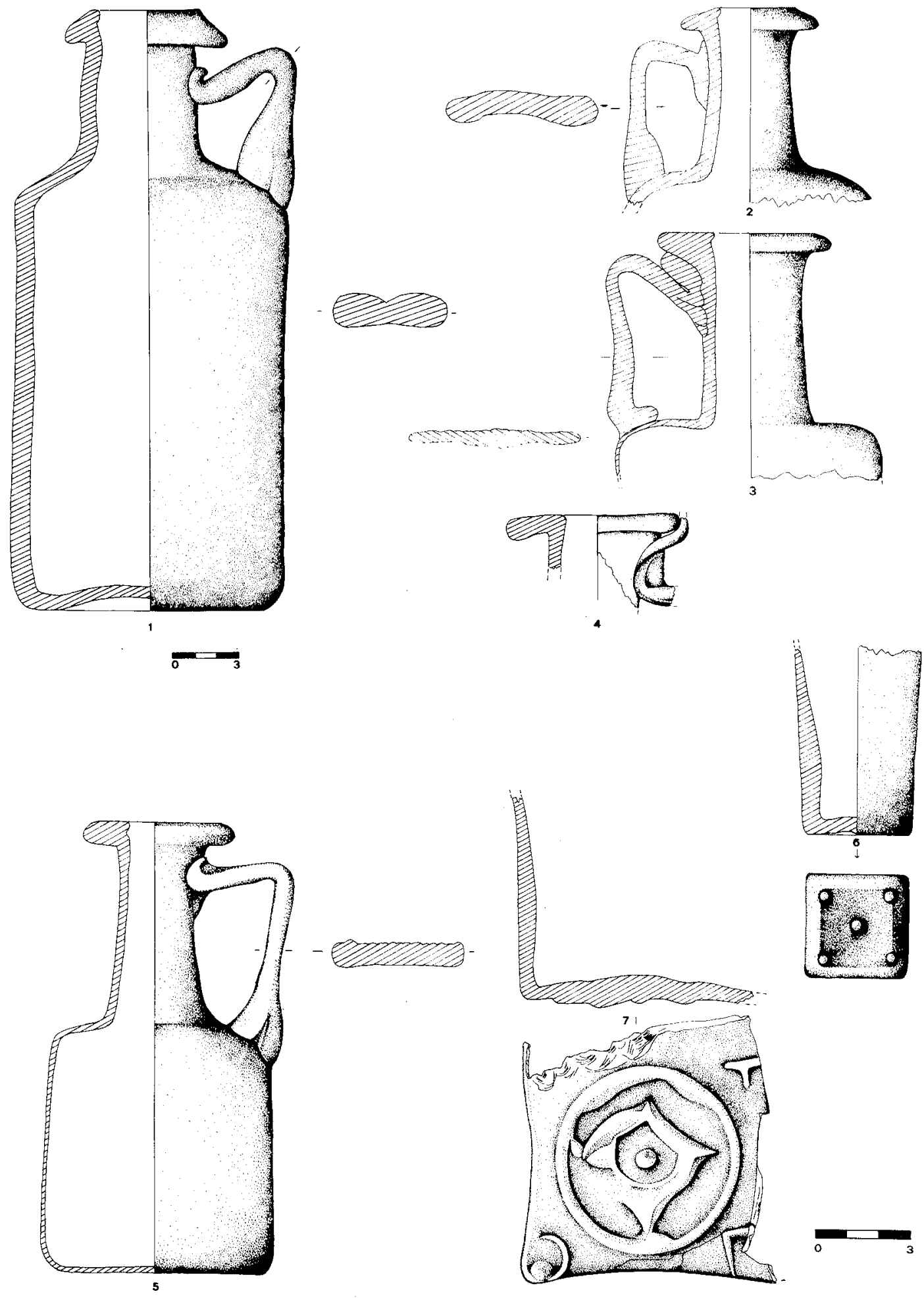

Figura 4.-Botellas: 1-7, botella cúbica. 

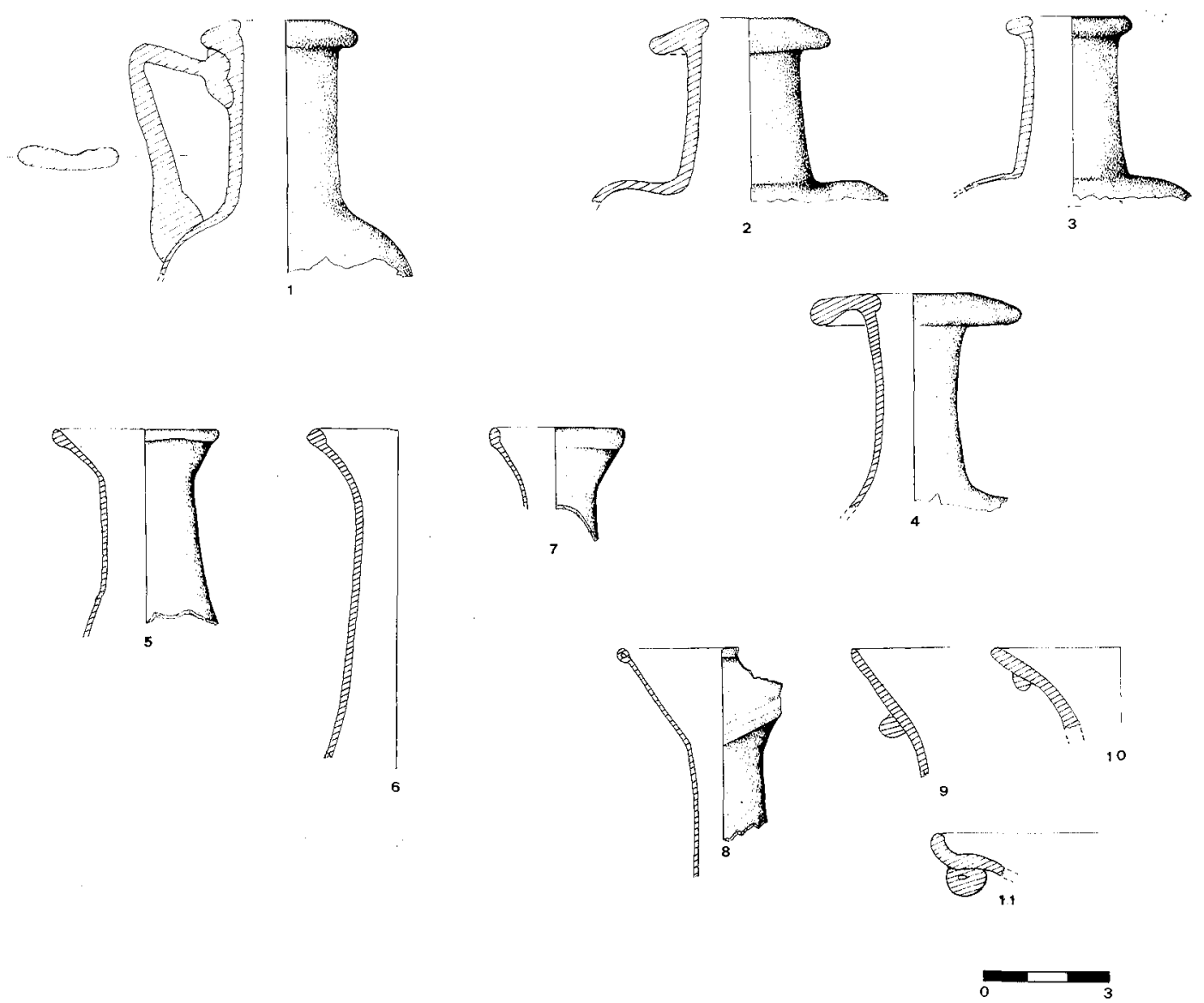

Figura 5.-Botellas: 1, botella cilíndrica. Frascos: 2-4, frasco con borde triangular; 5-11, frasco con boca de embudo.

\section{II.2. Frascos (Isings 102)}

Se trata de una forma muy corriente a partir del siglo III d.C. Los frascos podían ser esferoides, ovoides y sobre todo cilíndricos. Estos últimos se caracterizan principalmente por presentar una boca de embudo, muy frecuente en este siglo, sobre todo en la Galia, Egipto y Palestina. Los ejemplares recogidos se clasifican en dos grupos:

a) Frascos con borde triangular (Fig. 5, 2-4), que se pueden datar desde finales del siglo II al III d.C. Aunque en la Basílica paleocristiana de Alconétar (Cáceres), fue hallado un frasco de este tipo, por lo que parece continuar tras el siglo IV d.C. (CABALLERO, 1970, p. 43, Fig. 13, 54).

b) Frascos con boca de embudo (Fig. 5, 5-11), es una variedad muy numerosa, a veces está decorada con un grueso hilo de vidrio bajo el borde. El tipo parece proceder de Oriente, por el gran número de piezas halladas en Chipre, Egipto y Palestina, siendo muy escasas las procedentes de Occidente. En cuanto a su datación, Calvi (1968, p. 145) sostiene que su producción se iniciaría hacia mediados del siglo II d.C., siguiendo en la centuria posterior. Todas nuestras piezas proceden de yacimientos con clara cronología tardía, como son Lucentum, el Portus illicitanus y las Agualejas (Elda), cuyos materiales más significativos se datan en el siglo IV d.C. 


\section{VASO O CUBILETE}

Este recipiente suele presentar una altura que es el doble del ancho. El vaso será muy frecuente a partir de la segundá mitad del siglo I d.C., y tanto sus formas como decoraciones son muy variadas.

\section{III.1 Vaso soplado en molde (Isings 31)}

Este tipo de vaso debió ser de los más costosos, dado que se fabricaba con la técnica del soplado en molde, obteniendo un tipo de decoración que imita claramente a los vasos metálicos repujados. Tanto Calvi $(1968$, p. 101) como Hayes $(1975$, p. 48) apuntan un origen sirio para estos recipientes, aunque también pudieron fabricarse en el norte de Italia, hacia donde hubo una fuerte emigración de artesanos sirios a mediados del siglo I d.C., desde allí las exportaciones llegarían a todos los puntos del Imperio. El motivo decorativo que presentan es muy variado, pudiendo ser vegetal, animal o combinado. Cronológicamente se datan entre la segunda mitad del siglo I y principios del II d.C., no encontrándose con posterioridad. Nosotros hemos recogido dos fragmentos (Fig. 6, 1-2), éstos están decorados a base de hojas y brotes distribuidos a intervalos regulares, al igual que un ejemplar procedente de Pompeya (ISINGS, 1957, p. 45).

\section{III.2. Vaso con depresiones longitudinales (Isings 32)}

Este vaso se caracteriza precisamente por su decoración, que se obtenía al modelar la pared del mismo con un utensilio, cuando el vidrio estaba aún caliente. En general esta forma se difundió grandemente durante el siglo I d.C. por todo el Imperio, hallándose en toda el área del Mediterráneo: Pompeya, Thera, Corinto y Chipre. Ya en el siglo siguiente se extenderá por la región noroccidental, donde prevalecerá hasta el siglo IV d.C. (Forma 114 de Isings). En Karanis hallamos ejemplares procedentes de casas que se fechan hasta el siglo V d.C. En Alicante contamos con dos vasos fragmentados de este tipo (Fig. 6, 3-4), ambos proceden de la ciudad romana del Tossal de Manises, fechándose entre los siglos I y II d.C.

\section{III.3 Vaso con decoración aplicada (Isings 33)}

$\mathrm{Al}$ igual que el tipo anterior, este vaso presenta un motivo característico: anillos ovales o líneas onduladas en relieve. Se trata de un recipiente no demasiado común, aunque en Italia, Vindonissa y el Cantón Ticino se encuentran en gran número. Esa localización concreta y su contemporaneidad llevan a Calvi $(1968$, p. 58) a centrar su fabricación en la Italia septentrional. Cronológicamente, el tipo se origina en época de Claudio o Claudio-Nerón y continúa en auge durante las primeras décadas del siglo II d.C., para decaer casi totalmente a partir de la segunda mitad. En Alicante hemos recogido dos ejemplares, uno de la ciudad romana del Tossal de Manises (Fig. 6, 5) y el otro de Elche (Fig. 6, 6).

\section{III.4. EI vaso troncocónico (Isings 29-106)}

Este vaso es una de las formas aparecidas en el siglo I d.C., continuando en siglos posteriores, para imponerse a partir del siglo III d.C. El vaso troncocónico es muy frecuente entre el vidrio de la Galia, mientras que falta casi por completo entre el oriental. Este se adscribe a una cronología tardía, siglos III y IV d.C. Es interesante destacar el hallazgo de un vaso, de este tipo, liso, en la necrópolis de L'Horta Major (Fig. 6, 7), 

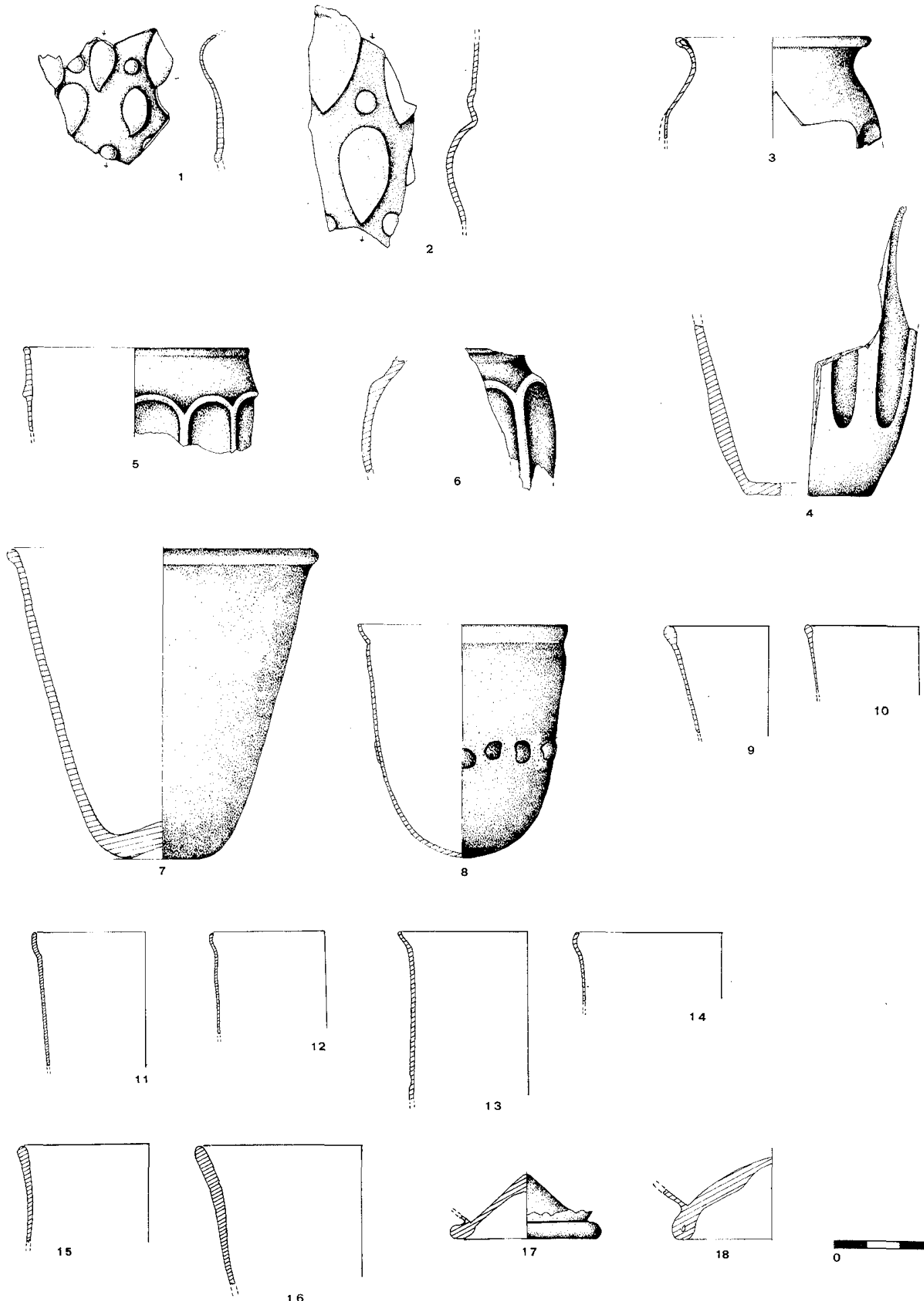

Figura 6.-Vasos o cubiletes: 1-2, vaso soplado a molde; 3-4, vaso con depresiones; 5-6, vaso con arcos ovales; 7-10, vaso troncocónico; 11-14, vaso cilíndrico; $15-18$, vaso cónico con pie. 
junto a él apareció cerámica sigillata hispánica, formas Dragendorff 27 y 37 , de amplia cronología. El paralelo más próximo lo encontramos en la necrópolis de Fuentespreadas (CABALLERO, 1974, fig. 43, 1).

Otro vaso muy peculiar presenta una decoración de cabujones, que son gruesas gotas de vidrio, de color más oscuro, que eran vertidas sobre la pared del vaso (Fig. 6, 8). Se trata de un motivo muy característico del siglo IV d.C. Su paralelo más próximo es un vaso depositado en el Museo de Barcelona (CARRERAS, 1982, p. 7, n. ${ }^{\circ} 187$ ).

\section{III.5 El vaso cilíndrico}

Es muy típico durante las dos primeras centurias de nuestra Era. Pero paulatinamente irá perdiendo terreno frente al vaso troncocónico, que se impondrá en el siglo IV d.C. En la provincia se han recogido algunos fragmentos de vasos cilíndricos (Fig. 6, 1114). Todos ellos presentan decoración, así acanaladuras o incisiones, que eran los motivos más populares en estos siglos, frente a otras más complicadas que se impondrán posteriormente, como los cabujones, los hilos fundidos o en relieve y el tallado.

\section{III.6 El vaso cónico con pie (Isings 109)}

Este vaso se caracteriza por presentar un pie anular, que ha sido obtenido al plegar la pared del mismo. Así su parte inferior se estrecha, dando la apariencia de un vástago. Se trata de un tipo muy común a partir del siglo IV d.C. e incluso llega a perdurar hasta el siglo VI. El tipo parece ser occidental, siendo muy abundante en la Galia. Nuestros ejemplares, muy fragmentados, proceden todos ellos de yacimientos tardorromanos, como Lucentum, Elche, el Monastil y las Agualejas (Fig. 6, 15-18). En la Península tan sólo hemos hallado un vaso de este tipo en Castiltierra (Segovia), que se conserva en el Museo del Instituto de Valencia de Don Juan (VIGIL, 1969, p. 170).

\section{CUENCOS}

El cuenco es un recipiente cuyo diámetro de boca es igual o algo inferior a su altura; su relativa profundidad es lo que establece la diferencia con los platos, que muchos autores denominan «Cuencos poco profundos» («Shallow Bowl»).

\section{IV.1 Cuencos de costillas (Isings 3)}

Estos constituyen un tipo muy característico del siglo I d.C. y deben su denominación a su peculiar decoración de suaves costillas en relieve que desde el borde descienden hasta el fondo de la vasija. En un primer momento, estos cuencos se fabricaban en vidrio mosaico, pero poco a poco se fue imponiendo el vidrio monocromo. Técnicamente, encontramos ejemplares moldeados, soplados e incluso soplados en molde.

Los cuencos moldeados imitan modelos metálicos que se remontan a época de los Ptolomeos. El vidrio viscoso se prensaba en un molde con los relieves en negativo, o bien se rellenaba éste de vidrio triturado que luego se calentaba al horno para su fundición. Los moldes podían ser sencillos o dobles. Esta técnica se usaba ya en el tercer milenio a.C., alcanzando su máxima difusión a mediados del primer milenio. En cuanto al soplado, el proceso era el siguiente: con un tubo de metal se recogía por un extremo un poco de vidrio del crisol y por el otro se soplaba hasta formar una bola de vidrio, a la que se le iba dando forma y moldeando dentro del horno. El cuenco soplado va generalmente decorado con hilos blancos fundidos. Otra técnica es el soplado en molde, con la que se obtenía directamente la decoración (Fig. 7, 2). Esta fue una producción de la ofi- 

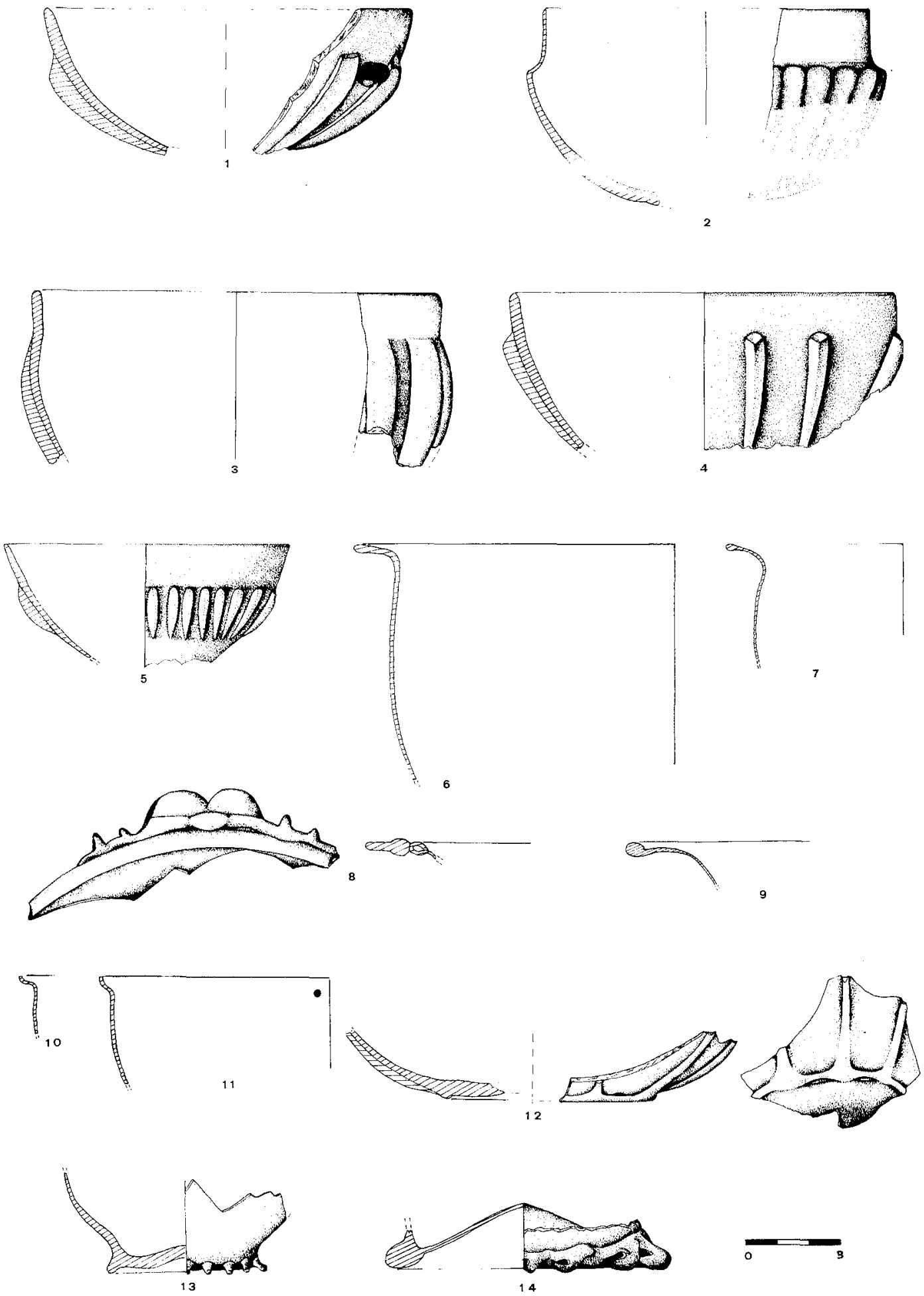

Figura 7.-Cuencos: 1-5, cuencos de costillas; 6-9, cuenco con pie anular; 10-11, cuenco elipsoide liso; 12-14, cuenco elipsoide pinzado. 
cina romano-siria, resultado de la fuerte emigración de artesanos sirios a otras regiones del Mediterráneo oriental e Italia a mediados del siglo I d.C. (CALVI, 1968, p. 101).

El cuenco de costillas se fabricará durante todo el siglo I d.C. Isings $(1957$, p. 17) divide al grupo en tres tipos, aquellos con nervios alargados hasta la base son frecuentes en época de Claudio-Nerón, continuando hasta los Flavios (Fig. 7, 1-4). Pero el cuenco con nervios sólo en el centro del cuerpo (Fig. 7,5 ) se origina en época de Claudio, ya que no existe ninguno en tiempos de Augusto. Por otra parte la pieza fabricada en molde $($ Fig. 7,2$)$ responde a un tipo muy frecuente en las provincias orientales, que se fabricaba según dos variantes: una más baja con molduras inferiores y otra más alta sin molduras. Nuestro ejemplar es muy similar a otro hallado en Conímbriga (ALARÇAO, 1976, PL XXXV, 43).

\section{IV.2. Cuenco con pie anular (Isings 42-43)}

Son varios los tipos que presentan este pie. Así el primero es de paredes convexas y borde horizontal con labio redondeado (Fig. 7, 6-7). Fue hallado en gran número entre el material de Herculano y Pompeya. Según Isings (1957, p. 21) este recipiente de vidrio es una copia de las formas metálicas y cerámicas, como la 35 de Dragendorff. Cronológicamente, se sitúan a partir de época flavia, siguiendo durante el siglo II d.C. e incluso se adentra algo en la centuria siguiente. En España conocemos el hallazgo de otro cuenco similar en la necrópolis del Pradillo (Badajoz), cuando se excavaba la tumba n $0^{\circ} 5$; junto a él apareció una botella hexagonal. El conjunto sería fechado entre Claudio y Vespasiano, dada la presencia de una lucerna del tipo II B3 de Ponsich (DEL AMO, 1973, p. 75).

El otro subtipo se caracteriza por las asas, las cuales se forman con gruesos hilos del mismo vidrio y se añaden al borde. Nosotros hemos recogido un ejemplar procedente del Tossal de Manises (Fig. 7, 8). Se trata de una pieza hecha en vidrio incoloro, por lo que la podemos datar a finales del siglo I d.C., momento en el que se generaliza este tipo de vidrio.

\section{IV.3. Cuenco elipsoide (Isings 96)}

Este se encuentra tanto liso como decorado. La variedad sin decoración forma en Chipre un grupo muy homogéneo, esto lleva a Calvi $(1968$, p. 67 , «Coppe» CY) a apuntar una misma procedencia para todos ellos, quizás de una fábrica chipriota. Este cuenco imita a los tipos metálicos del siglo I d.C., aunque en vidrio empieza a fabricarse como pronto en el siglo II d.C. Nosotros sólo hemos recogido dos fragmentos (Fig. 7, 1011). Ambos proceden del Monastil (Elda), yacimiento tardorromano, que alcanza su máximo esplendor en el siglo III, perviviendo hasta los siglos V y VI d.C.

En cuanto al cuenco decorado, encontramos variados motivos. Así el pinzado, decoración obtenida cuando el vidrio está aún caliente. Se trata de un tipo poco común en las regiones orientales e italianas, en cambio entre el vidrio galo es muy frecuente durante los siglos III y IV d.C. (CALVI, 1968, p. 51). En Alicante hemos recogido tres fragmentos de cuencos pinzados, dos de ellos (Fig. 7, 12-13) proceden del Tossal de Manises, mientras que el otro, de factura más tosca (Fig. 7, 14), procede del Portus illicitanus.

Otra decoración típica de estos siglos es el cabujón, que hemos visto en alguna pieza anterior. Estas gotas de vidrio quedaban aplastadas como un disco y solían ser de color más oscuro que el recipiente, así: verde, azul, violeta, o rojo, mientras que el vidrio del recipiente solía ser incoloro. Esta decoración es típica del siglo IV d.C., aunque en el Este perdurará durante el período árabe. En Renania estos cuencos fueron muy nume- 
rosos, extendiéndose por un área que parece tener como centro a Colonia; posteriormente aparecen por la zona danubiana e Italia, donde los cabujones son monocromos, frente a la policromía alemana. Nuestro único ejemplar (Fig. 8,1) procede de Elche y es muy similar a otro hallado en la necrópolis de San Miguel del Arroyo, que se fecha entre el 351-354 d.C. (CABALLERO, 1974, p. 146).

\section{IV.4. Cuencos poco profundos (Isings 11)}

Bajo esta denominación recogemos un tipo de cuenco característico de los siglos IV y V d.C. Estos se nos presentan tanto lisos como decorados, destacando las líneas talladas o hilos blancos fundidos, aunque la distinta decoración no conlleva una cronología diferenciada.

El tipo liso ha sido hallado en gran número en la ciudad romana de Lucentum (Fig. $8,2-21)$. El vidrio es incoloro o verde oliva, recubierto por una pátina negra. En Alconétar (CABALLERO, 1970, p. 54) se hallaron también varios fragmentos al hacer una cata al sur de la Basílica. Junto al vidrio apareció cerámica sigillata hispánica tardía, el nivel fue datado entre los siglos IV y V d.C.

Otros nos han aparecido decorados con líneas incisas (Fig. 8, 22-29), la mayoría proceden igualmente de Lucentum. Igual ocurre con los decorados con hilos blancos fundidos (Fig. 8, 30-34; Fig. 9, 1-7). Esta decoración es original de Siria y debió empezar a usarse a fines del siglo II d.C., aunque en Occidente se generalizaría a fines del siglo IV e incluso durante el siglo VI d.C., principalmente en Renania, Bélgica y NE. de Francia. Los hilos normalmente blancos se aplicaban en caliente, fundiéndose en la superficie del recipiente. Este tipo es frecuente en Lucentum, en Elda también se ha encontrado algo de este tipo, así se conserva un fondo decorado con una roseta (Fig. 9, 7) que encuentra su paralelo más próximo en otro de Conímbriga (ALARÇAO, 1976, PL/XLIII, 223) y en otro de Villaricos (SIRET, 1906, LXXVIII, 32).

Finalmente, hemos recogido otros con decoración soplada (Fig. 9, 9-10) ambos proceden de Lucentum. Resulta significativa esa frecuencia de aparición en el yacimiento de Lucentum, pudiéndose pensar que aquí existió una fábrica de vidrio que produciría, entre otros tipos, estos cuencos.

\section{COPAS}

En este grupo incluimos aquellos recipientes que presentan un vástago o peana sobre, la que se sustentan.

\section{V.1 Cántharos (Isings 38)}

El Cántharos clásico con altas y curvadas asas, no parece sobrevivir al siglo I d.C. Muchos eran hechos de vidrio coloreado y no sólo del vidrio corriente verde-azulado. En España se han encontrado algunos ejemplares en Palencia, Cádiz y Sevilla (VIGIL, 1969, p. 131). Entre nuestro material tenemos una pieza procedente de Elche (Fig. 10, 2), aunque fragmentada, y otra del Tossal (Fig. 10,1), a la que le falta tan sólo el borde.

\section{V.2 Copas de pie alto (Isings 111)}

En el siglo IV d.C. hay un tipo provisto con un alto pie con vástago, el cual podía quedar parcialmente hueco o totalmente sólido. Estas copas suelen encontrarse con relativa frecuencia entre el material de Karanis, donde Harden (1936, p. 167) las data a partir del siglo IV. Muchas de ellas aparecen decoradas con hilos serpentiformes, sobre 

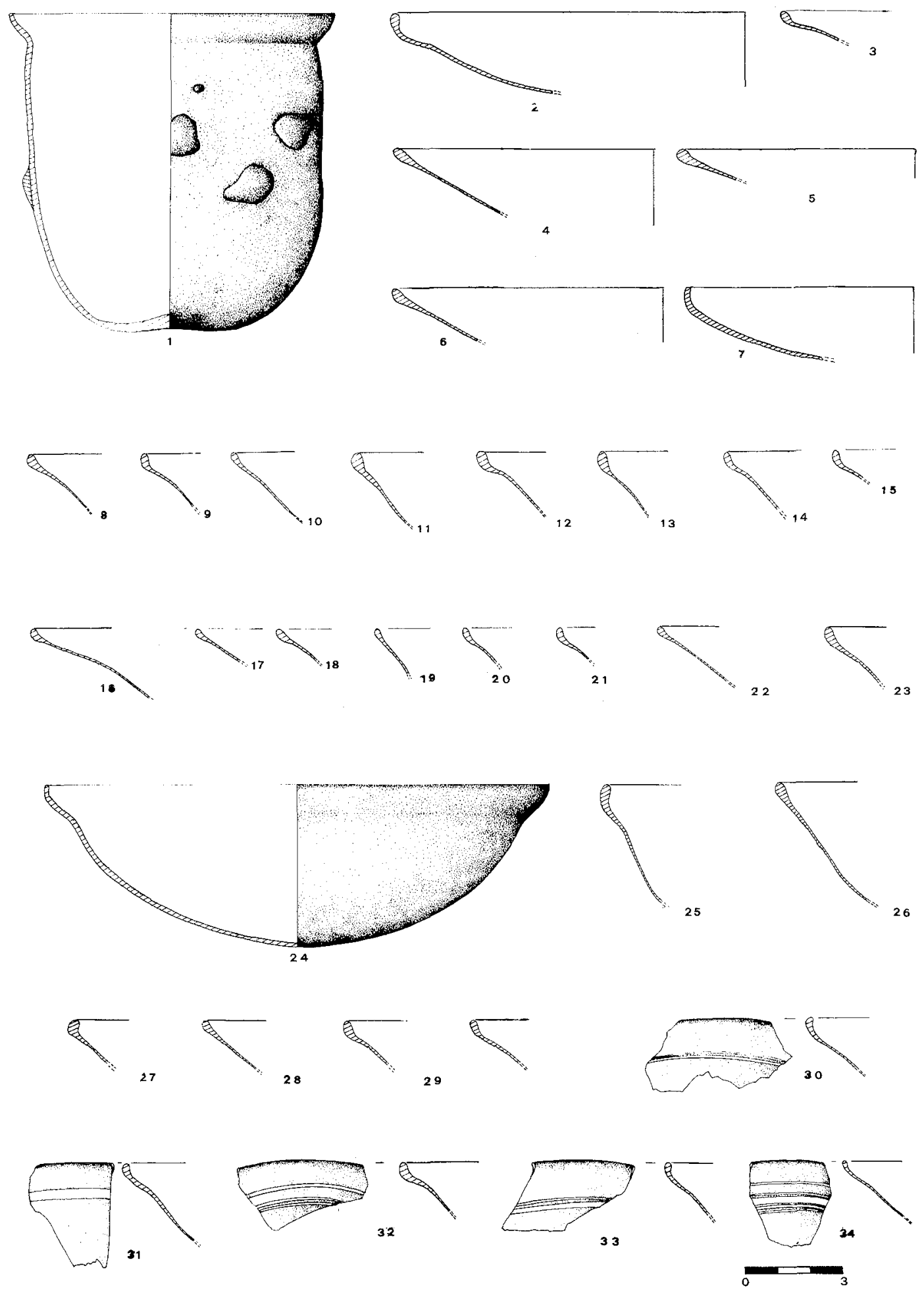

Figura 8.-Cuencos: 1, cuenco elipsoide con cabujones; 2-21, cuencos bajos lisos; 22-29, cuenco bajo con incisiones; $30-34$, cuenco bajo con hilos fundidos. 

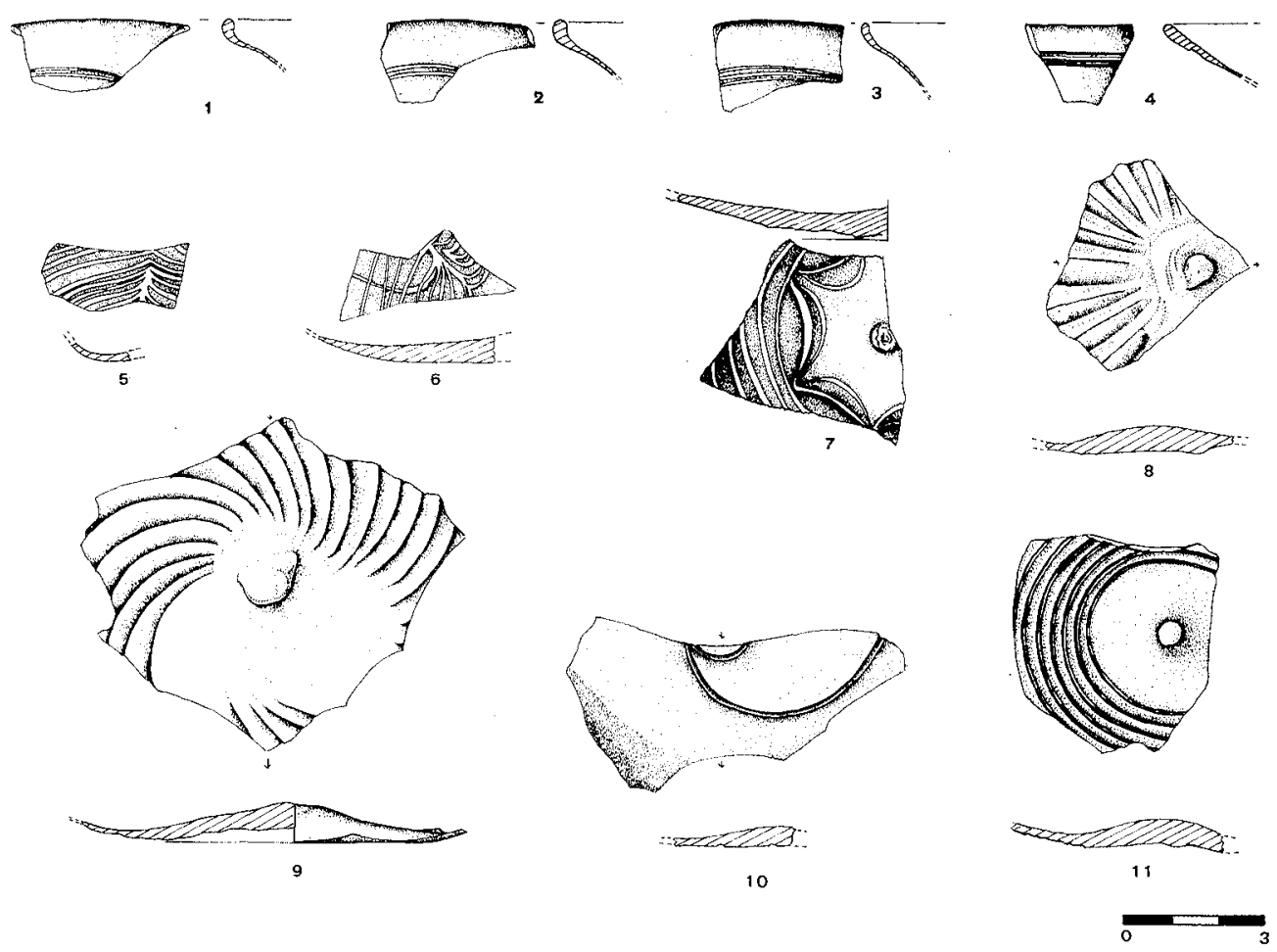

Figura 9.-Cuencos: 1-7, cuenco bajo con hilos fundidos; 8-11, cuenco bajo con decoraciones diversas.
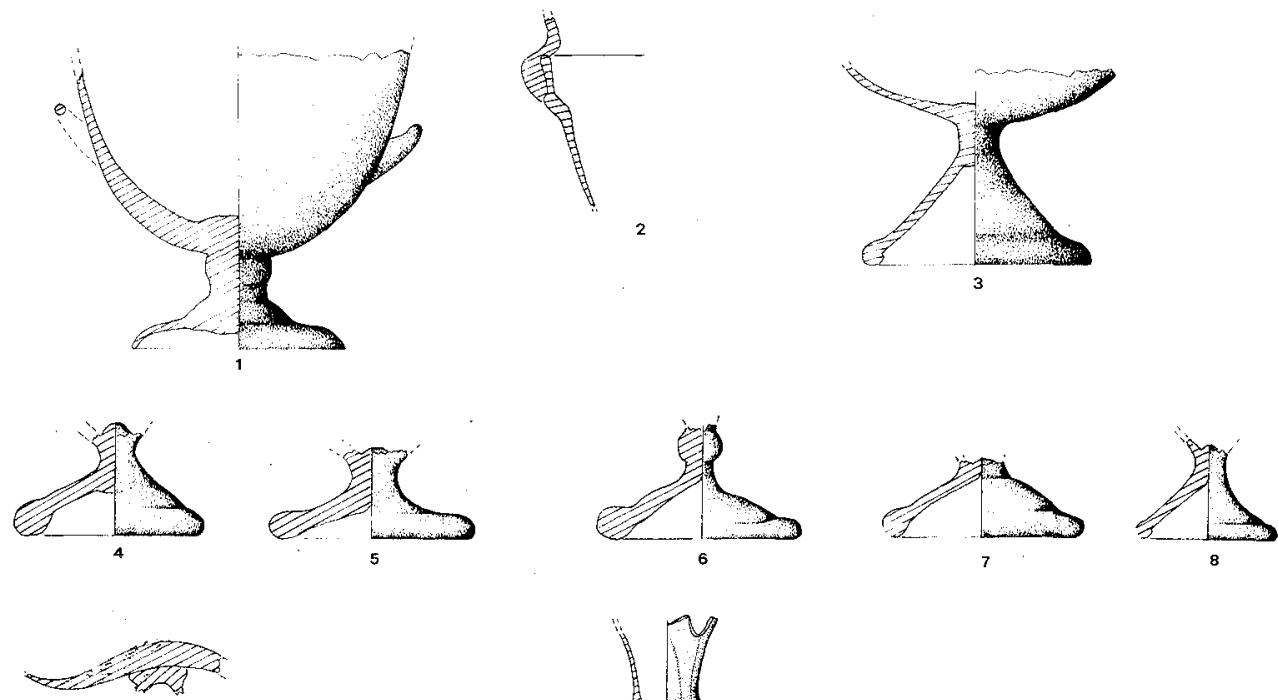

9
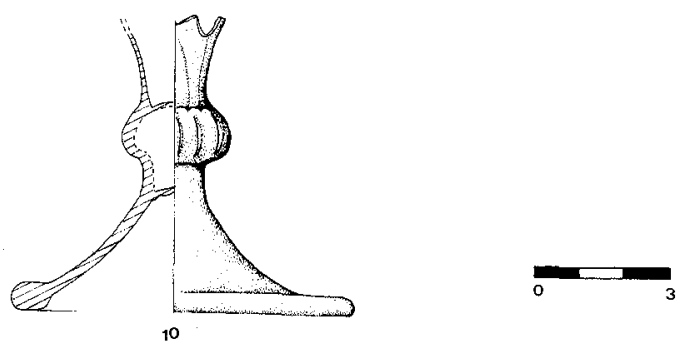

Figura 10.-Copas: 1-2, cántaros; 3-10, copas de pie alto. 
todo en Occidente. Así Harden llega a sostener la existencia de dos focos de producción, uno en Colonia y el otro en Alejandría, aunque en un principio el tipo fuera oriental (ISINGS, 1957, p. 139; VESSBERG, 1952, p. 199). Estas copas perviven largo tiempo, habiéndose encontrado ejemplares en Gerasa (s. VI-VII d.C), en el Mitreo de Santa Prisca, Roma (s. IV d.C) y en cementerios francos del siglo VII d.C.

En Lucentum hemos recogido varios vástagos que se relacionan con esta forma (Fig. 10, 4-9). Estos son muy similares a otros del Museo Real de Ontario (HAYES, 1975, Fig. 11, 381 y 653), que se datan entre los siglos V y VI d.C.

\section{PLATOS}

En las dos primeras centurias de nuestra Era se impone el plato circular, hecho generalmente de vidrio verde-azulado. Este tipo solía presentar pie y paredes verticales. Fue muy común en Italia, por el contrario falta casi por completo del vidrio egipcio y sirio. Pero a partir del siglo III d.C. se impondrá el plato oval de pie anular y borde plegado. Estos son muy numerosos entre el vidrio de Karanis y alcanzan su máxima difusión al inicio de la centuria siguiente.

\section{VI.1 Platos moldeados (Isings 2)}

Los platos hondos y moldurados, de vidrio incoloro, son relativamente frecuentes en Conímbriga (ALARÇAO, 1976, p. 171). Al parecer eran hechos dentro de moldes a presión y luego pulidos a torno. Hasta el 50-60 d.C. éstos se hacían de vidrio coloreado, para más tarde imponerse el vidrio incoloro. En nuestra provincia sólo hemos recogido cuatro platos moldeados, dos de ellos (Fig. 11, 2-3) proceden de la colección de los PP. Jesuitas, y están hechos de vidrio incoloro. La otra pieza mayor es de Lucentum (Fig. $11,4)$, se trata igualmente de un plato circular e incoloro. Entre el material de Pompaelo (MEZQUIRIZ, 1978, Fig. 43, 1-2) encontramos varios ejemplares iguales a nuestro plato, éstos se datan entre los siglos I-III d.C., ya que pertenecen a los estratos VI y V, donde aparecieron monedas de Cómodo y Alejandro Severo. Finalmente tenemos un plato moldeado con decoración, que procede del Tossal de Manises (Fig. 11, 1). Este es semejante a la forma 22 de Isings $(1957$, p. 38), que se data en época de Tiberio y Claudio, desapareciendo a mediados del siglo I d.C.

\section{VI.2 La pátera paleocristiana (Isings 118)}

Esta pátera, procedente del Portus illicitanus, se encuentra hoy depositada en el Museo Arqueológico Nacional. Posee un alto pie y está decorada con motivos grabados, técnica muy empleada a partir del siglo III d.C., tanto en Oriente como en Occidente. Su motivo central es un Crismón, el cual se ensancha mucho por sus extremos, lo que nos lleva a datar la pieza en el siglo IV d.C.

\section{JARROS}

El jarro fue un recipiente muy común en todo el Imperio. Según Harden (1936, p. 231) los tipos más elaborados fueron probablemente usados como jarros de mesa, para el vino o aceite; y otros más sencillos, serían usados para transportar líquidos. 

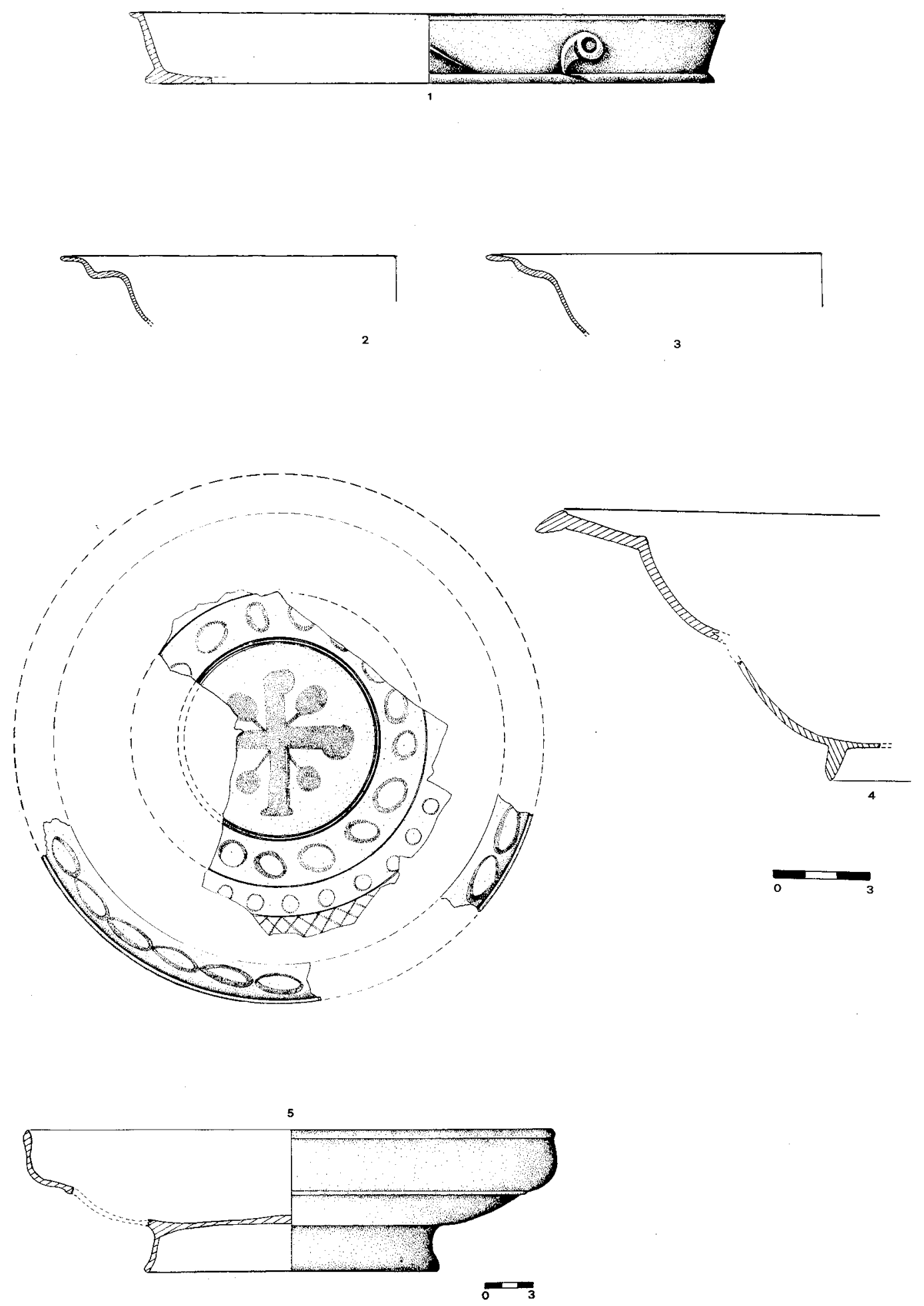

Figura 11._-Platos: 1-4, plato moldeado; 5, pátera paleocristiana. 

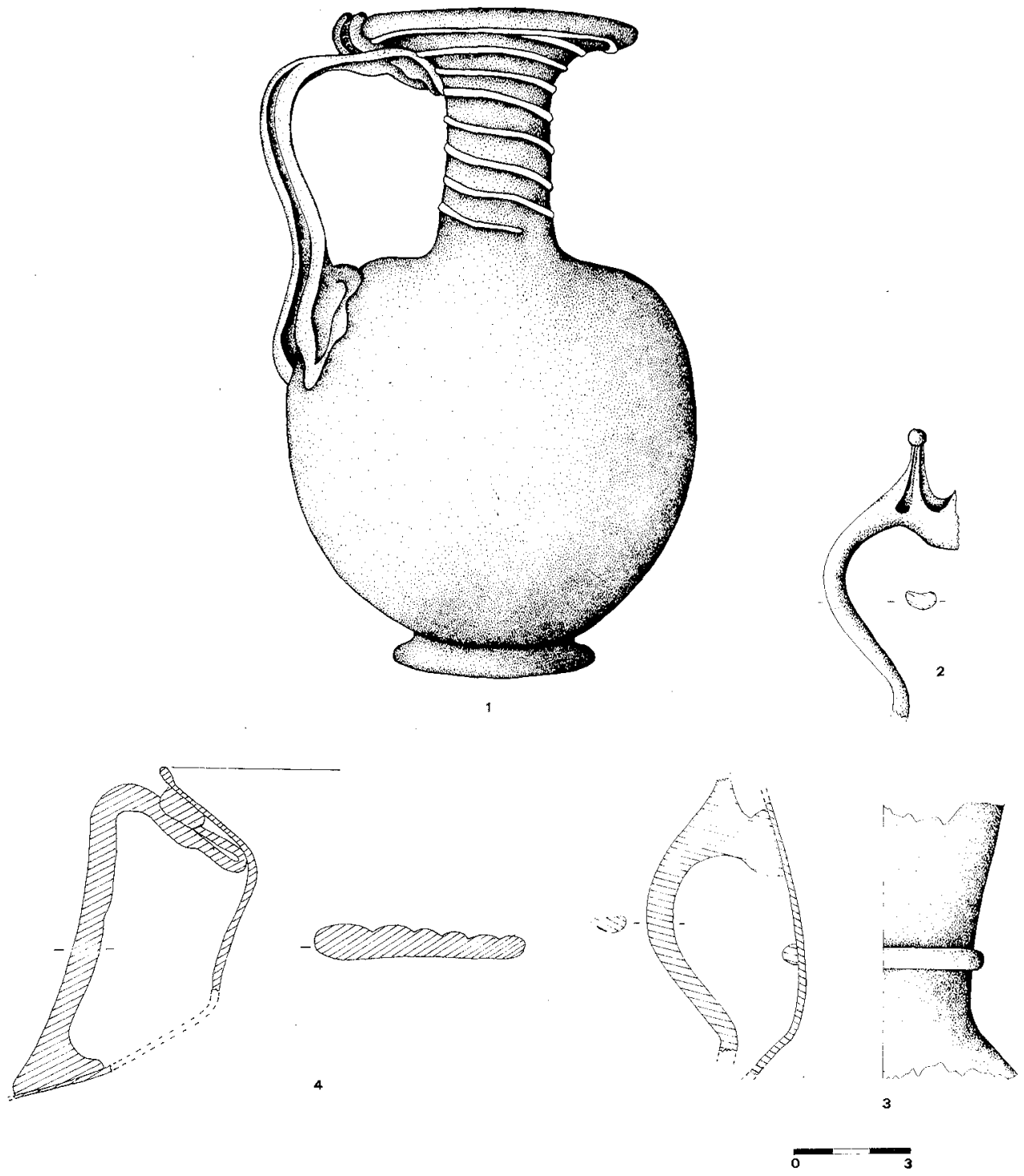

Figura 12.-Jarros: 1-4, jarros diversos.

En nuestra provincia los jarros hallados han sido muy escasos. Pero hay que destacar uno procedente de la Necrópolis del Montañar, Jávea (Fig. 12, 1); se trata de una pieza con cuerpo esférico y típica boca de embudo, su asa es alta y curvada replegándose sobre el borde. El cuello está decorado con hilos en relieve que lo rodean helicoidalmente. Todas estas características nos llevan a la forma 121 de Isings $(1957$, p. 150), que se data en el siglo IV d.C. La necrópolis tuvo una amplia cronología, habiéndose hallado materiales tardorromanos. 


\section{CONCLUSIONES}

El vidrio en nuestra provincia constituye una gran ayuda para el estudio de las relaciones comerciales. Así, ya desde el siglo IV a.C. nuestra costa estaba encuadrada en el Mediterráneo, como lo prueban las constantes apariciones en poblados y necrópolis de materiales importados. El cambio de Era no va a traer ningún cambio y España entra en las vías comerciales que van desde Egipto y Siria a la Europa noroccidental, pasando por Chipre, Grecia e Italia.

Otro aspecto interesante a resaltar del vidrio recogido es que sigue en general la evolución del romano. Así, en las dos primeras centurias de nuestra Era se trata de un vidrio de lujo, que imita frecuentemente a los recipientes metálicos (los vasos soplados en molde o los aríbalos) y a la cerámica, principalmente a la de paredes finas, a la que llegará a sustituir como servicio de mesa. Por otra parte destaca su marcado carácter oriental, como se demuestra por el gran porcentaje de piezas procedentes de aquella zona (los ungüentarios de candelero, de origen chipriota; los vasos decorados con depresiones; los cuencos soplados en molde, sirios; etc.). Técnicamente se impone el soplado al aire libre para la fabricación de recipientes, aunque sigamos encontrando ejemplares moldeados, que se irán haciendo cada vez más raros; también encontramos piezas sopladas en molde, que no es más que una variedad lujosa del soplado. El color es otra característica interesante, ya que, aunque en la primera mitad del siglo I d.C. hallamos vidrio coloreado, ya sea marrón o verde esmeralda, el vidrio verde-azulado va a imponerse hasta ser el predominante.

A partir del siglo III d.C. el cambio es patente en la evolución del vidrio, que ahora se nos presenta con un marcado carácter occidental (vaso troncocónico, las copas de pie alto o los cuencos elipsoides). Al mismo tiempo, aparecen nuevas y rebuscadas formas que se caracterizarán por sus decoraciones: los cabujones, los hilos fundidos o en relieve bajo el borde, las decoraciones pinzadas y el tallado, cuyo resultado más destacado fue la diatreta. Técnicamente, se trata principalmente de vidrio soplado, que ahora presenta una calidad más baja. Su interior suele aparecer lleno de burbujas y estrías, mientras que la superficie está normalmente recubierta por una pátina negra. Su color suele ser incoloro o de tono verde-amarillento, derivando hacia el melado.

En la provincia han sido varios los yacimientos que han proporcionado material tardorromano de estas características. En Elda destacamos el Monastil y las Agualejas; en Elche, el Portus illicitanus. Pero entre todos destaca Lucentum, yacimiento que permanece bajo un barrio de nuestra ciudad y cuyo material procede del vertedero, por lo que carece de cualquier estratigrafía. El vidrio aquí hallado es de gran homogeneidad, habiéndose hallado numerosas piezas del mismo tipo en cuanto a calidad y cronología. Este hecho junto al hallazgo de numerosos residuos vítreos localizados revueltos con el vidrio, nos hacen pensar en la existencia en esa ciudad de fábricas. Esta hipótesis no es nueva, pues ya en el siglo pasado Rico (1893, p. 69) sostenía la existencia de fábricas de vidrio y cerámica en Lucentum, pero la investigación posterior no consideró tales investigaciones, quizá por falta de pruebas, pues el yacimiento está muy arrasado, dadas las continuas obras que en él se efectúan constantemente.

Otro punto interesante es la constante aparición del vidrio en el mundo funerario. En la provincia hemos localizado diversas necrópolis que se sitúan en un período oscuro, que abarcaría entre los siglos V al VII d.C. Se trata de necrópolis hispanorromanas que se caracterizan por la pobreza de su ajuar, entre el que es fácil hallar elementos de adorno o recipientes vítreos, como en Les Jovades (Cocentaina) o Mas Blanc (Penáguila). 


\section{BIBLIOGRAFIA}

ALARÇAO, J. 1976: «Ceramiques diverses et verres», Fouilles de Conimbriga VI, París.

ALMAGRO BASCH, M. 1953-4: «Excavación en la necrópolis romana de Pollentia (Alcudia, Mallorca), Ampurias XV-XVI, Barcelona, pp. 246-247.

1955: Las necrópolis de Ampurias I-II, Barcelona.

CABALlERO, L. 1970: «Alconétar. En la vía romana de la Plata. Garrovillas (Cáceres)», E.A.E., 70, Madrid.

- 1974: «La necrópolis tardorromana de Fuentespreadas (Zamora)», E.A.E., 80, Madrid.

CALVI, M. C. 1968: I vetri romani del Museo di Aquileia, Aquilea.

CARRERAS, T. 1982: «El vidre antic», Bulletí informatiu de Prehistoria - Arqueologia de la Diputació de Barcelona, 38, vol. VII.

CORZO SANCHEZ, 1981: «La basílica visigoda de Alcalá de los Gazules», Estudios de Historia y Arqueología medievales, I, Cádiz, pp. 77-90.

CHARLESWORTH, D. 1966: «Roman Square Bottles», Journal of Glass Studies, VIII, pp. 26-40.

GRANADOS, J. 1977: «Estudios de cerámica romana barcelonesa: un vaso de cerámica corintia hallado en la necrópolis romana de las Cortes», Boletín del Seminario de Arte y Arqueología, XLIII, Valladolid, pp. 395-409.

HARDEN, D. 1936: Roman Glass from Karanis, Michigan.

HAYES, J. 1975: Roman and preroman Glass in the Royal Ontario Museum, 1975.

ISINGS, C. 1957: Roman Glass from dated Finds, Groningen.

MEZQUiRIZ DE CATALÀn, M. A. 1978: Pompaelo, I-II, Pamplona.

RAMOS FERNANDEZ, R. 1974: De Hélike a Illici, Alicante.

REMESAL RODRIGUEZ, J. 1979: «La necrópolis sureste de Baelo», E. A. E., 104, Madrid.

RICO GARCIA, M. 1893: «Fábricas de vidrio y cerámica en Alicante», El Archivo, VII, pp. 69-78.

SIRET, L. 1906: Villaricos y Herrerías, Madrid.

VESSBERG, D. 1952: «Roman Glass in Cyprus», Opuscula Archaeologica, VII, Stockholm.

VIGIL PASCUAL, M. 1969: El vidrio en el mundo antiguo, Madrid. 


\title{
APORTACIONES AL CONOCIMIENTO DEL PORTUS ILLICITANUS: RESEÑ DE LOS TRABAJOS DE URGENCIA DE 1976. LA TERRA SIGILLATA
}

\author{
ALFREDO GONZALEZ PRATS \\ Universidad de Alicante
}

A la memoria de mi padre

\begin{abstract}
En este trabajo se ofrece una reseña de las excavaciones de urgencia realizadas en 1976 en el Portus Illicitanus, con una visión de las fases culturales que allí se desarrollaron. Se presenta un catálogo de las cerámicas romanas imperiales halladas durante los trabajos, destacando Ios ejemplares de Clara Lucente y Clara B, así como los vasos con relieves aplicados, documentos que venían siendo considerados raros o inexistentes en esta parte del Pais Valenciano.
\end{abstract}

\begin{abstract}
A review of the emergency excavations carried out in 1976 at the Portus Mlicitanus is shown in this paper, as well as a view of the cultural stages which developed in that area. There is a catalogue of Imperial Roman ceramics found during the excavations, where the specimens from Clara Lucente and Clara B, had been considered rare or nonexistent in this part of the Valencian country.
\end{abstract}

\section{INTRODUCCION}

A pesar de que el Portus illicitanus jugó un papel de primer orden en la época romana y fue un centro neurálgico del comercio mediterráneo en la Antigüedad en la fachada oriental y sudoriental de la Península Ibérica, son escasas las noticias que aluden directamente a semejante lugar. Esta parquedad de las fuentes antiguas viene a afectar en menor grado a la colonia romana en función de la cual se constituyó o, mejor, afianzó su puerto comercial, es decir, Illici, poseyendo reiteradas citas en las fuentes de época visigoda al detentar una sede episcopal.

En segundo lugar, así como la Alcudia de Elche ha promovido desde el siglo pasado una creciente labor investigadora por parte de estudiosos locales y extranjeros -recogida por su propietario, el finado Ramos Folqués, y heredada por su hijo, el doctor Ramos Fernández, quien dedicó su tesis, al estudio del yacimiento- a la hora de querer presentar una visión coherente de lo que fue su puerto nos enfrentamos con grandes e insalvables lagunas, que sóló en los últimos tiempos parece que empiezan a rellenarse con el programa de excavaciones sistemáticas emprendidas en la zona por el Museo Arqueológico de Santa Pola, cuya directora ya ha adelantado algunos de los más recientes trabajos (SANCHEZ FERNANDEZ, 1983).

En este estado de cosas, hemos considerado oportuno presentar aquí los datos que poseemos sobre el Portus recogiendo algunos trabajos nuestros realizados tras la cam- 
paña de urgencia llevada a cabo en diciembre de 1976, para la que fuimos comisionados por el consejero provincial de Bellas Artes, el doctor Llobregat Conesa, y que permanecían almacenados en espera de su publicación, habiendo únicamente realizado una nota preliminar sobre las lucernas de aquella campaña (GONZALEZ PRATS, 1977).

\section{LAS FUENTES SOBRE EL PORTUS}

Reunimos en este apartado las fuentes antiguas que de una forma u otra hacen alusión al golfo o puerto ilicitano, incluyendo la del Anónimo de Ravenna y de Artemidoro de Efeso por haber llegado la investigación actual a la identificación del Portus con 'Ahwvis /Allon.

La primera mención del calificativo de ilicitano para designar la bahía o seno de Santa Pola se halla en la Historia Natural de C. Plinio el Viejo (23-79 DC) en su libro III, 19:

«luego la (región) de Contestania... En la costa que queda está el río Táder e Ilici, colonia inmune, de la cual recibe el nombre el seno ilicitano»

En el siglo II, al describir el litoral contestano en sus Tablas Geográficas, el matemático, geógrafo y astrónomo de Alejandría Ptolomeo utiliza ya la designación de puerto ilicitano:

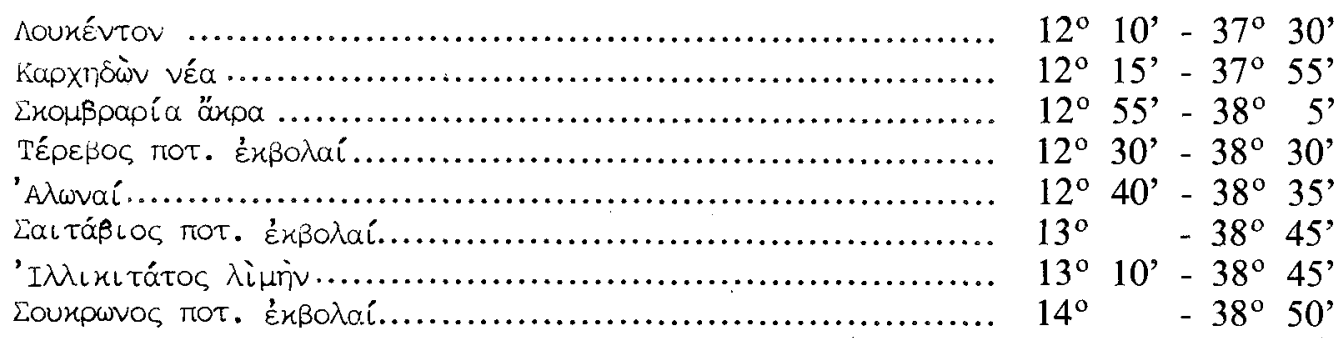

Pomponio Mela, por su parte, en su obra Chorographia describe:

II, 93: «(sinus) sequens Ilicitanus Allonem habet et Lucentiam et unde ei nomen est Ilicem»

Esteban de Bizancio, recoge la cita de Artemidoro de Efeso:

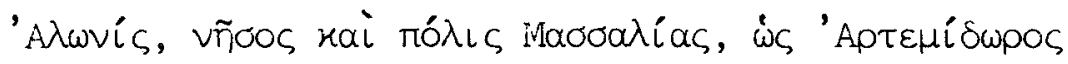

De aquí hemos de pasar al siglo $\mathrm{V}$, en que diversas fuentes recogen la noticia de la destrucción de la flota de Mayoriano en el mes de mayo de 460 por los vándalos. El topónimo citado es Elecem, pero lógicamente se refiere a su puerto. Las citas se hallan en:

HYDATIUS, p. 31, 200:

«Mense Maio Maiorianus Hispanias ingreditur imperator: quo Carthaginiensem provinciam pertendente aliquantas naves, quas sibi ad transitum adversum Vandalos praeparabat, de litore Carthaginiensi commoniti Vandali per proditores abripiunt. Maiorianus ita a sua ordinatione frustratus ad Italiam revertitur.» 
CHRONICA GALLICA, 664 (633-34):

«Maiorianus ingresus Arelatem (qui volens Africam proficisci naves eius in Hispanias a Wandalis captae sunt iuxta Carthaginem Spartariam).»

CHRONICA Marii Epicop. Aventicensis, p. 232;

«His consulibus (Magno y Apolinar) Maiorianus imperator profectus est ad Hispanias. Eo anno captae sunt naves a vandalis ad Elecem iuxta Carthaginem Spartariam.»

ISIDORUS, Historia Vandalorum, 76:

«Maiorianus autem imperator de Italia Spanias veniens cum in Carthaginiensi provincia aliquantas naves sibi ad transitum adversus Wandalos praeparasset, eas de litore Carthaginiensi conmoniti Wandali per proditores abripiunt sicque Maiorianus a sua dispositione frustratus, Italiam revertitur atque a Recimero fraude circumventus occiditur.»

Una referencia bélica de época visigoda la encontramos en la Crónica Mozárabe del 754 , en donde se menciona la victoria del almirante Teodomiro de Oriola rechazando una incursión de la flota bizantina en 700-702. No se alude claramente al Portus, pero dado que el otro gran puerto del litoral, Cartagena, había sido destruido por los godos, el de Santa Pola parece haber servido de base de acción a la flota visigoda:

CONTINUATIO HISP., p. 354, cap. 74:

«...nomine Theudimer qui in Spanie partes non modicas Arabum intulerat neces et, diu exageratos, pacem cum eis federat habiendus. Sed et iam sub Egicane et Witizane Gothorum regibus in Grecis qui equorei nabalique descenderant sua in patria, de palmam victorie triumphaverat.»

Con anterioridad, el Anónimo de Ravenna del siglo VII, que parece basarse en un mapa romano del siglo III, nos ofrece diversos nombres de localidades en esta área geográfica:
IV, 42 pp. 303
5 Saguntum
6 Valentia
7 Portum Sucrone
8 Asterum (Alternum)
9 Setavum (Setabi)
10 Turres
11 Eloe (Edelle)
12 Celeret (Celeri)
13 Dionio
14 Lucentes
15 Leones (Ad Leones)
16 Allon
17 Hilice (Ilice) 
Esta fuente ha dado pie a Llobregat a postular la identificación Allon = Portus Illicitanus (LLOBREGAT, 1983).

Posteriormente, las alusiones al puerto de Santa Pola provienen de geógrafos musulmanes como Al-Himyari, del siglo XIV, quien recoge las citas de AL-UDRI y de ALIDRIDI (s. XI y XII):

AL-HIMYARI: Kitab ar-rawd al-Mi'tar (p. 70 de la versión castellana):

«El distrito de Elche forma parte del círculo de Tudmir, y su cabeza de partido se encuentra a quince millas de Orihuela.

Elche es una gran ciudad situada en una llanura; está atravesada por un brazo del río vecino, que pasa bajo las murallas y abastece las termas, atravesando tiendas y calles; su agua es salobre.

De Elche a Alicante hay veinticinco millas. Se cuenta, entre ot ras cosas, que en el fondeadero llamado de Santa Pola, sobre la orilla cercana a Elche, hay piedras...»

En el siglo XVI poseemos una inscripción en lápida de mármol que estaba situada en el castillo de Santa Pola y en donde se mencionaba no el nombre actual, sino el referente al Puerto de Elche. Según Cristóbal Sanz se leía:

«Bernardino de Cárdenas, duque de Maqueda, lugarteniente del Potentísimo Filipo, Rey de las Españas. Por refugio de los navegantes y de la república christiana edificó este alcázar y castillo del puerto antiguo de Elche. Año 1557» (IBARRA, 1897).

En el siglo XVII, Gaspar Escolano redacta sus Décadas, en cuyo tomo II, libro VI, p. 26, al tratar de Santa Pola dice:

«En este sitio estaba el famoso puerto a quien llamaron los antiguos illicitano, que dio nombre al seno: y aquí mismo tuvo su asiento Illice la Vieja, que se la dio al puerto, como lo atestigua Pomponio Mela, y fue tan nombrada de los antiguos geógrafos cuanto poco atinada de los modernos. Descúbrese hoy día aquel puerto a tiro de arcabuz del castillo de Santa Pola, un grande aljibe donde estaba sita la ciudad. Y cerca del aljibe, al Poniente, muchos rastros del puerto en seco, más de quinientos pasos la tierra adentro, por haberse retirado el mar, como cada día lo experimentamos en la costa.»

Y así, ya hay que pasar a finales del siglo XIX y principios de éste con los datos de tipo arqueológico que nos proporcionan los hermanos Aureliano y Pedro Ibarra, alrededor de La Cenia, que detallaremos en el apartado siguiente.

\section{HISTORIA DE LA INVESTIGACION}

De quienes se han dedicado durante estas dos últimas centurias al estudio y a la recolección de datos sobre el Portus Illicitanus, constituyendo la base de partida para la moderna investigación arqueológica, destaca en primer lugar Aureliano Ibarra, con su obra Illici, su situación y antigüedades, publicada en Alicante en 1879. Allí se recogen diversas noticias, así como hallazgos propios referentes al Portus romano de Santa Pola. Los más importantes se detallan a continuación: 
- En 1602, en el Cap del Aljup y Castillo de Santa Pola se hallaron 52 monedas de Filippo.

- Hallazgo de una pátera o catino de vidrio, decorada en el centro con la cruz de tipo cristiano.

- En las excavaciones realizadas por el marqués de Lendínez se halló:

- una pequeña Victoria de bronce;

- una Venus acéfala de alabastro;

- sortija de oro con gema grabada;

- lucernas;

- monedas;

- ponderales;

- barros saguntinos (t. sigillata);

- dolia y ánforas.

- Hallazgo de un gran sarcófago de mármol con bajorrelieves, así como medallones de mármol con cabezas esculpidas.

- El lugar de La Cenia era conocido desde siempre como «bancal dels chavos» en orden a la ingente cantidad de monedas de bronce halladas.

- Hallazgo de un dolium con la siguiente inscripción de volumen: MXXIII. XXIIX.

Con el título Elche, materiales para su historia, publicado en Cuenca en 1926, Pedro Ibarra continúa la obra y comparte la preocupación hacia el Portus con su hermano Aureliano. Como hiciera éste, recoge datos útiles acompañados de preciosos hallazgos en la zona objeto de posteriores excavaciones, como:

- Los hallazgos de 1898 en La Cenia, traducidos en:

- un collar de cuentas y broche de oro;

- áureo de MAYORIANO (457-461): D.N. NLIVS MAIORIANVS PPAVE;

- sortija que en su chatón llevaba una moneda de MARCO AURELIO (161-180): ANTONINVS AVG. ARMENIACVS;

- collar de oro con cuentas de ágata;

- dos áureos de GALIENO (253-265): GALLIENVS P.F. AVS,

GALLIENVS AVG;

- un áureo de ARCADIO (395-408):

D.N. ARCADIVS PF AVG.

- En 1929, adquiere un áureo de HONORIO.

- En 1885, junto al cementerio, se halló gran cantidad de fragmentos de bronce, al parecer de una estatua de Augusto.

- Noticia, recogida a su vez de un manuscrito anónimo de 1752, de una lápida de cuatro palmos y cuatro dedos por dos palmos y dos dedos en uno de los muros del castillo de Santa Pola con la siguiente inscripción:

D.M.

VLP. MARCIANAE

VIXIT AN. XXX

L. CASSIVS. IVNIA

NVS. MARITAE

KARISSIMAE. 
- Los hallazgos conjuntos con el señor Múrtula en 1914 en La Cenia:

- molde de tres sellos abiertos en placa de pizarra;

- disco de plomo con un medallón con una cabeza varonil en relieve barbada y con diadema;

- fragmento de escultura (hombro derecho y pecho de un niño);

- paloma de cerámica de pasta clara;

- fragmentos de mosaicos polícromos;

- una lucerna;

- un vaso de sigillata de la forma DRAG. 27 con la marca OF. RVFI dentro de círculo;

- fragmentos de cerámica ibérica pintada;

- cerámica estampada gris y roja;

- medallón de lucerna con un Cupido sentado jugueteando con un perro.

Posteriormente, A. Ramos Folqués, en su Historia de Santa Pola, viene a recoger todas las anteriores citas y noticias de los hermanos Ibarra en su capítulo VII, que trata del Portus Illicitanus. Las noticias sobre actividades y hallazgos más recientes se resumen en:

- Las excavaciones en 1935 del padre Belda en los alrededores del cementerio, hallando cuatro sepulturas que consideró visigodas.

- Hallazgo de una boca de ánfora con la marca CRAMAR por don Claudio Miralles de Imperial y Gómez en su propiedad.

- Hallazgo por don Francisco Campello García, en los bancales al oeste del cementerio de una sepultura «con cuatro losas de ladrillos» que proporcionó un fragmento de frasco de vidrio, una jarrita de barro amarillento y un fino vaso decorado con relieves alusivos a los trabajos de Hércules.

En sus láminas pueden observarse diversos materiales, entre ellos, cerámicas ibéricas pintadas, cerámicas áticas de figuras rojas, cerámicas claras estampadas y ánforas del tipo Dressel 4 y 7.

\section{LAS EXCAVACIONES DE 1976}

Los trabajos tuvieron carácter de urgencia y salvamento, desarrollándose durante todo el mes de diciembre de 1976 y parte de enero siguiente.

El lugar en que se desarrollaron fue una zona de La Cenia, concretamente la finca a poniente del Palmeral, al otro lado de la calle. En una primera fase, adelantándonos al paso de la destructora pala excavadora, pudimos aflorar y delimitar los restos de tres grandes departamentos o almacenes que arrojaban medidas de $16 \mathrm{~m}$. por $5,5 \mathrm{~m}$. de ancho, con muros de $0,5 \mathrm{~m}$. de espesor. áreas:

Una vez se pudo detener las obras, el campo de trabajo quedó establecido en tres

- La BALSA 1, midiendo su interior 5 por $2,5 \mathrm{~m}$. y su exterior 6 por 3,5 $\mathrm{m}$., con paredes de hormigón de $0,5 \mathrm{~m}$.

- La BALSA 2, que alcanzaba una longitud de 15 por $1,80 \mathrm{~m}$., sin acabarse la misma.

- La ZONA A-B, más septentrional. 

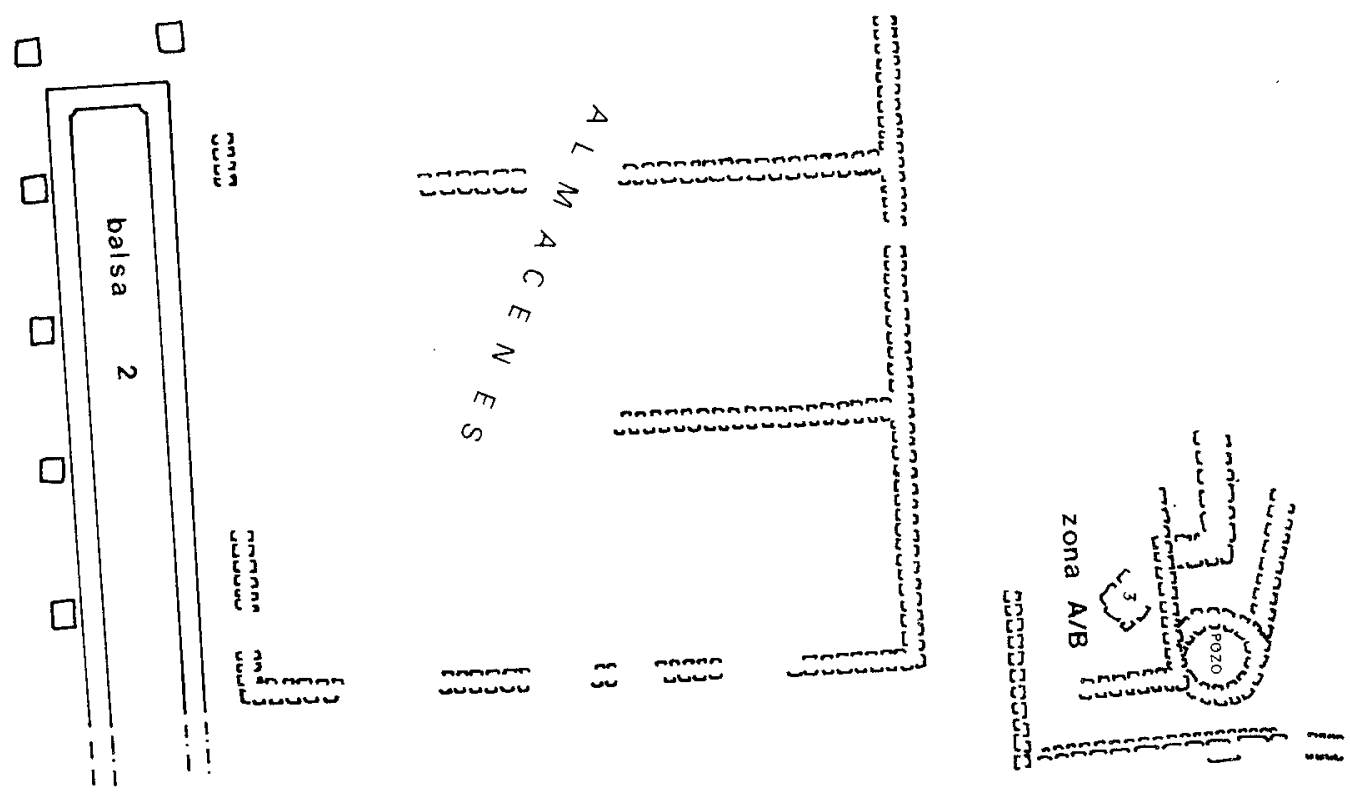

c a rretera

Plano de la excavación de 1976 
Inicialmente, se procedió al vaciado de las dos BALSAS, proporcionando ingente cantidad de materiales: fragmentos de mosaicos policromos, grandes platos o fuentes de mármol, lucernas de diversos tipos, abundantísima cerámica común y ánforas, cerámicas finas de importación (campanienses, itálicas, sudgálicas, hispánicas y un gran volumen de claras, aparte de numerosas monedas de bronce cuyo pésimo estado de conservación no permite una clara identificación.

Las BALSAS se construyeron con el duro OPUS CAEMENTICIUM y presentaban la superficie interna y el reborde superior alisados, con listones redondeados en los ángulos. Su altura conservada viene a alcanzar los $2,5 \mathrm{~m}$.

La BALSA 2 parece continuar al otro lado de la carretera, ya que al efectuar ésta nos notificaron que rompieron un fuerte foso que la cruzaba.

Los materiales, por tanto, se hallan revueltos y oscilan con una cronología del siglo I a. C. al V d. C. Da la impresión de que en un momento tardío del Bajo Imperio y seguramente a partir del siglo VI se rellenaron ambas balsas con escombros que procedían de otro lugar del Portus. En función de qué se realizó este relleno lo ignoramos por el momento. Lo que resulta obvio es que las BALSAS carecían ya de utilidad.

El área en donde se pudo trabajar con más calma pasó a denominarse Zona A y B, separadas por un testigo amplio. Alli se pudo establecer la estratigrafia siguiente:

0. Nivel superficial actual, creado a raíz del terraplenado de los antiguos bancales («dels chavos»), cuya altura venía a coincidir con los dos metros más que presenta el Palmeral.

I. Nivel de tierras grises y negruzcas, con fragmentos de cerámicas claras y lucernas con pico de corazón y agujero de alimentación umbilicado, que se puede fechar en el siglo III d. C. MURO I.

II. Nivel de color marrón anaranjado que ofreció abundante cerámica aretina y sudgálica en menor grado junto con lucernas de volutas de pico triangular, fechable en la primera mitad del s. I d. C. A nivel estructural, aparece el complejo de los MUROS II.

III. Nivel de color más grisáceo subyacente, que proporcionó alguna cerámica ibérica, fragmentos de campaniense B y lucernas preaugusteas del tipo con cabezas de pájaros, lo que nos permite fecharlo hacia la mitad del s. I a. C. Aparecieron restos de muros (MUROS III).

Contigua a esta zona se sondearon tres cortes denominados 1,2 y 3 , en los que se pudo establecer dos niveles:

II. El inferior, correspondiente a parte del vestíbulo de una casa con pavimento de OPUS SIGNINUM, amén de lo que parece ser la cocina. Proporcionó cerámicas sudgálicas y aretinas. Se corresponde con el nivel II anterior.

I. El superior, que clausura la estructura anterior, asentando un muro sobre el pavimento con placas de mármol, y que ofrecía entre otros materiales sigillatas claras, correspondiéndose con el nivel I de la Zona A-B.

Al SE. de ambas BALSAS y, al parecer, encerrando el conjunto, la pala excavadora fue extrayendo regularmente grandes sillares perfectamente escuadrados de forma rectangular o cúbica, que formarán una línea recta y de los que se conservaron los cinco que estaban casi adosados a la BALSA 2.

Igualmente, aprovechando un segundo desmonte de la pala excavadora en el ángulo oriental de la parcela de construcción, se pudo comprobar la existencia de un potente 


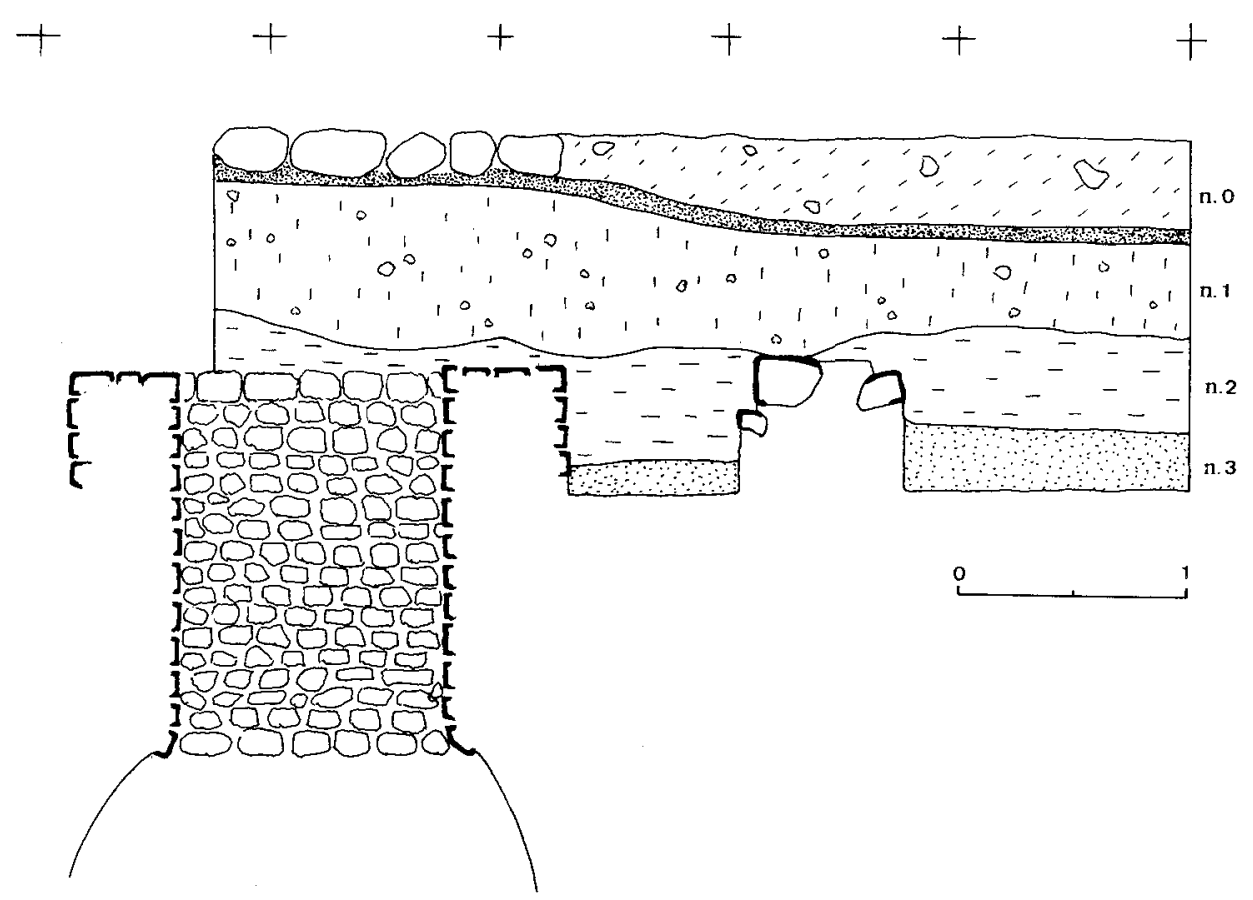

Fig. 2. Estratigrafías de la Zona A.

nivel preaugusteo que ofreció cerámica ibérica pintada del estilo ELCHE-ARCHENA y una forma LAMB. 7 de Campaniense B.

Lo mismo ocurrió en el Aljibe 1, cuya antigua construcción, con paredes de hormigón semejantes a las de las BALSAS, se efectuó cortando un nivel preexistente del que se recogieron cerámicas ibéricas pintadas.

Para confirmar estos hallazgos, con posterioridad a las excavaciones de diciembreenero se realizó un sondeo al oeste del cementerio, evidenciándose con gran sorpresa de todos un rico nivel ibérico contando con buena proporción de cerámica ática de barniz negro, fechable en el s. IV a. C y que por el momento viene a representar la fase más antigua del puerto que a raíz de la fundación de Illici tomó su nombre.

De los materiales exhumados en la campaña de urgencia de La Cenia estamos llevando a cabo - debido a la ingente masa de materiales - varios estudios parciales. Así, en lo que concierne a las lucernas, los tipos aparecidos son los siguientes:

I) Preaugusteos:

a) Con el pico decorado con cabezas de pájaros (DRESSEL-LAMBOGLIA, 4).

b) Delfiniforme, con decoración de glóbulos (DRESSEL-LAMBOGLIA, 2).

II) Imperiales:

a) De volutas sencillas y pico triangular (DRESSEL-LAMBOGLIA, $9 \mathrm{~B}$ ).

b) De alerones laterales (DENEAUVE, V G).

c) De disco y pico redondo (DRESSEL-LAMBOGLIA, 20).

d) Con pico de corazón y orla decorada (DRESSEL-LAMBOGLIA, 28 B y 30 A-B). 
e) De canal abierto corto y curvo (PONSICH, $4 \mathrm{~A}$ ).

f) De canal largo y recto (PONSICH, IV B).

Con lo que se convierte en un perfecto muestreo de la amplitud de vida del Portus romano, abarcando desde la mitad del s. I a. C. hasta el s. V d. C.

Si tomamos en consideración la distribución porcentual de las cerámicas sigillatas, se desprende la existencia de dos momentos en que el Portus Illicitanus se muestra más activo. El primero hacia la primera mitad del s. I a. C. y hasta la mitad del I d. C., con gran volumen de importaciones de lucernas de volutas y pico triangular, con sigillatas itálicas lisas y decoradas, así como sudgálica en menor grado.

Y otro momento, tal vez desde el último tercio del s. II d. C. hasta el s. V d. D. (sigillatas claras D y estampada, lucernas de canal corto o largo de tipo paleocristiano).

El primer movimiento se puede poner en relación con la creciente y nueva demanda que la recién fundada C. I. I. A. en el año 42 a. C. genera, así como secundariamente por los propios habitantes de la ciudad portuaria.

Los hallazgos muestran que los productos seguían llegando a lo largo de los siglos I, II y III, con un probable estancamiento durante la crisis de mediados de este último siglo, para cobrar nuevamente su actividad a lo largo de los dos siglos siguientes.

La cerámica estampada gris que presenta $\mathrm{P}$. Ibarra - reflejo de las bellas fuentes de Illici- y ciertas curiosas formas de cerámica común parecen marcar la última etapa alrededor de los siglos V y VI d. C., aunque sabemos que el Portus sigue viviendo con carácter comercial y militar hasta el siglo VIII como mínimo, y tal vez el estudio de las cerámicas comunes halladas en las BALSAS pueda documentar tipos que vendrían a cubrir ese vacío.

\section{CONCLUSIONES}

Con los datos proporcionados por Aureliano y Pedro Ibarra, y posteriormente por Ramos Folqués, y con los nuevos extraídos del estudio preliminar de los hallazgos de la campaña de salvamento de diciembre de 1976, podemos resumir el estado de la cuestión acerca de las fases de ocupación del Portus en los siguientes puntos:

1. Existencia de un habitat ibérico antiguo que por sus importaciones griegas puede ser fechado a lo largo de los siglos V-IV a. C. El área que ocupa parece extenderse al oeste del cementerio de Santa Pola.

2. Constatación de un nivel ibérico-republicano avanzado, fechable en la primera mitad del siglo I a. C., debajo de los niveles altoimperiales de La Cenia.

3. Un gran momento de esplendor comercial y urbanístico que se sitúa a partir de la segunda mitad del s. I a. C. El Portus Illicitanus debió decrecer y extenderse generando una verdadera ciudad portuaria que no sólo estaba en función de la demanda de Illici, sino que constituía de por sí un fuerte núcleo de consumo. Este momento continuó ininterrumpidamente con menor volumen de importaciones, al parecer, hasta la crisis del s. III d. C.

4. Paralela a la reconstrucción de que es objeto Illici, tras las destrucciones que acompañan la crisis, renace igualmente la actividad de su puerto. El gran volumen de sigillata clara D y estampada marcan bastante bien esta postrera etapa de vida del Portus, cuyo final no estamos en condiciones de determinar. 

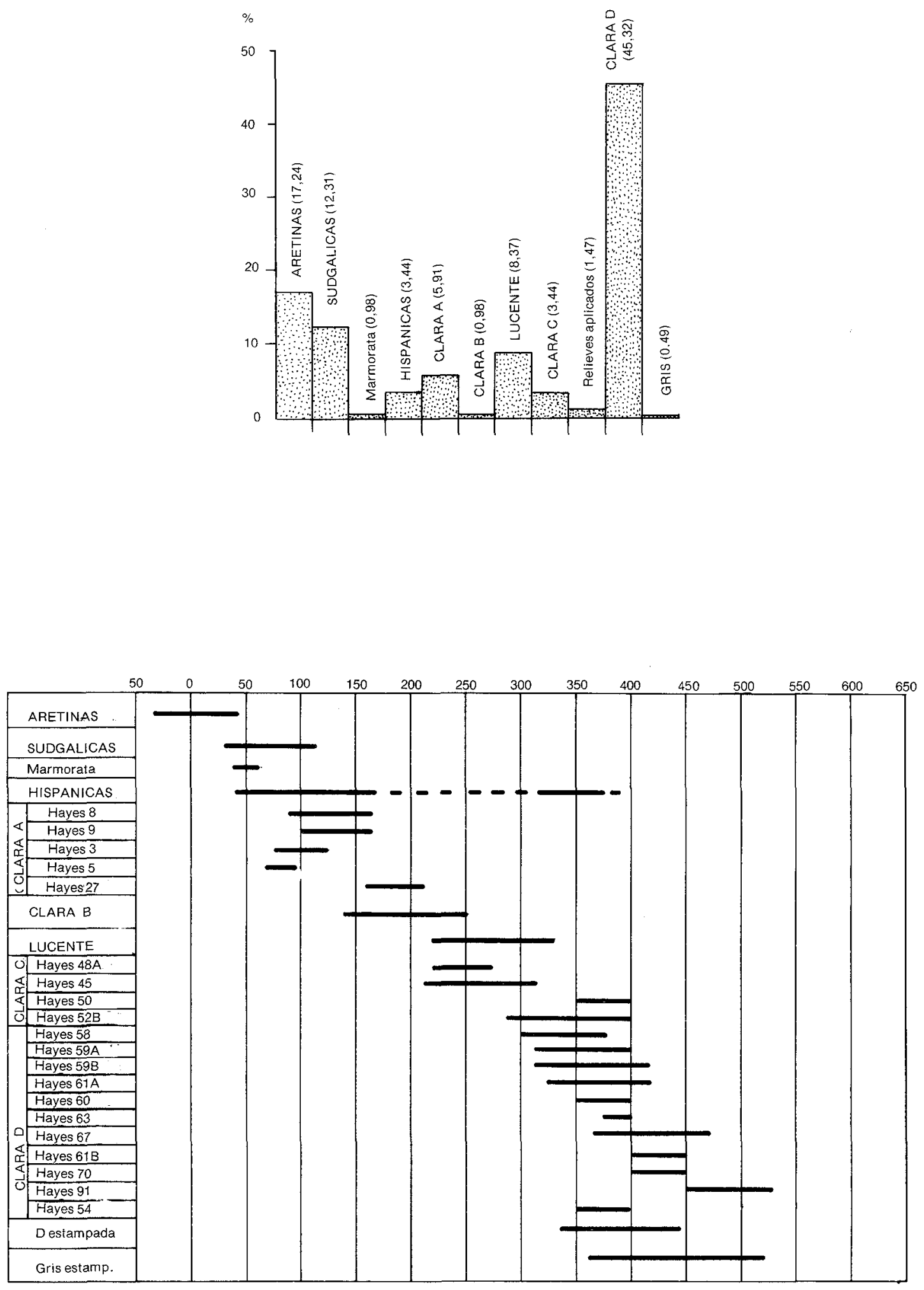

Fig. 3. Histograma de frecuencias de los distintos tipos de terra sigillata y cuadro cronológico. 
Arqueológicamente y con las reservas que debe implicar el extraer datos de una sola excavación, estos cuatro momentos parecen quedar bastante bien definidos. Con todo, la mayor importancia de los trabajos realizados estriba en la posibilidad de determinar la existencia de un asentamiento indígena por los albores del s. V-IV a. C. que creemos ya en función del mejor fondeadero y puerto del litoral contestano.

\section{LA TERRA SIGILLATA}

Este apartado que versa sobre las cerámicas finas de época imperial romana, en realidad incluye dos trabajos distintos realizados tras la campaña de 1976 con el fin de dar a conocer con la mayor rapidez los principales materiales arqueológicos recuperados. Es por ello que el conjunto de sigillatas rojas presenta una homogeneidad en su presentación que difiere del tratamiento que hicimos de la sigillata anaranjada o clara.

Por otro lado, es nuestro propósito presentar únicamente un catálogo de toda la terra sigillata hallada en los trabajos referidos, relegando para el futuro un estudio crítico que pensamos debe realizarse manejando también los últimos documentos aparecidos en las excavaciones que se llevan a cabo actualmente en la zona del Portus. Y, a mayor abundamiento, será imprescindible conocer todo el repertorio de formas y marcas hallados en el resto de la provincia, especialmente en La Alcudia, para llevar a feliz término un trabajo de este tipo y confeccionar las oportunas cartas de distribución y dispersión. En este ánimo, nuestro trabajo no es otro que el de facilitar al especialista el conocimiento de los materiales que se reseñan a continuación.

Dentro del primer grupo de terra sigillata, representado por los productos aretinositálicos, sudgálicos e hispánicos, destaca el mayor porcentaje correspondiente a las cerámicas itálicas, en su mayoría aretinas, que además nos ha permitido conocer las únicas marcas de este trabajo, pues las de las fábricas sudgálicas se presentan ilegibles en una primera apreciación. Estos porcentajes quedan reflejados a continuación:

$\begin{aligned} \text { Itálicas: } 51,4 \% & \text { (decoradas: 8,8 \%) } \\ & \text { (lisas: 42,6\%) } \\ \text { Sudgálicas: } 42,5 \% & \text { (decoradas: 17,6\%) } \\ & \text { (lisas: 22\%) } \\ & \text { (marmorata: 2,9\%) }\end{aligned}$

Hispánicas: $7,3 \%$.

Los talleres localizados a través de las marcas de alfarero son los siguientes, todos aretinos:

CN. ATEIUS
CN. ATEI MAHES
CN. ATEI PLOCAMI
M. GRATIDIUS
RASINIUS
UMBRICIUS
XANTHUS
GELLIUS (?).



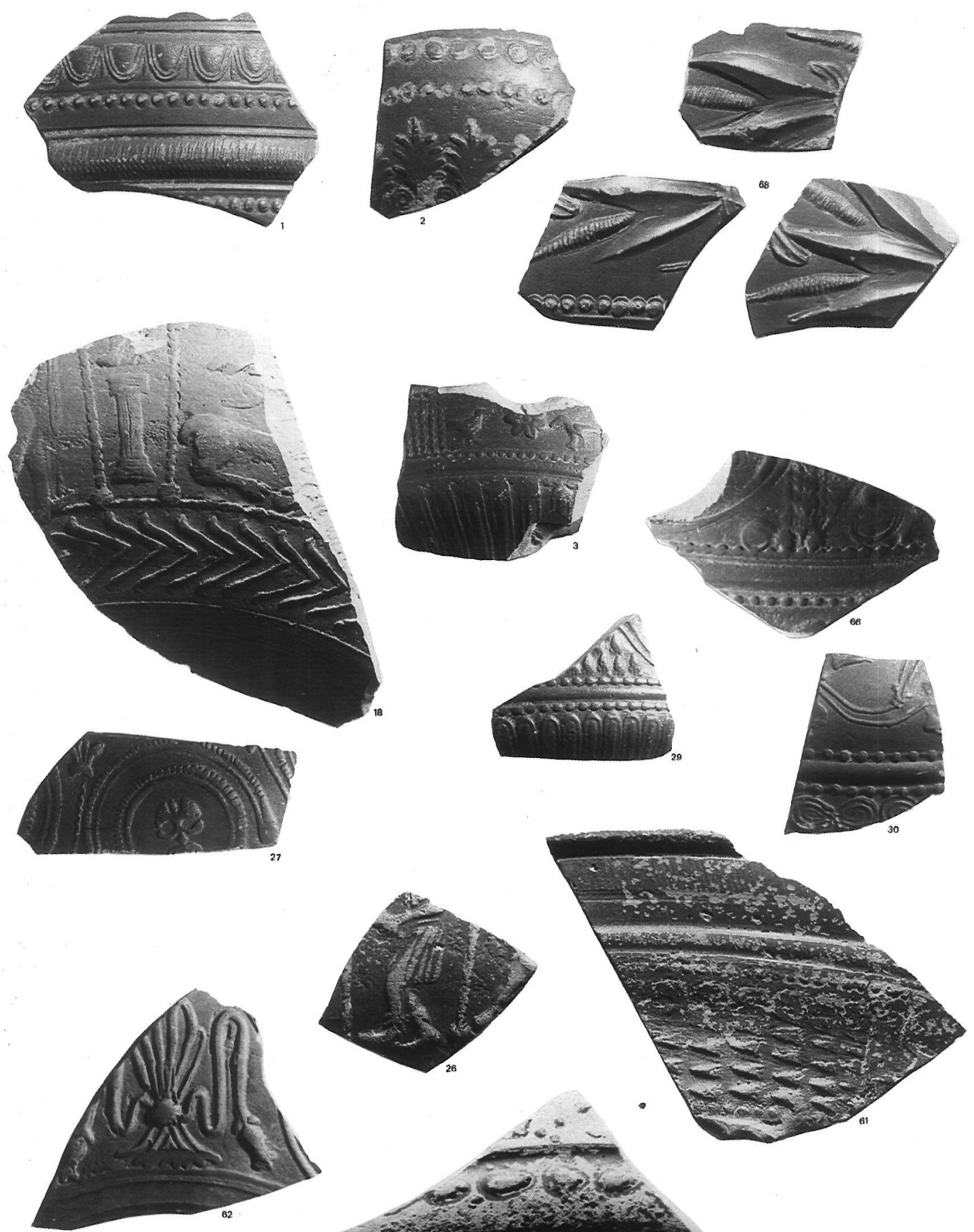

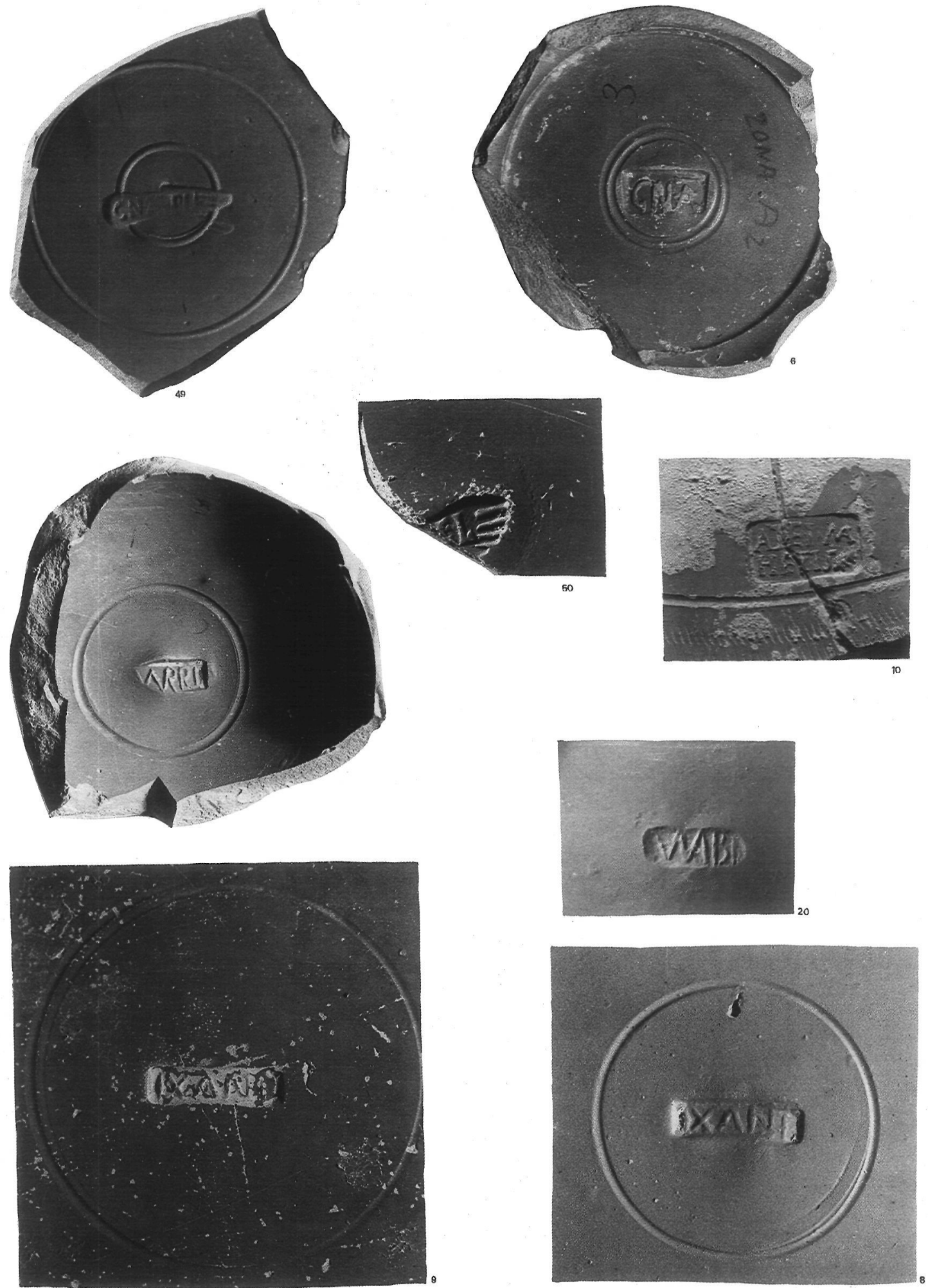

Lám. II. Selección de marcas de alfarero. 


\section{CATAlogo}

\section{Superficie}

1.- Fragmento de pared de una copa aretina decorada de la forma 11. Inv.: SPI-55.

2.-Fragmento de pared inferior de una copa aretina decorada de la forma 11 ó 13 . Inv. SPI-59.

3.-Fragmento de la parte inferior con carena de un vaso DRAG. 29 a de sudgálica decorada. Inv.: SPI-54.

4.-Fragmento de base de un plato de forma DRAG. 31 ó 33 de cerámica aretina lisa. Diámetro de la base: $4,7 \mathrm{~cm}$.

Marca en cartela cuadrangular dentro de circunferencia: M/CRATI. Del taller de M. GRATIDIUS (Oxé, 762). Inv.: SPI-45.

\section{Zona A}

5.-Base con parte de las paredes de un vaso aretino liso de la forma RITT. 5. Diámetro de la base: $6,7 \mathrm{~cm}$.

Marca en cartela cuadrangular con apéndices circulares en los ángulos: RASI. Del taller de RASINIUS (Oxé, 1485, 25.29). Grafito en el exterior de la base: BOC. Hallado en el nivel II.

Sin inventariar.

6.--Base de una forma HALTERN 7 de cerámica aretina lisa.

Diámetro: $4,2 \mathrm{cms}$.

Marca en cartela rectangular dentro de doble circunferencia: CN. ATE. Del taller de CN. ATEIUS (Oxé, 145). En el exterior del fondo, grafito de trazos tal vez numéricos.

Hallado en el nivel II.

Sin inventariar.

7.-Vaso completo de la forma DRAG. 27 de cerámica aretina lisa.

Diámetro del borde: $11,8 \mathrm{cms}$.

Diámetro de la base: $5,6 \mathrm{cms}$.

Altura: $6,7 \mathrm{cms}$.

Marca en interior de cartela rectangular con los ángulos ligeramente redondeados:

XANTHI. Del taller de XANTHUS (Oxé, 177). Grafito en el fondo externo.

Hallado en el nivel II.

Sin inventariar.

8.-Plato completo de la forma DRAG. 17 a de cerámica aretina lisa.

Diámetro del borde: $16 \mathrm{~cm}$.

Diámetro de la base: $8,7 \mathrm{~cm}$.

Altura: $3,6 \mathrm{~cm}$.

Marca en el centro del fondo interno y dentro de cartela rectangular: IXANTI, con el nexo NT. Corresponde al taller de XANTHUS, que trabajó en el de CN. ATEIUS (Oxé, 176). La I que precede al cognomen podría ser la letra final del cognomen ATEI tal como aparece en las marcas de doble línea (CN. ATE/IXANTHI) (Oxé, 176, 22), habiéndose tomado solamente la última de ellas. Parece ser la única posibilidad, dado que la marca aislada de XANTHUS no aparece nunca precedida de I. 

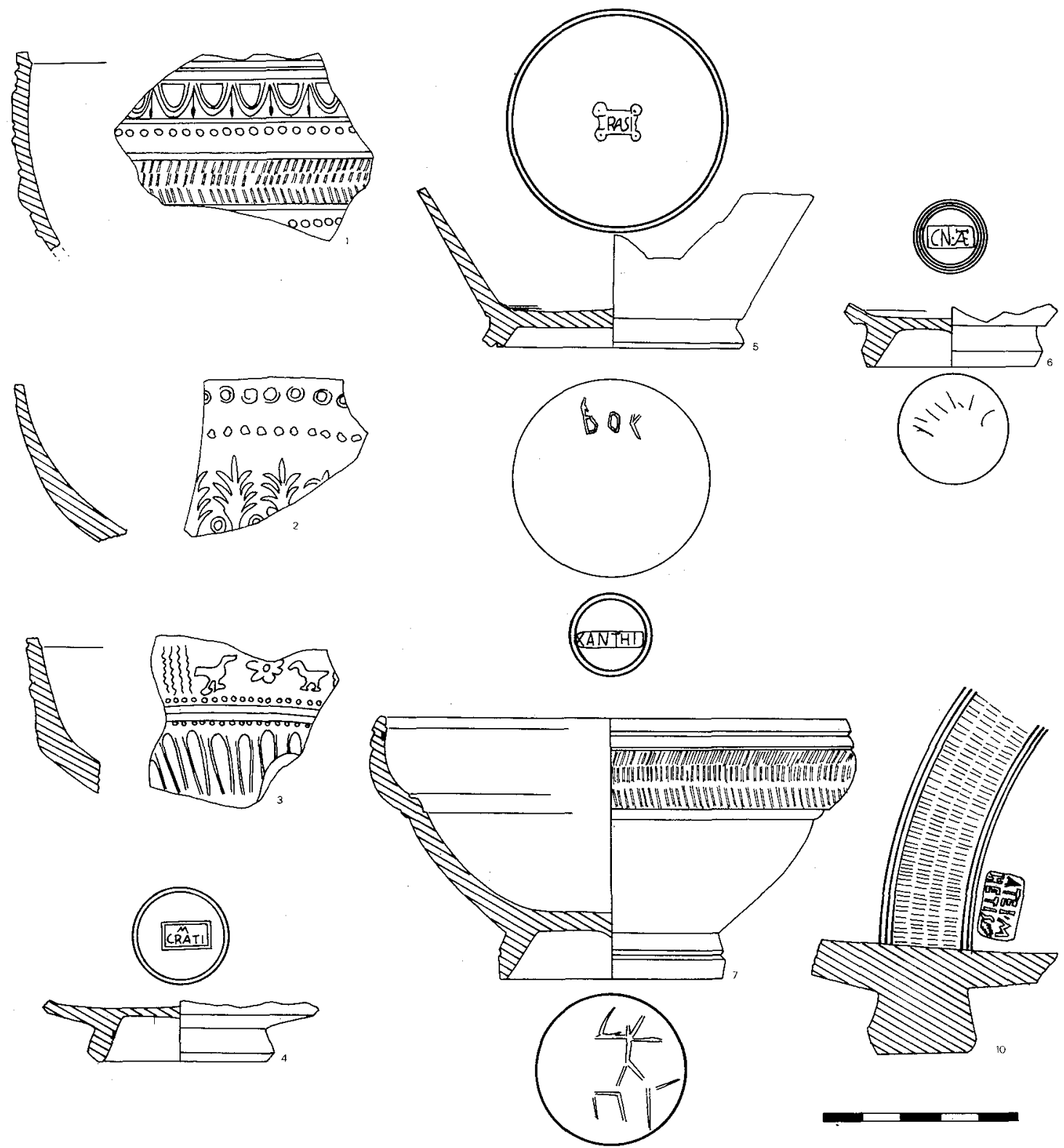

Fig. 4. Terra sigillata roja (aretina). Superficie y nivel II de la Zona A.

En el fondo externo, tres grafitos, uno posiblemente legible.

Hallado en el nivel II.

Sin inventariar.

9.-Plato completo de la forma DRAG. 17 a de cerámica aretina lisa.

Diámetro del borde: $16 \mathrm{~cm}$.

Diámetro de la base: $8,7 \mathrm{~cm}$.

Altura: $3,6 \mathrm{~cm}$.

Marca en el centro del fondo en cartela rectangular: IXANTHI, con el nexo NT. Del taller de XANTHUS. Ejemplar idéntico al anterior, con las mismas consideraciones en torno a la marca.

Hallado en el nivel II.

Sin inventariar. 

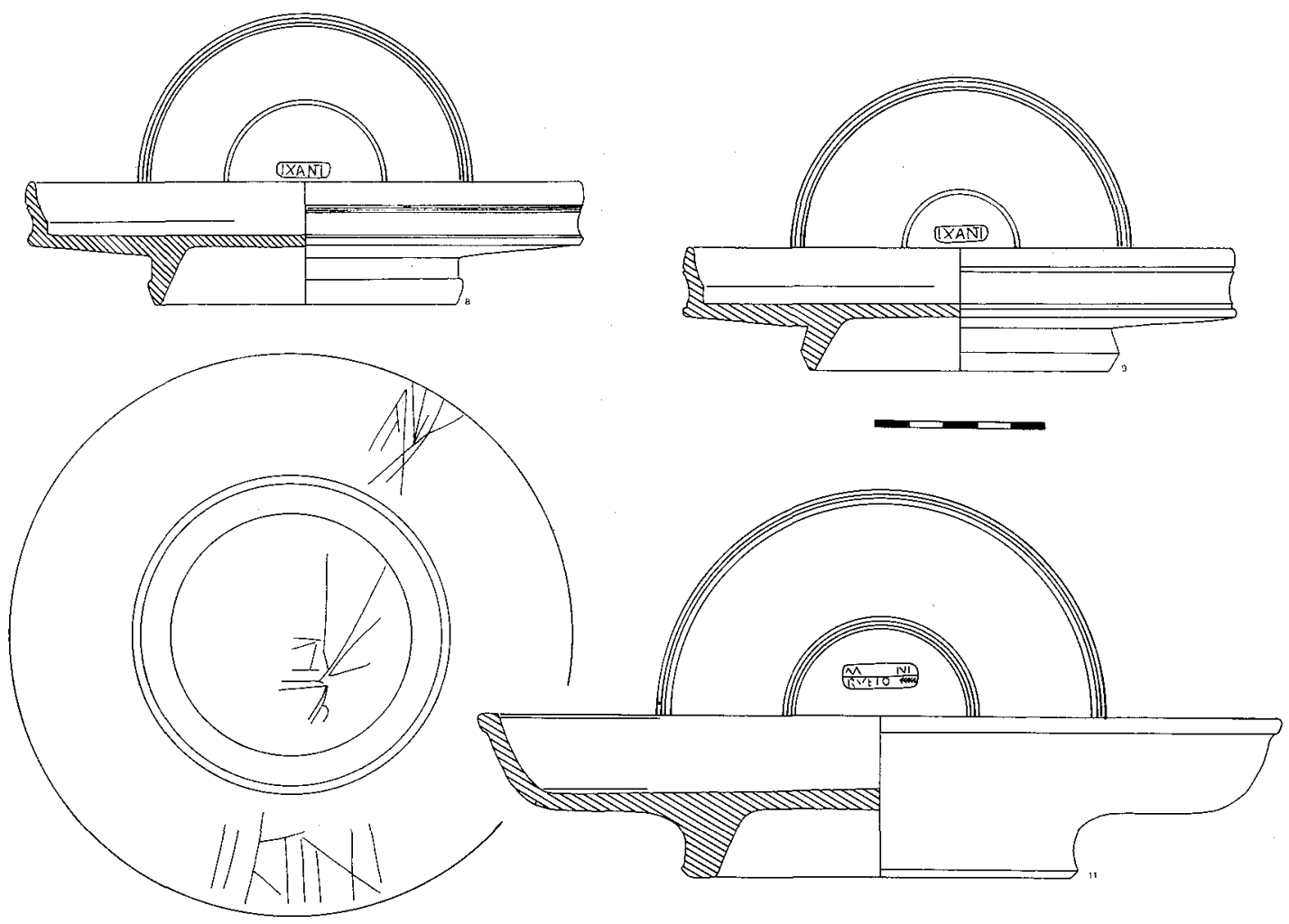

Fig. 5. Terra sigillata roja (aretina). Nivel II de la Zona A.

10.-Tres fragmentos que unen entre sí de una fuente de forma HALTERN I B de cerámica aretina lisa. Orla a ruedecilla y una marca en cartela cuadrangular: ATEIMA/HETIS. Del taller de CN. ATEI MAHES (Oxé, 168; similar a la 8.12, pero con el nexo MA y al final una estrella en lugar de la espiga de este ejemplar).

Procede del nivel II.

Sin inventariar.

11.-Plato de cerámica aretina lisa, de forma parecida a la DRAG. 18.

Diámetro del borde: $23,4 \mathrm{~cm}$.

Diámetro de la base: $11 \mathrm{~cm}$.

Altura: $4,7 \mathrm{~cm}$.

Fondo con dos grupos de dobles circunferencias y en el centro cartela rectangular con ángulos redondeados y marca en doble línea. Ha saltado el barniz y al ser débil la impresión prefiero no aventurar lectura alguna.

Procede del nivel II.

Sin inventariar.

\section{Zona B}

12.-Fragmento de borde y pared de una copa de la forma RITT. 5 de cerámica aretina lisa.

Procede del nivel II.

Sin inventariar. 
13. - Fragmento de borde y pared de un plato de forma HALTERN I A de cerámica aretina lisa.

Procede del nivel II.

Sin inventariar.

14.-Fragmento de borde y pared de una copa HALTERN 7 de cerámica aretina lisa. Procede del nivel II.

Sin inventariar.

15.-Fragmento de borde y pared de una forma DRAG. 27 de cerámica aretina lisa. Procede del nivel II.

Sin inventariar.

16.-Fragmento de fina pared de una copa aretina decorada, tal vez una forma 11 ó 13. Procede del nivel II.

Sin inventariar.

17.-Fragmento de borde de una forma HERMET 19 de cerámica sudgálica lisa. Sin inventariar.

18.-Fragmento de pared de una forma DRAG. 37 de cerámica sudgálida decorada: piernas de figura humana, estatua sobre columna y cuadrúpedo.

Sin inventariar.

19. - Base de una copa de cerámica sudgálica lisa, con marca ilegible en cartela rectangular de ángulos redondeados y rebasando la circunferencia en que se encuentra inscrita.

Diámetro de la base: $3,1 \mathrm{~cm}$.

Sin inventariar.

\section{Balsa 1}

20.-Base con parte de la pared de una forma RITT. 5 de cerámica aretina lisa. Diámetro de la base: $6,1 \mathrm{~cm}$.

Marca en cartela oblonga: VMBI, con el nexo VM. Del taller de UMBRICIUS (Oxé, 2385). Grafito en el fondo externo. Inv.: SPI-64.

21.-Fragmento de borde y pared de una copa de la forma RITT. 5 de cerámica aretina lisa. Inv.: SPI-391.

22. - Fragmento de borde y pared de la forma RITT. 9 de cerámica aretina lisa. Inv.: SPI-392.

23. - Fragmento de borde con ruedecilla, de cerámica aretina lisa. Inv.: SPI-400.

24. - Fragmento de borde de una forma RITT. 9 de cerámica aretina lisa. Inv.: SPI-393.

25. - Fragmento de borde de una fuente HALTERN I A de cerámica aretina lisa. Inv.: SPI-394.

26.-Fragmento de cerámica sudgálica o hispánica con personaje humano. Inv.: SPI-154.

27.-Fragmento de pared de una forma DRAG. 29 ó 36 de cerámica hispánica decorada.

Inv.: SPI-177.

28. - Parte de una copa de forma DRAG. $24 / 25$ de cerámica sudgálica lisa. Inv.: SPI-146.

29.-Fragmento de pared con inicio de la carena de una forma DRAG. 29 de cerámica sudgálica decorada.

Inv.: SPI-168. 
30.-Fragmento de pared de una forma DRAG. 29 a de cerámica sudgálica decorada. Inv.: SPI-170.

31.-Fragmento de borde de plato de cerámica sudgálica marmorata. Inv.: SPI-189.

32.-Fragmento de plato de la forma DRAG. 18 (?) de cerámica sudgálica lisa. Inv.: SPI-390.

33. - Fragmento de pared superior de una forma DRAG. 29 de cerámica sudgálica decorada. Inv.: SPI-397.

34.-Fragmento de borde de una forma DRAG. 18 (?) de cerámica sudgálica lisa. Inv.: SPI-395.

35.-Fragmento de borde de una forma DRAG. 18 (?) de cerámica sudgálica lisa. Inv.: SPI-398.

36.-Fragmento de borde de una forma DRAG. 18 (?) de cerámica sudgálica lisa. Inv.: SPI-399.

37. - Fragmento de borde y pared de una forma DRAG. $24 / 25$ de cerámica hispánica. Inv.: SPI-389.

\section{Balsa 2}

38. - Fragmento de borde de un plato DRAG. 17 a de cerámica aretina lisa. Inv.: SPI-429.

39. - Fragmento de borde de una fuente de forma HALTERN I A, de cerámica aretina lisa.

Inv.: SPI-441.

40.-Fragmento de borde de una forma HALTERN I A de cerámica aretina lisa. Inv.: SPI-452.

41.-Fragmento de borde de un plato de la forma DRAG. 17 a de cerámica aretina lisa. Inv.: SPI-433.

42.-Fragmento de pared de una copa aretina decorada de la forma 11. Inv.: SPI-444.

43.-Fragmento de pared de una forma RITT. 5 de cerámica aretina lisa. Inv.: SPI-445.

44.-Fragmento de plato de forma DRAG. 17 a de cerámica aretina lisa. Inv.: SPI-427.

45.-Fragmento de borde de una fuente de forma HALTERN I, de cerámica aretina lisa. Inv.: SPI-459.

46.-Fragmento de borde de una fuente de forma HALTERN I, de cerámica aretina lisa.

47.--Fragmento de borde de un plato de forma DRAG. 17 a con ruedecilla, de cerámica aretina lisa.

48. - Fragmento de base con arranque del pie de una copa aretina de la forma 11. Inv.: SPI-447.

49. - Base con arranque de las paredes de un vaso de cerámica aretina lisa, marca «in planta pedis» inscrita en circunferencia central: CN.ATE.PL. Del taller de Cn. Atei PLOCAMI (Oxé, 171, 1 c.h).

Diámetro de la base: $4,8 \mathrm{~cm}$. Inv.: SPI-428.

50.-Fragmento de base con parte de la pared de un plato de forma DRAG. 17 de cerámica aretina lisa. En el centro, restos de marca «in planta pedis»: EL. Posiblemen- 

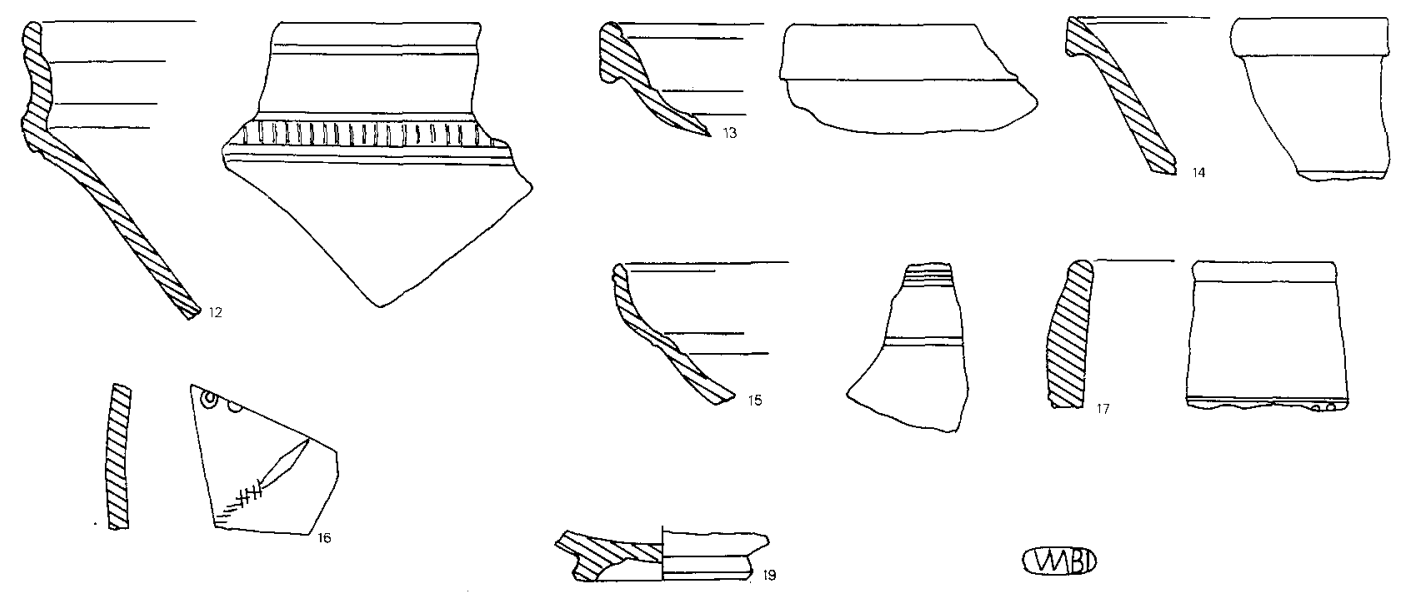

WBD
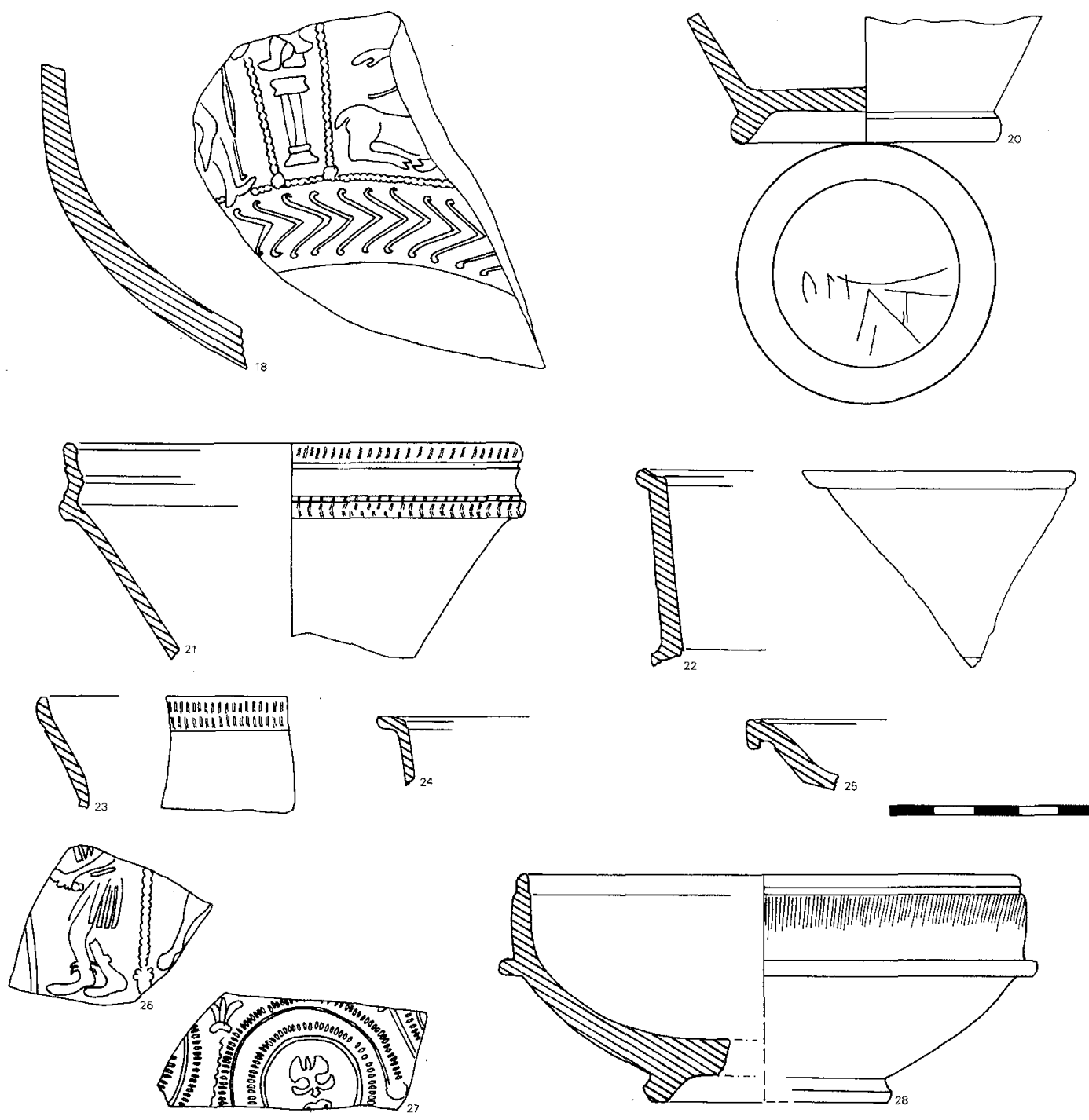

Fig. 6. Terra sigillata roja (aretina, sudgálica e hispánica). 

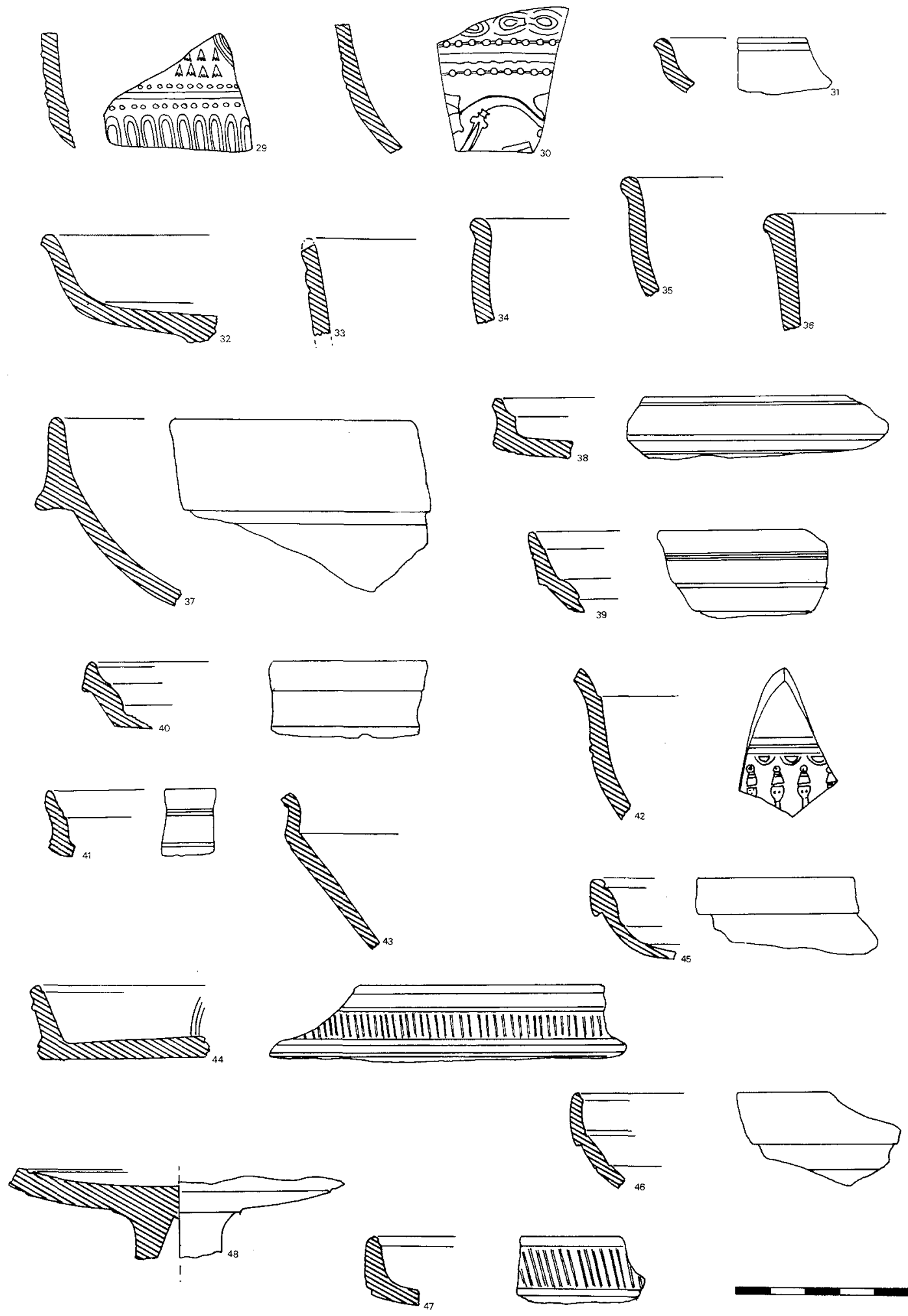

Fig. 7. Terra sigillata roja (aretina, sudgálica e hispánica). 

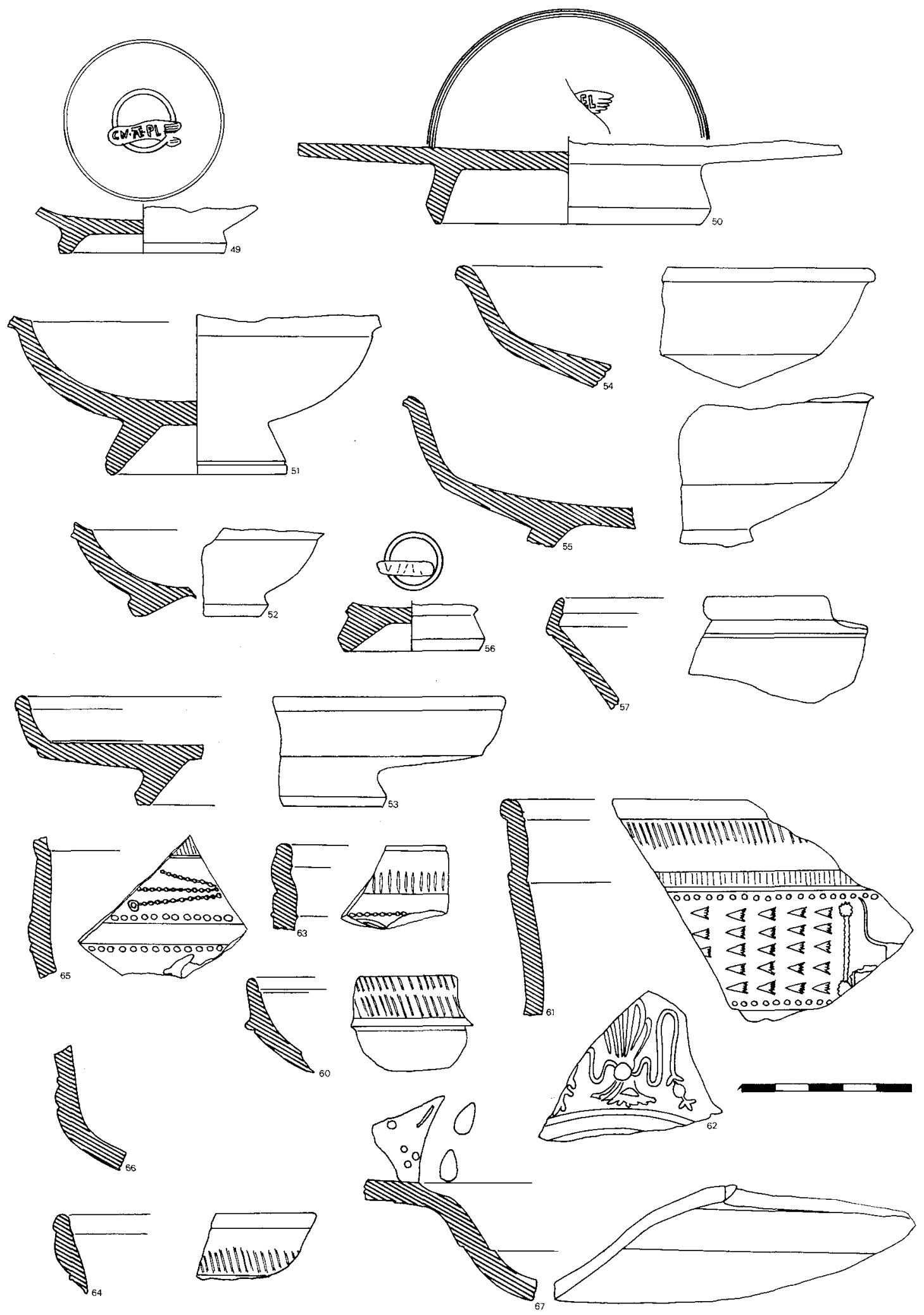

Fig. 8. Terra sigillata roja (aretina, sudgálica e hispánica). 
te, del taller de GELLIUS (Oxé, 736, 54.72 a.b).

Diámetro de la base: $7.7 \mathrm{~cm}$.

Inv.: SPI-427.

51.-Base y parte del primer cuerpo de una copa de forma DRAG. 27 de cerámica sudgálica lisa. Marca ilegible en cartela rectangular con los ángulos redondeados, inscrita en doble circunferencia.

Diámetro de la base: $5,2 \mathrm{~cm}$.

Inv.: SPI-439.

52.-Fragmento de una copa de forma DRAG. 27 de cerámica hispánica lisa. Inv.: SPI-446.

53.-Fragmento de plato de la forma DRAG. 18 (?) de cerámica sudgálica marmorata. Inv.: SPI-437.

54.-Fragmento de borde de un plato de la forma DRAG. 18 (?) de cerámica sudgálica lisa.

Inv.: SPI-436.

55. - Fragmento de borde, pared y arranque del pie de un plato de forma DRAG. 18 (?) de cerámica sudgálica lisa.

Inv.: SPI-434.

56. - Base de cerámica sudgálica lisa, con marca en cartela rectangular ilegible dentro de una circunferencia: VI...

Inv.: SPI-440.

57.-Fragmento de una copa RITT. 5 de cerámica sudgálica lisa. Inv.: SPI-449.

58.-Fragmento de una forma DRAG. 18 (?), de cerámica sudgálica lisa. Inv.: SPI-430.

59. - Fragmento de borde de un vaso de cerámica sudgálica o hispánica. Inv.: SPI-457.

60. - Fragmento de borde de una copa de forma DRAG. 24/25 de cerámica sudgálica lisa.

Inv.: SPI-450.

61.--Fragmento de borde y pared de una forma DRAG. 29 ó 30 de cerámica sudgálica decorada.

62.-Fragmento de la parte inferior de una forma DRAG. 29 de cerámica sudgálica decorada. Inv.: SPI-435.

63.-Fragmento de borde de una forma DRAG. 29 de cerámica sudgálica decorada. Inv.: SPI-438.

64.-Fragmento de borde de una forma DRAG. 29 de cerámica sudgálica decorada. Inv.: SPI-451.

65.-Fragmento de pared de una forma DRAG. 29 a de cerámica sudgálica decorada. Inv .: SPI-442.

66. - Fragmento de pared con carena de una forma DRAG. 29 de cerámica sudgálica decorada.

Inv .: SPI-432.

67.-Fragmento de pared con parte del borde decorado internamente, de una forma DRAG. 39 de cerámica hispánica lisa (Mezquiriz, lám. 17, A).

Inv.: SPI-443. 


\section{La Terra sigillata clara}

Este grupo cerámico, que arranca de fines del I d. C., es sabido que inaugura una nueva vajilla de lujo en el Mediterráneo central y occidental, mientras las áreas continentales van a seguir desarrollando la tradición de las sigillatas rojas. Dividida en diversas especies por el Prof. Lamboglia, Hayes integra los tipos A, C y D bajo el calificativo común de «African red slip ware», con una nueva nomenclatura de las formas. Seguiremos la doble denominación de estos autores, sin considerar las divisiones y nomenclatura de otros como Waagé y Salomonson, dado el cometido de este trabajo.

El lote que se presenta a continuación muestra notorias novedades, que creemos serán confirmadas por los últimos conjuntos procedentes de las actuales excavaciones en el Portus, como son la existencia de especies tales como la Clara B, lucente y la decorada con relieves aplicados, las cuales venían siendo consideradas por G. Martín como muy raras o inexistentes, según los casos, en el Levante y Sudeste peninsular.

La totalidad de los fragmentos proceden de las Balsas 1 y 2, a excepción del núm. 524 (lucente), y el núm. 522 (Clara D) procedentes ambos de un mismo estrato: el nivel I de la zona A.

\section{Clara A}

De la forma Lamboglia 1-Hayes 8 poseemos cuatro fragmentos, dos de ellos con decoración a ruedecilla, mientas los otros son lisos.
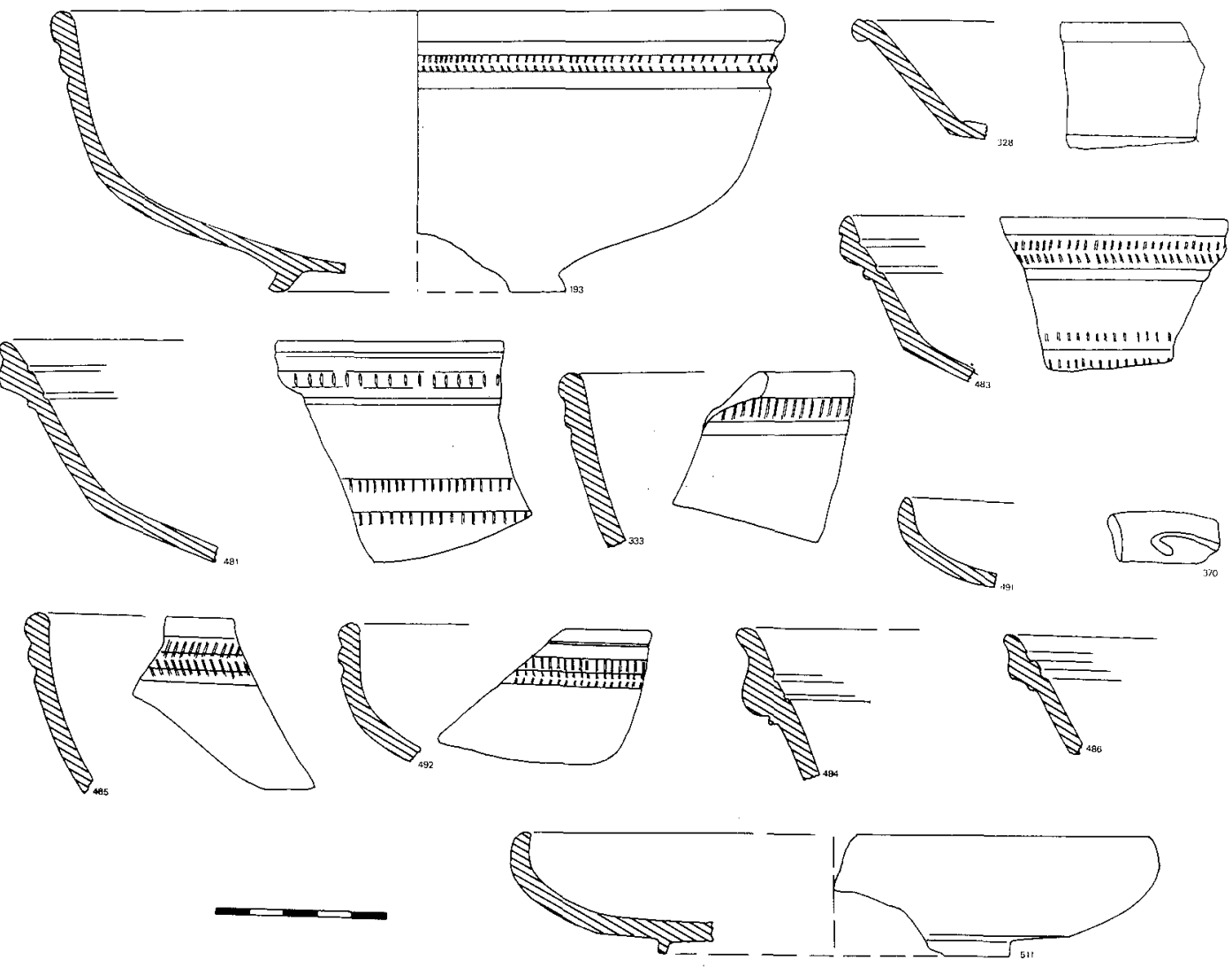

Fig. 9. Terra sigillata clara (A). Formas Hayes 8, 9, 3B, 5 y 27. 
Otros cuatro fragmentos representan a la forma Lamboglia 2A-Hayes 9, con datación idéntica a la de los vasos anteriores.

Hay un solo fragmento de la forma Lamboglia 4/36A-Hayes 3B con decoración de barbotina en el ala, mientras el núm. 328 corresponde a una forma Lamboglia 18Hayes 5 , de cronología flavia.

Finalmente, dos fragmentos de la forma Lamboglia 9-Hayes 27 , que se data por el primero entre fines del II e inicios del III, basándose en la estratigrafía de Albintimilium (estratos IIIA y IIIB).

\section{Clara B}

Parece ser que el centro productor de esta especie cerámica, de pasta más clara y tierna, que se raya fácilmente con la uña y tinta la mano, se localiza en el valle medio del Ródano, en donde hubieron de existir varios talleres. De uno de ellos poseemos en el Portus de Illici dos medios vasos, que, aunque los hemos englobado dentro de la forma Lamboglia 1/3, en realidad representan la forma Drag. 17 B de la cerámica itálica ya recogida por la Clara A. La pasta tizna y el barniz anaranjado pálido, a pesar de un leve reflejo, no alcanza el grado iridiscente que personaliza a la cerámica lucente.

Esta especie se data entre 150 y 250 , fecha que otorga Lamboglia al estrato IIIB de Ventimiglia y al II de Ampurias.

\section{Lucente}

La cerámica «lucente» representa una vuelta al gusto por la superficie de brillo metálico que había sido propio de la cerámica romana republicana. Su radio de difusión -como es el caso de la Clara B- se limita al ángulo NO. del Mediterráneo, con escasísimos ejemplares más abajo de Cataluña, por lo que los hallazgos port-ilicitanos vienen a representar un importante jalón que permite ampliar el alcance comercial de tan peculiar tipo cerámico.
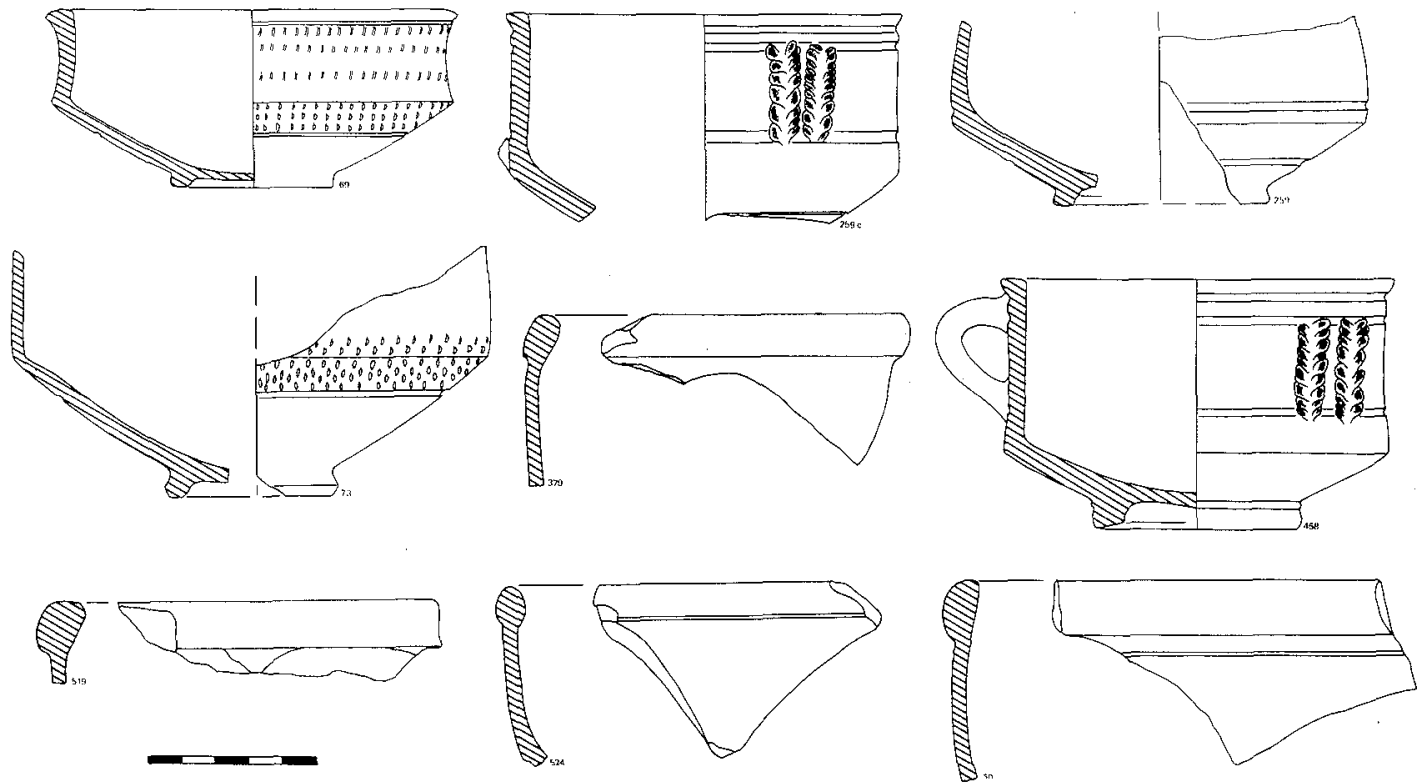

Fig. 10. Terra sigillata clara B y lucente. 

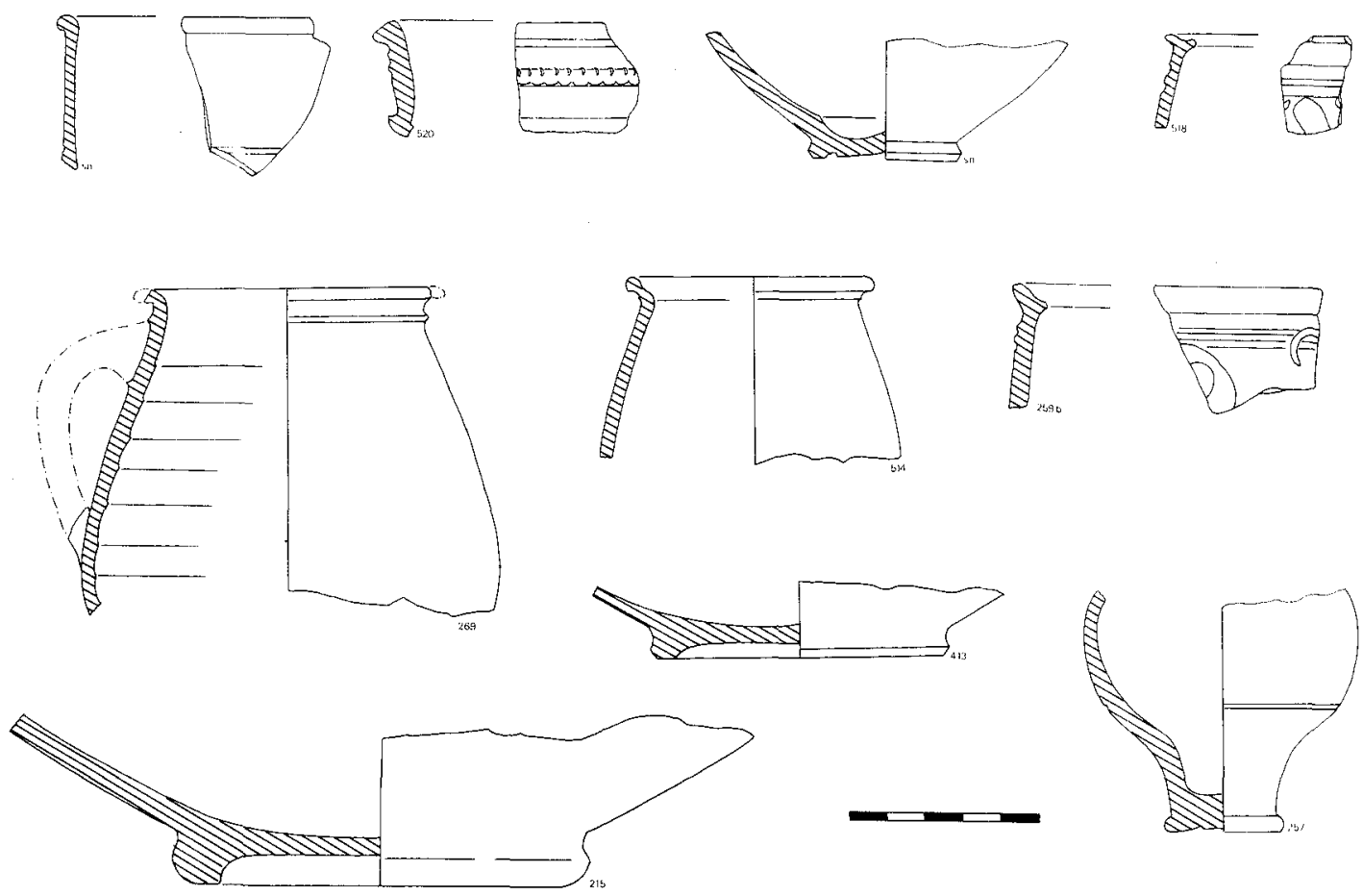

Fig. 11. Terra sigillata lucente.

Las verdaderas formas $1 / 3$ y $2 / 37$ de Lamboglia están bien representadas por varios fragmentos, con el típico borde almendrado. De nuevo, la forma Drag. $17 \mathrm{~B}$ la recoge el núm. 520, mientras dos tazas se incluyen como variantes de las formas $1 / 3$ y $2 / 37$ y nos ofrecen borde sencillo y una decoración estampada en forma de doble espiga.

La forma 14/26 de Lamboglia, característica según este autor del siglo IV, aparece también representada dentro de este grupo, con ejemplos de decoración a barbotina, junto con la parte inferior de un jarro de la forma 28 y otro fragmento de una copa de forma 45.

\section{Clara C}

Unicamente poseemos siete escasos fragmentos procedentes de las Balsas. De su más típica forma, Lamboglia 40-Hayes 50, hay cuatro fragmentos. Según el primer autor, se dataría en la segunda mitad del siglo III, mientras Hayes la sitúa un siglo más tarde.

La forma Lamboglia 41-Hayes 48A está presente con el fragmento núm. 475, y la forma Lamboglia 42 -Hayes 45 , con decoración de ruedecilla en la cara interna del borde, con dos fragmentos.

\section{Clara C y D con motivos aplicados}

En 1963, N. Lamboglia distinguía dentro de la Clara C una especie decorada con relieves aplicados que intentaba imitar la vajilla metálica decorada de esta guisa. Hoy parece evidente que su origen no es africano y derivaría, en cambio, de los vasos con apliques de medallones del Sur de Francia. 

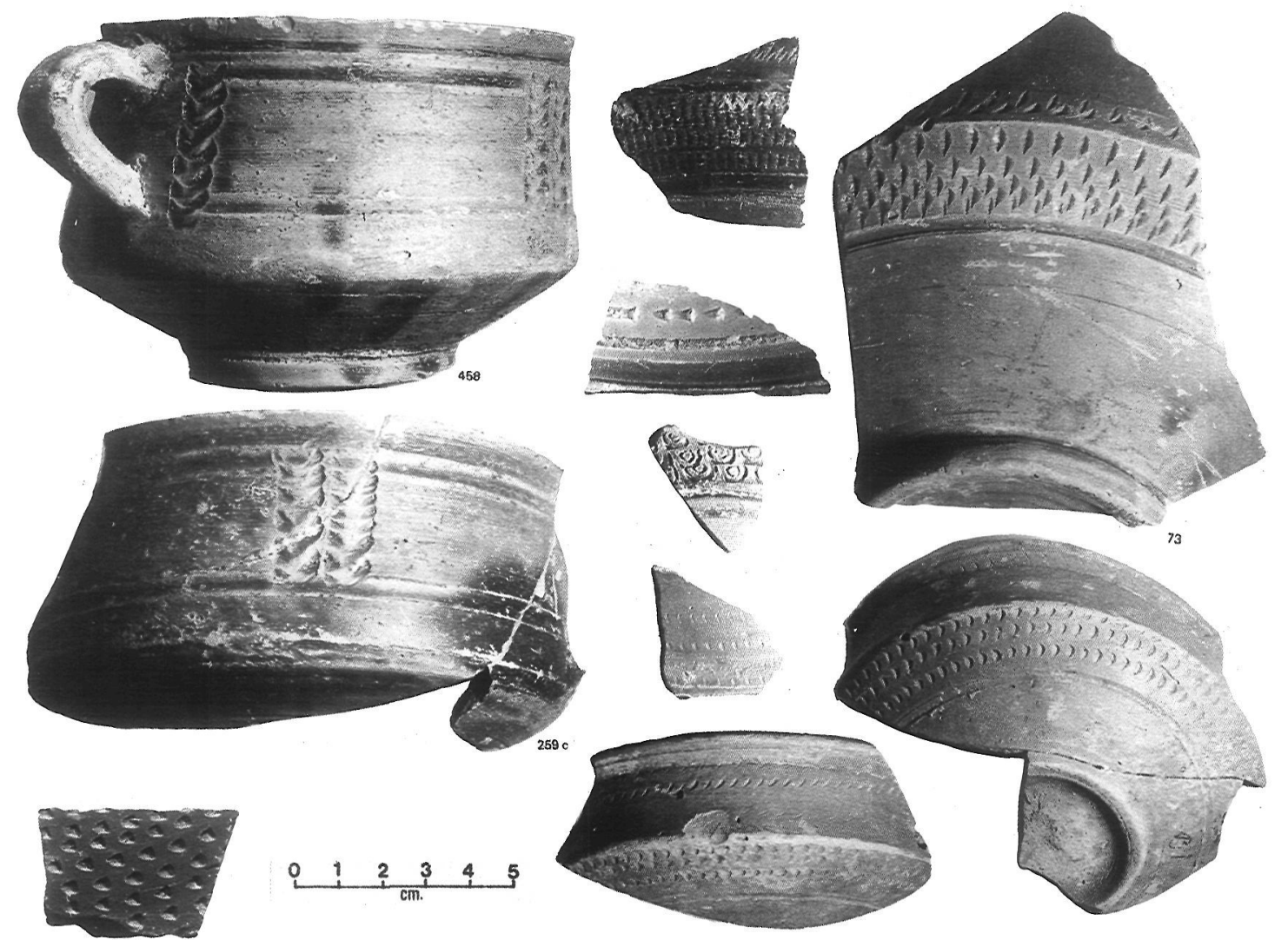

Lám. III. Cerámica clara B y lucente.

De los tres ejemplares port-ilicitanos, los pertenecientes a la forma Lamboglia 35Hayes $52 \mathrm{~B}$ entrarían en la Clara $\mathrm{C}$, pero el representante de la fuente de borde poligonal (forma Lamboglia 42/48-Hayes 54) ofrece una textura de peor calidad, asimilable a la Clara D.

Los motivos representados son para la forma Hayes 52B los cuartos traseros de un felino (león o leopardo) y una palmeta, como en los ejemplares alicantinos que estudia Martín, y para la forma Hayes 97 la parte delantera de un lobo.

\section{Clara D}

Los ejemplares del Portus ofrecen todos las características pastas con el barniz más mate que los tipos precedentes, quedando sin cubrir el exterior del recipiente. Su calidad, no obstante, depende del lugar de hallazgo, ya que en las Balsas se acumuló un elevado grado de humedad que no sólo afectó al numerario de bronce.

Dentro del grupo de la sigillata anaranjada constituye la especie más numerosa y muchos fondos de los vasos, sobre todo grandes fuentes, posiblemente estén recogidos en el corpus de decoraciones estampadas. Por ello, su cronología irá también ligada a la que arroje la propia decoración estampada, es decir, entre los siglos IV y V.

La forma Lamboglia 9-Hayes 63 cuenta con cinco fragmentos de otras tantas fuentes, mientras seis ejemplares representan a la forma Lamboglia 24/25-Hayes, 91, en parte con decoración de ruedecilla en el interior del fondo.

Catorce fragmentos pertenecen a la forma Lamboglia 42-Hayes 67, y la forma Lamboglia 51-Hayes 59A y B está documentada con 19 ejemplares. De la forma Hayes 60 sólo existe un ejemplar. 

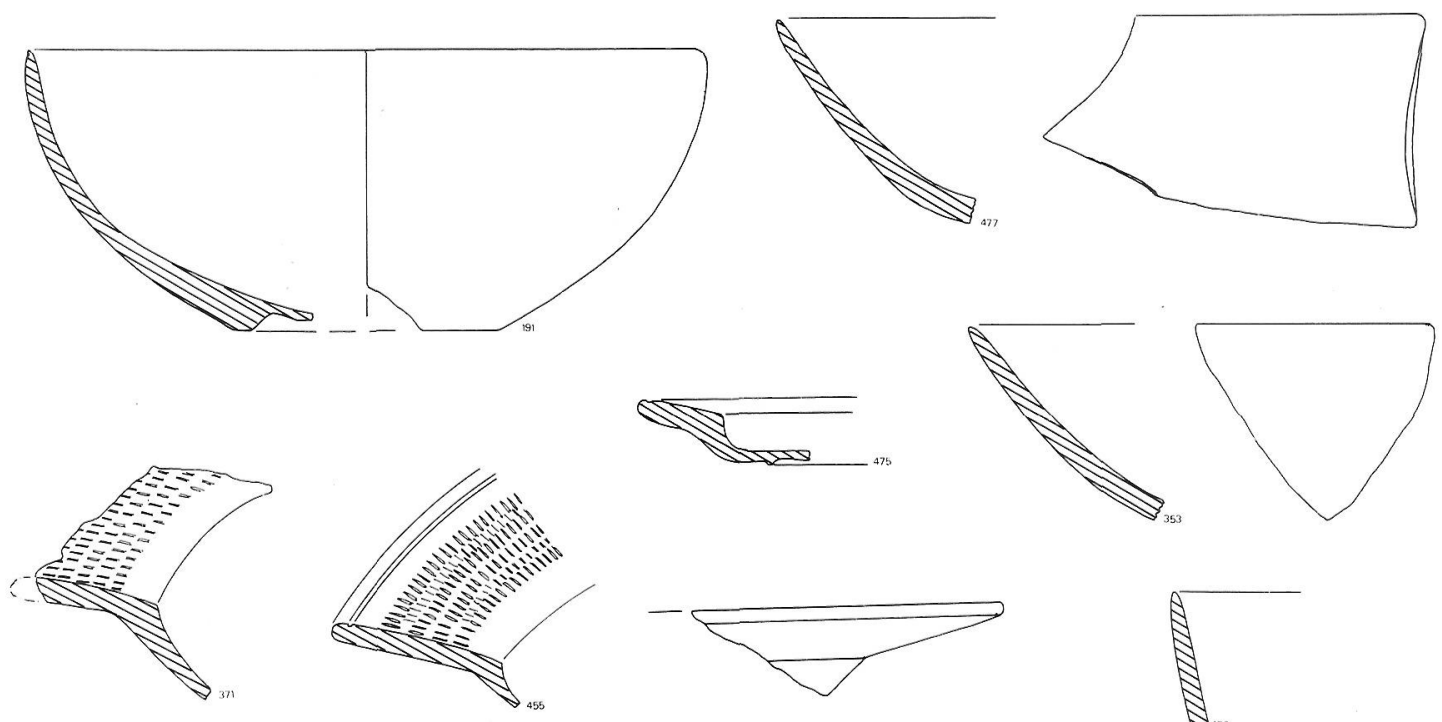

Fig. 12. Terra sigillata clara (C). Formas Hayes 50, 45 y $48 \mathrm{~A}$.

La forma Lamboglia 52-Hayes 58 es la más abundante, con 25 fragmentos, seguida de la forma Lamboglia 54-Hayes 61 A, con 20 fragmentos de borde triangular.

Otras formas se hallan poco representadas, como Lamboglia 55-Hayes $61 \mathrm{~B}$, con dos escasos ejemplos, y la forma Lamboglia 57 -Hayes 70, con uno solo. Por otro lado, es de destacar la ausencia de la forma Lamboglia 1-Hayes 99, más tardía, acompañada a menudo de temas cristianos estampados en su fondo.
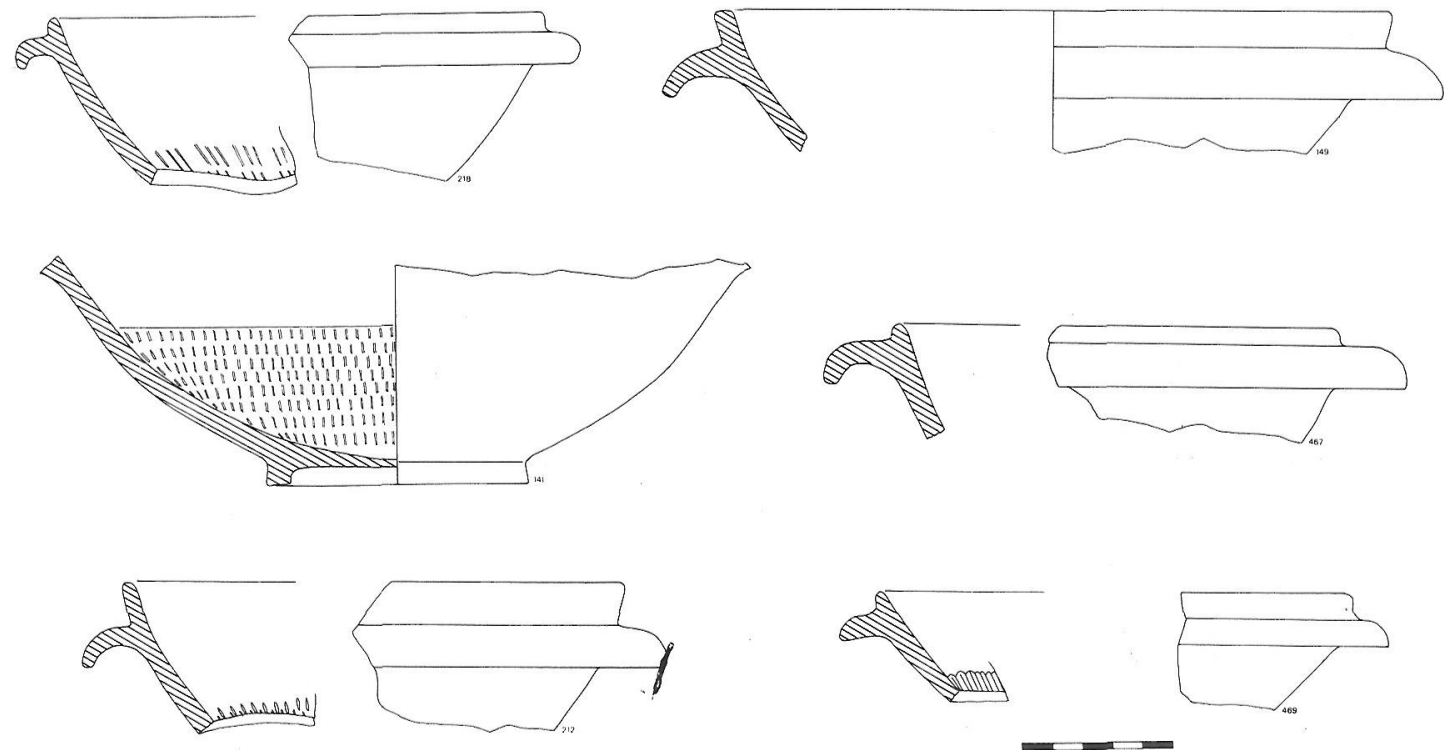

Fig. 13. Terra sigillata clara (D). Forma Hayes 91. 

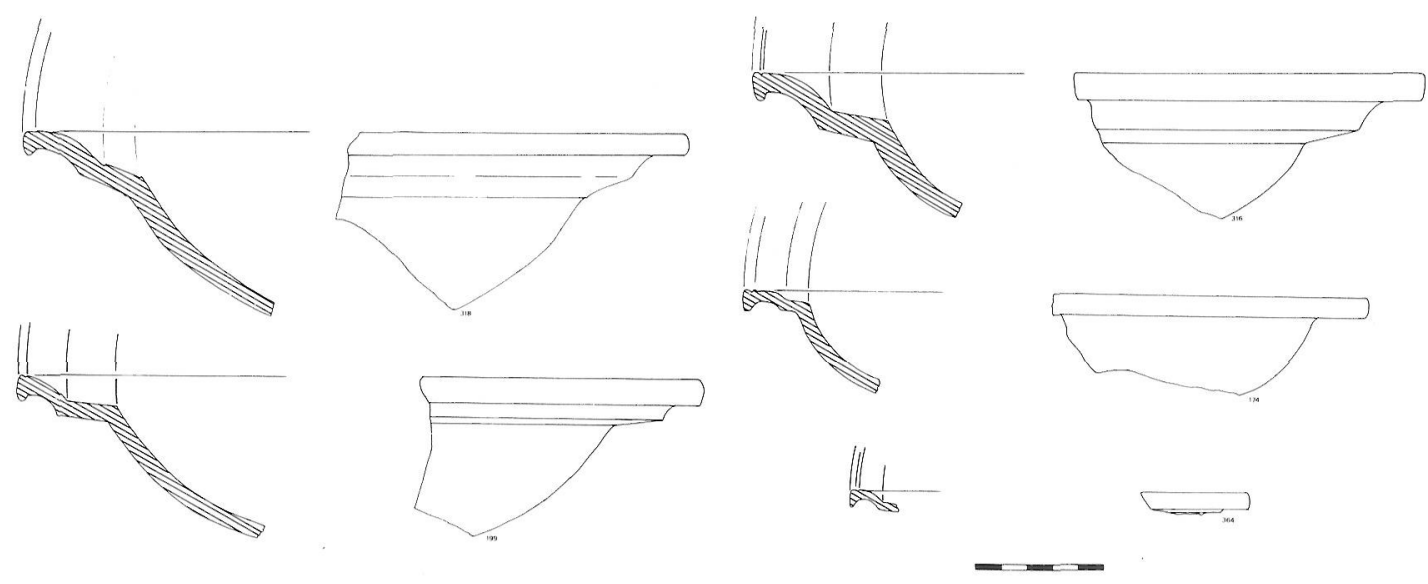

Fig. 14. Terra sigillata clara (D). Forma Hayes 67.

\section{Clara D estampada}

La totalidad de los fragmentos recuperados presenta una clara unidad decorativa, idéntica a la producción marroquí, con motivos geométricos bien conocidos: círculos concéntricos, palmas, rosetas de diversos tipos, crecientes y una forma geométrica con líneas internas entrecruzadas formando damero, que entrarían en los estilos A(i), A(ii), A(iii), B y C de Hayes, con una datación entre 340 y 440.

La identidad técnica con los ejemplares lisos es evidente y con total seguridad los fondos que aquí se recogen pertenecen a las formas 42, 51, 52 y 54 de Lamboglia arriba mencionados. Su descripción es la siguiente:

463.-Dos fragmentos del fondo de una fuente, decorado con palmetas radiales dentro de doble circunferencia.

290. - Fragmento de fondo con guirnalda compuesta a base de alternancia de crecientes rayados, enmarcando un conjunto de palmas radiales en torno de triple circunferencia central, todo ello enmarcado por doble circunferencia.
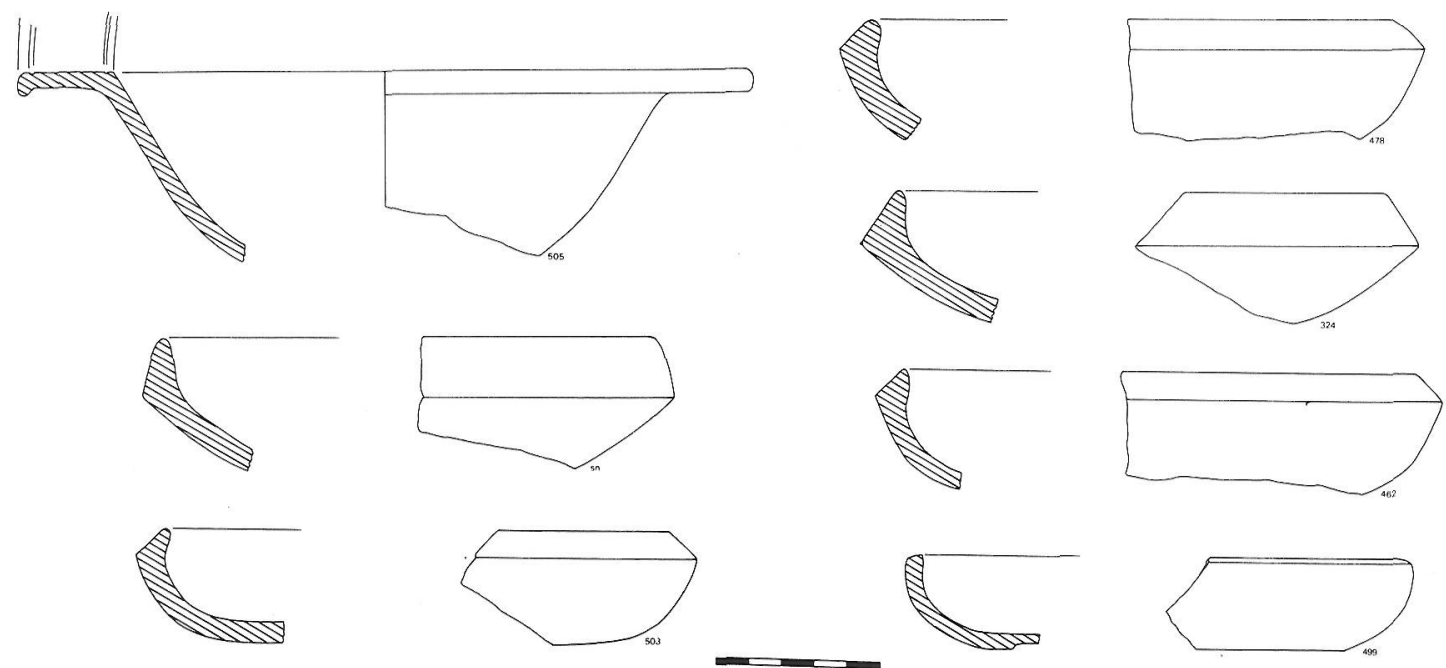

Fig. 15. Terra sigillata clara (D). Formas Hayes 70 y $61 \mathrm{~A}$. 

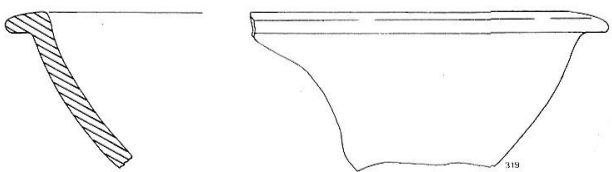

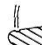
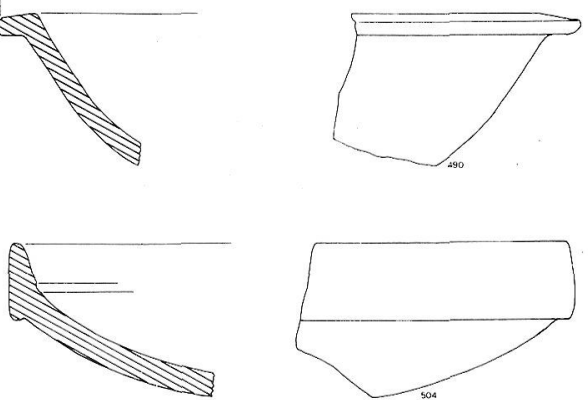
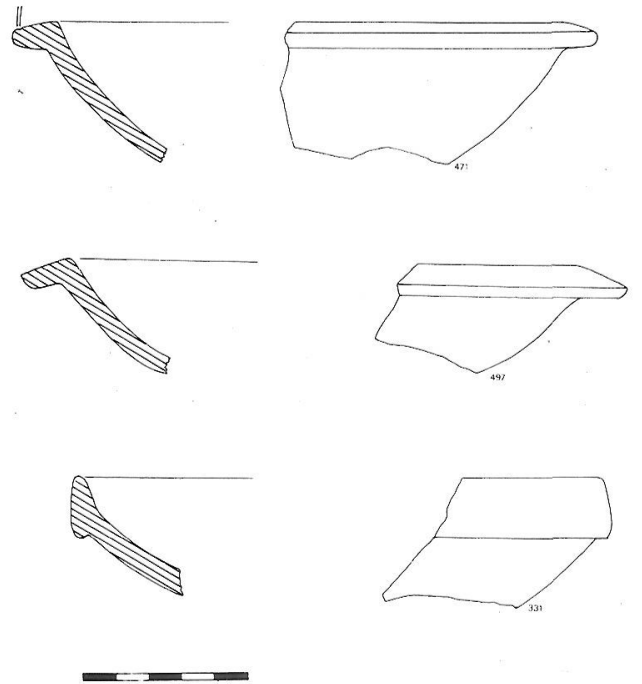

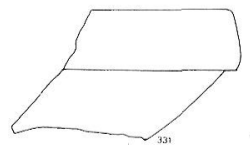

Fig. 16. Terra sigillata clara (D). Formas Hayes 61B y 58.

222.-Cinco fragmentos que conforman el fondo de una fuente decorado con grupo central de cinco palmetas con rosetas, enmarcado por cuádruple circunferencia, con orla de rosetas entre la segunda y la tercera.

242.-Tres fragmentos pertenecientes al fondo de una fuente, con decoración de un grupo central de palmetas radiales alrededor de doble circunferencia concéntrica y rodeado de pequeños circulillos concéntricos. Tras doble circunferencia, una cenefa de palmetas dispuestas oblicuamente da paso al último doble surco que enmarca la decoración.

305. - Tres fragmentos unidos que conforman parte del fondo, con decoración de orla de círculos concéntricos y rosetas alternantes, entre surcos.

291. - Dos fragmentos unidos de parte del fondo de una fuente decorada: dentro de triple surco, grupo de circulillos concéntricos y restos de palmeta.
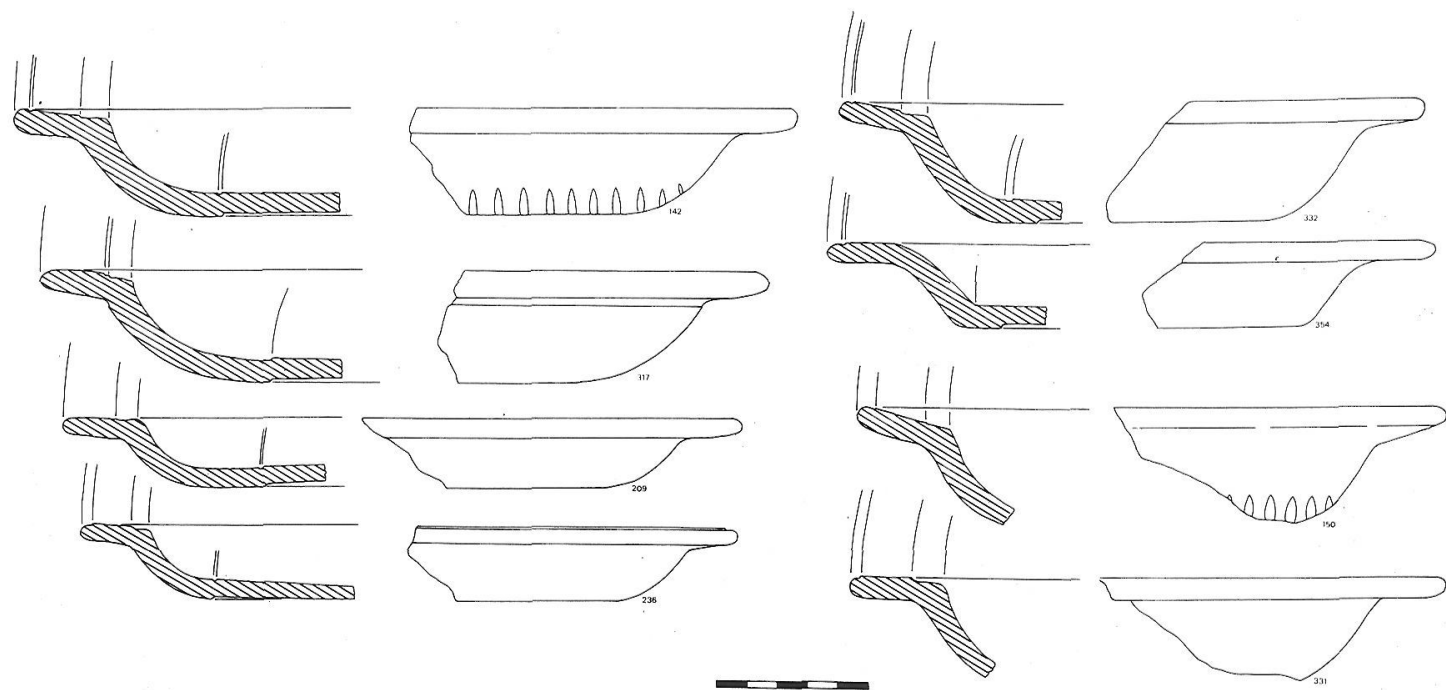

Fig. 17. Terra sigillata clara (D). Formas Hayes 59 y 60. 


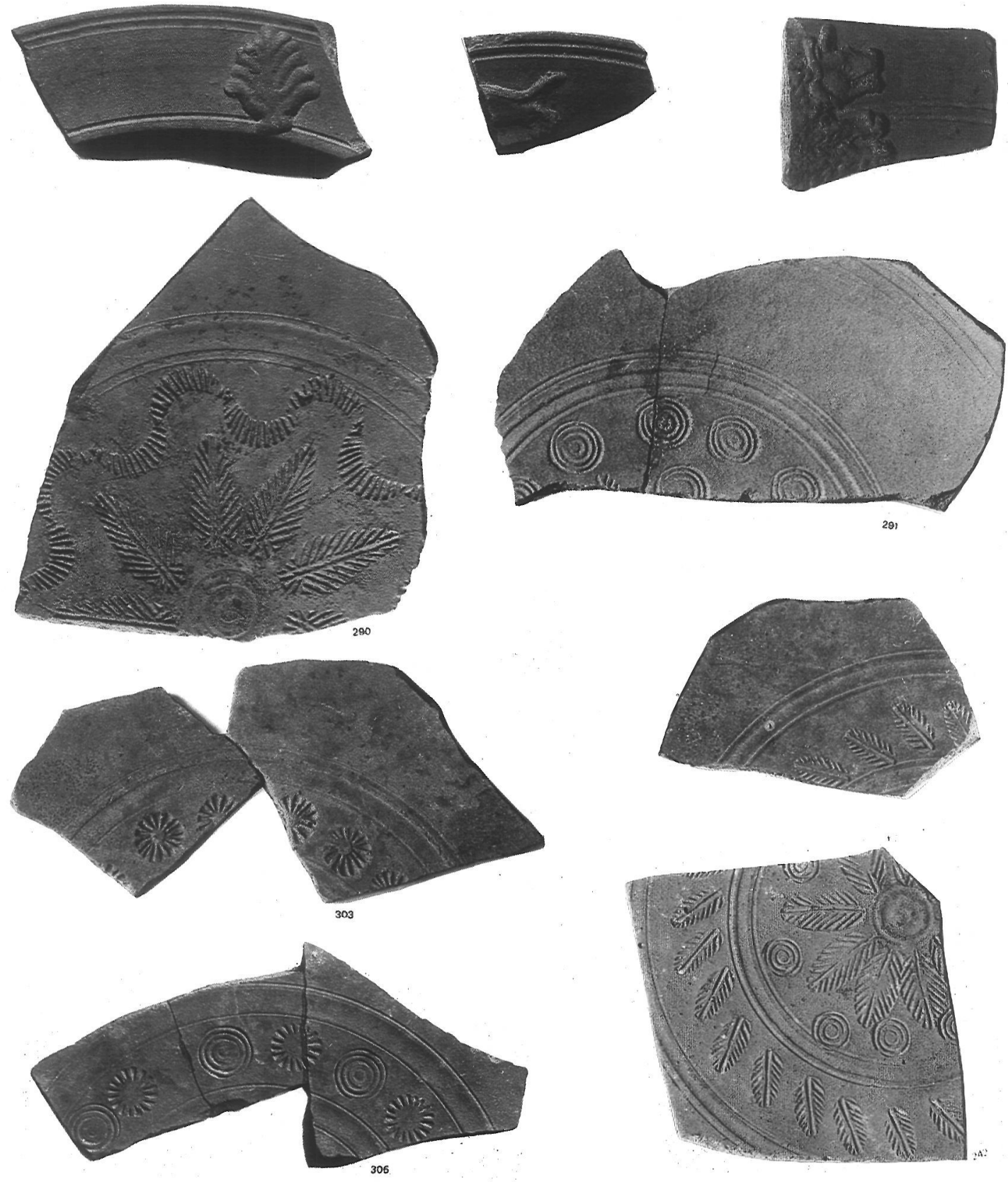

Lám. IV. Sigillatas clara C y D con relieves aplicados y con decoración estampada de tipo geométrico.

303. - Dos fragmentos del fondo de una fuente con orla de rosetas entre surcos concéntricos.

58.-Fragmento del fondo decorado de una fuente: orla de círculos concéntricos con pequeñas rosetas, entre dos surcos.

241.-Fragmento de fondo, con orla de rosetas dentro de doble circunferencia.

289. - Fragmento de fondo decorado: restos de grandes rosetas o crecientes en el interior de doble surco concéntrico. 


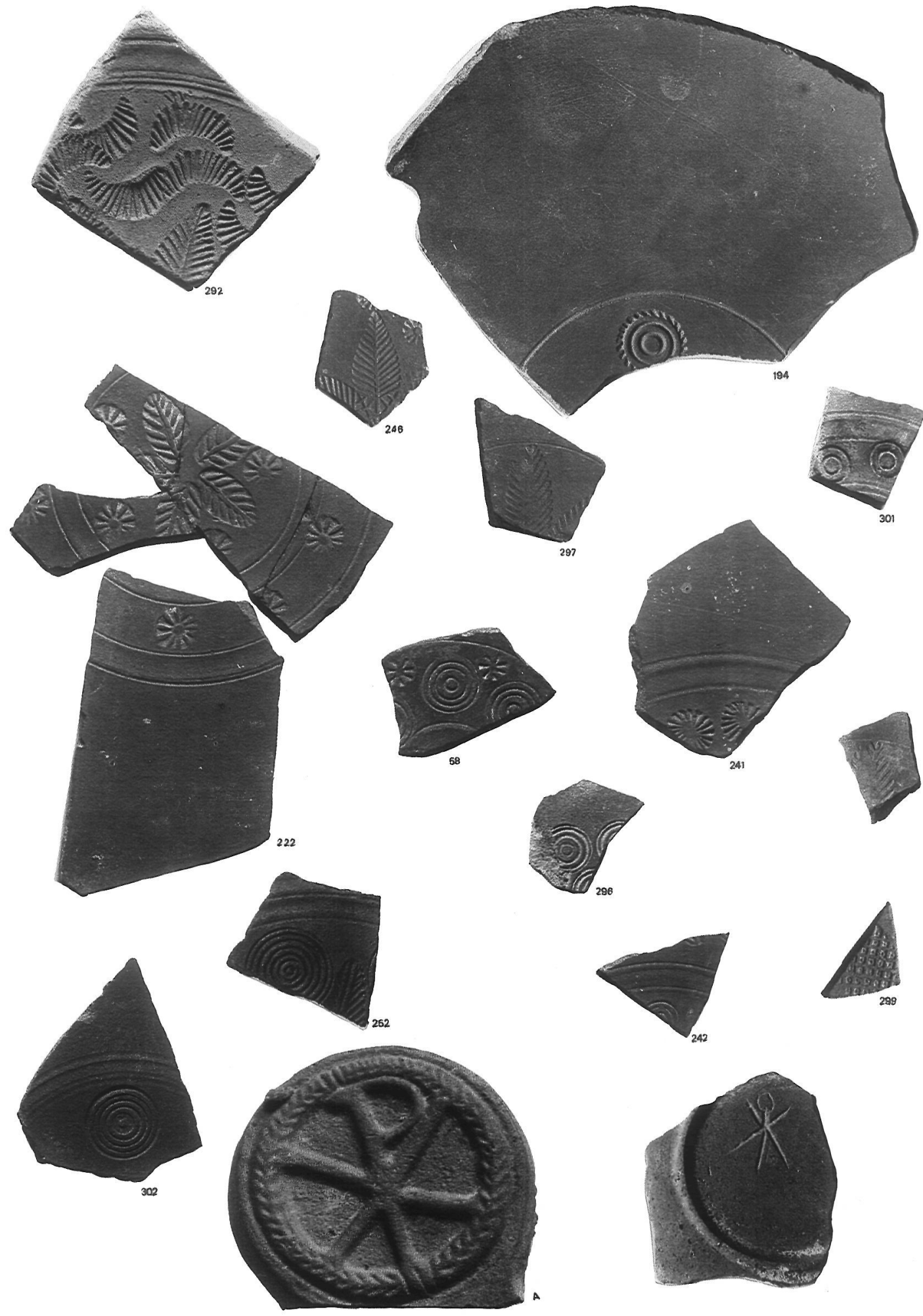

Lám. V. Sigillata anaranjada con decoración estampada. Disco reflector de lucerna paleocristiana y grafito con el crismón. 
194. - Fragmento de fondo decorado y pared, con círculo concéntrico con dentado espiral, dentro de circunferencia.

295. - Fragmento de fondo decorado: orla de circulillos concéntricos y rosetas alternantes, seguidos de doble surco que enmarcan un grupo central de palmetas (restos) y circulillos nuevamente concéntricos.

300.-Fragmento de fondo decorado: dentro de doble surco restos de palmetas radiales y entre ellas crecientes.

302.-Fragmento de fondo decorado: enmarcado con circunferencias un gran círculo concéntrico.

292. - Fragmento de fondo, con restos de un grupo central de palmetas radiales rodeado de crecientes enlazadas formando ondas.

246. - Fragmento de fondo con decoración de grupo central de palmetas radiales rodeadas de pequeñas rosetas.

297. - Fragmento de fondo decorado: restos de grupo central de palmetas radiales dentro de doble circunferencia.

298.-Fragmento con restos de una palmeta, en el interior de doble circunferencia.

252.-Fragmento de fondo decorado: en el interior de doble surco, restos de grupo de palmetas y grandes círculos concéntricos.

296. - Fragmento de fondo de una fuente con decoración de restos de grupo central de círculos concéntricos.

361.-Fragmento de fondo decorado: entre surcos, orla de circulillos concéntricos.

299. - Fragmento de fondo decorado: motivo estampado con interior cuadriculado.

\section{Sigillata gris}

Un solo ejemplo ha sido hallado en las excavaciones de 1976: un fragmento de borde de una escudilla o fuente de la forma 4 de Rigoir. Posiblemente el fondo se encontraría estampado.

Con una cronología que la mayoría de los autores sitúan en los siglos V y VI, es interesante recordar la hipótesis de Lamboglia según la cual este tipo de cerámica que vuelve al fuego reductor lejos de suceder a la Clara D lo haga de la Clara B tardía, con barniz más oscuro del tipo de la lucente, desprendiéndose de ello su contemporaneidad con la Clara D (10). La persistencia de la misma decoración que en la estampada roja, habla también en este sentido.

\section{Disco reflector de lucerna paleocristiana}

Aprovechamos este trabajo para dar a conocer un fragmento decorado de una lámpara cristiana. Se trata de un disco reflector decorado con orla de laurel que enmarca el Crismón. El parecido con el ejemplar de Tipasa es evidente (BARADEZ, 1954), viniendo a ser uno de los escasos ejemplos de iconografía cristiana proporcionados por el Portus Illicitanus. En fotogafía aparte recogemos otro fragmento de base de una pátera de sigillata clara D, en cuyo fondo externo se presenta grafitado un crismón.

\section{BIBLIOGRAFIA}

AL-HYMYARI, Kitab ar-rawd al-Mi'tar. Traducción del francés de Pilar Maestro. Anubar. Valencia, 1963.

BARADEZ, J., 1954, «Tipasa: disque réflecteur de lampe chrétienne».

BELTRAN LLORIS, M., 1978, Cerámica romana. Tipología y clasificación. Zaragoza. 
BALIL, A., 1983, «Terra sigillata africana de Els Antigons (Alicante)». IDEA, 40, 7-24. Alicante.

CABALLERO ZOREDA, L., 1966, «Estado actual del estudio de la cerámica sigillata clara en el Mediterráneo occidental». Ampurias, XXVIII. Barcelona.

- 1970, «Nuevos datos sobre cerámica sigillata hispánica, sigillata clara de tipo B y sigillata brillante», TP, 27. Madrid.

- 1971, «Cerámica sigillata clara decorada de los tipos A, A/C y C». TP, 28. Madrid.

- 1974, «Cerámica sigillata clara de tipo D estampada de las provincias de Murcia y Almería», Miscelánea Arqueológica, I. Barcelona.

ESCOLANO, G., 1879, Décadas de la Historia de la insigne y coronada ciudad y reino de Valencia, tomo II. Ed. Terraza, Aliena y Compañía. Valencia.

FONTES HISPANIAE ANTIQUAE, vols. VIII y IX. Universidad de Barcelona.

GONZALEZ PRATS, A., 1977, «Materiales para un conocimiento del Portus Illicitanus, I: las lucernas». ITEM, 4. Alicante.

HAYES, J. W., 1972, Late roman pottery.

IBARRA, A., 1879, Illici, su situación y antigüedades. Alicante.

IBARRA, P., 1962, Elche, materiales para su historia. Cuenca.

JODIN, A.-POSCHIN, M., 1960, «La céramique estampée du Maroc romain». B. A. M., IV. Rabat.

- 1967, «Nouvelles observations sur la céramique estampée du Maroc romain», $B . A . M$., ViI. Rabat.

LAMBOGLIA, N., 1958, «Nuove osservazioni sulla terra sigillata chiara (Tipi A e B)». R. S. L., XXIV. Bordighera.

- $\quad$ 1963, «Nuove osservazioni sulla terra sigillata chiara (II)». R. S. L., XXIX. Bordighera.

LLOBREGAT, E. A., 1973, Teodomiro de Oriola. Su vida y su obra. Alicante.

- 1983, «Relectura del Ravennate: dos calzadas, una mansión inexistente y otros datod de la geografía antigua del País Valenciano». Lucentum, II, 225-242. Alicante.

MARTIN, G., 1968, «Comercio y producción de cerámicas finas en época imperial». PLAV, 5. Valencia.

- 1975, «Un vaso de sigillata clara en el Museo de Alicante». IDEA, 25, 109-126. Alicante.

- $\quad 1979$, «Problemas de metodología, cronología y difusión de algunos tipos de sigillata clara y su localización en la provincia de Alicante». IDEA, 28, 7-76. Alicante.

MEZQUIRIZ, M. A., 1961, Terra sigillata hispánica. Vols. I-II. Valencia.

OXE, A.-OSWALD, F., 1914, Die ältesten Terra Sigillata-Fabriken in Montans am Tarn. Arch. Anzeiger, XXIX. Berlín.

OXE, A.-COMFORT, J., 1968, Corpus Vasorum Arretinorum. A Catalogue of the Signatures, Shapes and Chronology of Italian sigillata. Bonn.

OSWALD, F.-PRYCE, T. D., 1966, An Introduction to the study of Terra sigillata. Treated from a Chronological stadpoint. London.

PALOL, P. de, 1948, «La cerámica estampada romano-cristiana». IV, CASE, 450-469.

RAMOS FOLQUES, A., 1974, Santa Pola y su historia. Elche.

RAMOS FERNANDEZ, R., 1975, La ciudad romana de Illici. Alicante.

SANCHEZ FERNANDEZ, M. ${ }^{a}$ J., 1983, «Cerámica común romana del Portus Illicitanus». Lucentum, II, 285-317. Alicante.

Artículos aparecidos en diversos diarios durante la realización de la campaña de urgencia:

- «Posible localización del Portus Illicitanus, en Santa Pola» (INFORMACION, 15-XII-76).

- «Adquieren más importancia los descubrimientos arqueológicos» (INFORMACION, 17-XII-76).

- «Se cambia historia por un bloque de apartamentos» (LA VERDAD, 19-XII-76).

- «Se intensifican las excavaciones arqueológicas» (INFORMACION, 24-XII-76).

- «Descubrimiento de una ciudad romana en Santa Pola (Alicante)» (EL PAIS, 24-XII-76).

- «Que no se consume. la destrucción» (INFORMACION, 28-XII-76).

- «Consternación por el antiguo Portus Illicitanus» (LA VERDAD, 28-XII-76).

- «En apoyo de la conservación del Portus Illicitanus» (LA VERDAD, 31-XII-76).

- «Se ha confirmado la ubicación del famoso yacimiento arqueológico del Portus Illicitanus» (ABC, 2-I-77).

- «El Instituto de Estudios Alicantinos, contra la destrucción del patrimonio arqueológico» (INFORMACION, 4-I-77).

- «La destrucción del Portus Illicitanus» (INFORMACION, 5-I-77).

- «Santa Pola: nadie quiere destruir el Patrimonio arqueológico local» (INFORMACION, 6-I-77).

- «Se construirá sobre el Portus Illicitanus» (LA VERDAD, 14-I-77).

- «Comenzó la destrucción del Portus Illicitanus» (INFORMACION, 14-I-77).

- «Repulsa por la destrucción del Portus Illicitanus» (Cartas al Director, en INFORMACION, 18-I-77).

- «Suspendidas las obras en el Portus Illicitanus» (LA VERDAD, 18-I-77).

- «El Patrimonio Artístico suspende las obras realizadas sobre el Portus Illicitanus» (ABC, 18-I-77).

- «El Portus Illicitanus depende de Madrid» (INFORMACION, 15-I-77). 


\title{
ESTUDIO PRELIMINAR SOBRE LAS ANFORAS ROMANAS DEL PORTUS ILLICITANUS
}

\author{
M. ${ }^{\text {a }}$ JOSE SANCHEZ FERNANDEZ \\ y M. ${ }^{\mathrm{a}}$ TERESA LOBREGAD COLLADO \\ Museo Arqueologico de Santa Pola (Alicante)
}

\begin{abstract}
En este trabajo se anticipan algunos datos, referidos al estudio de un grupo significativo, que forma parte de un amplio conjunto de ánforas halladas en el curso de las últimas campañas de excavaciones (1982-83) realizadas en el Portus Illicitanus.

Se trata de un material que presenta una extensa cronología (siglos I al V), con unas formas representadas en la tipología de Dressel, que abarcan las familias Dr. 2-4 de asa bífida para transporte de vino; Dr. 7-11 destinadas al transporte de salsas de pescado, olearias Dr. 20, africanas y Almagro 51 entre otras, como formas más representativas numéricamente. Su estudio y clasificación permiten obtener los primeros datos sobre el tráfico marítimo mediterráneo de este sector costero, en época romana, así como su incidencia en el comercio de la época.
\end{abstract}

Ce travail avance quelques reférences aux études d'un groupe significatif formant partie d'un ensemble d'amphores trouvées pendant les dernières fouilles (1982-83) effectués auprès de Portus Illicitanus.

Il s'agit de matériaux appartenant à une cronologie assez vaste (siècles I-V) et des formes représentées par la typologie de Dressel, aparaissant les familles Dr. 2-4 d'anse bifide pour le transport du vin; Dr. 7-11 destinées au transport de sauces de poissons; oléacées Dr. 20, africaines et Almagro 51, parmi d'autres, comme formes plus abondantes. Leur étude et clasification nous permet d'obtenir les prémiers rapport de données sur le trafic maritime mediterranéen de ce secteur côtier à l'époque romaine, et même leur incidence auprès du commerce à ce temps-là.

Este trabajo tiene por objeto estudiar y dar a conocer una parte representativa de un gran lote de ánforas halladas en las excavaciones del Portus Illicitanus de Santa Pola, durante las últimas campañas realizadas en 1982-83 (1).

Hemos procedido a iniciar su estudio a partir de una muestra representativa de los distintos tipos, en base a la inmensa cantidad de recipientes anfóricos que componen mayoritariamente los distintos niveles de las excavaciones, y que confirma la actividad comercial desarrollada en el Portus Illicitanus durante la época romana a través del tráfico marítimo mediterráneo.

Para su clasificación hemos seguido básicamente la tabla tipológica de Dressel, así como diversos paralelos procedentes de otros yacimientos cronológicamente bien data-

(1) La totalidad de lạs ánforas aparecidas hasta el momento son objeto del estudio iniciado por M. T. Lobregad Collado, en lo que constituirá su tesis de licenciatura, dirigida por el profesor Abad Casal. 
dos. Es preciso señalar el estado de excesiva fragmentación que presenta el material en general, y por tanto la carencia de piezas completas, tratándose a lo sumo de bordes, cuellos, asas sueltas, o en el mejor de los casos del tercio superior del ánfora, lo cual, a menudo, dificulta la clasificación.

Por otra parte, nos encontramos en las excavaciones con algunos sectores donde el terreno ha sido removido a causa de labores agrícolas, rebaje para construcciones, etc., lo cual ha dado lugar a una alteración estratigráfica y a la consiguiente mezcla de materiales de diferente cronología.

Las conclusiones obtenidas en este trabajo se verán complementadas o sujetas a modificación, una vez concluido el estudio del resto de materiales hallados en estas excavaciones (2).

Los envases que aquí presentamos proceden de tres zonas distintas:

a) Plaza de los Aljibes

b) Avenida del Portus Illicitanus

c) Parque «El Palmeral» (fig. 4).

\section{a) Plaza de los Aljibes}

De los trabajos realizados en dicha zona ya dimos noticia con anterioridad al estudiar las cerámicas comunes del Portus Illicitanus (SANCHEZ, 1983). Es preciso destacar que los fragmentos de ánforas procedentes de dicha excavación carecen de contexto arqueológico por formar parte del relleno de unas balsas.

\section{b) Avenida del Portus Illicitanus}

Las excavaciones en esta zona dieron comienzo en marzo de 1982, con carácter de urgencia, a raíz de la inminente construcción de un bloque de viviendas. Los trabajos fueron realizados a cargo del Museo Provincial de Alicante, bajo la dirección de don Enrique Llobregat Conesa. Aquí pudimos constatar que los niveles tardíos, correspondientes a los siglos IV y V, se hallaban completamente arrasados, como consecuencia de los desmontes del terreno que años atrás se llevaron a cabo para construir la carretera y allanar los alrededores. El hallazgo de unas construcciones rectangulares, con un gran número de fragmentos de ánforas en su interior, nos hace suponer que se trata de almacenes para depositar temporalmente las mercancías procedentes de otros lugares del imperio.

El área excavada hasta este momento presenta una superficie de $1.100 \mathrm{~m} .^{2}$ y muestra dos niveles: en el primero aparece una capa de relleno, compuesta por una tierra muy suelta de color grisáceo, con mezcla de arena muy fina y materiales actuales. A partir de $\operatorname{los} 30 \mathrm{~cm}$. de profundidad, la tierra cambia de color y consistencia y aparecen estructuras arquitectónicas y materiales correspondientes al siglo III, de los cuales hay que destacar una gran cantidad de cerámicas africanas: Terra Sigillata Clara, ánforas y vasijas de cocina, junto a Terra Sigillata Hispánica tardía y cerámica común.

En un segundo nivel, compuesto de varias capas de cenizas y tierra ocre arenosa, se constata la presencia de materiales anfóricos correspondientes a los siglos I y II, junto a terra sigillata aretina y sudgálica, lucernas de volutas, paredes finas y abundante cerámica común, aunque los resultados definitivos para su datación se hallan pendientes de un estudio de conjunto del resto de materiales mencionados.

(2) El material procedente de las últimas campañas de excavaciones en el Portus Illicitanus está siendo estudiado en la actualidad por quienes suscriben este trabajo en colaboración con Elena Blasco Martínez y Araceli Guardiola Martínez, en el Museo Arqueológico Municipal de Santa Pola, en lo que constituirá la Memoria Científica de Excavaciones, de próxima publicación. 


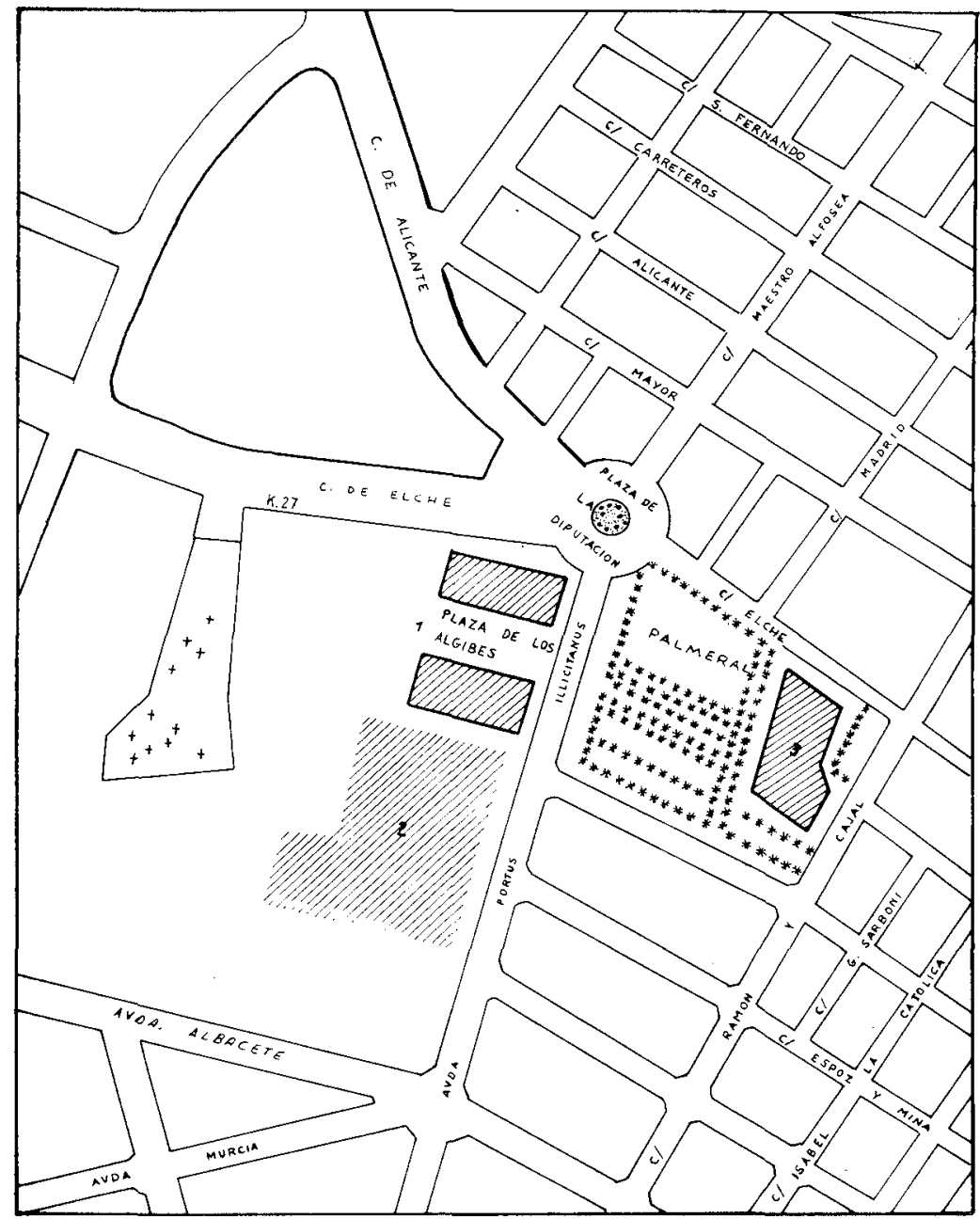

Fig. 1. Plano de Santa Pola. Localización de los hallazgos

La ausencia de ánforas de cronología anterior al siglo I de la Era se debe, fundamentalmente, al hecho de no haber proseguido la excavación en esta zona, profundizando hasta niveles más antiguos, tarea que dejamos para futuras campañas, de las cuales esperamos obtener un repertorio más amplio en lo que a ánforas se refiere y que vendrán a completar el panorama que en este estudio presentamos.

\section{c) Parque «EI Palmeral»}

En julio de 1983, a raíz de la construcción de una fuente en el parque público «El Palmeral», se procedió a realizar un sondeo de urgencia, el cual dio como resultado el hallazgo de un mosaico. En octubre del mismo año se excavó la zona, saliendo a la luz una casa con peristilo, que rodea un patio central de $14 \mathrm{~m}$. de lado y varias estancias a su alrededor. El pavimento de dicha casa se halla a la profundidad de un metro. En este nivel se han hallado materiales tardíos, fechables a lo largo del siglo IV, entre los cuales se observa un claro predominio de recipientes de procedencia africana.

A partir de un metro de profundidad, por debajo del pavimento, aparece una tierra de color grisáceo, compacta y con grandes manchas de cenizas. En este nivel abundan 
los fragmentos de ánforas, así como la terra sigillata clara, terra sigillata hispánica tardía y monedas del Bajo Imperio, materiales fechables todos ellos en la segunda mitad del siglo III.

\section{ANFORAS VINARIAS TIPO Dr. 2-4 (Figs. 2, 3)}

Desde el siglo I a. C., hasta comienzos del siglo II d. C., se fabrican en el Lacio y la Campania ánforas Dr. 2-4, utilizándose como envase para los vinos itálicos, según muestran los tituli picti. Se las puede considerar como una derivación de las ánforas greco-itálicas, con gran auge en la época de Augusto, en la que reemplazan a la Dr. 1, siendo imitadas en otros puntos del Mediterráneo occidental, entre los que destacan los talleres de la Tarraconense y la Bética (ENGUIX y ARANEGUI, 1977, 27).

La forma del labio varía, encontrando dentro del mismo tipo labios engrosados de sección redondeada, de sección triangular pendiente, o rectos ligeramente engrosados. La amplitud de la boca es de una media de $14 \mathrm{~cm}$. El cuello suele ser troncocónico o cilíndrico, con asas bífidas de sección redondeada que parten por debajo del labio.

El origen itálico o tarraconense de este tipo de recipientes se establece en base a la composición de la pasta como único criterio diferenciador (TCHERNIA y ZEVI, 1972, 37).

Los ejemplares que poseemos de la familia Dr. 2-4 posiblemente provienen de la Tarraconense. Estas ánforas han sido objeto de un estudio muy completo por parte de varios autores (TCHERNIA, 1972; FERNANDEZ IZQUIERDO, 1980; ARANEGUI, 1977; BELTRAN, 1970; NOLLA, 1974), los cuales atribuyen su origen a la Tarraconense. Se trata de tipos que imitan los itálicos, extendiéndose su producción por toda esta provincia romana, sin tener un tipo preestablecido, si bien presentan dos tipos de arcilla, correspondientes a dos centros diferentes de producción (FERNANDEZ IZQUIERDO, 1980, 176). En el primer caso la pasta es de color rojo-amarronado, poco depura$\mathrm{da}$, porosa y de textura muy basta, con abundante desengrasante de gruesos granos
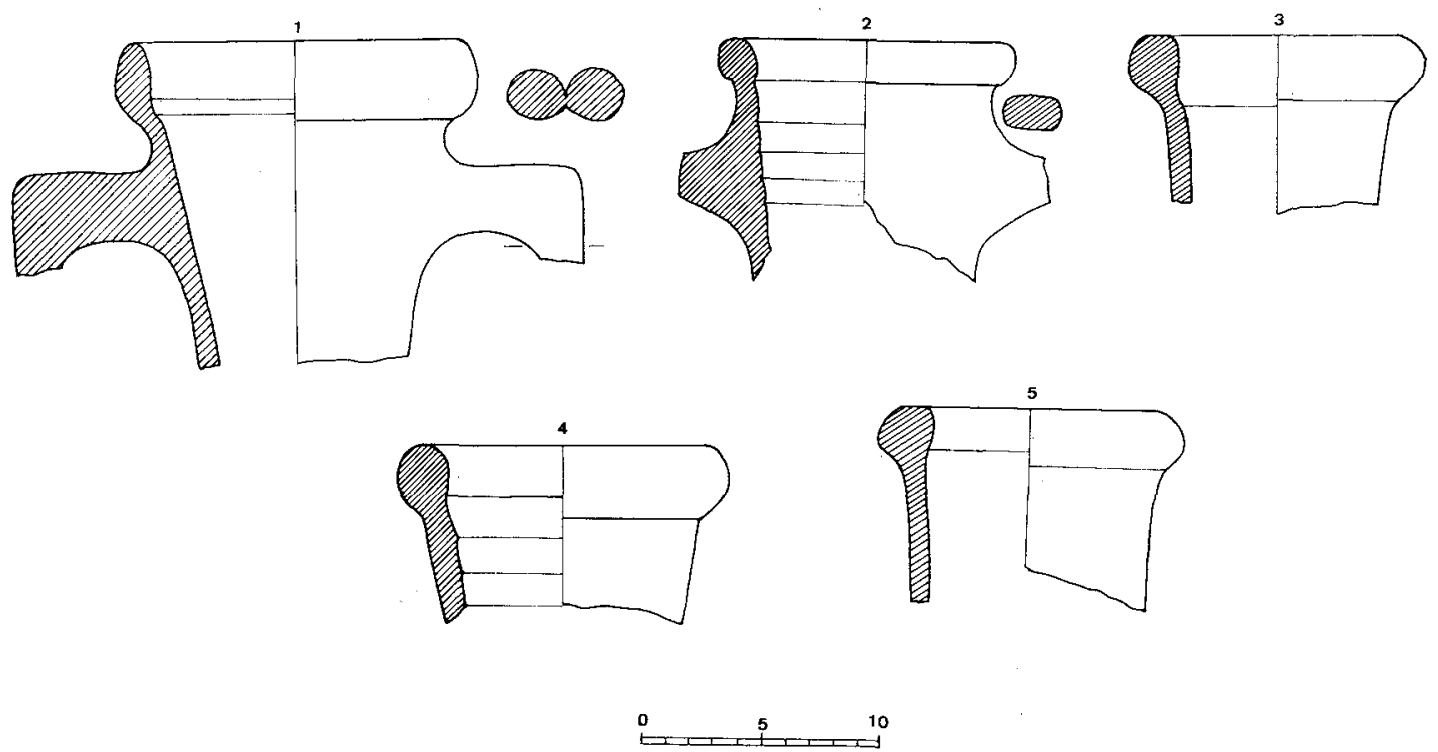

Fig. 2. Anforas vinarias del tipo Dr. 2-4 

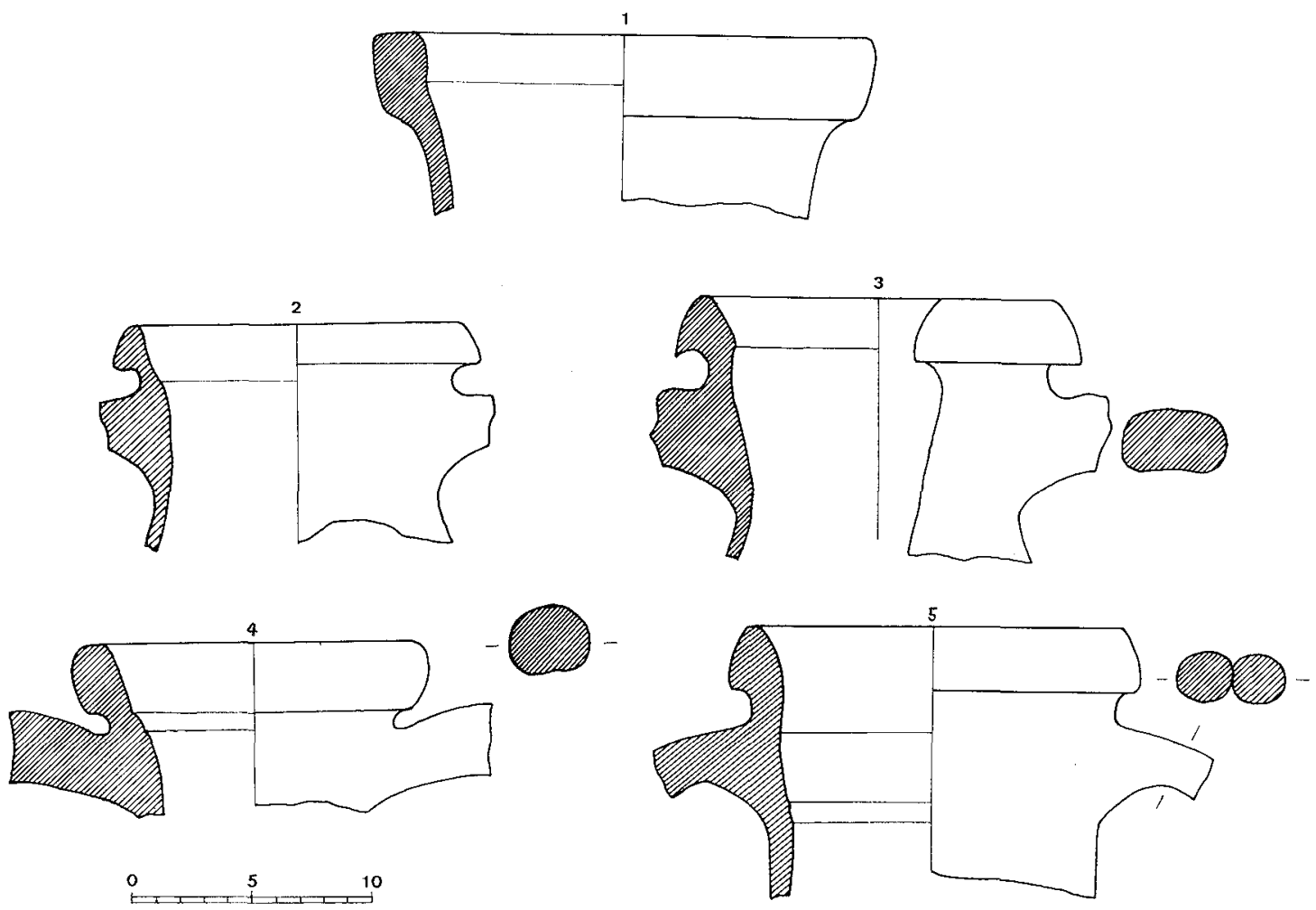

Fig. 3. Anforas vinarias del tipo Dr. 2-4

blancos de cuarzo. En ningún caso la superficie exterior se recubre con engobe. En las paredes internas del cuello se aprecia una serie de estrías.

Por otra parte, contamos con otros recipientes que presentan una pasta de color ocre-rosáceo, con desengrasante poco visible de escasos puntos blancos, en cuyas paredes exteriores se aprecian restos de engobe de color crema claro.

Las ánforas Dr. 2-4 del Portus Illicitanus, aparecen en un nivel estratigráfico altoimperial, sin que por el momento sea posible establecer una evolución de los tipos, hasta que esté concluido el estudio del resto de los materiales correspondientes a la excavación.

Para establecer el período de vigencia de las ánforas Dr. 2-4 contamos con estudios generales, entre ellos el de Zevi (ZEVI, 1966), que se centra en las fechas consulares encontradas en los títuli picti del yacimiento próximo al Castro Pretorio, datado en la primera mitad del siglo I d. C., y el de Tchernia y Zevi (TCHERNIA y ZEVI, 1972), que establecen la posibilidad de distinguir grupos de ánforas Dr. 2-4 de distinto origen, a través del estudio de las pastas, teniendo en cuenta su distribución en las estratigrafías de la Casa de las Paredes Amarillas y de las Termas de Neptuno de Ostia, donde siempre aparecen entre Tiberio y los Flavios.

Están presentes en el comercio mediterráneo desde el principado de Augusto, hasta el siglo II (ZEVI, 1966, 208). Aparecen en Ostia, constituyendo la forma L I (PANELLA, 1970, 102); se imitan en la Tarraconense (TCHERNIA y ZEVI, 1972, 35; ENGUIX y ARANEGUI, 1977, 30; TCHERNIA, 1971, 33), en la Bética (BELTRAN, 1974, 112 y ss.,), en la Gallia Narbonense (LABENHEINER y WIDEMANN, 1977, 80), e incluso en Africa (FERNANDEZ IZQUIERDO, 1980, 140) y en el Limes Germánico (TCHERNIA, 1972, 62). 


\section{ANFORAS PARA SALSAS TIPO Dr. 7-11 (Figs. 4-5)}

Los textos antiguos ya nos hablan de la elaboración de salazones en España, en época prerromana, según noticias de Eupolis Antífanes. Autores latinos como Plinio (N. H. XXXII, 146) y Marcial (VII, 7, 8) mencionan en su obra la importancia de dicho producto. Sin embargo, la gran difusión de este tipo de envases se produce con el cambio de era, durante el reinado de Augusto, perdurando a lo largo de todo el siglo II, y tal vez algunos decenios más (BELTRAN, 1977, 100).

Dieciséis fragmentos de boca, pertenecientes a la familia Dr. 7-11, hallados en el Portus Illicitanus, reproducen el tipo de ánforas para salsas de pescado propias de los talleres hispánicos. Dentro de esta familia, se aprecian ostensibles diferencias en la tipología, por lo que hemos procedido a su clasificación estableciendo dos grupos:

a) De labio exvasado moldurado, con un diámetro que alcanza la media de $19,5 \mathrm{~cm}$. (fig. 4).

b) De boca en forma de campana invertida, con un diámetro alrededor de los $14 \mathrm{~cm}$. Estas dimensiones menores que las del grupo anterior nos inducen a incluirlas dentro del tipo Dr. 8 (fig. 5).

El primer grupo presenta un labio ligeramente engrosado, exvasado y con moldura, cuello largo troncocónico y asas de sección oval surcadas por una profunda estría. La pasta suele ser de color ocre-rosáceo o rojizo, basta, porosa, poco depurada, con abundante desengrasante de puntos negros y superficie exterior recubierta por un engobe blanquecino de tacto rugoso, que en ocasiones se prolonga hacia el interior del labio.

El gran número de variantes dificulta el poder precisar su evolución tipológica, ya que conviven desde época augustea hasta finales del siglo II, a través de formas completamente distintas. Las formas más antiguas proceden de Oberaden, datadas antes del fin del reinado de Augusto, con el cuello poco desarrollado y perfil del labio recto y sin molduras (BELTRAN, 1970, 392).

Durante la primera mitad del siglo I los labios presentan un perfil sencillo en forma de campana, sin molduras, en la mayoría de los casos. A partir de la época de Claudio el borde se hace más exvasado, con molduras en la parte inferior de la boca, que son los que más abundan (ARANEGUI, 1978, 313).

Los centros de producción más conocidos se localizan en la Bética (GIMENEZ DE CISNEROS, 1958, 469; SOTOMAYOR, 1969, 389; PEMAN, 1959, 169), citados por Beltrán (BELTRAN, 1970, 388 y ss.). La divulgación de estas ánforas por el Mediterráneo occidental comienza a partir del siglo I a. C. (ZEVI, 1966, 229 y ss.) y en Ostia se encuentran desde la época tardoaugustea hasta fines del siglo I d. C., formando el tipo LII de dicha localidad (PANELLA, 1970, 121).

Su expansión tiene lugar en todo el litoral mediterráneo: Ampurias, Sagunto, Valencia, Portus Illicitanus, Cartagena y en general por toda la Bética (BELTRAN, 1970, 406 y ss.). También fuera de la Península esta forma alcanzó gran expansión, documentándose restos de este tipo en Italia, en la Gallia y en el Norte de Africa (BELTRAN, 1970,412 y ss.).

\section{ANFORAS OLEARIAS DEL TIPO Dr. 20 (Fig. 6)}

Sólo contamos con tres bordes engrosados al exterior, de sección triangular, y varias asas robustas de sección circular atribuibles al tipo Dr. 20 de ánforas olearias.

La pasta es de color ocre, de textura muy basta, con abundante desengrasante de puntos negros finos y brillantes. Al carecer de más datos, debido a la escasez y a la fragmentación de este material, no podemos establecer una cronología aproximada. 

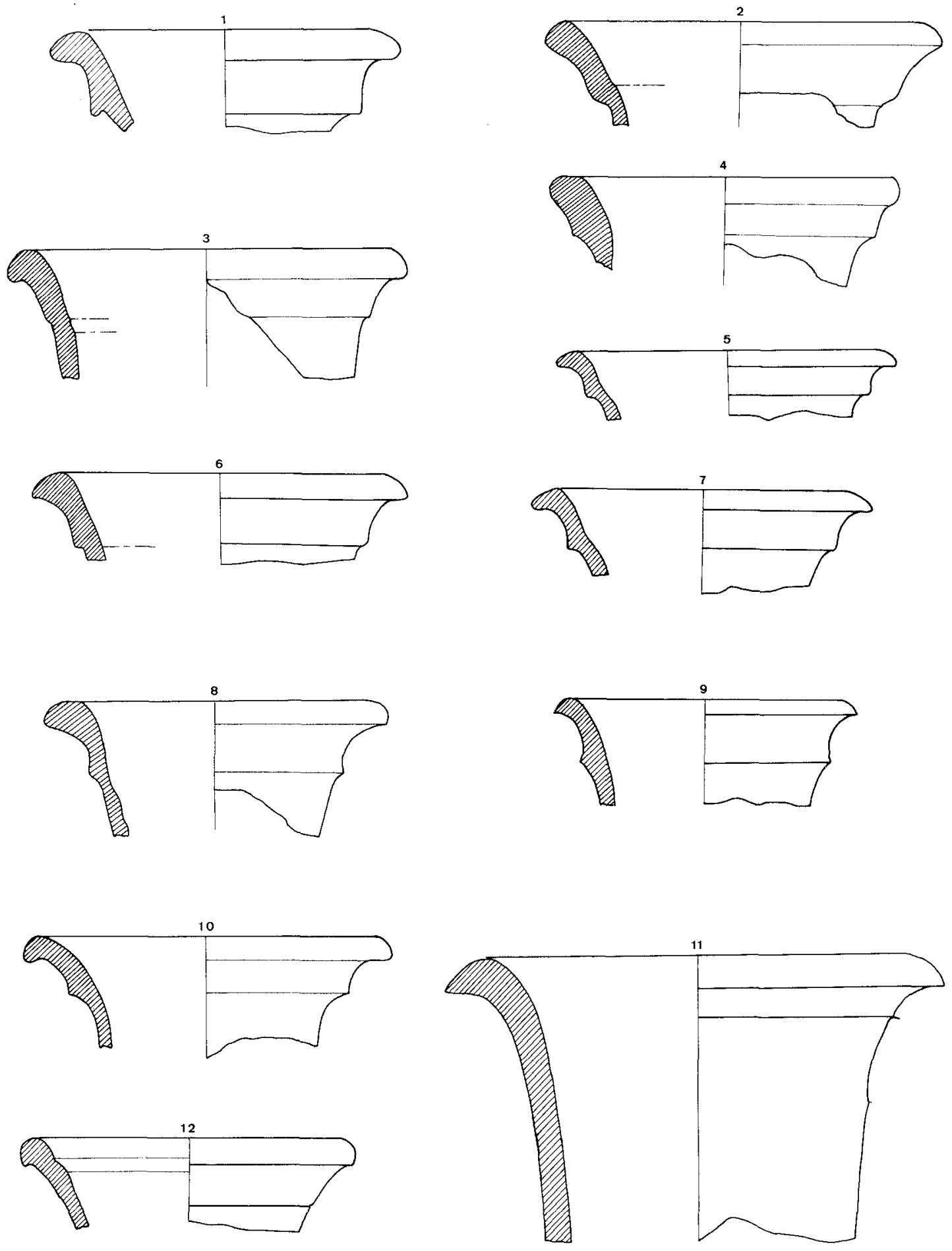

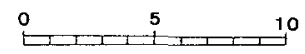

Fig. 4. Anforas para salsas del tipo Dr. 7-11 

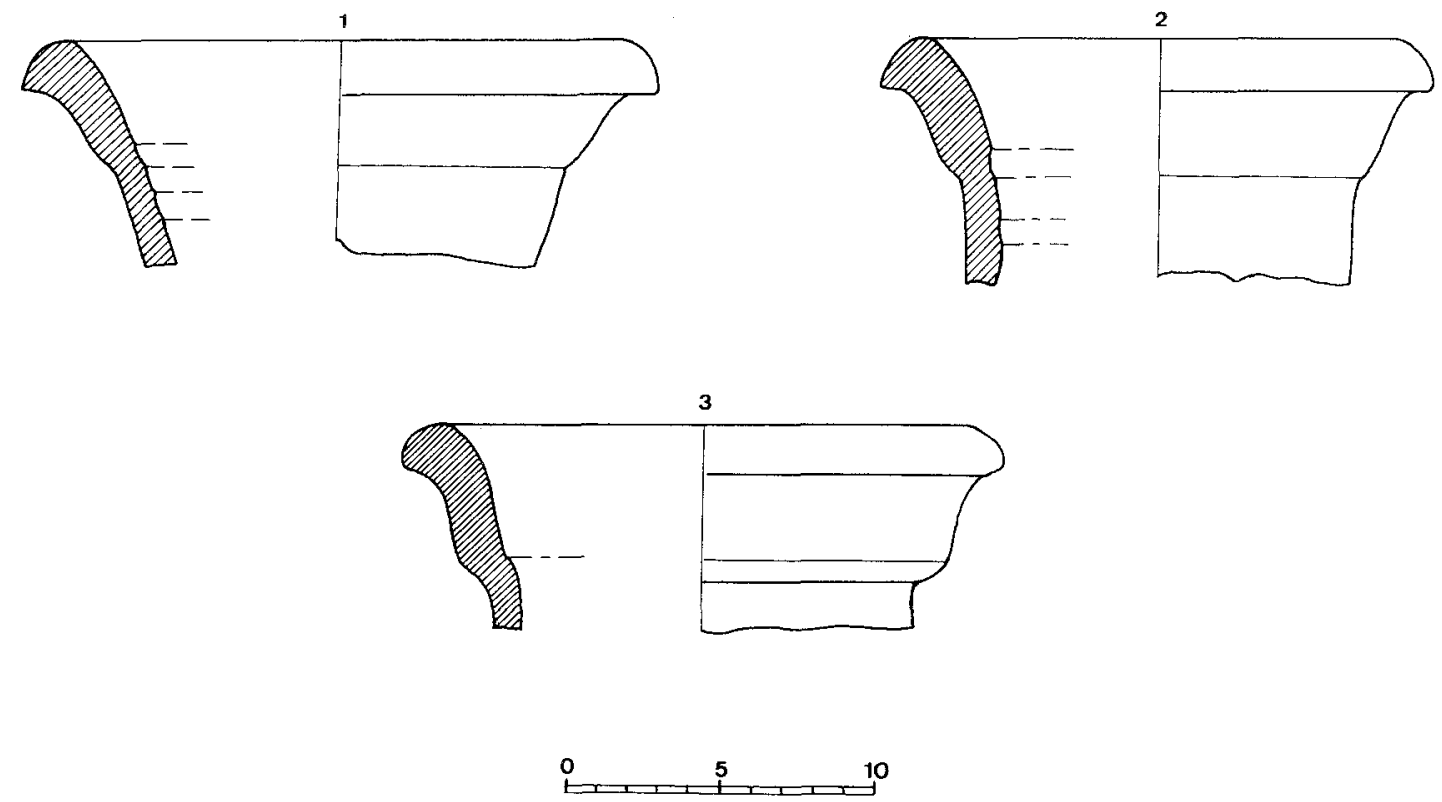

Fig. 5. Anforas para salsas del tipo Dr. 8

Cinco de estas asas ostentan marcas estampilladas, y otra marca de las mismas características se halla sobre un fragmento informe, posiblemente correspondiente a la panza. Todas estas marcas tienen en común las letras en relieve, en cartela de forma rectangular, correspondientes a las iniciales de los tria nomina y en ocasiones van separadas por puntos triangulares. Este sistema de marcas es propio de las ánforas de época altoimperial, datables en los siglos I y II (REMESAL, 1977, 93).

Las estampillas aparecidas son las siguientes:

$$
\begin{aligned}
& \text { N. }{ }^{\circ} 6 \text { - C N O V... } \\
& \text { N. } 4 \text { - L.P.M. } \\
& \text { N. } 5 \text { - M.P.F. } \\
& \text { N. } 8 \text { - P A L I S C A C } \\
& \text { N. } 7 \text { - G T } 12 \\
& \text { N. } 9 \text { - B V R B }
\end{aligned}
$$

La n. ${ }^{\circ} 6$ está reseñada por Callender (CALLENDER, 1965, 90) con el n. ${ }^{\circ} 408$, y se desarrolla $\left.\mathrm{C} \mathrm{N} \mathrm{O} \mathrm{V/1.} \mathrm{La} \mathrm{segunda} \mathrm{(n.}{ }^{\circ} 4\right)$ se encuentra en Callender con el n. ${ }^{\circ} 914$, si bien el facsímil (fig. 933) no reproduce exactamente la marca del Portus Illicitanus, cuyo desarrollo es L P ( ) M ( ) / servus/ ? Se puede considerar originaria del Sur de España, datable en el siglo II (CALLENDER, 1965, 163). La tercera $\left(n .^{\circ}\right.$ 5) corresponde al n. ${ }^{\circ} 35$ (fig. 11, 58-a) y se desarrolla (M.P. ( ) F ( )?). Los números 7,8 y 9 no han sido localizados en los Corpus de Inscripciones ni en la bibliografia consultada al respecto (3).

(3) La mayor densidad de hallazgos del tipo Dr. 20 proceden del mar, recuperadas por las barcas de pesca, las cuales forman parte del Museo Municipal de Santa Pola. En la actualidad están siendo objeto de estudio por A. Fernández Izquierdo y M. J. Sánchez Fernández. 


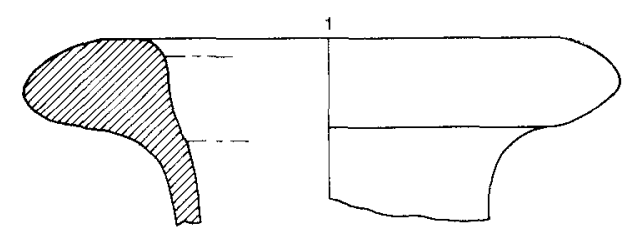

\section{[EP.4]}
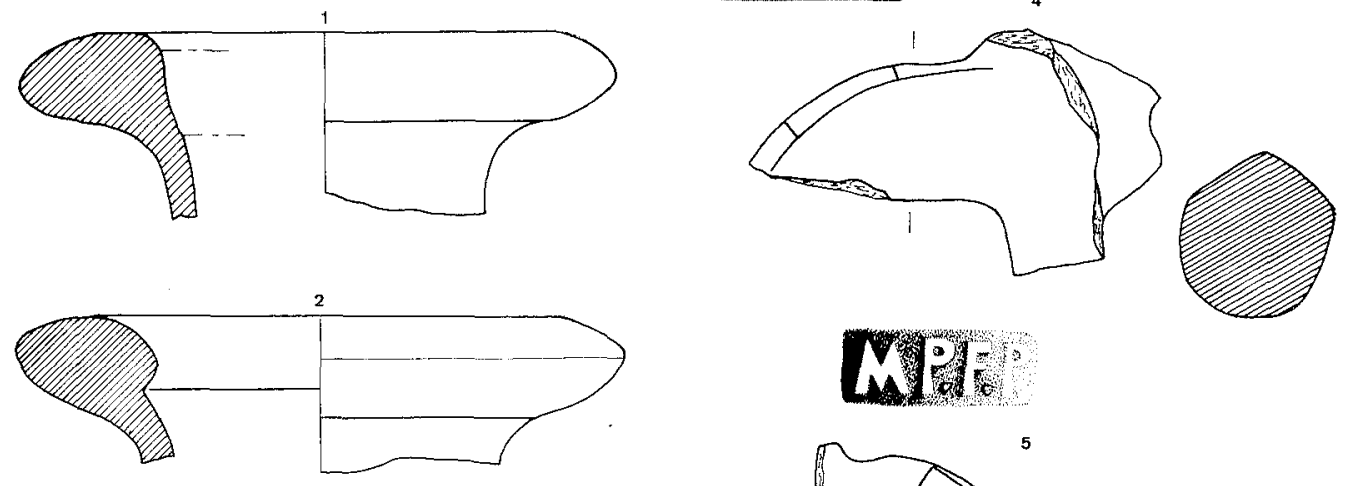

\section{CWII:}
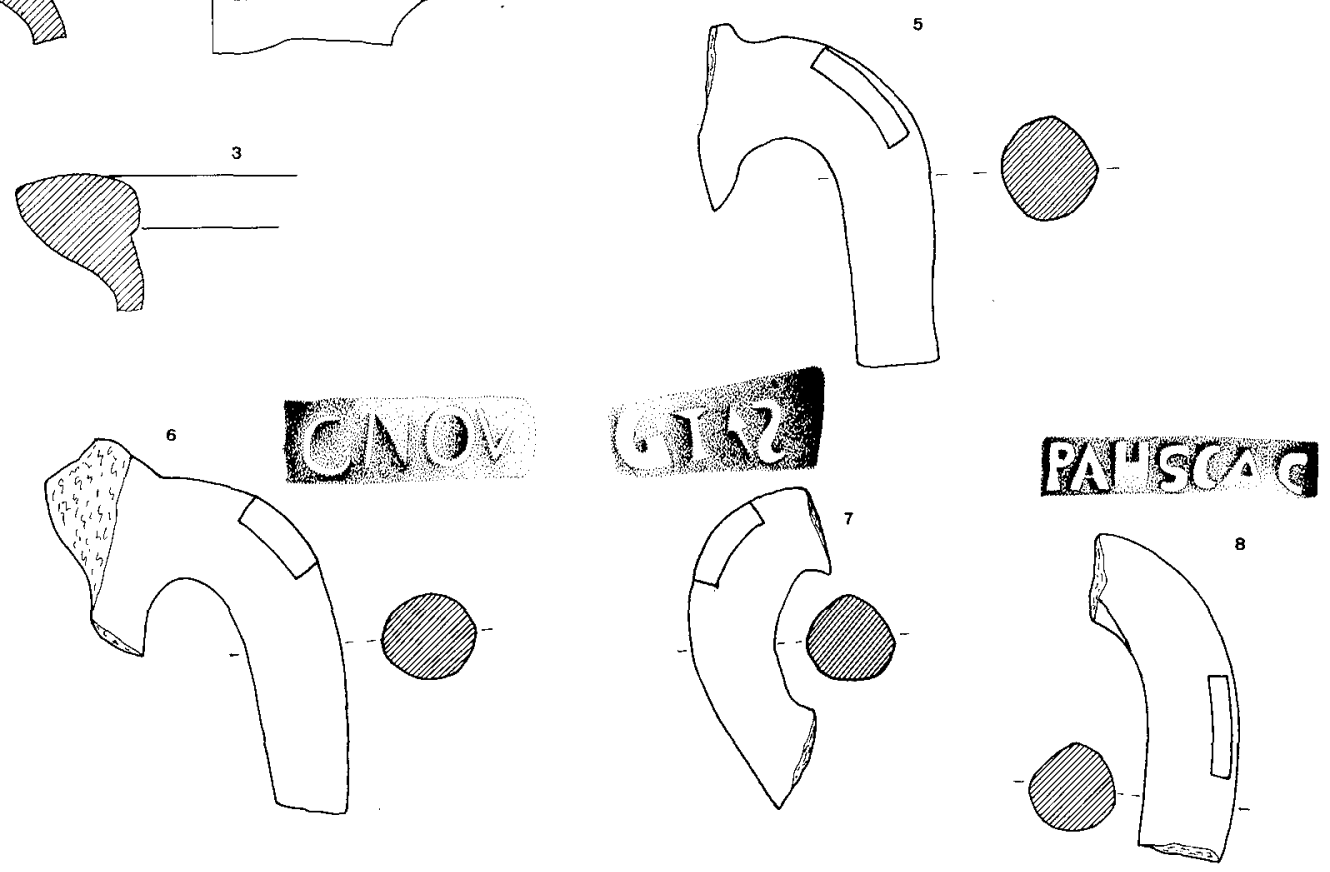

$\mathbf{9}$
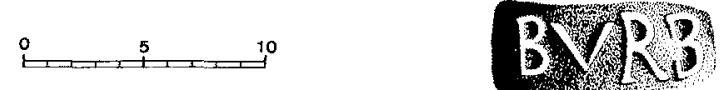

Fig. 6. Anforas olearias del tipo Dr. 20

\section{ANFORAS DE FONDO PLANO TIPO Dr. 28 (Fig. 7)}

Presentamos cinco ejemplares pertenecientes a la boca y parte superior del cuello, de alguno de los cuales ha sido posible completar el perfil hasta el hombro, teniendo en cuenta el estado de fragmentación en que se encuentra este material.

Se trata de un conjunto de ánforas de características muy homogéneas en cuanto a su morfología y a su técnica de fabricación.

De labio de doble moldura, más o menos acentuada, con una cavidad central de tres a cuatro $\mathrm{cm}$. de altura, vertical o ligeramente oblicuo. El diámetro de la boca oscila entre 14 y $17 \mathrm{~cm}$. Cuello corto y cilíndrico algo exvasado en la parte superior y asas que 

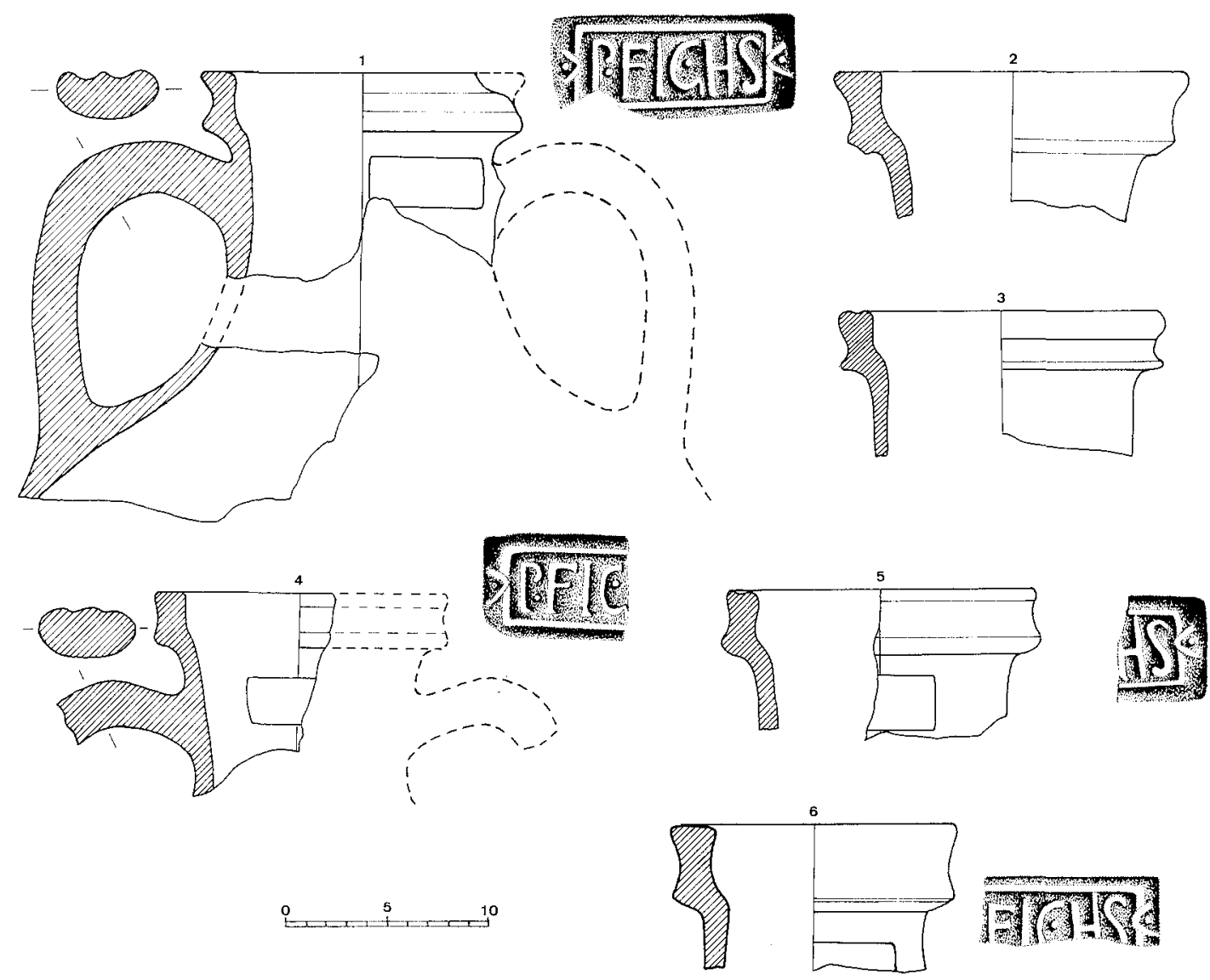

Fig. 7. Anforas del tipo Dr. 28

arrancan justo por debajo del labio con gran entrante en el cuello, las cuales se engastan a la altura del hombro formando un arco de círculo bastante regular, en forma de cinta con dos acanaladuras verticales.

En general es un ánfora de pequeñas dimensiones, de panza ovoide, con el fondo plano, aunque ambas partes no han sido identificadas como tales en nuestro yacimiento.

La pasta es porosa, muy compacta y bien cocida, de color beige-rosáceo con abundante desengrasante de puntos negros finos. En ningún caso presenta engobe.

Resulta problemático en el estado actual de la investigación definir el origen y la evolución tipológica del tipo Dr. 28. Aparecen en las excavaciones de Ventimiglia y en la nave de Albenga, datadas en los dós últimos siglos de la República (LAMBOGLIA, 1955, 265; 1952, 166), recogidas por Colls (COLLS, 1977, 46). En época augustea aparecen en Oberaden (forma Oberaden 74 ), con un labio de doble moldura, de cavidad central menos profunda, y asas de doble acanaladura. Las mismas características presentan en Enserune, con la marca PHILODAMUS, Haltern con la marca C. M. USSID (i) NEP (otis), parecida a la Oberaden 74 (COLLS, 1977, 46), Gabii i Vindonissa (BELTRAN, $1970,497)$. La perduración de este tipo se prolonga hasta la primera mitad del siglo II (PANELLA, 1970, 156; BELTRAN, 1970, 497 y ss.).

Los ejemplares del Portus Illicitanus presentan las mismas características que los de Haltern, Tivissa y Oberaden: la misma pasta, dura, compacta y depurada, y la misma tonalidad, por lo que posiblemente se les puede atribuir un origen catalán. 
Lo más destacable de estas ánforas es la aparición, en su mayoría, de la marca P. FIG,HS, idéntica en todos los casos, en cartela rectangular, situada en el centro del cuello por debajo del labio, perfectamente legible, la cual hemos desarrollado de la manera siguiente: P (hilodamus). FIG (linae). H S (?).

\section{ANFORAS AFRICANAS (Fig. 8)}

En el curso de los siglos III y IV, tiene lugar la exportación sistemática y organizada del aceite, en las ánforas denominadas «Africanas», atribuibles al Africa Proconsular
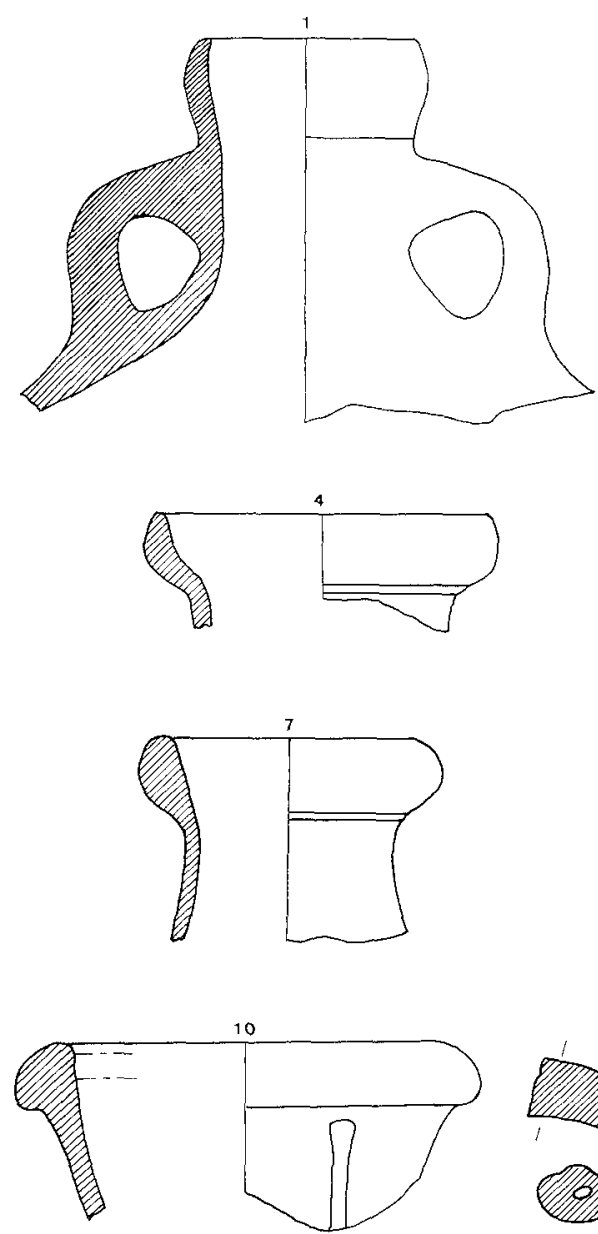

E्G

0 5
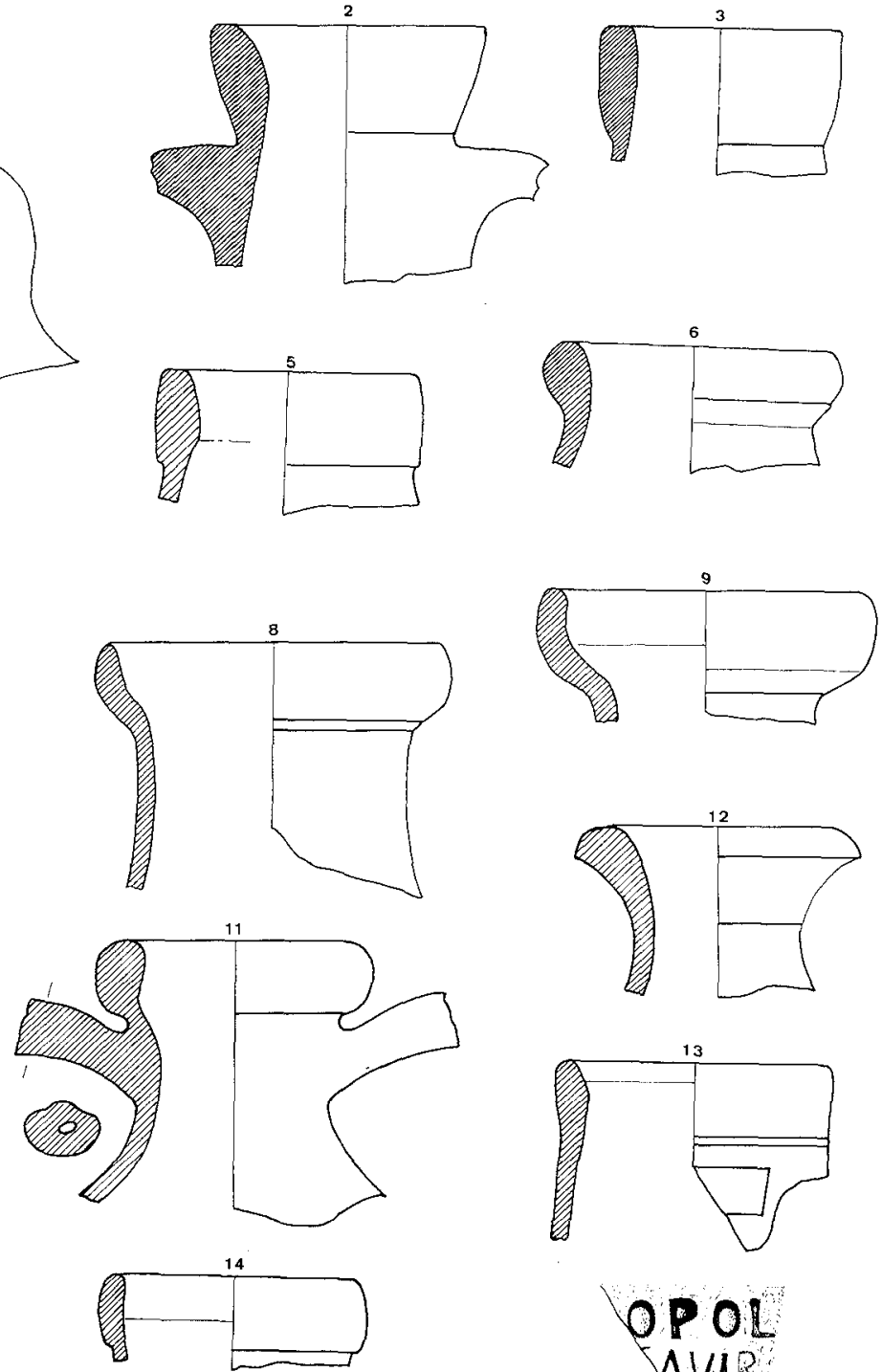

Fig. 8. Anforas africanas 
(FERNANDEZ IZQUIERDO, 1980, 141), región de gran riqueza agrícola, atestiguada en las fuentes antiguas (PANELLA, 1978, 585). Dichas ánforas, junto con la terra sigillata clara y la cerámica común africana, constituyen la documentación más significativa de la producción exportada, procedente de la Byzacena y de la Zeugitana.

Las ánforas africanas halladas en el Portus Illicitanus, tienen un claro paralelo en la «Africana II», o «Africana Grande». Se atribuyen genéricamente a este tipo todos los labios de perfil más o menos engrosado (PANELLA, 1978, 580), en ocasiones redondeado al exterior, caracterizado en su base por un ligero resalte como elemento de separación entre el labio y el cuello. La pasta es de color anaranjado en el núcleo, compacta y de aspecto rugoso, con la superficie exterior de color gris, recubierta por un engobe blanco-crema. Presenta un desengrasante de gruesas partículas blancas y abundantes puntos brillantes muy finos. Las asas arrancan por debajo del labio, en forma de cinta engrosada muy curva, con perfil en «oreja».

Aparecen dos estampillas sobre ánforas africanas (fig. 7, 10-13), impresas en cartela rectangular con caracteres incisos. En la primera se lee ..ECHONI, marca incompleta situada en sentido vertical debajo del labio. La segunda está situada en la parte central del cuello, por debajo del labio, colocada en doble línea, incompleta, en la que se lee ...OPOL / ... $\mathrm{OVIR}$.

Estas ánforas se encuentran bien documentadas durante los siglos III y IV en Ostia, aunque su fabricación comienza a finales del siglo II. En niveles datados entre el $3 .^{\circ}$ y el $5 .^{\circ}$ decenio del siglo III de «Las Termas del Nadador» de Ostia, la Africana II supera los índices de presencia de todas las ánforas atestiguadas. Tales índices tienden a aumentar en los estratos de los siglos IV y V (PANELLA, 1978, 590).

El área de difusión de este tipo se localiza en la Gallia, España, Yugoslavia, Portugal, Marruecos Occidental, Grecia (PANELLA, 1978, 590), Roma e Italia central, provenientes de la región de la Byzacena. Estos tipos, por ahora, no pueden fecharse con precisión en el Portus Illicitanus, si bien se debe señalar que nos aparecen en contextos tardíos, junto a materiales claramente datables en el siglo III. Estos datos indican que el gran auge del comercio africano se produce en la segunda mitad de dicho siglo, concretamente, como apunta Fernández Izquierdo (FERNANDEZ IZQUIERDO, 1980, 141), entre los años 250-280.

Dichos envases contenían aceite africano, que competía con el bético en los mercados de Roma y la Gallia en los años 270-280 d. C. (ZEVI y TCHERNIA, 1969, 173).

\section{ANFORAS TARDIAS, TIPO ALMAGRO 51 (Fig. 9)}

Recogemos en este apartado un grupo de ánforas pertenecientes al tipo Almagro 51 , las cuales no aparecen en la clasificación tipológica de Dressel. Dentro de este tipo, Almagro establece tres variantes: $51 \mathrm{a}, \mathrm{b}, \mathrm{c}$. Debido a la semejanza formal, incluimos nuestros ejemplares en la variante $c$.

Son ánforas de pequeño tamaño, con un diámetro medio de boca de $11 \mathrm{~cm}$., de labio engrosado, más o menos redondeado al exterior y de sección triangular. Cuello corto, troncocónico, que se une al hombro mediante una curva poco marcada, y asas aplastadas en forma de cinta, de sección oval. En algunos ejemplares se observan tres líneas incisas alrededor del cuello, lo que consideramos pueda tratarse de una imitación de dicha forma. (Fig. 9, núms. 3-4.)

La pasta oscila entre el color marrón al rojo anaranjado, porosa, laminosa, de textura basta con numeroso desengrasante de mica dorada. La pared exterior se halla recubierta por un engobe blanquecino de tacto harinoso, que salta con facilidad. La superficie interior presenta estrías, producidas por el torno. 

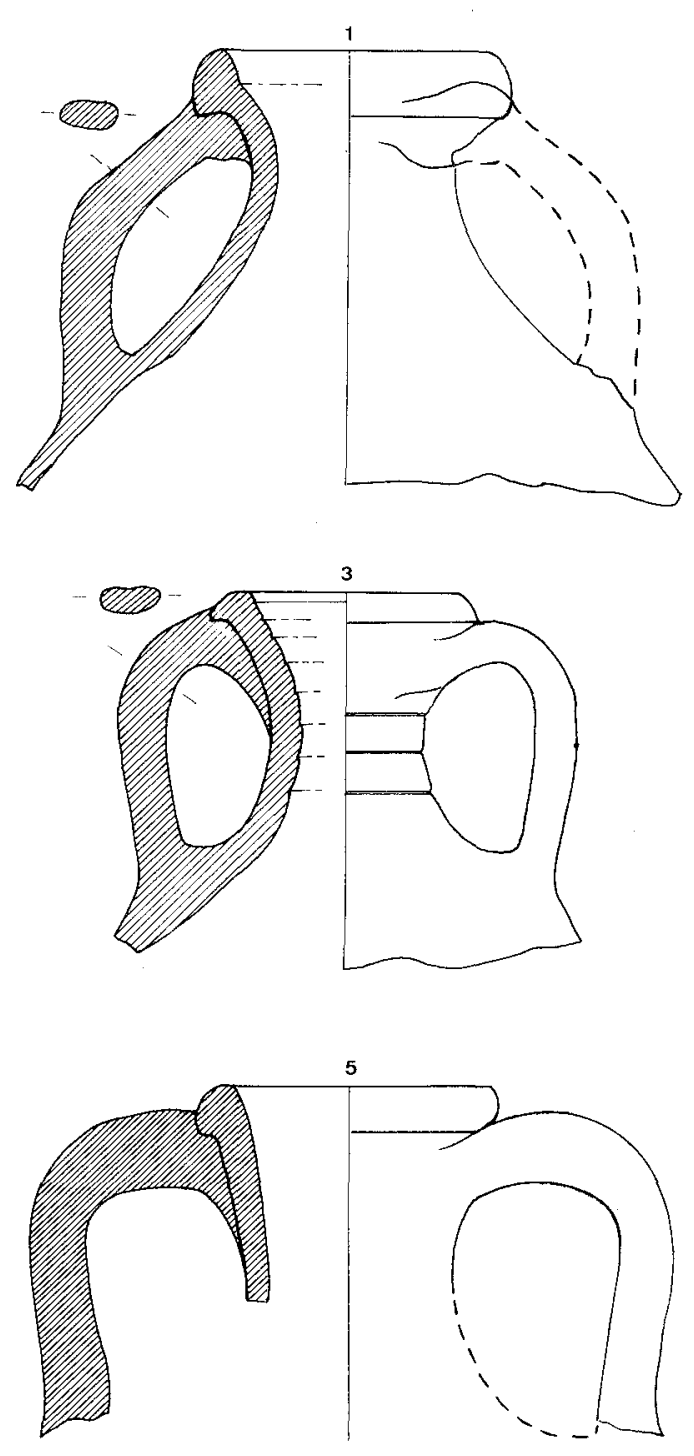
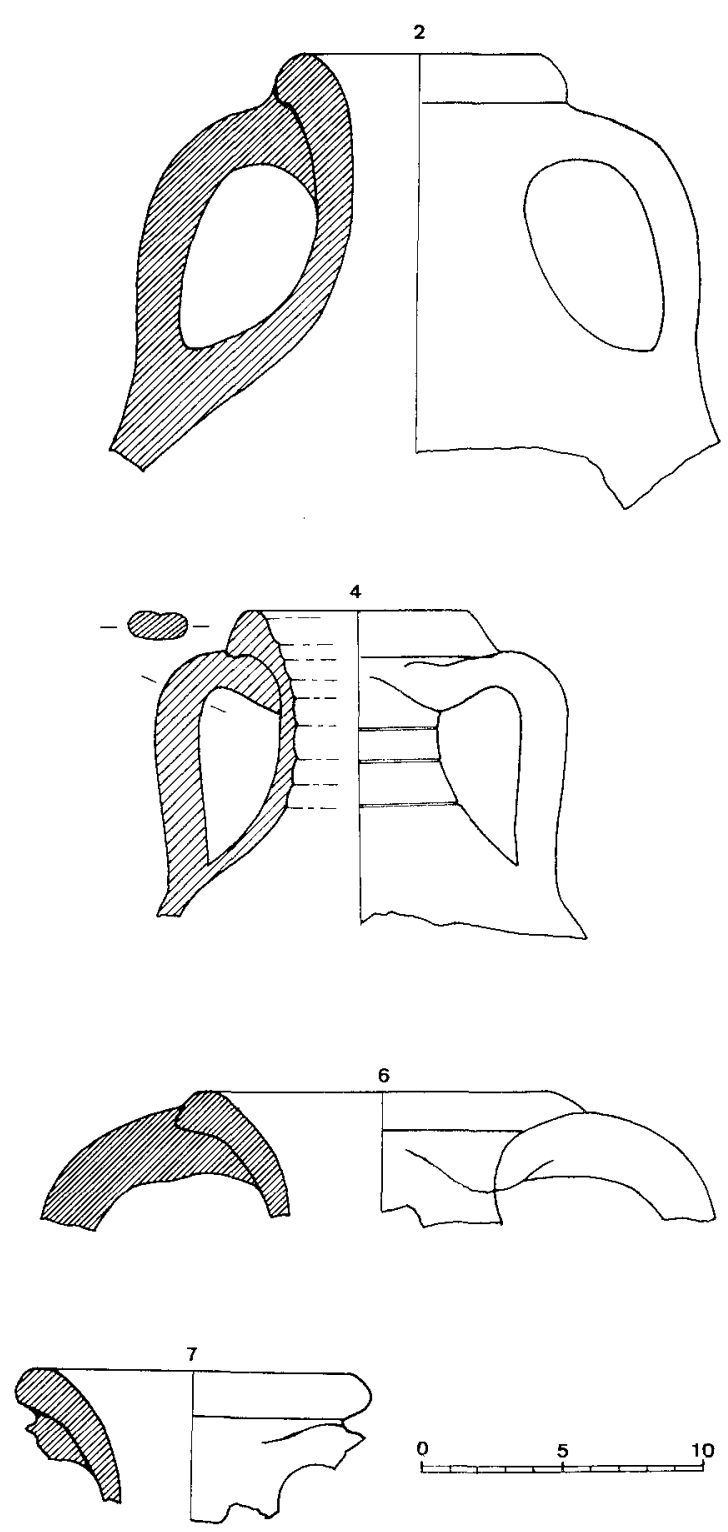

Fig. 9. Anforas del tipo Almagro 51

Esta variante Almagro $51 \mathrm{c}$, aparece en Ampurias en la inhumación Estruch, con el n. ${ }^{\circ} 21$ (ALMAGRO, 1955, 207, fig. 289), en la Necrópolis de les Foies de Valencia, en San Fructuoso de Tarragona, San Pedro del Pinatar, Cartagena (Murcia) y Almería, recogidas por Beltrán (BELTRAN, 1970, 543) y en la Necrópolis de la Boatella (Valencia), recogidas por Fernández Izquierdo (4), datable a fines del siglo III.

Esta variante c se considera la más tardía del tipo Almagro 51 al no aparecer en la inhumación del Castellet, donde este tipo es muy abundante. Dicha necrópolis es considerada por Almagro anterior a la de Estruch, datable en el siglo IV, y establece la datación de este tipo en la transición del siglo III al IV (ALMAGRO, 1955, 307). Aunque no

(4) Noticia oral, de A. Fernández Izquierdo, recogida después de la redacción de este trabajo. 
se puede precisar con exactitud la cronología de dichos envases, consideramos un dato a tener en cuenta su presencia en el Portus Illicitanus, junto a ánforas africanas, tipo II de Ostia, fechables entre los siglos III y IV.

Estos recipientes, posteriormente, fueron reutilizados para enterramientos en necrópolis de inhumación, como hemos mencionado anteriormente.

\section{ANFORAS INDETERMINADAS (Fig. 10)}

En nuestra clasificación hemos recogido tres ejemplares, hasta ahora no identificados en las tipologías consultadas. Proceden del relleno de una balsa, por lo que carecen de contexto arqueológico, si bien por su aspecto general nos inclinamos a considerarlas dentro de una época tardía.

Presentan un diámetro de boca reducido, cuello corto y estrecho, asas redondeadas de aspecto macizo, paredes gruesas y en general pequeñas dimensiones.

La pasta suele ser en todas ellas de color marrón claro, mal cocida, poco decantada, porosa, con abundante desengrasante de gruesos granos blancos y negros, y de factura muy tosca. En uno de estos recipientes (fig. 9, n. ${ }^{\circ}$ ) se observan estrías en el interior de la pared.

Próximos y futuros hallazgos, quizá aporten nueva luz a estos datos.
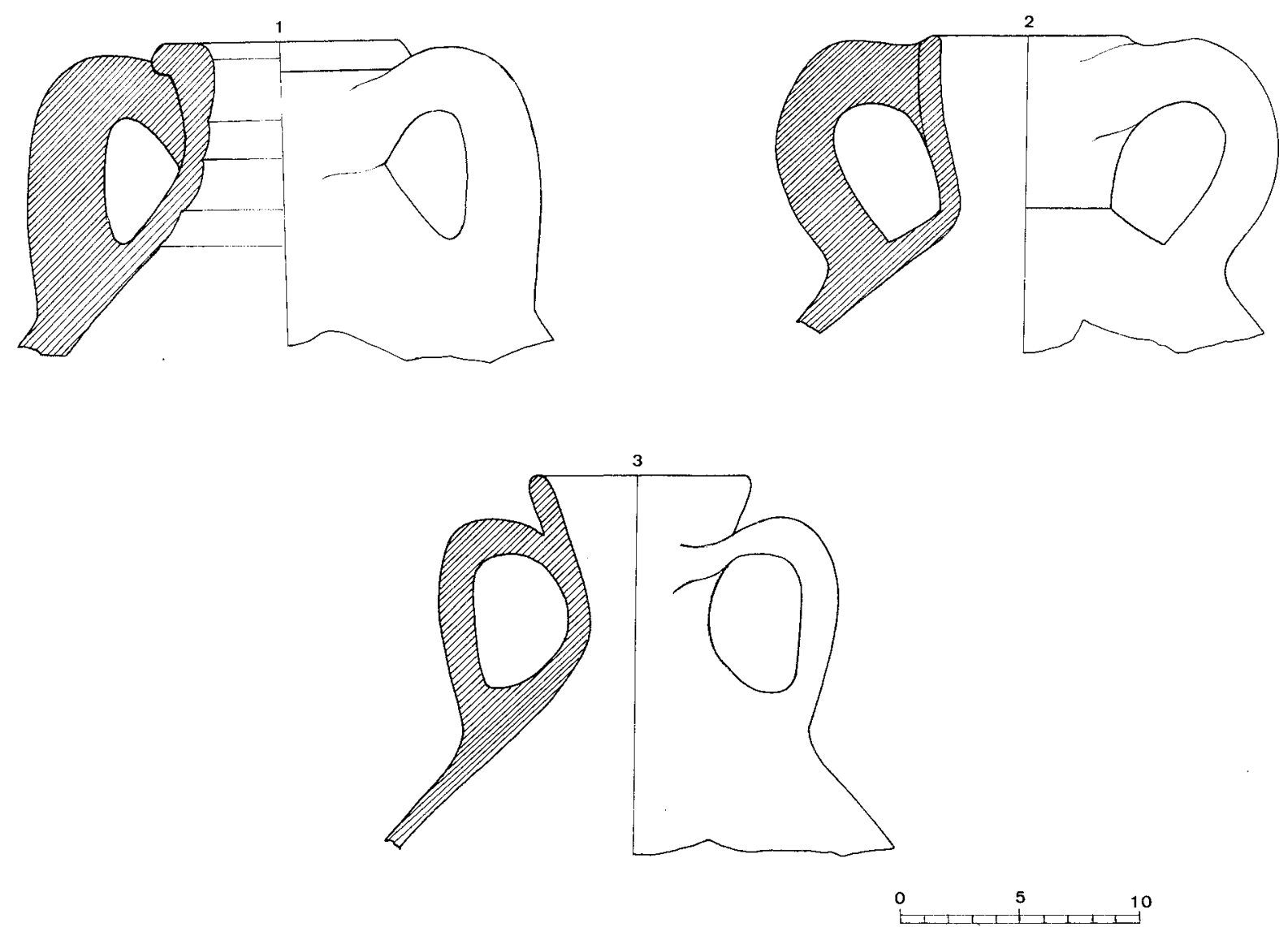

Fig. 10. Anforas tardías 


\section{CONCLUSIONES}

La gran cantidad de ánforas de diversas tipologías halladas en el Portus Illicitanus, supone una muestra del intenso comercio marítimo desarrollado en dicho puerto, en época romana, por espacio de más de cinco siglos. Los estratos republicanos se hallan aún por excavar. El material anfórico perteneciente a esta época aportará nuevos datos sobre los comienzos del comercio de esta zona.

Se observa una primera etapa, que abarcaría desde el cambio de era hasta la segunda mitad del siglo II, un neto predominio de los productos hispánicos, polarizándose los mercados entre la provincia tarraconense, atestiguada por la presencia de ánforas vinarias del tipo Dr. 2-4 y Dr. 28, y la Bética, con el hallazgo de un gran volumen de ánforas de salazones del tipo Dr. 7-11 y, en bastante menor proporción, de la olearia tipo Dr. 20.

Un dato de gran interés para el estado actual de nuestros conocimientos, se deriva de la afluencia al Portus Illicitanus de los productos más comercializados en el Mediterráneo a comienzos del Imperio: vino, envasado en ánforas de fabricación tarraconense, en su mayoría, y salsas de pescado y aceite, procedentes del Sur peninsular.

La presencia de las ánforas Dr. 2-4, viene a demostrar la importancia que el vino tenía en estos siglos, como producto comercializado a gran escala, dentro del mundo romano, manteniéndose en el mercado desde comienzos del reinado de Augusto hasta la segunda mitad del siglo II.

El tipo predominante en el Portus Illicitanus en época altoimperial es el ánfora de salazones Dr. 7-11, de origen bético, en la cual se inicia la exportación de salazones andaluces, los cuales se mantienen en uso desde época augustea hasta finales del siglo II, y tal vez algunos decenios más, con un gran número de variantes y una amplia difusión en todo el litoral mediterráneo y fuera de la Península. Dentro de esta misma familia, contamos con algunos ejemplares del tipo Dr. 8, que por su morfología se los puede incluir en un grupo diferenciado de los demás.

Al igual que en el resto de nuestra costa, queda constatada la escasa presencia del tipo Dr. 20, dedicado al transporte del aceite, reduciéndose a escasos fragmentos y algunas marcas en niveles altoimperiales. No ocurre así con el aceite africano, que a partir de la segunda mitad del siglo III, llega masivamente al Portus Illicitanus en ánforas de la forma «Africana II», también denominada por Zevi «Africana Grande», cuya presencia subsiste hasta finales del siglo IV. En lo referente a otros productos de importación africana se observa el mismo fenómeno, ya que aparecen grandes cantidades de sigillatas claras en todas sus variantes, platos de borde ahumado, cuencos de borde aplicado, cazuelas de fondo estriado, etc. La profusión de ánforas africanas, junto al resto de los productos mencionados, es un hecho que demuestra la gran demanda comercial de este momento. En niveles tardíos de finales del siglo III y comienzos del IV, las ánforas africanas superan los índices de presencia de todas las demás atestiguadas. La preponderancia cuantitativa de productos africanos en el Portus Illicitanus en los siglos III y IV se debe, sin duda, a la consecuencia de un proceso de explotación sistemática de los recursos agrícolas de la Tunisia, potenciado por los Severos en un intento conseguido de impulsar la producción de la oleicultura africana.

La problemática relativa al comercio del aceite africano, dentro de un contexto arqueológico, ha sido correctamente analizada por C. Panella (PANELLA, 1978) en las excavaciones de Ostia, lo cual constituye una síntesis de las cuestiones desarrolladas en torno a estos temas.

Otros tipos encontrados en el Portus Illicitanus son las Dr. 28, de posible origen catalán, la Almagro 51,y otras formas tardías, hasta ahora no identificadas en las tipolo- 
gías consultadas al réspecto, por lo que puede tratarse de producciones locales, fabricadas dentro de un área geográfica próxima al Portus Illicitanus.

Esta gran variedad tipológica presupone un comercio marítimo ininterrumpido desde el cambio de era hasta el siglo $\mathrm{V}$, y tal vez algunos decenios más. Se observan dos etapas de auge comercial atestiguadas por el número de ánforas y otros productos importados. La primera podría situarse desde la época de Augusto hasta fines del siglo II. Se produce una cierta decadencia en la primera mitad del siglo III, puesto que se aprecia un descenso de las importaciones. Una segunda etapa de resurgimento comercial y económico tiene lugar en la segunda mitad del siglo III, con el incremento del comercio con el Norte de Africa.

La extensa cronología de las ánforas objeto del presente trabajo, nos permite deducir que el Portus Illicitanus inicia el proceso de romanización en una época muy antigua, posiblemente antes del cambio de era y su actividad comercial perdura hasta bien entrado el siglo $\mathrm{V}$.

Cuando el estudio del resto de materiales esté concluido y próximas excavaciones proporcionen nuevos hallazgos, tendremos más elementos de juicio para dar como definitivas muchas de las conclusiones que aquí hemos expuesto, y que por el momento sólo tienen carácter profesional.

Alicante, abril de 1984 


\section{BIBLIOGRAFIA}

ALMAGRO, Martín, 1955, «Las Necrópolis de Ampurias», Ampurias, vol. I-II, Barcelona.

ARANEGUI GASCO, Carmen, 1978, «Anotaciones sobre las ánforas del nivel de relleno del Grau Vell, Sagunto (Valencia)», SAGUNTUM, 13, Papeles del Laboratorio de Arqueología de Valencia, Universidad de Valencia.

1981, «La producción de ánforas romanas en el País Valenciano, estado de la cuestión», Archivo de Prehistoria Levantina, vol. XVI, Valencia.

BELTRAN LLORIS, Miguel, 1970, Las ánforas romanas en España, Monografias arqueológicas, 7, Zaragoza.

- 1977, «Problemas de la morfología y del concepto histórico-geográfico que recubre la noción tipo. Aportaciones a la tipología de las án foras béticas», Méthodes Classiques et Méthodes Formelles dans l'Etude des Amphores, Ecole Française de Rome.

CALLENDER, M. H., 1965, Roman amphorae, Oxford University Press, London.

COLLS, Dalí, 1977, «L'Epave de Port-Vendres II et le commerce de la Bètique a l’époque de Claude», Editions du Centre National de la Recherche Scientifique, París. Archeonautica I.

ENGUIX, Rosa, y ARANEGUI, Carmen, 1977, El taller de ánforas romanas de Oliva (Valencia), Servicio de Investigación Prehistórica, Serie de Trabajos Varios, 54, Valencia.

FERNANDEZ IZQUIERDO, Asunción, 1980, «Estudio de los restos arqueológicos submarinos en las costas de Castellón», Cuadernos de Prehistoria y Arqueología Castellonenses, Diputación Provincial de Castellón de la Plana, Castellón de la Plana.

LAMBOGliA, Nino, 1952, «La Nave Romana di Albenga», Riv. Stud. Liguri, XVIII, Bordighera.

- 1955, «Sulla cronologia della anfore romane di etá republicana», Riv. Stud. Liguri, XXI, Bordighera.

LAUBENHEINER, F., y WINDERMANN, F., 1977, «L'atelier de Corneilhan (Hérault), Tipologie et analyse», Colloque Français d'Archeometrie, Rennes. (Citado por Aranegui, 1978.)

LUSUARDI, Silia, 1977, «Appunti su alcuni tipi di anfore lunensi», Méthodes Classiques et Méthodes Formelles dans l'Etude des Amphores, Ecole Françaịse de Rome.

NOLLA, José M. ${ }^{a}$, 1974-75, «Las ánforas romanas de Ampurias», Ampurias, 36, Barcelona.

PANEllA, Clementina, 1970, «Le Terme del Nuotatore», Ostia II, Estudii Miscellanei, 16, Roma.

- 1972, «Anotacioni in margine alle stratigrafie delle Terme Ostiensi del Nuotatore», Recherches sur les amphores romaines, Ecole Française de Rome, Rome.

- 1973, «Appunti su un gruppo di anfore della prima, media e tarda etá imperiale (Secoli del I-V d. C.)», Ostia III, Estudii Miscellanei, 21, Rome.

Producción y comercio del aceite en la antigüedad, 1980, Primer Congreso Internacional, Universidad Complutense, Madrid.

REMESAL RODRIGUEZ, J., 1977-78, «Economía oleícola bética: nuevas formas de análisis», Archivo Español de Arqueologia, 50-51, Madrid.

SANCHEZ FERNANDEZ, M. ${ }^{a} J^{J}$ osé, 1983, «La cerámica común romana del Portus Illicitanus», Lucentum, II, Universidad de Alicante, Alicante.

TCHERNIA, A., y ZEVI, F., 1971, «Amphores vinaires de Tarraconainse et leur exportation au début de l’Empire», Archivo Español de Arqueología, 44, Madrid.

- 1972, «Amphores vinaires de Campanie et de Tarraconainse a Ostie», Recherches sur les amphores romaines, Ecole Française de Rome, París.

TCHERNIA, A., 1977, «Note sur le matériel recuilli dans les fouilles d'un atelier d'amphores à Velaux (Bouches-du-Rhône)», Méthodes Classiques et Méthodes Classiques dans l'Etude des Amphores, Ecole Française de Rome.

ZEVI, F., 1966, «Appunti sulle an fore romane», Archeologia Classica, 18, 2, Roma. (Citado por Enguix y Aranegui, 1977).

ZEVI, F., y TCHERNIA, A., 1969, «Amphores de Byzacène au Bas Empire», Antiquités Africaines, 3, Centre National de la Recherche Scientifique, París. 



\title{
LOS DIOSES LARES EN LA HISPANIA ROMANA *
}

\author{
M. ${ }^{\mathrm{a}}$ ISABEL PORTELA FILGUEIRAS \\ Instituto Español de Arqueología. C. S. I. C.
}

\begin{abstract}
Los Lares se encuentran entre las divinidades que tuvieron una mayor aceptación en la Hispania romana. La finalidad del presente artículo es realizar una puesta al día de la bibliografía existente sobre el tema y recopilar toda la evidencia material de la que disponemos.
\end{abstract}

The Lares were some of the most beloved and worshipped deities in Hispania. This paper tries to give an up-to-date bibliography and to collect all the material evidence we have on this subject.

Los Lares fueron las divinidades que, junto con Júpiter, tuvieron una mayor aceptación en el Noroeste peninsular. La densidad de su culto en España respecto al resto del Imperio romano nos llamó la atención y decidimos adentrarnos en el estudio del mismo.

Nuestra finalidad es la de realizar una puesta al día del material existente. Las obras que tenemos resultan muy parciales, falta la gran obra de conjunto que analice a fondo todos los aspectos de este culto tan importante en la Península.

La pretensión de este trabajo ha sido más que la realización de grandes descubrimientos y la proposición de hipótesis brillantes, la recopilación del material del que disponemos.

\section{EL CULTO A LOS LARES EN LA RELIGION ROMANA}

Cualquiera que sea el origen de los dioses Lares, éstos están documentados desde época muy antigua como protectores de los campos, y, especialmente, como divinidades domésticas y de la familia. En cualquier caso, estos documentos presentan su nombre siempre en singular como Lar familiaris.

La prueba más evidente del carácter campestre de los Lares en su origen es la institución de un culto en honor de los Lares Compitales; cuando en los compita campestres se elevaron sacella en honor de los Lares Compitales, el número de éstos se duplicó.

* Este trabajo es un extracto de la Memoria de Licenciatura que, bajo la dirección del Prof. D. Antonio Blanco Freijeiro, Catedrático de Arqueología de la Universidad Complutense de Madrid, fue leída en esta Universidad en junio de 1982. Tengo que expresar mi especial agradecimiento al Dr. Javier Arce, sin cuya ayuda y orientación no habría sido posible la realización del presente trabajo. 
La división de Roma en vici, atribuida a Servio Tulio, fue sancionada por este culto que se convirtió en una gran fiesta móvil, celebrada durante los días que seguían a las Saturnalia. La religión de los Lares Compitales fue importada del campo y simplemente adaptada a las necesidades de la vida urbana.

Igual que en cada casa no se veneraba más que un solo Lar, como el caso más frecuente en los compita rurales era el de dos caminos cortándose en ángulo recto, los Lares eran dos. La pluralidad de la idea de los Lares parece derivada de la veneración de los Lares de las encrucijadas, antes de ser consagrada por su confusión con los Penates.

En el estudio de la evolución del culto a los Lares se aprecian dos etapas: una primera que terminará con la República, en la que los Lares conservan generalmente, incluso en las manifestaciones de la religión oficial, el carácter familiar y rústico que es el de sus orígenes; la segunda etapa se inicia con la reforma religiosa llevada a cabo por Augusto.

Como resultado de la reforma, las antiguas divinidades de las encrucijadas, los Lares, fueron convertidos en Lares Augusti. De esta forma, un ritual popular se centró en el emperador y su familia sin convertirse abiertamente en el culto del gobernante.

La creencia en los Lares como espíritus protectores y bienhechores estaba tan fuertemente arraigada en la conciencia religiosa del pueblo romano que en muchas zonas sobrevivió a la desaparición del sistema religioso del cual había formado parte en su origen.

La prueba de que el culto doméstico persistió hasta el final del paganismo e incluso en épocas posteriores, nos la proporcionan los ataques de los autores cristianos, que tienen mayor fuerza porque no derivan de fuentes literarias, sino que relatan directamente los hechos que se estaban produciendo en su época.

La tenacidad y la fuerza del culto doméstico romano estaban condicionadas por su adecuación al antiguo espíritu romano. Con el paso del tiempo se produjeron cambios y adiciones, pero eran sólo aspectos externos y poco importantes; el corazón y el centro de este culto permanecieron inalterables.

El golpe definitivo al culto doméstico tuvo lugar en una fecha tan tardía como es la del año 392 d. C., por medio de un edicto del emperador Teodosio (CODEX THEODOSIANUS, Libro XVI, título 10), por el cual se prohibía la veneración de los Lares y los Penates.

\section{EL CULTO A LOS LARES EN LA HISPANIA ROMANA}

\section{A. La introducción del culto}

Antes de tratar aspectos de carácter puramente religioso tenemos que estudiar, aunque sea de forma general, el fenómeno de la romanización de la Península Ibérica y su incidencia en la penetración de la influencia religiosa romana.

Es una opinión tradicional, y prácticamente generalizada, que Hispania, o al menos una parte de ella, fue una provincia romanizada muy intensamente y desde época muy temprana.

Algunos autores como GARCIA Y BELLIDO (GARCIA Y BELLIDO, 1967, 3-29) señalan tres etapas básicas en el proceso de romanización de Hispania: un primer impulso a este proceso sería el realizado por Augusto a través de sus fundaciones; seguiría una etapa iniciada en el siglo I d. C., caracterizada fundamentalmente por la creación de fora; un tercer y último impulso sería el realizado por los emperadores flavios, a partir de la segunda mitad del siglo I d. C.

Las obras de J. M. ROLDAN nos dan un panorama muy claro de lo que fue el proceso de romanización de la Península Ibérica (ROLDAN, 1972, 77-123). Considera 
que la romanización, tal y como hoy la entendemos, y, especialmente, para la época republicana precesariana, no es una meta consciente, sino simplemente una consecuencia derivada de una causa muy simple: la explotación material de la Península debida a su gran riqueza de recursos.

El contacto de los indígenas con Roma llevó consigo un deseo de éstos de imitar las formas de vida y de cultura de un pueblo que consideraban superior.

Roma nunca intentó imponer sus formas de vida, lengua, derecho, religión, etc., a través de la fuerza. Pero era necesario un elemento que sirviera de nexo de unión entre dominadores y dominados y éste fue la civitas romana. Los romanos trataron de conseguir que los indígenas tendieran a incluirse en la organización político-cultural mediante una hábil y lenta concesión de privilegios.

Pero toda esta política de integración en el mundo romano tiene una limitación clara: el proceso de romanización sólo se realiza en las zonas privilegiadas económicamente y utilizadas como asentamiento por los romanos de forma estable.

La pieza clave en el proceso de romanización peninsular fue, sin lugar a dudas, el elemento militar, tanto en época republicana, como durante gran parte del imperio. Su papel fundamental en la romanización estriba en el hecho de que, una vez terminado su servicio en las armas, muchos soldados no regresaron a Italia, sino que permanecieron en Hispania asentándose como colonos.

Ya hemos aludido antes a la limitación que constituía la elección de asentamiento por parte de los elementos itálicos; las zonas preferidas para este asentamiento eran el valle del Guadalquivir sobre todo y después el valle medio y bajo del Ebro; siendo éstas las únicas zonas en que el elemento indígena fue arrinconado desde fecha temprana, se desarrollaron según unas directrices culturales de tipo romano.

Por último, hay que señalar la importancia de la concesión de privilegios de manera individual o colectiva. Por su nueva categoría de ciudadanos romanos o por su contacto con el mundo romano a través de su ejercicio de las armas, los elementos indígenas al volver a su lugar de asentamiento, completamente imbuidos de la cultura romana, la transmitirían a su entorno.

Incluso las regiones del Norte y Noroeste hispano se romanizaron debido a la incorporación de tropas indígenas al ejército romano, a la influencia de las tropas romanas establecidas en estas regiones de forma casi permanente y también a la importante infraestructura viaria de estas zonas peninsulares; por todos estos factores no se puede subestimar la romanización de estas regiones ni sobrevalorar la pervivencia de elementos indígenas en las mismas.

Numerosos autores como GARCIA Y BELLIDO, BLAZQUEZ, VIGIL, PALOL, LOMAS, etc., sostienen la teoría de la escasa romanización del Norte que se manifestaría claramente en la pervivencia de las antiguas estructuras indígenas.

Esta pervivencia es un hecho real, pero, ya en época flavia, tiene una importancia menor de la que se le ha venido concediendo hasta ahora. En esta época las estructuras indígenas se encontraban muy impregnadas por la influencia romana, quedando sólo algunos reductos de indigenismo en las zonas montañosas de difícil acceso.

Una vez expuestas las líneas generales de lo que fue el proceso de romanización en la Península Ibérica, nos centraremos en las diversas opiniones que hasta hoy se han expresado sobre la introducción del culto de los Lares en la Hispania romana y sobre el carácter del mismo. ALARCÂO, ETIENNE Y FABRE $(1969,213-236)$ nos señalan que, aparte de la diferente distribución geográfica, hay que tener en cuenta el contraste cronológico por lo que se refiere a la localización de los distintos tipos de Lares.

Para ellos es evidente que la introducción del culto a los Lares Augusti en la Hispania romana data del mismo Augusto, según se deduce de la inscripción que se les dedica en Itálica (CIL II 1133); entre el 14 y el 19 se realizó la inscripción de Cartago Nova (CIL Suppl. 5929) y en el 28 la de Adamuz (CIL II 2181). 
En cambio, hay que esperar hasta la época flavia o comienzos de los Antoninos para encontrar las dedicatorias de Lares con epítetos indígenas. Este escalonamiento en el tiempo nos habla de los progresos de la romanización.

La idea que hasta hoy se ha tenido sobre este culto de los Lares es la de que solamente recubre una realidad religiosa claramente céltica. Está claro que los cultos romanos arraigaron de manera más fuerte y profunda en aquellas zonas donde preexistían cultos indígenas lo suficientemente semejantes a ellos como para asimilarlos fácilmente e incluso sustituirlos. Esto sucedió con divinidades de primer orden como es el caso de Júpiter o de Marte, pero tal vez en mayor grado con divinidades de segundo plano que, por su forma de culto más sencilla y por la especialización de su función, estaban más cercanas a estos pequeños dioses locales; éste fue el caso de las Ninfas, Genii, Lares y algunas abstracciones personificadas como Tutela.

Así pues, desde el momento en que los romanos hicieron su aparición en la Península Ibérica, comenzó a producirse un proceso de identificación y sincretismo entre las divinidades indígenas y estas divinidades tan queridas y populares entre los romanos.

TRANOY, ETIENNE, FABRE y LE ROUX (1976, 102-104) distinguen dos niveles diferentes en este proceso sincrético: el primer nivel sería representado por el simple bautismo lingüístico; el segundo nivel está muy cercano al anterior y se produce con gran rapidez, consiste en unir al nombre del dios indígena latinizado el de una divinidad romana, esto es lo que se denomina interpretatio romana, que se habría producido en la época de los Flavios o a comienzos de los Antoninos.

El hecho de que las dedicatorias a los Lares con epíteto indígena y a los Lares Viales se localicen esencialmente al norte del río Duero, mientras que los epígrafes dedicados a los Lares Augusti y a los Lares romanos propiamente dichos se localizan en el resto de la Península, nos indica que se habrían asentado estas divinidades en las regiones más recientemente anexionadas por Roma y que, por tanto, estaban menos romanizadas; en ellas las pervivencias indígenas tuvieron una mayor fuerza.

Por el contrario, en el Sur y en la costa mediterránea las influencias de los distintos conquistadores habían anulado esas expresiones locales, por ello aquí tuvieron acogida los Lares más propiamente romanos.

No podemos establecer una relación sistemática entre las nociones de medio romanizado y cultos clásicos; de la misma manera no existe una equivalencia entre los cultos indígenas y los medios no romanizados o con escasa romanización. La ciudad no jugó un papel repulsivo para las divinidades indígenas.

Ya hemos señalado en páginas anteriores que los emperadores flavios dieron un fortísimo impulso al proceso de romanización en la Península. Cabe preguntarse por qué razón los Flavios que introdujeron en Córdoba el culto imperial a nivel provincial, no aplicaron la misma política respecto al culto de los Lares; ello se debería a que se dieron cuenta de que la situación de la zona Norte de la Península era, en cierta forma, especial.

Conquistada desde hacía poco, esta región seguía ocupada por tribus indígenas, ligadas a su autonomía étnica; los Flavios prefirieron una evolución lenta, permitiendo que la romanización transformara lentamente no sólo la denominación de las divinidades sino, lo que es más importante, la mentalidad de la gente.

$\mathrm{Al}$ respetar las creencia de una población indígena, se canalizaba el impulso religioso hacia la dinastía reinante y se contribuía a la propia obra de romanización. Será pues en el siglo II de nuestra era cuando la gran cantidad de monumentos epigráficos nos atestigua la romanización progresiva de los cultos indígenas.

La interpretatio romana de la que hablamos con anterioridad se vio facilitada por la costumbre de los indígenas de añadir uno o más epítetos al lado del nombre de sus divinidades. Con respecto a este fenómeno tenemos que señalar la teoría de LAMBRINO (LAMBRINO, 1965); este autor señala que si hay interpretatio es, en cierto número de casos, más indígena que romana. 
La divinidad romana llegó a veces a sustituir a la indígena, aunque nada obligó a los autóctonos a renunciar a su vocabulario religioso.

Cuando llegan los romanos a la Península, a finales del siglo III a. C., comienza el proceso sincrético entre las divinidades de los recién llegados y las de los indígenas. Pero este proceso sincrético no es apreciable más que a partir del siglo II d. C., cuando se generaliza el proceso de asociación de las divinidades y después de la sustitución de la divinidad local por la divinidad romana.

Los Lares, juntamente con Júpiter y las Ninfas constituyen puntos de apoyo fundamentales en los que Roma trataba de basar su unificación de la vida religiosa del Noroeste peninsular. La evolución de los cultos en esta región demuestra que se está todavía en una fase intermedia, ya que son dioses como Júpiter los que asumen el papel de cohesión, desempeñado en otras regiones por el culto imperial.

Dentro de este mismo contexto hay que comprender el papel de los Lares Viales que, tras haber absorbido algunas divinidades locales, tienden a ser divinidades auténticamente oficiales con la misma función que los Lares Augusti.

Es probable que esta evolución hubiera conducido ẹn última instancia a un establecimiento más profundo del culto imperial en esta zona, pero el desfase cronológico no permitió esta realización, debido a que este culto iba a tener competencia por parte del cristianismo.

De esta forma vemos que el Noroeste peninsular estuvo abierto como el resto de Hispania a la penetración religiosa de las divinidades aportadas por los conquistadores, las cuales no se encontraron con una oposición sistemática. No hubo ningún tipo de coacción por parte de Roma, sino que este proceso es una consecuencia de los múltiples contactos que se produjeron entre ambos medios: el indígena y el romano, a través de los funcionarios y soldados y por medio de los intercambios comerciales.

Pero esta difusión tuvo sus limitaciones, no sólo por el carácter real del dios invocado bajo un nombre romano, pero que es a menudo una divinidad local, sino también por la distinción creada entre los medios oficiales y el medio indígena. La razón fundamental de esta situación es la fuerza y el dinamismo de los cultos locales.

En la vida religiosa sigue predominando el mantenimiento de las tradiciones locales, a pesar de las nuevas formas adoptadas tanto en la lengua como en los monumentos.

Observamos que las divinidades romanas, después de introducirse en el teónimo junto al dios indígena, terminaron en ciertos casos por sustituirlo. Este proceso sincrético fue el resultado de la penetración lenta y progresiva de la religión romana mediante la integración política y económica del Noroeste.

Este proceso se realizó según el grado de romanización de las distintas regiones; no se puede fijar con exactitud en el tiempo ya que el mantenimiento de los dioses indígenas y su interpretatio son acontecimientos que coexisten y que nos señalan al mismo tiempo los progresos de la romanización y sus limitaciones.

\section{B. LA EVIDENCIA}

Sin duda, tanto por su volumen como por su importante aportación de datos, el tipo de evidencia más significativo es la evidencia epigráfica. Otros tipos de evidencia: la literaria, la arqueológica, etc. son escasísimos en la Hispania romana.

\section{La evidencia epigráfica.}

Hemos sistematizado este material haciendo una serie de subdivisiones atendiendo a un criterio fundamental: la naturaleza de esos Lares, es decir, si llevan un epíteto de tipo indígena o de tipo romano, si no llevan ningún epíteto, etc. 


\section{a) Lares tópicos y gentilicios.}

Los Lares son los dioses clásicos que tuvieron más éxito en el proceso de asociación entre las divinidades indígenas y las romanas. Estos Lares que hemos denominado tópicos y gentilicios constituyen un grupo de dedicatorias a Lares que aparecen acompañados por epítetos de clara raigambre indígena. Es una tarea sumamente difícil separar los Lares tópicos de los gentilicios, pero lo intentaremos (1).

Hay que diferenciar un grupo que presenta un epíteto de carácter gentilicio: la adjetivación de la deidad se relaciona en este caso con la denominación del pueblo o tribu que le rinde culto, tal es el caso de los Lares Turolici y del Lar Pemaneiecus.

Otro grupo nos presenta un epíteto relativo a un oppidum, ciudad o región. El epíteto se refiere así de algún modo al nombre geográfico de un lugar o territorio, bien sean topónimos de procedencia indígena o romana.

Por último hay que indicar la categoría que presenta dos epítetos, pero la presencia de dos adjetivaciones no latinas es poco frecuente.

La división de las tribus galaicas en numerosas colectividades adscritas a sus correspondientes castros favorece en gran modo el nacimiento de dioses protectores de recintos amurallados o de las poblaciones que en ellos vivían o se refugiaban. Cuando las armas romanas o la intensificación de los trabajos agrícolas obligaron a abandonar la protección de los muros de los castros, convirtiéndose la colectividad guerrera en pacífica asociación de señor y colonos no debió quedar en el antiguo habitat otro recuerdo del pasado que el antiguo dios protector.

Los Lares gentilicios, honrados bajo el aspecto individual y quizás más personal o bajo el aspecto colectivo, son la exposición de un culto local de una familia, de un clan o de una comunidad étnica cuyo nombre está contenido en el epíteto que acompaña al nombre del dios.

Las relaciones entre los nombres de los dioses indígenas y los nombres de grupos sociales habían sido ya señaladas por numerosos autores que se preocuparon del mundo de los castros del Noroeste, pero el problema ha sido recientemente renovado por los trabajos de M. LOURDES ALBERTOS (ALBERTOS, 1969; íd., 1975; íd., 1977).

Revisando la lista de las divinidades indígenas de la Península Ibérica, esta autora señala que los términos, nombres o epítetos de estos dioses contienen referencias étnicas y abundan en las regiones donde están ausentes las gentilidades, pero donde se encuentran las centurias. Su razonamiento se apoya esencialmente en los nombres divinos en -aecus, -aegus, -ecus, -egus.

A pesar de estas relaciones, sigue siendo difícil saber con seguridad si el nombre o el epíteto divino se refiere a un grupo social, a una familia o a un lugar preciso.

Los Lares que presentan dos epítetos en -ecus nos aclaran el proceso de asociación entre los dioses romanos y los indígenas. Un gran número de estos últimos tiene un doble nombre en un principio: Bandua Verubrigus, Reva Laraucus, etc. La asimilación se hace esencialmente al nivel del primer nombre que expresa el elemento religioso fundamental, el segundo no hace más que precisarlo en función de un lugar o de un grupo.

Detrás del Genius o del Lar se esconde uno de estos numerosos dioses del panteón indígena, cuyo papel tutelar parece el más frecuente. En algunos casos el nombre indígena ha sido conservado enteramente con la adición de un sufijo en -ecus y el dios

(1) En total los Lares que aparecen con epítetos indígenas son: TRANOY, 1981, 303 y 304 ; CIL II 2469; CIL II 2470; AE, 1973, 320; AE, 1974, 409; AE, 1974, 410; CIL II 2471; CIL II 431; CIL II 2472; ILER 673; CIL II 2531; CIL II 2384; ILER 861; ILER 682; ILER 680. 


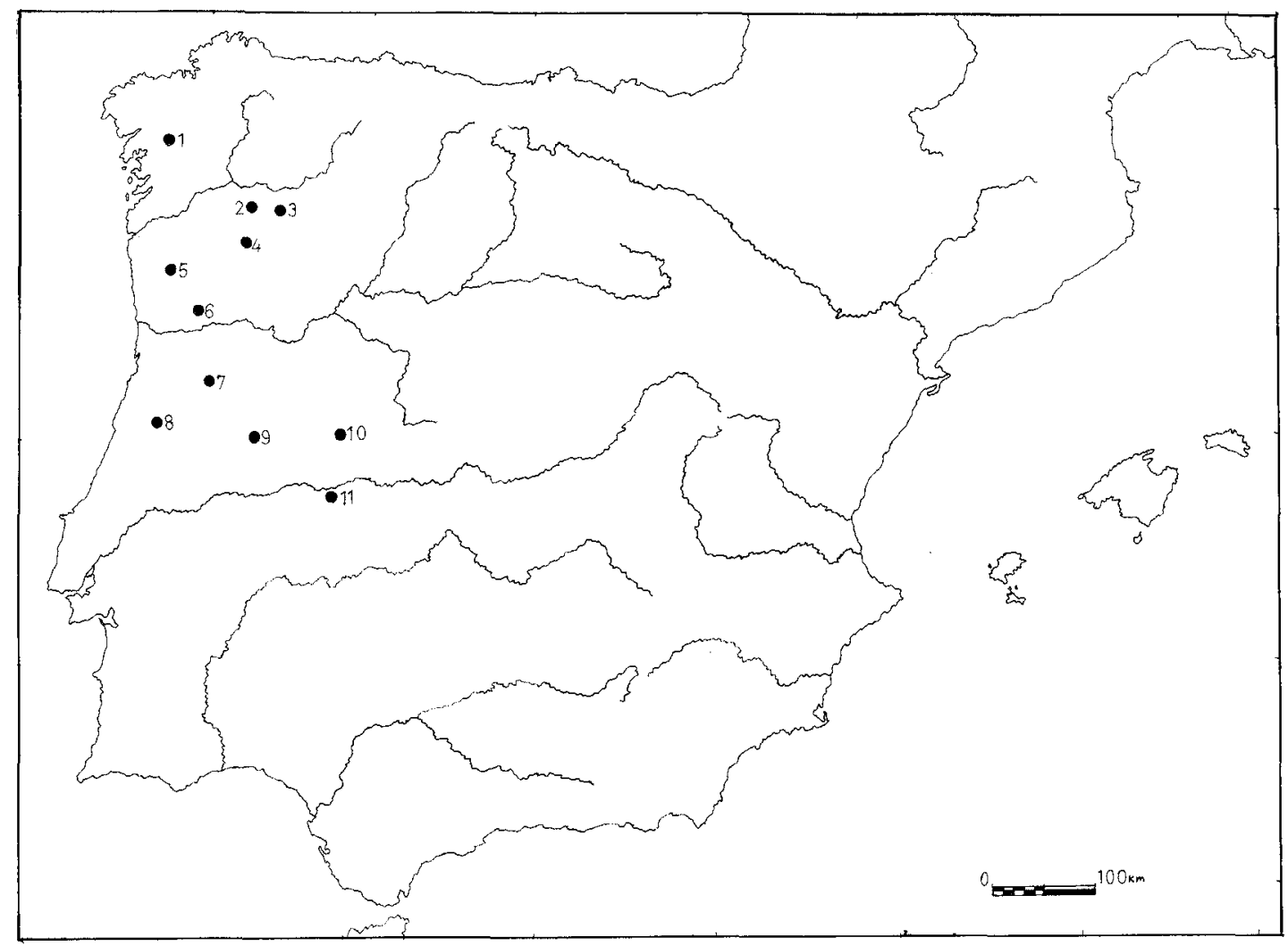

Fig. 1. Localización geográfica de los Lares Tópicos y Gentilicios.

1.--Una dedicación en S. Juan de Baños (Iria).

2.-Una dedicación en San Pedro de Reádegos (Orense).

3.-Una dedicación en Los Gozos (Orense).

4.-Cuatro dedicaciones en Aquae Flaviae (Chaves).

5.-Cuatro dedicaciones en Bracara Augusta (Braga).

6.-Una dedicación en Freixo de Numâo (Portugal).

7.-Una dedicación en Adaufé (Portugal).

8.-Una dedicación en Conimbriga (Coimbra).

9.-Una dedicación en Idanha-a-Velha (Portugal).

10.-Una dedicación en Capera (Oliva, Cáceres).

11.-Una dedicación en Villamiel (Cáceres).

romano se ha colocado en primera posición, antes del nombre indígena: Lar Circeiebaecus Proeneiaecus o Proenetiaegus y Lares Tarmucenbaeci Ceceaeci.

Ya la adopción del simple nombre romano señala el triunfo de una cierta concepción abstracta de lo divino, sin separarla definitivamente del medio indígena.

La multiplicidad de los epítetos locales para una misma divinidad romana, según S. Lambrino, demuestra que las distintas tribus de la región poseían un cierto número de divinidades distintas de nombre y unidas cada una a un rincón de tierra dado, pero muy semejantes en su esencia.

Cuando los Lares vienen de Roma, después del reinado de Augusto o, con más precisión, a comienzos del siglo II, sirvieron para unir a los distintos numina loci del lugar y pudieron a continuación aparecer fácilmente como Lares Viales, sin epítetos indígenas, haciéndose adorar en tierra lusitana como protectores de un territorio dado.

Este proceso debió desarrollarse desde la conquista del Norte de la Península (2919 a. C.); hasta el siglo II d. C. podemos encontrar dedicatorias a los Lares con epíteto 
indígena y a finales del siglo II y, sobre todo, en el siglo III, surgieron numerosas dedicatorias a los Lares Viales.

Del análisis de todo este material concluimos que las dedicaciones a Lares acompañadas de epítetos indígenas son abundantes, pero resulta imposible saber con precisión si estos epítetos se refieren a una familia, a una colectividad o a un lugar geográfico concreto.

La onomástica no resulta en este caso un elemento muy aclaratorio, pues si bien es cierto que algunos dedicantes presentan nombres romanizados pero con filiación indígena, también comprobamos que un número muy similar de estos personajes presenta una onomástica puramente romana.

La distribución geográfica resulta más clarificadora, pues la mayor parte de estos epígrafes se sitúan al norte del río Duero, esto es, en la antigua Gallaecia, y tan sólo cuatro se localizan en el territorio de la Lusitania; pero no encontramos ninguna huella de estos Lares con epítetos de tipo indígena en la Bética, la costa oriental peninsular, ni la zona de Cataluña y el valle bajo del Ebro, que eran las regiones más profunda y tempranamente romanizadas de la Península; esto prueba claramente que este tipo de Lares encubría una realidad religiosa de tipo indígena (fig. 1).

Pero no se puede menospreciar el avance de la romanización en las regiones donde se encuentran estas dedicaciones, ya que si los indígenas identificaron la divinidad romana con la local, es porque conocían los dioses romanos y comprendían las semejanzas existentes entre ambas entidades divinas.

\section{b) Lares augustos y romanos.}

Hemos incluido en este apartado no solamente los Lares Augusti, sino también aquellos Lares que, estén o no acompañados por un epíteto, parecen tener un carácter puramente romano.

Lares Augusti. Hasta ahora ninguna dedicatoria hecha a divinidades ligadas al culto imperial como los Lares Augusti, se ha descubierto en los conventus del Noroeste, contrariamente a lo que sucede en el resto de la Península Ibérica. Los dos únicos ejemplos de Genius Augusti y de Genius Caesaris se refieren solamente a la ciudad de Braga y son de datación incierta.

La rareza de las divinidades augustas y la ausencia de los Lares Augusti en estas zonas hay que ponerlas en relación con la vitalidad de los dioses indígenas en este sector de la Península.

Mientras que en las otras regiones los cultos locales habían ya sufrido transformaciones importantes por los contactos con los diferentes conquistadores que se sucedieron en la Península desde los fenicios y que prepararon el medio indígena para adoptar el culto imperial, el Noroeste conservó su personalidad propia hasta la época augustea; el fenómeno de aculturación y de sincretismo se produjo entonces a un primer nivel, el de las relaciones entre las divinidades indígenas y las divinidades clásicas. En estas condiciones el culto imperial difícilmente podía insertarse en un contexto mal preparado para recibirlo.

El culto imperial propiamente dicho, en su forma más elevada, interesó solamente a las minorías sociales más evolucionadas y que representan los cuadros romanizados de las comunidades políticas.

Merced al culto imperial y al culto de los Lares o del Genius, la sociedad indígena se transformó poco a poco; esta transformación, importante para la romanización de amplias zonas de Lusitania y de la Tarraconense, se puso en movimiento a gran escala con la dinastía flavia.

Existe todavía una oposición social entre un culto organizado en el marco de las comunidades políticas y el culto de los que están excluidos de éstas, jurídica y económicamente. 


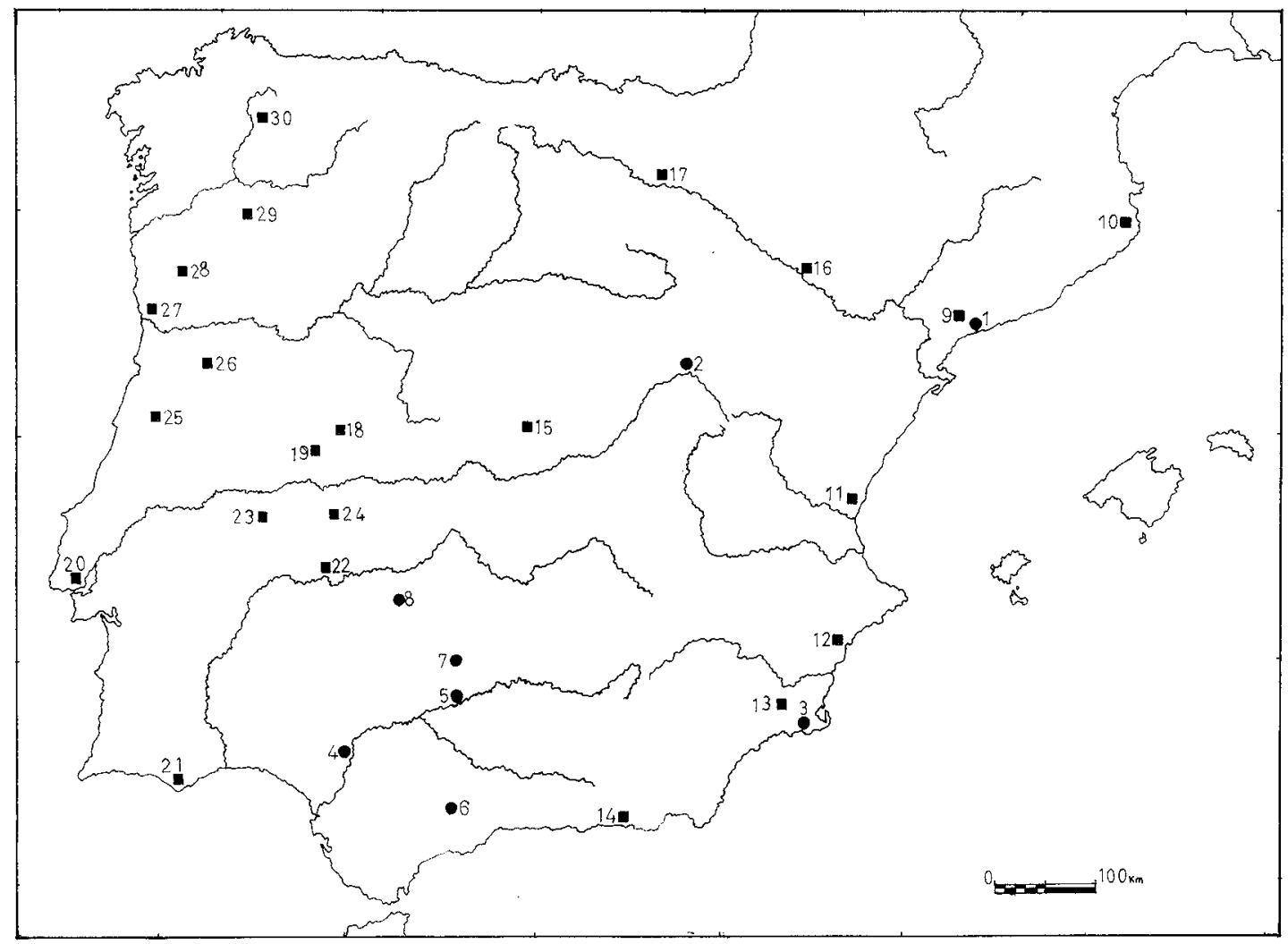

Fig. 2. Localización geográfica de los Lares Romanos y Augustos.

\section{Lares Augustos.}

Lares Romanos.

1.- Ocho dedicaciones en Tarraco (Tarragona)

2.-Una dedicación en Cabeza del Griego.

3.- Una dedicación en Cartago Nova (Cartagena).

4.- -Una dedicación en Italica.

5.- Una dedicación en Corduba (Córdoba).

6.- Una dedicación en Singilia Barba (Málaga).

7.- Una dedicación en Adamuz (Córdoba).

8. - Una dedicación en Esparragosa de la Serena (Badajoz).

9. - Cuatro dedicaciones en Tarraco (Tarragona).

10. - Una dedicación en Ampurias.

11.-Una dedicación en Saguntum (Sagunto).

12.- Una dedicación en Lucentum (Alicante).

13.-Una dedicación en la Sierra de Portman (Cartagena).

14.-Una dedicación en Abdera (Adra).

15.-Una dedicación en Villamanta (Madrid).

16. - Una dedicación en Caesaraugusta (Zaragoza).

17.- Una dedicación en Laguardia (Alava).

18.-Dos dedicaciones en Capera (Oliva, Cáceres).

19.- Una dedicación en Ibahernando (Cáceres).

20. - Una dedicación en Olisipo (Lisboa).

21.-Una dedicación en Ossonoba (Faro, Portugal).

22. - Una dedicación en Emerita Augusta (Mérida).

23. - Dos dedicaciones en Valencia de Alcántara (Cáceres).

24. - Una dedicación en Norba (Cáceres).

25.-Tres dedicaciones en Conimbriga (Coimbra).

26.--Una dedicación en Viseu (Portugal).

27. - Una dedicación en Porto (Portugal).

28.- Una dedicación en Penafiel (Portugal).

29. - Una dedicación en Civitatis Limicorum (Nocelo da Pena)

30.-Una dedicación en Lucus Augusti (Lugo). 
Los fieles de la segunda categoría: esclavos, libertos, seviri y magistri Larum, honran esencialmente a las divinidades augustas. No están, por tanto, alejados del culto imperial y juegan también un papel en el concierto universal.

Este culto de los Lares Augusti es, para ETIENNE, FABRE, LE ROUX y TRANOY $(1976,102-104)$, una transposición de cultos indígenas tópicos, ya que responde a la costumbre ancestral del genio tutelar de la tribu.

Estas divinidades augustas tienen además un carácter doméstico y familiar. En estos dioses que protegen al augusto, los indígenas romanizados encontraron como un eco de sus creencias, antiguas y siempre vivas, en divinidades protectoras del individuo y de la comunidad política y social; así las costumbres de la religión privada son trasladadas también al culto público.

Fundado por Augusto, este culto de los Lares Augusti se benefició de la restauración flavia. Permitió a las clases inferiores, esencialmente a los libertos, expresar su adhesión al soberano. Es digno de mención el hecho de que, a partir de Trajano, los seviri son, al mismo tiempo, magistri Larum augustorum augustales, y que un liberto, L. Flavius Chrysogonus, debe contarse entre ellos.

Lares romanos.-Dentro de este apartado incluimos no sólo las inscripciones que presentan a los Lares sin ningún epíteto, sino también un grupo de Lares que consideramos como romanos debido a los epítetos que lo acompañan o a las divinidades que aparecen junto a ellos en las dedicaciones.

Algunos de los ejemplos de estos Lares romanos son: Lares publici, Lares patrii, Lares Aquites, Lares Marini, Lares Callaeciarum, etc.

ALARCẤ, ETIENNE y FABRE $(1969,213-236)$ nos dicen que es sobre todo en las provincias donde el concepto de Lares o de Penates, en un principio preciso en la mentalidad romana, tomó, acompañado del epíteto patrii, la acepción más amplia, más vaga, de divinidad protectora, y se acercó a conceptos como Genius, Tutela, Fortuna, Numen; este hecho se deriva de la inadecuación del vocabulario romano a los diversos panteones indígenas.

Por lo que se refiere a la onomástica de las dedicaciones a los Lares romanos y a los Lares Augusti, el nombre que llevan algunos de los dedicantes de estos epígrafes, así como el epíteto que califica algunas de las ciudades en las que han aparecido, como Aquae Flaviae, que destaca por el gran número de inscripciones encontradas en ella, no pueden más que reforzar el lazo que existe entre las gentes del Noroeste y la dinastía flavia, pero el lazo es discreto.

En Conimbriga ni el Genius ni los Lares son llamados augustos, sino genio de la ciudad o Lares de la ciudad, mientras que en Itálica se encuentra un magister Larum Augustorum que lo es también del Genius Caesaris Augusti.

Entre los fieles se encuentra una mayoría de ciudadanos de origen humilde: esclavos, libertos; sobre todo, seviri y magistri Larum que no tienen todavía la capacidad jurídica de entrar en los cuadros de la ciudadanía romana y, por tanto, de ocupar un puesto de flamen; pero no están, sin embargo, alejados del culto imperial y juegan su papel en el mismo.

De las diecisiete inscripciones en que se alude a un culto de los Lares augustos, la mayor parte menciona a personajes que ostentan el cargo de Magister Larum; otra de ellas está dedicada por unos decuriones Larum y procede de Tarraco; en otra, procedente de Itálica, se habla de un magister Larum Augustorum que lo es al mismo tiempo del Genius Caesaris Augusti.

Por lo que se refiere a la onomástica propiamente dicha que aparece en estos testimonios, presenta unos nombres claramente romanos, con los tria nomina presentes en la mayor parte de los casos. En algunas ocasiones se especifica que se trata de libertos. Incluso en una inscripción de Tarraco (CIL II 4297) un liberto aparece como magister Larum augustalis. 
De los catorce epígrafes en que se hace alusión al culto de los Lares puramente romanos, se aprecia ya que los casos en que aparecen los tria nomina son muy escasos, siendo lo más frecuente la aparición de un solo nombre: Telesphor.. y Plate, Faustus, etcétera.

Podría pensarse que en la mayor parte de los casos se trata de libertos, de hecho en algunas ocasiones tenemos testimonios totalmente seguros; por ejemplo, en la inscripción de Abdera (CIL II 1980) los dedicantes son Suavis libertus y Faustus vilicus.

Si estudiamos la distribución geográfica de los epígrafes, vemos que el culto de los Lares Augusti floreció en la Tarraconense: nueve inscripciones en total, siete de las cuales son de Tarraco (CIL II 4302; 4304; 4307; 4309; 4293; 4297; AE, 1929, 231); una de Cabeza del Griego (CIL II 3113) y una de Cartago Nova (CIL, Suppl. 5929).

En la Bética hay también una representación importante, con cinco epígrafes en total: en Singilia Barba, Itálica, Corduba, Adamuz y Esparragosa (CIL II 2013; 1133; 2233; 2181; ILER, 597). Para confirmar que excepcionalmente este culto alcanzó la Lusitania, sólo una inscripción lo menciona en Emérita.

El culto de los Lares romanos conoce adeptos dos veces en Capera, una en Olisipo, una en Viseu, una en Ossonoba, una en Valencia de Alcántara y una en Norba (CIL II 816; 817; 174; 404; 5135. ZEPHYRUS, 1967, p. 98, n. ${ }^{\circ} 10 ;$ id., p. 93, n. ${ }^{\circ} 7$ ).

En la Tarraconense tenemos también la mayor densidad de dedicaciones: cuatro en Tarraco, una en Emporiae, una en Sagunto, una en Toledo, una en Lucentum y una en la Sierra de Portmann (CIL II 4082; 4306; 6106; AE, 1900, 118; HAEp. 1574; CIL II 3081; 3563; AE, 1953, 17). En la Bética solamente tenemos una, la de Abdera (CIL II 1980).

El reparto geográfico demuestra que, por lo que respecta al culto de los Lares Augusti, la Tarraconense y la Bética se equilibran, mientras que los testimonios recogidos en Lusitania no representan más que el $10 \%$ del conjunto de las dedicaciones.

De todo este material sacamos la conclusión clara de que el culto a los Lares más propiamente romanos y a los Lares ligados al culto imperial se localiza en las zonas más temprana e intensamente romanizadas de Hispania: la Bética y la zona de la Tarraconense (fig. 2).

En cambio, nos encontramos con que en el resto de la Península no hay huellas de estos cultos, aunque tenemos que en esta región peninsular hay zonas, como Callaecia, en donde el culto a los Lares con epíteto indígena y a los Lares Viales tiene una densidad enorme.

Los nombres de los dedicantes nos demuestran la importancia de los ciudadanos que podríamos llamar "de segunda categoría», los cuales juegan un papel muy importante en el culto de los Lares Augusti; este papel de los esclavos y libertos ya lo hemos resaltado al hablar del culto de los Lares Compitales.

\section{c) Un caso especial: los Lares Viales.}

El culto de los Lares Viales representa, con el de Júpiter, el culto romano que ha sido mejor aceptado por las poblaciones del Noroeste de la Península. La proporción importante de los Lares Viales en esta región española y su concentración en los dos conventus galaicos habían ya atraído la atención de los historiadores.

$\mathrm{Su}$ culto representa para algunos autores como LAMBRINO y BLAZQUEZ (LAMBRINO, 1965, 233-234; BLAZQUEZ, 1970, 63 y ss.), la última evolución de los Lares de las localidades o de la gentilidades.

Estas divinidades están muy escasamente testimoniadas con esta denominación en el resto del Imperio romano; por este motivo, su concentración en la Península Ibérica ha llevado a suponer a la mayoría de los investigadores que esta denominación latina oculta una serie de numina indígenas, que sobrevivieron en época romana e incluso pa- 


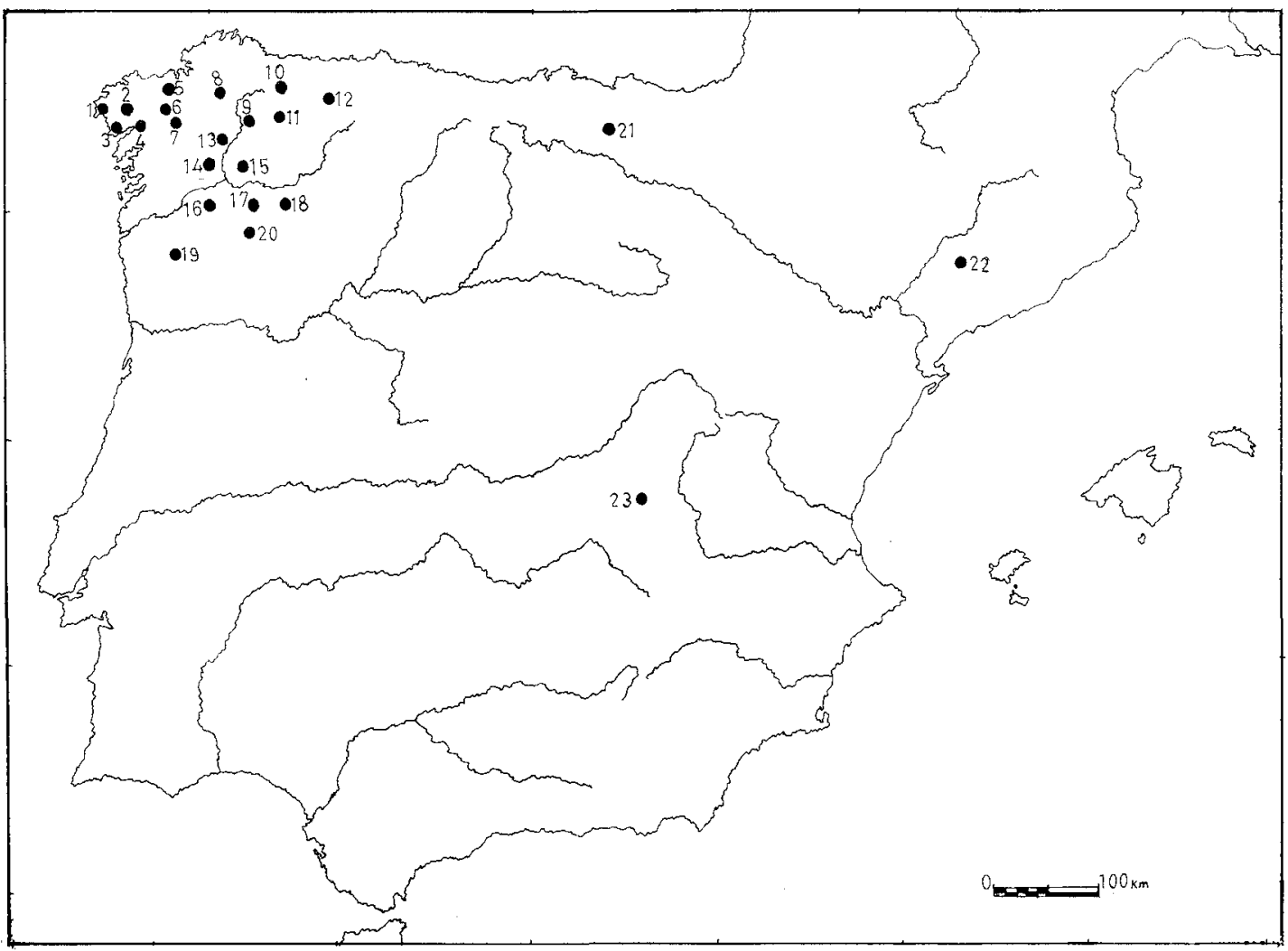

Fig. 3. Localización geográfica de los Lares Viales.

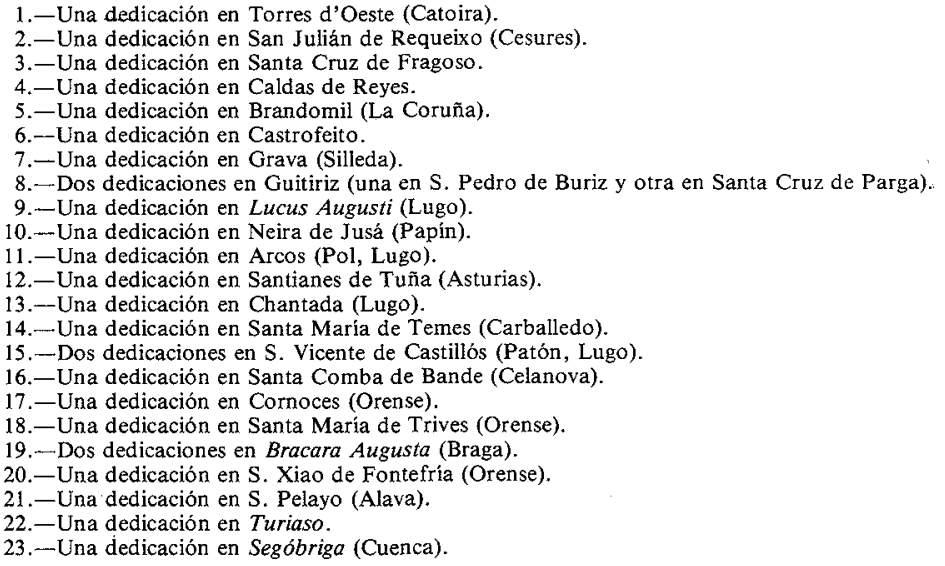

recen tener una presencia clara en épocas posteriores. Esta opinión fue expresada ya por LOPEZ CUEVILLAS y SERPA PINTO $(1934,295$ y ss.).

S. LAMBRINO afirma que los Lares como divinidades latinas llegan de Roma al Noroeste peninsular a comienzos del siglo II, y sirven como medio de unión y de asimilación con los numina loci.

Esto representaría un proceso de sincretismo entre la religión romana y la religión indígena, que se extiende entre el año 19 a. C. y finales del siglo II. Cuando ya se había concluido este proceso, en el siglo III, surgen las dedicaciones a los Lares Viales. 
F. ACUÑA CASTROVIEJO siguió sosteniendo esta misma teoría (1971, 353-357). ALARÇÂO, ETIENNE y FABRE consideran que esta forma romana de los Lares recubre una realidad religiosa y céltica, cuyo carácter bárbaro desaparece recubierto por la denominación romana. Para estos autores, por medio del culto de los Lares se pasa de una sociedad céltica a otra céltico-romana; este culto no sería más que una etapa hacia una romanización total y hacia una transformación de la mentalidad indígena.

Hay una serie de matices de tipo regional en el culto a los Lares Viales que se pueden deducir por medio de su localización geográfica. En el conventus de Braga este culto tiene una representación bastante débil: cinco altares y una inscripción en una de las caras de un cipo (CIL II 2518; AE 1973, 310; BOL. AUR. II, 1972, 309-311; CIL II 2417; IRG IV 93). En cambio, los Lares con epíteto indígenas son más numerosos.

En el conventus de Lugo el fenómeno es totalmente diferente. Aquí el culto a los Lares Viales es prácticamente idéntico en número de dedicaciones al de Júpiter, pues tenemos diecisiete altares (BOL. AUR. IX, 1979, 311-315; IRG II 9; IRG III 25; IRG III 26; A. TRANOY, 1981, 217; IRG II 8; HAEp. 1-3, 308; IRG III 23; IRPL 63; IRG II 10; IRPL 65; íd., 66; IRG III 22; CIL Suppl. 5634; IRG III 24; IRPL 64; CIL II 2572). Sin embargo están ausentes las divinidades romano-indígenas, como son los Lares con epíteto local.

En este conventus los cultos indígenas eran menos fuertes y los Lares Viales cubren a los dioses locales sin pasar por el estado intermedio de las divinidades con un tipo de denominación mixta. En estas condiciones, el papel de unificación que podía realizar Júpiter le es disputado por los Lares Viales, cuyo carácter más personal fue mejor asimilado por los Callaeci Lucenses.

Por el contrario, el dinamismo de los cultos indígenas fue un obstáculo para el éxito total de los Lares Viales entre los Callaeci Braccari, donde paradójicamente la difusión más rápida de las influencias romanas permitía el establecimiento de Júpiter que tenía suficiente fuerza para imponerse a los cultos locales.

Así, la penetración de las influencias romanas favorecía a la vez a la manifestación más clara de los cultos indígenas por la adopción de los tipos de monumentos romanos y de la lengua latina.

El culto de los Lares Viales, como el de Júpiter, ilustra la voluntad de Roma de mantener en torno a estos dioses la cohesión religiosa de los múltiples pueblos de Galicia. La dispersión de las dedicaciones es también el reflejo de la penetración bastante amplia de Roma en el interior del país.

En el conventus Asturum la actitud fue también diferente. El desarrollo de los servicios administrativos, del ejército y de las zonas mineras dio más importancia a ciertos sectores geográficos, sobre los cuales se concentraron los esfuerzos de poder. Este hecho condujo a la polarización de los testimonios culturales en estas regiones, apareciendo las zonas rurales a menudo descuidadas, en especial las zonas montañosas.

El resultado de este fenómeno es la débil proporctón de los cultos indígenas y la rareza de los Lares Viales, representándolos solamente por dos epígrafes (IRG IV 101; CIL Suppl. 5734).

Así observamos que cada conventus reaccionó a su manera ante este culto en función del proceso y del grado de penetración de las influencias romanas. En la Península Ibérica solamente hay tres inscripciones dedicadas a los Lares Viales que se localicen fuera de la región Noroeste: una en Segóbriga, otra en Turiaso y una última en Alava (AE 1903 185; CIL II 2987; ELORZA, 1972) (fig. 3).

Es aún más significativo en el estudio de esta distribución geográfica el hecho de que sólo existan cinco inscripciones dedicadas a los Lares Viales en todo el Imperio romano: una en la Dacia, en Sarmizegetusa; una en Mauritania, en Portus Magnus; una en la Galia, en Narbo, y dos en Italia, una en Falerii y otra en Roma (CIL III 1422; CIL VIII 9755; CIL XII 4320; CIL XI 3079; CIL VI 36812). 
Como se puede observar, los testimonios de culto a los Lares Viales resultan abrumadores en la Península Ibérica con respecto al resto del mundo romano.

A. TRANOY $(1981,322-324)$ señala que la distribución geográfica de este culto es significativa, ya que los Lares Viales están en relación estrecha y lógica con la red viaria del Noroeste, aunque, según este autor, el hecho de que no aparezca este tipo de dedicaciones en el resto de la red viaria peninsular demuestra que no estaba únicamente ligado a las vías.

La red viaria sirvió solamente como infraestructura a la difusión de la romanización que, en el plano religioso, se cristaliza en torno a los Lares Viales, transmitidos a través de los grandes ejes de circulación y utilizados como elemento de reagrupación de las fuerzas religiosas locales de estas regiones recientemente conquistadas.

Son quizás estas fuerzas múltiples las que se expresan en los altares de varios foci, característicos del Noroeste; en la mayoría de los casos este tipo de altares se ofrece a los Lares Viales y suelen provenir del conventus de Lugo: Arcos, Castrofeito, Parga, San Pedro de Buriz, San Vicente de Castillones (IRG II 9; TRANOY, 1981, 217; IRPL 66; íd., 65; IRPL 63; íd., 64).

Este culto, junto con el de Júpiter, representa una etapa de la asimilación y del sincretismo entre las religiones locales y la religión romana. $\mathrm{Si}$, en este aspecto, un dios como Mercurio no tuvo en Galicia y en Asturias más que un papel modesto, en cambio, Júpiter, los Lares y las Ninfas constituyen las divinidades fundamentalmente sobre las que Roma pudo apoyarse para tratar de unificar la vida religiosa del Noroeste peninsular.

La administración y el ejército fueron agentes de propagación de estos cultos, siguiendo los grandes ejes de comunicación y gracias a las dedicaciones oficiales.

La evolución de los cultos en Asturias y Galicia muestra que se está todavía en una fase intermedia en que son los dioses como Júpiter los que asumen el papel de cohesión que tiene en otras regiones el culto imperial.

En este mismo espíritu hay que situar a los Lares Viales que, después de haber absorbido a divinidades locales, tienden a ser verdaderas divinidades oficiales, comparables a los Lares Augusti. Es probable que esta evolución hubiera llevado a un establecimiento más profundo del culto imperial en estas regiones, pero el desfase cronológico no permitió la realización de este proceso, ya que este culto se vio enfrentado con el cristianismo.

Como nos sugieren LOPEZ CUEVILLAS y DE SERPA PINTO $(1934,295$ y ss.) el acentuado localismo de las invocaciones a estos espíritus protectores de las vías hace sospechar fundadamente que bajo ellos yacía un numen o un grupo de númenes galaicos asimilados o suplantados completamente por dichos Lares.

De la supervivencia de su culto tenemos un testimonio evidente en un texto de San Martín Dumiense (S. MARTIN DUMIENSE, De correctione rusticorum, XVI, 4-5) que recomienda que no se enciendan luces en las encrucijadas, trivia, aludiendo de esta manera al culto que se tributaba a los Lares en los cruces de caminos.

Como vestigios más modernos de la supervivencia de este culto algunos autores consideran los cruceros y los amilladoiros, que son grupos de piedras erigidos por romeros y caminantes.

Es un hecho cierto que, de la misma manera que no hay otra región de la Península más rica en invocaciones a los Lares Viales que el Noroeste, no hay tampoco ninguna zona que cuente con tantos cruceros. Hay que destacar que su área de mayor densidad se encuentra en los territorios de los antiguos conventus Bracaraugustanus y Lucensis, es decir, en el área de mayor densidad de las dedicaciones a los Lares Viales.

Para López Cuevillas y Serpa Pinto la falta de continuidad entre los cruceros y las lápidas erigidas para honrar a los Lares puede muy bien deberse a la fuerza destructora del tiempo. 
En las obras que hemos consultado sobre la Galia, Britania, etc., no encontramos referencias a este culto de los Lares Viales. En ellas se nos habla sobre todo del culto doméstico, pero no de los dioses protectores de los caminos.

Autores como ALARCÂO, ETTIENNE y FABRE (1969, 213 y ss.), así como LOPEZ CUEVILLAS y SERPA PINTO $(1934,297)$, aseguran que la forma romana del nombre de los Lares recubre una realidad religiosa céltica.

No podemos negar de forma absoluta esta afirmación, pero resulta sorprendente el hecho de que no se encuentren dedicaciones a esta advocación de los Lares en territorios claramente célticos como la Galia o Britania.

Se ha dicho que el culto de los Lares Viales presentaría un paralelo evidente con el culto de las Matres galas, cuando son invocadas con los epítetos de biviae, triviae, quadriviae, pero no hemos encontrado este testimonio en ninguna de las obras consultadas; en todas ellas se alude a las Matres como diosas relacionadas más bien con la fecundidad, una especie de Diosas Madres. En alguna ocasión encontramos Matres invocadas bajo los epítetos anteriormente mencionados, pero se trata de ejemplos aislados que no nos permiten sacar conclusiones claras ni establecer paralelos.

Por otra parte, hay que señalar que J. C. BERMEJO BARRERA, en su estudio sobre los dioses de los caminos (1978, 77-177), analiza detenidamente las semejanzas de los Lares Viales galaicos con otras divinidades de tipo céltico como el Mercurio galo, Lug, Bran, etc., y llega a la conclusión de que ninguna de estas divinidades es el modelo de los Lares Viales galaicos, sino que éstos presentan mayor número de semejanzas con el Hermes griego.

Nos parece significativo el hecho de que este autor no encuentre similitudes entre otros Lares galaicos y los dioses célticos de los caminos.

Esto no quiere decir que no aceptemos que este culto de los Lares Viales representa una fusión clara entre la religión romana y los númenes indígenas; simplemente nos ha llamado la atención esta falta de coincidencia entre los Lares galaicos y los dioses de la Galia o de Britania, ya que muchos autores han supuesto que bajo la denominación de Lares se esconde una realidad religiosa céltica.

Habría que considerar la posibilidad de que se trate simplemente de divinidades precélticas, puesto que su carácter indígena parece indudable.

LAMBRINO $(1965,233-234)$ señala que no se puede decir que las dedicaciones a los Lares Viales no son de la misma esencia que las de los Lares tópicos y gentilicios, pretextando que los primeros representan el culto imperial que asociaba a los Lares de las encrucijadas con el Genius Augusti desde el año 7 a. C.

Si esto fuera así, como monumentos del culto al emperador no se habrían confinado en el territorio del Noroeste peninsular, el más recientemente conquistado y el menos romanizado, sino que se habrían extendido con profusión por el resto de la Península, más profundamente romanizada, pero esto no sucede así.

\section{Otros tipos de evidencia.}

Hemos reunido en un solo epígrafe los restantes tipos de material que, sobre el culto a los Lares, poseemos en la Península, porque estas muestras son muy reducidas.

Por lo que se refiere a la estatuaria, vemos que los Lares son siempre representados como figuras juveniles. Lo más corriente es que las estatuillas sean de bronce.

Se distinguen tradicionalmente dos tipos en la iconografía de los Lares: uno, que nos presenta al Lar en reposo, con un pátera en la mano derecha y una cornucopia en la izquierda, siempre con chiton y manto; algunos autores como WISSOWA han relacionado este tipo iconográfico con el Lar familiaris; el otro tipo presenta a los Lares no en reposo, sino con un movimiento suave y armonioso, que recuerda una danza; derraman el líquido de un rhyton que elevan con la mano derecha en una pátera o sítula 
que sostienen con la izquierda; a menudo visten sólo chiton; este tipo de representación se relaciona con los Lares Compitales.

Tenemos gran abudancia de estatuillas que representan Lares en la Península Ibérica, pero la mayor parte pertenecieron a colecciones privadas y por ello es muy difícil conocer su lugar de procedencia con exactitud, aunque la mayoría parecen ser importaciones itálicas.

Conocemos tan sólo cinco estatuillas que procedan con seguridad de la Península Ibérica y las vamos a estudiar a continuación (fig. 4).

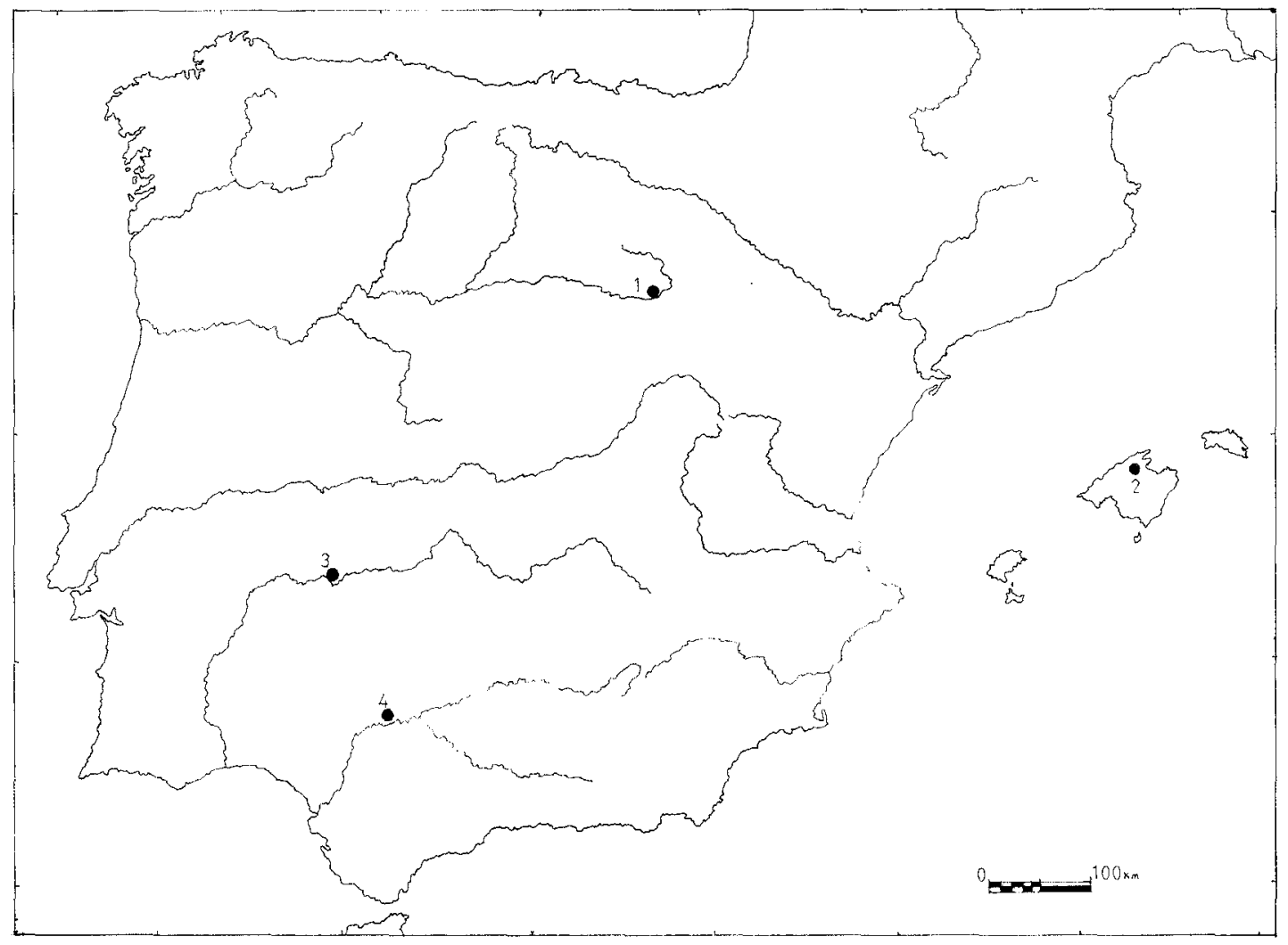

Fig. 4. Localización de las estatuillas de Lares.

1.-Almazán (Soria).

2.--Pollentia (Pollensa). Dos estatuillas.

3.-Emerita Augusta (Mérida).

4.-Lora del Río.

La primera de ellas se encuentra en el Museo Arqueológico Nacional y es el conocido Lar de Lora del Río (Sevilla) (fig. 5). Descripciones de esta figurilla se encuentran en varias publicaciones (THOUVENOT, 1927, 50-52; DEL RIVERO, 1927, 28-29), pero nos basaremos en la descripción que de ella nos hace GARCIA Y BELLIDO $\left(1949,104, \mathrm{n}^{\circ}{ }^{98}\right)$.

Se trata de un bronce de pátina verdosa y concreciones terrosas, fundido en hueco. Presenta una altura de $22 \mathrm{cms}$. Es una obra de buena factura, una de las más bellas representaciones de estas divinidades que tenemos en la Península. Su cabeza va ceñida con una diadema de palmetas, atada por detrás con unas cintas cuyos largos cabos cuelgan por ambos lados hasta tocar los hombros. En la mano izquierda lleva un cuerno de 


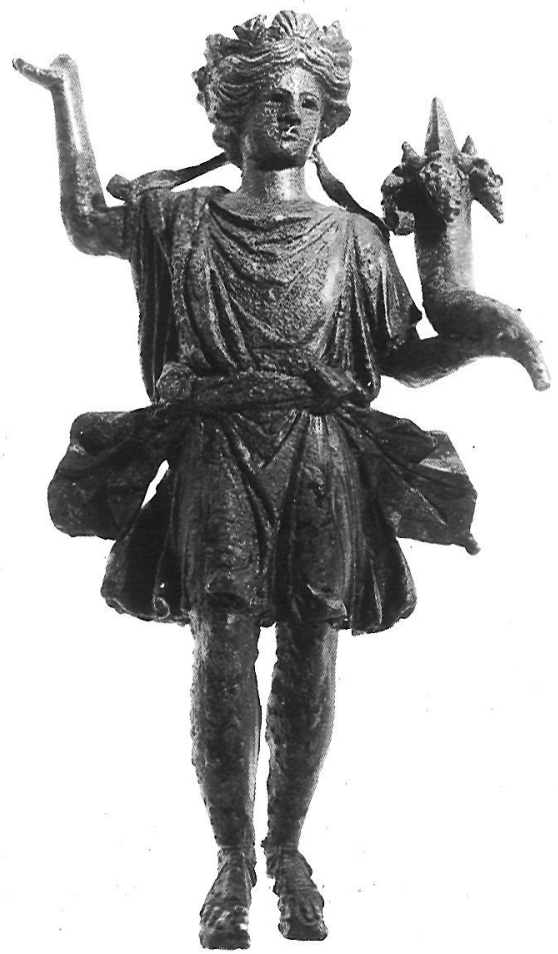

Fig. 5. Lar. Bronce. Procedente de Lora del Río. (Foto Museo Arqueológico Nacional).

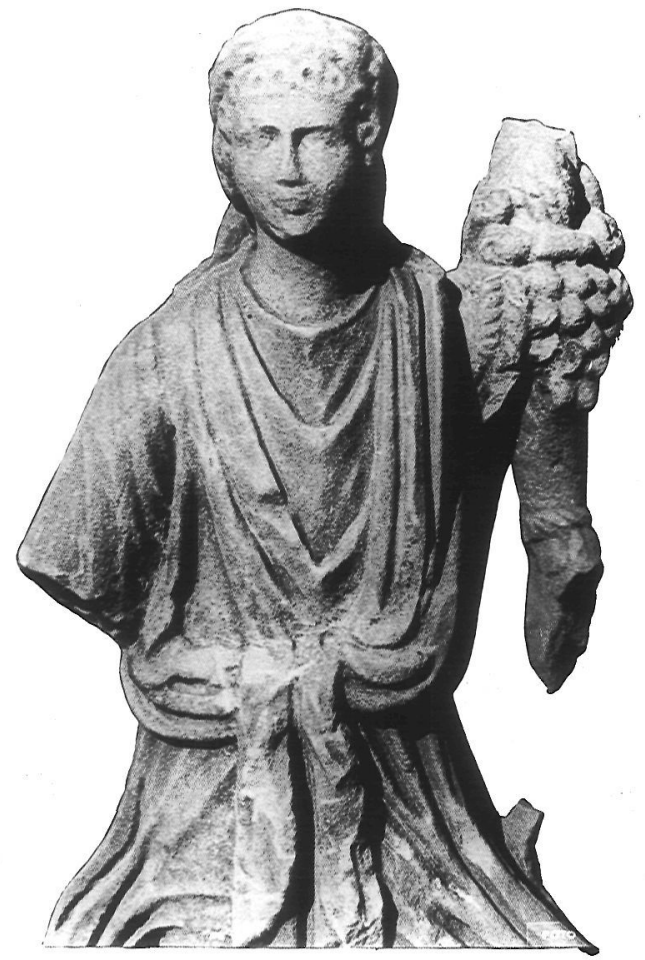

Fig. 6.-Lar. Mármol blanco. Procedente de Mérida. Museo Arqueológico Provincial de Badajoz.

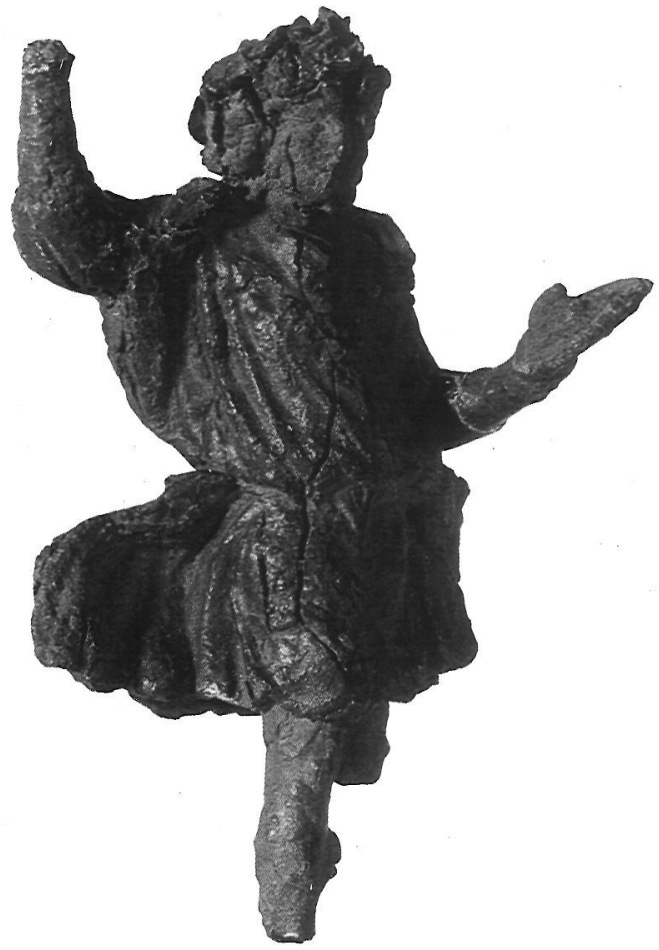

Fig. 7.-Lar. Bronce. Procedente de Pollentia. (Foto Museo Arqueológico Nacional). 


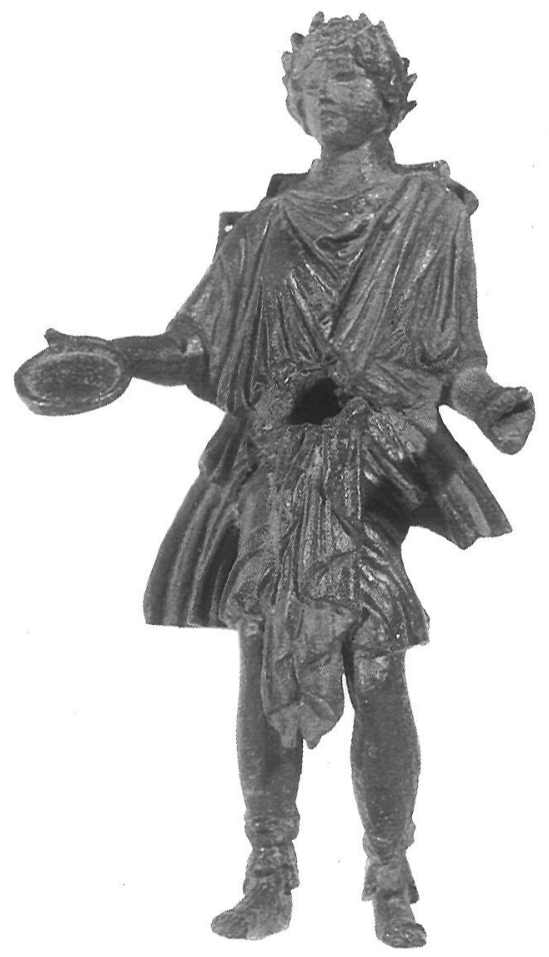

Fig. 8.-Lar. Bronce. Procedente de Pollentia. (Foto Museo Arqueológico Nacional).

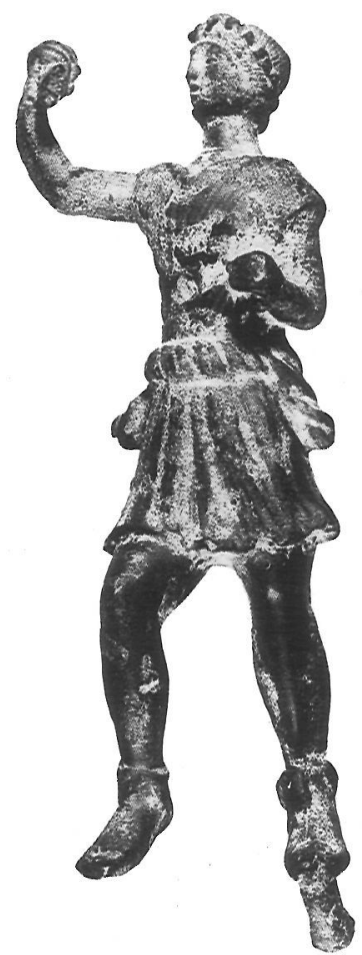

Fig. 9.-Lar. Bronce. Procedente de un campamento militar de Almazán (Soria). (Foto Museo Arqueológico Nacional).

la abundancia. En la derecha, levantada, tal vez llevase el acostumbrado rhyton, aunque no se ve huella del mismo.

Viste un corto chiton o túnica con abundantes pliegues y, sobre él, un manto que, tras cruzar el pecho y el hombro derecho se anuda a la cintura, para dejar colgando al aire sus dos cabos, de la forma que es característica en las representaciones de los Lares. Presenta un ligero movimiento, avanzando un poco la pierna derecha. Los ojos, ahora huecos, debieron llevar piedras incrustadas. Los pies calzan sandalias.

No tenemos ningún otro ejemplar que se adapte precisamente a este modelo, especialmente por lo que se refiere al brazo derecho levantado, pues la otra representación de Lar con cornucopia que conocemos tiene este brazo bajo y no levantado.

La siguiente pieza que vamos a analizar es la que se encuentra en el Museo Arqueológico Provincial de Badajoz (fig. 6). Ha sido también publicada en varias ocasiones, pero nos atendremos a la publicación más reciente, la de ALVAREZ MARTINEZ $(1975,869-872)$.

Esta figura es algo diferente de las demás no sólo por su mayor tamaño, sino también por el material en que está realizada, ya que es de mármol blanco de pátina amarillenta, procedente probablemente de las canteras de Borba-Estremoz, en Portugal. Fue hallada en las inmediaciones de Mérida. La figura sin el plinto, que tiene una elevación de 7 centímetros, alcanza una altura de 0,96 metros.

Falta todo el antebrazo derecho, que era una pieza aparte que se ajustaba en el brazo, lo cual es un elemento curioso. También falta la mano izquierda. Se trata, como siempre, de un adolescente en pie, en actitud serena y reposada, aunque sus piernas y los pliegues de la túnica denotan un leve movimiento. 
Todo el cuerpo se apoya en el tronco de un árbol colocado junto a la pierna derecha. Viste túnica corta con mangas y manto. Calza unas botas altas, sujetas con correas que dejan libres las puntas de los pies, con adorno de carátulas a la altura de los tobillos (endromides).

La escultura está bien trabajada, aunque algo más esquemática en su parte posterior. Por lo que se refiere a la cronología de la escultura José María Alvarez cree que hay una particularidad que puede dar una pista sobre su fecha de realización: el peinado. Este es muy parecido al que vemos en las efigies de Agripina, caracterizado por rizos en forma de caracolillos que rodean la frente y que se resuelven por detrás en un moño, a la altura de la nuca. Esto permitiría fechar esta estatua hacia la mitad del siglo I d. C.

Otras dos estatuillas que representan Lares proceden de Pollentia y se encuentran en el Museo Arqueológico Nacional.

La primera de ellas (fig. 7), en muy mal estado de conservación, presenta todas las características típicas de las representaciones de estas divinidades: túnica corta, manto enrollado en torno a la cintura de forma característica, cabeza ceñida por una diadema. Faltan las piernas. La mano izquierda sostiene la pátera y la derecha, que se ha perdido, levantaría el rhyton sobre la cabeza.

La otra representación procedente de Pollentia (fig. 8) presenta las mismas características, pero su estado de conservación es mucho mejor. La figura además aparece en una actitud mucho más reposada que la anterior. La mano izquierda ha desaparecido. Hay que resaltar que la pátera la lleva en la mano derecha y no en la izquierda como es usual; además ninguno de sus brazos está levantado en actitud de derramar el líquido; no sabemos lo que llevaría en la mano izquierda, ya que ha desaparecido.

Por último tenemos una estatuilla procedente de un campamento militar en Almazán (Soria) (fig. 9); parece que se puede fechar en los siglos I-II aproximadamente. Es una representación que, a primera vista, parece muy distinta de las otras por su ejecución; su movimiento es más brusco, pero parece tener todos los atributos de un Lar; la túnica corta, el manto enrollado en la cintura de forma característica, la cabeza ceñida por la diadema, aunque sin ínfulas; el brazo derecho está levantado, pero tanto la pátera como el rhyton han desaparecido.

No tenemos noticia deøque las estatuillas de Pollentia y la de Almazán hayan sido publicadas.

Hay que hacer una diferenciación en estas representaciones; el Lar de Lora del Río y el del Museo de Badajoz parecen responder al tipo iconográfico que se relaciona con el Lar familiaris, en actitud más reposada y con la cornucopia en la mano izquierda, aunque el de Lora del Río presenta la particularidad de tener levantado el brazo derecho.

El primero de los Lares de Pollentia que hemos descrito, el peor conservado, y el de Almazán, se identifican más con el tipo de representación del Lar compitalis, con un mayor movimiento, la pátera en la mano izquierda y el rhyton en la derecha que se eleva sobre su cabeza.

La segunda de las estatuillas de Pollentia parece responder también al tipo de Lar familiaris, como parece indicar su actitud reposada y el hecho de no llevar el rhyton en actitud de derramar el vino, pero no podemos asegurarlo, ya que falta el objeto que llevaba en su mano izquierda, que pudo haber sido una cornucopia.

Hay que resaltar que ninguna de las estatuillas que hemos mencionado se localiza en Galicia, sino que proceden una de Sevilla, una de Soria, una de Badajoz y dos de Mallorca.

Por lo que se refiere a los restos arquitectónicos, en la Península Ibérica es muy difícil encontrar lararia, debido a que de las construcciones romanas habitualmente nos restan solamente los cimientos y los lararia se situaban en la mitad de la pared. Nos han proporcionado noticias de un posible lararium en las proximidades de Itálica, pero es un extremo que no hemos podido comprobar. 
En un Catálogo del Museo Arqueológico de Tarragona, una publicación muy antigua de 1894, encontramos la noticia de la existencia de un altar de mármol blanco que parecía proceder de un templo a los Lares, Tutela y el Genio (CIL II 4082).

ALMAGRO $(1966,35)$ nos habla de lo que parece una evidencia importante del culto doméstico, la presencia en el jardín de una casa romana de un altar cubierto con estuco y pintado a la manera de los lararia. Dos serpientes flanquean un altar encendido sobre este templo en forma de herma.

El profesor Almagro cree que esto significa un culto cthónico de los muertos y que se trata de hecho de una herma. Pero la similitud de las serpientes y la decoración, junto con su colocación en el jardín, un lugar común en Campania para un templo, señalan su papel de vigilancia y protección más que su relación con el ritual mortuorio.

Por lo que se refiere a la evidencia literaria, carecemos de noticias directas sobre el culto de los Lares. Sólo hay un texto de ESTRABON (III, 3, 7), en que nos informa de que a los enfermos los sacaban a los caminos para que los viandantes los observaran y si habían tenido una enfermed parecida, les dieran el remedio, lo cual puede aludir a la sacralidad de los caminos y encrucijadas; pero la referencia es tan mínima que es imposible obtener una información de cierta significación a partir de la misma.

\section{Algunas notas sobre los colegios religiosos relacionados con el culto a los Lares.}

Los colegios religiosos romanos podían ser oficiales o semioficiales y privados; los primeros, encargados del culto público por el Estado, no nos interesan aquí. Los colegios religiosos privados son aquellos que, libremente, rinden culto a una divinidad por ellos escogida. Estos colegios existen desde época republicana y proliferaron mucho.

También se consideran colegios religiosos privados los formados por grupos que honran a los emperadores vivos o muertos, o a los Lares de una ciudad o de una persona importante, y están formados generalmente por gente humilde, fundamentalmente libertos y esclavos.

Las medidas restrictivas adoptadas por el Senado romano durante la época republicana en materia asociativa, excepto algunas restricciones de carácter particular, al parecer, solamente afectaron a Roma. Este estado de cosas, con mayor razón, se mantuvo en las provincias, donde las asociaciones no constituían peligro político alguno.

La situación de libertad asociativa en provincias cambió con la Lex Iulia de collegiis, que disolvió todos los colegios, salvo los tradicionales y legítimos. Desde este momento, todo colegio necesitaba una autorización estatal para constituirse. La aplicación de esta Ley en Roma se hizo inmediata, y después se extendió gradualmente a Italia y a las provincias.

Un tipo muy peculiar de colegios religiosos es el de los cultores Larum. Ya desde época republicana había asociaciones cuya finalidad era rendir culto a los Lares en unas aediculae que se colocaban en los cruces de las vías. WALTZING $(1968 ; 99)$ cree que estos colegios son exclusivamente funerarios, pero tienen también una finalidad cultural.

Estaban formados generalmente por esclavos y libertos que podían pertenecer a una familia o ser públicos. En el primer caso, se trata de colegios domésticos, y su finalidad es honrar a los Lares de esa familia. En el segundo se trata de familias públicas de esclavos y libertos que honran a los Lares públicos.

En Portugal, en Olisipo, hay un ejemplo de este tipo de colegios domésticos (CIL II 174): los cultores Larum Maliae Malioli, que hacen una dedicación a Esculapio Augusto. Este tipo de cultores Larum domésticos es muy frecuente en la epigrafía romana.

En Abdera, el liberto Suavis y el esclavo Faustus hacen una dedicación (CIL II 1980), a mediados del siglo I, a los Lares y al Genio. Las iniciales CCN son interpreta- 
das por Hübner como C(ultorum) C(ollegii) N... (nombre de una divinidad que se supone sería Némesis). M. Vigil indica que probablemente se trata de un colegio constituido en un fundo de un particular, con su vilicus (Faustus). La inscripción estaría dedicada a los Lares del propietario y al genio del fundo, y seguramente el nombre N... es el del propietario del mismo.

Un caso parecido de un colegio doméstico aparece en Ampurias, donde los cultores Larum de M. Cornelius Saturninus, edil, duumvir y flamen, le hacen una dedicación.

Hay también en Hispania colegios de cultores Larum publicorum: en Capera (CIL II 816; CIL II 817), los cultores Larum publicorum hacen una dedicación a su colega, el liberto Peculiaris, y otra a un desconocido, Albini filio, a su muerte; en Balsa (CIL II 4989) aparece una lista de amici curatores Larum.

El que estos cultores Larum publicorum deben considerarse como colegios está claro en la primera dedicación de Capera (CIL II 816), en que se emplea el término collega aplicado a uno de sus miembros. Su carácter funerario parece evidente en la segunda dedicación de Capera a un desconocido (CIL II 817), que es una lápida funeraria. Y, por último, su carácter religioso se muestra en la dedicación de Abdera a los Lares y al Genio cum aedicula (CIL II 1980).

Aparte de aquellas asociaciones cuya finalidad es exclusivamente religiosa, hay que señalar que todos los colegios romanos, del tipo que sean, a pesar de que su objetivo principal sea de otra clase, tienen siempre un carácter religioso, pues sus miembros se unen bajo la advocación de una divinidad.

Una inscripción hispana de interés en este sentido procede de Cartago Nova (CIL Suppl. 5929); en ella los piscatores et propolae de la ciudad hacen una dedicación, de pecunia sua, a los Lares Augustales et Mercurium.

No es demasiado abundante la epigrafía hispana que contiene datos sobre las divinidades adoradas por los colegios. Esto se debe a varias causas: primero, muchas inscripciones están incompletas, otras aluden a los colegios de forma indirecta, y otras son dedicaciones a emperadores, a patronos o personajes destacados, el resto son funerarias.

Hay que suponer que los colegios religiosos hispanos tendrían la misma organización que los del resto del Imperio, muy bien expuesta por WALTZING.

Los colegios formados por esclavos y libertos de familias ricas son los que se denominan cultores Larum y tienen un marcado carácter religioso, ya que adoran a los Lares de una familia, cuando se trata de colegios domésticos, o a los Lares públicos, si se trata de familias públicas.

Ya hemos hecho alusión a los ejemplos de cultores Larum domésticos en Olisipo y Ampurias, y cultores Larum publicorum: las dos inscripciones de Capera y de Balsa (CIL II 816; CIL II 817; CIL II 4989).

En ocasiones en estos colegios mixtos de esclavos y libertos aparecen también algunos ciudadanos libres. Este es el caso de la inscripción de Tavira (Balsa, en Lusitania) dedicada por unos amici curatores Larum que eran personajes libres. Hay que señalar la dedicación hecha por unos decuriones Larum que aparece en Tarraco (DRIT 166).

Tenemos que consignar aquí el gran número de inscripciones aparecidas en la $\mathrm{Pe}$ nínsula Ibérica en que se alude a un magister Larum, que en la mayor parte de los casos es, al mismo tiempo, sevir augustalis. El número de estas inscripciones en que aparece mencionado un magister Larum es de diecisiete (no incluimos las inscripciones ya mencionadas que aluden a colegios).

Cinco de estos epígrafes proceden de la Bética: Corduba, Singilia Barba, Adamuz, Esparragosa de la Serna e Itálica (CIL II 2233; CIL II 2013; CIL II 2181; ILER 597; CIL II 1133); esta última es digna de una mención aparte, se trata de una lápida funeraria en memoria de $C$. Marcius Apilus, que fue al mismo tiempo magister Larum Augustorum y magister Genii Caesaris Augusti. 
Dos de las inscripciones proceden de Lucentum (Alicante) y de Cabeza del Griego (CIL II 3563; CIL II 3113). Los otros diez testimonios proceden de Tarraco o de lugares muy próximos a esta ciudad (CIL II 4293; CIL II 4297; CIL II 4304; CIL II 4306; CIL II 4082; CIL Suppl. 6106; DRIT 166; DRIT 429; DRIT 408; DRIT 425).

Este culto de los Lares Augusti, fundado por Augusto, se benefició de la restauración flavia. Permitió a las clases inferiores, esencialmente a los libertos, expresar su adhesión al soberano; es digno de mención el hecho de que, a partir de Trajano, los seviri son al mismo tiempo magistri Larum Augustorum, y que un liberto, L. Flavius Chrysogonus se cuenta entre ellos.

Por lo que se refiere al estudio de la onomástica de todos estos epígrafes, ésta parece indicar en la mayor parte de los casos una romanización muy profunda en los nombres de los dedicantes, que en su mayoría presentan los tria nomina latinos. En ciertos casos los dedicantes son libertos, ya hemos señalado que incluso uno de ellos era magistri Larum.

La preocupación fundamental de los emperadores, ya desde Augusto, fue no alejar a ninguna clase social de la religión oficial. Los colegios de los seviri augustales y los magistri Larum permiten resolver un problema importante: la integración en el culto imperial de los grupos que en la ciudad no gozan de todos los privilegios jurídicos, pero que cuentan socialmente por su papel económico.

El hecho de que los seviri augustales a partir de Trajano honren a los Lares Augusti y ostenten también el título de magistri Larum Augustorum no significa en absoluto que los colegios de los Lares Augusti daten todos de esta época y no se encuentren en otra. Esto sería muy raro, puesto que ya sabemos que los Lares están ligados a los orígenes mismos del culto imperial; desde el primer emperador los Lares privados de Augusto reciben un culto público.

Por último, de la distribución geográfica de todas estas dedicaciones se saca la conclusión interesante de que las menciones de magistri Larum y de colegios religiosos relacionados con el culto de los Lares están totalmente ausentes de la Lusitania y del Norte y Noroeste de la Península, situándose especialmente en la Bética y la Tarraconense, las regiones más romanizadas de la Península Ibérica.

Este hecho es significativo y coincide con lo que ya hemos mencionado en otras ocasiones: que este culto de los Lares Augusti, ligado íntimamente al culto imperial, se da sólo en las zonas más profundamente romanizadas. En cambio, en el Noroeste, es el culto de los Lares Viales el que realiza el papel de cohesión, ya que el culto imperial no cuajó en esta región de manera profunda.

\section{CONCLUSION.}

El primer hecho que llama poderosamente nuestra atención al realizar el análisis del culto a los Lares en la religión romana es la enorme amplitud de atribuciones que eran referidas a estas divinidades, que nos es demostrada muy claramente por los textos antiguos.

Este factor habría contribuido enormemente a facilitar su asimilación con deidades indígenas en las diversas zonas en las que los romanos se asentaron.

En el culto de los Lares en la Península Ibérica hay que hacer una diferenciación entre los Lares Viales, tópicos y gentilicios, por una parte, y los Lares romanos y augustos, por otra.

Los primeros esconden una realidad religiosa indígena. Resulta imposible saber con precisión si estos epítetos indígenas que acompañan a los Lares tópicos y gentilicios se refieren a una familia, a una comunidad o a un lugar geográfico concreto.

El área de localización geográfica del primer grupo de Lares que hemos distinguido coincide con la zona de Hispania en la que la romanización fue más tardía; no obs- 
tante, consideramos que esta romanización estuvo más presente de lo que se ha dicho hasta ahora.

Es cierto que existe en estas regiones una pervivencia indígena fortísima y que estas divinidades ocultan dioses indígenas, como lo indican los epítetos locales que se añaden al nombre romano de Lar, pero el hecho mismo de que las divinidades se asimilen a unos dioses romanos tan populares indica un conocimiento de estas deidades que demuestra que la romanización en estas zonas, aunque menor que en la Bética, no fue tan superficial y poco importante como se ha considerado.

Así pues, si los indígenas identificaron la divinidad romana con la local, es porque conocían los dioses romanos y comprendían las semejanzas existentes entre ambas entidades divinas.

El culto de los Lares más propiamente romanos y de los Lares augustos, ligados al culto imperial, presenta también una densidad importante, que quizás no se ha tenido en cuenta suficientemente.

La estructura de este culto de los Lares Augusti parece muy bien establecida; buena prueba de ello son las numerosas dedicaciones en que se alude a magistri Larum.

Destacan además las menciones de asociaciones de cultores Larum y decuriones Larum.

Los nombres de los dedicantes nos demuestran la importancia de los ciudadanos que podríamos llamar «de segunda categoría» en el culto de estos Lares relacionados con el culto imperial.

Hemos dejado en último lugar el culto de los Lares Viales porque es el que parece haber llamado más la atención de los estudiosos y porque su proporción en la Península Ibérica con respecto al resto del imperio romano resulta sorprendente.

Incluso si el contenido religioso de las dedicaciones a los Lares Viales sobrepasa muchas veces el simple papel de dioses protectores de los caminos, hay que considerar su presencia en función de ejes de caminos.

Esta relación entre las vías y las dedicaciones a los Lares Viales se ha podido establecer en la mayor parte de los casos; además, en este aspecto hay que tener en cuenta la gran obra constructora y reparadora de vías que fue llevada a cabo por los romanos en el Noroeste de la Península.

Los Lares Viales asumen un papel particular de cohesión, juntamente con Júpiter; este papel fue realizado en otras regiones más romanizadas por el culto imperial.

Las dedicaciones a estos Lares son abundantísimas con respecto a todo el resto del imperio romano, que en total presenta solamente cinco dedicaciones a estos dioses. Es significativo que unas divinidades tan populares en la religiosidad romana tengan tan pocos testimonios de devoción en todo el Imperio, contrastando de manera tan clara con la enorme abundancia del Noroeste peninsular.

Por último, hemos de señalar que, aunque no se puede negar de forma rotunda la hipótesis de la naturaleza céltica de los Lares Viales, puesto que no hay suficientes pruebas para ello, sí cabría al menos preguntarse si tiene una base lo suficientemente probada como para poder afirmarlo de manera tan categórica como han hecho muchos autores.

Hay que tener en cuenta que el celtismo de Galicia ha sido puesto en duda por algunos investigadores, que si bien admiten la presencia de etnias celtas en el área del Noroeste peninsular y su influencia en la cultura de la misma, sostienen, sin embargo, que lo genuino de esta cultura derivaba de una gran mezcla étnica de gentes asentadas en esta región desde la Edad del Bronce.

Además hay que considerar el hecho sorprendente de que otras zonas célticas como la Galia o Britania no presenten testimonios del culto a los Lares Viales.

Las formas que adoptan muchas de las dedicaciones a los Lares Viales son puramente romanas, por ejemplo, las aras de tres foci. 
La hipótesis que proponemos es la de considerar la influencia romana en este culto de los Lares Viales más importante de lo que se ha considerado hasta el momento.

No pretendemos olvidar el fondo indígena subyacente en este culto, pero no nos convence la afirmación tan asentada en la concepción tradicional de que esa realidad indígena sea una realidad religiosa de tipo céltico.

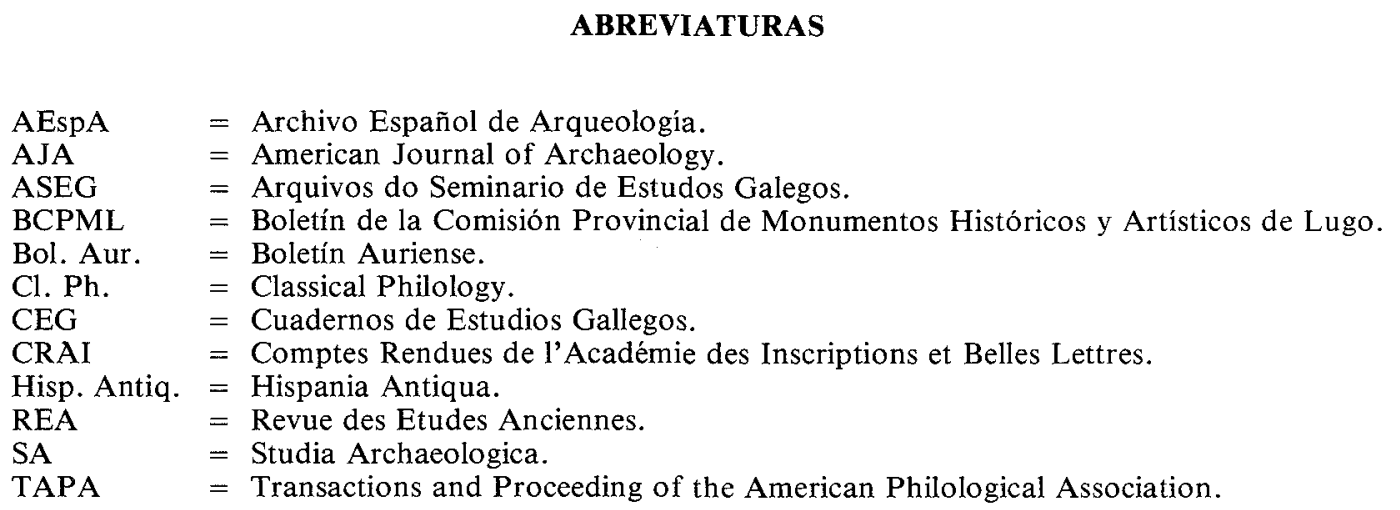




\section{BIBLIOGRAFIA}

ACUÑA CASTROVIEJO, F. 1969-1970: «Nueva ara romana de Parga (Lugo)». BCPML, VIII, 223-227. 1971: «Los Lares en la Galicia romana». Actas do II Congresso Nacional de Arqueología. Coimbra. Vol. II, 353-357.

ADAMS HOLLAND, L. 1937: «The Shrine of the Lares Compitales». TAPA. LXVIII, 428-431.

ALARCÂO, J.-ETIENNE, R.-FABRE, G. 1969: «Le culte des Lares à Conimbriga». $C R A I, 213$ y ss.

ALBERTOS, M. L. 1952: «Nuevas divinidades de la antigua Hispania». Zephyrus. III, 49-63.

- 1956: «¿Mercurio, divinidad principal de los Celtas peninsulares?». Emerita. XXIV, 294-297.

- 1966: Onomástica primitiva de Hispania. Tarraconense y Bética. Salamanca.

- 1975: «Organizaciones suprafamiliares en la Hispania antigua». St. A. Valladolid.

- 1977: «Perduraciones indígenas en la Galicia romana: los castros, las divinidades y las organizaciones gentilicias en la epigrafía». Actas del Coloquio Internacional sobre el Bimilenario de Lugo. Lugo, 17-29.

ALFOLDY, G. 1975: Die Römischen Inschriften von Tarraco. Madrider Forschungen. Band 10.

ALMAGRO, M. 1966: Ampurias. Barcelona.

ARES VAZQUEZ, N. 1973: «Hallazgo de tres lápidas romanas». $B C P M L$, IX, 75-86.

ARES VAZQUEZ, N.-ARIAS VILAS, F.-DELGADO, X. 1979: «Unha ara aos Lares Viales no conxunto arqueolóxico de Termes (Carballedo, Lugo)». Bol. Aur. IX, 311-315.

ARIAS VILAS, F. 1973: «Novo achádego epigráfico nas murallas romanas de Lugo».CEG, XXVIII, 235243.

ARIAS VILAS, F. 1974: «La religión en la Galicia romana». Publicaciones del Liceo Franciscano. XXVII, 69-77.

ARIAS VILAS, F.-LE ROUX, P.-TRANOY, A. 1979: Inscriptions romaines de la province de Lugo. París. Diffusion de Boccard.

BAILEY, C. 1932: Phases in the Religion of Ancient Rome. London. Oxford University Press.

BALIL, A. 1973: «Algunos aspectos y problemas de la Galicia romana». CEG. XXVIII, 161-180.

BAYET, J. 1959: Histoire politique et psychologique de la religion romaine. París. Bibliothèque Historique.

BEAUJEU, J. 1976: "Cultes locaux et cultes d'Empire dans les provinces d'Occident aux trois premiers siècles de notre ère». Assimilation et résistance à la culture gréco-romaine dans le monde ancien. Travaux du VI. ${ }^{e}$ Congrès International d'Etudes Classiques. París, 440 y ss.

BELTRAN, A. 1976: Symposion de ciudades augusteas. I, 249-260.

BENNET PASCAL, C. 1964: «The Cults of Cisalpine Gaul». Latomus. LXXV.

BERMEJO BARRERA, J. C. 1978: La sociedad en la Galicia castreña. Santiago de Compostela. Follas Novas Edicións.

BLANCO FREIJEIRO, A. 1977: «El panteón romano de Lucus Augusti». Actas del Coloquio Internacional sobre el Bimilenario de Lugo. 107-123.

BLAZQUEZ, J. M. 1957: «Aportaciones al estudio de las religiones primitivas de España». AEspA. XXX, $52-53$.

- 1960: «El legado indoeuropeo en la Historia romana». Primer Symposium de Prehistoria de la Península Ibérica. Pamplona.

- 1970: «Las religiones indígenas del NO. de la Península Ibérica en relación con Roma». Legio VII Gemina. León, 65 y ss.

- 1971: «La Iberia de Estrabón». Hisp. Antiq. I, 11-94.

- 1975: Diccionario de las religiones prerromanas de Hispania. Madrid. Edic. Istmo.

BLAZQUEZ, J. M. 1976: «Rechazo y asimilación de la cultura romana en Hispania (siglos IV y V)». Assimilation et résistance à la culture greco-romaine dans le monde ancien. Travaux $d u V I .{ }^{e}$ Congrès International d'Études Classiques. París.

- 1977: «La romanización del NO. de la Península Ibérica». Actas del Coloquio Internacional sobre el Bimilenario de Lugo. 67-83.

BOSCH-GIMPERA, P. 1932: Etnología de la Península Ibérica. Barcelona.

- 1939: «Two Celtic Waves in Spain». Proceedings of the British Academy. XXVI. London.

- 1950: «Infiltraçoês germánicas entre os Celtas peninsulares». Rev. de Gimarâes. LX, 339-349.

BOYCE, G. K. 1937: «Corpus of the Lararia of Pompeii». Memoirs of the American Academy in Rome. XIV.

BULARD, M. 1926: «La religion domestique dans la colonie italienne de Délos d'après les peintures murales et les autels historiés». Bibliothèque des Ecoles françaises d'Athènes et de Rome. CXXXI. París.

CARDOZO, M. 1965: «A romaniçao do Noroeste da Península Hispanica». Ethnos. IV, 75-82.

CARO BAROJA, J. 1943: Los pueblos del Norte de la Península Ibérica. Madrid.

- 1957: España primitiva y romana. Barcelona.

CARTER, J. B. 1906: The religion of Numa. London. 
CAVADA NIETO, M. 1981: «Nuevas aras romanas de la provincia de Orense». Primera reunión gallega de estudios clásicos. Santiago de Compostela. 152-158.

CLEBERT, J. P. 1970: Provence antique. II: L'époque gallo-romaine. París. Ed. Robert Laffont.

COLLINGWOOD, R. 1969: The Archaeology of Roman Britain. Oxford.

DARBY NOCK, A. 1972: Essays on Religion and the Ancient World. I. Oxford. Clarendon Press.

DELATTE, L. 1937: «Recherches sur quelques fêtes mobiles du calendrier romain». L'Antiquité classique. VI.

D’ENCARNAÇAO, J. 1972: «Vestigios do culto dos Lares em territorio portugués». Rev. de Gimarâes. LXXXII, 91-105.

- 1975: Divinidades indigenas sob o dominio romano em Portugal. Lisboa.

D'ORS, A. 1942: «Sobre los orígenes del culto al emperador en la España romana». Emerita. X, 197-227.

DUMEZIL, G. 1961: «Quaestiunculae Indo-Italicae, 8-10». Latomus. XX, 262-265.

- 1966: La religion romaine archaïque. París. Payot.

DUVAL, P. M. 1952: La vie quotidienne en Gaule pendant la paix romaine. París. Librairie Hachette.

- 1957: Les dieux de la Gaule. París. Presses Universitaires de France.

ELORZA, J. C. 1967: Ensayo topográfico de epigrafía alavesa. Vitoria.

1972: La romanización del País Vasco. Bilbao.

ETIENNE, R. 1958: «Le culte impérial dans la Péninsule Ibérique d'Auguste à Dioclétien». Bibliothèque des Ecoles Françaises d'A thènes et de Rome. París.

- 1973: «Les syncrétismes religieux dans las Péninsule Ibérique à l'époque impériale». Les syncrétismes dans les religions grecque et romaine. (Colloque de Strasbourg 9-1 1 juin 1971). 153163.

ETIENNE, R.-FABRE, G.-LE ROUX, P.-TRANOY, A. 1976: «Les dimensions sociales de Ia romanisation en la Péninsule Ibérique des origines à la fin de l'Empire». Assimilation et résistance à la culture gréco-romaine dans le monde ancien. Travaux de VI. ${ }^{e}$ Congrès International d'Etudes Classiques. París. 440 y ss.

GARCIA Y BELLIDO, A. 1947: «Estudios sobre escultura romana en los museos de España y Portugal». Revista de Archivos, Bibliotecas y Museos. LIII.

- 1949: Esculturas romanas de España y Portugal. Madrid.

- 1950: «Cuatro esculturas romanas inéditas del Museo Arqueológico de Sevilla». AEspA. LXXXI, 361-371.

- 1959: «Las colonias romanas de Hispania». Anuario de Historia del Derecho Español. XXIX, 447-512.

- 1966-67: «La latinización de España». AEspA. XXXIX-XL, 3-30.

GIL, L. 1969: Therapeia. La medicina popular en el mundo clásico. Madrid.

GORGES, J. 1979: Les villes de la Péninsule Ibérique. París. Diffusion de Boccard.

GRENIER, A. 1945: La Gaule Celtique. Toulouse. Didier.

- 1945: Les Gaulois. Bibliothèque Historique. París. Payot.

1946: La Gaule. Province romaine. Toulouse. Didier.

HARMON, D. P. 1978: «The Family Festivals of Rome». Aufstieg und Niedergang der Römischen Welt. Band II, 16,2. 1592-1603.

HATT, J. J. 1965: «Essai sur l'évolution de la religion gauloise». REA. LXVII, 80 y ss.

1970: Histoire de la Gaule romaine (120 av. J. C.-451 apr. J. C.). París. Payot.

KRUTA, V. 1977: Los Celtas. Madrid. Colec. Edaf Universitaria.

LAING, G. J. 1921: «The Origin of the Cult of the Lares». Cl. Ph. XVI.

1963: Survivals of Roman Religion. New York. Cooper Square Publishers.

LAMBRINO, S. 1965: «Les cultes indigènes en Espagne sous Trajan et Hadrien». Les empereurs romains de l'Espagne. Colloques Internationaux du Centre National de la recherche scientifique. París.

LEITE DE VASCONCELOS, J. 1905: Religiôes da Lusitania. 3 vols.

LE ROUX, P.-TRANOY, A. 1973: «Notes d'épigraphie romaine de Galice». CEG, XXVIII, 221-234.

- 1973: «Rome et les indigènes dans le nord-ouest de la Péninsule Ibérique. Problèmes d'épigraphie et d'histoire». Mélanges de la Casa de Velázquez. IX, 177-231.

1974: «Contribution à l'étude des régions rurales du NO. hispanique au Haut Empire: deux inscriptions de Penafiel». Actas do III Congresso Nacional de Arqueología. Vol. I. Porto, 249-258.

LIEBESCHUETZ, J. H. W. G. 1979: Continuity and Change in Roman Religion. Oxford. Clarendon Press. LIVERSIDGE, J. 1968: Britain in the Roman Empire. London. Routledge and Kegan Paul.

LOPEZ CUEVILLAS, F. 1934: "Estudos sobre a Edade do Ferro do noroeste da Peninsula. A relixion». $A S E G$. VI, 295 y ss.

- 1953: La civilización céltica en Galicia. Santiago de Compostela.

- 1958: «Lápidas romanas de la provincia de Orense». CEG. XIII, 343-358. 
LORENZO, J.-D'ORS, A. 1961: «Inscripciones romanas de Galicia. IV: Provincia de Orense». CEG. L, 267 y ss.

LORENZO, J.-BOUZA BREY, F. 1965: «Inscripciones romanas votivas de la provincia de Orense». CEG. LXII, 261 y ss.

MALUQUER DE MOTES, J. 1954: «Los pueblos de la España Céltica». Historia de España, dirigida por Menéndez Pidal. T. I, vol. III. Madrid.

MARINER, S. 1973: Inscripciones romanas de Barcino. Barcelona.

MESLIN, M. 1969: «Persistances païennes en Galice vers la fin du VI.e siècle». Hommages à Marcel Renard. II. Bruxelles, 512-524.

MOCSY, A. 1974: Pannonia and Upper Moesia. A History of the Middle Danube Provinces of the Roman Empire. London. Routeledge and Kegan Paul.

NILSSON, M. P. 1954: «Roman and Greek Domestic Cult». Opuscula Romana. Vol. I, 77-85.

ORR, D. G. 1978: «Roman Domestic Religion: The Evidence of the Household Shrines». Aufstieg und Niedergang der Römischen Welt. Band II, 16, 2, 1557-1591.

OTERO PEDRAYO, R. 1980: Historia de Galiza. Dirigida por...

PETERSON, R. M. 1919: «The Cults of Campania». Papers and Monographs of the American Academy in Rome. I.

PICARD, R. 1923: Marbres antiques du Musée du Prado à Madrid. Bordeaux.

PICCALUGA, G. 1965: Elementi spettacolari nei rituali festivi romani. Roma. Edizioni dell'Ateneo.

POULSEN, F. 1933: Sculptures antiques des musées de province espagnols. Copenhague.

POWELL, T. G. E. 1965: «Os Celtas». Primero volume da colecçâo Historia mundi. Lisboa. Edit. Verbo.

RINCON, M. A. 1970: «Consideraciones generales acerca de la romanización de las tribus galaicas». Pyrenae. VI, 71-77.

RIVAS FERNANDEZ, J. C. 1972: «La capilla de San Xiao de Fontefría y su ara votiva a los Lares Viales». Bol. Aur. II, 303 y ss.

- 1973: «Nuevas aras romanas orensanas». Bol. Aur. III, 57-96.

RIVERO, C. M. 1927: Los bronces antiguos del Museo Arqueológico Nacional. Primera parte: Figuras. Toledo.

RODRIGUEZ COLMENERO, A. 1972: «Sobre los pueblos prerromanos del sur de Galicia». Bol. Aur. II, 193-240.

1973: «Epígrafes inéditos de tierras orensanas». Durius. I, 361-366.

- 1977: Galicia meridional romana. Univ. de Deusto.

ROLDAN, J. M. 1972: «El elemento indígena en las guerras civiles en Hispania. Aspectos sociales». Hisp. Antiq. II, 77-123.

ROSS TAYLOR, L. 1914: «Augustales, Seviri Augustales and Seviri: a Chronological Study». TAPA. XLV, 231-235.

- 1925: «The Mother of the Lares». AJA. XXIX, 299-313.

SALWAY, P. 1981: Roman Britain. Oxford. Clarendon Press.

SANTERO, J. M. 1978: Asociaciones populares en Hispania romana. Publicaciones de la Universidad de Sevilla.

SCHILling, R. 1979: Rites, cultes, dieux de Rome. Etudes et commentaires. 92. París. Editions Klimcksieck.

SJOESTEDT, M. L. 1949: Gods and Heroes of the Celts. London. Methuen and Co.

TABOADA CHIVITE, J. 1975: «La encrucijada en el folklore de Galicia». Bol. Aur. V, 101-112. 1976: «Nuevos testimonios del culto a los Lares Viales en la Gallaecia». Gallaecia. II, 193-200.

THEVENOT, E. 1948: Les Gallo-Romains. Coll. "Que sais-je?». París. Presses Universitaires de France. 1949: Histoire des Gaulois. Coll. «Que sais-je?». París. Presses Universitaires de France.

- 1968: Divinités et sanctuaires de la Gaule. París. Fayard.

THOUVENOT, R. 1927: Catalogue des figurines et objets de bronze du Musée Archéologique de Madrid. París.

TORRES RODRIGUEZ, C . 1952: «El culto al emperador en Galicia». CEG. VII, 197-230.

TOUTAIN, J. Les cultes païens dans l'Empire romain. 3 vols. París. Bibliothèque de l'Ecole des Hautes Etudes. XX.

TOVAR, A.-NAVASCUES, J. M. de. 1950: «Algunas consideraciones sobre los nombres de divinidades del Oeste peninsular». Miscelánea en memoria de Francisco Adolfo Coelho. Lisboa.

TRANOY, A. 1980: «Religion et societé à Bracara Augusta au Haut Empire romain». Actas do Seminario de Arqueología do Noroeste peninsular, 67 y ss. Gimarâes.

- 1981: La Galice romaine. Recherches sur le nord-ouest de la Péninsule Ibérique dans la Antiquité. París. Diffusion de Boccard.

- 1981: «Romanisation et monde indigène dans la Galice antique: problèmes et perspectives». Primera reunión gallega de estudios clásicos. 105 y ss. Santiago de Compostela.

VARIOS AUTORES. 1979: Prehistoria e Arqueoloxía de Galicia. Estado da cuestión. Sección de Arqueoloxía e Prehistoria do Instituto de Estudos Galegos «Padre Sarmiento». Lugo. 
VARIOS AUTORES. 1980: The Archaeology of Roman Pannonia. Budapest. The University Press of Kentucky. Akadémiai Kiadó.

VIVES, J. 1971: Inscripciones latinas de la España romana. Barcelona.

VRIES, J. de. 1975: La réligion des Celtes. París. Payot.

WAITES, M. 1920: «The Nature of the Lares and their Representation in Roman Art». AJA. XXIV, 241 261.

WALTZING, J. P. 1968: Etude historique sur les corporations professionnelles chez les Romains depuis les origines jusqu'à la chute de l'Empire d'Occident. 4 vols. Roma. «L'Erma» di Bretschneider. 


\title{
LA TUMBA DEL EMPERADOR JULIANO
}

\author{
JAVIER ARCE MARTINEZ \\ Instituto Rodrigo Caro (C. S. I. C.)
}

\begin{abstract}
El lugar de enterramiento del emperador Juliano ha sido objeto de numerosas controversias ya desde la antigüedad. En este artículo se relacionan las fuentes que tratan del tema, así como las circunstancias en que tuvo lugar la muerte de Juliano y el traslado de su cadáver desde Persia a Tarso y desde aquí a Constantinopla.

The burial place of the emperor Julianus has been the object of a great number of controversies even from antiquity. In this article, the sources dealing with this topic are related, as well as the circumstances surrounding Julianus' death and the transfer of his corpse from Persia to Tarsus and from here to Constantinople.
\end{abstract}

\section{INTRODUCCION}

A la entrada del actual emplazamiento del Museo Arqueológico de Istambul, el visitante puede contemplar una serie de magníficos sarcófagos de pórfido, que con razón han sido identificados como los sepulcros de los emperadores tardo-romanos y bizantinos que originariamente estuvieron en la famosa Iglesia de los Santos Apóstoles, hoy completamente desaparecida. Esta iglesia era de planta cruciforme y su descripción se encuentra tanto en el tratado De Aedificiis de Procopio (I. 4.9-24) del s. VI, cuanto -y esta vez más detalladamente- en Nicolás Mesarites, s. XII, en su Descripción de la Iglesia de los Santos Apóstoles. Poseía dos mausoleos donde se hallaban los sarcófagos imperiales. En una primera fase - como muy bien ha estudiado Ph. Grierson- en uno de ellos, el llamado Mausoleo de Constantino, hubo sólo tres tumbas: la del propio Constantino El Grande (con Helena o Faustina); la de Constancio II, uno de sus hijos, y la de Teodosio I (1). Sabemos que tres Emperadores del s. IV, además de Constantino, Constancio y Teodosio, fueron enterrados en la Iglesia de los Santos Apóstoles, en diferentes momentos: Juliano, Joviano y Valentiniano.

Juliano fue sepultado en Tarso y de allí fue llevado a la capital del Imperio Oriental para ser enterrado. Su traslado tuvo lugar en un momento que discutiremos más adelante; Joviano murió en Dadastana (entre Galatia y Bitinia) y su cuerpo fue también trasladado a Constantinopla; Valentiniano I acabó sus días en la Galia, pero fue también trasladado a la ciudad de Constantino ut... inter divorum reliquias humaretur, como indica Ammiano Marcelino en 30. 10. 1.

(1) Para más detalles sobre la Iglesia y sobre los mausoleos debe consultarse Ph. GRIERSON (1962, 3-63) con la bibliografía fundamental. Igualmente es básico el estudio de G. DOWNEY (1959, 27-51), así como K. WULZINGER (1932, 7-39); R. JANIN (1953, 46-55); J. EBERSOLT (1951, 31-43). 
Valente, Graciano y Valentiniano II, que completan la lista de Emperadores del s. IV, no encontraron, sin embargo, el reposo final junto a sus colegas citados: el cuerpo de Valente no se encontró después de la desastrosa batalla de Adrianópolis, como señala Ammiano. Graciano y Valentiniano II fueron enterrados en Milán.

Cuando muere Joviano en el año 364, en el Mausoleo había pues, solamente, dos sepulcros: el de Constantino y el de su hijo Constancio. Joviano fue, sin duda, en un principio enterrado con ellos ya que, según el texto de Ammiano, su cuerpo se llevó a Constantinopla $u t$ inter Augustorum reliquias conderetur. Poco más tarde y según la sugerente hipótesis de Grierson, Joviano fue desplazado de lugar para dejar sitio a Teodosio. A su vez Joviano fue enterrado entonces en la denominada «stoa» norte de la iglesia y junto a él se colocó el sepulcro del Emperador Juliano, puesto que había sitio suficiente (2). ¿Por qué enterrar juntos a ambos Emperadores? Grierson piensa que, aunque no había entre ellos ningún lazo de consanguinidad, fueron enterrados en el mismo sitio por haber sido anteriormente compañeros de armas y porque Juliano había mantenido en el cargo a Joviano a pesar de ser cristiano. Explicación, a mi entender, un tanto forzada, pero cualquier otro razonamiento lo sería igualmente y es por lo tanto innecesario añadir algo más.

En este trabajo pretendo hacer un análisis detenido de todos los argumentos y datos en pro y en contra para un posible acceso a la identificación segura del sarcófago del Emperador Juliano y al mismo tiempo hago un estudio de las circunstancias y hechos que ocurrieron en la muerte y traslado de cadáver de Juliano de Persia a Tarso y de aquí a Constantinopla. Se analiza además el epigrama que estaba inscrito en su tumba y la problemática de su transmisión literaria.

Debemos en primer lugar recordar brevemente los problemas relativos a la muerte, enterramiento y traslados del cadáver del Emperador.

\section{ENTERRAMIENTO DE JULIANO EN TARSO: CIRCUNSTANCIAS Y DATOS}

El historiador Ammiano Marcelino, que estuvo en la campaña de Persia acompañando a Juliano y que, sin duda, fue también testigo de su muerte, señala que, tras el 26 de junio del 363, última fecha en la vida del joven Emperador, Joviano, su sucesor, envió a Procopio, unido al difunto por lazos de parentesco, a fin de acompañar el cadáver a Tarso donde iba a ser enterrado (3). ¿Por qué a Tarso? Juliano, en efecto, había prometido solemnemente no volver a Antioquía después de la expedición a Persia y había mandado disponerlo todo para establecer su residencia en Tarso: disposuisse enim aiebat, hiemandi gratia per compendiariam viam, consumato procinctu, Tarsum Ciliciae reversurum, scripsisseque ad Memorium praesidem ut in eadem urbe cuncta usui congrua pararentur. Et hoc haud diu postea contigit. Corpus namque eius illuc relatum exequiarum humili pompa, in suburbano sepultum est, ut ipse mandarat (4). Este pasaje

(2) Downey pensó que la «stoa» era un edificio separado de la iglesia principal mientras que Grierson cree que era simplemente una especie de capilla lateral, idea que parece más convincente. Confrontar $\mathrm{Ph}$. GRIERSON (1962, 36 ss.).

(3) Confrontar Ammiano Marcelino (25.9.12). Como Procopio no se unió al grueso del ejército hasta algún tiempo después del 26 de junio el cadáver de Juliano fue embalsamado y transportado con el ejército durante la retirada. Y de hecho asi lo atestigua Efrén Sirio en su Carmina Nisibena, confrontar Ephraem des Syriers Hymnen de Paradiso und contra Julianus, Corpus Scriptorum Orientalum, 79, Lovaina, 1957.

(4) Am. Marc. 23.2.5. Este texto, por otro lado, da una idea bastante clara de la verdadera dimensión que de la campaña tenía en la mente Juliano, ya que, contrariamente a lo que algunos han supuesto, Juliano pretendía regresar a Tarso hiemandi gratia, es decir, a los pocos meses. Su expedición es una expedición de castigo del tipo de las que llevó a cabo en las Galias aunque más aparatosamente montada. 
significa solamente que Juliano había ordenado prepararlo todo en Tarso para su estancia, pero no, como piensa G. Downey, que Juliano hubiese dado órdenes para que se le enterrase allí, ya que el Emperador confiaba y esperaba volver con vida de la expedición (5). En última instancia se podría pensar que lo que Juliano había ordenado es que, si moría, se le enterrase humili pompa, hecho que concuerda bien con la sobriedad y el estilo de vida que gustaba y caracterizaba al Emperador. Ammiano no hace más que constatar aquí una coincidencia tristemente cierta: volvió Juliano a Tarso, como había dispuesto, pero volvió muerto.

Un poco más adelante el mismo historiador señala que Joviano, meses después, de regreso ya de Persia, pasó por Tarso y ordenó adornar el sepulcro de su predecesor: Exindeque egredi nimium properans exornari sepulchrum statuit Iuliani in pomerio situm itineris, quod ad Tauri montis angustias ducit, cuius suprema et cineres, siqui tunc ad perpetuandam gloriam recte factorum praeter lambere Tiberis, intersecans urbem aeternam divorumque veterum monumenta praestingens (Am. Marc. 25.10.5). Varios aspectos importantes ilustra este pasaje que merece, a nuestro propósito, un comentario detallado.

En primer lugar el que se refiere al emplazamiento del sepulchrum de Juliano, que estaba situado - como por otro lado era lo normal - in pomerio itineris (cfr. BESNIER, s. v. Pomerium en DAREMBERG-SAGLIO), lo cual coincide, no sólo con afirmaciones anteriores del propio Ammiano (in suburbano Tarsensi dice en $23.2 .5 \mathrm{y}$ 25.9.12), sino con las afirmaciones de otros historiadores tales como Zósimo ( $\varepsilon^{\prime} \vee$ Tív

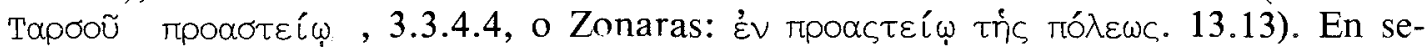
gundo término hay que observar en este pasaje el hecho de que a los pocos meses de ser nombrado Emperador, Joviano mismo sea quien disponga adornar el sepulcro de su predecesor, en este caso un pagano que no merecería tal honor dentro del pensamiento de un emperador cristiano como Joviano, al menos en teoría y a priori. Este texto, efectivamente, no ha sido suficientemente valorado por quienes se han planteado el problema del traslado en la Iglesia de los Santos Apóstoles, bien esto haya tenido lugar en época de Teodosio I bien en tiempos de León I (vid. infra), pues algunos autores consideran un obstáculo - y no el menor - para el traslado a Constantinopla el hecho de que Juliano fuera pagano. En concreto este texto de Ammiano desvirtúa en cierto modo la argumentación de A. A. Vasiliev — basada en una hipotética reconstrucción de los hechos según la cual el epitafio del que más adelante hablaremos no fue puesto sobre el sarcófago del Emperador, sino sobre una piedra o placa adyacente al mismo y ésta, por su indudable carácter laudatorio hacia Juliano, fue considerada inadmisible para Joviano, que la destruyó (VASILIEV, 1948, 1-26, esp. 19). Nada de esto es seguro y, más bien, los indicios llevan a pensar lo contrario. Es cierto, sin embargo, que Joviano pudo preocuparse por el sepulcro de Juliano por imperativos políticos, a fin de congraciarse con los partidarios de éste, pero aún así la hipótesis de Vasiliev es prácticamente inadmisible.

El exornari sepulchrum del texto que comentamos es también significativo en otro sentido: por cuanto que permite hacerse una idea y explica cómo llevó a cabo Procopio la misión que le fue encomendada, es decir, con precipitación y desorden: quid ad exsequendum profectus, confestim corpore sepulto discessit (Am. Marc. 25.9.13).

(5) La opinión de G. DOWNEY $(1959,46)$ es para mí errónea interpretación del $u t$ ipse mandarat. Recientemente R. TURCAN $(1975,125)$ insiste en la idea de que Juliano quiso expresamente ser enterrado en Tarso basándose en Am. Marc. 25.5.1 y 10.5, y lo pone en relación con los posibles defensores del mitraísmo del Emperador. Pero en 25.5.1 Ammiano vuelve a ser ambiguo refiriéndose como en 23.2.5 al hecho de que había ordenado volver a Tarso, pero vivo, no muerto; 25.10 .5 no dice más que Juliano está enterrado en esta ciudad. 
Da idea también el texto de que el prestigio de Juliano, último representante de la dinastía constantiniana y al fin y al cabo y pese a cristianos o fanáticos, Emperador de Roma, no se eclipsó fácilmente a pesar de los denodados esfuerzos de los cristianos para que así fuera (6).

Aún se pueden sacar otras conclusiones del texto citado de Ammiano. La más obvia e importante de ellas es de orden cronológico y fue $\mathrm{Ph}$. Grierson quien la puso de relieve con anterioridad. Queda claro que cuando Ammiano está escribiendo (más propiamente recitando a su auditorio romano), Juliano seguía aún enterrado en Tarso y no se había llevado a cabo su traslado a Constantinopla. El libro XXV de Ammiano fue escrito probablemente en 390-391 y recitado en Roma en plena época teodosiana (MAENCHEN-HELFEN, 1955, 384; PIGHI, IX —que fecha en 391-392-; CAMERON, 1971, 255 ss.). El traslado del Emperador tuvo que ocurrir forzosamente con posterioridad a esa fecha y quizás - como piensa Grierson- como consecuencia precisamente de esta apelación pública del gran historiador (7). Siendo esto perfectamente posible, R. Calza ha propuesto otra fecha para el traslado que parece bastante convincente ya que piensa que pudo ser hecho, como consecuencia del edicto de León I (13 del 8 del 457 ) que requería una digna sepultura para el último emperador de la dinastía constantiniana (CALZA, 1973, 366, n. 7; El edicto de León I en $C J$ 1.5.9). Ambos argumentos, pero sobre todo y sin duda alguna el primero, invalidan la reciente afirmación de C. C. B. Amstrong, según la cual el círculo de amigos de Juliano en Efeso y concretamente el gobernador Clerco, que tenía cierta influencia sobre Valente, forzaron a éste al traslado a Constantinopla del cadáver del Emperador (8). Sea lo que fuere el hecho es que en 390 Juliano estaba aún enterrado en Tarso y Ammiano, en un rasgo de romanismo, proclamaba que era en Roma, en la Roma Aeterna, donde debería estar enterrado y no en Tarso. Por contraste, Libanio, escribiendo en 365, pensaba que era en Atenas, junto a la Academia, al lado de Platón, el lugar donde debía reposar Juliano (Or. 18.306; NORMAN, XXXIV). De las dos opiniones de estos dos grandes panegiristas de Juliano es posible comprender la distinta visión que ambos tenían de su héroe: Ammiano veía en él antes que nada al Emperador romano, militar, que merecía estar asociado para siempre con las hazañas de la Ciudad Eterna y sus tradiciones; Libanio entendía, por su parte, mucho más el aspecto filosófico e intelectual de Juliano y su vinculación al neoplatonismo. Por azar Juliano no fue enterrado en ninguna de las dos ciudades que sus panegiristas propugnaban, sino en Constantinopla, capital del Imperio Oriental, donde probablemente no hubiera deseado estar.

Para finalizar el comentario a este significativo pasaje de Ammiano sólo una observación: la precisión in pomerio situm itineris quod ad Tauri montis angustias ducit, ha-

(6) Confrontar Eutr. 10.16; Libanio, Or. 18.304; Eunapio, fr. 23; A. D. NOCK (1957, 115 ss.) que estudia el pasaje de Libanio citado; J. STRAUB (1962, 310-326). Recientemente R. CALZA $(1973,388)$ rechaza la identificación de Juliano en su apoteosis en el famoso díptico del Museo Británico, entre otras razones porque «non risulta che i successori di Giuliano (Gioviano, Valentiniano, Valente) abbiano avuto cura di promovere l'apoteosi». Esto es cierto, al menos en parte, pero la argumentación no es suficiente, porque por ejemplo Archer ST . CLAIRE (1964, 205 ss., esp. 290) demuestra con razones mejores que el representado en el dístico es Juliano. R. Calza no menciona este importante estudio. Por otro lado y además, Gregorio Nazianceno nos habla de un templo dedicado al culto de Juliano erigido en Tarso (LIBANIO, V. $8)$.

(7) Ph. GRIERSON (1962, 40-41). Este autor cree que el silencio de Zósimo (s. VI) al respecto no es relevante y piensa que precisamente por ser pagano (como su fuente Eunapio de Sardes) no quiso mencionar el traslado a la capital cristiana. La apelación de Ammiano pudo llegar a Teodosio durante su visita a Italia en 391-392.

(8) Confrontar Proceedings of Classical Association, 1972, vol. LXIX, 30, con un resumen del trabajo de C. C. B. AMSTRONG. 
ce pensar en la posibilidad de que el propio Ammiano visitase personalmente la tumba de su admirado Juliano (9).

El relato del traslado del cadáver de Juliano lo hallamos también en Zósimo, expresado de forma más escueta y concisa (Zos. 3.34), quien dice que, en compañía de su guardia personal, el Emperador Joviano llegó a Antioquía, mientras el grueso del ejército acompañó al cadáver de Juliano a Tarso. R. T. Ridley ha querido ver en esta afirmación un error, ya que Ammiano no menciona al ejército como acompañante, sino sólo a Procopio (RIDLEY, 1972, 277 ss., esp. 293 ss.). Nada impide pensar - sin embargoque acompañase a Procopio un gran contingente de tropas, tanto de seguidores fieles a Juliano cuanto de otros deseosos ya de regresar tras la penosa campaña. Zósimo continúa diciendo que el cuerpo de Juliano fue enterrado en un sarcófago en el que se grabó

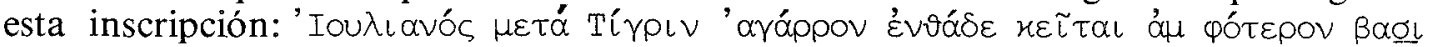

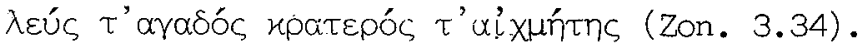

I. Zonaras, siglos más tarde, recoge en su Epitome Historiarum la misma versión de los hechos añadiendo, sin embargo, algún dato fundamental. Repite que fue el ejército el que acompañó el cadáver a Tarso y señala que fue enterrado en un barrio de la ciudad (Zonaras sigue aquí, sin duda, la misma fuente que Zósimo, esto es, Eunapio), y añade que en su sarcófago se inscribió un epigrama de cuatro versos. Añade el historiador que más tarde, sin precisión cronológica alguna, fue trasladado a Constantinopla (Zon. 13.13).

Es el momento ahora de hacer frente, vistos los datos de las fuentes literarias, a dos problemas: 1) el problema de la inscripción o epitafio y 2) el problema del sarcófago donde fue inscrito.

\section{EL EPITAFIO DEL EMPERADOR JULIANO}

Hemos visto que tanto Zonaras como Zósimo dan el texto de la inscripción que se puso en el sarcófago de Juliano. Lo primero que salta a la vista es que ambos presentan diversas versiones de la misma: en Zósimo es un dístico y en Zonaras son cuatro versos, siendo el último idéntico en ambas versiones. El dístico de Zósimo fue recogido en la Antología Palatina (ed. Waltz) 7.747 y fue atribuido a Libanio. Esta atribución fue negada hace tiempo por Förster (10).

En el lemma del epigrama no aparece ninguno de los apelativos que normalmente se asignan a Juliano en la Antología (Anth. Pal. 14.148 y 11.108) y el dístico, formado por dos hexámetros dactílicos, tiene evidentes recuerdos homéricos (Il. III, 179 y II, 845). La traducción del primer verso, sin embargo, ha sido interpretada de diversas formas. Yo creo que la más apropiada podría ser ésta: «Juliano, que pasó el Tigris de rápida corriente, yace aquí enterrado». La razón es obvia: si el epitafio se inscribió en el sarcófago de Tarso, es ésta la única traducción coherente del $\mu \varepsilon \tau \alpha$ Ti Toı porque interpretar $\mu \varepsilon \tau \alpha ́$ como «al otro lado del Tigris», como pretenden algunos, sería una

(9) Después de su participación en la expedición a Persia Ammiano va a Antioquía. Confrontar 29.1.24 ss.

(10) Confrontar FÖRSTER (1876, 213-214). La identificación es rechazada también por Waltz y Beckby en sus ediciones del epigrama en la Antología. 
contradicción (11). Hemos visto ya que estos dos versos aparecen por primera vez en Zósimo. El primer punto a resolver es saber de dónde tomo Zósimo esta información.

Es bien sabida la problemática que encierra un autor como Zósimo cuyo sentido de la exactitud histórica deja mucho que desear (12). Esta inexactitud que caracteriza a Zósimo se agudiza, si cabe, en el libro III y concretamente en el relato de la campaña persa; dilucidar cuál es la fuente (o fuentes) que sigue para este libro sigue siendo causa de interminable controversia entre los especialistas (v. PASCHOUD, I, XLIII), aunque se puede afirmar con certeza que normalmente Zósimo sigue a Eunapio y, en el caso concreto que nos ocupa, esto es, en la transmisión del epitafio que luego pasará a la Antología, cabe pensar con bastante probabilidad que Zósimo seguía a Eunapio (13). Aunque poseemos muy fragmentariamente la obra de este historiador, se observa en sus Historias una cierta tendencia a consignar oráculos, versos o textos similares referentes al Emperador (ARCE, 1975, 94 ss.). No tendría nada de extraño que Eunapio, pues, hubiera recogido también el epitafio con anterioridad (14). El tono homérico del mismo -muy en consonancia con los gustos de Juliano- hace pensar que fuera redactado por alguno de sus amigos íntimos, quizás Oribasio mismo (15). El autor debió conocer directamente la tumba y en este caso lo transmitido por Zósimo sería la versión más exacta. Sin embargo no hay más remedio que dudar de su completa autenticidad, ya que parece que Zósimo resumió de alguna forma el original, pues, como hemos visto, Zonaras -que deriva de una fuente indudablemente pagana y probablemente de Eunapio (16)da una versión más extensa del epitafio, versión que el cronógrafo bizantino Cedrenos recoge igualmente $(\mathrm{I}, 539)$. Sin duda el transmitido por estos dos últimos autores debió de ser el original y lo conservado en Zósimo puede ser un resumen del texto inicial en el que procuró mantener la idea central de la campaña persa y el último verso que condensaba muy bien las virtudes del Emperador de acuerdo con la propia visión de Zósimo sobre él.

\section{EL SARCOFAGO DEL EMPERADOR JULIANO}

El problema se centra ahora en el sarcófago donde fue grabada la inscripción. Sería lógico pensar que si se hubiese hallado dicho sarcófago apareciera en él la inscripción que, tanto Zósimo como Zonaras y Cedrenos, dicen que se inscribió aunque den versiones distintas de su contenido.

(11) Beckby traduce: «Hinter dem reissenden Tigris liegt hier Julianus begraden»; Waltz: «Julien, aprés avoir franchi le Tigre au cours rapide, est ici couché»; Platón (Loeb): «Julian lies here on the further bank of the strong current of Tigris»; PEECK $(1960,214)$ : «Julian, der den breitströmenden Tigris überschift, liegt hier nun begraden»; BIDEZ $(1930,330)$ : «des bords du Tigris impétueux Julien est venu dormir

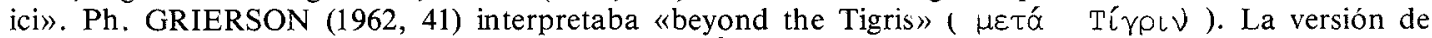

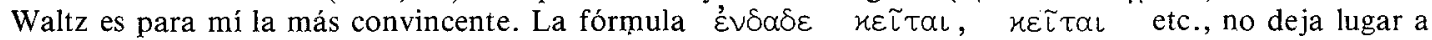
dudas. Confrontar $M A M A$, VII, n. ${ }^{\circ} 104$ a-b-c-d; VIII, 144; $155 ; 317 ; 272$.

(12) A. CAMERON (1969, 106-110) para la fecha; F. PASCHOUD (I, XVII); sobre los numerosos errores de Zósimo - además de la introducción de F. Paschoud a su edición y sus notas-confrontar R. T. RIDLEY (1972, 277 ss.) y DILLEMANN (1961, 87 ss., esp. 144 ss.). Puede verse también J. ARCE (1975, 138 ss.).

(13) Eunapio a su vez seguía a Oribasio. Confrontar F. PASCHOUD (I, LV).

(14) Para esta tendencia de Eunapio confrontar fr. 27.24.26 (FHG, Müller, vol. IV).

(15) Para los gustos y aficiones homéricos en Juliano confrontar Jul. 112 C; 351 C (BIDEZ, 1930); Am. Marc. 16.7.6; Lib. Or. 12.27; $\operatorname{BIDEZ~}(1930,21)$, etc.

(16) BIDEZ (1930, 338); P. ALLARD (1910, III, 399); K. ZIEGLER (XA, 729) declara simplemente que por el libro XIII la fuente es desconocida. 


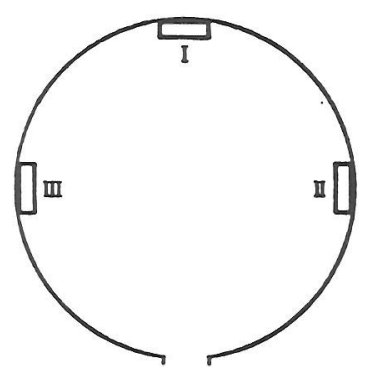

Stage $A$

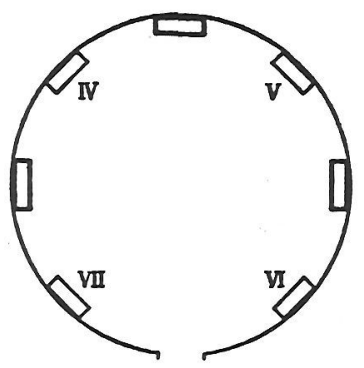

Stage $B$

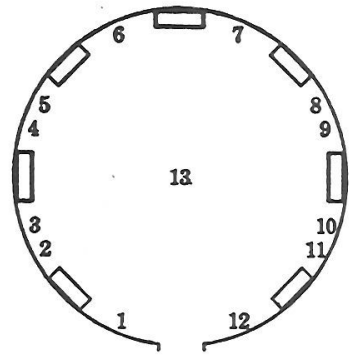

Stage C

Figura 1.-Planta esquemática del mausoleo de Constantino.

En la descripción que hace el Libro de las Ceremonias (II, 42) del sarcófago de Ju-

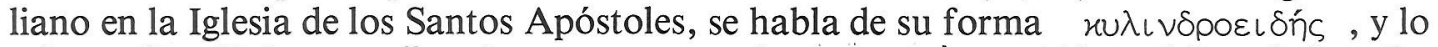

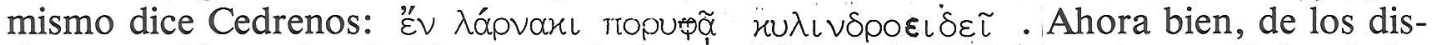
tintos sarcófagos de pórfido que están hoy en la entrada del Museo Arqueológico de Istambul y en el patio de Sta. Irene que pertenecieron al Mausoleo de la Iglesia de los Santos Apóstoles, sólo hay uno que responde de alguna manera a esas características -esto es, que sea de forma cilíndrica o redondeada- por tener ambos extremos semicirculares (f. 1). Este sarcófago fue identificado por Ebersolt y luego por R. Delbrueck como el sarcófago del Emperador Juliano (17). La dificultad para esta identificación (el propio Ebersolt - 1921, 13 - ya dudaba debido a la inexactitud de los autores bizantinos) reside, a mi entender, en que en él no hay inscripción ni rastro de ella, además de que el calificativo de «de forma cilíndrica» puede ser discutible respecto a la propiedad del término. Para salvar el inconveniente de la no existencia de inscripción Vasiliev estableció la siguiente ingeniosa hipótesis: la inscripción se grabó no sobre el sarcófago, sino sobre una piedra o placa adyacente al mismo (fenómeno, por otro lado, ni imposible ni infrecuente y que se usaba para diferenciar un sarcófago; sobre ello véase GRIERSON, $1962,9)$. Más tarde - continúa Vasiliev- Joviano, al comprobar el tono laudatorio de la inscripción, la consideró inadmisible y la mandó quitar. De aquí que por ello no haya que esperar ninguna inscripción en el sarcófago de Constantinopla (VASILIEV, 1948, 20).

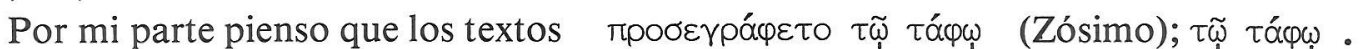

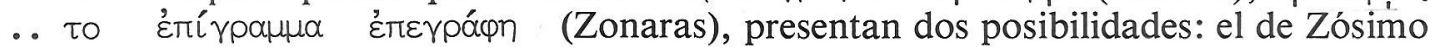
puede referirse (por la preposición) a que la inscripción era adyacente, pero Zonaras parece indicar que se hizo encima (la posibilidad de que se haya pintado la inscripción no se excluye del significado del verbo). Sin embargo el exornari no deja lugar a dudas respecto a la acción de Joviano que hizo justamente lo contrario que propone Vasiliev.

A. Maricq propuso otra solución al problema partiendo de la base de que la identificación hecha por Delbrueck era correcta: el cronógrafo Cedrenos - que es quien señala que en el sarcófago de Constantinopla se grabó la inscripción- cometió una equivo-

(17) J. EBERSOLT (1921, 6, 11, 13, 1.XII); R. DELBRUECK (1932, 14 y 214). R. Delbrueck cree que se trata no obstante de un sarcófago tolemaico trasladado de Alejandría a Constantinopla para sepultar a Juliano: «Es ist, wie gesagt, vielleicht ein ptolemaisches Stück und nicht für Julianus gearbeitet», esto es, el sarcófago no fue hecho expresamente para Juliano.

(18) Cedrenos, en efecto, es el único que dice que «fue trasladado (su cuerpo) a Constantinopla y colocado en un sarcófago de pórfido cilíndrico sobre el cual se inscribió el siguiente epigrama..., etc.». El texto es ambiguo porque Cedrenos está tomando su información de otros autores - en este caso de Leo Grammatico- quienes a su vez confunden y mezclan sus datos. Confrontar A. MARICQ (1952, 320-321). 


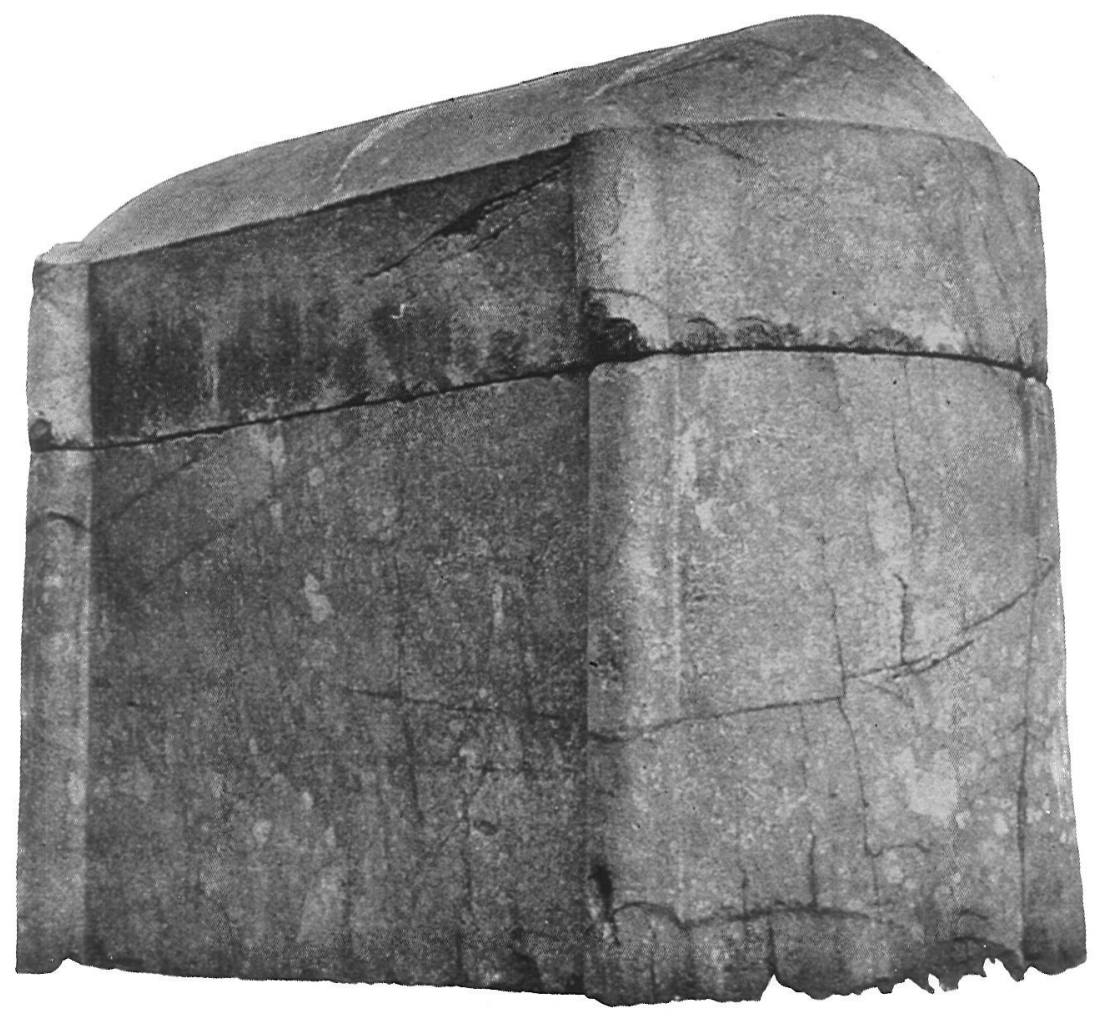

Figura 2.-Sarcófago de Constantinopla.

cación debido a su peculiar forma de redactar y lo que dice como grabado en el sarcófago de Constantinopla es falso y que sólo se refería a lo que se grabó en el de Tarso, que resultaba ser distinto que el de la Iglesia de los Santos Apóstoles donde fue depositado luego; por lo tanto - concluye Maricq-, «no hay motivos para extrañarse de la ausencia de restos de inscripción en el sarcófago de Constantinopla» (18). Ph. Grierson cree por su parte que el sarcófago cilíndrico que normalmente se atribuye a Juliano puede ser el suyo, aunque admite la posibilidad de que sea otro, publicado y estudiado por C. Mango. Rechaza la hipótesis de Maricq señalando que para él los textos de Zonaras y Cedrenos son suficientemente claros (lo cual es válido en todo para el de Cedrenos y de ninguna manera para el de Zonaras), aunque reconoce que no se puede dar crédito total a los cronistas bizantinos cuando mencionan inscripciones. Se inclina a creer que el epitafio de Zonaras/Cedrenos es el verdadero considerando que el transmitido por Zósimo es una cita de memoria (19). Por último, Cyril Mango, estudiando la descripción que dio de los sarcófagos descubiertos en Constantinopla en 1750 por el mercader francés J. C. Flachat (f. 2), llega a la conclusión de que puesto que uno de ellos es cilíndrico y de pórfido, éste podría ser, quizá con más probabilidad, el de Juliano a pesar de que lleve inscrita una cruz en uno de los lados. Este sarcófago podría haber llevado la inscripción, aunque resulta muy extraño que Flachat no la hubiese registrado en su descripción (MANGO, 1962, 401).

(19) Ph. GRIERSON $(1962,41)$. La poca credibilidad de los autores bizantinos citando inscripciones analizada en G. DOWNEY (1935, 55-72). Ph. Grierson piensa a propósito del epitafio citado en Zósimo en una segunda posibilidad: esto es, que fuera «a first draft of the epigramm formulated when the news of Julian's death had reached his friends and nothing had yet been determined regarding his place of burial». Esta hipótesis está hecha en base a una interpretación del epigrama que yo creo equivocada. 


\section{CONCLUSION}

Expuesta ya la problemática es conveniente ahora hacer un resumen de lo dicho para llegar a establecer unas posibles conclusiones.

Hemos dejado establecido que Juliano fue transportado desde el lugar de su muerte a Tarso porque él había expresado su deseo de residir en esta ciudad a la vuelta de la campaña y no porque hubiera ordenado expresamente que se le enterrase allí. Acompañó su cadáver Procopio, al parecer con parte de sus tropas. Su enterramiento fue precipitado debido a la prisa de Procopio en desaparecer u ocultarse. En su sarcófago se grabó un epitafio que fue recogido por Oribasio (si es que no lo redacto él mismo). Eunapio lo tomó de Oribasio y Zósimo lo repite resumiendo la idea central del mismo. El compilador del libro VII de la Antología (o uno de ellos) - como señaló ya Preger-- habiendo leído a Zósimo, incluyó los versos atribuyéndoselos «sua sponte» a Libanio. Zonaras recoge el epitafio in extenso que se conservó igualmente en Cedrenos. Según Zósi-

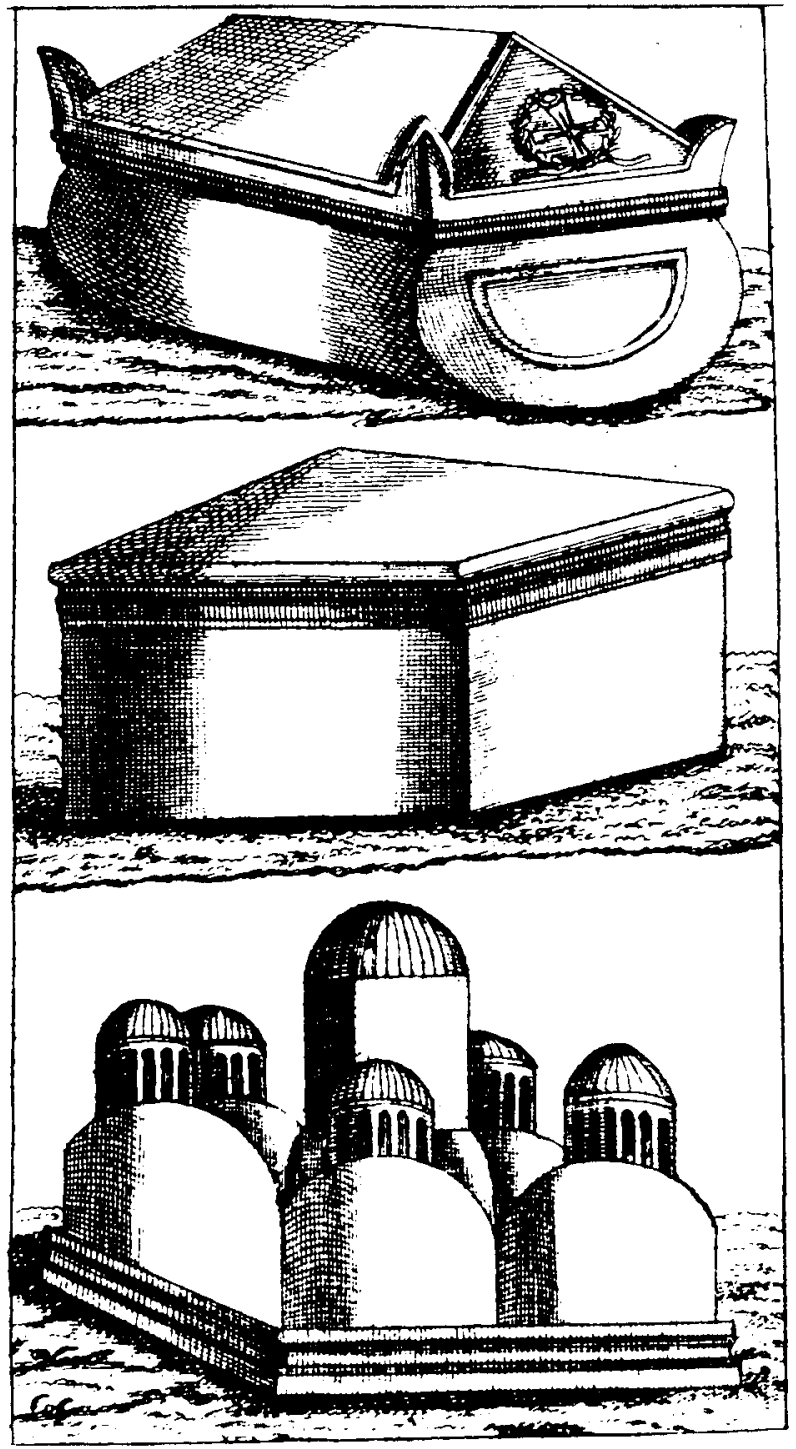

Figura 3.-Sarcófagos bizantinos. 
mo y Zonaras el epitafio se grabó en el sepulcro o sarcófago de Tarso. Según Cedrenos estaba, al menos, en el de Constantinopla. Ahora bien, si el sarcófago de Constantinopla que pasa por ser el de Juliano es el mismo que el de Tarso, tendría que conservar entonces la inscripción. Pero ello no es así, y por lo tanto hay que considerar las siguientes posibilidades:

a) Que la inscripción no fuera escrita en el sarcófago sino en una piedra o placa adyacente al mismo (Vasiliev).

b) Que el sarcófago de Tarso no fue el mismo que el de Istambul, y por eso no aparece en él la inscripción (Maricq). Esto implicaría que Cedrenos no es exacto en su relato, lo cual es altamente posible y lícito de suponer.

c) Que el sarcófago de Istambul no tenga en absoluto nada que ver con Juliano (en realidad la expresión $\quad x u \lambda \iota v \delta p o \varepsilon \iota \delta n ́ s$ no se aviene perfectamente con el sarcófago supuesto), y que, en cambio, sea el descrito por Flachat, descubierto en 1750, de forma cilíndrica también. Puesto que éste no se conserva (MANGO, $1962,400)$ no podemos saber si llevaba o no la inscripción. Flachat al menos no dice nada de ella en su descripción, lo cual es significativo, pues si hubiera existido la hubiera descrito también.

Por lo tanto y puesto que la hipótesis de Vasiliev es insostenible -como hemos dicho- hay que considerar que Maricq está en lo cierto al afirmar que hubo al menos dos sarcófagos para Juliano: uno, el de Tarso, desaparecido y con la inscripción-epitafio; el otro, el de pórfido de forma cilíndrica sin inscripción. Abonaría esta hipótesis el hecho de la aseveración de Delbrueck de que el de Istambul es un sarcófago tolemaico. Ahora bien, ¿se puede pensar que se trajo un sarcófago de Alejandría a Tarso a los tres meses de su muerte, o es más lógico que esto se hiciera a Constantinopla al cabo de varios años y como consecuencia del traslado solemne del cadáver del Emperador a la capital de la Pars Orientis? Este traslado debió de suceder o en 391-392 -porque en 390 todavía estaba Juliano enterrado en Tarso como se desprende del texto de Ammiano 25.10.5 - o como consecuencia del Edicto de León I recogido en $C J$ I.9.5 en 457.

No obstante, la posibilidad de que el sarcófago descrito por Flachat sea el de Juliano es muy digna de tener en cuenta y tiene a su favor el hecho de que se aviene mejor con la descripción de los historiadores bizantinos. Aunque ello fuera así hay que afirmar que hubo dos sarcófagos para Juliano.

Así pues, el sarcófago que hay a la entrada del Museo Arqueológico de Istambul que reproducimos en la figura 1, puede ser el que tuvo el cuerpo del gran Juliano, pero no es absolutamente seguro. Quizá se haya perdido para siempre como se perdieron todas las ilusiones y energías de aquel hombre extraordinario.

\section{ABREVIATURAS}
AJPh American Journal of Philology.
$B Z \quad$ Bizantinische Zeitschrift.
CJ Classical Journal.
DOP Dumbarton Oaks Papers.
FHG C. Müller's Fragmenta Historicorum Graecorum. (París).
JHS Journal of Hellenic Studies.
JRS Journal of Roman Studies.
MAMA W. M. Calder (ed), Monumenta Asiae Minoris Antiqua, Manchester, 1928-1962, vols. VII y VIII.
$P W \quad$ Pauly-Wissowa-Kroll's, Real Encyclopädie der Classischen Altertumswissenschaft.
TAPA Transactions of the American Philological Association. 


\section{BIBLIOGRAFIA}

ALLARD, P. 1910: Julien l'Apostat. III, París.

ARCE, J. 1975: Estudios sobre las fuentes literarias, epigráficas y numismáticas para la historia del Emperador Juliano, Tesis Doctoral mecanografiada.

BIDEZ, J. 1930: La vie de l'Empereur Julien, París.

CALZA, R. 1973: Iconografia Romana Imperiale, Roma.

CAMERON, A. 1969: The Date of Zosimus New History, Philologus, 113, 106-110.

- 1971: Ammianus and the Historia Augusta, JRS, 61, 255 ss.

DELBRUECK, R. 1932: Antike Porphywerke, Berlín, T. 107.

DILLEMANN, L. 1961: Ammien Marcellin et les pays de l'Euphrate et du Tigre, Syria, 38, 87-158.

DOWNEY, G. 1935: References to inscriptions in the Chronicle of Malalas, TAPA, 66, 55-72.

- 1959: The Tombs of the Bizantine Emperors at the Church of the Holy Apostles in Constantinople, JHS, 79, 27-51.

EBERSOLT, J. 1951: Constantinople: Recueil d'études d'Archéologie et d'Histoire, París.

EPHRAEM DES SYRIERS, 1957: Hymnen de Paradiso und contra Julianus, Corpus Scriptorum Orientalum, 79, Lovaina.

FÖRSTER, R. 1876: Die Schriftstellen des Libanios, Jahrbücher für Classische Philologie, 22, 213-214.

GRIERSON, Ph. 1962: The Tombs and Obits of the Byzantine Emperors (337-1042), DOP, 16, 3-63.

JANIN, R. 1953: La Géographie ecclésiastique de l'Empire Byzantin, I, París.

MAENCHEN-HELFEN, O. 1955: The Date of Ammianus Marcellinus' Last Books, $A J P h, 76,385$ ss.

MANGO, C. 1962: Three Imperial Byzantine Sarcophagi discovered in 1750, DOP, 16, 401.

MARICQ, A. 1952: Notes Philologiques: 4. Les sarcophages impériaux de Constantinople, Bizantion, 22, 320-321.

NOCK, A. D. 1957: Deification and Julian, JRS, 47, 115 ss.

NORMAN, A. F. 1969: Libanius Selected Works, I, Cambridge Mass. (Loeb Series).

PASCHOUD, F. 1971: Zosime. Histoire Nouvelle. I, París.

PEECK, W. 1960: Griechische Grabgedichte, Berlín.

PIGHI, G. B. 1935: Ammiani Marcellini Rerum Gestarum, Milán.

PROCEEDINGS of the Classical Association, vol. LXIX, 1972.

RIDLEY, R. T. 1972: Zosimus the Historian, BZ, 65, 277 ss.

ST. CLAIRE, A.: The Apotheosis Diptych, Art Bulletin, 205 ss.

STRAUB, J. 1962: Die Himmelfahrt des Julianus Apostata, Gymnasium, LXIX, 310-326.

TURCAN, R. 1975: Mithras Platonicus. Recherches sur l'Héllénisation philosophique de Mithra, Leiden. VASILIEV, A. A. 1948: Imperial Porphyry Sarcophagi in Constantinople, DOP, 1-26.

WULZINGER, K. 1932: Die Apostelkirche und die Mehmedije zu Konstantinopel, Byzantion, 7, 7-39. 



\title{
ARCOS ROMANOS EN EL PAIS VALENCIANO: LOS TESTIMONIOS EPIGRAFICOS
}

\author{
LORENZO ABAD CASAL \\ Universidad de Alicante
}

\begin{abstract}
Varias inscripciones de Castellón y Alicante en las que se menciona la palabra arcum permiten suponer la existencia de al menos dos arcos honorarios, construidos por particulares en recuerdo de allegados fallecidos.

Several inscriptions from Castellon and Alicante in which the word arcum appears lead us to suppose that there existed at least two honorary arches, built by citizens in memory of dead relatives.
\end{abstract}

Entre los monumentos romanos atestiguados por la epigrafía en el País Valenciano figuran varios arcos a los que aún no se les ha prestado la atención que merecen. Son los siguientes:

1. CIL, II, 3558:

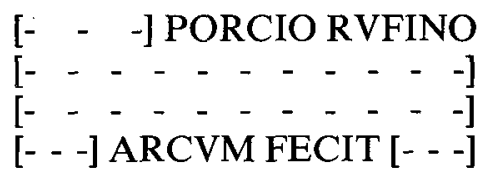

Se trata de una inscripción hoy desaparecida que, según Hübner, se encontró «en los antigones, hasta donde llegava el sitio de la antigua Ilici; tenía 4 palmos de ancho, 6 de largo, comidas las letras del tiempo, de las aguas y del viento del mar...; se cree que estava junto al arco, que se hizo para conducir por él agua que de la Alcornia (?) venía a esta ciudad (de Alicante); pues hasta en los antigones donde se halló esta lápida se descubren vestigios del conducto. Está en el huerto de Baver». La fuente de donde la recogió Hübner es el Anonymus Montfauconii, obra probablemente de Bernard de Montfaucon, escrita a mediados del siglo XVII.

2. CIL, II, 3997 (fig. 1):

QVINTIA.PROBA

SIBI.ET.PORCIO

RVFO.ET.PORCIO

RVFINO.ARCVM

FECIT.ET.STATVAS

SVPERIMPOS.HS.N.XL.E(...) 


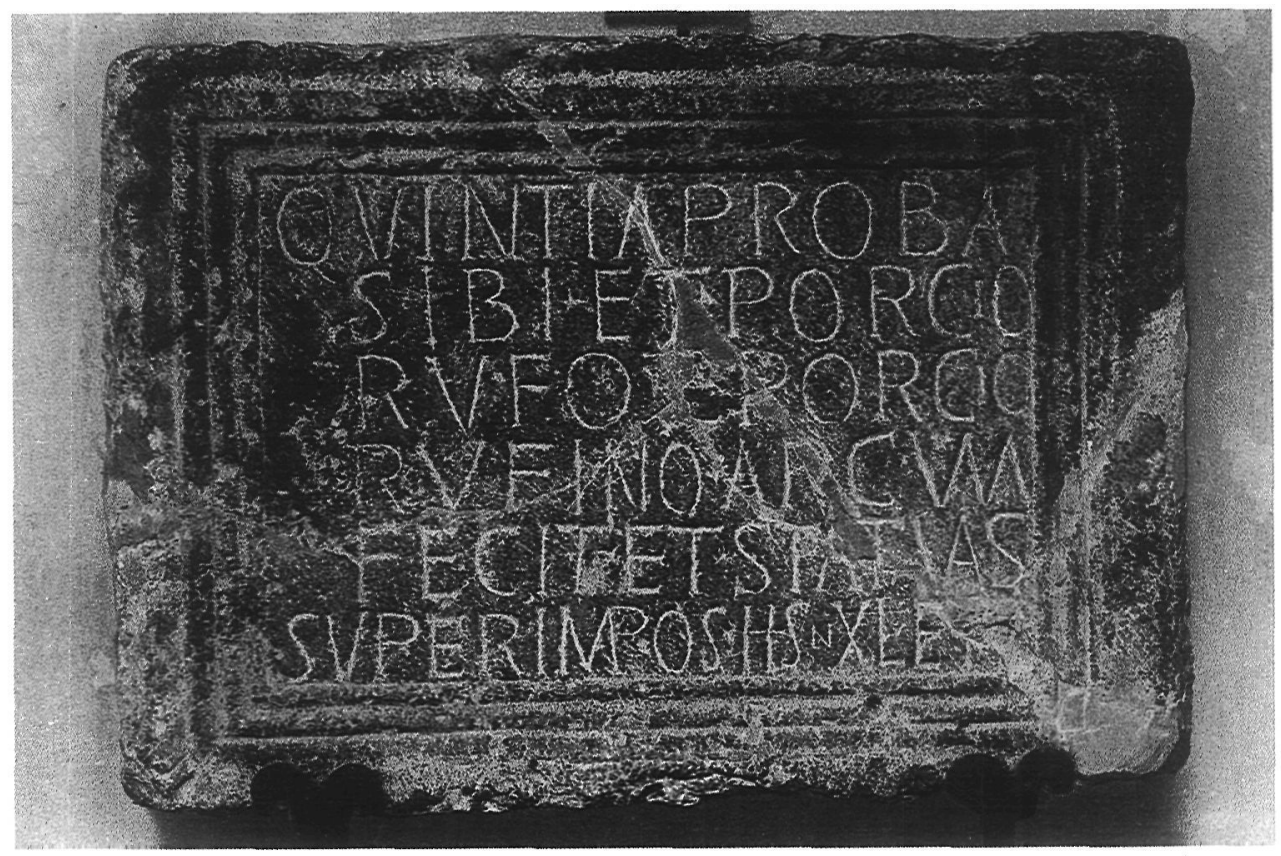

Figura 1. - CIL, II, 3997

Corresponde a una inscripción realizada sobre un bloque de mármol negro, dentro de una cartela moldurada. Ya aluden a ella Diago y Escolano, a comienzos del siglo XVII y, años más tarde, el Conde de Lumiares y otros escritores valencianos. Aunque casi todos los autores la dan como procedente de Jérica, en cuyo museo se conserva actualmente, en alguna ocasión se cita como aparecida en Ondara (cf. RIPOLLES, 1976, 82).

3. MONTESINOS, ms., t. IX, f. 1066, s. v. Petrel:

QV.I...) (...RVFA. SIBI.ET (

MALCO. PAMBINO. ARCVM. FECIT

ET... STATVAS

SVPERI.... HS XXIIII. EA ?

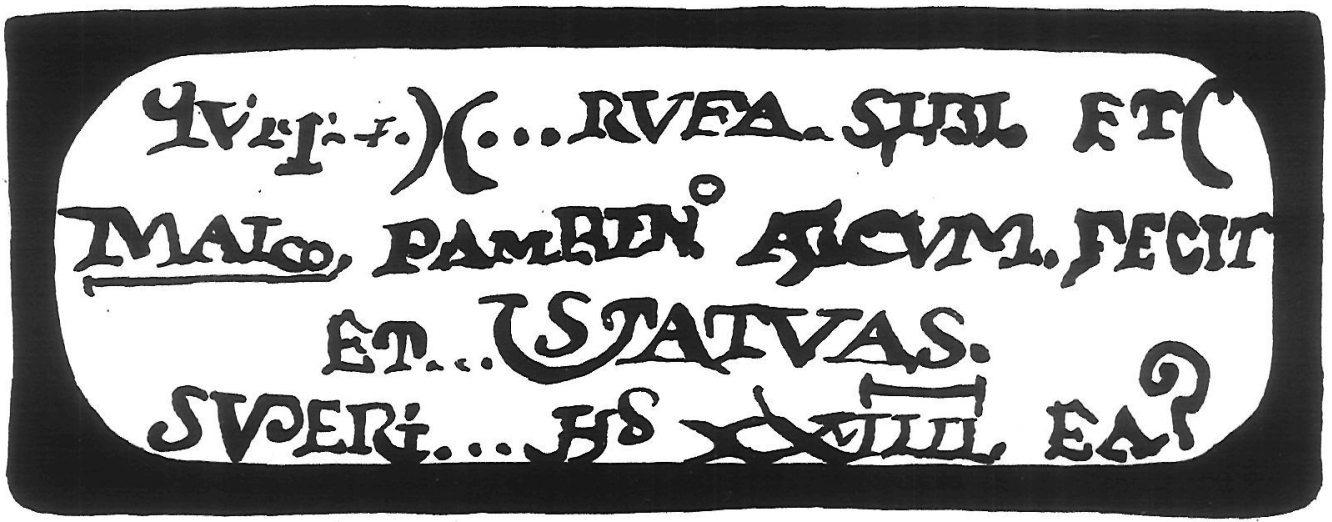

Figura 2.- Supuesta inscripción de Petrel. 
Presenta esta inscripción numerosas lagunas y dificultades de interpretación, como otras muchas de las que se recogen en la obra del canónigo Montesinos. Parece que puede identificarse el nombre de una posible dedicante, Quintia (?) Rufa, el de aquel al que se le dedica, Malco (sic) Pambino, el objeto dedicado, arcum et statuas, y su valor, 24.000 (o 29.000, ya que la cifra no se aprecia con total claridad) sestercios. Albergamos serias dudas sobre la veracidad de este epígrafe, ya que por una parte es conocido que este autor no tuvo reparos en aducir en favor de sus teorías pruebas documentales inexistentes, y por otra esta inscripción nos trae inmediatamente el recuerdo de la de Jérica, que ya era conocida en el momento en que el canónigo Montesinos escribe su obra. Malco podría interpretarse como una mala lectura de Marco, aunque resulta extraño que aparezca completamente desarrollado, y el nomen Pambino no se encuentra atestiguado, ni siquiera como cognomen, en la epigrafía romana peninsular. Además, curiosamente, ambas inscripciones se interrumpen al final de manera muy parecida.

Todas estas inscripciones, excepto la última, que ha permanecido inédita hasta ahora y hemos podido conocer gracias a la amabilidad de $\mathrm{C}$. Navarro, han sido publicadas en varias ocasiones, aunque no siempre se las ha puesto en relación, como hizo ya Hübner en el $C I L$. La primera ha sido adscrita tradicionalmente a la ciudad de Illici, siguiendo a este autor, aunque creemos más fundada la tesis de Tarradell $(1970,16$ ss.) de que debería corresponder a la de Alicante, ya que el topónimo con el que se designa su lugar de aparición (Los Antigones), si bien es citado por Escolano entre Illici y Lucentum, parece más bien corresponder al área occidental de la ciudad de Alicante, donde debió alzarse la ciudad de Lucentum (ABAD, 1984). Tarradell (op. cit.) supuso - y en ello le siguieron otros autores - que la palabra arcum haría referencia a un acueducto que, como ya indicaba Hübner, conduciría el agua desde las fuentes de La Alcornia hasta la ciudad. Sin embargo, ya expusimos en otro lugar (ABAD, 1983) nuestras sospechas de que este término no debía referirse a un acueducto, que casi siempre aparece citado en la epigrafía como aqua o aquae ductus, y en las escasas ocasiones en que realmente se refiere a una traída de aguas, lo hace acompañado por otros vocablos que precisan su significado; es lo que ocurre, por ejemplo, con una inscripción del siglo I d. C. que nos informa de que (...) arcus ductus aquae Virginis disturbatos per C. Caesarem / a fundamentis novos fecit ac restituit (CIL, VI, 1252), y con otra del cónsul Sextus Vitulasius, que da cuenta de que en el año 78 d. C. aquam Augustam adiect(am) fontibus novis sua pec(unia) perduxit et arcus novos fecit (CIL, VI, 32.362).

En la inmensa mayoría de los casos, el término arcus se refiere a construcciones monumentales exentas, de uno o más vanos, y de carácter conmemorativo u ornamental (KAEHLER, 1939 [1974], 374 ss.), adornados frecuentemente con estatuas en su parte superior y relieves en sus paredes. Según Plinio, estos arcos tuvieron una finalidad muy semejante a la de las columnas honorarias anteriores: elevar la figura -o las figuras - a las que sirven de pedestal sobre el mundo cotidiano: columnarum ratio erat attoli super ceteros mortales, quod et arcus significant novicio inventu (NH, XXXIV, 27). Los arcos romanos más antiguos de que tenemos noticia por las fuentes literarias, los de L. Sterninius, de 196 a. C.; P. Cornelius Scipio, de 190; Q. Fabius, de 121, etc., son construidos por generales victoriosos, aunque poco después los mandarán construir también personas que desempeñaban cargos públicos de índole administrativa, como Verres en Sicilia. Con la llegada del Imperio, el triunfador por antonomasia es el emperador, por lo que la inmensa mayoría de los arcos serán construidos por los emperadores o para los emperadores, exaltando sus victorias o sus obras de cualquier tipo (MANSUELLI, 1954, 107 ss.; 1978, 15 ss.). Pero junto a estos arcos, que podemos considerar «oficiales», hay otros que son, incluso en plena época imperial, erigidos por particulares para conmemorar el desempeño de un cargo, contribuir al embellecimiento de la ciudad o recordar a algún allegado fallecido. Este último es el grupo que aquí nos interesa. 
Se trata de arcos que tienen un marcado carácter funerario, aunque en casi ningún caso constituyen verdaderas tumbas (cf. EAA, s. v. monumentum funerarium a fornice). Son más bien monumentos honorarios, erigidos en lugares públicos, fuera de las. necrópolis, en memoria de una persona o de una familia destacada.

Arco de este tipo es el de la familia Sergia en Pola (Italia), datado, según la mayor parte de los investigadores, en época augústea; reúne todas las características de un arco monumental honorario (KAEHLER, 1939, 407; SCAGLIARI CORLAITA, 1979, 52; TRAVERSARI, 1971). Lo dedicó Salvia Postuma, de sua pecunia, y mostraba, sobre cuatro pedestales destacados en el ático del monumento, las estatuas de otros tantos miembros de la familia $(C I L, \mathrm{~V}, 50)$, con sus correspondientes inscripciones.

Otro arco de este tipo es el de la familia Gavia en Verona (Italia), también del siglo I d. C. y situado, en este caso, en las afueras de la ciudad, sobre una de las vías de acceso (KAEHLER, 1939, 413; SCAGLIARI CORLAITA, 1979, 63 ss.; TOSI, 1983). Estaba adornado con estatuas y bustos de la familia constructora; las primeras estaban situadas sobre el ático, y los segundos en hornacinas en las paredes. Aún hoy se conservan algunos de los epígrafes con los nombres de los representados.

El arco de Aix-les-Bains (Francia) se incluye también en este grupo; se trata de un monumento construido en el siglo I d. C. por L. Pompeius Campanus, en vida, para sus familiares y amigos (KAEHLER, 1939, 414; CIL, XII, 2473). Muestra dos hileras de ocho inscripciones cada una, las inferiores al pie de nichos que debieron acoger otros tantos bustos, ya que no parece lógico que las urnas cinerarias estuviesen en sitio tan accesible, y las superiores bajo otras tantas estatuas colocadas sobre el ático del monumento.

Arco honorario dedicado por y para particulares es también el cuadrifronte de Cáparra, estudiado no hace muchos años por A. García y Bellido (1972-74, 45 ss.); presenta estatuas sobre basamentos adosados a las pilas del arco, con sus correspondientes inscripciones, que nos indican quién mandó construir el monumento (M. Fidius Macer) y en honor de qué familiares lo hizo, aunque en este caso todo ello se encuentre bajo la advocación de la diosa indígena Trebaruna.

Pero el arco que mayor relación muestra con los valencianos, al menos en lo que a la inscripción se refiere, es el de Zara (Yugoslavia), erigido en el siglo III d. C., según Kaehler $(1939,451)$, delante de una de las puertas de la ciudad, en honor de Q. Laepicius Bassus por su esposa, tal y como reza la inscripción (CIL, III, 2922): Melia Anniana in memor(iam) Q. Laepici Q. f. Serg(ia tribu) Bassi mariti sui / emporium sterni et arcum fieri et statuas superponi test(amento) iuss(it) ex sextertiis DC d(educta) XX p(opuli) r(omani). Su carácter funerario y conmemorativo es muy claro en este caso, pues fue construido por mandato testamentario de una mujer, en memoria de su marido, junto con un emporium, y sirvió de basamento a unas estatuas que, aunque no se diga, debieron representar a los miembros de la propia familia. Todo el conjunto costó una cantidad de 600.000 sestercios, una vez deducido el impuesto correspondiente. Esta inscripción nos reafirma en la creencia, antes expresada, de que estos monumentos no constituyen tumbas propiamente dichas, ya que es de suponer que arco y emporium estuviesen próximos, y difícilmente podemos concebir un mercado junto a un recinto funerario.

En ocasiones, y como indica Scagliari Corlaita $(1979,65)$, algunos de estos arcos, erigidos fuera de la ciudad, pudieron indicar el límite entre el territorio urbano y el de la necrópolis, lo que permitiría explicar mejor su condición de monumento en parte honorífico y en parte funerario.

Las inscripciones de Zara, Jérica y Petrel —esta última tomada con toda clase de reservas- son bastante semejantes, pues mencionan la construcción de un arco, ornado con estatuas, en tanto que la de Alicante sólo conserva la mención del arco, aunque es 
posible que su desarrollo originario fuera parecido al de las anteriores. Esta semejanza de fórmulas entre todas las inscripciones valencianas, y el que en todas ellas se repitieran los mismos nombres, nos hizo sospechar en un primer momento que sólo una de ellas fuera auténtica, aunque tras un estudio más detenido creemos que lo son las de Jérica y Alicante, ya que las fuentes que las recogen por primera vez (Diago y Escolano para la primera, Montfaucon para la segunda) son casi contemporáneas y dignas de confianza. Es más, no parece lógico que un falsario que tomara como modelo la lápida de Jérica se limitara a copiar tan sólo dos palabras que hacen que la inscripción sea en buena parte ininteligible. No ocurre así, en cambio, con la de Petrel, para la que ni el transmisor ni el contenido ofrecen demasiadas garantías de autenticidad.

La información que podemos obtener del estudio de las inscripciones valencianas es bastante escasa, ya que no se conserva resto alguno de los monumentos a que pertenecieron y ni siquiera conocemos su procedencia exacta. La vía más importante, el estudio antroponímico, nos indica que todas las personas relacionadas con estos monumentos pertenecen a las familias Porcia o Quintia y llevan como cognomen Rufus, Rufinus o Probus. Parece que es en el triángulo Bejis-Jérica-Viver donde más abundan estos nombres, ya que aquí encontramos una Cornelia Proba (RIPOLLES, 1976, 38), un L. Quintius Prob(us) (RIPOLLES, 1976, 79), un cognomen Rufino (CIL, II, 3999) y un L. Porcius Probus (o Reprobus), este último en una inscripción también en mármol negro, empotrada en la torre de la iglesia de Viver (CIL, II, 4010; RIPOLLES, 1976, 134).

Pero la inscripción más interesante de todas es sin duda otra de Viver $(C I L$, II, 4011; RIPOLLES, 1976, 125), publicada como la anterior por Diago y Lumiares, quien afirma $(s f, 355)$ que se encontraba también en la torre de la iglesia, algo más arriba que aquélla. De las palabras de Hübner (iuxta praecedentem) se desprende que aún en su tiempo se encontraba en este sitio, pero hoy ha desaparecido. Su autenticidad parece comprobada, no obstante, por el hecho de que todavía se conserva la número 4010, junto a la que se encontraba ésta, y porque el Conde de Lumiares, que vio las dos, hizo pública su sospecha, recogida por Hübner, de que la número 4010 era falsa o al menos estaba muy retocada, mientras que no expresó duda alguna acerca de la que aquí nos interesa, la número 4011. De ésta se han publicado varias lecturas, aunque las que creemos más aceptables son las del Conde de Lumiares y Hübner, seguida esta última por Ripollés. Como ambas lecturas difieren en algunos puntos, y son de interés para la interpretación que más adelante haremos del epígrafe, las reproducimos a continuación:

Lumiares: Marco Porcio, Galeria, Rufino: Marcus Porcius, Marcifilius, Rufus annorum septuaginta et quinque...tia, Marci filia Proba.

$\begin{array}{ll}\text { Hübner: } & \text { M. PORCIV̦ m.fil } \\ & \text { GAL.RVFINus an... } \\ & \text { M.PORCIVS.M.f.gal } \\ & \text { RVFVS.AN.LXV grat } \\ & \text { TIA .M.F.PRima mater }\end{array}$

Las diferencias de lectura se deben al diferente desarrollo que ambos autores hicieron de la parte derecha de la inscripción, que ya entonces faltaba, tal y como puede observarse en el dibujo correspondiente del Conde de Lumiares. Este transcribe el primer nombre en dativo porque creyó ver restos de una $\mathrm{O}$ en el borde derecho del fragmento, donde Hübner, en cambio, observó trazas de las letras IV, por lo que lo desarrolló en nominativo, caso en que se encuentran los demás nombres. Pero lo más importante, desde nuestro punto de vista, es que en esta inscripción tenemos atestiguados dos de los tres nombres que aparecen en la del arco de Jérica y el que podía leerse en la del de Ali- 
cante: $M$. Porcius Rufus y $M$. Porcius Rufinus. Es más, creemos que también es posible identificar el tercero: Quintia Proba. La última línea es de lectura difícil, tanto que el primer editor de la lápida, Diago, la suprimió por completo, pero los demás autores coinciden en transcribir tia.m.f.pr(...). Lumiares desarrolla el Pr final como Proba, Hübner como Prima mater y Ripollés como Prima. La -tia inicial debe ser la parte final de un nombre cuyas primeras letras, por encontrarse al final de la cuarta línea, han desaparecido, como toda la parte derecha de la inscripción. Lumiares lo suplió como Ces, suponiendo la existencia de una Cestia Proba, y Hübner y Ripollés como Grat, con lo que nos encontraríamos ante Gratia Prima. Cualquiera de estas soluciones es teóricamente correcta, pero si en la cuarta línea supliéramos Quin y en la quinta desarrolláramos $\operatorname{Pr}$ como Proba, tendríamos el nombre de Quintia Proba, el mismo que encontramos como dedicante del arco de Jérica, aunque en este caso haciendo mención de su filiación. La inscripción, pues, quedaría de la siguiente forma: $M$. Porcius [m(arci) f(ilius)] / Gal(eria tribu) Rufin[us an...] / M. Porcius M(arci) [f(ilius) Gal(eria tribu)] / Rufus.an(norum) lxv [Quin] / tia.m(arci).f(ilia).Pr[oba].

De su cotejo con la inscripción de Jérica se deduce claramente que nos encontramos ante la lápida funeraria de las tres personas que fueron honradas en el arco allí erigido, lo que confirma plenamente que éste no era en realidad su tumba, sino un verdadero monumento honorífico, y que fue la propia Quintia Proba la que mandó hacer tanto el arco como el epitafio en honor y recuerdo de su marido Porcius Rufus, de su hijo Porcius Rufinus y de ella misma. Cabría, no obstante, la sospecha de que ambas inscripciones, pese a encontrarse en lugares distintos, formasen parte originariamente del mismo monumento, esto es, del arco. Sin embargo, en los demás monumentos conocidos, las inscripciones nunca indican la edad de las personas a que se hace referencia, lo que sí ocurre en la inscripción de Viver de que estamos tratando en este momento. Parece claro, por tanto, que ésta es una inscripción funeraria y que nunca formó parte del arco monumental.

Como ya antes indicamos, los nomina y cognomina de todas estas personas aparecen con gran frecuencia en el triángulo Bejis-Jérica-Viver, lo que parece demostrar que era aquí donde estaban establecidas estas familias. El nomen menos frecuente, el de Quintia, no aparece en los territorios vecinos de Saguntum ni Valentia, y en cambio se encuentra en otras inscripciones de la zona; así, en $C I L$, II, 3998, encontramos un Quin(tius) Urb(icus) idéntico al Q(uintius) (?) Urbicus de una inscripción de Tarragona (CIL, II, 4163 y 6071; ALFOELDY, 1975, 370), si es que ambos desarrollos son correctos; en su favor viene el hecho de que el Quintius Urbicus de Tarragona aparece como codedicante, ya en el siglo III d. C., de una inscripción funeraria junto con un Porc(ius) Paris, con lo que tendríamos asociados a dos personajes cuya relación familiar está claramente demostrada por los testimonios epigráficos de Jérica.

El nomen Porcius, bastante frecuente en la Península Ibérica, tampoco aparece en el vecino territorio de Saguntum, aunque sí en el de Valentia (PEREIRA, 1979, 45) y en el más lejano de Tarraco (ALFOELDY, 1975). Rufus y Rufinus, asimismo de larga tradición epigráfica, aparecen nuevamente en la misma provincia de Castellón, algo más al norte, en el término de Alcora (RIPOLLES, 1976, 5 y 6), pero en Sagunto sólo se encuentran ẹn una ocasión cada uno (BELTRAN, 1980, 41, 44) y son desconocidos en Valencia. Más extraño es el Proba utilizado como cognomen, que en su forma masculina aparece en dos ocasiones en Sagunto (BELTRAN, 1980, 79 y 189).

La importancia de este enclave epigráfico castellonense y su relativa independencia de Sagunto y Valencia ya fue puesta de manifiesto por M. Bèltrán (1980, 355 ss.), quien sugirió una posible relación con Edeta, donde sin embargo no se encuentran atestiguados los nombres que aquí nos ocupan. Más bien podríamos pensar en una relación con Tarraco, ya que los nombres, e incluso las asociaciones familiares propias de Jérica- 
Viver-Belchís están allí bien representados. El propio Beltrán (loc. cit.), y Oliver y Palomar $(1980,123)$ hacen ver que entre estas inscripciones se encuentran varias que mencionan monumentos importantes, lo que interpretan como un evidente signo de romanización. A las inscripciones que aquí hemos comentado habría que añadir otra, también de Viver, en la que se menciona la erección de estatuas: (...) P. Domitio Sabino / (...) Fabiae Atticae / (...) statuas posuit (...) (CIL, II, 4009).

La cronología de los arcos mencionados en estas lápidas es bastante difícil de precisar, ya que los nombres de los dedicantes son, como hemos indicado, muy corrientes (cf. KAJANTO, 1982 (r), s. v., para los cognomina), y de la observación paleográfica es bien poco lo que puede deducirse: que aquellas inscripciones que aún hoy son visibles parecen de datación altoimperial. Dos de los epígrafes (CIL, II, 4010 y 3997) presentan motivos decorativos complementarios que pueden servirnos para el establecimiento de una datación aproximada, aunque la relación del primero de ellos con el tema que nos ocupa es mínima. El otro, precisamente en el que se menciona el arco de Jérica, es un bloque de mármol negro en el que la inscripción aparece rodeada por un marco moldurado. Pese a que el estudio de los aspectos formales de los epígrafes se encuentra aún en sus comienzos, el de M. Beltrán para una zona tan próxima como Sagunto puede constituir un buen punto de partida. Este epígrafe podría incluirse, aunque con reservas, en su grupo IIIc, estrechamente relacionado con el IIIf, y datables ambos «a partir del siglo II d. C.», fecha que creemos podría convenir a nuestra lápida de Jérica sin ningún problema.

El interés de esta inscripción se acrecienta aún más por el hecho de que en ella se nos indica la cantidad que Quintia Proba pagó para la construcción del arco: unos cuarenta mil sestercios. En este precio deben incluirse tanto el arco propiamente dicho como las estatuas colocadas sobre él, que deben ser dos o, más probablemente, tres. Esta cantidad puede parecer modesta si se compara con los seiscientos mil sestercios de la inscripción de Zara, aunque hemos de tener en cuenta que en ésta se incluye, además del arco y las estatuas, un emporium que debió ser asimismo de elevado costo. Hemos de convenir, de todas formas, que el arco costeado por Quintia Proba debió ser bastante menos ostentoso que aquél, que es de un solo vano y regulares dimensiones; más pequeño debería ser aún el arco de Petrel, en el caso, que creemos poco probable, de que esta inscripción fuera auténtica, ya que arco y estatuas no sobrepasaron los $24.000-0$ 29.000, en el mejor de los casos- sestercios.

Aunque hay factores de gran importancia que se nos escapan, como el del valor del sestercio en el momento de construcción de uno u otro arco (no se olvide que para el de Zara se ha propuesto una datación de mediados del siglo III, momento de inflación galopante), creemos interesante llamar la atención sobre el costo de algunos monumentos en el siglo II d. C., fecha a la que probablemente corresponde nuestro arco. En este momento, el coste de un monumento de este tipo en Africa (aunque es difícil precisar sus dimensiones y riqueza ornamental) oscilaba entre 30.000 y 70.000 sestercios (DUNCAN JONES, 1982(r), 91; RAMIREZ SADABA, 1983, 238), y el valor medio de una estatua era de unos 5.500 sestercios. Por 30.000 sestercios se podía construir un templo, un pórtico o un mercado de no muy grandes dimensiones. El precio de los monumentos funerarios oscilaba en Africa entre 100 y 800.000 sestercios y entre 120 y 500.000 en Italia. Hemos de concluir, pues, que en el siglo II d. C., fecha probable de construcción del monumento de Jérica, con 40.000 sestercios, sólo pudo erigirse un arco en línea con los más modestos que por entonces se construían en otros lugares del Imperio. 


\section{BIBLIOGRAFIA}

ABAD CASAL, L. 1893 [1985]: «Arqueología romana del País Valenciano». Arqueología del País Valenciano: panorama y perspectivas. Anejo II de la revista Lucentum. Alicante.

- 1984: Los orígenes de la ciudad de Alicante. Alicante.

ALFOELDY, G. 1975: Die römischen Inschriften von Tarraco. Berlín

BELTRAN LLORIS, M. 1980: Epigrafía latina de Saguntum y su territorio. Valencia.

CIL: Corpus Inscriptionum Latinarum.

DIAGO, F. de, 1920: Anales del Reyno de Valencia. Madrid.

DUNCAN JONES, R. 1982(r): The Economy of the Roman Empire. Cambridge.

EAA: Enciclopedia dell'arte antica.

GARCIA Y BELLIDO, A. 1972-74: «El arco tetrápylon de Cáparra (Cáceres)». AEspA, 45-47.

HÜBNER, E. Vid. CIL, II.

KAJANTO, I. 1982(r): The Latin Cognomina. Helsinki.

KAEHLER, 1939: «Triumphbogen». RE, VIIA, s.v.

LUMIARES, Conde de, sf: Inscripciones y antigüedades del Reyno de Valencia. Memoria de la Real Academia de la Historia.

LLOBREGAT, E. 1980: Nuestra Historia. II: La romanización. Valencia.

MASUELLI, G. 1954: «El arco honorífico en el desarrollo de la arquitectura romana». AEspA, 27.

- 1979: «Fornix e arcus. Note di terminologia». Studi sull'arco onorario romano. Roma.

MONTESINOS PEREZ Y MARTINEZ DE ORUMBELLA, J., sf: El Compendio histórico de Orihuela, XII vols. $M$ s.

OLIVER, A., y PALOMAR, V. 1980: «Inscripciones ibéricas del Alto Palancia. Notas para el estudio de la latinización de Castellón». Cuadernos de Prehistoria y Arqueología de Castellón, 7.

PEREIRA, G. 1979: Inscripciones romanas de Valentia. Valencia.

RIPOLLES, P. P. 1976: «Sinopsis de epigrafía castellonense». Cuadernos de Prehistoria y Arqueología de Castellón, 3.

SCAGLIARI CORLAITA, D. 1979: «La situazione urbanistica degli archi onorari nella prima età imperiale». Studi sull'arco onorario romano. Roma.

TARRADELL, M., y MARTIN, G. 1970: Els Antigons-Lucentum. Una ciudad romana en el casco urbano de Alicante. Valencia.

TOSI, G. 1983: L'arco dei Gavi. Roma.

TRAVERSARI, G. 1971: L'arco dei Sergi. Padova. 


\title{
REFLEXIONES ACERCA DE LA SOCIEDAD HISPANA REFLEJADA EN LA «GEOGRAFIA» DE ESTRABON *
}

\author{
ADOLFO J. DOMINGUEZ MONEDERO \\ Universidad Autónoma de Madrid
}

\begin{abstract}
Con el presente trabajo me planteo una reflexión acerca de la visión que transmite el geógrafo griego Estrabón, de Iberia, desde el punto de vista de algunos de los elementos que configuran la vida organizada socialmente de sus pueblos, pero también del papel que dentro de la misma ocupa el fenómeno conocido como «romanización», al menos según la visión del geógrafo. De la misma forma, intento esbozar una hipótesis, hasta cierto punto avalada por Estrabón, acerca del proceso que determinó que el bandolerismo se convirtiese en una fuente económica de primer orden en toda la Iberia interior y Atlántica, y forma de vida predominante en esas áreas, ya antes de la presencia romana. Finalmente, basándome en datos económicos, pero que resultan apoyados por otros tipos de pruebas, considero que en la Península pueden distinguirse dos regionés claramente diferenciables: la levantino-meridional y el resto de Iberia y que, por otra parte, Estrabón percibió perfectamente tal disparidad, de modo que sus testimonios son como son porque se ordenan sobre este presupuesto.
\end{abstract}

In this work my purpose is thinking about Greek geographer Strabo's view of Iberia, from the view-point of some of the elements which shape the socially-ordered life of its people, but also about the part which inside it occupies the phenomenon known as «Romanization», at least, according to the geographer. Likewise I am trying draw an hypothesis, partially supported by Strabo himself, about the process through which brigandage became an outstanding economic source throughout Interior and Atlantic Iberia, and prevalent way-life in those areas, even before the Roman presence. Lastly, resting upon economic facts, but also supported by other sorts of evidence, I believe that in the Iberian Peninsula, two parts are easily appreciated, neatly different each other: the Eastern-Southern one, and the rest of Iberia; besides, Strabo knew so accurately such disparities, that his witness is such as it is, because it is built over that assumption.

Hablar de sociedad hispana en época de Estrabón (65/63 a. C.-19/20 d. C.) es, en el mejor de los casos, inexacto e incorrecto. Efectivamente, hemos de pensar, por una parte, que los conceptos geográfico-nacionales no significan apenas nada dentro del orbis romanus; por otra, que la heterogeneidad geográfico-cultural dentro de la Península Ibérica era muy grande, debido a una serie de factores, que pretendo ir exponiendo. Fi-

* Este trabajo recoge, modificadas donde y cuando ha sido necesario, las principales conclusiones de nuestra memoria de licenciatura «La sociedad hispana a través de la "Geografía" de Estrabón» que, dirigida por el doctor don José María Blázquez Martínez, fue leída en septiembre de 1980 en la Facultád de Geografía e Historia de la Universidad Complutense de Madrid. 
nalmente, que la época de Estrabón tampoco es, en líneas generales, la descrita en el libro III de su Geographiké sino que, en ocasiones, es una visión con una antigüedad no menor a los cincuenta años, pero que suele ser mayor, debido ello a la diversidad de fuentes que el geógrafo de Amaseia emplea. Por todo ello, el hablar de sociedad hispana no deja de ser un convencionalismo para indicar la «suma» de todas y cada una de las sociedades que habitan en Iberia (Hispania para los romanos), y de las que trata el autor helénico, pudiendo ser individualizadas en cada uno de los pueblos que él mismo menciona. (Así podremos hablar de sociedad arévaca, sociedad lusitana, sociedad edetana, etc.).

No obstante, y puesto que no podemos tratar in extenso de todas y cada una de estas sociedades, tendremos, por fuerza, que hacer abstracción de los rasgos fundamentales que cada una de ellas aporta, e intentar estudiarlos en su conjunto para, de esta forma, trazar las líneas maestras que las caracterizan y, en definitiva, ver qué tipo de estructuración percibió Estrabón en el ámbito ibérico, y podemos percibir también nosotros.

Voy a prescindir de la problemática estrictamente geográfica que plantea Estrabón (vide mapa número 1), y de la enumeración concreta y detallada de todos y cada uno de los pueblos peninsulares que este autor menciona (y de los que no menciona), para lo cual remito al mapa número dos, así como de otras cuestiones secundarias, para centrarme en los diversos aspectos que configuran la vida organizada socialmente de los mismos; igualmente, conviene aclarar que voy a tratar de ceñirme, en lo posible, a la obra de Estrabón, no pretendiendo dar una visión de conjunto en base a testimonios de otras fuentes, escritas o arqueológicas, sino la visión que de Estrabón puede extraerse.

Por lo que se refiere a la economía, podemos decir que las fuentes principales de riqueza eran las derivadas del cultivo de la tierra y de la ganadería, con mayor o menor importancia de una sobre la otra, según las zonas, pero siendo predominantes ambas actividades con relación a terceras, y básicas para el desarrollo de la vida. (Renuncio a relacionar todas las referencias a la agricultura y ganadería, que figuran en el libro III por su gran abundancia, lo que nos indica, indirectamente, su importancia cuantitativa). Pero además de estas fuentes primarias, nos encontramos con otra actividad, harto generalizada, que es el bandidaje o bandolerismo (III, 3, 5; III, 3, 7; III, 3, 8; III, 4, 5; III, $4,13 ; \mathrm{III}, 4,15)$, al menos en algunas regiones. En este fenómeno cabe hacer un poco más de hincapié. Antes de la llegada de los romanos y, posteriormente, tras la misma, el bandolerismo, generalmente bastante bien organizado, llegó a ser un importantísimo medio de subsistencia de ciertas comunidades indígenas en zonas bastante amplias de la Península, especialmente en las regiones interiores, no siendo, pues, en su origen, una forma de resistencia a Roma. La causa de este fenómeno generalizado entre muchos de los pueblos antiguos de Iberia, aunque en proceso de desaparición en el momento en que escribe nuestro autor, parece ser la misma: la falta de tierras que obliga a los más pobres a buscarse el sustento arrebatándoselo a los vecinos (III, 3, 5). Sin embargo, yo me atrevo a apuntar una causa más, combinada con la anterior que, según Estrabón, obliga a un grupo determinado de individuos (aunque en ocasiones a unidades sociales completas) a poner en marcha su capacidad bélica, con la finalidad de arrebatar a otras sociedades los artículos que han producido: y esta causa es el carácter guerrero que Estrabón observa en gran parte de los pueblos peninsulares (III, 4, 5) en general, aunque haga alguna matización en algún caso (III, 3, 8). Si examinamos más de cerca el texto del geógrafo griego vemos que (a pesar de las confusiones y peligrosas generalizaciones en que incurre), son los pueblos de la Meseta, los pueblos del Norte y los pueblos de Occidente los que más «afectados» se hallan por este carácter guerrero (coincidiendo, en líneas generales, con los pueblos más afectados por el bandolerismo, según III, 3, 5). Es por ello por lo que me permito relacionar el bandolerismo con el carácter guerrero de determinados pueblos, además de con su evidente trasfondo económico. 


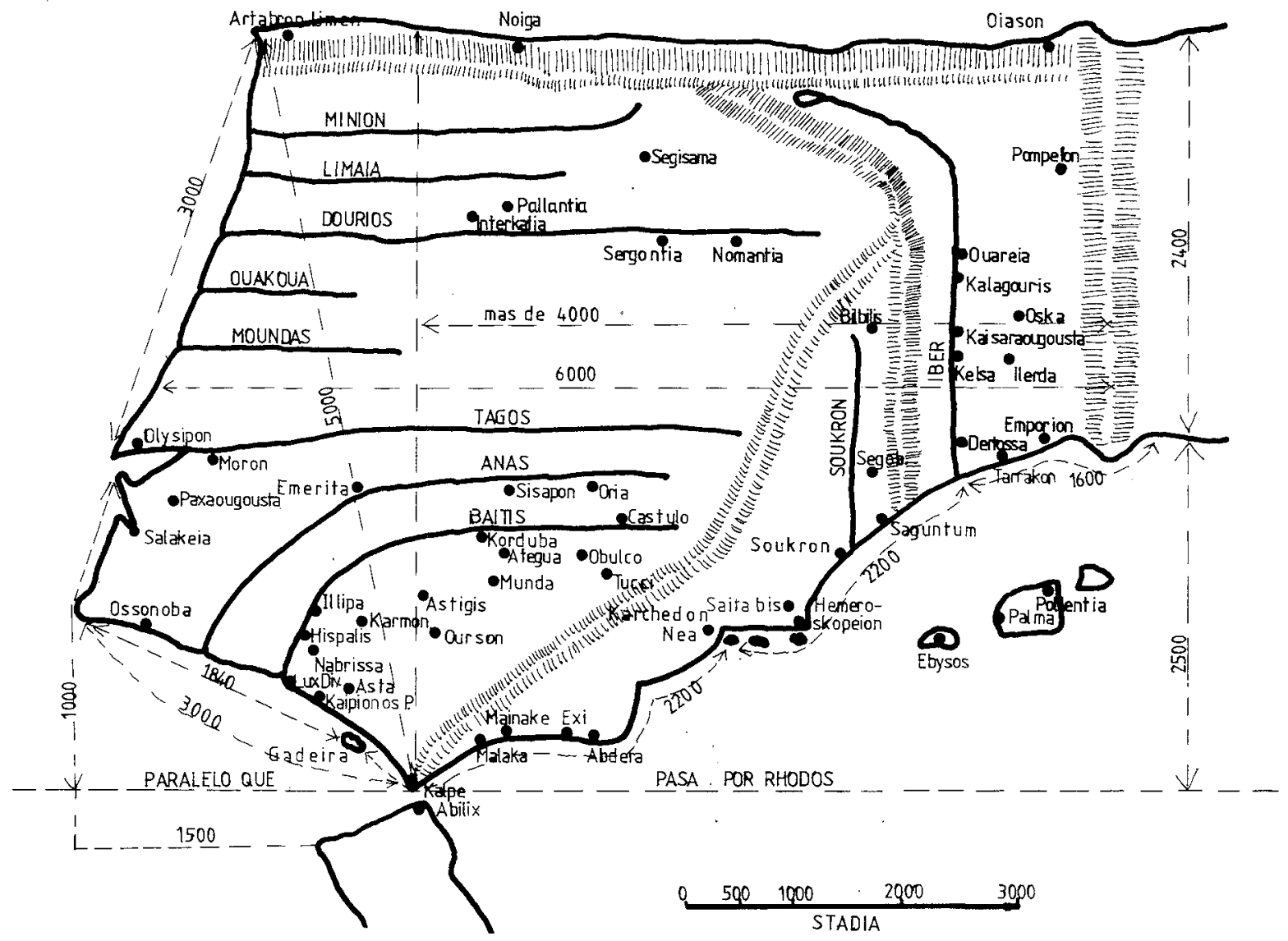

Figura 1. - Iberia según Estrabón (según García y Bellido)

Con relación a esto creo, particularmente, que no hay «pueblos guerreros» por naturaleza (en contra de lo que parece implicar III, 3, 8), sino que cuando hay algún pueblo «guerrero», es decir, una de cuyas actividades habituales es el ejercicio de la violencia, esto se debe a un motivo determinado (o a una sucesión de ellos), que se convierte en objeto de estudio. En el caso de los pueblos peninsulares, estos motivos pueden ser variados, pero el principal de ellos puede ser la presencia de unos pueblos recientemente asentados (entendiéndose el «recientemente» en sentido relativo), que plantean una serie de problemas. Nos estamos refiriendo, obviamente, a los pueblos indoeuropeos. Vamos a prescindir aquí del tratamiento de la problemática inherente a su presencia en la Península, así como a los testimonios de todo tipo de la misma; igualmente, no vamos a entrar en cuestiones de denominación, por más que el propio Estrabón conozca a éstos como Celtas y Celtíberos, emigrantes (III, 4, 5; III, 4, 12) y ya asentados plenamente en la época en la que él escribe. Simplemente diremos que, si según las últimas interpretaciones, entre los indoeuropeos hispanos no hay elementos de la cultura de La Tène, deberá fijarse, teniendo también en cuenta retardamientos locales, una fecha en torno al 500 a. C. como último momento posible de penetración de estos individuos en Iberia, aunque probablemente sea anterior, estableciéndose fundamentalmente en la Meseta Oriental (Celtiberia), pero afectando de diferentes formas a todos los territorios peninsulares más o menos próximos. 
Hemos de pensar que la larga marcha de estas sociedades emigrantes desde sus remotos hogares centroeuropeos no estuvo exenta de dificultades, que se materializarían en la existencia, más o menos organizada, de los habitantes indígenas de las regiones por las que atravesaban y en las que, eventualmente, se asentaban, siquiera fuese con carácter temporal. Este hecho, indudablemente, ha ido creando una serie de hábitos guerreros, de la misma forma que de sus enemigos vencidos han ido obteniendo un botín, difícilmente cuantificable, pero sin duda alguna importante desde el punto de vista del prestigio, pero también del de la economía. En efecto, la economía de estos pueblos en marcha es, fundamentalmente, ganadera pero sin desdeñar tampoco la práctica de una agricultura de tipo itinerante que no ha de bastar para satisfacer todas las necesidades de la sociedad (hombres, mujeres y niños, ya que sabemos que viajaban todos juntos). Esto hace que la práctica del saqueo en los lugares por los que pasan, sea imprescindible para atender a las necesidades económico-alimenticias de la misma; saqueo, pues, fundamentalmente de productos alimenticios conservados como excedentes por las poblaciones sedentarias, o simplemente destinados al consumo inmediato de las mismas.

En un momento determinado, estos pueblos indoeuropeos empiezan a hacer acto de presencia en la Península, estableciéndose, cabe pensar que por la fuerza (III, 4, 5), y en un proceso que puede abarcar varias generaciones, en amplias zonas peninsulares (ya hemos mencionado antes cómo, muy probablemente, en la Meseta Oriental, al menos los más recientes, y zonas limítrofes).

Se produce un fenómeno complejo, lamentablemente muy difícil de estudiar por falta de datos, pero cuyos rasgos esenciales pueden ser:

- Creación de una superestructura indoeuropea, centrada en organizaciones suprafamiliares de carácter gentilicio, que se hará con los principales recursos productivos.

- Existencia de elementos que podríamos calificar de «indígenas», sin entrar en más detalles acerca de su origen étnico-cultural que, en gran medida, se verían desposeídos de sus tierras y ganados, en beneficio de los recién llegados o, en el mejor de los casos, obligados al trabajo de la tierra al servicio de sus nuevos dueños.

- Previsible aumento de la población, debido a las mejores condiciones de vida derivadas de la forma de vida sedentaria que parece ser la adoptada.

- Agricultura y ganadería desarrolladas posiblemente a un mero nivel de subsistencia, incapaces de abastecer eficazmente a la población, unido a la situación de desposesión en la que se ven incluidos ciertos elementos sociales «indígenas», pero tal vez también «indoeuropeos», desvinculados de la organización gentilicia, y simples «guerreros», no relacionados con las gentes dominantes.

Las consecuencias de este proceso son fundamentalmente dos:

- De una parte, la emigración de los elementos «sobrantes» de la población a otros territorios, en forma más o menos pacífica, según los casos, y que daría lugar (sin duda en unión de otros factores) a la indoeuropeización de gran parte de la Península. A la larga estos individuos provocarán el desequilibrio entre producción y consumo en los territorios en que se integren, planteándose alli, nuevamente, los mismos problemas a los que su marcha pretendió poner remedio en sus lugares de procedencia.

- De otra parte, el surgimiento del bandolerismo como práctica habitual de subsistencia, ejercido tanto contra sociedades «indoeuropeas» como no indoeuropeas, por parte de individuos «marginados» de una u otra forma.

De esta manera, el «carácter guerrero» de algunos de los pueblos peninsulares puede explicarse por el hecho de que, efectivamente, tienen que estar permanentemente en pie de guerra, frente al ataque de bandoleros. De la misma manera, el bandolerismo tiene más oportunidades de surgir en sociedades donde, tradicionalmente, el arrebatar sus propiedades a los vecinos es la práctica fundamental, como debió de haber sido el caso entre los pueblos indoeuropeos en movimiento, como veíamos anteriormente. 
De modo que, en mi opinión, el origen del bandolerismo en Iberia hay que achacarlo a la presencia de individuos indoeuropeos que, gracias a su cohesión social y.a su superioridad bélica, se apropian de una serie de territorios, desposeyendo a sus anteriores propietarios o reduciéndoles a un estado de necesidad tal, que les obliga emigrar a su vez (siendo esto causante de problemas si no inmediatamente, sí en el plazo de varias generaciones) $\mathrm{y} / \mathrm{o}$ a dedicarse al bandolerismo como único medio de vida, junto con elementos de origen indoeuropeo (o indoeuropeizado) no vinculados con los grupos dominantes que se han ido formando. La solución violenta es lógica si se piensa en que la práctica del saqueo había sido lo normal durante la emigración (el «carácter guerrero» de estos individuos). Al tiempo, la acción de estas bandas contra las sociedades organizadas (de reciente o de antigua creación), contribuye a forjar el tópico del «carácter guerrero» de los pueblos que habitan en Iberia.

El bandolerismo, así introducido, presumiblemente, engendra a su vez más bandolerismo. Y esto es algo que percibe claramente Estrabón cuando en III,3,5, habla de los pueblos al Norte del Tajo y dice:

«Como es natural, las poblaciones montañesas habían sido las primeras en dar ejemplo de este modo de existencia ajeno a toda legalidad, porque a fuerza de vivir sobre un suelo miserable y de escaso beneficio, habían llegado a desear los bienes de otros pueblos. Al rechazarlos, éstos perdieron fatalmente el control de sus propios asuntos, hasta tal punto que entre ellos la guerra reemplazó también a la agricultura de modo que, a consecuencia de ello, el país, privado de cuidados, dejó de producir sus riquezas naturales y se pobló, en cambio, de bandidos». Del texto puede deducirse un excesivo simplismo por parte de Estrabón por lo que se refiere al origen del bandolerismo, pues no es tanto la causa (aunque influya) el vivir en «un suelo miserable y de escaso beneficio» cuanto la desigualdad económica entre los distintos miembros de la sociedad de la que se hacen eco, empero, los autores que tratan de la conquista romana. En lo que sí acierta Estrabón es en la descripción del desarrollo del bandolerismo, engendrado por el bandolerismo. En efecto, desde el momento en que un pueblo es atacado y privado de sus recursos año tras año, ha de plantearse la cuestión de su propia supervivencia, que se le demuestra no puede lograr por la vía pacífica, por lo que ha de tomar las armas, por una parte para defender lo que es suyo y, por otra, para arrebatar al atacante o, si llega el caso, a un tercero, lo que él necesita y que le han arrebatado.

Así, este fenómeno se va extendiendo paulatinamente de tal manera que, obviadas otras consideraciones, se convierte en medio habitual de vida, al menos para partes importantes de las distintas comunidades involucradas, activa o pasivamente, en el fenómeno, puesto que cabe pensar que el mismo afectaría a un grupo concreto de individuos, fundamentalmente a aquellos cuyas tierras fuesen sólo suficientes para su autoabastecimiento y a los que cualquier revés o imprevisto llevaría a la ruina, acompañada del hambre. De esta forma, el bandolerismo, ejercido por los elementos más débiles económicamente de una sociedad, va a afectar, fundamentalmente, a los representantes del mismo nivel económico-social de las sociedades vecinas, aunque también es probable que en otras regiones (especialmente, según parece, entre los pueblos del Norte), sea el grupo social el que, en su conjunto, practique esta actividad, como puede desprenderse de Estrabón III, 3, 7; en otros lugares, además, esta práctica debió de dar lugar al debilitamiento de los lazos gentilicio-familiares, al formarse una serie de «partidas» cuyo único vínculo común entre sus miembros es la sumisión a la autoridad de un jefe, y su también común deseo de obtener un rápido beneficio económico, al margen de los cauces «normales» de la sociedad. Es también este hecho el que, por otra parte, refuerza los vínculos familiares entre aquellos que no se ven afectados de modo directo y acuciante por el problema, hasta tal punto que perdurarán en amplias zonas durante la época imperial romana. 
Según lo anterior, pues, y recapitulando, habría que buscar el origen remoto del bandolerismo en la presencia indoeuropea en la Península, bien motivado por la violencia ejercida por ellos entre los pueblos entre los que se asientan y limítrofes para hallar recursos (o, al menos, por las capas más pobres de los mismos) o bien por el hecho de constituirse en grupos dirigentes en los territorios ocupados, usurpando grandes extensiones de tierra a sus propietarios, que no tienen más remedio que dedicarse a esta actividad, o bien por estos y otros factores combinados. Evidentemente, los orígenes de este proceso pueden estar más o menos olvidados en época de Estrabón (no totalmente, empero), pero la vigencia del bandolerismo en su época (o en la que recoge de sus fuentes), y el mecanismo de su transmisión que propone, sí quedan bien patentes en su obra.

El cuadro trazado es más o menos válido para los pueblos lusitanos y los de la Meseta, en gran parte influidos por la presencia indoeuropea, más o menos intensamente, y para los pueblos del Norte, que presentan algunas particularidades, como hemos visto anteriormente. En Estrabón no parece atestiguarse ya la existencia de un claro bandolerismo en las regiones meridional y levantina, aunque también existió, como atestiguan autores anteriores. Las causas, en este caso, serían relativamente similares, aunque sustituyendo, al parecer, la presencia indoeuropea (aparentemente rastreable en determinados lugares, empero), por la creación de una poderosa aristocracia terrateniente, en contacto más o menos intenso con los pueblos colonizadores mediterráneos.

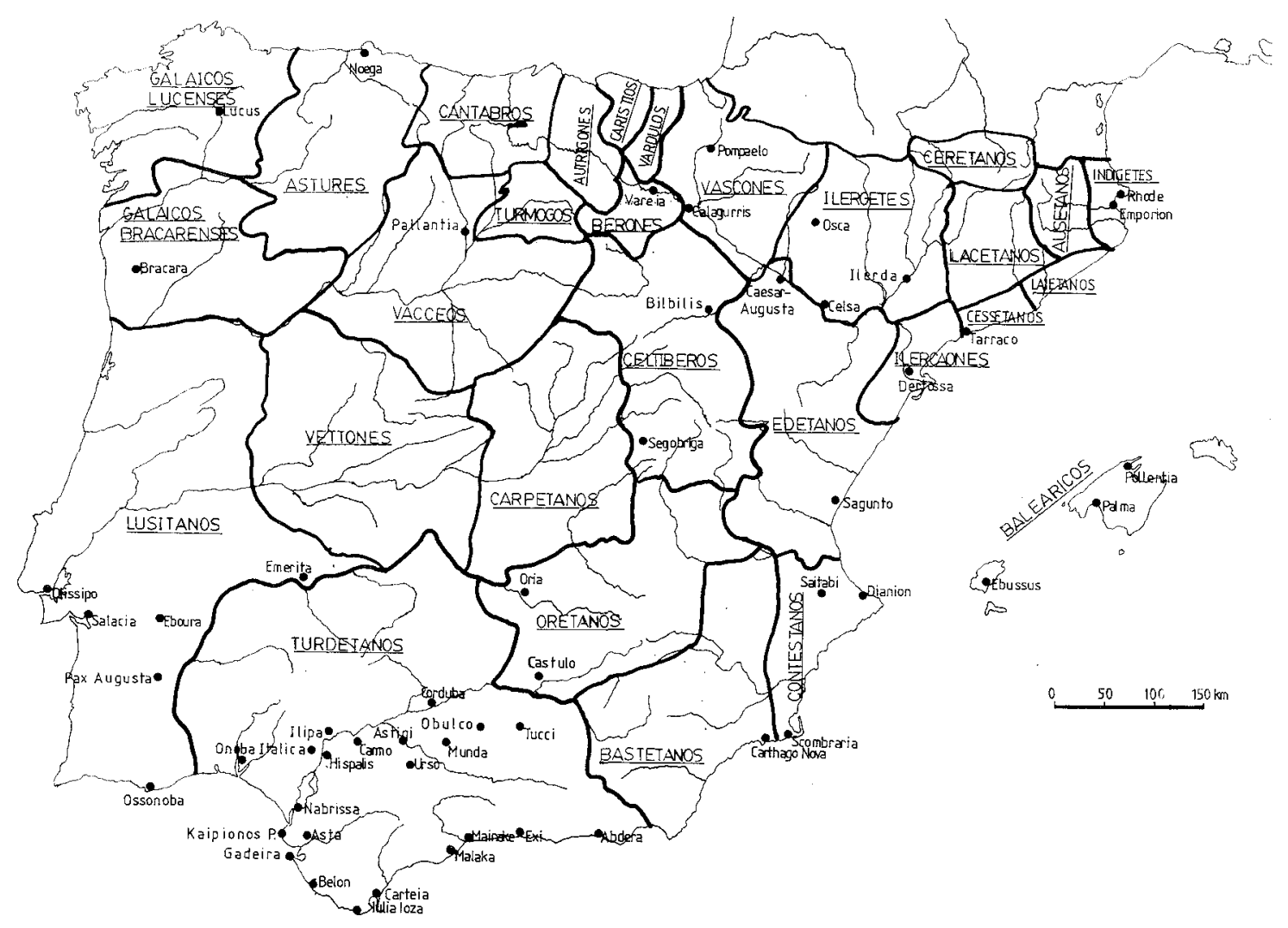

Figura 2.- Principales pueblos de Iberia. 
De todas formas, y sean unas u otras las causas y los agentes originadores, está claro que el problema que subyace al bandolerismo es la carencia de tierras, ya por parte de una comunidad completa (?) o por parte de una serie determinada de individuos. Y también complementario de lo anterior, la poca calidad y productividad de las mismas, agravada por el estado de guerra permanente en que se vive. Todo ello hace que el bandolerismo sea, a falta de otras, la principal, o una de las principales fuentes de riqueza en la antigua Iberia (pero también, qué duda cabe, causa de empobrecimiento), hasta que los romanos obvien el problema mediante repartos de tierra, como el propio Estrabón hace ver (III, 3, 5). Y que es la carencia de tierras o, incluso, de técnicas adecuadas de cultivo el factor desencadenante del mismo, puede verse teniendo en cuenta el caso vacceo, pueblo que con un sistema, si no original, sí innovador en la Península (Diodoro, $\mathrm{V}, 34$ ), consigue un sistema de tenencia de tierras estable, al tiempo que comunitario, y unos excedentes anuales, lo que le hace el blanco de los ataques de los pueblos limítrofes, aunque sus recursos debían ser lo suficientemente importantes como para no verse ellos mismos avocados al bandolerismo, puesto que no poseemos referencias a este fenómeno entre ellos. Es, pues, obvio, que los otros pueblos no habían aún encontrado un sistema equitativo de distribución de la tierra, lo que origina estos problemas sociales que se van arrastrando desde siglos, antes de que Estrabón nos dé cuenta puntual de ellos.

Finalmente, una duda; y es que, a pesar de lo dicho, el propio carácter de las fuentes, incluido Estrabón, impide saber hasta qué punto era elevada la incidencia real del fenómeno. No obstante, quizá nos hallemos más próximos a la verdad en el punto medio: Ni tan grande como las fuentes tratan de hacérnoslo ver, ni tan insignificante como algunos autores modernos pretenden.

Tratado este punto, retornamos a otras actividades económicas «normales».

Zonas de gran importancia agrícola y ganadera, debido al gran desarrollo alcanzado para la época, son las meridionales y levantinas (III, 4,16 ), donde, por otra parte, no es muy grave la incidencia del bandolerismo propio, aunque haya de sufir ataques de los pueblos vecinos. Estas actividades, en estas zonas y, muy especialmente en la turdetana, aunque también en Levante, se basan en la propiedad latifundista, como se desprende del carácter casi «industrial» de las explotaciones, con unos cultivos típicamente mediterráneo's a gran escala, y con vistas a la exportación (III, 2, 4; III, 2, 6), favorecida sin duda por la economía mundial introducida por Roma, y con centro en ella (III, 2, 5), pero también ayudada por los establecimientos coloniales romanos (III, 2, 1), y por las facilidades naturales (III, 2,4 ) sin perjuicio todo ello de que los propios romanos no hayan hecho otra cosa que heredar y desarrollar unas estructuras ya existentes, lo que parece bastante probable. Es, pues, en estas zonas donde la agricultura y la ganadería tendrán un papel realmente importante en cuanto que formas económicas preponderantes, y enfocadas más a unos propósitos, llamémosles «industriales», que de autoabastecimiento.

Siguiendo dentro de los aspectos económicos, otro es la artesanía. Esta, entendida en un aspecto de producción a gran escala, y con vistas a una ulterior comercialización es poco importante en gran parte de la Península, especialmente en las partes centrales y septentrionales de la misma, no por carencia de materias primas, sino más bien por falta de conocimientos suficientes entre los habitantes de esas tierras para su aprovechamiento, a lo que quizá también se una la lejanía de los centros de decisión del momento, y la dificultad de las comunicaciones (III, 3, 8). Por el contrario, de la región costera, meridional y levantina, y sus áreas de influencia, es de donde proceden la mayor parte de las exportaciones, tanto de productos agrícolas como de productos manufacturados (III, 2, 6). Ello no quiere decir, empero, que la artesanía a pequeña escala no exista; por el contrario, la confección de tejidos, armas, artículos de uso doméstico, etc., por parte de estos individuos nos la atestigua perfectamente Estrabón. 
Por lo que se refiere a la minería, sabemos que, aparte de las alabanzas generalizadas, estaban a pleno rendimiento, en época de Estrabón, las minas turdetanas (III, 2, 3; III, 2, 8-9) y las de Carthago Nova (III, 2, 10) y.levantinas (III, 4, 6), fundamentalmente; y también se conoce la existencia de minerales en las regiones al Norte del Tajo, pero nos informa Estrabón de que, al menos en época de Posidonio, no se practicaba una auténtica minería, sino más bien la recogida del mineral nativo arrastrado por las aguas (III, 2, 9); así, a pesar de ser regiones naturalmente ricas, los indígenas no sacan beneficio de estas riquezas (III, 3, 5), de donde se desprende que la minería está al servicio de los colonizadores, romanos en este momento, pero que heredan, qué duda cabe, esta actividad de los colonizadores anteriores, que fueron quienes enseñaron a los indígenas el valor del mineral, iniciando la explotación, que proseguirán los romanos.

Otra importante fuente económica, en determinadas zonas, y a la que ya hemos aludido, es el comercio (III, 2, 6). Del mismo modo, éste es intenso, alcanzando niveles verdaderamente importantes en las regiones meridional y oriental de Iberia, realizado, en la época en que escribe Estrabón, casi fundamentalmente con Roma y con Italia, lo que nos está indicando, en definitiva, que es Roma quien está marcando la pauta en la vida económica hispánica, importando, precisamente, aquellos productos que necesita, o bien para el abastecimiento de la propia ciudad, o bien, como parece probable también, para redistribuirlos, de forma que la $u r b s$ se arrogaría un importante papel dirigista dentro de la economía mediterránea del momento, a pesar de las opiniones frecuentes al respecto, lo que, por otra parte, tampoco es de extrañar, dado el papel que Roma empieza a desempeñar de cara a todo el mundo mediterráneo, enteramente bajo su control. Acerca, por otra parte, del comercio interior, poco es lo que sabemos, aunque no deber ser excesivamente importante en grandes partes de la Península, hasta tal punto que el propio Estrabón menciona el desconocimiento de la moneda por gran parte de los pueblos del cuadrante noroccidental de Iberia, que practican el intercambio, aunque también menciona que dan pequeñas láminas de plata recortada (III, 3, 7), esto último, sin duda, por influencia romana, y donde hay que ver el lento tránsito de una economía de intercambio a otra pre-monetal (junto al aprecio de los metales preciosos por parte de los indígenas, también enseñado por Roma). Causa importante, sin duda, que contribuye negativamente al desarrollo del comercio, es la mala red de comunicaciones (III, $1,2)$, unida al aislamiento secular y a la inseguridad de las rutas existentes por problemas de bandolerismo; situación que, posiblemente, empiece a remediarse con la pacificación del Norte peninsular y con la recuperación de Hispania, que tiene lugar en el mismo momento en que escribe Estrabón (III, 4, 20) que, obviamente, no puede conocer los resultados concretos de la misma, aunque la Arqueología (principalmente por lo que se refiere a la distribución de las ánforas y otras cerámicas), demuestra que ya en los últimos momentos del siglo I a. C., y durante el siglo I d. C., las relaciones del interior peninsular y el Norte con las regiones costeras meridionales y levantinas son mucho mayores que en momentos anteriores, lo que viene a corroborar el relativo éxito que ha alcanzado esta política augústea mencionada por Estrabón.

En el aspecto económico, pues, el libro III de Estrabón nos da a conocer la existencia de dos zonas bien delimitadas: la levantino-meridional y el resto de la Península, con una serie de características propias cada una de ellas, que las hacen bastante diferentes entre sí; por más que puedan diferenciarse las distintas regiones que constituyen cada uno de estos dos grandes conjuntos, no creo que ello sea obstáculo para reconocer que existen una serie de características comunes dentro de ellos, que hacen perfectamente válida esta distinción:

- En la primera, tenemos la existencia de una agricultura y ganadería a gran escala, basadas en la concentración de tierras, cultivadas por clientes y por una mano de obra servil (a juzgar por la rentabilidad de las mismas), y tendente en gran medida a la 
exportación de los productos obtenidos. Igualmente, alcanzan un desarrollo importantísimo la minería, la artesanía «industrial» y, a consecuencia de ello, el comercio. Aunque puede haber algún tipo de inestabilidad social a causa de ello, ésta no llega a determinar fenómenos que dificulten el normal desarrollo de la producción en tales áreas, y que lleguen a constituirse en forma habitual de vida de individuos «marginados». Las causas de este desarrollo económico hay que buscarlas en la temprana presencia de colonizadores orientales, que propician el mismo, junto con la presencia, desde un primer momento también, de los romanos que, en líneas generales, prosiguen este tipo de política.

- Por lo que se refiere a la segunda zona considerada, destacaremos que, salvo la posible excepción que constituye el pueblo vacceo, la agricultura y ganadería apenas se hallan desarrolladas o, por mejor decir, lo están a un nivel insuficiente como para atender al abastecimiento absoluto de los pueblos que allí viven, unido a los problemas de mala distribución de tierras y al no menos importante, y quizá esencial para comprender el problema, de baja rentabilidad de las mismas, debido a lo arcaico de los procedimientos empleados. Estas dos actividades primarias tienen que ser complementadas, parcialmente, con la recolección de frutos que crecen espontáneamente y, en menor medida y según las zonas, por la caza; además, la otra gran fuente de recursos para importantes grupos humanos es la práctica del bandolerismo, que hemos de considerar perfectamente organizado. Por lo que se refiere al resto de las actividades económicas (minería, «industrià», comercio), puede decirse que la existencia es casi nula o, al menos, apenas suficiente para el autoabastecimiento. Es, pues, prácticamente, una economía de subsistencia la practicada por el conjunto de estos pueblos o, al menos, por una parte de sus miembros, puesto que también hay individuos que forman parte de los grupos sociales privilegiados, que también existen, y cuyas fuentes de riqueza proceden, en el mejor de los casos, de la explotación del resto de los miembros del grupo social.

Hemos, pues, distinguido dos zonas fundamentales, cuyas diferencias en el aspecto económico son importantes y que fueron, en mayor o menor medida, ya identificadas por el propio Estrabón (III, 4, 13; III, 4, 16). Pero es un hecho que los autores de la Antigüedad no se suelen caracterizar, precisamente, por su afición a transmitirnos datos meramente económicos per se, sino que, de aparecer, lo hacen dentro del marco de una argumentación concreta, con unos fines determinados; con ello quiero decir que hemos hecho afírmar a Estrabón algo que él, sin duda, no habría planteado jamás, basándose en datos económicos. Pero realmente esto tampoco quiere decir, como acabamos de ver, que Estrabón no hubiese percibido ya la realidad peninsular. Y, en efecto, así era; lo que ocurre, sin embargo, es que la preocupación del geógrafo se centra, en cierto modo, en ver hasta qué punto se ha producido la «romanización» o, si se quiere, y ya que este término parece suscitar actualmente alguna polémica, hasta qué punto, y en qué medida, las comunidades indígenas han asimilado y han rechazado elementos culturales introducidos por los romanos, y cuáles han sido éstos. Esto puede verse en la relativa insistencia con la que nos transmite las «ventajas» que se derivan de la presencia de Roma, y el matiz peyorativo con que habla de los que no se ven sometidos a las mismas, así como en el cierto «romanocentrismo» (a pesar de su carácter "orgullosamente» helénico) de algunas de sus afirmaciones (por ejemplo, III, 5, 3).

Evidentemente, la respuesta que nos proporciona Estrabón es parcial e incompleta, pero a pesar de ello, nos permite ver cuál es el grado de influencia cultural romana en Hispania en el cambio de Era. Podemos decir que la labor de «romanización» estaba completada en todo el Sur peninsular y en el Levante, prácticamente completada en la Meseta Central y en la zona lusitana (III, 2, 15; III, 4, 20), apenas iniciada en la cornisa septentrional, aunque el geógrado nos da noticias de los progresos que se han hecho desde el final de las guerras hasta el momento en que él escribe, gracias al establecimien- 
to de unas legiones que mantienen la paz, al tiempo que sirven de elementos civilizadores (III, 3, 8). Sus resultados, por lo que sabemos de la Historia posterior de la zona, no debieron ser muy brillantes, porque su rudeza y primitivismo, así como su cultura, netamente indígena, son objeto de comentario en autores muy posteriores.

En muchas zonas, como en la Turdetania (o Bética), la lengua hablada era el latín, como indica el propio Estrabón y la forma de vida e, incluso, la indumentaria eran netamente romanas (III, 2, 15). Por lo general, pues, a través de la obra estraboniana puede verse un nivel bastante alto de romanización juzgando, al menos, por los datos que nos suministra, correspondientes a su propia época, pues por él mismo sabemos que cien años, y más, antes en época de Posidonio y Polibio, por ejemplo, la situación era muy otra, como puede verse si se tiene en cuenta lo que hemos venido diciendo acerca del bandolerismo y de su área de expansión, lo cual no se contradice con lo que aquí indicamos por cuanto que ambos fenómenos se hallan separados por un importante espacio cronológico e, incluso, pueden servirle al propio Estrabón para demostrar lo beneficioso de la presencia de Roma.

Esta «romanización», pues, en líneas generales, se extiende a los dos tercios meridionales de la Península y toda la zona costera catalana, abarcando el interior, aunque en algunos lugares con carácter discontinuo. Prueba de que la romanización de estas zonas en el cambio de Era, era ya aceptable, es que siglos después, el eje económico y social de la Hispania romana se trasladará a la Meseta, especialmente a la Submeseta Norte y Valle del Ebro, que en la época de Estrabón están en vías de integrarse totalmente al modo de vida romano.

Por lo que se refiere al tercio septentrional, por una parte, por lo reciente de la conquista (que acababa, prácticamente, de concluir cuando escribe Estrabón) y, por otra, por la ausencia casi total de colonos, que refleja dicho autor y cuya importancia se muestra decisiva (III, 2, 1; III, 2, 2; III, 2, 15 y especialmente III, 3, 5), siendo insuficiente, con vistas a una aculturación profunda, la presencia de fuertes contingentes militares (de lo que sí se hace eco nuestro autor), esta romanización es prácticamente inexistente, por más que pueda traslucirse una indudable atracción de estos indígenas por parte de los romanos, siquiera con fines militares (III, 3, 8); no obstante, y a pesar de decir el propio Estrabón que las guerras están ya terminadas, no puede dejar de reconocer, en el mismo pasaje, que no en todo el territorio han penetrado las dos «ventajas» principales, la paz y la llegada de los romanos.

Debemos decir igualmente algo acerca de lo que nos transmite Estrabón sobre dos grupos de ciudades que siguen manteniendo unos caracteres propios y perfectamente distinguibles. Nos referimos a las ciudades fenicias y griegas. Por lo que se refiere a las primeras, nos informa el autor griego que gran parte de las regiones meridionales de la Península (especialmente las costeras) y las regiones vecinas, estuvieron habitadas por los fenicios, y lo seguían estando en su propia época (III, 2, 13). Lamentablemente, no sabemos gran cosa del modo de vida de sus habitantes y, por consiguiente, si seguían conservando tradiciones y formas de vida propias (ello no quiere decir que no pueda saberse por otras vías, como la Arqueología o la Numismática). En la ciudad más importante de todas ellas, Gades, por desgracia Estrabón se pierde en excesivas divagaciones acerca de fenómenos naturales; no obstante, sí podemos llegar a saber que, aparte de su Cronion y su Herakleion, que permiten suponer la existencia, como tantas veces se ha dicho, de una serie de formas de vida genuinamente semíticas, en época del autor se realizó un censo que arrojó la cifra de quinientos caballeros (equites) gaditanos (III, 5, 3). Esto puede interpretarse como un indicio claro de romanización, pero también debe pensarse que la mayor parte (si no todos) estos equites no eran otra cosa que los descendientes de los grandes personajes acaudalados, de origen semítico, en cuyas manos había estado el control de la economía fenicia primero, y cartaginesa después, en la Penín- 
sula. Este «rápido» ascenso social, cuyos exponentes principales serían los Balbos, auténticos evergetes locales (III, 5, 3), sería debido a su temprana alianza con Roma en el transcurso de la Segunda Guerra Púnica (III, 1, 8; III, 2, 1) y a su importante actividad comercial (III, 5, 8).

Con respecto a las ciudades griegas, junto a los tan debatidos datos acerca de Mainake (III, 4, 2), Hemeroskopeion, Sagunto y otras ciudades secundarias (III, 4, 6), y Rhode (III, 4, 8; XIV, 2, 10), acerca de las cuales nada diremos por no transmitirnos Estrabón apenas datos, debemos mencionar a Emporion. Los datos que acerca de esta ciudad nos transmite nuestro autor (III, 4, 8), parecen no corresponder a su propia época, puesto que las noticias que nos da son similares a las que otros autores nos transmiten, y no se hace referencia a otros hechos posteriores, como la probable concesión del status colonial por parte de César. No obstante, puede verse cómo esta ciudad mantenía su propia forma de vida y su peculiar forma de relación con el elemento indígena, que terminaría por desembocar en la asimilación del modo de vida romano, por los contactos intensos con ellos, y sin que supusiera una transformación sustancial de sus formas tradicionales de vida.

De esta forma, podemos ver cómo la asimilación del modo de vida romano por parte de las ciudades griegas y fenicias es relativamente rápido y en absoluto nada traumático, pero junto a este proceso, que tal vez afectase, de hecho, más a la forma que al fondo, no es improbable que estas entidades urbanas mantuviesen largo tiempo sus peculiares formas de vida e, incluso, su lengua (al menos por lo que se refiere a las fenicias). Ello, sin duda, se debe precisamente al hecho de que ya eran ciudades, exactamente iguales, en sus líneas generales, a lo que era, o había sido, Roma; y ya sabemos que «romanización» equivale a «urbanización», si es que pretendemos que la aculturación ha sido profunda, siendo la ciudad el parámetro que permite medir el grado de «civilización» de un territorio o un país concreto, de lo que es consciente el propio Estrabón (III, 4, 13).

Finalmente, otro aspecto del que podremos decir algunas palabras es el de la organización social de los pueblos peninsulares. Los datos que a este respecto nos transmite Estrabón son, lamentablemente, escasos; vamos aquí, simplemente, a comentarlos, sin complementarlos con los que nos proporcionan otras fuentes, ya que aquí lo que nos interesa es ver la visión de Estrabón. Hay una primera e importante diferenciación: salvo en las costas mediterráneas, no puede hablarse de la existencia de ciudades (poleis), pues las condiciones físicas no lo permiten (III, 4, 13). Así, pues, la mayor parte de la población de la Iberia interior vive en aldeas (komai); conocida es la digresión que se permite el autor cuando dice que muchos generales llaman ciudades a lo que no son otra cosa que aldeas grandes (megale komai) (III, 4, 13), de donde puede deducirse que, a pesar de la no existencia de ciudades, en algunos casos estos núcleos debían ser considerablemente importantes, hasta tal punto que, en ocasiones, Estrabón, contradiciéndose, les dará el nombre de ciudades (III, 3, 5). Sabe también el geógrafo que, al menos entre el Tajo y la costa cantábrica, estas entidades de población estaban enclavadas en los altos, aunque en su propia época, los romanos han obligado a los individuos a establecerse en el llano (III, 3, 5); frente a ello, las poleis de Turdetania se alzan junto a los ríos, los esteros o el mar (III, 2, 1-2).

Por lo que se refiere a los datos que nos pudieran hablar de una estratificación social, éstos, aunque pequeños en número, también existen. Entre los pueblos del Norte predomina una situación social basada en la cohesión de la familia (genos) materializada en la celebración de banquetes, en los que la colocación de los comensales viene determinada por la edad (helikía) y el rango (timé) (III, 3, 7); acerca del eventual carácter matriarcal (o matrilineal, más probablemente) de estos pueblos o de parte de ellos, del que tanto se ha hablado, sistema que Estrabón llama gynaikokratía, creo probable que 
las noticias que él ha recibido acerca del papel social de la mujer (o de los parientes masculinos por línea materna) no ha sabido interpretarlas correctamente, no existiendo esta gynaikokratía; por lo demás, no es inconveniente alguno para el sistema de los banquetes en común, con situación jerárquica en el mismo, que la transmisión de los bienes se haga por la línea femenina. Dentro también de todo esto está la cuestión de la «covada» (III, 4, 17), en la que no entraremos por haber sido objeto ya de detallados estudios. Dentro del contexto de los pueblos del Norte, aunque probablemente no aplicado sólo a ellos, menciona Estrabón también la costumbre de que ciertos individuos se consagren (kataspendein) hasta la muerte a alguien (III, 4, 18), sin duda sus jefes. La importancia del liderazgo personal queda puesta de manifiesto por el propio autor cuando hace referencia a un suceso ocurrido a los «celtas» que viven en torno al río Limia, que no supieron qué hacer cuando murió su jefe (III, 3,5).

Sabemos también que la importancia de la cohesión familiar es muy grande entre los celtíberos y sus «vecinos del Norte» (III, 4, 16); estos vecinos del Norte a que aquí se alude no pueden ser otros que los berones, como explícitamente atestigua Estrabón en III, 4,12 , que, al igual que los celtíberos, procedían de la «emigración céltica». Es decir, que entre el elemento indoeuropeo de la Península, es la unidad familiar (posiblemente también una unidad económica, a juzgar por el nombre, panoikia, que recibe) la fundamental, al menos por lo que se refiere a la realización de las ceremonias destinadas a honrar a sus dioses, aunque siendo, por ello mismo, probable que esta unidad familiareconómica hubiese determinado una serie de fenómenos sociales concretos (vid. supra, con respecto a los orígenes del bandolerismo); no obstante, poco más es lo que puede decirse de su carácter.

Finalmente, podemos también observar cómo entre los lusitanos hay presente una diferenciación social y, probablemente, económica, manifestada en el empleo de distintos tipos de armamento, los más costosos, empleados por unos pocos, y los más baratos, por la mayoría. De la misma manera, puede hablarse de una probable «especialización» sacerdotal.

De los datos de Estrabón creo que no pueden deducirse directamente más cosas acerca de la organización y estructura social de los pueblos ibéricos, a no ser lo que anteriormente apuntábamos sobre el debilitamiento de las vinculaciones gentilicias (en algunos casos) a causa de la persistencia del bandolerismo, gracias al surgimiento de jefescaudillos de cuya importancia, en ocasiones, nos habla Estrabón, pero de la que nos transmiten más datos autores anteriores.

Otro aspecto importante, como es la religión, lo dejaremos de lado, porque lo controvertido del tema, la escasez relativa de los datos que presenta Estrabón, y la imprecisión, en muchos casos, de ellos, y el necesario recurso a otros testimonios ajenos al mismo, harían que esta exposición resultase harto prolija y engrosase considerablemente el volumen de las presentes líneas. No obstante, diremos que el autor centra su interés en las religiones indígenas (donde parece que tiene ideas poco claras), religión fenicia y religión griega, estas dos brevemente; no parece prestar atención a las formas de la religión romana.

No iremos más adelante; como visión rápida acerca del carácter de la sociedad peninsular en el cambio de Era, creo que es suficiente. Por otra parte, el propio texto de Estrabón no permite ir mucho más allá en base exclusivamente al mismo; pero creo, y sirva a modo de conclusión, que la idea que tiene el geógrafo griego de Iberia es la de un país (en sentido geográfico) cuyas regiones costeras meridional y oriental, y su respectivo hinterland, se encuentran en un proceso de casi absoluta integración al modo de vida romano, mientras que las regiones interiores se encuentran en un estado realmente atrasado, por más que se hayan introducido «recientemente» álgunas mejoras; de la misma manera, no parece importarle apenas el hecho de que las fuentes más próximas a su épo- 
ca, que maneja, tengan una antigüedad de más de sesenta años (iy no digamos nada de las menos próximas!), lo que viene a decirnos que los cambios ocurridos presumiblemente en ese período, no aparecen reflejados más que esporádicamente. Por todo ello, la visión que nos proporciona Estrabón de la sociedad hispana no deja de ser, en cierto sentido, una visión diacrónica, evolutiva incluso, aunque este concepto no parece estar presente en nuestro autor, para quien Iberia, como objeto de estudio, parece hallarse como algo intemporal, abierto a su indagación en base a unas fuentes más o menos anticuadas, $\mathrm{y}$ a las que se concede crédito o no según unos criterios estrictamente subjetivos y personales de nuestro autor (III, 1, 5; III, 2, 11; III, 2, 13; III, 4, 4; III, 5, 7), habiendo ocasionalmente atisbos de la realidad de su época. No sólo no nos está reflejando Estrabón la sociedad hispana de su época, sino que lo que quizá pudiera verse, de no ser tan parcas las noticias que en muchos casos nos transmite, es el concepto que acerca de Iberia han tenido los autores griegos, al menos desde Homero, tanto de su Geografía como de su Historia; lo que ocurre es que esta visión diacrónica es traducida a otra mucho más «intemporal» por Estrabón, que en su composición intenta «definir» cada una de las regiones o territorios en base a los testimonios de que dispone, o que le parecen más adecuados; de esta forma, la ingente cantidad de datos que los geógrafos griegos (conocidos o no) habían ido acumulando sobre Iberia a medida que fue siendo conocida, son empleados por nuestro autor en cuanto que útiles para la visión que pretende dar del país, o rechazados en el momento en que plantean problemas a esta visión. El inconveniente para nosotros de este modo de proceder es que la causa profunda de muchos de los aspectos y problemas que se tratan no nos viene dada, realmente, por nuestro autor, al menos de forma explícita, por lo que es necesario, en ocasiones, intentar ver qué es lo que calla, o por desconocimiento, o por desinterés (y éste es otro problema), con los evidentes peligros que ello entraña.

No obstante, y a pesar de todos sus defectos, Estrabón sigue siendo la fuente insustituible para el estudio de la Península Ibérica, al menos para el período histórico que se inicia con el desembarco de los Escipiones en Emporion en 218 a. C., momento a partir del cual, los romanos, apoyándose en las regiones ya «conocidas», iniciarán el «descubrimiento» del interior de Iberia, cuyas características nos transmitirán, fundamentalmente, autores griegos, como recalca Estrabón cuando, con el orgullo y autosuficiencia propia del «heleno» ante el «bárbaro», nos habla con desdén de la capacidad romana para la observación (III, 4, 19). Es ese período de tiempo el que empieza a proporcionar datos más concretos para las zonas interiores; por ello, la imagen que Estrabón nos da de ellas es bastante más «reciente», mientras que los datos disponibles para las regiones costeras son de una mayor antigüedad.

Finalmente, la Geografía de Estrabón, y concretamente su libro III, nos permiten comprobar hasta qué punto el trabajo de «gabinete» o de «biblioteca», con sus ventajas e inconvenientes, empieza a sustituir al conocimiento directo, adquirido por los propios viajes y observaciones (que también llevará a cabo nuestro autor para redactar otras partes de su obra geográfica); pero a pesar de, o quizá precisamente a causa de ello, no hay que quitar o añadir mérito a su obra, ni justificar sus errores ni alabar sus aciertos; simplemente, tomarla como lo que es, una sistematización (subjetiva, como todas las sistematizaciones) de los conocimientos de su época sobre el mundo conocido; podríamos, incluso, teniendo en cuenta la elección consciente de sus fuentes, y de sus temas, achacar la responsabilidad de sus afirmaciones al propio Estrabón. De esta forma, la sociedad hispana que queda reflejada en su Geografía es, en definitiva, la que él quiso que conociésemos ( $\mathrm{y}$ lo cierto es que, en muchos casos, es la única que podremos conocer). 


\section{BIBLIOGRAFIA}

ADVERTENCIA.-El planteamiento del presente trabajo hace que en el mismo no se reflejen de forma inmediata las opiniones de otros autores. No obstante, en su redacción original éste formaba parte del apartado de conclusiones, por lo que las mismas se vieron condicionadas por el estudio pormenorizado de los distintos pueblos peninsulares, para el cual se empleó una amplia bibliografía, de la que destacamos los siguientes títulos:

- Ediciones y traducciones de Estrabón:

GARCIA Y BELLIDO, A., 1945: España y los españoles hace dos mil años según la «Geografía» de Strábon. Madrid.

JONES, H. C., 1924: The Geography of Strabo. London.

LASSERRE, F., 1966: Strabon. Géographie. Paris.

MEINEKE, A., 1877: Strabonis Geographica. Leipzig.

MÜLLER, C.; DÜBNER, F., 1853: Strabonis Geographica. Paris.

SCHULTEN, A., 1952: Estrabón. Geografía de Iberia. Barcelona.

VELOZO, F. J.; CARDOSO, J., 1965: Estrabâo: Livro III da «Geografia». Primeira contribuçâo para una nova ediçâo critica. Oporto.

- Obras de carácter general y de temas concretos:

ABAD, L., 1975: El Guadalquivir como vía fluvial romana. Sevilla.

ALMAGRO BASCH, M., 1951: Las fuentes escritas referentes a Ampurias. Barcelona.

ALONSO FERNANDEZ, C., 1969: «Relaciones políticas de la tribu de los arévacos con las tribus vecinas». Pyrenae, V, 131-140.

APARICIO, J., 1977: Las raices de Mogente: prehistoria y protohistoria. Valencia.

ARRIBAS, A., 1976: Los iberos. Barcelona.

ARTEAGA, O., 1978: «Los Pirineos y el problema de las invasiones indoeuropeas». II Col-loqui internacional d'A rqueologia de Puigcerdá. 13-30.

AUJAC, G., 1966: Strabon et la science de son temps. Paris.

BALIL, A., 1975: Historia Social y Económica. La España Antigua (Indigenas y colonizadores). Madrid.

BARANDIARAN, J. M., 1973: Obras completas. Bilbao.

BARANDIARAN MAESTU, I., 1965: «Problemas de la Prehistoria y la Etnología vasca». Caesaraugusta, XXV-XXVI, 128-131.

BARANDIARAN MAESTU, I., 1978: «Los pueblos vascos». II Col-loqui internacional d'Arqueologia de Puigcerdá. 225-229.

BARBERO, A.; VIGIL, M., 1971: «La organización social de los cántabros y sus transformaciones en relación con los orígenes de la Reconquista». Hispania Antiqua, I. 197-232.

BARREIRO, X. R., et alii, 1976: Los Gallegos. Madrid.

BELTRAN, A., 1963: «El río Ebro en la Antigüedad». Boletín de la Real Sociedad Geográfica.

BLANCO, A., 1960: «La cultura castreña». I Symposium de Prehistoria de la Península Ibérica. 179-194.

BLAZQUEZ, J. M., 1957: «La economía ganadera de la España antigua a la luz de las fuentes literarias griegas y romanas». Emerita, XXV, 159-184.

BLAZQUEZ, J. M., 1958 a: «La religiosidad de los pueblos hispánicos vista por los autores griegos y latinos». Emerita, XXVI, 79-110.

BLAZQUEZ, J. M., 1958 b: «Sacrificios humanos y representaciones de cabezas en la Península Ibérica». Latomus, XVII, 27-48.

BLAZQUEZ, J. M., 1962 a: «La expansión celtibera en Bética, Carpetania y Levante y sus causas». Celticum, III, 409-428.

BLAZQUEZ, J. M., 1962 b: Religiones primitivas de Hispania. I. Fuentes literarias y epigráficas. Madrid.

BLAZQUEZ, J. M., 1966: «Los vascos y sus vecinos en las fuentes literarias griegas y romanas de la Antigüedad». IV Simposio de Prehistoria Peninsular. 177-206.

BLAZQUEZ, J. M., 1967: «Estructura económica de la Bética al final de la República Romana y a comienzos del Imperio». Hispania, XXVII, 7-62.

BLAZQUEZ, J. M., 1968: «Economía de los pueblos prerromanos del área no ibérica hasta la época de Augusto». Estudios de Economía Antigua de la Península Ibérica. 191-269.

BLAZQUEZ, J. M., 1970: «Las religiones indígenas del Noroeste de la Península Ibérica en relación con Roma». Legio VII Gemina. 65-76.

BLAZQUEZ, J. M., 1971: «La Iberia de Estrabón». Hispania Antiqua, 1. 11-94.

BLAZQUEZ, J. M., 1972: «Economía de Hispania al final de la República romana y a comienzos del Imperio, según Estrabón y Plinio». Revista de la Universidad de Madrid, XX. 3 y ss.

BLAZQUEZ, J. M., 1974: La Romanización. Madrid.

BLAZQUEZ, J. M., 1976: «Música, danza, competiciones e himnos en la Hispania Antigua». Bellas Artes, LI. 41-60. 
BLAZQUEZ, J. M., 1977: Imagen y mito. Estudios sobre religiones mediterráneas e ibéricas. Madrid. BOSCH-GIMPERA, P., 1974: Paletnología de la Península Ibérica. Colección de Trabajos sobre los Celtas, Iberos, Vascos, Griegos y Fenicios. Graz.

BRANCATI, A., 1963: Augusto e la guerra di Spagna. Urbino.

CABRE, J., 1939-40: «La Caetra y el Scutum en Hispania durante la Segunda Edad del Hierro». BSEAA; 57 y ss.

CAMPMAJO, P.; PADRO, J., 1978: «Els Ceretans». II Col.loqui internacional d'Arqueologia de Puigcerdá. $189-210$.

CARO BAROJA, J., 1943: «Regímenes sociales y económicos de la España prerromana». Revista Internacional de Sociología, 1-3; 149-190. 285-317.

CARO BAROJA, J., 1946: Los pueblos de España (reimp.). Madrid.

CARO BAROJA, J., 1954: «La escritura en la España pre-romana. (Epigrafía y Numismática)». Historia de España Menéndez Pidal, I, 3. 679-812.

CARO BAROJA, J., 1970. «Organización social de los pueblos del Norte de la Península Ibérica en la Antigüedad». Legio VII Gemina. 9-62.

CARO BAROJA, J., 1971 a: Etnografia histórica de Navarra. Pamplona.

CARO BAROJA. J., 1971 b: «La 'realeza' y los reyes en la España Antigua». Cuadernos de la Fundación Pastor, 17. 51-159.

CARO BAROJA, J., 1977: Los pueblos del Norte. San Sebastián.

CARRIAZO, J. M., 1974: Protohistoria de Sevilla. Sevilla.

CARVALHO, J., 1956: «A cultura castreja. Sua interpretaçao sociologica». Occidente, L.

CASTRO GARCIA, L., 1970: Pallantia prerromana. Burgos.

COSTA, J., 1879: Organización política, civil y religiosa de los celtíberos. Madrid.

COSTA, J., 1891: Estudios ibéricos. (La servidumbre entre los iberos. -Litoral español del Mediterráneo en los siglos VI-V a. C.) Madrid.

COSTA, J., 1898: Colectivismo agrario en España. Doctrinas y Hechos. Madrid.

CUADRADO, E., 1960: «El mundo ibérico. Problema de la cronología y de las influencias culturales externas». I Symposium de Prehistoria de la Península Ibérica. 221-256.

CUADRADO, E., 1968 a: «Corrientes comerciales de los pueblos Ibéricos». Estudios de Economía Antigua de la Península Ibérica. 117-142.

CUADRADO, E., 1968 b: Un pueblo prehistórico hispano: Los Iberos. Madrid.

CURA-MORERA, M., 1971: «El poblament prerromà en les comarques centrals de Catalunya». Bol. Arq. de la Real Sociedad Arqueologica Tarraconense, fasc. 113. 66 y ss.

CURA-MORERA, M., 1978: «Contribució a l'estudi de les poblacions prerromanes de l'interior de Catalunya». II Col-loqui internacional d'Arqueologia de Puigcerdá; 177-188.

ESTEFANIA, M. D., 1963: «Aspecto económico de la penetración y colonización romana en Asturias». Emerita, XXXI, 43-52.

FATAS, G., 1971: «Sobre suessetanos y sedetanos». AEspA, XLIV; 109-125.

FATAS, G., 1973: La Sedetania. Las tierras zaragozanas hasta la fundación de Caesaraugusta. Zaragoza.

FATAS, G., 1978: «La población prerromana del Pirineo central según las fuentes y los testimonios antiguos. (Estado de la cuestión)». II Col-loqui internacional d'Arqueologia de Puigcerdá. 221-223.

FERNANDEZ NIETO, J., 1968: «Beribraces, edetanos e ilercaones. (Pueblos pre-romanos en la actual provincia de Castellón)». Zephyrus, XIX-XX. 115-142.

FERNANDEZ NIETO, J., 1970: Aurifer Tagus. Zephyrus, XXI-XXII; 245 y ss.

FERRER SOLER, A., 1947: «El poblamiento ibérico del Panadés y extensiones». Ampurias, IX-X, 272-286.

FLETCHER VALLS, D., 1960: «Estado actual del conocimiento de la cultura ibérica». I Symposium de Prehistoria de la Península Ibérica. Pamplona.

FLOREZ, E., 1877: La Cantabria. Disertación sobre el sitio y extensión que en tiempo de los romanos tuvo la región de los Cántabros. ( $3 .^{\mathrm{a}}$ ed.). Madrid.

FORT FORNAS, A., 1963: «Notas para un estudio de la vida en la Cataluña Ibérica». II Symposium de Prehistoria Peninsular. 89-100.

FORTEA, J., 1970: Recintos y fortificaciones en la Bética. Salamanca.

GARCIA Y BELLIDO, A., 1943: «Los Albiones del Noroeste de España y una estela hallada en el Occidente de Asturias». Emerita, XI, 418-430.

GARCIA Y BELLIDO, A., 1944: «Música y danza entre los pueblos primitivos de España». Investigación y Progreso, XV, 65-76.

GARCIA Y BELLIDO, A., 1945: «Bandas y guerrillas en las luchas con Roma». Reimpr. en Conflictos y estructuras sociales en la Hispania Antigua. Madrid (1977).

GARCIA Y BELLIDO, A., 1954: «Arte Ibérico». Historia de España Menéndez Pidal, I, 3. 373-675.

GOMEZ TABANERA, J. M., 1966: Ethnogenesis of the Spanish Peoples. Madrid. 
GOMEZ TABANERA, J. M., 1968 a: Las poblaciones prehistóricas de la Península Ibérica. Madrid.

GOMEZ TABANERA, J. M., 1968 b: Los pueblos antiguos de la Península Ibérica. Madrid.

GONZALEZ, J. M., 1976: Antiguos pobladores de Asturias. Protohistoria. Salinas.

GONZALEZ, J. M., 1952: «Noega - un problema de la antigua geografía astur». Boletín del Instituto de Estudios Asturianos. XV, 35-55.

GONZALEZ, J. M., 1958: «La costa cantábrica desde Bilbao a Figueras del Eo en los geógrafos romanos». Revista de la Sociedad Geográfica, n. ${ }^{\circ} 389$, pp. 11 y ss.

GONZALEZ ECHEGARAY, J., 1949: «Tribus y ciudades de Cantabria». Altamira, 87-103.

GONZALEZ ECHEGARAY, J., 1955: «La Geografía de Cantabria a través de los escritores romanos». Anthologia Annua, III, 339-404.

GONZALEZ ECHEGARAY, J., 1959: «Sobre la Geografia humana de Cantabria». Altamira, 3-69.

GONZALEZ ECHEGARAY, J., 1960: «Las noticias históricas sobre el pueblo cántabro». Altamira, $52-167$.

GONZALEZ ECHEGARAY, J., 1966: Los Cántabros. Madrid.

GONZALEZ ECHEGARAY, J., 1977: Cantabria a través de su Historia. Santander.

HERNANDEZ HERNANDEZ, F., 1976: La cultura de los castros en el Occidente de la Meseta. Salamanca.

HOYOS SAINZ, L., 1943: Etnogenia española y sus fases. Madrid.

HOYOS SAINZ, L., 1947: «Un avance a la etnogenia cántabra». Boletín de la Biblioteca «Menéndez Pelayo», n. ${ }^{\circ} 1.29-56$.

HOYOS SAINZ, L., 1949: "Las tribus de la Romanización como base de la Antropología Española». $B R A H$, CXXV, 207-233.

HOYOS SAINZ, L., 1953: «Sobre la antigua Vettonia y la actual Extremadura». Estudios Geográficos, XIV, 409-420.

IGLESIAS GIL, J. M., 1977: «Estructura social, poblamiento y etnogenia de Cantabria». Memorias de Historia Antigua, I. 179-189.

KARST, J., 1954: Essai sur l'origine de basques, iberes et peuples apparentes. Strasbourg.

LAMBRINO, E., 1957: «Les Lusitaniens». Euphrosyne, I. 117-145.

LEJEUNE, M. 1955: Celtibérica. Salamanca.

LE ROUX, P.; TRANOY, A., 1973: «Roma et les indigenes dans le nord-ouest de la Péninsule Ibérique». $M C V$, IX. 177-231.

LOMAS, F. J., 1974: «En torno a Noega y los Pésicos». Habis, V. 131-139.

LOMAS, F. J., 1975: Asturias prerromana y Alto-Imperial. Sevilla.

LOPEZ CUEVILLAS, F., 1952: «La etnografía de la cultura castreña». Zephyrus, III; 5-13.

LOPEZ CUEVILLAS, F., 1953: La civilización céltica en Galicia. Santiago.

LLOBREGAT, E. A., 1972: Contestania Ibérica. Alicante.

MALUQUER DE MOTES, J., 1954 a: «Los pueblos Celtas». Historia de España Menéndez Pidal, I, 3, 5-194.

MALUQUER DE MOTES, J., 1954 b: Los pueblos Ibéricos. Historia de España Menéndez Pidal, I, 3; 305-370.

MALUQUER DE MOTES, J., 1955: «EL proceso histórico de las primitivas poblaciones peninsulares». Zephyms, VI, 146-149; 241-255.

MALUQUER DE MOTES, J., 1966: «Consideraciones sobre el problema de la formación de los vascos». IV Symposium de Prehistoria Peninsular, 115-128.

MALUQUER DE MOTES, J., 1968: La España de la Edad del Hierro. Madrid.

MALUQUER DE MOTES, J., 1972: Proceso histórico económico de la primitiva población peninsular. Barcelona.

MALUQUER DE MOTES, J., 1977: «El poblamiento prerromano en la Meseta del Duero». Symposium de Arqueología Romana. Bimilenario de Segovia. 17-31.

MANARICUA, A. E., 1973: «Fuentes literarias de época romana acerca del pueblo vasco». II Semana Internacional de Antropología Vasca, 273-291.

MANGAS, J., 1977: «Servidumbre comunitaria en la Bética prerromana». Memorias de Historia Antigua, I. 151-161.

MARCOS POUS, A., 1966: «Esquema sobre la relación cultural entre los vascos, indoeuropeos y romanos en la región navarra». IV Symposium de Prehistoria Peninsular, 169-172.

MARTIN TOBIAS, R., 1960: Estudio del poblamiento layetano en el Maresme y sus estribaciones. Barcelona.

MARTIN TOBIAS, R., 1963: «Poblamiento y demografía ibérica». II Symposium de Prehistoria Peninsular. 77-87.

MARTIN VALLS, R., 1974: Protohistoria y romanización de los vettones. Valladolid.

MARTINEZ SANTAOLALLA, J., 1946: Esquema paletnológico de la Península Ibérica. Madrid.

MONTEAGUDO, L., 1957: «Localizaçao das Casiterides e Oestrymnides». Revista de Guimarâes, LXVII, $372-416$. 
MONTENEGRO, A., 1971: «Los orígenes de los vascos». Hispania Antiqua, I, 271-334.

PASTOR MUÑOZ, M., 1977: «Participación indígena astur en la vida social romana». Memorias de Historia Antigua, I, 191-200.

PEDECH, P., 1976: La Géographie des Grecs. Paris.

PERICOT, L., 1952: L'Espagne avant la conquête romaine. Paris.

PITA MERCE, R., 1948: Los ilergetes. Lérida.

PITA MERCE, R., 1975: Lérida ilergete. Lérida.

PONSICH, M., 1974: Implantation rurale antique sur le Bas-Guadalquivir. Paris.

PRIETO ARCINIEGA, A., 1977: «La organización social de los celtíberos». Symposium de Arqueología Romana. Bimilenario de Segovia, 329-343.

RAMOS LOSCERTALES, J., 1924: «La devotio ibérica». Anuario de Historia del Derecho Español.

RAMOS LOSCERTALES, J., 1942: «Hospicio y clientela en la España Céltica». Emerita, X, 308-337.

RAURET DALMAU, A. M., 1963: El proceso de la primitiva población del Panadés. Barcelona.

RIPOLL PERELLO, E., 1978: «El problema dels Indiquetes en relació amb la ciutat d'Empúries». II Col-loqui internacional d'Arqueologia de Puigcerdá, 137-146.

RODRIGUEZ ADRADOS, F., 1946: «La 'Fides' ibérica». Emerita, XV, 176 y ss.

RODRIGUEZ ADRADOS, F., 1948: El sistema gentilicio decimal de los indoeuropeos occidentales y los origenes de Roma. Madrid.

RODRIGUEZ ADRADOS, F., 1950: «La rivalidad de las tribus del Nordeste español y la conquista romana». Estudios dedicados a Menéndez Pidal, I, 536 ss.

RODRIGUEZ BLANCO, J., 1977: "Relación campo-ciudad y organización social en la Celtiberia Ulterior». Memorias de Historia Antigua, I, 167-178.

RODRIGUEZ COLMENERO, A., 1972: «Sobre los pueblos prerromanos del Sur de Galicia». Boletín Auriense, II, 193-240.

RODRIGUEZ COMENERO, A., 1977: Galicia Meridional Romana. Bilbao.

RODRIGUEZ COLMENERO, A., 1979: Augusto e Hispania. Conquista y organización del Norte Peninsular. Bilbao.

RODRIGUEZ DUQUE, J. I., 1978: «Els Pirineus a les fonts classiques». II Col-loqui internacional d'Arqueologia de Puigcerdá, 315-318.

RODRIGUEZ NEILA, J. F., 1973: Los Balbos de Cádiz. Dos españoles en la Roma de César y Augusto. Sevilla.

ROLDAN HERVAS, J. M., 1968: «Fuentes antiguas para el estudio de los vettones». Zephyrus, XIX-XX, 315-318.

ROMERO MASIA, A., 1976: El habitat castreño: asentamientos y arquitectura de los castros del NO. peninsular. Santiago.

ROSELLO BORDOY, G., 1965: Prehistoria i protohistoria de Mallorca. Mallorca.

RUIZ RODRIGUEZ, A., 1977: «Las clases dominantes en la formación social ibérica del Sur de la Península Ibérica». Memorias de Historia Antigua, I, 141-150.

SANCHEZ ALBORNOZ, C., 1929: «Divisiones tribales y administrativas del solar del reino de Asturias en la época romana». $B R A H, \mathrm{XCV}, 315-395$.

SANCHEZ PEREZ, J. A., 1933: «La covada». IP, VII, 215-221.

SCHULTEN, A., 1927: «Las referencias sobre los vascones hasta el año 810 después de J. C.». Revista Internacional de Estudios Vascos, 225-240.

SCHULTEN, A., 1945 a: Historia de Numancia. Barcelona.

SCHULTEN, A., 1945 b: Tartessos. Madrid.

SCHULTEN, A., 1959: Geografía y etnografia antiguas de la Península Ibérica. Madrid.

SCHULTEN, A., 1962: Los Cántabros y Astures y su guerra con Roma. Madrid.

SERRA RAFOLS, J. C., 1942: «El poblamiento de la Maresma o Costa de Levante en la época anterromana». Ampurias, IV, 69-110.

SIRET, L., 1934: Les premiers celtes en Espagne. Madrid.

SOLANA, M., 1957: Los Cántabros, su manera de ser y de vivir. Aportación al estudio de la Historia económica de la montaña. Santander.

SOLANA SAINZ, J. M., 1974: Los Autrigones a través de las fuentes literarias. Vitoria.

SOLANA SAINZ, J. M., 1976: Los Turmogos durante la época romana. Valladolid.

SOLANA SAINZ, J. M., 1978: Autrigonia Romana. Zona de contacto Castilla-Vasconia. Valladolid.

SYME, R., 1934: "The Spanish War of Augustus (26-25 a. C.)». The American Journal of Philology, LV, 293-317.

SYME, R., 1970: «The conquest of North-West Spain». Legio VII Gemina.

TARACENA, B., 1933: «Tribus celtibéricas. Pelendones». Homenagem a Martins Sarmento.

TARACENA., B., 1954: «Los pueblos celtíberos». Historia de España Menéndez Pidal, I, 3, 197-299.

TARRADELL, M., (ed.), 1968: Estudios de Economía antigua de la Península Ibérica. Barcelona.

TORRES RODRIGUEZ, C., 1948: «Galicia en las guerras Cántabras. La tragedia del Monte Medulio». Bol. Univ. Santiago, 50-51; 24 págs. 
TOVAR, A., 1950: «Sobre la complejidad de las invasiones indoeuropeas en la Península». Zephyrus, I, 33 ss.

TOVAR, A., 1955: Cantabria prerromana o lo que la lingüística nos enseña sobre los antiguos cántabros. Madrid.

TOVAR, A., 1968: Lingüística y Arqueología sobre los pueblos primitivos de España. Madrid.

TRIVIÑO, J. M., 1953: «La idiosincrasia localista en la España prerromana». Cuadernos de Historia de España, XX, 12-44.

UGARTECHEA, J. M., 1970: «Etnología prerromana del Pirineo Occidental». Estudios de Arqueología Alavesa, IV. 79-106.

URIA RIU, J. Cuestiones relativas a la etnología de los astures. Oviedo.

VIGIL, M., 1963: «Romanización y permanencia de estructuras sociales indígenas en la España septentrional». BRAH, CLII, 225-235.

VIGIL; M., 1973: Historia de España. Edad Antigua. Madrid.

VIÑAS Y MEY, C., 1959: «Apuntes sobre Historia Social y Económica de España». Arbor, 157-158; pp. 33-57, 202-276.

WATTENBERG, F., 1959: La región vaccea. Celtiberismo y romanización en la cuenca media del Duero. Madrid.

WATTENBERG., F., 1960: «Los problemas de la cultura celtibérica». I Symposium de Prehistoria de la Península Ibérica. 151-177. 


\title{
LOS COGNOMINA DE PARENTESCO EN LA PENINSULA IBERICA. A PROPOSITO DEL INFLUJO ROMANIZADOR EN LA ONOMASTICA
}

\author{
JUAN MANUEL ABASCAL PALAZON \\ Universidad de Alicante
}

\begin{abstract}
El objeto de este artículo es analizar la forma en que los cognomina de parentesco se introducen en la onomástica hispana. Se trabaja sobre datos cuantitativos y se pretende extrapolar una serie de características sobre status y grado de romanización, que se hacen visibles en la mayor parte de los individuos que poseen este tipo de cognomina. Asimismo, el análisis temporal de la dispersión permite sugerir las posibles zonas de irradiación y los motivos por los que ésta se produce.
\end{abstract}

The aim of these article is to analyze the way in which cognomina of kinship are introduced in Hispanic proper names. Work has been based on quantitative data and we intend to carry out the extrapolation of a series of characteristics about status and degree of romanization, which can be seen in most of the individuals having this kind of cognomina. Moreover, temporal analysis of their diffusion allows us to suggest what the possible areas or eradiation were, and its causes.

El proceso de aculturación iniciado en la Península Ibérica a partir de las definitiva pacificación el año 19 a. C., propició la extensión de las influencias latinas a todos los ámbitos de la vida hispana. En ese proceso de transformación, manifestado en muchas ocasiones por la imbricación de elementos indígenas y romanos, la onomástica nos permite en muchas ocasiones rastrear el ritmo con el que se produjeron las modificaciones en las estructuras indígenas, así como los ámbitos en que éstas se desarrollaron (1).

Un conjunto de trabajos en estos últimos años ha dado magníficos resultados (2) sobre la base de un minucioso estudio de los conjuntos epigráficos conocidos. Nuestro interés aquí es rastrear el comportamiento de determinados cognomina que aparecen estrechamente vinculados al proceso de conversión de la onomástica indígena y, por tanto, al proceso de identificación cultural de los hispanos con los nuevos modos latinos.

No pensamos que sea casualidad el que los cognomina de parentesco aparezcan con excesiva frecuencia en la Península Ibérica y en el resto de las áreas célticas, hecho sobre el que han llamado ya la atención Kajanto (1965), Untermann (1975) y Móscy

(1) Agradecemos al doctor Géza Alföldy, de la Universidad de Heidelberg, su gentileza al leer el manuscrito y sus observaciones al texto original. Igualmente nos encontramos en deuda con el doctor U. Stylow, del Instituto Arqueológico Alemán de Madrid, que nos facilitó la consulta de los ficheros que se están elaborando para la revisión del CIL II, de donde tomamos valiosas referencias.

(2) En las consideraciones estadísticas y cuadros de resumen, los individuos que hacen constar su origo, aun siendo emigrantes, han sido remitidos a sus zonas de procedencia. 
(1983), así como otros muchos autores, ni es aconsejable atribuir al azar la proliferación de conocidos gentilicios latinos en estas mismas zonas, máxime cuando con frecuencia es difícil justificarlos en razón de la filiación paterna. Es por eso que hemos elegido los tres cognomina de parentesco más significativos (con sus derivados), para estudiar el ambiente y época en que se desarrollan, así como el componente social del grupo que los porta.

Maternus/a, Paternus/a y Fraternus/a son cognomina que aparecen con mucha frecuencia en la epigrafía hispana (KAJANTO, 1965, 18 y 86). Sus portadores fueron cónsules, individuos de rango ecuestre, mandos militares, soldados, magistrados municipales, libertos, etc., sin que a primera vista parezca posible extrapolar una característica común a todos ellos, debido a su elevado número y a la diversidad de niveles sociales y geográficos que cubren.

Aunque en un principio estos cognomina tuvieron diferentes ámbitos de incidencia (por lo que en su estudio no podemos evitar la existencia de compartimentos estancos), aparecen en algunos momentos unidos, dándose el caso de que la hija de un hombre con el cognomen Maternus, se llame Paterna (3), o que cualquiera de las dos formas aparezca sin vinculación con la onomástica familiar del individuo (4).

En primer lugar, hemos procedido a la recogida de cuantos testimonios aparecen en la Península Ibérica, sin despreciar las escasas inscripciones de aquellos individuos que, aun sabiendo con seguridad que no son hispanos, pueden haber propiciado en determinados ámbitos la proliferación de estos cognomina. Asimismo, hemos computado los testimonios extrapeninsulares referidos a hispanos, que mayoritariamente corresponden a soldados. Sobre este conjunto de 289 individuos para los tres cognomina y sus derivados, hemos aplicado criterios estadísticos, ateniendo al número y tipo de los gentilicios que presenten, distribución porcentual, posición social, desempeño de magistraturas, adscripción a tribu, religión, etc., tratando así de definir un modelo mayoritariamente válido.

Presentamos a continuación el material epigráfico seleccionado, clasificado según el gentilicio, y ordenado dentro de éste de la siguiente manera: Fraternus, Fraterninus, Fraterna, Maternus, Maternianus, Materna, Materniana, Paternus, Paternianus, Pater$n a$. A continuación figuran los individuos que sólo presentan cognomen. En el caso de que un personaje figure en varias inscripciones, se incluye una sola vez en su correspondiente grupo. Aun sabiendo el riesgo que implica, hemos procurado fechar el mayor número posible de inscripciones. Én algunos casos, esta cronología podrá ser rebatida, pero no pensamos que afecte básicamente a la valoración estadística y a las consideraciones globales que hemos desarrollado.

\section{LOS TESTIMONIOS EPIGRAFICOS}

\section{Aelius}

1.-G. Aelius Paternus, en Oliva de Plasencia (Cáceres), Cluniensis, de la tribu Galeria. Difunto de 45 años, hijo de Segontius y hermano de Aelia Aia. Quizá de la segunda mitad del siglo I (CIL II 818. HURTADO, 1977, 176, n. 366. BLAZQUEZ, 1966, 33-34).

(3) Como ocurre en Isona. Vide LARA 1973, n. 73.

(4) Como ejemplo puede servir CIL II 832 de Caparra (Cáceres). 


\section{Aemilius}

2.-M. Aemilius Fraternus, en Isona (Lérida), hijo de Lucius, praefectus fabrum, hermano de L.Aemilius Paternus (núm. 14). Principios del siglo II d. C. (CIL II 4460. LARA, 1973, n. 87. ALFÖLDY, 1979, n. 356).

3.-C. Aemilius Fraterninus, en Tarraco, hijo de C(aius), de la tribu Galeria, praef. fabr. II, trib.mil. legionis $V$ Alauda[r(um)], flamin.p.H.c. hic censum egit in provinc. Gallia Aquitanic. Ultimo cuarto del siglo I d. C. (CIL II 4188. ALFÖLDY, 1973, n. 1; RIT 252).

4.-L. Aemilius Maternus, en Isona (Lérida), casado con Fabia Fusca, y padres de Aemilia Materna. IIvir de Aeso. Fines del siglo I/principios del II (5).

5.-Aemilius Maternus, en Angostina (Alava), difunto de 20 años, hijo de Florius. Siglo I (6).

6.- Aemilius Maternus, en Bayona de Tajuña (Madrid), casado con Acilia Anneza y padre de Aemilia Materna. Siglo II (CIL II 3069. ILER 4917).

7.-Aemilius Maternus, alfarero, Tritiensis, en dos sellos recogidos por Mayet (1983, n. 16 y 17. Aem.Mat. y Ae.M.Tr.). Quizá siglo II d. C.

8.-Aemilius Maternus, en Vizmanos (Soria), difunto de 40 años, hijo de un padre anónimo de 67 años, con su madre y su hija. Quizá siglo I (JIMENO, 1980, 141, n. 122, lám. XXXIX, 2).

9.-Aemilia Materna, en Barcelona, probablemente la esposa de Aemilius Zosimus, en la primera mitad del siglo II $(H A E 795$. IRB, pp. 126 y 154, con la literatura anterior).

10. - Aemilia Materna, en Sasamón (Burgos), Suestatiensis, difunta de 30 años, casada con Scribonius Fronto, madre de Scribonia Frontina (difunta de 5 años), y nuera de Scribonius Fuscinus (Suestatiensis, difunto de 55 años). Probablemente de fines del siglo I ( $A E$ 1911, 130; GARCIA MERINO, 1975, n. 168).

11.- Aemilia Materna, en Isona (Lérida), en una inscripción funeraria dedicada a la Luna Augusta. Hija de L. Aemilius Maternus y Fabia Fusca. Fines del siglo I/ principios del II (7).

12.- Aemilia Materna, en León. Hermana de Aemilius Flavus, miles. Probablemente del siglo II (8).

13.- Aemilia Materna, en Bayona de Tajuña (Madrid), hija de Aemilius Maternus y de Acilia Anneza. Siglo II (9).

(5) CIL II 4458. Inscripción consagrada a la Luna Augusta por L. Aemilius Maternus y su esposa, en recuerdo de su hija. LARA 1973, 209 ss., n. 86. ILER 640. ALFÖLDY 1979, 258, n. 353. La gran familia aesonense de los Aemilii ha proporcionado un gran número de inscripciones. El grupo parece corresponder a una misma época, y el principal apoyo cronológico son los beneficios que de Trajano obtuvo un miembro de la familia, L. Aemilius Paternus, que fue centurión a principios del gobierno de este emperador. (Vide núm. 14). En relación con esta familia, Hübner construyó un stemma basado en hallazgos de Tarragona y Aeso, que Lara completa con la posibilidad de que el grupo guarde relación con un Terentius de Sagunto (CIL II 3842), y algunos otros Aemilii tarraconenses. Vide LARA 1973, 211, con toda la bibliografía anterior.

(6) ELORZA 1967, 124. ILER 6184. CRESPO 1981, 241 ss., en especial 244, nota 64, con toda la bibliografía.

(7) CIL II 4458. Hija del personaje número 4 y en la misma inscripción. Sobre la familia, vide nota 5. ALFÖLDY 1979, 258, n. 353.

(8) CIL II 2669. ILER 4962. LE ROUX 1982a, 250, n. 261 y 348, n. 5. LE ROUX, 250 piensa que no se deben poner en relación los dos fragmentos de esta inscripción (el primero con cuatro líneas y el segundo con las dos finales) tal y como propone Hübner en CIL II 2669 y Vives, dudando también de la suposición que en su día hizo ROLDAN HERVAS 1974, n. 637 sobre la pertenencia de este soldado a la legio VII. En cualquier caso, Le Roux no duda en afirmar la pertenencia al medio indígena del soldado y, añadiríamos nosotros, de su hermana, si se confirma su identidad.

(9) Hija del personaje número 6 . 
14. - L. Aemilius Paternus, en tres inscripciones de Isona (Lérida). Natural de esta ciudad, de la tribu Galeria, hijo de Lucius y posiblemente casado con Atilia Vera (10). A principios del gobierno de Trajano fue centurión. Por los datos que conocemos, su carrera comenzó como praefectus fabrum, para pasar a ser centurión de la legio VII Gemina y comenzar un largo cursus de mando militar fuera de la península, como centurión de las legiones I Minerva, VII Claudia, XIIII Gemina, de las cohortes X Urbana? y IV Praetoria, trecenario de la legio II A ugusta y primipilar de la misma, puesto en el que terminó su carrera. Su participación en las campañas Dacica y Parthica con Trajano le valió el premio del emperador, según consta en dos inscripciones de Isona (11), la segunda de las cuales contiene su cursus honorum completo, aunque ligeramente alterado en el orden, pues la indicación $p$ (rimi)p(ilaris), que alude al puesto terminal de su carrera (LE ROUX, 1982a, 296, n. 31) encabeza la relación del cursus. Si hubiera que establecer un orden cronológico para las tres inscripciones de L.Aemilius Paternus, nos inclinamos a pensar que la más antigua sería el fragmento encontrado hace unos años en Isona (LARA, 1973, 199, n. 79) en la que este personaje no es todavía primipilar. Le seguiría en orden la dedicación a su hermano L.Aemilius Fraternus, en la que Paternus figura ya como primipilar (12), y la más reciente sería la que su mujer le dedicó probablemente tras su fallecimiento. Las inscripciones conservadas son de época de Trajano.

15.-Aemilius Paternus, en Urbina de Basabé (Alava), casado con Domitia Prima. Probablemente de finales del siglo II y comienzos del III (13).

16.-Aemilia Paterna, Aesonensis, en inscripciones de Isona y Tarragona. A propósito de CIL II 4458, Hübner intentó componer la familia de los Aemilii de Aeso, a la que pertenece Aemilia Paterna, hija de Lucius (14), quizá relacionada con los números 4, 11 y 14 (vide supra) y algunos otros de Tarraco (15). Fue flaminica perpetua p.H.c. (16), y dedicó en Isona una inscripción a la Victoria Augusta (17), quizá aludiendo a alguno de los éxitos de Trajano, y alcanzó el flaminado perpetuo de la Citerior en los primeros veinte años del siglo II (18).

17. - Aemilia Paterna, en Lerate (Navarra), en una dedicación a Losa, fechada entre los siglos II y III (19).

18.-Aemilia Paterna, en Lara de los Infantes; tiene dos siervos. Probablemente del siglo II (20).

(10) Esta relación de parentesco no queda clara en CIL II 4461. DOBSON 1978, n. 111, no duda en mantener este parentesco, como tampoco lo hace LE ROUX 1982a, 295-6, n. 31. La existencia de un centurión que a comienzos de la época flavia fue primipilar de la legio VII en Hispania, cuyo nombre es L.Atilius Verus, ha sugerido en ocasiones la posibilidad de que la esposa de Paternus sea hija o nieta de este individuo. A favor y en contra, vide LE ROUX 1982a, 295, y 1972, 119-120, n. l.

(11) LARA 1973, 199, n. 79, lám. XXXVIII, inédita hasta entonces. Para la segunda pieza, CIL II 4461, ILER 1684 y LARA 1973, 214, n. 88 y lám. XLVII. ILS 2661. ALFÖLDY 1979, n. 357.

(12) LARA 1973, 212, n. 87. CIL II 4460. ILER 1695. ALFÖLDY 1979, n. 356.

(13) CIL II 2921. ELORZA 1967, 176. CRESPO 1981, 244, nota 69 con el resto de la bibliografía.

(14) Su filiación sólo consta en CIL II 4190.

(15) ALFÖLDY 1975. RIT 319, la pone en relación con RIT 252 y RIT 287.

(16) CIL II 4190. ALFÖLDY 1973, n. 101; LARA 1973, 195, n. 102. ALFÖLDY 1979, n. 354.

(17) PITA 1968, 340, n. 5. LARA 1973, 239, n. 102. ALFÖLDY 1979, n. 354. 319.

(18) CIL II 4190, Tarragona. ILER 165Ia. ALFÖLDY 1973, n. 101, quien fecha la inscripción. RIT

(19) BLAZQUEZ 1962, 80. ILER 864. BLAZQUEZ 1975, 117. CASTILLO 1981, 51, n. 24 con el resto de la bibliografía.

(20) EE VIII, 153. MANGAS 1971, 147. ABASOLO 1974, n. 101. 


\section{Aitanius}

19.-Aitanius Paternus, en Lugo. Indígena que dedica una inscripción a Virrore Viliaego, en el siglo II (21). Aitanius es un nombre infrecuente. En La Coruña existe un Attanius (CIL II 2562).

\section{Albulus}

20.- Albula Paterna, en Marco de Canavezes (Portugal), dedicado a Mater Deum (HAE 2700. ILER 378).

\section{Alfius}

21.-P. Alfius Avitus Numerius Maternus, en una inscripción de Tarragona dedicada a su padre, $P$. Alfius Maximus Numerius Licinianus, un senador de fines del siglo II o principios del III, con un brillante cursus (22). Alföldy emparenta a ambos personajes con $P$.Alfius Maximus Numerius Avitus, que fue, entre otros cargos, legado en la Betica bajo Alejandro Severo (CIL VI 1474 de Roma. ALFÖLDY, 1969, 275). Tribu Galeria.

\section{Allius}

22.-Allia Paterna, en Hinojosa del Duero (Salamanca), difunta de 35 años, quizá del siglo I (HAE 1263. ILER 2621).

\section{Annius}

23.-Annius Maternus, alfarero de Bezares (zona de Tritium Magallum, Logroño), documento en dos sellos (Of. An. Mater. y OfAn M... MAYET, 1983, n. 40 y 41). Segunda mitad del siglo I. Las cronologías estimadas para los alfareros son las que Mayet $(1983,94)$ supone para los talleres riojanos.

\section{Antistius}

24.-Antistius Paternus, en Narbona; difunto de la tribu Galeria, soldado de la legio IV Macedonica, reclutado antes del año $40 \mathrm{~d}$. C. Probablemente es hispano. La inscripción es de finales de época claudia (CIL XII 4365. LE ROUX, 1982a, 188, n. 64).

\section{Antonius}

25.-Antonius Maternus, en Monasterio de Rodilla (Burgos), difunto de 40 años, hijo de Venius. Siglo II (ABASOLO, 1982, 163-64).

26.-M. Antonius Paternus, en Borines (Asturias), hijo de padre anónimo, ex gente Ablaidacoru $(m)$. Difunto de 60 años con hijos anónimos. Siglos II-III. (CIL II 2710. ILER 6323).

(21) CIL II 2575. VAZQUEZ SACO y VAZQUES SEIJAS 1960, n. 15. BLAZQUEZ 1962, 218. ILER 951. ARIAS 1979, 40, n. 14.

(22) CIL II 4110. ILS 2931. PIR I, 190, n. 535. ALFÖLDY 1969, 179. RIT 127. 
27. - T. Antonius Paternus, en Pamplona, testigo en un pacto de hospitalidad del año 185 d. C. (23).

28.-Antonius Paternus, en Corao (Asturias), Vad(iniensis) Arcaedum, difunto de 40 años, hijo de Arrenius, con hijos anónimos. Quizá II-III (24).

\section{Aponius}

29. - G. Aponius Maternus, en León, casado con Licinia Atla (difunta de 38 años). Quizá mediados siglo II (25).

\section{Arrius}

30. - Arria Paterna, en Clunia. Madre de ... Viscunos (difunto de 20 años) y Sempronia. Siglo II (CIL II 2809).

\section{Arruntius}

31.-C. Arruntius Paternus, en Játiva (Valencia). Difunto de 30 años. Probable siglo I (CIL II 3627).

\section{Asclepius}

32. - Asclepius Paternus, en Barbarín (Navarra), dedicaNdo a S(elatsa). Siglos I-II (26).

\section{Asturia}

33.-Asturia Materna, en Zamora, hija de Capito y casada con L. Lucretis? Quizá siglo II (CIL II 5650. ALBERTOS, 1966, 38).

\section{Atilius}

34.-M. Atilius Fraternus, en Tarraco, dedicando una inscripción a su amigo L. Grattius Glaucus (hijo de Caius, tribu Galeria, Segobrigensis, flamen p.H.c. entre los años 70 y 180 d. C.) (CIL II 4220. ETIENNE, 1958, 142; ALFÖLDY, 1973, n. 30; RIT 282).

35.-At(ilius) Fr(aternus)? en Poza de la Sal (Burgos), dedicando un ara al Genius Loci (AE 1916, 74; ILER 556).

36.-G. Atilius Maternus, en Quintanaélez (Burgos), hijo de Atilius y casado con Vivatia Ambada (FITA 1916, 123 ss. SOLANA 1978, 121, n. 52).

37.-Atilius Maternus, en Isona (Lérida), que figura en un monumento a su hija Atilia Paterna, difunta de 75 años. Siglo II (LARA, 1973, 185 ss., n. 73). Vide núm. 39 infra.

38. - Atilius Paternus, en Tricio (Logroño), hermano de Atilius Maxumus y tío de Atilius Capito. Siglo II (27).

(23) CIL II 2960. ILS 6108. Figura junto a Caecilius Festivus, y probablemente ambos desempeñan una magistratura colegiada en la ciudad.

(24) CIL II 2706. ILER 5461. GARCIA MERINO 1975, n. 222.

(25) CIL II 2683. RABANAL 1982, 71, n. 30 con foto que permite corregir la lectura Atte que hizo Hübner en el nombre de la difunta. Sin efectuar la corrección, LE ROUX 1982a, 350, n. 39.

(26) ILER 924. BLAZQUEZ 1975, 167. CASTILLO 1981, n. 21.

(27) CIL II 2894 y 5805 . ELORZA 1980, 41 ss., n. 50, fig. 30, con la bibliografía anterior, que la fechan en época de Trajano. 
39.-Atilia Paterna, en Isona (Lérida), Aesaonensis (sic), difunta de 75 años hija de Atilius Maternus (núm. 37), y suegra de L.Licinius Oppidanus. Fines del siglo II (28).

40.- Atilia Paterna, en Monte Cildá (Olleros de Pisuerga, Palencia), madre de L. Atilanus Reburrinus. Finales del siglo II y principios del III (29).

\section{Attius}

41.-Attius Paternus, alfarero de Tritium Magallum, cuyo nombre figura completo en algunos sellos (Atti.Paterni.of.) y que se presenta con algunas variantes (MAYET 1983, n. 58-65). Quizá siglo II.

42. - Attia Paterna, en Caparra (Cáceres), hija de M. Attius Silvanus y de Caeria Severa. Principios del siglo II (30).

\section{Aurelius}

43.-G. Aurelius Fraternus, en León, de la tribu Quirina, difunto de 20 años (CIL II 2681). Siglo II.

44.-Aurelia Materna, en Vigo (Pontevedra), Cluniensis. Casada con Q. Arrius Mansus (Cluniensis, 40 años, Cn.f.). Es la segunda mujer de este individuo, del que conocemos una gran parte de la filiación. Fines del siglo II y principios del III (31).

45.-Aurelia? Materna, en Conimbriga, con 1 liberto. Fines del siglo II (32).

\section{Avitius}

46.-Avitius Paternus, en Luyego (León). Decurión de la Cohor. I Gallic. el 10 de junio de 181 (33).

$\mathbf{B}(\ldots)$

47. - B. Paternus, en Puebla de Montalbán (Toledo), Maganiq(um), padre de Licinia Moenicu(m), difunta (EE IX, 317. HAE 8-11, p. 28). Fines del siglo I/principios del II.

\section{Bovia}

48.-Bovia Materna, en Condeixa la Nueva (Aeminium), hermana de Iulia Maxima e hijas ambas de G.Iulius Maternus (núm. 101). Finales del siglo II. Vide nota 54.

(28) CIL II 4462. LARA 1973, 185, n. 73 y 77. ALFÖLDY 1979, n. 370

(29) HAE 2595. ILER 6821. IGLESIAS 1976, n. 52 lee Tal... interpretando de forma distinta el anagrama que nosotros leemos Atil por comparación con una inscripción de Alcalá de Henares: ILER 6199, ABASCAL y FERNANDEZ-GALIANO 1984, 22 śs., fig. 17, con el resto de la bibliografía.

(30) CIL II 832. ILER 4062. HURTADO 1977, n. 2.

(31) HAE 1506. ILER 4644. Sobre su filiación, HAE 1512 y 2668 . En torno a la cronología, TRANOY 1981, 355. Sobre el significado de la presencia cluniense en Vigo, GARCIA MERINO 1974, 9 ss. En detalle sobre la estela y su significado, con lectura distinta a la propuesta en $H A E$, vide JULIA 1971, 6, n. 1, lám. Ia.

(32) CIL II 369. ILER 4078. ETIENNE 1976, n. 46.

(33) $A E$ 1967, n. 230; HAE 2348; ILER 5946; ROLDAN 1974, 460; LE ROUX 1982a, n. 247. 


\section{Caecilius}

49.-Q. Caecilius Maternus, en Lisboa, difunto, hijo de $C(. .$.$) . Probablemente siglo I$ (CIL II 298. ILER 2409).

50.-Caecilia Materna, en León, Caibaliq. Uxamen. difunta de 38 años casada con $T i$ tus. Siglo I (34).

51.-Caecilia Materna, en Ecija (Sevilla), hija de D. Caecilius Hospitalis. Quizá del siglo I (CIL II 1474. ILER 1728).

52.-C. Caecilius Semp. Paternus, en Braga, hijo de Materna. Principios del siglo III (vide núm. 251). El doble gentilicio puede ser el testimonio de la adopción del muchacho por un tal Sempronius Paternus, hecho del que no hay evidencia.

\section{Caelius}

53.-C. Caelius Paternus, en Oliva de Plasencia (Cáceres), Cluniensis de la tribu Galeria. Difunto de 25 años, en una inscripción dedicada por Vicinia Cluniensium. Quizá de la segunda mitad del siglo I (CIL II 821).

\section{Calpurnius}

54.-Calpurnius Paternus, en San Justo de la Vega (León), con motivo de la celebración de las Lemuria (35).

55.-Calpurnia Paterna, en Ranera (Burgos), hija de Severus, dedicando a Velonsa (36).

\section{Camilius}

56.-C. Camilius Paternus, en Tarragona, en una inscripción dedicada por su amigo $M$. Aemilius Valerianus, de mediados o segunda mitad del siglo II (CIL II 4345. RIT 455, p. 244).

\section{Campilius}

57._L. Campilius Paternus, en León. Eques secundae alae Flaviae opt(io) [eq]uitu[m leg(ionis)?]. Siglo II (37).

\section{Cassius}

58.-Cassia Materna, en Madre de Deus (Sintra, Portugal), dedicando a Mandiceus (38).

59. - Cassia Materna, en Yanguas (Soria), dedicando a las Matres, casada con Cor. Celsus? Quizá del siglo III (39).

(34) ILER 5428. JIMENO 1980, n. 171. RABANAL 1982, n. 44. LE ROUX 1982a, n. 21.

(35) MAÑANES 1982, n. 130, lám. L, con la bibliografía anterior.

(36) CASTILLO 1981, n. 28 con la bibliografía anterior.

(37) CIL II 5682; GOMEZ MORENO 1925, 31; ILER 1532; ROLDAN 1974, 440; RABANAL 1982, n. 17; LE ROUX 1982a, 217, n. 160, quien afirma que Campilius es un gentilicio único, originario probablemente de la zona astur o del conventus de Clunia, lo que encaja con el esquema que defendemos en este trabajo.

(38) CARDOZO 1958, 25 ss.; BLAZQUEZ 1962, 62, fig. 4; ILER 877; BLAZQUEZ 1975, 124.

(39) TARACENA 1941, 179; ILER 385; JIMENO 1980, 51-52, n. 35, lám. XI. 
Cel(...)

60.-Cel(...) Materna, en Segobriga, probablemente vinculada familiarmente a Lucretia Parthenope, en cuya inscripción funeraria figura. Fines del siglo I (ALMAGRO 1984, 257, n. 119).

\section{Coelia}

61.-Coelia Materna, en Poza de la Sal (Burgos), difunta de 30 años, hija de Quoelius. Tiene varios libertos. Inicios del siglo II (40).

\section{Cornelius}

62.-G. Cornelius Maternus, en Clunia, difunto de 20 años, hijo de Cor. Avianus y Aemilia Atta. Mediados del siglo II (41).

63.-L. Cornelius Maternus, en Benifairó (zona de Sagunto, Valencia). Quizá fines del siglo I (CIL II 3896. ILER 2159. BELTRAN 1980, n. 295).

64. - L. Cornelius Maternus, en Belorado (Burgos), difunto de 25 años e hijo de Cornelius. Probablemente del siglo III (42).

65.-M. Cornelius Nigrinus Curiatius Maternus, Edetanus, de la tribu Galeria, hijo de $M$ (...). Cónsul del año 83 d. C. legatus pr.praetore prov. Syriae entre 97-98 y 100101 (ALFÖLDY-HALFMANN 1973, 49), y mando en Moesia en años anteriores. Los mismos autores suponen que era hijo adoptivo de Curiatius Maternus, el senador muerto poco después del año 75 (id. 22, 24), en torno a cuyo origen bético (LE ROUX 1982b, 457) hay opiniones encontradas (CASTILLO 1982, 500), y que no incluimos entre los testimonios epigráficos de este trabajo por los citados moti$\operatorname{vos}(43)$.

65 bis.- T. Cor(nelius) Mate(rnus), en Clunia, IIIIvir que figura en acuñaciones fechables entre los años 14-37 d. C. (BELTRAN 1978, n. 137. CNR, X, 60, 531, citada por BELTRAN).

66.-Q. Cornelius Maternus, en Medina Sidonia (Cádiz), difunto de 30 años. Quizá de la segunda mitad del siglo I (44).

67.-Cornelius Maternus, en Baza (Granada) dedicando a Mercurio (CIL II 3404. ILER 258).

68.-Iulia Cornelia Materna, en Antequera (Málaga), hija de $M(. .$.$) dedicando al genio$ del municipio de Anticaria, madre de Mu.Cor.Agricola (CIL II 2034. ILER 570).

69.-Cornelia Materna, en Astorga (León), hija de $M(. .$.$) , madre de Antonia Aeianiana$ (17 años). Fines del siglo II (45).

70.-Cornelia Materna, en Peña Amaya (Santander), difunta de 44 años, madre de Flavia (difunta de 25 años). Quizá del siglo II (CIL II 6338s. IGLESIAS 1976, n. 6).

71.-Cornelia Materna, en Cáceres, difunta, Uxame(n)sis Arg(a)elorum, hija de G(...). Fines del siglo I (CIL II 696. JIMENO 1980, n. 163).

(40) GARCIA MERINO 1975, 401, n. 153, con la bibliografia anterior. ALBERTOS y ABASOLO 1976, 398 y 403 , n. 6 .

(41) CIL II 2789 y 5791. ILER 4104. GARCIA MERINO 1975, n. 144.

(42) SOLANA $1978,99, \mathrm{n} .6$, con la bibliografía anterior.

(43) Las inscripciones sobre el personaje en: CIL II 3783 y 6013; SYME 1958, 670 ss.; MARTI FERRANDO 1972; $A E$ 1973, 283; ALFÖLDY-HALFMANN 1973; ALFÖLDY 1979, 274-75, 448-450; LE ROUX 1982b, 457, n. 4; CASTILLO, 1982, 500.

(44) CIL II 1322; ILER 2548; GONZALEZ 1982a, n. 11.

(45) CIL II 2653; ILER 4278; MAÑANES 1982, n. 47. 
72.-L. Cornelius Paternus, en Torremocha (Teruel), difunto de 60 años con un liberto. Fines del siglo I (CIL II 3170. VENTURA CONEJERO 1975, 218, n. 54, fig. 1, lám. 2).

73.-M. Cornelius Saturninus Paternus, en Ampurias, hijo de M(...), fue aedilis, IIvir y flamen, según consta en una inscripción dedicada por los cultores larum. Fines del siglo I (46).

74. - Cornelius Paternus, en Villafranca Montes de Oca (Burgos), hijo de Cornelia Ambada. Primera mitad del siglo III (CIL II 2908. GARCIA MERINO, 1975, n. 173).

75.-Cornelia Paterna, en Lara de los Infantes (Burgos), madre de Fuscula (difunta de 35 años, casada con Victor). Segunda mitad del siglo II (47).

\section{Crasicius}

76. - A(ulus) Crasicius Paternus, en Braga, dedicando a Aemipicer. Siglo II (ILER 717. BLAZQUEZ 1962, 169).

\section{Domitius}

77.-C. Domitius Maternus, en Barcelona, Acucensis (Aquincensis?), hijo de $L(\ldots)$. Decurión en Barcino por D.D. en el siglo III (48).

78.-Domitius? Maternus, en Gastiain (Navarra), padre de Domitia Semproniana. Quizá de fines del siglo I (CASTILLO 1981, 72, n. 43, lám. XLIII).

79.-[DJomi[tio?] [...Jrno, en Frómista (Palencia), difunto de 25 años, casado con Valeria? ... na. Quizá siglo II (FITA 1900, 174. EE IX, 301. CRESPO 1978, n. 2).

\section{Egma??}

80.-Egma?? Pat(erna), en Bermellar (Salamanca), dedicando a I.O.M. (ILER 159).

\section{Eonina}

81.--Eonina Materna, en Monte Cildá (Olleros de Pisuerga, Palencia), difunta de 40 años, madre de Sempronius (difunto de 20 años?). Probablemente del siglo II (CIL II 6300. ALBERTOS 1966, 115. CRESPO 1978, n. 19).

\section{Fabius}

82.-Q. Fabius Maternus, en Barcelona, de la tribu Galeria, hijo de $Q$ (uintus) y de Licinia Numantina (M.f.) (IRB 1; ALFÖLDY 1979, n. 364), hermano de Q.Fabius Licinianus (ALFÖLDY 1979, n. 361) y nieto de M.Licinius Celtiberus (tribu Quirina, Aedilis y IIvir de Aeso) (ALFÖLDY 1979, n. 361). El personaje es de finales del siglo I y principios del II d. C. (ALFÖLDY 1979, 260).

\section{Felicius}

83.-Cn. Felicius Ursianus Maternus Lapillus??, en Poza de la Sal (Burgos), en una inscripción dedicada por Aemilianus Ursianus. Siglo III (49).

(46) ALMAGRO 1952, 90 ss., n. 3, lám. y p. 91 con el resto de la bibliografía. ILER 1566.

(47) Agradeceos àl doctor Alföldy su interpretación de esta pieza. ILER 4451; ABASOLO 1974, 117, n. 157, lám. LXXIV, 2, con el resto de la bibliografía; GARCIA MERINO 1975, n. 121.

(48) CIL II 6153. ILER 1375. IRB 53, y p. 63 con toda la bibliografia anterior.

(49) SOLANA SAINZ 1978, 119, n. 46, con toda la bibliografía anterior. 


\section{Flavius}

84.-Flavius Maternus, en Tarragona, casado con Porcia Eucheria (difunta de 20 años). Siglos II o III (50).

85.-Flavia Materna, en Renieblas (Soria), madre de Valeria Flavina (difunta de 16 años). Quizá siglo II (JIMENO 1980, 109, n. 90).

86. - Flavia Materna, en Queizas (Orense) dedicando a I.O.M. (RODRIGUEZ COLMENERO 1973, 365).

87. - Flavia Paterna, en Lugo, natural de Lucus Augusti, madre de Iulia Flacilla (difunta de 18 años). Fines del siglo II y principios del III (51).

\section{Fonteius}

88.-L. Fonteius Maternus Novatianus, en Tarragona, Tarraconensis de origen. Adscrito a la tribu Galeria, hijo de $M(. .$.$) y quizá de Valeria C.f., Aedilis, IIvir,$ Quaest. Iudex III dec. Equo publico donato por Nerva, flamen p.H.c. entre los años 96 y 98 (52).

\section{Frontonius}

89.-Frontonius Paternus, alfarero de Bezares (zona de Tritium Magallum, Logroño. MAYET 1983, n. 209. O.Front.Pa.). Segunda mitad del siglo I.

\section{Fulvius}

90.-G. Fulvius Paternus (Exo.G.F.Pat. con variantes), alfarero, quiza de Tritium Magallum (MAYET 1983, n. 228 a 230).

91.-Ti(tus) Fulvius Paternus (of.Ti.Fu.Pa.), alfarero, probablemente de Tritium Magallum (MAYET 1983, n. 641).

92.-Fulvius Paternus Festus ([Ex.]oFul.Pat.Festi. con variante), alfarero, quizá de Tritium Magallum (MAYET 1983, n. 215 y 216), quizá identificable con Fulvius Paternus (Fulv.Pat. con variantes) que figura en algunos sellos (MAYET 1983, n. 211 a 214). Se trata en cualquier caso del mismo grupo familiar que los anteriores).

\section{Geminius}

93.-Geminia Paterna, en Tarragona, nieta de Titus Geminius Philippus (ex. conv. Bracaro). Siglo I (RIT 378).

(50) CIL II 4396. ILER 4388. RIT 647, p. 323 con la bibliografía anterior.

(51) CIL II 2586. VAZQUEZ SACO Y VAZQUEZ SEIJAS 1960, 35; ILER 4263; ARIAS 1981, 57 , n. 30 , sugieren la posibilidad de que la pieza no proceda de Lugo, sino de León.

(52) Este importantísimo personaje figura en dos inscripciones tarraconenses: CIL II 4216 (ILER 1634 y RIT 278) y CIL II 6095 (ILER I587, RIT 279). Existen ligeras diferencias entre las opiniones de los investigadores que han intentado definir la carrera de este individuo, aun admitiéndose comúnmente su localización en época flavia. ETIENNE 1958, 135, piensa que su flaminado provincial debe situarse en época de Domiciano, fecha que rebaja PFLAUM 1965, 98, quien sostiene que la concesión del equo publico le debió ser hecha por Nerva mientras desempeñaba el flaminado provincial. ALFÖLDY 1973, 72, piensa que esta concesión debió ser inmediatamente anterior al desempeño del cargo provincial y que, en cualquier caso, ambas inscripciones se le dedicaron durante el gobierno de Nerva (idéntica opinión en RIT, p. 153). RODRIGUEZ NEILA 1978, 16, ha estudiado recientemente este cursus y apunta la posibilidad de que Fonteius ejerciera las magistraturas locales y la judicatura durante el reinado de Vespasiano y el flaminado bajo Nerva. En cuanto a la filiación del individuo, ALFÖLDY (RIT, p. 153) sugiere la posible relación que puede tener con M.Fontenius Novatianus de Aquae Calidae (CIL II 4487). 


\section{Genutius}

94. - Genutia Materna, en Clunia, muerta a los 3 años. Hija de Genutius y de Iulia Paterna. Quizá del siglo II (53).

\section{Gr(attius)}

95.--Gr(attius?) Patern(us), en Talavera de la Reina (Toledo), Caesarobrigensis ex Cast.Ciselli, de la tribu Quirina, difunto de 65 años, casado con Ambata. Siglo II (CIL II 5320).

\section{Herennius}

96.-Herennia Paterna, en Segovia, difunta de 14 años casada con G.Vale(...) (...ianus) (difunto de 19 años e hijo de L.Fabius Sigerus). Quizá del siglo II (CIL II 2752. GARCIA MERINO 1975, 422, n. 305).

\section{Hiberius}

97.-Hiberia Materna, en Tarragona, casada con L. Valerius Barbarus, miles de legio $V I I$ b.f. cos. (difunto de 37 años). Primera mitad del siglo II (RIT 198. LE ROUX $1982 \mathrm{a}, 207$, n. 127).

\section{Hirrius}

98.-Q. Hirrius Maternus, cerca de Azevedo (Lisboa), de la tribu Galeria, hijo de M(...) Quizá del siglo I (CIL II 217).

\section{Iulius}

99.-L. Iulius Fraternus, en Idanha, de la tribu Quirina, hijo de Rufinus, y quizá casado con Iulia Modesta (hija de Quintus). Probablemente de fines del siglo II (HAE 1134, ILER 3758).

100.-M. Iulius Fraternus, en León, hijo de Fabia Alla (GOMEZ MORENO 1925, n. 35. LE ROUX 1982a, 349, n. 28).

101.-G. Iulius Maternus, en Condeixa a Nueva (Aeminium), difunto de 64 años. Padre de Bovia Materna y de Iulia Maxima. Tiene varios libertos. Siglo II (54).

102.-Ti. Iulius Maternus, en Tarragona, de la tribu Fabia, domo Roma, hijo de Tiberius, muerto a los 28 años. Centurión de la leg.VII Gem. Siglo I (55).

103.-Iu(lius?) Ma(ternus), alfarero, quizá de Tritium Magallum (OfIuMa. MAYET 1983 , n. 251, con otras variantes en n. 246 a 256), acaso identificable con $L u(. .$. Ma(ternus) (MAYET 1983, n. 321).

104.-C. Iulius Paternus?, quizá cluniensis, hijo de Paternus, en Apulum (Dacia), vete-

(53) CIL II 2792 contiene diferentes interpretaciones de la pieza. Una propuesta de lectura en GARCIA MERINO 1975, n. 142.

(54) CIL II 378. ILER 3949 y 4976.

(55) CIL II 4322. HAE 864. RIT 399. Una nueva revisión de la pieza ha permitido al doctor Alföldy formular la lectura que nosotros utilizamos gracias a su amable ayuda. 
rano de la legio XIIII, en una inscripción dedicada a la Victoria Augusta. Principios del siglo II (56).

105. - C. Iulius Paternus, en Palencia. Adscrito a la tribu Quirina. Difunto de 30 años, hijo de Ata y de C(...). Siglo II (57).

106. - Iulius Paternianus, en San Sebastián de Freixo (Collippo), hijo de Paternus. Quizá fines del siglo II (CIL II 358).

107. - Iulia Paterna, en Barcelona, casada con P.Lupianus. Segunda mitad del siglo II (58).

108. - Iulia Paterna, en Clunia, madre de Genutia Materna. Probablemente del siglo II (vide núm.94).

109.-Iulia Paterna, en Lisboa, casada con Marcus, y madre de Iulia (difunta de 27 años, Olisiponensis). Siglo II o III (59).

110. - Iulia Paterna, en Pax Iulia, difunta de 15 años, liberta de Iulia Terpsicore. Siglos II-III (CIL II 60).

111. - Iulia Paterna, en Alcalá de Guadaira (Sevilla), casada con M.Iunius Brutus Luc. Urgent(...) (difunto de 23 años). Siglo I (CIL II 1264).

\section{Iunius}

112.-M. Iunius Maternus, en Villavieja del Cauche (Antequera, Málaga), en la segunda mitad del siglo I, post. 70 (60).

113. - M. Iunius Maro Aemilius Paternus, en Tarragona, Lanciensis, de la tribu Quiri$n a$, hijo de Blandus? Desempeñó todas las magistraturas de Lancia. Sacerdos Conv.Astur. Adlectus V dec.Romae. Flamen p.H.c. entre 110 y 140 (61).

114.-M. Iunius Paternus, en Gastiain (Navarra), difunto de 30 años, hijo de Cantaber. Primera mitad del siglo II (62).

115.-M. Iunius Paternus, en Cástulo, de la tribu Galeria, hijo de $C(. .$.$) y de Cornelia$ Caesiana, casado con Cornelia Severa(P. filia) y padre de Iunia Severina. IIvir, flamen municipal entre 97 y 138 d. C. (63).

\section{Laberius}

116.-Laberia Materna, en Cascais (Lisboa), probablemente de principios del siglo II (CIL II 6270. ILER 6685).

(56) CIL III 1158. ILS 2477. ROLDAN 1974, 737. LE ROUX 1982a, n. 167. La dedicación alude sin duda a algún éxito militar en la guerra dácica de Trajano, y el soldado, como apunta LE ROUX, debió ser reclutado en época flavia.

(57) FITA 1917, 336. GARCIA MERINO 1975, n. 278. CRESPO 1978, n. 82.

(58) HAE 2489. ILER 4365. IRB I7I.

(59) ILER 3513. Sobre el origen de la madre, vide infra en los comentarios finales.

(60) CIL II 2056. ILER 1447. Independientemente de los datos que proporciona la inscripción, se puede fechar gracias a lo que sabemos sobre $C$. Fabius Fabianus y su familia, uno de los amigos que dedican la inscripción de Antequera a M.Fulvius Senecio. Vide SERRANO RAMOS y ATENCIA PEREZ 1981, n. 6 (CIL II 1956. ILER 2054).

(61) CIL II 4223. ILS 6932. ETIENNE 1958, 131 y 136 ss.; ILER 1550; RIT 287; RODRIGUEZ NEILA 1978, n. 4. ALFÖLDY (1973, 76 y $R I T$, p. 158) sugiere su posible adopción por Aemilius Paternus, quizá el $L$. Aemilius Paternus de Aeso (CIL II 4460-61 y LARA 1973, n. 79).

(62) CIL II 2971 y 5832. ILER 2578. CASTILLO 1981, n. 44, lám. XLIV con toda la bibliografía anterior.

(63) ILER 1716, que sólo informa del nombre de la esposa y del cursus de este individuo. Para el resto de la filiación, vide CIL II 3322 y 3305. 


\section{Licinius}

117.-M. Licinius Maternus, en San Pablo (Lisboa), difunto de 7 años. Siglo II (CIL II 231. ILER'3325).

118. - Licinia Materna, en Espinosa de Henares (Guadalajara), dedicando a Aside?, casada con P.F.Pontius y madre de L.P.Licinianus. Siglo II (ABASCAL 1983, n. 26, 27 y 28 ).

119. - Licinia Materna, en Riotinto (Huelva), Novaugustana, difunta de 30 años, hija de Paternus. Mediados del siglo I (BLANCO 1962, 31 ss. HAE 2172).

120. - Licinia Materna, en Chipriana (Celsa, Zaragoza), casada con L.Fabius Fabullus y madre de L.Fabius Gallus. Quizá del siglo II (64).

121.-C. Licinius Paternus, en Prats del Rey (Barcelona), de la tribu Galeria, hijo de Licinius Silo (C.f.Gal.). Fines del siglo I/principios del II d. C. (CIL II 4483. ALFÖLDY 1979, 257, n. 350).

122.-Q. Licinius Paternus, en Mérida, Interanniensis, difunto de 75 años, casado con Licinia Flavina y padre de Licinia Paterna. Probablemente de la primera mitad del siglo III (CIL II 511. ILER 5332).

123. - Licinius Paternus, en Villalís (León), centurión de la legio VII el 10 de junio del año 163 (65).

124.--Licinius Paternus Secundus, en Nieva de Cameros (Logroño), difunto de 16 años, amigo (?) de Valeria Saturnina (66).

125.-Licinia Paterna, En Canales de la Sierra (Logroño), hija de Aurelianus, dedicando a la Fortuna Augusta (67).

126. - Licinia Paterna, en Mérida, hija de Q.Licinius Paternus (n. 122) (vide n. ${ }^{\circ} 122$ ).

\section{Lollius}

127.-Lollius Maternus, en León, padre de L.Lollius Lollianus (Saldaniensis, difunto de 18 años). Probablemente de mediados del siglo II (68).

\section{Lorei(us?)}

128. - M. Lorei(us?) Maternius, en Caparril (Lisboa) de la tribu Galeria, difunto de 25 años, hijo de M(...) y Caesia Avita. Quizá siglo II (CIL II 5022. ILER 4348).

\section{Lucretius}

129. - Lucretius Maternus, en Villalís (León), imaginifer de la legio VII el 16 de octubre del 167 (69).

130.-Lucretius Paternus, en Villalís (León), decurión de la cohor.I.Celtib. el 10 de junio del año 163 (70). El 22 de abril o el 16 de octubre de algún año entre 161 y 165 , excepto el 163, ostentaba el mismo cargo.

(64) CIL II 3018. ILER 4097. FATAS y MARTIN BUENO 1977, n. 14.

(65) CIL II 2552; ILS 9125; AE, 1910, 3; ROLDAN 1974, 453; RABANAL 1982, n. 158; LE ROUX 1982a, n. 242.

(66) ELORZA 1980, 32, n. 35, fig. 20, recogiendo toda la bibliografía anterior.

(67) FITA 1907, 293. ELORZA 1980, n. 15 con la bibliografía.

(68) CIL II 2670. ILER 5404a. LE ROUX 1982a, 350, n. 40.

(69) CIL II 2553; ILS 9127; AE, 1910, 4; ILER 25; ROLDAN 1974, n. 455; RABANAL 1982, n. 159;

MAÑANES 1982, 120, n. 116, lám. XLIV; LE ROUX 1982a, 244.

(70) CIL II 2552. ILS 9125. AE, 1910,3. Vide nota 65. 
131. - Lucretia Paterna, en Tricio (Logroño), casada con C.Val.Firminus (vet. legio VII). Madre de Valeria Paterna, de 8 meses y 11 días de edad. Primera mitad del siglo III (71).

\section{Mallius/Manlius}

132.-Mallius o Manlius Maternus, alfarero/s, de origen imprecisable, documentado en dos sellos portugueses (Mall.Mat.T y Manli.Mat. T. MAYET 1983, n. 344) sobre Drag. 18. Puede tratarse de dos individuos más que de una corrupción en uno de los sellos y, en cualquier caso, la $T$ final puede interpretarse Tritiensis, como se hace en otros casos (Cfr. MAYET 1983, n. 363-367).

\section{Marius}

133. -Maria Materna, en Huesca, de la tribu Galeria, hija de M.Marius Nepos (M.f. IIvir, flamen). Fines del siglo I (HAE 2211).

\section{Marcius}

134.-L. Marcius Maternus, en Idanha (Portugal), hijo de Tanginus, eques del ala I sing.c.R., que alcanzaría posteriormente el puesto de decurión del mismo cuerpo, protegido probablemente por $L$. Marcius Avitus, que ejerció la prefectura de este ala, entre otros honores, y con quien seguramente compartía el origen. Finales del siglo I (72).

135.-Marcia Paterna, en Quinzano (Huesca), madre de Pompeius Fest/us] (difunto de 20 o más años). Principios del siglo III (73).

\section{Minicius}

136. - Q. Min(icius) Pater(nus), en Matalebreras (Soria), difunto de 14? años (JIMENO 1980, núm. 69 con la bibliografía anterior).

137.-Minicia Paterna, en Mérida, difunta de 35 años, esposa de Geminius Gargilianus (miles de la legio VII). Primera mitad del siglo III (74).

\section{Mittius}

138. - M. Mittius Maternus, en Cádiz, de la tribu Galeria, difunto de 70 años, hijo de $M(. .$.$) . Trib.leg.XII Fulm. Fines del siglo I y principios del II (75).$

\section{Montanius}

139.-T. Montanius Maternus, en León, de los Zoelae, liberto, curator ff(iscorum) ll(egionarum), de principios del siglo III (76).

(71) CIL II 2888. ROLDAN 1974, n. 668; LE ROUX 1982a, n. 232.

(72) Sobre el eques: $A E, 1961,358$ y 1967, 145. HAE 1077. ILER 6379. ROLDAN 1974, n. 433; LE ROUX 1982a, n. 188. Sobre el Decurión, $A E, 1961,359 ; H A E$ 1078; ILER 6394; LE ROUX $1982 \mathrm{a}, \mathrm{n} .188$.

(73) HAE 2194. ILER 5399. DOMINGUEZ ARRANZ 1984, n. 224 con la bibliografía anterior.

(74) GARCIA Y BELLIDO 1949, n. 290. LE ROUX 1982a, n. 221.

(75) CIL II 1726. ILER 6391. GONZALEZ 1982a, n. 122.

(76) CIL II 5684. ILER 6395. ROLDAN 1974, n. 593. LE ROUX 1982a, n. 225 y p. 236. TRANOY 1981,173 piensa que este individuo podría tener sus talleres de armas en las canabae de la legio VII en Astorga. Sobre los Zoelae existe muy poca información. TRANOY 1981, 52 ha aportado todos los testimonios epigráficos que sobre los mismos existen, y los sitúa en la zona de Bragança, Miranda do Douro y Valle del Aliste, con una ciudad que tenía por nombre Curunda. 


\section{Numisius}

140.-Numisia Fraterna, en Córdoba (HAE 2051-53. ILER 5915).

\section{Octavius}

141.-Octavius Maternus, alfarero, quizá Tritiensis (Oct. Ma.of.). (MAYET 1983, n. 438, con variantes hasta el n. 446). No es posible establecer su relación con Oc.M.Fron. (MAYET 1983, 447) en el supuesto de que sean distintos personajes y de que no se trate de una corrupción en dos sellos distintos. En ese caso, Fron. podría ponerle en relación con Frontonius Paternus, de Bezares (vide supra) y concretar su vinculación tritiense, así como su cronología.

142. - Octavia Materna, en Monte Cildá (Olleros de Pisuerga, Palencia), casada con Sulpicius (Duratoni $f .40$ años). Probablemente de principios del siglo III (HAE 2591. IGLESIAS 1976, n. 46).

143. - M. Octavius Paternus, en Arancón (Soria), difunto de 20 años hijo de Brateo? Miles de legión desconocida (CIL II 2835. JIMENO 1980, n. 46).

\section{Paetinia}

144.- Paetinia Paterna, en Tarragona, Amocensis Cluniensis ex gente Cantabrorum, hija de Paternus, casada con L.Antonius Modestus (Intercatiensis ex gente. Vaccaeor(um) Cluniensis, habiendo desempeñado todas las magistraturas en su ciudad, flamen municipal y provincial en la segunda mitad del siglo II). Flaminica p.H.c. entre el 140 y el 180 (77).

\section{Pedanius}

145. - L. Pedanius Paternus, en Barcelona. Padre de L.Pedanius Atilianus (aedilis en Barcino). Fines del siglo I y principios del II (78).

\section{Petelius}

146. -G. Petelius Paternus, en Clunia, difunto de 56 años, hijo de G. Haericius y casado con Annia Maluca. Quizá de la primera mitad del siglo II (79).

\section{Petronius}

147.-G. Petronius Maternus, en Añavieja (Soria), missicius, hijo de Q(uintus), dedicando una inscripción a Marte en época flavia (80).

148. - Q. Petronius Maternus, en Beja, IIvir en Pax Iulia entre 139 y 161, dedicando dos inscripciones al menos a Antonino Pío (81).

(77) Sobre ella, CIL II 4223; ETIENNE 1958, 167; ALFÖLDY 1973, n. 5 y RIT 323. Sobre su marido: CIL II 6093. ALFÖLDY 1973, n. 5a; RIT 256.

(78) CIL II 4529. IRB 6I. Sobre los Pedanii barceloneses, vide RODA DE MAYER 1977, 246 ss. Sobre la filiación de este individuo, RODA DE MAYER 1977, 248.

(79) $A E, 1906$; GARCIA Y BELLIDO 1949, 358, n. 343; GARCIA Y BELLIDO 1956-61, 230, n. 3, fig. 14; PALOL 1959, lám. XXVI; HAE 2036; ILER 4564; ALBERTOS 1983, 863.

(80) FITA 1893, 484-5; $A E$ 1894, 11; EE VIII, 149; ILER 256; JIMENO 1980, n. 6; LE ROUX $1982 \mathrm{a}, \mathrm{n} .189$.

(81) CIL II 47 y 48 . ILER 1125 y 1145 . 
149. - Petronia Materna, en Fuentedecantos (Badajoz), difunta de 35 años, casada con M. Iunius Placidius. Segunda mitad del siglo II (CIL II 1033. ILER 4462).

\section{Placidius}

150.-Placidius Paternus, en Lugo, difunto de 17? años. Siglo II (ARIAS 1979, n. 81).

\section{Pompeius}

151.-T. Pompeius Fraternus, en El Centenillo (Jaén), Cluniensis, de la tribu Galeria, hijo de $G(\ldots)$ y difunto de 15 años. Quizá de fines del siglo I (SANDARS 1921, 276-77; AE 1922, 8; ILER 6334).

152.- Pompeia Materna, en Asa (Puebla de la Barca, Alava), casada con C. Sempronius Aemilianus (hijo de T.Semp.Titullus, de 50 años, y de Aemilia Titulla, de 30). Madre de Sempronius Titullus. Siglo II (CIL II 2923).

153. - L. Pompeius Paternus, en Clunia, adscrito a la tribu Quirina, muerto a los 19 años, hijo de Paternus y hermano de Pompeia Paterna. Fines del siglo I (CIL II 2798).

154. - L. Pompeius Paternus, en Riba de Saelices (Guadalajara), dedicando a Arco. Quizá siglo II (82).

155.-L . Pompeius Paternus, en Ponferrada (León), dedicando a Mandica (83).

156. - Pompeius Paternus, en León, difunto de 30 años, hijo de Licinia Marcella. Siglos II-III (84).

157.-Pompeia Paterna, en Clunia, hija de Paternus y hermana de L. Pompeius Paternus (vide núm. 153).

158. - Pompeia Paterna, en Tarragona, Viminaciensis, hermana de Lic. Flaccilla (Palentina). Siglos II-III (85).

159. - Pompeia Paterna, en Calles (zona de Liria, Valencia), casada con L. Valerius Tempestivus. Quizá del siglo II. (CIL II 4027).

\section{Pomponius}

160. - L. Pomponius Maternus, en Onda (Castellón), difunto de 9 años, hijo de $L(. .$.$) y$ de Pomponia Marcella. Quizá de fines del siglo I (CIL II 4036).

\section{Popilius}

161.-Popilia Materna, en Mérida, esposa de L.Popillius Primus? Probablemente fines del siglo I (MELIDA 1911, 195. ILER 5129).

\section{Porcius}

162.- L. Porcius Maternus, en Fuente Tójar (Córdoba), Iliturgicolensis de la tribu Galeria, IIvir, en un pedestal dedicado por tres de sus libertos. Segunda mitad del siglo I (86).

(82) La inscripción se conserva en el Museo Arqueológico Nacional, y permanece inédita. Agradecemos esta información y los datos utilizados aquí al doctor Alföldy.

(83) CIL II 5669. BLAZQUEZ 1962, 61-62; ILER 876; TRANOY 1981, 298; RABANAL 1982, n. 15 .

(84) CIL II 2687. LE ROUX 1982a, 350, n. 49.

(85) CIL II 6115. ILER 5448. RIT 380.

(86) CIL II 1648, Add. p. 703. ILER 6017. STYLOW 1983, 276, IIb. 
163. - Porcia Materna, en Tarragona, Osicerdensis, hija de M(...), casada con L.Numisius Montanus (flamen p.H.c. entre 120 y 140). Flaminica perpetua de Osicerda, Tarraco y Caesaraugusta. Flaminica p.H.c. entre 120 y 140 (87).

164.- Porcia Antistia Materniana, en Mengíbar (Jaén), hija de Publius, casada con $M$. Aemilius Eugenetus M.f., difunta de 60 años. Fines del siglo II-principios del III (ROMERO DE TORRES 1915, 10).

165.-L. Porcius Paternus, en un grafito sobre un vaso Drag. 37 con borde almendrado de Ampurias, indicando quizá la posesión de la pieza (MAYET 1983, II, lám. CCXXVIII, núm. 109). La forma y el tipo de borde sitúan la pieza en el último cuarto del siglo I y principios del II (MAYET 1983, 84).

\section{Postumius}

166. - Ti. Pos(tumius) Maternus, en Bretal, Ribeira (La Coruña), casado con Rustia Flavia (difunta de 34 años). Principios del siglo III (CIL II 2567. ILER 3794).

\section{Rennius}

167. - Rennius Paternus, en Lara de los Infantes, dedicando a Epona (88).

\section{Rufius}

168. - L. Rufius Maternus, en Astorga (León), difunto de 15 años, hijo de L.Rufius y de Tryphena. Mediados del siglo II (89).

169. - Rufia Paterna, en Lugo, Civis Asturicensis, casada con Rufonius Rufinus, madre de Iulius Rufinus Leontius (difunto de 27 años, ex tabulario). Mediados o segunda mitad del siglo III (90).

\section{Scribonius}

170.-Scribonius Maternus, en Tricio (Logroño), difunto de 13 meses, hijo de Scribonius Epaphras y de Scribonia Calisste. Principios del siglo III (91).

171.-Q. Scribonius Paternus, en Santiago de Cacem (Portugal), de la tribu Quirina, hijo de L.Scribonius Saturninus, probablemente de fines del siglo I (CIL II 29).

\section{Sempronius}

172. - L. Sempronius Maternus, en Tarragona, speculator de la legio VII; primera mitad del siglo II (92).

(87) CIL II 4241. ETIENNE 1958, 132; ILER 1656; ALFÖLDY 1973, n. 108; RIT 325; FATAS y MARTIN BUENO 1977, n. 81. Sobre la familia, vide RIT, p. I78, en donde Alföldy sugiere que puede estar emparentada por L. Porcius L.f. Gal.Maternus Iliturgicolensis, IIvir (CIL II 1648). Sobre la situación de Osicerda, y el cursus del marido, vide RODRIGUEZ NEILA 1978, 33.

(88) FERNANDEZ FUSTER 1957, 219-220; ABASOLO 1974, n. 40, lám. XX, 1; ILER 350; ABASCAL 1983, nota 77 .

(89) CIL II 2659. ILER 4058. MAÑ ANES 1982, n. 45.

(90) $E E, V I I I, 310$; VAZQUEZ SACO y VAZQUEZ SEIJAS 1960, n. 29. HAE 299; ILER 5696 y 6392; ARIAS 1981, n. 28; MANANES 1982, n. 92.

(91) CIL II 2896 y 5806. ILER 4099. ELORZA 1980, 42, n. 52.

(92) CIL II 4143. ILS 2373. ILER 6366. ROLDAN 1974, n. 600. RIT 205. LE ROUX 1982a, n. 114. 
173. - Sempronius Maternus, en Iruña (Alava), de la tribu Quirina, difunto de 40 años, hijo de Maternus. Fines del siglo I (93).

174.-Sempronius Maternus, en Poza de la Sal (Burgos), difunto de 22 años, hijo de Sempronia Pusinca (difunta de 62 años). Probablemente de mediados del siglo II (94).

175.-Sempronia Materna, en Tarragona, hija de M(arcus), casada con L. Pomponius Avitus, madre de C. Caecilius Iubatus Sempronius Maternus (probable hijo de segundas nupcias). Siglo II (95).

176. - L. Sempronius Paternus, en Tarragona; siglo III (HAE 873. RIT 659).

177.-Sempronius Paternus, alfarero, quizá de Tritium Magallum (Of.Semp.Pa. MAYET 1983, n. 597).

178. - Se(...) Paternus, en Gastiain (Navarra), difunto de 40 años. Quizá del siglo II (96).

179.-Sempronia Paterna, en Varea (Logroño), dedicando a Iovi O.M. en el siglo II (97).

180.- Sempronia Paterna, en Zarza de Granadilla (Cáceres), Cluniensis, difunta de 6 años, hija de Firmius y hermana de Edicroco. Siglo III (98).

181. - Sempronia Paterna, en Clunia, mencionada en la inscripción funeraria de varios de sus siervos. Fines siglo I, principios II (CIL II 6338 n. NAVAL 1906, 410, n. 5; ILER 6472).

182. - Sempronia Paterna, en Iglesia Pinta (zona de Lara de los Infantes, Burgos), a mediados de siglo II (99).

\section{Sentius?}

183.-Sentius? Maternus, alfarero, Tritiensis (OSMaTr. MAYET 1983, n. 609 y 610. La interpretación S(entius) y no S(empronius) la hace Mayet sobre la base de la existencia del gentilicio completamente desarrollado en algunos sellos (MAYET 1983, n. 603, Sentius, y n. 607, Sentius Saturninus). Siglo II.

\section{Sergius}

184.-M. Sergius Paternus, en Almanzora (Sagunto, Valencia), difunto de 30 años, liberto de M.Sergius Numida, probablemente del siglo II (100).

\section{Sertorius}

185.-M. Sertorius Maternus, en Aroche (Huelva), difunto de 27 años, quizá de la segunda mitad del siglo I (101).

186. - L. Sertorius Paternus, en Santibáñez del Val (Burgos), difunto de 55 años, casado con Sertoria Septumina (difunta de 90 años). Probablemente de mediados del siglo II (102).

(93) HAE 1778; ILER 5213 y 6809.

(94) GARCIA MERINO, 1975, n. 152, con la bibliografía anterior dentro del apéndice epigráfico.

(95) CIL II 4395. ILER 4604. RIT 465. Sobre el hijo: CIL II 4403. ILER 3877. RIT 47I.

(96) ILER 3302. CASTILLO 1981, n. 46, con la bibliografía anterior.

(97) FITA 1903, 304; MORESTIN 1976, 181-82; ELORZA 1980, n. 63 con la bibliografía anterior.

(98) HURTADO 1977, n. 663 , p. 275. Sobre esta pieza de forma indirecta, RIT, p. 328.

(99) CIL II 2867; ILER 5003; ABASOLO 1974, n. 20, lám. XII, 2.

(100) CIL II 4033; ILER 4985; BELTRAN 1980, XX.

(101) GONZALEZ 1982b, 153-172. En especial 165-66, n. 19 y fig. 9.

(102) GARCIA MERINO 1975, núm. 67, con la bibliografía anterior. 


\section{Spedius}

187.-Spedius Maternianus, en Tarragona, marido de Latinilla, en una dedicación a Venus. Mediados del siglo II (CIL II 4415; ILS 8059; RIT 461).

\section{Stabilius}

188.-C. Stabilius Pom(ponius) Maternus, en Lambaesis (Numidia), natural de Iuliobriga, difunto de 30 años, miles de la legio VII, con 11 años de servicio. Primera mitad del siglo II (103).

\section{Sullius}

189.-Sullia Materna, en Braga, difunta de 80 años. Siglo II (RIGAUD DE SOUSA, 1973, 16).

\section{Sulpicius}

190.-Sulpicius Maternus, en Barcina de los Montes (Burgos), hijo de Latiurus, dedicando a Vurovius (104).

191.-Sulpicia Materna, en Segovia, difunta de 29 años, hija de Sulpicius. Quizá de fines del siglo I (CIL II 2751. ILER 2623).

192. - Sul(picius) Paternus, en Poza de la Sal (Burgos) (105).

193. - Sulpicius Paternus, en Barcina de los Montes (Burgos), hijo de Proculus, dedicando a Vurovius (106).

$\mathbf{T}(\ldots)$

194. - T. Fraternus, en Clunia, dedicando un ara a las Matres Gallaicae (CIL II 2776).

\section{Terentius}

195. - L. Terentius Fraternus, en Sagunto (Valencia). Siglo I (CIL II 3842).

196. - L. Terentius Paternus, en San Esteban de Gormaz (Soria), Eburanco(n), de la tribu Quirina, difunto de 56 años, hijo de Titus, casado con Terentia Aucia y padre de Terentia Paterna (difunta de 17 años). Segunda mitad del siglo II (CIL II 2828. JIMENO 1980, n. 94).

197.-M. Terentius Paternus, en Roma, Aesonensis, difunto de 18 años, en una inscripción dedicada por Licinius Politumius, liberto y educador (LARA 1973, n. 103).

198. - Terentius Paternus, alfarero en el taller de Abella-Solsona (Lérida), que Mayet interpreta Ter(tius) (MAYET 1983, n. 633 a 635). Siglo II.

199.-Terentia Paterna, en San Esteban de Gormaz (Soria) difunta de 17 años (vide número 196).

(103) CIL VIII 3245. LE ROUX 1972, n. 18. ROLDAN 1974, n. 627. LE ROUX 1982a, n. 126.

(104) MONTENEGRO 1975; SOLANA 1978, 177, nota 226, núm. 64 c.

(105) MONTENEGRO 1975; SOLANA 1978, 120, n. 48.

(106) SOLANA 1978 , p. 176 , nota 226, n. 64b. 


\section{Triarius}

200.-Triarius Maternus Lascivius, en Braga, Itálico, Leg.Iur.Astur. et Gall. entre 157 y 178, cónsul ordinario del 185 (107). Dedicando a I.O.M.

\section{Teius}

201.-Q. Teius Paternus, en Cáceres, difunto de 16 años, hijo de $C(. .$.$) . Quizá de fina-$ les del siglo I (108).

\section{Valerius}

202.-L. Valerius Maternus, en Tarragona, speculator de la legio VII G.F. Primera mitad del siglo II (109).

203. - L. Valerius Maternus, en Monte Cillas (Coscojuela de Fantobas, Huesca), Boletanus, de la tribu Galeria, hijo de $L(. .$.$) , casado con Aemilia Placida, difunto de$ 55 años. Figura en cuatro inscripciones. Segunda mitad del siglo I (110).

204.-Valerius Maternus, en Avila, dedicado a Togotus? (111).

205.- Valerius Maternus, en Segovia, difunto de 15 años, hijo de Valeria Aemiliana. Probablemente de la primera mitad del siglo III (CIL II 2755).

206. - Valerius Maternus, alfarero, quizá de Tritium Magallum (Ex.of.Val.M. MAYET 1983, n. 673).

207.--Valerius Natalis Maternus, en Duratón (Segovia), que figura en una inscripción «cum suis» (CIL II 3089).

208.-C. Valerius Paternus, en Lara de los Infantes (Burgos), difunto de 55 años, hijo de Flavius y hermano de Materna (112).

209. - G. Valerius Paternus, en Loussa (Guimarâes, Portugal), dedicando a Ilurbeda. Siglo I (HAE 362. BLAZQUEZ 1962, 78).

210.- L. Valerius Paternus, en Clunia, dedicando a Iovi Augusto Ultori, optio centuria censoris, miles de la legio $X$, reclutado hacia el año 50, en una inscripción fechada hacia el año 70 (113).

211.-L. Valerius Paternus, en Pancorbo (Burgos), hijo de Capito y hermano de V. Valerius (114).

212.-L. Valerius Paternus, alfarero, Tritiensis. Siglo II (115).

213.-Valerius Paternus Vatricus, en Clunia, de la tribu Galeria, casado con Valeria y padre de $L$. Valerius Marcianus (difunto de 29 años). Probablemente cluniensis, pues los cinco testimonios de Vatricus conocidos son de Clunia (ALBERTOS 1983, 862). Fines del siglo I (CIL II 2807).

(107) CIL II 2415; ALFÖLDY 1969, 87, 230 y 239.

(108) CIL II 714. EE IX 714. HURTADO 1977, n. 135, leyendo Trius, de ninguna manera aceptable como gentilicio.

(109) CIL II 4143. ILS 2373. ILER 6366. RIT 205. ROLDAN 1974, n. 600. LE ROUX 1982a, n. 114.

(110) CIL II 5843 a 5846. ILER 5267, 3752, 4437 y 3753. DOMINGUEZ ARRANZ 1984, 77, con toda la bibliografía.

(111) CIL II 5861. ILER 935. RODRIGUEZ ALMEIDA 1981, n. 63.

(112)) CIL II 2864, p. 709, con las diferentes versiones del epígrafe. La misma exposición en ABASOLO 1974, 62 ss., n. 63, lám. XXX, 1. ILER 4733.

(113) ILS 9239. AE, 1908, 147; PALOL 1969, 118-123; AE, 1969-70, 274; ILER 6825. ROLDAN 1974, n. 554; LE ROUX 1982a, n. 38.

(114) ABASOLO 1974b, 65, n. 17; SOLANA 1978, 116, n. 42, con el resto de la bibliografía.

(115) Ex.Of. Val. Pat. MAYET 1983, núm. 675, con más variantes entre los números 674 y 712 . Sobre la dispersión de sus piezas en Lusitania, MAYET 1970, 5-41. 
214._Valerius Paternus, en Muez (Navarra), veterano de la legio II Aug. T. Segunda mitad del siglo I (116).

215.-V(alerius) Pate(rnus), en Córdoba, en una inscripción votiva fragmentada (ALBERTINI 1918-19, 314).

216.-G. Valerius Paternianus, en Lara de los Infantes (Burgos), difunto de 25 años (ABASOLO 1974, n. 90, lám. XL, 2).

217. - Valeria Paterna, en Tricio (Logroño), hija de C. Valerius Firminus (vet. de la legio VII) y de Lucretia Paterna. Difunta de 8 meses y 11 días. Primera mitad del siglo III (117).

218. - Valeria Paterna, en El Olmo (Duratón, Segovia), casada con C.S. Sempronianus, y padres de C.S. Valerianus (difunto de 23 años). Tienen un liberto. Principios del siglo II (CIL II 2766).

219. - Valeria Paterna, en San Esteban de Gormaz (Soria), hija de L. Val. Silo (Letondiq. difunto de 50 años). Siglo II (118).

220.-Valeria Paterna, en Clunia, hija de L. Valerius Crescentius (C.f. Bundalico, Gal.) Segunda mitad del siglo I (CIL II 2785).

\section{Varius}

221.-Q. Varius Maternus, en Astorga (León), Seurrus Transminiensis, difunto de 18 años, hijo de Reburrus. Probablemente del siglo I (119).

Vir...

222.-Vir... Matern(a), en Vandoma, entre Oporto y Peñafiel (Portugal), casada con Sev. Severus (difunto de 23 años). Probablemente de fines del siglo II (120).

\section{Voconius}

223. - Voconia Materna, en Segobriga (Saelices, Cuenca), Uxenensi?, casada con $C$. Porcius Marinianus (Deniensis). Quizá de la segunda mitad del siglo II (121).

\section{Volusius}

224. - Volusia Paterna, en Tarragona, casada con Terentius Primus. Mediados del siglo II (122).

(116) AE, 1951, 283. ILER 5598. ROLDAN 1974, n. 503. LE ROUX 1982a, n. 51.

(117) CIL II 2888. Vide núm. 131, nota 71, con la bibliografía correspondiente a propósito del nombre de sus padres.

(118) EE VIII, 145. JIMENO 1980, n. 99. De la lectura de la pieza quizá pudiera inferirse (?) su parentesco con L.Val(erius), del que sería, en todo caso, hermana.

(119) $E E, I X, 292$ f. ILER 6347. MAÑANES 1982, n. 36. TRANOY 1981, 59-60, recoge la inscripción y el resto de los testimonios epigráficos de este pueblo, que sitúa en las regiones de Sarriá y Taboada, a ambos lados del Miño, al sur de Lugo. Sobre la onomástica del padre del difunto, en CIL II 6290 (EE VIII, 126), de Felgar (Moncorvo), hay un Reburrus, hijo de Arrus, del pueblo de los Seurri, de la centuria Narelia.

(120) CIL II 2379. ILER 4641 y 6128.

(121) CIL II 3125. ILER 5429. JIMENO 1980, 195, n. 161. ALMAGRO 1984, n. 77.

(122) CIL II 4419. ILER 3811. RIT 692. 
$\operatorname{Vr}(\ldots)$

225._- Vr(...) Paternus, alfarero, de origen imprecisable (ExOVrPate. MAYET 1983, n. 727).

...linius

226. -...linius Maternus, en Argavieso (Huesca). Fechada la inscripción entre Domiciano y Trajano (123).

\section{INDIVIDUOS QUE NO PRESENTAN GENTILICIO}

\section{Maternus}

227.-Maternus, en Caparra (Cáceres), difunto de 3 años, hijo de Fuscius. Quizá de principios del siglo II (124).

228. - Maternus, en La Coruña, sin que la inscripción permita distinguir el nexo que le une a Materna, difunta que figura en el texto (HAE 1710. ILER 4117).

229.-Maternus, en Iruña (Alava), padre de Sempronius Maternus (tribu Quirina, difunto de 40 años). Fines del siglo I (vide nota 93).

230.-Maternus, en Barruecopardo (Salamanca), padre de Menena (difunta de 9 años). Fines del siglo I (HAE 1248. ILER 2845).

231.-Maternus, en San Vicente del Río Almar (Salamanca), padre de C. Sempronius Flaccus. Quizá de principios del siglo II (HAE 1331. ILER 2322).

232.-Maternus, en Braga, hijo de Rufus, dedicando un ara a los Lares Viales (CIL II 2417).

233. - Maternus, en Idanha, padre de Proculus. Inicios del siglo II (HAE 1197. ILER 3721).

234. - Maternus, en Braga, dedicando a Frovida, hijo de Flaccius (125).

235. - Maternus, en Varzea do Douro (Marco de Canavezes, Portugal), casado con Pomp. Albura y padres de Pompeius Annus (difunto de 20 años). Quizá de inicios del siglo II (HAE 2124. Vide-HAE 2123).

236. - Maternus, en Yecla de Yeltes (Salamanca), padre de Materna. Fines del siglo II (MARTIN VALLS 1982, 186).

237. - Maternus, en Almenara, junto a Sagunto (Valencia). Siglo II (126).

238.-Maternus, en Andión (Navarra), hijo de (Mar)ci Anda(...) (CASTILLO 1981, n. 73).

239.-Maternus, en Santa Marta do Bouro (Orense), dedicando a Júpiter (TRANOY 1981, 317).

240.-Maternus, en Cercedillo, cerca de Guimarâes (Portugal), hijo de Flavus, dedicando a Coronus (127).

241.-Maternus, en Iruña (Alava), padre de Sempronius Maternus (Quirina. 40 años. Vide nota 93).

(123) CIL II 5839. ILER 5820. DOMINGUEZ ARRANZ 1984, n. 40.

(124) CIL II 838. ILER 4I80. HURTADO 1977, n. 365.

(125) EE. VII, 116, p. 403. BLAZQUEZ 1962, 176. ILER 853.

(126) CIL II 3975. BELTRAN 1980, n. 331.

(127) CIL II 5562. BLAZQUEZ 1962, 117. ILER 787. D'ENCARNAÇAO 1975, 160, con otra interpretación. TRANOY 1981, 273. 
242.-Maternus Capito(?), alfarero, Tritiensis (OMateCap. MAYET 1983, n. 361 y 362). Quizá Maternus Capito(nis) filius. Siglo II.

243.-Maternus, alfarero, Tritiensis, quizá identificable con alguno de los individuos con este cognomen que desarrollan esta actividad en el citado taller (Materni.T. MAYET 1983, n. 363-367). Siglo II.

244.-Maternus Acc(...), alfarero, en el taller de Abella-Solsona (Lérida) (MAYET 1983, n. 354). Siglo II.

245.-Maternus Blandus, alfarero, quizá de Tritium Magallum (Of.Mat.Blan. MAYET 1983, n. 355-360).

246. - Maternianus, en Foronda (Alava), hijo de Exuperius y de Materna, difunto de 30 años. Fines del siglo II (vide nota 128).

\section{Materna}

247.-Materna, en Foronda (Alava), casada con Exuperius y madre de Maternianus. Fines del siglo II (128).

248. - Materna, en Yecla de Yeltes (Salamanca), hija de Maternus, difunta de 52 años. Fines del siglo II (MARTIN VALLS 1982, 186).

249.-Materna, con el gentilicio borrado, en Oliva de Plasencia (Cáceres), casada con Fuscius (CIL II 850. ILER 6513).

250.-Materna, en Braga, hija de Paternus, difunta de 19 años. Fines del siglo II, principios del III (EE VIII, 122).

251.- Materna, en La Coruña, difunta relacionada de forma imprecisa con Maternis; segunda mitad del siglo II (129).

252. - Materna, en Braga (Portugal), hija de M(...), madre de C.Cecilius Semp. Paternus. Principios del siglo III (130).

253.-Materna, en Conimbriga, difunta de 40 años, hija de Caenon y madre de Maelia Martialis. Fines del siglo II (CIL II 385. ILER 4032).

254.-Materna Aula, en Peña Amaya (Santander), casada con Saturninus (difunto de 61 años) y madre de Mansicina (difunta de 20 años). Quizá de fines del siglo II (131).

255.-Materna, en Lara de los Infantes (Burgos), hija de Flavus y hermana de C.Val. Paternus. (132).

\section{Paternus}

256.-Paternus, en Avila, hijo de Ana Tucia Areinicum? Siglos II-III (RODRIGUEZ ALMEIDA 1981, n. 23).

257.-Paternus, en Clunia, probablemente de la tribu Quirina, padre de Pompeia Paterna y de L.Pompeius Paternus. Fines del siglo I (CIL II 2798).

258. - Paternus, en Lara de los Infantes, hijo de Ambata Aionca (Titif. difunta de 55 años). Quizá de principios del siglo II (133).

259.- Paternus, en el mismo lugar, padre de Arcea Elanioca (difunta de 30 años, casada con G.Petelius). Probablemente de fines del siglo I (134).

(128) HAE 2537. ILER 6806. ELORZA 1976, 142. CRESPO 1981, 251.

(129) HAE 1710. FITA 1911, 409. ILER 4117.

(130) CIL II 2436. ILER 3892 y 6433.

(131) CIL II 6338r. IGLESIAS 1976, n. 5.

(132) CIL II 2864. Vide núm. 208. ABASOLO 1974, n. 63, lám. XXX, 1.

(133) GARCIA MERINO 1975, n. 96. ABASOLO 1974, 115-116, n. 155, lám. LXXIII, 2.

(134) ABASOLO 1974, n. 146, lám. XIX, 1. GARCIA MERINO 1975, n. 95. 
260.-Paternus, en La Molina (Burgos) (HAE 2609).

261. - Paternus, en La Molina (Burgos), padre de Elios? (135).

262.--Paternus, en Riotinto (Huelva), natural de Novaugusta, padre de Licinia Materna. Mediados del siglo I (vide núm. 119).

263. - Paternus, en el Centenillo (Jaén), Can(taber) Orgenom(escis?), difunto de 20 años. Fines del siglo I (HAE 1831. ILER 5482).

264. - Paternus, en Riaño (León), padre de Elanius Veliagus (difunto de 30 años). Primera mitad del siglo III (136).

265.-Paterni, en Lugo. Varios individuos dedicando a Caelestis Augusta. Siglo II (137).

266. - Paternus, en Lugo, difunto de 26 años de padre anónimo. Siglo III (138).

267. - Paternus, en Braga, padre de Materna (difunta de 19 años). Fines del siglo II, principios del III ( $E E$ VIII, 122).

268. - Paternus, en Lugo, hijo de Primus, dedicando a Veroce. Siglo II (139).

269. - Paternus, en Saldaña (Palencia), quizá del siglo II (140).

270.- Paternus, en Idanha (Portugal), hijo de Cilia Caenon. Probablemente del siglo II (HAE 1197. ILER 3721).

271.-Pate(r)n(us), alfarero, quizá Tritiensis, hecho éste que no confirma Mayet con el ejemplo que proporciona: Pat.(hedera)Entri (1983, n. 462).

272. - Paternus, en San Sebastián de Freixo (Collippo), padre de Iulius Paternianus. Fines del siglo II (CIL II 358).

273. - Paternus, en Alcubilla de Avellaneda (Soria), Balatuscum, hijo de Omolmanus? Siglo I (CIL II 2795. JIMENO 1980, 60, n. 41).

274. - Paternus, en Tarragona, padre de Paetinia Paterna (Amocensis Cluniensis, flaminica p.H.c.) (Vide núm. 144 con toda la bibliografía).

275.-Paternus, en Tarragona, padre de L. Antonius Modestus (Intercatiensis ex gent. Vaccaeor. Cluniensis) (Vide núm. 144).

276. - Paternus, en Apulum (Dacia), padre de C. Iulius Paternus?, quizá Cluniensis (vide núm. 104).

277. - Paternus, en Barcina de los Montes (Burgos) (141).

278. - Paternus, en Moral de Sayago (Zamora), padre de Annia (difunta de 50 años) (142).

279._Paternus, alfarero Tritiensis (Ofic.Patern. con variante. MAYET 1983, n. 452 a 460). Siglo II.

280.-Paternus Ale(...), alfarero Tritiensis (Pater.Ale. con variantes. MAYET 1983, n. 463-469). Siglo II.

(135) SCHLUNK, 1965, 164, lám. HAE 2608. ILER 6352.

(136) CIL II 5715. ILER 6161. RABANAL 1982, n. 83.

(137) CIL II 2570. VAZQUEZ SACO y VAZQUEZ SEIJAS, 1960, n. 68; GARCIA Y BELLIDO, 1967, n. 2; ILER 322. ARIAS 1981, n. 1, interpretan Paternus Constantius (dos individuos).

(138) HAE 315 y 1722 . VAZQUEZ SACO y VAZQUEZ SEIJAS 1960, n. 43; ILER 6443 y 3440. ARIAS 1981, n. 43.

(139) CIL II 2577. BLAZQUEZ 1962, 217; VAZQUEZ SACO y VAZQUEZ SEIJAS, 1960, n. 14; ILER 952; ARIAS 1981, n. 11.

(140) IGLESIAS 1976, Addenda 15. CRESPO ORTIZ DE ZARATE 1978, núm. 89.

(141) SOLANA 1978, 114, n. 37. La zona de Bárcina de los Montes es especialmente rica en hallazgos, y se convirtió en uno de los principales enclaves del grupo de cognomina estudiados a raíz de los hallazgos de las inscripciones dedicadas a Vurovius (MONTENEGRO 1975).

(142) ILER 2285. GOMEZ MORENO 1917, n. 31. 


\section{Paterna}

281.- Paterna, en Mérida, difunta de 40 años, hija de Alli(...) y madre de Procula Marci(...). Quizá de fines del siglo I (CIL II 582).

282. - Paterna, en Santa Eulalia de Castro de Escuadro (Orense), madre de Dovaecia. Quizá del siglo II (143).

283. - Paterna, en Varzea do Douro (Marco de Canavezes, Portugal). Hija de Fabius (Capitonis $f$. difunto de 70 años) y hermana de Capito. Quizá de inicios del siglo III (HAE 2123).

284. - Paterna, en San Lourenço dos Francos (Miragaia, Portugal), casada con C. Iulius Severus y madre de Iulia Maxima (difunta de 30 años). Quizá fines del siglo II (144).

285.-Patern[us/a], en Barcina de los Montes (Burgos), en una inscripción votiva muy deteriorada, sin que se pueda precisar la divinidad a la que estaba dedicada (145).

286. - Pater [...], en Segobriga, en una inscripción funeraria hoy perdida (CIL II 3142. ALMAGRO 1984, núm. 97).

287.-Pat(ernus /a), en Mérida, difunto del que sólo se conserva la indicación ann(orum) habiendo desaparecido el numeral (FITA 1894, 124. EE VIII, 64).

\section{INDETERMINADOS}

288.-(...)atern(...), en Santa Coloma de Somoza (León), Clu(niensis), difunto de 60 años, hijo de (...)nnius (146).

El número total de individuos consignados en cada período, así como el conjunto de los que poseen gentilicio, se resume en el cuadro 1 .

Como puede observarse, las diferencias, aunque no elevadas, señalan un mayor número de individuos con el cognomen Paternus durante casi todos los intervalos, si bien la relación se invierte cuando nos fijamos en el porcentaje de individuos con gentilicio: en el siglo I, casi todos los Materni consignados presentan gentilicio, mientras que sólo el 70 por ciento de los Paterni (14 sobre 20) cumple este requisito. En el siglo II, en cambio, se advierte un mayor equilibrio entre ambos grupos, aunque las diferencias vuelven a ser notorias entre los Materni y Paterni de cronología imprecisa, en que los segundos han superado con creces a los primeros $(77,2 \%$ de individuos con gentilicio frente al $60 \%$ ).

Por lo que se refiere a las mujeres, el predominio de Maternae y Paternae es alternativo, si bien globalmente hay una ligera ventaja a favor de las primeras (48 casos sobre 44). De nuevo nos fijamos en el gentilicio para establecer diferencias, observando que en el siglo I todas las Maternae poseen gentilicio, mientras que sólo 83,3 por ciento de las Paternae cumple este requisito. De nuevo en el siglo II se invierten las diferencias entre ambos grupos, y las segundas presentan un mayor porcentaje que las primeras $(89,3 \%$ frente a $82,1 \%)$. En el siglo III y entre el grupo de individuos de cronología imprecisa, estas diferencias se acentuarán aún más.

(143) FITA 1904, 335. ILER 6291.

(144) BELEZA MOREIRA 1976, 127-131, fig. 1. La relación con la Iulia Maxima (CIL II 378) de Aeminium puede ser sólo casual.

(145) ELORZA y ABASOLO. Durius, 2-3 (1974), núm. 3, p. 118-119, lám. II, 2. Sobre el lugar del hallazgo y su importancia para el conjunto de los cognomina de parentesco, vide nota 141 .

(146) HAE 2144. MAÑANES 1982, n. 131. 
CUADRO 1

\begin{tabular}{|c|c|c|c|c|c|c|c|}
\hline $\begin{array}{l}\text { Siglos } \\
\text { Cognomen }\end{array}$ & I & I-II & II & II-III & III & $\begin{array}{l}\text { Sin } \\
\text { fechar }\end{array}$ & TOTAL \\
\hline Fraternus ........ & & & & & & & \\
\hline Fraterna ......... & & & & & & & \\
\hline Fraterninus...... & & & & & & & \\
\hline Maternus ........ & & & & & & & \\
\hline Materna.......... & & & & & & & \\
\hline Maternianus .... & & & & & & & \\
\hline Materniana...... & & & & & & & \\
\hline Paternus .......... & & & & & & 7 & \\
\hline Paterna ........... & & & & & & & \\
\hline Paternianus ..... & & & & & & & \\
\hline
\end{tabular}

En este sentido, hay que resaltar que, si bien existen acusadas diferencias porcentuales por períodos, en el aspecto global, Paterni/ae constituye un grupo mayoritario (140 casos y 110 individuos con gentilicio), frente a Materni/ae (128 casos y 101 con gentilicio).

El estudio de los gentilicios proporciona además algunas valiosas informaciones: Paterni/ae en el siglo I presentan un total de 14 gentilicios distintos (Aelius, Allius, Antistius, Arruntius, Caelius, Cornelius, Frontonius, Geminius, Iulius, Licinius, Pompeius, Scribonius, Teius y Valerius), mientras Materni/ae muestran 22 (Aemilius, Annius, Caecilius, Cornelius, Domitius, Fonteius, Hirrius, Iunius, Iulius, Licinius, Marius, Marcius, Mittius, Petronius, Pomponius, Popillius, Porcius, Sempronius, Sertorius, Sulpicius, Valerius y Varius). Como puede verse, entre los Materni/ae son más frecuentes los antiguos gentilicios itálicos, y son pocos los comunes con los Paterni/ae (Cornelius, Iulius, Licinius y Valerius).

En el siglo II, incluyendo a estos efectos los testimonios fechados hacia el cambio de siglo, el número de gentilicios que aparece en ambos grupos es similar, presentando los Paterni/ae 28 (Aemilius, Aitanius, Antonius, Arrius, Atilius, Attius, Avitius, Camilius, Campilius, Cornelius, Grattius, Herennius, Iulius, Iunius, Licinius, Lucretius, Paetinia, Pedanius, Petelius, Placidius, Pompeius, Porcius, Sempronius, Sergius, Sertorius, Terentius, Valerius y Volusius), y los Materni/ae 33 (Aemilius, Antonius, Apo- 
nius, Asturia, Atilius, Aurelius, Bovia, Coelia, Cornelia, Eonina, Fabius, Flavius, Genutia, Hiberia, Iulius, Laberia, Licinius, Lollius, Loreius, Lucretius, Petronius, Pompeius, Porcius, Rufius, Sempronius, Sentius, Stabilius, Sullia, Triarius, Valerius, Virius?, Voconius y ...linius). En este mismo período, las similitudes entre ambos grupos aumentan de número, y frente a los cuatro gentilicios compartidos por Paterni/ae y Materni /ae en el siglo I, el número se eleva ahora a once (Aemilius, Antonius, Atilius, Cornelius, Iulius, Licinius, Lucretius, Pompeius, Porcius, Sempronius y Valerius).

Finalmente, en el grupo de inscripciones fechadas de forma imprecisa entre los siglos II y III y entre las pertenecientes a todas luces a este último, los Paterni/ae presentan 14 gentilicios (Aemilius, Antonius, Atilius, Caecilius, Flavius, Iulius, Licinius, Lucretius, Marcius, Minicius, Pompeius, Rufius, Sempronius y Valerius), frente a los 12 de los Materni/ae (Alfius, Aurelius, Cassius, Cornelius, Domitius, Felicius, Flavius, Montanius, Octavius, Postumius, Scribonius y Valerius). Como puede verse, los Paterni/ae, que aparecen con un grupo minoritario de gentilicios en el siglo I d. C. han remontado las diferencias sobre los Materni/ae a lo largo de los dos primeros siglos, hasta mostrar una franca superioridad en el III, en el que las coincidencias entre ambos grupos se reducen a dos (Flavius y Valerius).

Así pues, tanto en el porcentaje de individuos que poseen gentilicio, como en el espectro de los mismos, el grupo de los Paterni/ae va ganando vitalidad hasta alcanzar el siglo III d. C. Por lo que se refiere al grado de indigenismo de estos gentilicios, es muy significativa la proporción que muestra el siguiente cuadro:

CUADRO 2

\begin{tabular}{|l|c|c|c|c|c|c|}
\hline Gentilicios Siglos & I & I-II & II & II-III & III & $\begin{array}{c}\text { Sin } \\
\text { fechar }\end{array}$ \\
\hline Indígenas & 2 & 1 & 12 & 0 & 0 & 1 \\
\hline Latinos & 31 & 9 & 37 & 9 & 16 & 19 \\
\hline
\end{tabular}

En este gráfico (cuadro 2), se observa cómo en el siglo I la proporción de gentilicios latinos sobre los indígenas es mayoritaria, pero en el siglo II las diferencias han disminuido levemente, y frente a un ligero aumento del número de gentilicios latinos, el número de indígenas se ha multiplicado por seis, probablemente en razón de la completa asimilación del proceso romanizador por parte de la población autóctona, que, al igual que Lambrino (147) ha comprobado en el mundo religioso de este siglo, debió ocurrir con la onomástica.

Al margen de estas consideraciones, creemos necesario, en esta presentación de los datos, llamar la atención sobre la proporción de los Paterni/ae y Materni/ae dentro de los gentilicios de mayor frecuencia, cuya distribución figura en el cuadro 3.

Se observa que Materni/ae son mayoritarios en dos de los gentilicios más usuales: Aemilius y Cornelius, mientras que Paterni/ae lo son en Valerius y en el resto. En esta distribución tienen un fuerte peso específico algunas de las grandes familias de los municipios hispanos del siglo II, en concreto la de los Aemilii de Aeso (Isona, Lérida), cuyo

(147) LAMBRINO, 1965, 239, aunque hoy día estos argumentos se pueden completar debido al aumento vertiginoso en el número de hallazgos realizados desde entonces; los cálculos de Lambrino están hechos sobre un número reducido de ejemplos en relación con los existentes hoy. 
elevado número de miembros (vide supra) contribuye a agudizar este desequilibrio. Este panorama no difiere del que presentara hace algunos años R. Syme para Hispania y Narbonense (SYME 1958, Apéndice 78).

\section{CUADRO 3}

\begin{tabular}{|l|c|c|c|c|c|}
\hline & Fraternus/a & Fraterninus & Maternus/a & Paternus/a & Paternianus \\
\hline Valerius (18) & & & 6 & 12 & 1 \\
\hline Aemilius (17) & 1 & 1 & 10 & 5 & \\
\hline Cornelius (15) & & & 11 & 4 & \\
\hline Iulius (13) & 2 & & 3 & 7 & 1 \\
\hline Sempronius (11) & & & 4 & 7 & \\
\hline Licinius (10) & & & 4 & 6 & \\
\hline Pompeius (9) & 1 & & 1 & 7 & \\
\hline Atilius (7) & 2 & & 2 & 3 & \\
\hline Terentius. (5) & 1 & & & 4 & \\
\hline
\end{tabular}

Datos tan interesantes como los que proporciona el análisis de los gentilicios, nos suministra el estudio de las tribus a las que figuran adscritos los individuos, y la existencia o ausencia de praenomen. Esta consideración es válida fundamentalmente para el siglo I, pues la extensión de la ciudadanía a partir de Vespasiano y su generalización quizá incluso antes de Caracalla, así como la transcripción incompleta de la onomástica en las inscripciones del siglo III, impiden dar un valor efectivo a los testimonios. En el cuadro 4 aparecen los datos tal y como figuran en el material epigráfico, sin inferir elementos que pudieran resultar equívocos y excluyendo los escasos ejemplos femeninos.

El número de individuos adscritos a la tribu Galeria es similar para los Materni y para los Paterni en el siglo I, si bien las diferencias se observan en el origen de los individuos y lugar de los hallazgos. Los cinco Materni proceden de Fuente Tójar (Córdoba. CIL II 1648), Boletum (Coscojuela de Fantobas, Huesca. CIL II 5843-46), cercanías de Lisboa (CIL II 2I7), Tarraco (CIL II 4216) y Liria (M.Cornelius Nigrinus Curiatius Maternus. ALFÖLDY-HALFMANN 1973, passim), mientras que los Paterni proceden en un caso de Prats del Rey (Barcelona) y en los otros tres de Clunia. Un Paternus pretendidamente hispano, que figura en una inscripción de Narbona (Antistius Paternus. CIL $X I I$ 4365), de época flavia (LE ROUX 1982a, n. 64), sería un quinto testimonio sobre Paterni de la tribu Galeria en el siglo I, aunque no sea posible fijar su procedencia. Como puede verse, los Materni referidos proceden de puntos muy distantes y, en algunos casos, lugares en los que la presencia de individuos itálicos fue importante desde muy pronto. En esencia, estos Materni no guardan entre sí ningún vínculo importante, salvo un cognomen, mientras que en el caso de los Paterni, tres de los cuatro testimonios (cinco si se incluye el narbonense), proceden de Clunia, adscrita a la tribu Galeria y privilegiada ya en época de Tiberio. Es bastante plausible suponer que en el caso de los cinco Materni nos encontramos ante individuos pertenecientes a las grandes aristocracias locales, impregnados desde muy temprano por los influjos latinos, máxime si tenemos en cuenta sus nomina (Porcius, Valerius, Fonteius, Cornelius e Hirrius), que tres de ellos desempeñan el duumvirado en la ciudad, perteneciendo a este grupo L . Fonteius Mater- 
CUADRO 4

\begin{tabular}{|c|c|c|c|c|c|c|c|c|}
\hline Cognomen & Tribu & Praenomen & I & $\mathrm{I}-\mathrm{II}$ & II & Total & Total & TOTAL \\
\hline \multirow{5}{*}{ FRATERNUS } & \multirow{2}{*}{ GALERIA } & Con praen. & 1 & & 1 & 2 & \multirow[b]{2}{*}{2} & \multirow{5}{*}{6} \\
\hline & & Sin praen. & & & & & & \\
\hline & \multirow{2}{*}{ QUIRINA } & Con praen. & & & 2 & 2 & \multirow{2}{*}{2} & \\
\hline & & Sin praen. & & & & & & \\
\hline & Sin tribu & Con praen. & 1 & 1 & & 2 & 2 & \\
\hline \multirow{7}{*}{ MATERNUS } & \multirow{2}{*}{ GALERIA } & Con praen. & 5 & 3 & 1 & 9 & \multirow{2}{*}{9} & \multirow{7}{*}{30} \\
\hline & & Sin praen. & & & & & & \\
\hline & \multirow{2}{*}{ QUIRINA } & Con praen. & & & & & \multirow{2}{*}{1} & \\
\hline & & Sin praen. & 1 & & & 1 & & \\
\hline & \multirow{2}{*}{ OTRAS } & Con praen. & 1 & & & 1 & \multirow{2}{*}{1} & \\
\hline & & Sin praen. & & & & & & \\
\hline & Sin tribu & Con praen. & 10 & & 9 & 19 & 19 & \\
\hline \multirow{5}{*}{ PATERNUS } & \multirow{2}{*}{ GALERIA } & Con praen. & 4 & 2 & 1 & 7 & \multirow{2}{*}{8} & \multirow{5}{*}{32} \\
\hline & & Sin praen. & 1 & & & 1 & & \\
\hline & \multirow{2}{*}{ QUIRINA } & Con praen. & 2 & & 3 & 5 & \multirow{2}{*}{6} & \\
\hline & & Sin praen. & & & 1 & 1 & & \\
\hline & Sin tribu & Con praen. & 6 & 2 & 10 & 18 & 18 & \\
\hline FRATERNINUS & GALERIA & Con praen. & 1 & & & 1 & 1 & 1 \\
\hline
\end{tabular}

nus Novatianus, uno de los hispanos promocionados por Nerva al orden ecuestre (148), y que $M$. Cornelius Nigrinus Curiatius Maternus desempeñó un activo papel en los asuntos políticos y militares de fines del siglo I (ALFÖLDY-HALFMANN 1973). Por el contrario, la limitada procedencia de los Paterni, y el modesto papel que parecen desempeñar en sus municipios, hace pensar, al menos en el caso de los clunienses, en individuos indígenas que han adoptado un nombre latino. Por lo que respecta a la tribu Quirina en el siglo I, un individuo de cognomen Maternus manifiesta su adscripción en Iruña (Alava) (HAE I778), mientras dos Paterni lo hacen en Clunia (CIL II 2798) y Santiago de Cacem (Portugal. CIL II 29) respectivamente, sin que el primero haya recibido la tribu en esa ciudad, pues los clunienses pertenecían a la Galeria (KUBITSCHEK 1882, 170).

Tan importante como la tribu para determinar la ciudadanía, es la presencia de tria nomina, al menos hasta principios del siglo II, en que su uso de hecho, aunque no de derecho, deja de ser exclusivo, en muchos casos, de los ciudadanos.

(148) PFLAUM, 1965, 98. Sobre el individuo, vide núm. 88, nota 52, a propósito de su carrera y de su filiación. 
Pues bien, diez individuos con el cognomen Maternus presentan en el siglo I tria nomina sin hacer constar la tribu. El número no es significativo, pero sí su distribución geográfica: Clunia (BELTRAN 1978, n. 137), Medina Sidonia (Cádiz. CIL II 1322), Aroche (Huelva. GONZALEZ 1982, n. 19), Antequera (Málaga. CIL II 2056), Astorga (León. EE IX, $292 f$.), Idanha (Portugal. AE 1961, 359), Lisboa (CIL II 298), Añavieja (Soria. JIMENO 1980, n. 6), Benifairó (Sagunto, Valencia. CIL II 3896) y Onda (Valencia. CIL II 4036). Frente a esta dispersión, los seis Paterni con tria nomina sin tribu del siglo I no salen de la mitad norte peninsular: Clunia $(A E 1908,147)$, Cáceres (CIL II 714), Ampurias (ALMAGRO 1952, n. 3), Guimarâes (Portugal. HAE 362), Torremocha (Teruel. CIL II 3170) y Játiva (Valencia. CIL II 3627); es decir, el mismo fenómeno que en los individuos de la tribu Galeria parece repetirse aquí.

En el siglo II d. C. el panorama ha cambiado totalmente. Sólo un Maternus figura adscrito a la Galeria, frente a un Paternus, pero la Quirina pasa a ser exclusiva de estos últimos, con cuatro testimonios muy significativos: uno en Palencia (CRESPO 1978, n. 82), otro en San Esteban de Gormaz (Soria. CIL II 2828), un Caesarobrigensis (Talavera de la Reina, Toledo. CIL II 5320), y un Lanciensis (Lancia, León. CIL II 4223), lo que inevitablemente nos pone en relación con la promoción jurídica que experimentan las ciudades de la meseta norte en época flavia, y que en el siglo II ha arrojado ya frutos interesantes, pues alguno de estos individuos, como es el caso del Lanciensis, llegan a ser, a principios de siglo, flamines de la Citerior (CIL II 4223. ALFÖLDY 1973, n. 36).

Por lo que respecta a los individuos sin tribu pero con praenomen en este mismo siglo II, son nueve Materni y diez Paterni los que reúnen esta característica y, aunque los Materni siguen manifestando una mayor tendencia a la dispersión, frente a una mayor concentración en la meseta norte de los Paterni, las diferencias no son tan notables.

En líneas generales, y omitiendo los escasos testimonios de individuos que presentan tribu o praenomen en el siglo III, a todas luces no indicativos tras el Edicto del 212, y haciendo lo mismo con los testimonios de cronología dudosa, salvando lo relativo de los criterios, 30 Materni y 32 Paterni poseen la ciudadanía romana, lo que sobre el total de testimonios de los siglos I y II d. C. supone un 52,5 por ciento.

Capítulo importante en estas consideraciones es el mundo de la religión. Entre los Paterni/ae y Materni/ae hispanos, se atestigua un total de 34 inscripciones votivas, repartidas según indica el cuadro 5 .

Se puede observar que el mayor número de dedicaciones corresponde a divinidades indígenas, con 20 testimonios, de los cuales no es posible fechar 11, siendo mayoritario el grupo de las que pertenecen al siglo II, fenómeno que ya observó Lambrino (1965, 239 ss.). Por cognomina, Paternus/a muestra una clara superioridad sobre Maternus/a, con 12 de los 20 testimonios, lo que permite intuir el nivel de indigenismo que encubre este cognomen. Ello es más notorio si observamos que ésta es la única diferencia en el tipo de vinculaciones religiosas de ambos grupos, pues por lo que respecta al resto de las divinidades, Paternus/a y Maternus/a aparecen igualados en número, con 3 dedicaciones a Júpiter y otras 4 al resto de las divinidades latinas y orientales para cada grupo.

Por lo que respecta al disfrute de cargos públicos y magistraturas (cuadro 6), es muy reducido el número de individuos con estos cognomina que hay que destacar. Tan sólo 9 de ellos obtuvieron cargos municipales, siendo diferente el porcentaje de ambos grupos, y su distribución en el tiempo. Mayores diferencias se observan en los cargos religiosos. El siglo II presenta un mayor volumen de testimonios, con siete ejemplos, de los cuales una es una mujer que ostentó el flaminado municipal y el provincial. De los tres flamines y flaminicae municipales, dos presentan como cognomen Paternus/a, y una sola Materna. Igualmente, de los cinco flamines y flaminićae provinciales, todos los cuales lo fueron en la Citerior, tres son Paterni/ae y dos Materni/ae. La mayor proliferación de ejemplos para el siglo II se acentúa si tenemos en cuenta que Iulius Paternus, 
CUADRO 5

\begin{tabular}{|c|c|c|c|c|c|c|c|c|c|}
\hline Divinidad & Cognomen & I & I-II & II & $\begin{array}{c}\text { II } \\
\text { III }\end{array}$ & III & $\begin{array}{c}\text { Sin } \\
\text { fecha }\end{array}$ & Total & TOTAL \\
\hline \multirow{4}{*}{ INDIGENA } & Maternus & & & & & & 5 & 5 & \multirow{4}{*}{20} \\
\hline & Materna & & & 1 & & 1 & 1 & 3 & \\
\hline & Paternus & 1 & 1 & 4 & & & 3 & 9 & \\
\hline & Paterna & & & & 1 & & 2 & 3 & \\
\hline \multirow{4}{*}{ JUPITER } & Maternus & & & 1 & & & 1 & 2 & \multirow{4}{*}{6} \\
\hline & Materna & & & & & & 1 & 1 & \\
\hline & Paternus & 1 & & & & & & 1 & \\
\hline & Paterna & & & 1 & & & 1 & 2 & \\
\hline \multirow{4}{*}{ OTRAS } & Maternus & 1 & & & & & 1 & 2 & \multirow{4}{*}{8} \\
\hline & Materna & & 1 & & & & 1 & 2 & \\
\hline & Paternus & & 2 & & & & & 2 & \\
\hline & Paterna & & & 1 & & & 1 & 2 & \\
\hline \multicolumn{9}{|l|}{ TOTAL } & 34 \\
\hline
\end{tabular}

CUADRO 6

\begin{tabular}{|c|c|c|c|c|c|c|c|c|}
\hline & Cognomen & I & I-II & II & $\begin{array}{c}\text { II } \\
\text { III }\end{array}$ & III & Total & TOTAL \\
\hline \multirow{4}{*}{$\begin{array}{l}\text { MAGISTRATURAS } \\
\text { MUNICIPALES }\end{array}$} & Maternus & 3 & 1 & 1 & & 1 & 6 & \multirow{4}{*}{9} \\
\hline & Materna & & & & & & & \\
\hline & Paternus & 1 & 1 & 1 & & & 3 & \\
\hline & Paterna & & & & & & & \\
\hline \multirow{4}{*}{$\begin{array}{l}\text { FLAMINADO } \\
\text { MUNICIPAL }\end{array}$} & Maternus & & & & & & & \multirow{4}{*}{3} \\
\hline & Materna & & & 1 & & & 1 & \\
\hline & Paternus & 1 & 1 & & & & 2 & \\
\hline & Paterna & & & & & & & \\
\hline \multirow{5}{*}{$\begin{array}{l}\text { FLAMINADO } \\
\text { PROVINCIAL } \\
\text { CITERIOR }\end{array}$} & Maternus & 1 & & & & & 1 & \multirow{5}{*}{6} \\
\hline & Materna & & & 1 & & & 1 & \\
\hline & Paternus & & & 1 & & & 1 & \\
\hline & Paterna & & & 2 & & & 2 & \\
\hline & Fraterninus & 1 & & & & & 1 & \\
\hline
\end{tabular}


flamen municipal de Castulo, ostenta el cargo en un momento impreciso entre el 98 y el 138 d. C., y que Fonteius Maternus Novatianus, es flamen de la Citerior durante el reinado de Nerva, es decir, a finales de siglo.

Hasta aquí lo referente a las valoraciones estadísticas de tipo general sobre los $\operatorname{cog}$ nomina estudiados. Se trata ahora de buscar causas y explicaciones a las, en algunos casos leves, oscilaciones registradas. Para ello hemos procedido en primer lugar al análisis de los focos que registran mayor intensidad de ejemplos.

Se observa en primer lugar que en el siglo I d. C., Clunia es el enclave mayoritario de los Paterni/ae, con 7 casos de los 26 registrados, mientras que el resto (19) se encuentra disperso por toda la península, sin que se observe ningún otro fenómeno de concentración. En este período, el cognomen no se registra aún en León, Lugo ni Palencia, provincias en las que los testimonios comienzan a aparecer con relativa frecuencia en el siglo II. Es en este período cuando el cognomen comienza a generalizarse al norte del Duero, probablemente como resultado del influjo que ejerce el área de Clunia y de los tremendos desplazamientos de población que desde esła ciudad se dirigen a puntos dispersos de la meseta norte. Clunia fue una de las ciudades de la región que con más prontitud se integró en el proceso municipalizador, pues desde Tiberio estuvo dotada de un sistema de administración romana que queda suficientemente probado en los IIIIviri que figuran en sus acuñaciones bilingües (COR.MATE. Vide núm. 65 bis. BELTRAN $1978, \mathrm{n} .137)$. A partir de este momento, la ciudad inicia un despegue urbanístico y económico, con plena integración en los modelos latinos, como muestran, entre otros muchos elementos, las influencias que sus alfareros recogen de la cerámica romana y que aplican a sus características cerámicas pintadas. El proceso de desarrollo se verá impulsado tras la proclamación de Galba y la participación de Clunia en este acontecimiento, mediante la revelación del oráculo que narra Suetonio y la consiguiente conversión en colonia (Suetonio, Galb. 9, 5 y 6).

A partir de esa fecha, Clunia ejercerá un tremendo influjo sobre el mundo indígena de la meseta norte y será pieza fundamental para la asimilación de los modelos romanos en la región, que se manifestarán con fuerza a través de la concesión del estatuto municipal para muchas poblaciones de la región por parte de Vespasiano (ESPINOSA RUIZ 1984, con el análisis de este hecho en algunas ciudades de la región). Paralelamente, se debió producir en las comunidades de la zona un proceso de latinización de la onomástica indígena que comenzaría con la adopción de cognomina latinos, que en muchos casos son utilizados por los individuos como nombre único (una situación similar se observa en otras zonas. $C f r$. ALFÖLDY 1977, 261). Es lógico pensar que estos cognomina fueran en un principio los más fáciles de asimilar, y en este sentido hay que entender los cognomina de parentesco: Paternus, Maternus, Fraternus, etcétera, de los que los dos primeros alcanzarían mayor difusión.

En el siglo I se documentan en Hispania 26 menciones de los cognomina Pater$n u s / a$. En el cambio hacia el siglo II, y en este mismo siglo, el número ha pasado ya a 62 , y en la distribución geográfica la tónica ha sido la ampliación del área de cobertura a partir de la zona cluniense y al norte del Duero, manteniendo el papel hegemónico del área burgalesa y afectando de lleno a la región de Lara de los Infantes, que recoge en este período un número considerable de menciones.

En algunos casos, los individuos que ostentan este cognomen, posiblemente en base a al coincidencia de grupo generada por vinculaciones de sangre o de procedencia étnica, se denominan en plural, como es el caso de los Paterni que ofrecen un ara a una divinidad indígena en Lugo en pleno siglo II (CIL II 2570).

En la difusión del cognomen Paternus/a a partir de Clunia o de los escasos testimonios aislados de la región, contemporáneos a los más antiguos de Clunia, jugó sin duda un papel importante el movimiento de la legio VII desde su creación hasta su definitivo 
emplazamiento en León. En efecto, en la provincia de León, los individuos que presentan el cognomen Paternus/a aparecen en el siglo II, y de los cinco casos registrados en ese momento, cuatro son militares de la región y sus cuerpos auxiliares. Lo mismo ocurre en Tricio, en donde se establece una vexillatio de la legión. En este lugar, se concentra el 75 por ciento de los Paterni/ae de la provincia de Logroño. Los dos casos del siglo III son dos mujeres (Lucretia, Valeria) ligadas a militares y con gentilicios frecuentes entre los soldados y veteranos de la legio VII, y seis de los doce Paterni/ae tritienses son alfareros. Significa esto que la presencia del cognomen en las regiones citadas, excluyendo la población estable, como es el caso de los alfareros, está en función de los desplazamientos de la guarnición, y que los hombres y mujeres a que aludimos serían en su mayor parte bien soldados, de los que en muchos casos no consta esta condición, bien hombres y mujeres que residían en las canabae de la legión, y que se desplazaban con ésta.

\section{CUADRO 7}

\begin{tabular}{|c|c|c|c|c|c|c|c|c|c|}
\hline Cognomen & Lugar & I & I-II & II & $\begin{array}{c}\text { II } \\
\text { III }\end{array}$ & III & $\begin{array}{l}\text { Sin } \\
\text { fecha }\end{array}$ & Total & $\begin{array}{c}\text { TOTAL } \\
\text { provincia } \\
\text { de Burgos }\end{array}$ \\
\hline \multirow{2}{*}{ PATERNUS } & Clunia & 6 & & 2 & & & & 8 & \multirow{2}{*}{20} \\
\hline & Resto de Burgos & 1 & & 2 & & 1 & 8 & 12 & \\
\hline \multirow{2}{*}{ PATERNA } & Clunia & 1 & 1 & 2 & & 1 & & 5 & \multirow{2}{*}{8} \\
\hline & Resto de Burgos & & & 2 & & & 1 & 3 & \\
\hline \multirow{2}{*}{ MATERNUS } & Clunia & 1 & & 1 & & & & 2 & \multirow{2}{*}{8} \\
\hline & Resto de Burgos & & & 2 & & 2 & 2 & 6 & \\
\hline \multirow{2}{*}{ MATERNA } & Clunia & & & 1 & 1 & & & 2 & \multirow{2}{*}{4} \\
\hline & Resto de Burgos & & & 1 & & & 1 & 2 & \\
\hline \multirow{2}{*}{ FRATERNUS } & Clunia & 1 & & & & & 1 & 2 & \multirow{2}{*}{3} \\
\hline & Resto de Burgos & & & & & & 1 & 1 & \\
\hline
\end{tabular}

De hasta qué punto el área cluniense es el cențro de irradiación de estas influencias da idea el volumen de hallazgos de las zonas cercanas a la ciudad y en las provincias periféricas a la burgalesa. De esta forma, y según muestran los cuadros 7 y 8 , Clunia no sólo presenta el grupo mayoritario de los Paterni/ae en el siglo I, sino que considerando globalmente todo el Alto Imperio, la ciudad representa el 9,2 por ciento del total de los hallazgos peninsulares.

Esta cifra alcanza el 20 por ciento si consideramos toda la provincia de Burgos, y el 35,7 por ciento si añadimos las periféricas de Soria y Logroño. Si nos extendemos hacia el oeste, cinco provincias (Burgos, Soria, Logroño, Palencia y León) engloban el 49,2 por ciento de los hallazgos, y la inclusión de la franja cantábrica permite aumentar esta concentración hasta el 62,8 por ciento, con lo que queda claro que se trata de una irradiación de influencias cuyo origen debe ser situado efectivamente en el centro del área burgalesa. 


\section{CUADRO 8}

\begin{tabular}{|l|c|r|r|r|l|}
\hline Lugar, Cognomen & Paternus/a & Maternus/a & Fraternus & $\begin{array}{c}\text { Pater- } \\
\text { nianus }\end{array}$ & $\begin{array}{c}\text { Mater- } \\
\text { nianus }\end{array}$ \\
\hline Clunia .................. & $13-9,2 \%$ & $4-3,1 \%$ & $2-22,2 \%$ & & \\
\hline Provincia de Burgos ... & $28-20,0 \%$ & $12-9,3 \%$ & $3-33,3 \%$ & $1-50 \%$ & \\
\hline $\begin{array}{l}\text { Provincias de Burgos, } \\
\text { Soria y Logroño ....... }\end{array}$ & $50-35,7 \%$ & $25-19,5 \%$ & $3-33,3 \%$ & $1-50 \%$ & \\
\hline $\begin{array}{l}\text { Provincias de Burgos, } \\
\text { Soria, Logroño, Palen- } \\
\text { cia y León ............. }\end{array}$ & $69-49,2 \%$ & $34-26,5 \%$ & $5-55,5 \%$ & $1-50 \%$ & \\
\hline $\begin{array}{l}\text { Provincias de Burgos, } \\
\text { Soria, Logroño, Palen- } \\
\text { cia, León, Lugo, Astu- } \\
\text { rias, Santander, Alava } \\
\text { y Navarra............... }\end{array}$ & $88-62,8 \%$ & $47-36,8 \%$ & $5-55,5 \%$ & $1-50 \%$ & $1-50 \%$ \\
\hline
\end{tabular}

Esta tónica se confirma si consideramos que de los cinco Paterni encuadrados en la tribu Galeria, en el siglo I d. C., tres son de Clunia, según vimos en el cuadro 4.

El análisis de las dedicaciones a divinidades indígenas nos muestra hasta qué punto el citado cognomen, Paternus/a, encubre un alto grado de indigenismo. En el cuadro 5 habíamos visto cómo doce de los veinte individuos que aparecen en estas inscripciones portan este cognomen, con un ejemplo en el siglo I y cuatro en el II. Estas cifras contrastan con las de los Materni/ae, cuyo porcentaje es mínimo.

Ahora bien, si el siglo I es el momento en que el cognomen Paternus/a se fortalece y comienza a generalizarse en la población indígena, a partir del área mencionada, en el siglo II se extiende definitivamente, al tiempo que los individuos que lo portan dan muestra de un acusado grado de indigenismo, pues la mayor parte de las inscripciones dedicadas a dioses indígenas en las que figuran, corresponden a este período, incluyendo algunas que por elemental prudencia no hemos querido fechar y que figuran en el grupo de cronología imprecisa. La explicación a este fenómeno debe buscarse en el grado de asimilación que la población del siglo I, principalmente en Clunia, como núcleo tempranamente romanizado, tiene de la vida romana, por lo que el indigenismo de la ciudad pasa a ser un elemento consustancial del mundo cotidiano, aunque no visible en razón de la euforia colectiva que anima el desarrollo de la ciudad. Ahora bien, a raíz de la difusión del cognomen en el área, éste empieza a definir no solamente a un grupo de individuos que han optado por unas formas de vida distintas a las suyas, sino a un número determinado de indígenas que, en vías de integrarse en este modelo, han comenzado a adoptar determinados elementos superficiales entre los que figura la onomástica, pero sin renunciar aún a formas de vida y de pensamiento que les son propias.

Así, muchos de ellos siguen manifestando su culto a divinidades indígenas, al tiempo que la extensión de los estatutos municipales a partir de Vespasiano, permite rastrear la integración de estos individuos en las nuevas comunidades urbanas de la meseta, cuyo testimonio epigráfico es la adscripción a la tribu Quirina de un número considerable de Paterni en las ciudades de la mitad norte, y de un sólo Maternus en estas mismas condiciones. 
Simultáneamente, y dado que el grupo comienza a formarse a partir del siglo I, en el siglo II un gran número de individuos ha debido ya integrarse plenamente en el sistema romano, pues frente a la notoria superioridad de los Paterni en las dedicaciones indígenas, el número de inscripciones dedicadas a divinidades latinas y orientales es equiparable al del grupo de los Materni. Por añadidura, algunos de estos individuos han alcanzado el nivel de renta preciso, 100.000 sextercios, para asumir las magistraturas municipales ( 3 entre los siglos I y II), en número casi equiparable a los Materni, y el grupo onomástico desempeñará en el siglo II el flaminado municipal y provincial en un número de ocasiones mayor incluso que los Materni/ae.

Durante este siglo II, y además del altísimo grado de concentración en el Conventus Cluniensis y al norte del Duero, aparecen algunos focos de Paterni dispersos por puntos de la mitad norte. Se trata en general de individuos aislados, excepto en el caso de la familia de los Aemilii de Aeso (Isona, Lérida), uno de los grupos de la élite local, que desempeña un importante papel en su ciudad y cuyos miembros alcanzaron puestos de gran importancia.

El repliegue experimentado por el cognomen Paternus/a se consuma en el siglo III, cuando la mayor parte de los testimonios se sitúan al norte del Duero, siendo los restantes individuos cuya presencia en los diferentes enclaves peninsulares puede tener explicaciones muy concretas: el individuo que aparece en Tarragona es probablemente un soldado destacado ante el gobierno de la Tarraconense (RIT 659); de los tres casos de Mérida, dos corresponden a una familia en la que el padre se dice Interamniensis (CIL II 511), y el tercero es una mujer casada con un soldado de la legio VII (LE ROUX 1982a, n. 221); el hallazgo de Beja corresponde a una niña de 15 años, liberta, cuyo origen es probablemente otro (CIL II 60); en Lisboa, Iulia Paterna afirma la condición de Olisiponensis de su hija difunta (ILER 3513), en razón probablemente de que dicha condición no le afecte a ella, etcétera.

El cognomen Maternus/a parece obedecer a planteamientos distintos. En el siglo I d. C. existen 33 testimonios fechados en la Península Ibérica, que, en general, manifiestan un alto grado de dispersión, sin que exista ningún núcleo hispano que presente un claro predominio numérico sobre el resto. El cognomen en este siglo incluye un heterogéneo grupo de individuos en los que de forma global sólo es notoria la mayor presencia de gentes plenamente romanizadas y con posesión de ciudadanía con anterioridad a los emperadores flavios. En este sentido hay que interpretar también el que casi todos los personajes conocidos ostenten gentilicio ( 22 gentilicios para 33 personajes), mayoritariamente latinos y, en su mayor parte, característicos de las viejas familias republicanas.

Por lo que se refiere a los individuos adscritos a tribu en este siglo I, 5 Materni pertenecen a la Galeria, siendo sus procedencias distintas (Fuente Tójar, Córdoba; Boletum, Huesca; Lisboa, Liria y Tarraco), al igual que ocurre con los que presentan praenomen y no tribu, que en número de diez aparecen desperdigados, con una relativa presencia en Andalucía y litoral mediterráneo.

En el siglo II, se producirá un repliegue generalizado hacia la mitad norte del $\operatorname{cog}$ nomen Maternus/a, circunstancia que exceptúan algunos hallazgos aislados en la zona de Lisboa y en el cuadrante suroeste. Este repliegue coincide con el incremento de los testimonios en la mitad norte, especialmente en el conventus de Clunia, y con la aparición de un foco muy activo en Aeso, que es una característica compartida con los Paterni/ae.

En el siglo III, los testimonios de Materni/ae están definitivamente ceñidos a la periferia burgalesa, con excepción de cuatro testimonios: un caso de Braga (CIL II 2436), uno en Tarragona (CIL II 1410, probablemente itálico), uno en Segovia (CIL II 2755, cuyo cognomen, Valerius, puede remitirnos a un veterano), y uno en Ribeira (La Coruña. CIL II 2567). 
En nuestra opinión, este repliegue debe obedecer al mayor uso que la población indígena de la meseta norte hace de este cognomen a medida que se va produciendo la integración en el mundo romano. Si Paternus caracterizaba a indígenas tempranamente romanizados en el siglo I, Maternus comparte con Paternus el proceso de integración en el siglo II, si bien la mayor tradición de este último atrae el mayor número de testimonios, pues, como puede verse, la onomástica paterna influye aquí muy poco.

A esta misma conclusión se llega si se observa que entre los 61 individuos con el cognomen Maternus/a fechados con imprecisión entre los siglos I y II, y los que con seguridad pertenecen al II, ya sólo 47 poseen gentilicios, cuyo número es ahora de 33 , de los cuales, 10 son indígenas. Es decir, al tiempo que los hallazgos se repliegan hacia la zona norte, se incrementa el número de individuos que usan el cognomen por todo onomástico, y en el número de gentilicios empleados, sube vertiginosamente la proporción de indígenas.

Como grupo más tardíamente integrado en el proceso romanizador, se observa la no participación de los individuos con este cognomen en determinados cargos. Así, ningún hombre con el cognomen Maternus desempeñará el flaminado municipal o provincial en este siglo II, y la única mujer que asume ambas funciones es Porcia Materna, natural de Osicerda (Zaragoza), cuyo origen y gentilicio la desvincula directamente de este grupo de indígenas en proceso de romanización, y sugieren para ella un origen familiar quizá plenamente itálico. Lo mismo podemos decir de las magistraturas municipales, pues sólo dos individuos alcanzan el duumvirado, uno en Aeso (L.Aemilius Maternus, a finales del siglo I y principios del II), cuya pertenencia a los Aemilii Aesonenses de la tribu Galeria le define fuera del grupo que intentamos identificar, y otro en Pax Iulia $(Q$. Petronius Maternus), sobre el que sólo conocemos su insistencia en las dedicaciones a Antonino Pío durante el tiempo en que ocupó el cargo municipal.

Deteniéndonos una vez más en la tardía proliferación del cognomen en la meseta norte, cabe señalar que en Clunia aparece en el siglo I con un testimonio solamente, y que en el resto de la provincia burgalesa hasta finales del siglo II sólo se conocen tres casos, siendo del siglo II los primeros testimonios riojanos (procedentes de Tricio). Por ello, si repetimos para los Materni/ae la valoración estadística que hicimos en el cuadro 8 para los Paterni/ae, el resultado es completamente distinto: en primer lugar, la provincia de Burgos ya sólo registra el 9,3 por ciento de los hallazgos y el grupo de provincias situadas al norte del Duero que contenían el 62,8 por ciento de los hallazgos de Paterni/ae peninsulares, sólo condensan ahora el 36,8 por ciento de los Materni/ae. La explicación estriba en que la asimilación del cognomen Maternus/a por parte de la población de la meseta norte, no se generaliza hasta el siglo II, y en cualquier caso, su repliegue hacia esta zona no es tan rápido ni completo como en el caso de los Paterni/ae.

Haremos aquí una mención a la existencia de un tercer cognomen de parentesco cuya frecuencia es mucho menor. Se trata de Fraternus/a, que aparece en algunas ocasiones en la Península Ibérica, pero en número insuficiente para permitirnos extraer algún tipo de conclusiones.

Conocemos diez casos hispanos del cognomen Fraternus/a, que aunque de distribución irregular, sigue ciñéndose a la mitad norte, salvo un caso cordobés (núm. 140), y los lugares de procedencia de los individuos guardan mucha relación con los Paterni y Materni: Clunia (núms. 151 y 194), León (núms. 43 y 100), Sagunto (núm. 195), Tarragona (núm. 34), Isona (núm. 2), Idanha (núm. 99) y Poza de la Sal (núm. 35). Siete de estos individuos presentan algunos de los gentilicios más frecuentes que hemos recogido en el cuadro 3. Fraternus se coloca en orden de importancia tras Paternus y Maternus, en cuyo origen deben ser los tres contemporáneos, si bien no presenta oscilaciones dignas de mención, y ni siquiera el reparto geográfico o la tribu de los individuos (vide cuadro 4) proporciona datos dignos de mención, exceptuando que todos poseen gentilicio. 
Del mismo modo, en el siglo II comienzan ya a aparecer algunos cognomina derivados de Maternus/a y Paternus/a, como es el caso de Maternianus/a y Paternianus, que ahora sí obedecen a derivaciones sobre el cognomen de los padres, y no ya a una moda que en muchos casos no respeta la onomástica paterna como había ocurrido con los cognomina Maternus/a y Paternus/a. El número de ejemplos es ya muy reducido, como ocurre en el resto del Imperio (MOSCY 1983, 181 y 216) y el reparto sigue la tónica habitual: Collippo (núm. 106), Lara de los Infantes (núm. 216), Tarragona (núm. 187), Foronda (núm. 245) y Mengíbar (núm. 164).

Una última consideración que creemos necesaria es la relativa a la trasmisión de la filiación. Al principio de este trabajo justificamos la consideración conjunta en las estadísticas de los cognomina estudiados por la interrelación que guardan y por la ausencia de barreras que impidan el que el hijo de Paternus se llame Maternus o viceversa. En efecto, aunque son pocos los casos en que conocemos los nombres completos de los padres, los ejemplos conservados permiten observar que no existe una norma fija para la aparición de estos cognomina, lo cual está en consonancia con su adopción en razón de un influjo externo. Si en muchos casos el padre o la madre presentan el mismo cognomen Maternus /a o Paternus / a que partarán los hijos, en otros ejemplos, Paterna es hija de Maternus y viceversa. Asimismo, cuando los padres no poseen estos cognomina se dan muchos casos en que los adoptan los hijos, pero en ese caso, existe una mayor preferencia hacia Paternus/a que hacia Maternus/a, preferencia que, por lo exiguo de las diferencias, debe radicar en el mayor número de hallazgos epigráficos del primero.

En conclusión, el cognomen Paternus/a aparece en el siglo I d. C. vinculado con mucha fuerza al área burgalesa, en donde se concentra el mayor número de testimonios de esta época, para desde ahí iniciar una fase de expansión por las regiones periféricas, al norte del Duero, caracterizando a grupos de población indígenas tempranamente romanizados. La fuerte expansión del cognomen en el siglo II en estos ámbitos permite distinguir tras él un alto grado de indigenismo, tal y como muestran las inscripciones votivas, sin que ello impida que los individuos más tempranamente incorporados participen plenamente en este período en las tareas de gobierno de sus municipios, alcanzando incluso el flaminado provincial. Simultáneamente, el cognomen Maternus/a en el siglo I d. C. no define a ningún grupo en especial, si bien, entre los individuos que lo portan, un alto porcentaje pertenece a familias tempranamente romanizadas en las que, en este período no existen ya rasgos de indigenismo, pues en muchos casos forman parte de las élites urbanas de los municipios de la Bética y Levante. En el siglo II, por asimilación a Paternus, el cognomen Maternus comienza a hacerse más frecuente en la mitad norte peninsular, cambiando la condición social de sus portadores, como muestra la no posesión de nomen en muchos casos y el elevado número de gentilicios indígenas que se documentan, a lo que hay que añadir la no participación plena en las tareas de gobierno de los municipios en razón de esa reciente latinización de la mayor parte de los individuos. En este siglo II, ambos cognomina definen por tanto ya, mayoritariamente, a población autóctona romanizada, acentuándose el repliegue hacia el norte del Duero, que será una característica general en la tercera centuria. 


\section{BIBLIOGRAFIA}

ABASCAL PALAZON, J. M., 1983, «Epigrafía romana de la provincia de Guadalajara». Wad-al-Haya$r a, \mathrm{n}^{\circ} 10$.

ABASCAL PALAZON, J. M. y FERNANDEZ-GALIANO, D., 1984, «Epigrafía complutense». Museos 3.

ABASOLO, J. A., 1974a, Epigrafía romana de la región de Lara de los Infantes (Burgos). Burgos.

- 1974b, Carta arqueológica de la provincia de Burgos. I. Partido judicial de Belorado y Miranda de Ebro. SA, 33. Valladolid.

ABASOLO, J. A., ALONSO, J. M. y SAINZ, F. (ABASOLO 1982), 1982 «Nuevas inscripciones romanas procedentes de Briongos y Monasterio de Rodilla». BIFG, LXI, n. ${ }^{\circ} 198$.

ALBERTINI, E., 1918-19, «Inscriptions d'Espagne». MEFR XXXVII.

ALBERTOS, M. ${ }^{2}$ L., 1966, La onomástica personal primitiva de Hispania Tarraconense y Bética. Salamanca.

- 1983, «Onomastique personelle indigène de la Péninsule Ibérique sous la domination romaine». Aufstieg und Niedergang der römischen Welt. II, 29, 2. Berlín.

ALBERTOS, M. ${ }^{a}$ L. y ABASOLO, J. A., 1976, "Acerca de unas inscripciones romanas de Poza de la Sal». BSAA, XLII.

ALFÖLDY, G., 1969, Fasti Hispanienses. Wiesbaden.

- 1973, Flamines Provinciae Hispaniae Citerioris. Madrid.

- $\quad$ 1975, Die römischen Inschriften von Tarraco (RIT) Berlín.

- 1977, «Die personennamen in der römischen provinz Noricum» en L'Onomastique Latine. París, 1975. Coloquio n. ${ }^{\circ} 564$ del CNRS, pp. 249 ss.

- 1979, «Bildprogramme in den römischen Städten des Conventus Tarraconensis. Das Zeugnis der Statuenpostamente». Revista de la Universidad Complutense, vol. XVIII, n. ${ }^{\circ} 118$ (Homenaje a García y Bellido IV).

ALFÖLDY-HALFMANN, 1973, El edetano M. Cornelius Nigrinus Curiatius Maternus, general de Domitiano y rival de Trajano. Trabajos varios del SIP, n. ${ }^{\circ} 44$. Valencia. CHIRON, 3.

ALMAGRO BASCH, M., 1952, Las inscripciones ampuritanas griegas, ibéricas y latinas. Barcelona.

1984, Segobriga II. Inscripciones ibéricas, latinas paganas y latinas cristianas. EAE 127.

ARIAS, $1979=$

ARIAS VILAS, F., LE ROUX, P. y TRANOY, A., 1979, Inscriptions romaines de la province de Lugo. París.

BELEZA MOREIRA, J., 1976, «Duas inscriçoes funeràrias romanas na Igreja de S. Lourenço dos Francos». Conimbriga, XV.

BELTRAN LLORIS, F., 1978, «Los magistrados monetales en Hispania», Numisma, 150-155, pp. 169 ss. 1980, Epigrafía latina de Saguntum y su territorium. Trabajos varios del SIP. n. ${ }^{\circ} 67$. Valencia

BLANCO FREIJEIRO, A., 1972, «Antigüedades de Riotinto». Zephyrus XIII.

BLAZQUEZ, J. M. ${ }^{\mathrm{a}}$, 1962, Religiones primitivas de Hispania. I. Fuentes literarias y epigráficas.

- 1966, Caparra II. EAE 54.

- $\quad$ 1975, Diccionario de las religiones prerromanas de Hispania. Madrid.

CARDOZO, M., 1958, «Novas inscriçoes romanas do Museu Arquéológico de Odrinhas (Sintra)». Publicaçoes da Câmara Municipal de Sintra.

CASTILlO, C., 1982, «Los senadores béticos. Relaciones familiares y sociales». Epigrafía e Ordine Senatorio. Tituli, 5. Roma.

CASTILLO, $1981=$

CASTILLO, C., GOMEZ PANTOJA, J. y MAULEON, M. ${ }^{a}$ D., 1981, Incrpiciones romanas del Museo de Navarra. Pamplona.

$\mathrm{CNR}=$

BANTI, A. y SIMONETTI, L., 1972-77, Corpus Numorum Romanorum. Florencia.

CRESPO ORTIZ DE ZARATE, S., 1978, Epigrafia romana de la provincia de Palencia. Valladolid. 1981, «Aspectos de la romanización de Alava. Prosopografía y sociedad». EAA, 10. Vitoria.

D'ENCARNAÇAO, J., 1975, Divinidades indigenas sob o dominio romano em Portugal.

DOBSON, B., 1978, Die primipilares Entwicklung und Bedeutung Laufbahnen und Persönlichkeiten eines römischen Offiziersranges. Colonia.

DOMINGUEZ ARRANZ, $1984=$

DOMINGUEZ ARRANZ, M. ${ }^{a}$ A., MAGALLON BOTAYA, M. ${ }^{a}$ A. y CASADO LOPEZ, M. ${ }^{a}$ P., 1984, Carta arqueológica de España. Provincia de Huesca.

ELORZA, J. C., 1967, Ensayo topográfico de epigrafía romana alavesa.

ELORZA, $1980=$

ELORZA, J. C., ALBERTOS, M. ${ }^{a}$ L. y GONZALEZ, A., 1980, Incripciones romanas en La Rioja.

ESPINOSA RUIZ, U., 1984, «Las ciudades de Arévacos y Pelendones en el Alto Imperio. Su integración jurídica». I Symposium de Arqueología Soriana. Soria, 1983.

ETIENNE, R., 1958, Le culte imperial dans la Péninsule Ibérique d'Auguste a Diocletiane. París. 
ETIENNE, $1976=$

ETIENNE, R., FABRE, G. y LÉVÊQUE, P. et M., 1976, Fouilles de Conimbriga. Vol. II. Epigraphie et Sculpture. París.

FATAS, G. y MARTIN BUENO, M. A., 1977, Epigrafía romana de Zaragoza.

FERNANDEZ FUSTER, L., 1957, «Un ara a Epona en el Museo de Burgos». IV CNA. Burgos. 1955. Zaragoza.

FITA, F., 1893, «Inscripciones inéditas de Añavieja y Oyarzun». $B R A H$, XXIII.

- 1894, «Excursiones epigráficas». BRAH, XXV.

- $\quad 1900$, «Noticias». $B R A H, \mathrm{XXXVI.}$

- 1903, «Excursión epigráfica por Villar del Rey, Alhambra, Venta de los Santos, Cartagena, Logroño y Orense». $B R A H, \mathrm{XLII}$.

- 1904, «Nuevas inscripciones romanas en las provincias de Cádiz, Córdoba, Cáceres y Orense». $B R A H$, XLIV.

- 1911, «Noticias». BRAH, LVIII.

- 1916, «Inscripciones romanas de Peñaflor en la Provincia de Sevilla y de Quintanaélez en la de Burgos». BRAH, LXIX.

1917, «Nuevas inscripciones romanas en Palencia y Santa Cecilia». $B R A H, \mathrm{LXX}$.

GARCIA Y BELLIDO, A., 1949, Esculturas romanas de España y Portugal. Madrid. 2 vols.

- 1956-1961, «Las más bellas estelas geométricas hispanorromanas de tradición céltica». $N A H, \mathrm{~V}$.

- 1967, Les religions orientales dans l'Espagne romaine. Leyden.

GARCIA MERINO, C., 1974, «Las tierras del NO., foco de atracción para los emigrantes de la Meseta en época romana». $H A$, III.

- 1975, Población y poblamiento en la Hispania romana: El Conventus Cluniensis.

GOMEZ MORENO, M., 1917, Catálogo Monumental de la provincia de Zamora.

1925, Catálogo Monumental de la provincia de León.

GONZALEZ, J., 1982a, Inscripciones romanas de la provincia de Cádiz.

- 1982b, «Miscelánea epigráfica andaluza». AeArq. LV.

$\mathrm{HAE}=$ Hispania Antigua Epigraphica .

HURTADO DE SAN ANTONIO, R., 1977, Corpus provincial de inscripciones latinas. Cáceres.

IGLESIAS GIL, J. M., 1976, Epigrafía cántabra. Santander.

ILER = VIVES, J., 1971, 72.

IRB $=$ MARINER, D., 1973.

JIMENO, A., 1980, Epigrafia romana de la provincia de Soria.

JULIA, D., 1971, Etude épigraphique et iconographique des stéles funéraires de Vigo. Heildelberg.

KAJANTO, I., 1965, The Latin Cognomina. Helsinki.

KUBITSCHEK, W., 1882, De romanarum tribuum origine ac propagatione. Wien.

LAMBRINO, S., 1976, «Les cultes indigénes en Espagne sous Trajan et Hadrien». Les Empereures romains d'Espagne. París.

LARA PEINADO, F., 1973, Epigrafía romana de Lérida.

LE ROUX, P, 1972, «Recherches sur les centurions de la legio VII Gemina». MCV, VIII. Madrid.

- 1982a, L'armée romaine et l'organisation des provinces ibériques d'Auguste a l'invasion de 409. París.

1982b, «Les senateurs d'Hispania Citerior». Epigrafía e Ordine Senatorio. Tituli, 5. Roma.

MANGAS MANJARRES, J., 1971, Esclavos y libertos en la España romana. Salamanca.

MAÑANES, T., 1982, Epigrafía y numismática de Astorga romana y su entorno. León.

MARINER, S., 1973, Inscripciones romanas de Barcelona.

MARTI FERRANDO, L., 1972, «Lápidas romanas de Liria». APL, XIII.

MARTIN VALLS, R., 1982, «Las necrópolis del Castro de Yecla de Yeltes. Datos arqueológicos y epigráficos para su estudio». Zephyrus, XXXIV-XXXV.

MAYET, F., 1970, «A propos de deux poitiers de Merida: Valerius Paternus et Lapillius». MCV, VI. Madrid.

1983, Les céramiques sigillées hispaniques. París.

MELIDA, J. R., 1911, «Inscripciones romanas de Mérida y Reina». $B R A H$, LVIII.

MONTENEGRO, $1975=$

MONTENEGRO, A., SOLANA, J. M., SAGREDO, F. y LAZARO, A., 1975, «Inscripciones inéditas de Bárcina de los Montes (Burgos) y el nuevo dios indígena Vurovius. Durius, V.

MORESTIN, H., 1976, «Inscriptions religieuses et pierres funéraires inédites ou peu connues de la province de Logroño». AeArq, IL. n. ${ }^{\circ} 133-34$.

MÓSCY, A., 1983, «Nomenclator provinciarum Europae latinarum er Galliae Cisalpinae cum indice inverso». Dissertationes Pannonicae. Ser. III, vol. I. Budapest.

NAVAL, F., 1906, «Nuevas inscripciones de Clunia». BRAH, XLIX.

PALOP, P., 1959, Clunia Sulpicia. Ciudad romana. Burgos.

- 1969, «Una nueva inscripción de Clunia». AeArq, XLII, n. 119 y 120. 
PLAUM, H. G., 1965, «La part prise par les chevaliers romains originaires d'Espagne á l'administration impériale» en Les Empereures romains d'Espagne. París.

PITA MERCÉ, R., 1968, «Notas de arqueología de Cataluña y Baleares. Isona». Ampurias, XXX.

RABANAL ALONSO, M. A., 1982, Fuentes literarias y epigráficas de León en la antigüedad.

RIGAUD DE SOUSA, J. J., 1973, Subsidios para a carta arqueologica de Braga. SA, 23.

RIT = ALFÖLDY, 1975.

RODA DE MAYER, I., 1977, «La gens Pedania barcinonense». HA, V.

RODRIGUEZ ALMEIDA, E., 1981, Avila romana.

RODRIGUEZ COLMENERO, A., 1973, «Epígrafes inéditos de tierras orensanas». Durius, I, 2.

RODRIGUEZ NEILA, J. F., 1978, «Los jueces de las cinco decurias oriundos de la España romana». $H A$, VIII.

ROLDAN HERVAS, J. M., 1974, Hispania y el ejército romano. Salamanca.

ROMERO DE TORRES, E., 1915, «Nuevas lápidas romanas de Jimena y Mengíbar». BRAH, LXVI.

SANDARS, H., 1921, «Apuntes sobre el hallazgo de una inscripción sepulcral romana cerca de las Minas de El Centenillo en Sierra Morena». BRAH, LXXIX.

SCHLUNK, H., 1965, «Zu den frühchristlichen Sarkophagen aus der Bureba (Provincia Burgos)». MM, 6.

SERRANO RAMOS, E., y ATENCIA PEREZ, R., 1981, Inscripciones latinas del Museo de Málaga.

SOLANA SAINZ, J. M., 1978, Autrigonia romana. Valladolid.

STYLOW, A. U., 1983, «Inscripciones latinas del sur de la provincia de Córdoba». Gerion, I.

SYME, R., 1958, Tacitus. I y II. Oxford.

TARACENA, B., 1941, Carta arqueológica de España. Provincia de Soria.

TRANOY, A., 1981, La Galice romaine. París.

UNTERMANN, J., 1975, Elementos de un atlas antroponímico de la Península Ibérica.

VAZQUEZ SACO, F., y VAZQUEZ SEIJAS, M., 1960, Inscripciones romanas de Galicia. II. Provincia Lugo.

VENTURA CONEJERO, A., 1975, «Inscripciones romanas de la provincia de Teruel». Teruel $\mathrm{n} .^{\circ} 54$.

VIVES, J., 1971-72, Inscripciones latinas de la España romana. 2 vols. 


\title{
OBSERVACIONES SOBRE UN EMPERADOR CRISTIANO: FI. Jul. CONSTANTE
}

\author{
ELISA GARRIDO GONZALEZ \\ Universidad Autónoma de Madrid
}

\begin{abstract}
La vida del hijo menor de Constantino el Grande, Fl. Jul. Constante, tiene planteada una serie de cuestiones aún sin resolver; por tal razón, este trabajo constituye un estudio sobre toda la etapa anterior a su toma del poder en todo el territorio occidental del Imperio, con la pretensión de ofrecer una explicación verosímil de un conjunto de hechos controvertidos, a la luz de la documentación disponible. En definitiva, se analizan temas como la instrucción recibida por Constante, su nombramiento como césar; igualmente se estudia de qué manera le afectó la distribución territorial del año 335 realizada por su padre y el posterior reparto acordado con sus hermanos en el 337; cómo se desarrolló la masacre de la mayoría de los miembros de la familia constantiniana, tras la muerte de Constantino y cómo surgió el conflicto con su hermano mayor Constantino II, cuyo resultado fue la implantación de su autoridad en toda la pars occidentis durante una década.
\end{abstract}

There are some unresolved problems concerning the life of the youngest son of Constantine the Great, Fl. Jul. Constante. This paper focuses on the period before his leading the occidental part of the Empire. We intend to offer a sound explanation of the whole range of relevant facts in the light of the available documentation. We analize subjects such as the intruction received by Constantine, his appointment as Caesar, the way in which the territorial distribution carried out by his father in 335 affected him and the later distribution arranged between his brothers in 337 . We also investigate how the massacre of the majority of the constantinian family developed itself, after Constantine death. Finally, we study how originated the conflict with his elder brother Constantine the 2 nd, that gave as a result the consolidation of his authority over the whole pars occidentis during a decade.

Constantino el Grande murió el 22 de mayo del año 337; a los tres meses, el 9 de septiembre, sus tres hijos: Constantino, Constancio y Constante, se proclamaron Augusti (Anon. Val., 35; AUR. VICT., Epit., 41, 20; EUS. Vita Const., 4, 51; ZOS. 2, 40-1; EUTR., Brev., 10, 9). Aquí me interesa estudiar de cerca al menor de ellos, Flavio Julio Constante, ya que este emperador parece haber sufrido en la historiografia moderna una damnatio memoriae, debido a que su vida, obra política y período de gobierno prácticamente no han despertado ningún interés entre los historiadores (1). Este hecho

(1) Hay estudios en los que, de alguna manera, Fl. Jul. Constante está incluido, cfr. BARNES, 1975, 325-333; BARNES, 1978, 53-75; BARNES, 1980, 160-166; BURCKHARDT, 1982, reimp.; CHASTAGNOL, 1982; DEMOUGEOT, 1979, 229-253; FORTINA, 1955; GIGLI, 1959; HAUSCHILD, 1966, 8692; KRAFT, 1958; MAURICE, 1911; MOREAU, 1959, 179-184; PALANQUE, 1938, 241-250; PALANQUE, 1944, 47-64; PALANQUE, 1955, 257-263; PIGANIOL, 1972 2; SEECK, 1898, 17-65; SEECK, 1919; SEECK, 1901, 948-952; THIRION, 1965, 5-21; TOYNBEE, 1944; VOGLER, 1979. 
causa, cuando menos, extrañeza ya que Constante durante una década completa ejerció la autoridad suprema en todos los territorios que comprendían el occidente imperial; ello significa que durante un período de tiempo considerable tuvo bajo su poder la mitad del Imperio; a pesar de lo cual, ha merecido una atención menor que otros emperadores bajoimperial. El evidente desinterés en la investigación actual manifestado para con este reinado es, en realidad, una consecuencia clara de la misma actitud sostenida desde la Antigüedad, pues no contamos por ejemplo con ninguna obra biográfica sobre Constante, o con algún o algunos documentos en que se nos proporcione un informe detallado respecto de dicho reinado. Así pues, contamos únicamente con noticias aisladas y dispersas en las obras de los autores de la época o posteriores como Zósimo, Sócrates, Atanasio, Ammiano, etc.; asimismo nos han llegado pocas inscripciones y monedas y conocemos algunas leyes suyas en el CTh, quizá la documentación más interesante (2).

El motivo de este silencio documental resulta ciertamente difícil de explicar, aunque ésta sea una circunstancia que se da y encontramos con bastante frecuencia en el mundo antiguo. No obstante, parece extraño que en un período de gobierno tan extenso no hubiera surgido algún biógrafo, panegirista o, en fin, cualquier otro tipo de cronista; desgraciadamente no fue así, por lo cual, en estos momentos y en el estado actual de la investigación ésta es la realidad de la que debemos partir (3).

A pesar de todo ello, está claro que se han podido esbozar las líneas generales de la vida de este emperador, así como de su actividad política. Ahora bien, igualmente es cierto que persisten aún muchas incógnitas y hechos controvertidos objeto de polémica para la investigación moderna; por lo cual, se hace necesaria, en la actualidad, una exposición de conjunto de toda esta problemática.

En primer lugar, se ha manifestado ya una inseguridad con respecto de la fecha de nacimiento de nuestro emperador, ya que se le puede asignar bien el año 320 o el año 323. Esta disparidad cronológica tiene su origen en las fuentes que indican, en realidad, la edad que tenía en el año de su muerte, el cual está bien establecido en el 350 (AUR. VICT., Epit., 41, 23; EUTR. Brev., 10, 9, 4; HIERON. Chron., 237 C; JUAN CRISOSTOMO, in epist. ad Philipp., 4, 5; JUL. Or., 2, 26 C; 2, 5 D; MALALAS, 325 Bonn; Chron. Min. 1, 237; ZON. 13, 6; ZOS. 2, 42; SOCR. HE 2, 25, 7; SOZ. HE 4, 1).

(2) La dispersión de las fuentes obliga a una precisa recopilación: AMM. 15, 5, 16;16, 7, 5; 20,1,1; $20,11,3 ; 21,6,2 ; 27,8,4 ; 28,3,8 ; 30,7,5 ;$ Anon. Val. 35; ATHAN. Apol. c. Arian. 51-57; ATHAN. Apol. c. Const. 2-15; ATHAN. Hist. Ar. 69; ATHAN. Apol. Sec. 87, 4; ATHAN. Synod. 25; ATHAN. Festal Index 17; AUG. c. Cresc. 3, 49; AUR. VICT. Epit. 41, 19-24. AUR. VICT. Caes. 41, 13-24; AUS. Commen. Prof. Burdig 16, 15; CJ 1, 3, 1; 3, 26, 6; 10, 48, 7; Chron. Min. 1, 232-238; CTh 2, 6, 5; 2, 7, 3; 3, 5,$7 ; 7,1,2 ; 7,9,1 ; 8,2,1 ; 8,7,3 ; 9,7,3 ; 9,17,1 ; 9,21,6 ; 9,23,1 ; 9,24,2 ; 10,10,4 ; 10,10,5 ; 10,10,6$; $10,10,8 ; 10,10,7 ; 10,14,2 ; 10,14,3 ; 10,15,3 ; 11,12,1 ; 11,1,4 ; 11,7,6 ; 11,16,5 ; 11,30,23 ; 11,36,4$; $12,1,3 ; 12,1,24 ; 12,1,25 ; 12,1,26 ; 12,1,27 ; 12,1,29 ; 12,1,31 ; 12,1,36 ; 12,1,38 ; 12,6,5 ; 12,9,29$; $16,2,8 ; 16,8,1 ; 16,8,6 ; 16,9,2 ; 16,10,2 ; 16,10,3 ; 16,10,4 ; 15,1,5 ;$ EUN. V. Soph $6,3,8 ; 90$; EUS. Vita Const. 4, 40-68; EUS. Laud. 3; EUTR. Brev. 10, 6; 10, 9-2-4; FIRM. MAT de err. prof. rel. 28, 6; Frag. Vat. 35; HIER. Chron. 2356, 2358, 2866; HILAR. Frg. Hist. 2, 21; CIL 3, $12330=$ ILS 8944; CIL 2, 6029=ILS 725; CIL 3, 4180=ILS 727; CIL 3, 2829; ILS 726; ILS 724; CIL 11, 5265=ILS 705; CIL 3, $6375=$ ILS 728; CIL 3, $5207=$ ILS 723; AE 1925, 72=I.L. Tun. 814; JUAN CRISOSTOMO, in ep. ad. Philipp. 4, 5; JUL.. Or. 1, 19 A; 1, 20 B; 2, 94 B; 2, 56; 2, 57 D; 2, 58 C; 2, 59 B; 1, 26 B; 1, 26 C; 2, 5 D; 1, 9 D; 2, 52 B; LIB. Or., 3, 283-323; 1; 59; MALALAS, 325, Bonn; MANSI 3, 144; COHEN 7, 402-35; OPT. 3, 1-3; Pan. Lat. 10, 36; PHILOST. HE 3, 1-12; RIC 7, 580; RIC 5, 268-300; SOCR. HE 2, 5-25; 1, 38; SOZ. HE 3, 2-20: 2, 34; 4, 1; SYMM. Rel. 8, 4; THEOD. HE 2, 3-8; 5, 21; Vita Olympiadis 2; ZON. Epit. 13,$5 ; 13,6$; ZOS. 2, 35-47.

(3) Este hecho ha llamado la atención de los historiadores modernos sin que hayan sido capaces de explicarlo satisfactoriamente. Cfr. JONES, $1973^{2}$, $1088 \mathrm{n}$. 1; BARNES, 1980, 160, pone de manifiesto que el período posterior a la muerte de Constantino es el más oscuro de la historia imperial romana. Sospecho que la falta de documentación sobre Constante pudiera ser responsabilidad de Constancio II, interesado probablemente en que el reinado de sus hermanos cayera en el olvido. 
Así pues, los datos de que disponemos al respecto son los siguientes. Eutropio y Zonaras afirman que a su muerte tenía 30 años, por lo cual debió nacer en el 320 (EUTR. Brev., 10, 9, 4; ZON. 13, 6). Por su parte, Aurelio Víctor y Malalas suponen que contaba con 27 años en el momento de su muerte; en consecuencia, habría nacido en el 323 (AUR. VICT. Epit., 41, 23; MALALAS, 325 Bonn). Por último, se conoce una moneda, por la cual posiblemente pudiera confirmarse en cierta medida una de estas dos fechas de nacimiento; de hecho, la consideración que ha merecido es que podría apoyar con más fuerza la datación del año 320, por lo que a su muerte Constante contaría 30 años (SEECK, 1901, 948; SEECK, 1898, 39; COHEN, 1955, 402-35). Como es fácil observar la dificultad es enorme, pues no cuenta ninguna de las dos opciones con argumentos lo suficientemente sólidos como para obligar a un rechazo de la contraria. Esta opinión se refleja perfectamente en la valoración expuesta por la historiografía moderna, que no se ha resuelto de una forma clara en favor de una u otra propuesta. De este modo, advertimos que la actitud adoptada por J. Moreau de no decantarse por una fecha u otra (MOREAU, 1959, 179) ha sido retomada recientemente por A. H. M. Jones, J. R. Martindale y J. Morris en PLRE I, $220 \mathrm{n}$. 3. Sin embargo, la tesis tradicional representada por O. Seeck $(1898,38$; SEECK, 1901, 948) suponía que lo más probable era que el nacimiento de Constante hubiera tenido lugar en el año 323; asimismo, E. Stein $(1959,131)$ recogió esta postura y en la actualidad el defensor más representativo de esta tesis es T. D. Barnes (1981, 252; BARNES, 1982, 45; GAUDEMET, 1979, 255-6), quien advierte que a pesar de la dificultad que presenta esta cuestión, el año 323 cuenta con un apoyo más eficaz: «About his date of birth, the evidence diverges... However, a medallion which clearly celebrates his proclamation as Caesar depicts Constans as significantly younger than his brothers (RIC 7.580, Constantinople 67), so that 323 should be preferred over 320 for the date of his birth» (BARNES, 1982, 45). No obstante, ha surgido un sector historiográfico que se ha inclinado hacia el 320 como fecha más probable para el nacimiento de Constante; entre ellos ha destacado recientemente A. Chastagnol que se fundamenta en la edad que tenía en el momento de su nombramiento como César: «Le nombre des Césars fut notablement augmenté dans les dernières années: il passa à trois le 25 décembre 333 avec la proclamation du dernier fils de Fausta, Constant, alors âgé de 13 ans» (CHASTAGNOL, 1982, 128; cfr. PIGANIOL, 1972², 81; PALANQUE, 1938, 241).

Por todo lo expuesto se comprueba que no hay en modo alguno unanimidad respecto de esta cuestión, pero creo que es lógico intentar fijar, lo más aproximadamente posible, la fecha de nacimiento de Constante; por lo cual, se contará con un criterio preciso que permita determinar su capacidad de llevar el gobierno por sí mismo o si éste quedó en manos de otros en el momento en que se llevaron a cabo los repartos territoriales, tanto el del 335 como el del 337 , a la muerte de su padre.

En mi opinión, hay un dato que puede representar un papel importante a la hora de dilucidar este oscuro problema. En efecto, disponemos del testimonio proporcionado en el año 321 por Pan. Lat. 10, 36: «Caesaribus nobilissimis habet eorumque fratribus» y que continúa con alabanzas hacia Crispo. La opinión expresada por E. Galletier con respecto de esta frase es clara: "Crispus et Constantin II et leurs frères Constance et Constant. Ces derniers sont si jeunes en 321 (étant nés en 317 et 320) que le panégyriste ne peut pas décemment leur souhaiter une proche accession à l'empire» (GALLETIER, 1952, 196 n. 1; PLRE I, 220 n. 3). En consecuencia, esta información significa específicamente un elogio para los césares existentes en el 321, que no son otros que Crispo y Constantino II (BARNES, 1982, 7-8; PLRE I, 233 n. 4; PLRE I, 233 n. 3), mientras que la referencia a sus hermanos no puede ser interpretada de otra forma más que como una referencia a Constancio y Constante, nacido hacía poco tiempo.

Con respecto del nombre de este emperador no se presenta dificultad alguna, puesto que está bien documentado por inscripciones y monedas que era conocido como 
Flavio Julio Constante (CIL II 6029= ILS 725; ILS 724; ILS 726; CIL III 2829; CIL III $6375=$ ILS 728; CIL XI 5265 = ILS 705; BCH, 1946, 260 b; COHEN, 1955, 402-35). Por otra parte, era el cuarto o quinto hijo de Constantino el Grande, por lo cual debe entenderse que su madre era la segunda esposa del emperador cristiano: Flavia Máxima Fausta, hija de Maximiano Hercúleo. A pesar de que la mayor parte de la documentación, tanto inscripciones como textos literarios, coinciden en este punto (CIL II $6029=$ ILS 725; CIL III $5207=$ ILS 723; LIB. Or. 59, 14; EUN. V. Soph. 6, 3, 8; JUL. Or. 1, 9 D; JUL. Or. 2, 52 B; LIB. Or. 59, 17; SOCR. 1, 38; SOCR. 2, 25; SOZ. 2, 34, 1; ZOS. 2, 35, 1; AUR. VICT., Caes. 41, 13; AUR. VICT., Epit. 41, 19), hay sin embargo un testimonio contrario, proporcionado por Zósimo (2, 39), según el cual Fl. Jul. Constante era hijo de una concubina de Constantino y no de Fausta, su esposa legítima. La opinión generalmente admitida en la historiografía moderna es que era hijo tanto de Constantino como de Fausta (SEECK, 1901, 948; SEECK, 1898, 42: MOREAU, 1959, 179; BARNES, 1982, 43-45: PLRE I, 220 n. 3), por lo cual se supone que Zósimo en dicho párrafo lo habría confundido con Crispo, quien efectivamente no era hijo de Fl. Max. Fausta, sino de Minervina, que probablemente fue la primera esposa de Constantino (PLRE I, 220 n. 3; BARNES, 1982, 44-45). Hay otra posibilidad, aunque sea difícil de demostrar, y es que Zósimo, en realidad, no estuviera confundiendo a los hijos de Constantino entre sí, sino que simplemente quisiera referirse tanto a los tres hijos de Constantino y Fausta, que fueron los que heredaron el Imperio, como a aquellos que no eran descendientes de Maximiano Hercúleo, aunque esta circunstancia no lo expresara con la claridad suficiente.

La educación recibida por este príncipe es igualmente una cuestión de gran interés, puesto que si llegáramos a conocerla estaríamos en disposición de comprender en qué medida había determinado su posterior programa de gobierno o había influido en su trayectoria política.

Hay constancia de que era una preocupación de Constantino la educación de sus hijos; en este sentido, debe recordarse que hace venir a Lactancio a la Galia encomendándole la instrucción de su hijo Crispo (JER. de vir. ill., 80; PLRE I, 233 n. 4). Pues bien, si es evidente que Constantino se ocupó de la formación de sus hijos, para nosotros también tendrá una gran significación, puesto que el conocimiento que tengamos de ello nos va a permitir calibrar los rasgos y características predominantes que se manifiestan en un individuo que estaba destinado a dirigir y gobernar el Imperio, o al menos una parte de él; por lo tanto, llegar a saber qué aspectos educativos — políticos, económicos, culturales, religiosos, militares, etc.-, configuraron su instrucción interesa en gran medida. El mejor medio que se puede utilizar para estudiar esta cuestión consiste en analizar a los profesores encargados de impartirle su enseñanza. En primer lugar, es necesario citar el testimonio de Libanio, quien afirma que Constante fue educado por profesores famosos (LIB. Or. 3, 283); ello supondría que aquellos intelectuales mejor formados en los diversos campos del conocimiento fueron encargados de proporcionar a Constante una educación adecuada a su rango. Al menos, se conoce el nombre de uno de sus maestros, el de Emilio Magno Arborio (PLRE I, 220 n. 3; PLRE I, 98 n. 4; AUS. Prof. 16, 15; LIB. Or. 59, 31), con quien estudió latín; este individuo era un rhetor y abogado por lo cual no solamente le proporcionaría un conocimiento de la lengua latina y la oratoria, sino que también es de suponer que le ofrecería una formación técnica, desde el punto de vista literario, cultural y jurídico (4). En este aspecto, es interesante

(4) MARROU, $1975^{3}, 353$, opina que «tal era, en efecto, la gran originalidad de la enseñanza latina ofrecer a la ambición de los jóvenes la carrera judicial... en rigor de verdad, el juris prudens es un tipo original: es el hombre que sabe derecho, que conoce a fondo las leyes, las costumbres, las reglas de procedimiento...»; 348: «La enseñanza del rhetor latinus, como la del sophistés griego, tiene por objeto la maestría o el domino del arte oratoria, tal como lo asegura la técnica tradicional, el complejo sistema de reglas, procedimientos y hábitos progresivamente empleados por la escuela griega a partir de la generación de los sofistas». 
destacar el hecho de que Constantino prefiriese mandar llamar a un individuo de la Galia para que se desplazase a la corte imperial de Constantinopla, a pesar de que en esta zona del Imperio existían escuelas y maestros famosos e importantes, lo que era una circunstancia que no escapaba a nadie (5). Los motivos que pudieran haber inducido a Constantino a solicitar la presencia de este personaje, de una familia curial del lejano territorio de la Galia -región más atrasada culturalmente que el Oriente - pudieran muy bien encontrarse en una conciencia por parte del emperador de sus propias raíces occidentales; aparte de que indudablemente conservaba lazos de unión con las gentes de esta zona; sabemos que Emilio Magno Arborio mantenía una amistad con los hermanos de Constantino (AUS. Prof. 17, 9-12; PLRE I, 98 n. 4). Así pues, se puede suponer que Constantino optó por dar a su hijo una imagen real o lo más exacta posible del Occidente imperial y una formación claramente occidental, con el fin de facilitarle posteriormente el gobierno de esta pars, a la que según parece lo había destinado. Aun cuando todas estas consideraciones no sean muy precisas tampoco hay rażón alguna, en mi opinión, que obligue a rechazarlas o no poder aceptarlas, al menos, en sus rasgos generales.

Por otra parte, llama la atención el que este maestro de Constante, Emilio Magno Arborio, no parece que estuviera adscrito de una forma clara a una determinada ideología religiosa (PLRE I, 98 n. 4); por ello, la afirmación que hace Eusebio de que los hijos de Constantino habían sido educados en el temor de Dios (EUS. Vita Const. 4, 51) no puede ser confirmada, por lo menos a partir del testimonio de este maestro. Con todo, esta cuestión la examinaré en otra ocasión, pues lo cierto es que, según parece, éste fue el único hijo de Constantino que se bautizó (OPT. 3, 3; ATHAN. Apol. ad Const. 7), hecho que posiblemente estuviera más en relación con las actitudes que Constante adoptara durante una etapa posterior de su vida que con el período de su educación en la corte oriental. Además Eusebio afirma también que Constante y sus hermanos eran educados en todas las virtudes imperiales. Ahora bien ¿en qué consisten las virtudes de un emperador según Eusebio? Es evidente que solamente es buen emperador aquel que practica las virtudes cristianas, puesto que, como ha indicado recientemente Barnes, Eusebio ha recogido la idea helenística de que la monarquía es el reflejo de un orden sobrenatural, el cual es lógicamente cristiano (BARNES, 1981, 253-271).

Hemos visto que para Constantino la educación de sus hijos era un tema que le preocupaba. Pues bien, de la misma forma se va a advertir que se interesa y ocupa de sus matrimonios. En concreto, en el caso de Constante, va a formalizar su compromiso con Olympia (PLRE I, 642 n. 1), la hija del PPO Fl. Ablabio (PLRE I, 3 n. 4), aunque el matrimonio sea aplazado porque ella no era núbil (AMM. 20, 11, 3; ATHAN. Hist. arr. 69; Vita Olympiadis 2 (ed. A. M. MARLINGREY, SC 13 bis, 1968, 408). Es evidente que interesa considerar las razones que movieron a Constantino para concertar este noviazgo; T. D. Barnes ha observado que «Constantine also arranged dynastic marriages for his sons... And although Constans, whose birth probably fell in 323, was too young for wedlock in his father's lifetime, he was betrothed to Olympias, the daughter of Ablabius. These matches clearly reflects Constantine's intention to leave his sons under the tutelage of advisers he had himself chosen» (BARNES, 1981, 252). Estoy de acuerdo con esta opinión, pues parece claro que Constantino pretendía que sus hijos se encontrasen bajo la tutela de aquellos consejeros que él previamente hubiese seleccionado; por lo tanto, ello bien puede significar que un objetivo de tales uniones consistía en

(5) MARROU, $1975^{3}, 372$, opina que «...en el siglo IV tales escuelas aparecen más o menos por todas partes... se hallan atestiguadas en la Galia por Ausonio en las ciudades de Lyón y Besançón y probablemente en Tolosa; por San Agustín en Cartago y Milán; en Oriente, por Libanio, en Constantinopla, Nicomedia y Nicea y también en Antioquía. Puede admitirse que para aquel entonces toda ciudad, por escasa que fuera su importancia, había tomado a su cargo el sostén de un profesor o varios». 
fortalecer o afianzar los lazos con ciertos sectores de poder. Ahora bien, en el caso de Constante, ¿por qué deseaba el emperador cristiano llegar a una relación tan estrecha, como es la de parentesco, con Fl. Ablabio, un individuo de baja extracción social (LIB. Or.. 42, 23; EUN. V. Soph. 6, 3, 1; PLRE I, 3 n. 4), a quien con esta medida elevaba sociopolíticamente de forma tan extraordinaria? (6). Es de suponer que alguna ventaja presentaría para la familia imperial dicho matrimonio, pero ¿qué tipo de ventaja?; no debemos olvidar que Constante era enviado a Occidente y se le encargaba el mando, cuidado o vigilancia de territorios occidentales; regiones donde no parece que Fl. Ablabio tuviera ningún poder o influencia, puesto que él, que era originario de Creta, prácticamente desarrolló toda su carrera en Oriente (7); además, sus posesiones: tierras y una casa, se encontraban igualmente en la pars orientis (EUN. V. Soph. 6, 3, 10; SYN. Ep. 61). Así pues, creo que estas razones parecen confirmar la idea de que sus contactos y relaciones con la zona occidental no debían revestir importancia alguna. Por otra parte, hay un hecho que debe tenerse en cuenta y es que Fl. Ablabio había sido nombrado PPO de Constancio (8); en consecuencia, se le había concedido un área muy amplia de influencia, puesto que no sólo estaba en relación, eminentemente favorable, con respecto de Constante, sino que también se le había situado muy cercano de Constancio, el próximo emperador de Oriente. Por lo tanto, pudiera ser que con tales medidas Constantino pensara que había asegurado a su hijo menor un apoyo seguro y eficaz por parte de Constancio y de las fuerzas orientales gracias a la presencia y presión de Fl. Ablabio, de tal manera que estarían neutralizadas posibles amenazas, quizá no muy bien precisadas, aunque sí advertidas con anterioridad. Al respecto, se debe recordar un dato proporcionado por Aurelio Víctor (Caes. 41, 14), según el cual la noche que siguió al nombramiento de Constante como césar hizo su aparición una aurora boreal; dicha circunstancia fue interpretada como de mal agüero para su reinado. En definitiva, si se puede aceptar esta explicación, es decir, que en efecto existe una relación entre estos hechos, quizá pudiera entenderse mejor el compromiso establecido entre Constante y Olympia. Otro aspecto de esta cuestión que debe considerarse se refiere a la actitud de Constancio. En efecto, se advierte que los lazos de unión previstos por Constancio entre su propia dinastía y Fl. Ablabio no eran del agrado de Constancio II, quien no estaba dispuesto a hacerse cargo en su totalidad de los compromisos o proyectos de su padre y esto lo demostró de inmediato, ya que tras morir su padre, procedió rápidamente a deponer a su PPO, Fl. Ablabio, y ordenó su ejecución al año siguiente, en el 338 (EUN. V. Soph. 6, 3; ZOS. 2, 40, 3; JER. Chron. s. a. 338). Todo ello corrobora la hipótesis de que Constantino pretendía que Constante conservara apoyos políticos en el Oriente, cerca de Constancio, lo cual se lograría a través de Fl. Ablabio.

El nombramiento de Flavio Julio Constante como césar tuvo lugar en una fecha muy temprana, pues tanto si tenía 13 ó 10 años -en los casos de que hubiera nacido en el 320 o en el 323-, lo cierto es que dicho nombramiento sucedió en el año 333, más exactamente el 25 de diciembre del 333 (AUR. VICT. Caes. 41, 14; Chron. Min. 1, 232235; EUS. Laud. 3; EUS. V. Const. 4, 40; LIB. Or. 3, 283). La elección de esta fecha concreta es muy significativa, con claras implicaciones ideológicas, lo cual ya fue advertido por A. Piganiol, quien destacó el hecho de que el 25 de diciembre era el día en el que tradicionalmente se conmemoraba el nacimiento del sol (PIGANIOL, 1972², 61),

(6) CHASTAGNOL, 1968, 334, opina que Fl. Ablabio era un «hombre nuevo» y que su ascensión al clarisimado había sido por vía de adlectio, seguramente antes de ser nombrado PPO. sul.

(7) Fue oficial del gobernador de Creta, senador de Constantinopla, Vicario de Asiana, PPO y cón-

(8) Hecho que está ampliamente documentado: CTh 11, 27, 1; 16, 2, 6; 13, 5, 5; 16, 8, 2; 5, 9, 1; P. Oxy. 990; P. Lond. 3, p. 232, n. 978; ATHAN. Fest. Ep. 4; CTh 3, 16, 1; 7, 22, 5; ILT 814; EUN. V. Soph. 6, 2, 10-12; AMM. 20, 2, 3; ZOS. 2, 40; PALL. Hist. Laus. 56; cfr. PLRE I, 3 n. 4; BARNES, 1982. 132. 
por lo cual la nueva ideología dominante trataba de imponer, a partir de ahora, la identificación de este día con el nacimiento de Cristo (GARCIA IGLESIAS, 1979, 367; HERZ, 1975; LIEBESCHUETZ, 1979); en este sentido, el acto solemne que representa la proclamación de un nuevo césar podría muy bien ser considerado y mostrado como una especie de «revelación», que en este caso daba a conocer un nuevo defensor de la fe cristiana.

Tras su nombramiento como césar, Constante permaneció aún unos años en Constantinopla, junto a su padre, según el testimonio de Libanio (Or. 59, 42; BARNES, 1982,86 ), hasta el año 335; es probable que se adoptara esta decisión en espera de que el joven hijo de Constantino adquiriese una edad más adecuada para desempeñar ciertas tareas de gobierno.

En efecto, ya en el 335 Constantino procede a llevar a cabo un reparto de áreas de gobierno entre sus herederos, hijos y sobrinos, con adjudicaciones concretas de territorios a cada uno de ellos, tal y como testimonian diversos documentos (9). De tal forma que la opinión generalmente admitida es que a Constantino le correspondió Galia, Hispania y Britania; a Constancio, Asia y Oriente; a Constante, Italia, Africa e Ilírico; a Dalmacio, la ripa Gothica (Tracia y Macedonia), y a Anibaliano le entregó Armenia (PIGANIOL, 1972² , 60-1; STEIN, 1959, 131; JONES, 1973² I, 85; BURCKHARDT, 1982, 323; MOREAU, 1959, 179; SEECK, 1901, 948; PALANQUE, 1944, 47; BARNES, 1981, 252; BARNES, 1982, 198). No obstante, es de interés examinar, en el caso de que sea posible, si este reparto territorial previsto por Constantino se materializa en la realidad con la entrega de la soberanía de tales gobiernos y si, en efecto, cada uno de los césares y en concreto Constante, acuden a hacerse cargo de las responsabilidades que se les habían encomendado, mediante su establecimiento en el territorio. En el caso de que no se diera dicha circunstancia, es decir, que no se hubieran dirigido ni tampoco hubieran residido en estas regiones, se podría concluir que el reparto gubernamental del 335 era únicamente un estudio en el plano teórico y que las fuentes documentales habían informado exclusivamente sobre un proyecto político de Constantino como era el de la herencia imperial. Por otra parte, es necesario observar si la relación de cada uno de los césares con respecto de sus territorios era diferente: el que unos hubieran acudido a ellos y otros no, etc.; ello supondría que la realidad consistía en que se trataba de una prefiguración de lo que exactamente se pretendía fueran los gobiernos imperiales posteriores a Constantino.

En primer lugar, se dispone de un dato y es que a la muerte de Constantino, como se verá, ninguno de sus presuntos herederos se encontraba en Constantinopla; este hecho puede interpretarse precisamente como una muestra de que residían en las regiones que el monarca cristiano les había encomendado en el 335. En efecto, si nos detenemos en comprobar documentalmente el lugar de residencia de cada uno de los césares observamos que Constantino II se encuentra en Tréveris (ATHAN., Apol. Sec. 87, 4); Constancio reside en Antioquía (ZON. 13, 4); Dalmacio estaba en Naissus (CJ 5, 17, 7); mientras que Anibaliano se había establecido en Cesarea de Capadocia (CHRON. Pasch. 531, Bonn; PIGANIOL, 1972 2 , 61-2); con respecto de Constante, o bien se admite que «nous ignorons où il réside» (PIGANIOL, 1972², 81-2), o bien se supone que en ese momento se encontraba en Milán (BARNES, 1982, 86); esta alternativa no es posible resolverla en la actualidad debido al estado de la documentación que silencia totalmente la situación del hijo menor de Constantino en este período de tiempo (10); sin

(9) BARNES, 1982, 198, opina que «Eusebius, VC 4. 51, 1, deliberately confusing the divisions of 335 and 337». Anon. Val. 35; AUR. VICT. Epit. 41, 20; EUS. V. Const. 4, 51, 1.

(10) BARNES, 1980, 160, opina que «The period after the death of Constantine on 22 May 337 is among the most obscure in Roman imperial history". 
embargo, una prueba de que probablemente su estancia la había fijado en Milán o en definitiva en Italia, podía proceder de la evidencia prosopográfica proporcionada por L. Papio Pacatiano (PLRE I, 656 n. 2), quien fue PPO desde el 332 al 337 y que, sin duda, se encontraba en Italia en el 335 (CTh. 8, 9, 1); por lo cual, este PPO adscrito a Constante le acompañaba mientras que el césar residía en la Península.

En definitiva, se puede concluir que la documentación apoya la idea de que Constante - como el resto de los césares-, ya en el 337, se había hecho cargo del gobierno de los territorios que Constantino le había adjudicado en el reparto imperial del 335 . Así pues, si esto se acepta, se advierte que la idea tradicional expresada por A. Piganiol: «Les jalousies entre les fils et les neveux de Constantin expliquent que le partage préparé per Constantin en 335 ne fut pas réalisé» (PIGANIOL, 1972², 82; STEIN, 1959, 131, 484) no puede ser acertada, puesto que si bien el conflicto que surge en el 337 tras la muerte del emperador se debe a distintos condicionamientos, entre los que efectivamente hay que contar con los de las competencias y tensiones entre los diferentes herederos, lo que no creo que sea correcto es considerar que los tumultos tras el 22 de mayo del 337 son una prueba de que no se había puesto en práctica el reparto del 335. En mi opinión, sucede lo contrario, creo que se habían adjudicado los gobiernos territoriales en el 335 a cada uno de los césares; por lo que naturalmente cada uno de ellos se había establecido en su región y se había hecho cargo de su administración. En consecuencia, era precisamente esta circunstancia lo que suponía una grave amenaza para el objetivo de lograr la hegemonía estrictamente constantiniana en todo el Imperio y lo que provocó la masacre del 337.

Como se sabe, la muerte de Constantino tiene lugar el 22 de mayo del 337. Este acontecimiento no parece provocar en el Imperio ningún vacío de poder y en el conjunto territorial del Estado no se manifiesta ningún signo de inestabilidad. Ello viene a confirmar lo que anteriormente se había supuesto: que cada uno de los césares estaba ya instalado y en el ejercicio del gobierno de las regiones que les habían correspondido en el reparto del 335. Por lo tanto, la continuidad en el mando estaba asegurada; además, es muy probable que la falta de alborotos se debiese a la idea que pudieran tener los ciudadanos romanos de que la sucesión hereditaria había sido llevada a cabo antes de que se produjera el fallecimiento de Constantino; en consecuencia, para ellos la suprema autoridad de éste como único emperador del Imperio, durante esta etapa de tiempo, bien pudo ser exclusivamente un hecho teórico, puesto que la realidad inmediata era que el gobierno de cada uno de los territorios que componían el Estado se encontraba en manos de sus hijos y sobrinos. Es muy posible que esta hipótesis tenga más fuerza respecto de Occidente debido a la especial circunstancia que suponía su lejanía del poder central. Por todo ello, las distintas fuerzas sociopolíticas debían considerar que no se habia producido ruptura en la continuidad del poder imperial en razón a que un césar, acompañado por un equipo de gobierno, hacía tiempo que estaba instalado en estos territorios y dirigía su administración con libertad. En definitiva, la desaparición del lejano Jefe del Estado no podía provocar un trastorno importante en la relación de fuerzas imperantes.

Ahora bien, la muerte de Constantino sí provocó una conmoción que se manifestó en la más elevada área del poder: entre los herederos. En efecto, la crisis estalla en el mismo aparato gubernamental y creo que no participan de ella el resto de las fuerzas sociopolíticas.

Se hace necesaria una explicación más detenida de este fenómeno. En primer lugar, considero conveniente tomar este conflicto como una crisis «sostenida» por los hijos de Constantino, puesto que ellos son los responsables del mantenimiento durante los meses posteriores al 22 de mayo de una situación cuando menos extraña y sin lugar a dudas confusa, al no proclamarse augustos; esto significaba que el Estado romano se encontraba acéfalo, aunque se continuara legislando en nombre del emperador muerto (CTh 
13, 4, 2; PIGANIOL, $1972^{2}$, 82: VOGLER, 1979, 16 n. 14). El sentido de este estado de cosas puede entenderse ahora con cierta claridad. Los hijos de Constantino perseguían un objetivo: ser ellos los únicos dueños de la inmensa herencia legada por su padre; para ello, precisaban disponer de cierto tiempo, un compás de espera en el que seguramente organizarían sus fuerzas y consolidarían sus posiciones. Es evidente que para lograr la total hegemonía y un completo dominio del Estado no había más alternativa que la de eliminar a sus rivales, los parientes que el emperador fallecido había designado también como legítimos herederos del Imperio. Por lo tanto, mi opinión es que los trágicos sucesos del $\mathbf{3 3 7}$ hay que entenderlos y explicarlos como una consecuencia de los conflictos y tensiones existentes en el mismo aparato gubernamental.

No obstante, se ha señalado en repetidas ocasiones que el inmediato responsable de estos acontecimientos fue el ejército (EUS. Vita Const. 4, 69, 2; ZOS. 2, 39-40; JUL. Ep. ad Atha. 270 C; ATHAN. Hist. Arian. 19; JUL. Pan. 5, 3; BURCKHARDT, 1982, 326-7; SEECK, 1901, 948; STEIN, 1959, 131; PIGANIOL, 1972², 83; OLIVETTI, 1915, 67-79; BARNES, 1981, 262; CHASTAGNOL, 1969, 24; CHASTAGNOL, 1982, 131-2; REMONDON, 1973, 75). En efecto, se ha sostenido que esta institución era partidaria de que la sucesión estuviese reducida a la línea dinástica directa: los hijos. Por esta razón debió tramar y llevar a cabo la masacre de gran parte de la familia constantiniana; igualmente, se indica que Constancio II participó de dicha responsabilidad, puesto que no intervino para evitar los asesinatos.

No creo que esta explicación sea la acertada, puesto que hace únicamente al ejército, como institución, directo responsable de esta acción y según parece se trata del ejército de Constancio, puesto que él es el único a quien se le menciona en relación con estos hechos. La objeción inmediata que se me ocurre es que si esto hubiera sido así lo lógico sería que toda la acción hubiera ido dirigida a consolidar exclusivamente el poder de Constancio, quien no desearía compartirlo con nadie, por lo que también hubieran sido eliminados sus hermanos. Sin embargo, nada de eso ocurrió; lo que hace que me reafirme en la idea de que la masacre no fue un acto urdido y programado por el ejército, sino que fue una actuación realizada por los soldados de Constancio, quien sin lugar a dudas estaba en connivencia con Constantino y Constante. En definitiva, el complot fue obra de los hijos de Constantino el Grande.

Por otra parte, se hace preciso tener en cuenta la explicación que sobre estos acontecimientos ha dado recientemente T. D. Barnes $(1981,262)$. El interpreta, por las palabras de Eutropio: sinente potius quam iubente (EUTR. Brev. 10, 9, 1), que la voluntad imperial no intervino de forma alguna y que estos hechos fueron causados, dirigidos y realizados por dos generales del ejército: Fl. Urso (PLRE I, 984 n. 4; BARNES, 1974, 226-7) y Fl. Polemio (PLRE I, 710 n. 4), que luego en el 338 fueron designados cónsules, lo que provocó el desplazamiento del cónsul nombrado para ese año con anterioridad, Q. Fl. Egnatio Lolliano Mavortio (PLRE I, 512 n. 5).

De hecho T. D. Barnes ofrece una visión simplista de este problema, sin que en él se den implicaciones de mayor envergadura. Por mi parte, opino que en las palabras de Eutropio debe verse precisamente una acusación contra el poder imperial, ya que si afirma que éste ha permitido que se realice la acción, ello es como decir que hay un conocimiento y por lo tanto una participación; además, conocemos un dato que merece ser recordado, y es que los dos oficiales del ejército, autores de los crímenes, van a ser recompensados, y es evidente que siempre se premia a aquellos que han cumplido con las órdenes recibidas. Así pues, aunque no comparto la hipótesis de T. D. Barnes en cuanto a que libera de responsabilidad a los hijos de Constantino, lo cierto es que su explicación no afecta negativamente a una parte de mi suposición, la de que la actuación de Fl. Urso y Fl. Polemio no implica necesariamente que éstos fueran las cabezas visibles de una conjura militar. En efecto, sostengo que estos generales no pueden ser considerados como los representantes, ni tan siquiera, de una facción del ejército que pusiese de ma- 
nifiesto, con la masacre de los familiares de Constantino, un proyecto político o una alternativa de poder; ellos únicamente han realizado un acto, instigado y favorablemente consentido por una autoridad superior, su césar (11).

Sea como sea, lo cierto es que la desaparición de gran parte de los miembros colaterales de la familia constantiniana significó que los hijos de Constantino contasen con una total libertad para llevar a cabo un reparto territorial según sus propios intereses. En primer lugar, se constituyen como un nuevo colegio imperial, pues el 9 de septiembre los tres hermanos se proclaman augustos, lo cual es confirmado por el Senado de Roma (EUS. Vita Const. 4, 68; CHRON. MIN. I, 235; PALANQUE, 1944, 55; DEMOUGEOT, 1979, 243; BARNES, 1981, 252). A continuación, celebran una entrevista en Viminacium (12), donde acuerdan una nueva distribución del Imperio, la cual presenta bastantes dificultades para ser establecida en la actualidad a pesar de que se fundamenta y reposa en la del 335 (13). En efecto, está claro que cada uno de los hermanos conserva el gobierno de las regiones que su padre les había asignado. Así pues, Constantino mantiene bajo su autoridad Galia, Britania e Hispania, sin que haya noticias de que aumente su área de gobierno; Constancio domina ahora todo Oriente y toda Asia Menor; mientras que Constante tiene en su poder Panonia, Italia, Africa y se hace con Macedonia. Por ello, el problema es muy concreto, pues sólo es conflictiva la adscripción de la diócesis de Tracia debido a la ambigüedad que presentan los textos antiguos (PHILOST. HE 3, 1. ${ }^{\text {; }}$ ZON. 13, 5; ZOS. 2, 39; AUR. VICT., Epit. 41, 20), los cuales permiten dos interpretaciones opuestas: la que dio E. Stein, seguido por la mayoría de los historiadores, que consiste en considerar que Tracia correspondió a Constancio (STEIN, 1959, 132; JONES, 1973², 112-115; PETIT, 1974, 599; BARNES, 1981, 252, 262; BARNES, 1982, 198-199), o bien la propuesta por O. Seeck, quien supuso que fue entregada a Constante, quien la cedió a Constancio en el 339, una vez que inició la guerra contra su hermano mayor Constantino (SEECK, 1895-1921, IV, 42, 46, 397, 400; SEECK, 1901, 949; PALANQUE, 1944, 57 n. 4). Recientemente C. Vogler, en su fundamental estudio sobre Constancio II, ha tratado igualmente el tema; pretendió resolver la cuestión por la información que diera el Código de Teodosio y comprobó que ello no ofrecía ninguna posibilidad, por lo que concluyó que ignoramos cuál es la atribución de Constantinopla y Tracia hasta el año 340 (VOGLER, 1979, 16 n. 14). Por mi parte, he considerado que sería necesario recurrir a otro tipo de documentación: la prosopográfica, con la suposición de que el conocimiento que obtuviera de los magistrados de esta región, en el trienio 337-340, me permitiría determinar a qué emperador había correspondido. Desgraciadamente la evidencia prosopográfica, en esta ocasión es muy escasa (PLRE I, Fasti, 1085 ss.), ya que solamente tenemos los nombres de dos individuos que desempeñaron una función del Estado en esta región durante esas fechas. En primer lugar, tenemos a

(11) BARNES, 1981, 398 n. 17, reconoce que no sabemos prácticamente nada de Fl. Urso y Fl. Polemio en fechas anteriores y posteriores al 337-338. Esto puede interpretarse en el sentido de que no eran personajes importantes y que no desempeñaban ningún papel de valor en la política del gobierno imperial; lo cierto es que su papel se había reducido exclusivamente al jugado en favor de los intereses de su césar.

(12) La fecha de esta reunión no se ha podido determinar con exactitud; pudo realizarse en el mismo año 337 o bien en el 338. ATHAN. Apol. Sec. 87, 4; Frag. Vat. 35; JUL. Or. 1, 19 A; LIB. Or. 3 , 297 ; cfr. CHASTAGNOL, 1982, 132; SAYAS, 1981, 29; MOREAU, 1959, 179; SEECK, 1901, 949; JONES, 19732, 112-115; BARNES, 1981, 252, 262; BARNES, 1980, 160; PIGANIOL, 1972 2, 82; DEMOUGEOT, 1979, 243.

(13) Hay diversos testimonios documentales que dan lugar a diferentes interpretaciones en la actualidad. Anon. Val. 35; ATHAN. Apol. Sec. 87, 4; Chron. Min. 1, 235; AUR. VICT. Epit. 41, 20; EUS. V. Const. 4, 51; 4, 68; EUTRO. Brev. 10, 6; JUL. Or. 1, 19 A, 20 B; LIB. Or. 3, 297; Pass. S. Artemii 8 = PHILOST. HE 3, 1; ZON. 13, 5, 1; ZOS. 2, 39; 2, 41; BARNES, 1982, 198-199; BARNES, 1981, 252; JONES, 1973 2 , 112-115; SEECK, 1901, 949; DEMOUGEOT, 1979, 243; BARNES, 1980, 160; VOGLER, 1979, 14 ss.; CHASTAGNOL, 1982, 132; SAYAS, 1981, 29; STEIN, 1959, 131-2; PIGANIOL, 1972 2, 83; PETIT, 1974, 599. 
Fl. Palladio (PLRE I, 661 n. 16 y n. 17; JONES, 1974, 270; GARRIDO, 1984). Si se pudiera determinar fehacientemente el año exacto dentro del período en cuestión, en el que ocupó su cargo, entonces el hecho de que la carrera administrativa de Fl. Palladio muestra que debió a todas luces ser un hombre de confianza de Constancio (GARRIDO, 1984), apoyaría la suposición de que fue este emperador quien administró dicha diócesis. Con todo, como no es posible establecer exactamente dicho año, carece de fundamento concluir la posible administración de este territorio por parte de Constancio.

En segundo lugar, conocemos a Sappo (PLRE I, 803), quien fue dux de Scytia, igualmente entre el 337 y el 340 . Por ello, los autores de la Prosopografía han supuesto que estuvo bajo la autoridad de Constantino II; sin embargo, dicha hipótesis es totalmente gratuita, porque la inscripción por la que se le conoce no ofrece ningún dato que la apoye (CIL III, 12483 = ILS 724). Al contrario, creo que en ella se ofrece una información, respecto de un hecho militar, que puede interpretarse en favor de Constante. En el caso de que esta interpretación fuera acertada se concluiría que Sappo fue un $d u x$ nombrado por Constante para que cumpliera su función en un territorio que estaba bajo su autoridad.

En efecto, en dicho epígrafe se da el título de Sarmaticus a Constancio y a Constante; ello significa que ambos llevaron a cabo una expedición victoriosa contra los Sármatas en el año 337 (BARNES, 1981, 262; BARNES, 1980, 162; BARNES, 1976, 154; THOMPSON, 1956, 372-381). Por lo tanto, deduzco como probable el que fuera Constante el responsable de haber organizado tal campaña en una gran zona incluida en su área de poder y Constancio acudió únicamente como fuerza de apoyo.

Las razones en las que baso mi suposición son tanto la premura con la que se realiza esta acción militar, como la misma participación de Constante en ella.

En mi opinión estos dos hechos se entienden si se admite que es Constante quien domina la Tracia, pues en tal caso es comprensible que desee iniciar rápidamente las hostilidades contra un peligro que amenaza o puede amenazar su territorio; lógicamente su participación se debe a que interviene en defensa de una zona que está directamente bajo su autoridad. En este mismo supuesto no es difícil explicar la participación de Constancio, porque sabemos que le interesaba en gran medida la salvaguarda de esta región de la Tracia, territorio sobre el que pretende establecer su dominio, como se demuestra años después.

Por otra parte, si aceptamos la hipótesis de que Constancio dominaba la Tracia en estas fechas, resulta difícil de explicar la rapidez con la que se comenzó la expedición sármata, pues considero como más probable que hubiese esperado a que finalizara la campaña proyectada en Oriente, la cual llevó a cabo en el 338 (BARNES, 1980, 162; BARNES, 1976, 154). Además, si la primera acción bélica hubiera obedecido a motivos muy graves, Constancio no habría emprendido una nueva campaña dejando a otro emperador la responsabilidad de dirigir la defensa de su propio territorio. Ahora bien, si la acción en Tracia no se debía a un peligro muy serio, sino únicamente consistía en una demostración de fuerza o en un acto de represalia, en tal caso no hubiera sido necesaria la participación de las fuerzas de Constante.

En definitiva, sostengo que la actuación conjunta de los dos emperadores en la expedición de Tracia contra los sármatas en el 337, se explica más fácilmente si se reconoce que esta diócesis se encuentra en esas fechas bajo la autoridad de Constante.

En conclusión, creo que, en el estado actual de nuestros conocimientos, es preferible mantener la teoría de que fue Constante quien obtuvo el dominio de la diócesis de Tracia en el 337.

Incluido en el límite cronológico del trienio 337-340 hay un tema que ha resultado siempre polémico en la historiografía moderna. Me refiero a la supuesta supremacía de Constantino II en el colegio imperial formado con sus hermanos y en concreto a la tute- 
la ejercida por éste sobre el menor Constante, al cual incluso se le ha llegado a calificar como un augusto «sans terre» (PALANQUE, 1944, 58). La documentación que ha servido de base para la formulación de esta hipótesis es variada: inscripciones, leyes y textos literarios (CTh 12, 1, 28; ZOS. 2, 39, 2; LIB. Or. 59, 46; AUR. VICT. Epit. 41, 20; ANON. VAL. 35; CIL II 474 = ILS 130; AE 1927, 165; MITFORD, 1939; 187).

Por mi parte pretendo demostrar que la supuesta preeminencia de Constantino II se dio en efecto; pero únicamente con carácter honorífico, sin que en la realidad aquélla se correspondiera con una tutela o una soberanía sobre alguno de sus hermanos o respecto de sus territorios.

El primero que expuso la teoría de que el territorio occidental no se había dividido entre Constantino II y Constante fue O. Seeck, quien se basó en los testimonios de Zósimo, Anónimo Valesiano y Aurelio Víctor, y supuso que el primogénito de Constantino el Grande había ejercido una tutela sobre su hermano menor (SEECK, 1895-1921, IV, 41-2, 397).

La crítica a la teoría de O. Seeck fue presentada por J. R. Palanque, quien afirmó rotundamente que «cette solution ne résiste pas à l'examen». Este investigador nos obliga a recordar que los textos mencionados se refieren a la distribución territorial que se realizó en vida de Constantino entre sus hijos y sobrinos; por lo cual, dichos documentos no tienen relación con los acontecimientos sucedidos, ni con los repartos nuevamente practicados, después de la muerte de Constantino, y una vez que sus hijos han eliminado a sus parientes (PALANQUE, 1944, 56-58). Así pues, la conclusión propuesta por el sabio francés es que en el 9 de septiembre del 337 no se llevó a cabo un reparto territorial más que entre dos hermanos: Constantino II y Constancio II, mientras que Constante quedaría con el título de augusto, pero «sans terre»; por lo cual, la posterior rebelión de éste tenía por objetivo la usurpación de la soberanía de Constantino II en todo Occidente (PALANQUE, 1944, 58).

En mi opinión, considero muy acertada la crítica de J. R. Palanque a las teorías de $\mathrm{O}$. Seeck, pero su deducción posterior me parece carente de fundamento, debido a que no cuenta realmente con ningún apoyo documental. Además, como ya ha señalado C. Vogler, en el caso de que se admita la supremacía de Constantino II sobre Constante se hace preciso responder satisfactoriamente a una interrogante: «... a-t-on le droit de supposer que Constant ait été privé des prérogatives afferentes à son titre d'Auguste?» (VOGLER, 1979, 16 n. 14); por mi parte, lo creo muy improbable.

En definitiva, no hay base literaria alguna que permita sostener que Constante estaba bajo la autoridad de su hermano mayor Constantino II y que, por lo tanto, no ejercía sus legítimos poderes de augusto sobre los territorios que le habían correspondido. Ahora bien, lo que sí se puede aceptar es que en el colegio imperial se le reconocía a Constantino II una supremacía honorífica por ser el mayor, y ello se reflejaba en sus títulos y en la preeminencia del lugar que ocupaba en los monumentos.

Por otra parte, difiero de la suposición de J. R. Palanque de que la causa de la guerra entre ambos hermanos fue debida al intento del menor de usurpar el poder en Occidente. Considero por el contrario que la provocación procedió de Constantino II, quien pretendía hacer efectiva una supremacía que sólo era reconocida en el plano honorífico.

Las inscripciones son otro tipo de documentación utilizado en favor de la tesis de la tutela de Constantino II sobre Constante. En concreto se trata de dos epígrafes: uno procedente de Mérida y otro de Chipre (AE, 1927, 165; CHASTAGNOL, 1976, 260 ss.; MITFORD, 1939, 187; PIGANIOL, 1972² 83 n. 3); en ambos se puede leer el título de maximus atribuido a Constantino II; en cambio, Constancio II y Constante llevan únicamente el título de victor. Estas diferencias en la titulación han hecho pensar a prestigiosos historiadores que la tesis tradicional era acertada.

No obstante, creo que tampoco este testimonio apoya dicha interpretación. Al con- 
trario, sirve más bien para demostrar la suposición que he propuesto más arriba: a Constantino II le correspondió únicamente una supremacía honorífica.

En efecto, es preferible pensar que a Constantino II, por el hecho de ser el augusto de mayor edad, le corresponde un título de mayor honor: el de maximus; pero ello no implica necesariamente que tuviera más prerrogativas de poder o autoridad que sus hermanos y desde luego no contaba con ninguna soberanía sobre los territorios gobernados por los otros emperadores.

Por otra parte, aun en el caso de que fuera cierto que tenía alguna supremacía, debo luego entender que ésta debía ejercerla por igual sobre los demás augustos y no sobre uno solo de ellos; además, su tutoría se extendería sobre todos los territorios y no estaría limitada a una parte de ellos. Sin embargo, nadie duda que Constantino II no contaba con ninguna autoridad sobre Constancio II y Oriente; por lo tanto, si el título de maximus no presupone que Constantino dominara a Constancio, que sólo lleva el título de victor, habrá que considerar que el mismo tipo de relación se habría establecido entre Constantino y Constante, pues se repiten las mismas condiciones.

Las mismas objeciones se le pueden presentar a otro argumento de O. Seeck, fundamentado en un medallón del año 338, en el que figuran los tres hermanos, pero únicamente Constantino II lleva el nimbo (SEECK, 1894, 44; PIGANIOL, 1972², 83 n. 3; TOYNBEE, 1944, 199; BARNES, 1981, 399 n. 25; BARNES, 1982, 45; VOGLER, $1979,16 \mathrm{n} .14)$. Creo que precisamente ello se debe a que los otros dos augustos reconocen en el mayor una preeminencia de tipo honorífico. Ahora bien, en el caso de que aceptáramos que ello es la representación de una tutoría sobre Constante, entonces necesariamente tiene que representar también una tutoría sobre Constancio; como tal interpretación no parece que se pueda mantener de momento, tampoco se debe admitir en el otro caso. Además, no se debe olvidar la crítica de $\mathbf{M}$. Thirion, quien asegura que la tesis de $\mathrm{O}$. Seeck se basa en una apreciación errónea de las monedas conmemorativas que fueron emitidas después del 9 de septiembre del 337 (THIRION, 1965, 8 ss.).

Por último, la tesis tradicional ha presentado también como dato a su favor la ley CTh 12, 1, 27 enviada por Constantino II desde Tréveris al procónsul de Africa Aurelio Celsino (PLRE I, 192 n. 4; GARRIDO, 1983, 924, 1003), el 8 de enero del 339; por ella se ha afirmado que el acto de legislar le correspondía exclusivamente a Constantino II, porque él era el único emperador de Occidente (BARNES, 1981, 399 n. 1; BARNES, 1982, 200).

En mi opinión, esta interpretación debe ser reconsiderada, pues hay una explicación más satisfactoria de por qué Constantino II dio una ley para un territorio incluido en la jurisdicción de Constante. Puede plantearse que muy posiblemente en enero del 339 se encontraba aún Constante en la campaña que había emprendido contra los sármatas en el 337 ó 338 (ILS 724; ZON. 13, 5, 9; BARNES, 1980, 164; BARNES, 1982, 86; SEECK, 1919, 187; cf. supra); por lo tanto, durante su ausencia, Constantino II se habría visto obligado a tomar una decisión de gobierno que se hacía precisa.

Por otra parte, J. R. Palanque propuso, en su fundamental trabajo del año 1944, un nuevo método por el cual se podría comprobar si un emperador ejercía una verdadera soberanía. Según él era necesario, en primer lugar, que se hubieran conservado en el Código constituciones indudablemente promulgadas por dicho augusto; una segunda condición consistía en que el emperador tuviera ministros: un magister officiorum, un quaestor palatii, un comes rei privatae y un comes largitionum; por último, que hubiera nombrado magistrados para el desempeño de ciertas funciones administrativas. En definitiva, él concluía que «l'existence d'une cour ou d'une législation indépendantes est donc nécessaire pour nous permettre en toute rigueur d'affirmer la souveraineté d'un Auguste du Bas-Empire» (PALANQUE, 1944, 49).

En mi opinión, es preciso llevar a cabo una comprobación de que las condiciones exigidas por J. R. PALANQUE se dan en el gobierno de Constante durante el trienio 
337-340; de forma que se confirme la idea de que el hijo menor de Constantino el Grande ejerció su soberanía desde el primer momento, al igual que sus hermanos.

Con respecto a la legislación hay que advertir que nos estamos moviendo en un período de tiempo muy corto, motivo por el cual no debe extrañar que el volumen de leyes conservadas no sea muy elevado; además, es útil recordar la observación de C. Vogler en cuanto a que las constituciones recogidas en el Código presentan frecuentemente una gran dificultad a la hora de intentar establecer su procedencia; especialmente ello afecta a la legislación anterior al 350; en realidad, C. Vogler sospecha que la atribución de las leyes del trienio 337-340 quedará como un problema insoluble (VOGLER, 1979, 14-16).

No obstante, destacan algunas leyes inscritas en tales límites cronológicos y que según parece se pueden atribuir a Constante: CTh 11, 36, 4 (29 agosto 339), CTh 12, 1, 26 (1 noviembre 338), CTh 12, 1, 27 (8 enero 339), CTh 12, 1, 28 (26 noviembre 339) (BARNES, 1980, 164-166; SEECK, 1919, 184 ss.). En consecuencia, la primera exigencia de J. R. Palanque se cumple.

Con respecto a las otras dos condiciones impuestas sólo hay un método válido que permite su comprobación: el prosopográfico.

En efecto, gracias a la evidencia prosopográfica se aprecia un hecho indiscutible: el que no se conoce ningún magister officiorum, quastor palatii, comes rei privatae ni comes largitionum de ninguno de los tres hermanos durante este trienio, y los que se registran de Constante y Constancio II son únicamente de una fecha posterior al 340 (PLRE I, Fasti 1060-1064).

Por lo tanto, opino que la circunstancia de que no nos haya llegado el nombre de ningún «ministro» de Constante, perteneciente a las fechas 337-340, no puede considerarse como un argumento decisivo en contra de la soberanía de este augusto, y ello por dos razones: la primera, es porque tampoco ha llegado el nombre de ninguno de los ministros de Constantino II y nadie duda de su autoridad; incluso se le llega a adjudicar un poder superior que al resto de los emperadores. La segunda razón es que con Constancio II se repite la misma situación que la de Constante; los funcionarios que se le conocen ejercen el cargo en fechas posteriores al $340 \mathrm{y}$, sin embargo, nadie duda que cuenta con una soberanía efectiva desde el 337.

Seguidamente se ve que el método prosopográfico vuelve a ser determinado en relación a la última condición de $\mathbf{J}$. R. Palanque, la necesidad de que un augusto nombre magistrados para que pueda ser considerado soberano. Pues bien, puedo ciertamente demostrar que tal caso se da, puesto que se registran once nombres de funcionarios nombrados por Constante entre el 337 y el 340: L. Turcio Aproniano (PLRE I, 88 n. 9), Aco Catullino Philomatio (PLRE I, 187 n. 3), Eutherio (PLRE I, 314 n. 1), Munatio Gentiano (PLRE I, 391 n. 2), Maecilio Hilariano (PLRE I, 433 n. 5), Lucio Crepereio Madaliano (PLRE I, 530), Martiniano (PLRE I, 563 n. 3), M. Maecio Memmio Furio Baburio Caeciliano Plácido (PLRE I, 705 n. 2), L. Aradio Valerio Próculo Populonio (PLRE I, 747 n. 11), Fl. Julio Rufino Sarmentio (PLRE I, 804), Anónimo (PLRE I, 1014 n. 51).

En conclusión, creo haber demostrado que se le puede atribuir a Constante una corte y una legislación desde el 337. De ello se deduce, según las condiciones impuestas por J. R. Palanque, que el hijo menor de Constantino obtuvo plenos poderes soberanos desde aquella fecha, al igual que sus hermanos.

Una vez comprobado que Constante no se encontraba bajo la tutela de su hermano mayor Constantino II, debe observarse el conflicto que estalla entre ambos bajo una perspectiva diferente a como se ha venido haciendo hasta ahora. En efecto, el enfrenta- 
miento armado se desencadena en el 340 (14). Se ha interpretado que ello fue debido a una rebelión de Constante, quien quería librarse de la tutela de su hermano (15); sin embargo, el fundamento de esta suposición ha sido rebatido más arriba, por lo cual, ella misma queda desmentida. Lo cierto es que la provocación procedió de Constantino II (BARNES, 1980, 162 n. 9; BARNES, 1981, 263) porque no se conformó con ocupar una posición superior exclusivamente honorífica, sino que deseó hacer efectiva dicha preeminencia; es decir, quiso implantar su autoridad en todo Occidente; por ello, Constantino II invadió Italia, territorio de su hermano, lo cual es otro dato a favor de que la responsabilidad fue de Constantino y no de Constante, pues éste ni siquiera se encontraba allí, sino que estaba en Naiso (16) y la defensa se improvisó con las fuerzas que estaban allí estacionadas. A partir de ese momento el desarrollo de los acontecimientos es bien conocido; el ejército fiel a Constante hace frente al invasor, Constantino II, quien muere en Aquileya; cuando Constante llega a Italia todo había concluido (17).

(14) Son diversas las fuentes que informan sobre este hecho: AUR. VICT. Epit. 41, 21; AUR. VICT Caes. 41, 22; Chron. Min. 1, 236; EUTR. Brev. 10, 9, 2-4; HIER. Chron. 2356; JUL. Or. 2, 94 B; PHILOST. $H E ~ 3,1$ a; SOCR. $H E$ 2, 5; SOZ. 3, 2; ZON. 13, 5, 5-9; ZOS. 2, 41.

(15) Opinión expuesta en ZOS. 2, 41; cfr. PALANQUE, 1944, 58 ss.; MOREAU, 1959, 179; SEECK, 1901, 949; PIGANIOL, $1972^{2}, 84$.

(16) Hay abundantes testimonios de ello: CTh $2,6,5 ; 10,10,5 ; 10,15,3 ; 12,1,29 ; 12,9,29 ; \mathrm{ZON}$. $13,5,9$.

(17) Véase nota 14; cfr. BARNES, 1982, 86-87. 


\section{FUENTES}

AMMIANUS MARCELLINUS, 1978, ed. W. Seyfarth, Teubner. L'ANNÉ ÉPIGRAPHIQUE.

ANONYMUS VALESIANUS, 1874, ed. V. Gardthausen, Teubner.

ATHANASIO, Patrologia Graeca, vols. 25-26.

AUGUSTIN, contra Cresconium, ed. Petschenig, CSEL, 52.

AURELIO VICTOR, 1961, de Caesaribus, ed. Pichlmayer, Teubner.

AUSONIO, 1968, Works, ed. E. White, Londres.

CHRON. MIN., 1892, Chronica Minora, Monumenta Germanicae Historica, AA 9, ed. Th. Mommsen, Berlín.

CHRONICON PASCHALE, 1832, ed. L. Dindorf, Bonn.

CODEX IUSTINIANUS, 1967 (reimp.), ed. P. Krüger, Berlín.

CODEX THEODOSIANUS, 1971 (reimp.), ed. Th. Mommsen, Berlín.

CORPUS INSCRIPTIONUM LATINARUM, 1864-1943, ed. W. de Gruyter, Berlín.

EUNAPIO, 1894, Vitae Sophistarum, ed. Boissonade.

EUSEBIO, 1975, de vita Constantini, ed. F. Winkelmann, GCS, Berlín. Laudes Constantini, PG, vol. 20.

EUTROPIO, 1965, Breviarium ab urbe condita, ed. B. Calvi, Turín.

FIRMICO MATERNO, 897-1913, ed. W. Kroll - F. Skutsch, Teubner.

FRAGMENTA VATICANA, FIR ${ }^{2}$ II, 461-540.

HIERONIMUS, 1965, Eusebius Werke 7: Die Chronik des Hieronymus, ed. R. Helm, GCS 47, Berlín., 1924 , de viris illustribus, ed. Herding.

HILARIO, 1916, ed. Feder, CSEL, t. LXV.

INSCRIPTIONES LATINAE SELECTAE, 1892-1916, ed. H. Dessau, Berlín.

INSCRIPTIONS LATINES DE LA TUNISIE, JUAN CRISOSTOMO, Patrologia Graeca. París.

JULIANO, 1924-1932, Oeuvres Complètes, ed. J. Bidez, París.

LIBANIO, 1903-1922, Orationes, ed. R. Foerster, Teubner.

MALALAS, 1831, Chronographia, ed. Dindorf, Bonn.

MANSI, 1960, Sacrorum Conciliorum nova et amplissima collectio, Graz.

OPTATUS, 1893, ed. K. Ziwsa, CSEL 26, Viena.

P. LOND, 1893-1917, Greek Papyri in the British Museum, ed. F. G. Kenyon. H. I. Bell, Londres.

THE OXYRHYNCHUS PAPYRI, 1898, ed. B. P. Grenfell y otros, Londres.

PALlADIO, 1928, Historia Lausiaca, PG, ed. Norton.

PANEGYRICI LATINI, 1952, ed. Galletier, París.

PHILOSTORGO, 1972, Kirchengeschichte, ed. Bidez (2. a ed. F. Winkelmann) GCS, Berlín.

ROMAN IMPERIAL COINAGE, 1920, Londres.

SOCRATES, 1853, Historia eclesiástica, ed. Hussey, Oxford.

SOZOMENO, Historia Eclesiástica, PG 67, 843-1630.

SYMMACO, 1883, Relationes, MGH, AA VI.

SYNESIO, 1893, Epistulae, ed. Hercher.

THEODORETO, 1911, Historia Ecclesiastica, ed. Parmentier, Berlín.

VITA OL YMPIADIS, 1968, ed. A. M. Marlingrey, $S C, 13$ bis.

ZONARAS, 1868-1875, Epitome Historiarum, es. L. Dindorf, Teubner.

ZOSIMO, 1971-1979, Histoire Nouvelle, ed. F. Paschoud, París. 
ARNHEIM, M. T. W., 1982. The Senatorial aristocracy of the Later Roman Empire. Oxford.

BARNES, T. D., 1974. «Another forty missing persons (A. D. 260-395)», Phoenix, 28, 224-33.

- 1975. "Constans and Gratian in Rome», HSCPh, 79, 325-333.

- 1976. «The victories of Constantine», $Z P E, 20,149-55$.

- 1978. «Emperors and bishops, A. D. 324-44. Some Problems», $A J A H, 3$, 53-75

- 1980. «Imperial Chronology, A. D. 337-350», Phoenix, 34, 160-66.

- 1981. Constantine and Eusebius, Harvard.

- 1982. The New Empire of Diocletian and Constantine, Harvard.

BRUUN, P., 1966. Roman Imperial Coinage VII, A. D. 313-337. Londres.

BURCKHARDT, J. 1982 (reimpresión). Del paganismo al cristianismo. La época de Constantino el Grande. Madrid.

COHEN, H. 1955. Description historique des monais frapées sous l'Empire romain, Graz.

CHASTAGNOL, A. 1968. "Les préfets du prétoire de Constantin», REA, 70, 321-52.

- 1969. Le Bas-Empire. París.

- 1976. «Les inscriptions constantiniennes du Cirque de Mérida», MEFR 88, 259-76.

- 1982. L'évolution politique, sociale et economique du Monde Romain de Dioclétien à Julien. La mise en Place du Régime du Bas-Empire (284-363). París.

DEMOUGEOT, E. 1979. «Le partage des provinces de l'Illyricum entre la pars occidentis et la pars orientis, de la Tétrarchie au regne de Théodosio». Actes du Colloque de Strasbourg 14-16 juin 1979. La Géographie administrative et politique d'Alexandre à Mahomet, 229-253.

FORTINA, M. 1955. La legislazione dell'imperatore Costante. Novara.

GALLETIER, E. 1952. Panégyriques Latins. París.

GARCIA IGLESIAS, L. 1979. «Paganismo y cristianismo en la España romana». La Religión romana en Hispania (Symposio organizado por el Inst. de Arqueología «Rodrigo Caro» del C. S. I. C. del 17 al 19 de diciembre de 1979). Madrid, 363-79.

GARRIDO GONZALEZ, E. 1983. Los gobernadores provinciales en el siglo IV d. C. Estudio de la estructura sociopolitica de Occidente a través de la administración. Madrid (Tesis de doctorado inédita).

- 1984. «Una aproximación al conocimiento de la administración provincial del s. IV: la diócesis de Thracia». AEArq. (en prensa).

GAUDEMET, J. 1979. «Mutations politiques et géographie administrative: L’Empire romain de Dioclétien (284) à la fin du Ve siècle». Actes du Colloque de Strasbourg 14-16 juin 1979. La Geógraphie administrative et politique d'Alexandre à Mahomet. 255-72.

GIGLI, G. 1959. La dinastia dei Secondi Flavii; Costantino II, Costante, Costanzo II (337-361). Roma. HAUSCHILD, Th. 1966. «Die Grabungen in Centcelles», $A A, 86-92$.

HERZ, P. 1975. Untersuchungen zum Festkalender der römischen Kaiserzeit. Mainz.

JONES, A. H. M. 1973. The Later Roman Empire 284-602. A social economic and administrative survey. Oxford. 2. ${ }^{\text {a }}$ edición.

- 1974 (Reimpresión). «The date and value of the Verona List». The Roman Economy. Studies in Ancient Economic and Administrative History (ed.) P. A. Brunt, Oxford, 263-79.

KRAFT, K. 1958. «Die Taten der Kaiser Constans u. Constantius II», JNG, 9.

LIEBESCHUETZ, J. H. W. G. 1979. Continuity and Change in Roman Religion. Oxford.

MARROU, H. I. 1975. Historia de la educación en la Antigüedad. Buenos Aires. 3. a edición.

MAURICE, J. 1911. «La dynastie solaire des seconds Flaviens». $R A$.

MITFORD, J. 1939. «Milestones in western Cyprus». JRS, 29, 184-198.

MOREAU, J. J. 1959. «Constans, Constantius II, Constantinus II», JbAC 2, 179-84.

OLIVETTI, A. 1915. "Sulle stragi di Constantinopoli succedute alla morte di Costantino il grande» Riv. Fil. 43.

PALANQUE, J. R. 1938. «Chronologie Constantinniene». REA, 40, 241-50.

- 1944. «Collégialité et partages dans l'Empire romain aux IVe et Ve siècles». $R E A, 46,27-64$.

- 1955. «Les préfets du prétoire sous les fils de Constantin». Historia, 4, 257-63.

PETIT, P. 1974. Histoire Générale de l'Empire romain. París.

PIGANIOL, A. 1972. L'Empire Chrétien. París. 2. ${ }^{\text {a }}$ edición.

REMONDON, R. 1973. La crisis del Imperio Romano. De Marco Aurelio a Anastasio. Barcelona.

ROBERTSON, A. S. 1982. Roman Imperial Coins in the Hunter coin cabinet. University of Glasgow. V. Diocletian (Reform) to Zeno. Oxford.

SAYAS, J. J., GARCIA MORENO, L. A. 1981. Romanismo y Germanismo. El despertar de los pueblos hispánicos. Barcelona.

SEECK, O. 1898. «Zu den Festmünzen Constantius und seiner Familie». ZNum., 21, 17-65.

- 1895-1921. Geschichte des Untergangs der Antiken Welt. Stuttgart. 
- 1901. «Constans», $P W 4,948-52$.

- 1919. Regesten der Kaiser and Päpste für die Jahre 311 bis $476 \mathrm{n}$. Chr., Stuttgart.

STEIN, E. 1959. Histoire du Bas-Empire. París.

THIRION, M. 1965. «Les vota impériaux sur les monnaies entre 337 at $364 » S N R, 44,5-21$.

THOMPSON, E. A. 1956. "Constantine, Constantius II and the lower Danube frontier». Hermes, 84, 372-81.

TOYNBEE, J. M. C. 1944. Roman Medallions. New York.

VOGLER, C. 1979. Constance II. Estrasburgo. 


\title{
IDEOLOGIA Y POLITICA EN EL EMPERADOR MARCO AURELIO
}

\author{
JESUS DAZA MARTINEZ \\ Universidad de Alicante
}

\begin{abstract}
El análisis de los «Soliloquios» de Marco Aurelio permite poner de manifiesto su unidad formal, pese a su aparente falta de sistematización, y obtener importantes conclusiones acerca del pensamiento ético, jurídico y político del emperador, así como de los motivos que ocasionaron su fuerte oposición al cristianismo.

The analysis of Marcus Aurelius's «Soliloquies» allows us to show their formal unity, in spite of their apparent lack of systematization, and also to draw important conclusions about the emperor's ethical, juridical and political opinions, as well as his motives for strongly opposing Christianism.
\end{abstract}

El nombre de Marco Aurelio se asocia, como ya vio Renan a finales del siglo XIX, con la idea del «fin del mundo antiguo» (1). Aunque Arístides de Esmirna caracterizó el período que va desde Adriano a Marco Aurelio como el más dichoso del género humano, era indudable que la humanidad «del universo grecorromano había envejecido y sentía confusamente este envejecimiento» (W. GÖRLITZ, 1962, 8). En realidad, la época del apogeo romano estaba ya llegando a su fin y comenzaban a anunciarse los primeros síntomas de decadencia. La conciencia de la precariedad de las cosas, de la fragilidad del hombre y de sus obras, del carácter efímero de todo lo terreno, que veremos aflorar continuamente en la reflexión de Marco Aurelio, respondía, entre otras cosas, a su capacidad de «leer» e interpretar eso que actualmente llamamos «signos de los tiempos».

La llamada crisis del Imperio Romano, que iba a alcanzar caracteres dramáticos durante el siglo III, comienza a insinuarse ya ahora, tanto en su aspecto más externo (ataque contra el limes del Imperio por parte de los pueblos bárbaros) como en su dimensión interna y espiritual (la vida social y religiosa, la economía y la política). Teniendo presente la idea de G. Murray según la cual el hombre del período helenísticorromano estaba dominado por una especie de neurosis, J. Alsina ve como manifestación más importante de la misma, entre otras, el cansancio espiritual (abandono de la búsqueda científica y preferencia por lo irracional y supersticioso, huida del mundo para refugiarse en la propia intimidad), la incapacidad creadora y la falta de energía vital (2). Por

(1) E. RENAN, 1881. A propósito del título de esta obra, Marc-Aurèle et la fin du monde antique, ha observado recientemente A. BIRLEY, 1966, 308, que es ya todo un problema en sí mismo (is a programme in itself).

(2) J. ALSINA, 1971, 164 ss.; a propósito de la crisis a que aludimos antes, cf. por ejemplo, G. WALSER-T. PEKARY, 1962; R. REMONDON, 1967; desde un punto de vista más próximo a la época de MARCO AURELIO, pueden verse importantes observaciones en A. JONES, 1966. 
otro lado, la sociedad romana había ido experimentando una serie de cambios (S. DILL, 1956, $8 \mathrm{ss}$.), dando lugar a nuevas exigencias y necesidades, a nuevos problemas, interrogantes y planteamientos. Más en concreto, V. A. Sirago ha hablado recientemente de la involución política y espiritual en el Imperio del siglo II (3). Entre otras cosas, señala que el programa de Adriano, que había obtenido el consentimiento unánime de sus contemporáneos, comenzó a poner de manifiesto ahora la insuficiencia de sus presupuestos. En esta situación, pues, la tarea que asumía Marco Aurelio no era fácil ni carecía de riesgos.

A la hora de hacer un balance de su vida y de su obra, suele reconocérsele más importancia como filósofo y moralista que como hombre de estado y responsable del gobierno del Imperio. El autor de la Vita Marci recuerda que fue acusado de artificioso (effictus), esto es, poco hábil para afrontar y resolver los complejos problemas prácticos con que hubo de enfrentarse (Vita Marci, 19, 5). Sin embargo, es indudable que, consciente de su misión como gobernante (4), intentó buscar soluciones y no rehuyó el tomar medidas, hacer reformas y estar presente en los lugares más conflictivos, ya se tratara de las guerras contra los pueblos bárbaros, de los movimientos populares de rebelión, de la reorganización y administración de las provincias (A. GUARINO, 1975, 368), del intento del general Avidio Casio por proclamarse emperador, de la peste y las inundaciones de Roma, o, en fin, de las relaciones con el cristianismo y con los pueblos de Oriente.

Pese a que no renunció a ampliar las prerrogativas imperiales, buscó y consiguió una relación más estrecha con el Senado. Durante su mandato se desarrolló notablemente la organización burocrática que había adquirido ya importancia en la época de Adriano. En general, el sentimiento de respeto hacia el pasado y la veneración por las costumbres y doctrinas tradicionales está siempre presente en Marco Aurelio, manifestándose tanto en su actitud frente a la religión como en la forma de entender y dirigir la vida social y política del Imperio. Esto explica por qué, pese a la importante obra legislativa que llevó a cabo, con el asesoramiento de los importantes juristas que formaban parte de su Consilium (y entre los cuales hay que destacar la personalidad de Q. C. Scaevola), se prestó más atención a la reelaboración de las doctrinas precedentes que a crear nuevas reglas de derecho. Con todo, su aportación al perfeccionamiento de la administración de la justicia y del ius privatum fue, sin duda, notable (L. PARETI, 1960, 348). Baste pensar, en el campo del derecho formal, en el decreto de vi privata (D. 48, 7, 7); en otro orden de cosas, es obligada la referencia a la compensación in stricitis iudiciis (I. IV, 6, 30), a la institución del crimen expilatae hereditatis (D. 47, 19, 1), a la addictio bonorum libertatum servandarum causa $(\mathrm{I}, 3,11)$ y a la extensión del periculum tutoris sobre los tutores en general (D. 26, 7, 1).

En el presente estudio, apoyándonos en sus afirmaciones explícitas y en los presupuestos filosóficos que subyacen a las mismas, intentamos poner de relieve la unidad

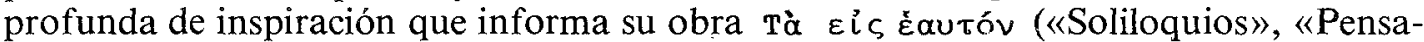
mientos») (5), pese a la aparente dispersión de los temas, a la falta de sistematización y al estilo aforístico en que se expresa; de ella veremos derivarse importantes conclusiones

(3) V. A. SIRAGO, 1974; en las páginas 9-229 estudia sobre todo los hechos, deteniéndose luego a analizar las ideas. Una descripción interesante de la época de MARCO AURELIO y de su mundo, puede encontrarse también en A. S. L. FARQUHARSON, 1952.

(4) En un pasaje de sus Soliloquios alude a su condición de guía de los hombres en la comunidad política, del mismo modo que el toro y el carnero lo son en sus respectivos rebaños (XI, 18). A. PUECH, 1964, III, asegura que MARCO AURELIO estaba preparado, por su extraordinaria cultura intelectual y moral, para hacer frente a los problemas interiores y exteriores del Imperio; de hecho, durante sus 19 años de reinado «ni l'intelligence, ni la volonté del l'empereur n'ont faibli... il n'a jamais fermé l'oreille aux appels du devoir».

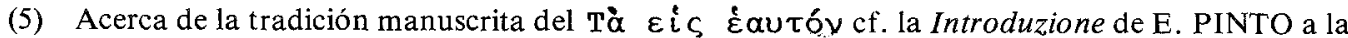
edición italiana de los «Pensieri», editada por la «Librería Scientifica» de Nápoles, p. 19 ss. 
de orden ético, jurídico y político (6). Por último, y supuesto que durante su mandato como Emperador tiene lugar un «turning-point» en las relaciones entre el Estado romano y la Iglesia cristiana (A. BIRLEY, 1966, 328), aludiremos también a la problemática de fondo que se esconde tras la oposición de Marco Aurelio al cristianismo (J. DAZA, 1975, 37).

El libro I de los Soliloquios, que probablemente fue el último escrito por Marco Aurelio, constituye un instrumento valioso para conocer las fuentes en que se inspira su obra (L. ALFONSI, 1960, 101). Entre los grandes bienes que él considera haber recibido de los dioses en su vida, enumera el «haber conocido a Apolonio, Rústico y Máximo» (Soliloquios, I, 17), filósofos estoicos, a los cuales se había referido poco antes por separado para recordar los vínculos intelectuales y humanos que le unían a ellos. De Rústico recuerda haber aprendido, entre otras cosas, a forjar el carácter; a no hacer exhibición de beneficencia para causar admiración a las gentes; a no contentarse con una lectura superficial de las obras de los grandes maestros; en particular, le agradece el haberle prestado los libros en que se conservaban las lecciones de Epicteto (Soliloquios, I, 7). De Apolonio, la independencia, la decisión y el no guiarse nunca más que por la razón (Soliloquios, I, 8). De Máximo, el dominio de sí, el valor en todas las circunstancias, el cumplimiento de las tareas, la benevolencia, la lealtad y el dar la imagen de un hombre recto más bien que la de un hombre enderezado y corregido por los demás ( Soliloquios, I, 15).

Otro filósofo estoico de quien dice haber aprendido lo que es vivir conforme a la naturaleza es Sexto, sobrino de Plutarco (Soliloquios, I, 15). Al sabio Diognetes le atribuye el haberse familiarizado con la filosofía (Soliloquios, I, 6) y a su maestro Frontón el haber conocido a tiempo los defectos de los tiranos (7). Entre los restantes recuerdos que se recogen en este libro primero, destaca particularmente la larga mención de las enseñanzas y ejemplos recibidos de su padre adoptivo Antonino Pío y que van desde la firmeza en las decisiones hasta el amor al trabajo; desde la indiferencia a la vanagloria hasta la desconfianza en las apariencias; desde la vigilancia permanente a los intereses del Imperio hasta la sobriedad y moderación en todo; desde el respeto a las costumbres de los antepasados hasta el estudio minucioso de todos los detalles en su plan de gobierno; $\mathrm{y}$, en suma, una religiosidad profunda, libre del miedo supersticioso; la voluntad de servir al pueblo, sin la obsesión de ganarse el aplauso de la multitud; una vida según la razón, aunque sin manifestar desprecio al ignorante; amor a sí mismo y cuidado del cuerpo, pero coraje y decisión para afrontar valerosamente la muerte (Soliloquios, I, 16).

Aunque cita rara vez a los grandes maestros del estoicismo primitivo, es indudable que las doctrinas de la tradición estoica constituyen un punto permanente de referencia para Marco Aurelio: la lógica (que incluía una teoría del conocimiento, el estudio del lenguaje, la dialéctica y el silogismo), la física (en la que se incluía la teología, las ciencias naturales y la metafísica) y la ética (estudio de la vida recta, de la felicidad, del fin último) (8). Las relaciones existentes entre su propia doctrina y la de los estoicos inme-

(6) A propósito de la teoría jurídica de MARCO AURELIO, ha observado E. JARRA, 1932, 489, que en este campo su importancia no corresponde a los méritos del Emperador en el campo del derecho privado.

(7) Soliloquios, I, 11; cf. M. VAN DEN HOUT, 1950, 33. Es sabido que MARCO AURELIO mantuvo una prolongada correspondencia con este maestro de su juventud, especialmente durante los años 142 y 143. Estas cartas no sólo son un instrumento insustituible para conocer en profundidad su vida privada sino que demuestran hasta qué punto la influencia de este hombre fue importante y duradera. La edición de las cartas ha sido hecha por C. R. HAINES, 1955.

(8) Cf., por ejemplo, M. POHLENZ, 1959; sobre la lógica puede verse M. MIGNUCCI, 1965; los más importantes conceptos éticos de este movimiento han sido estudiados por G. KILB, 1939, y G. MANCINI, 1940. 
diatamente anteriores han sido estudiadas por V. Agostino, Neuenschwander, Fusci y otros (9).

Su ideal personal (como hombre, como filósofo estoico y como emperador) puede entreverse a través de la serie de exhortaciones y consejos que se da a sí mismo en un pasaje del libro VI que se inicia con una llamada a la vigilancia para mantenerse libre de la tentación de "cesarizar» o ambición desmesurada de poder, continuando con la enumeración de una serie de cualidades y virtudes que quisiera ver realizadas en su vida: honradez, piedad, benevolencia, amor de la justicia, firmeza en el cumplimiento de los deberes. Marco Aurelio manifiesta, en suma, su aspiración a permanecer siempre tal como la filosofía quiso formarlo, reverenciando a los dioses, sirviendo a los hombres y buscando en todo el bien de la comunidad política a cuyo frente se encuentra (Soliloquios, VI, 30).

No es posible, sin embargo, dejar de señalar los contrastes - $\mathrm{e}$ incluso contradicciones - que, por diferentes causas, se dieron de hecho entre sus ideales teóricos y su actuación concreta como hombre de Estado. Aparte de las dificultades externas que obstaculizaron la normalidad política de su reinado (presión de los pueblos bárbaros — partos, quados y marcomanos-, rebeliones militares, cataclismos naturales), hay que reconocer en él una serie de limitaciones importantes (idealización del pasado; falta de una visión dinámica de la historia y, por consiguiente, de la vida política; escasa sensibilidad para proyectar y promover una integración más profunda entre Oriente y Occidente; desconocimiento de las aspiraciones de las gentes de las provincias del Imperio, etc.). En cualquier caso, es indudable que intentó siempre mantenerse a la altura de su deber y cumplir la consigna que se había dado a sí mismo: «muéstrate en todo como el discípulo de Antonino» (Soliloquios, VI, 30).

\section{II}

Aparte de las ideas estoicas tradicionales y del magisterio siempre presente de Platón y Aristóteles, hay que destacar de modo singular la vinculación de su doctrina con el pensamiento de Heráclito, el cual condicionará en gran medida su visión del mundo y su entendimiento de la política y de la justicia.

A.- Aunque este filósofo presocrático mantiene la idea de que todo es uno y que «de todas las cosas el uno y el uno de todas las cosas» (10), esto es, la unidad de la naturaleza y del principio primordial, subraya, por otra parte, con un vigor admirable, la idea de que todo fluye, de que nada permanece en un ser fijo. El cambio, la transformación, el continuo «hacerse» y devenir constituye la esencia de las cosas. Hay aquí, pues, una antítesis de la filosofía de Parménides, que concibe el ser como siempre igual, estable y universal, como una duración siempre idéntica a sí misma. La metáfora del río y de las aguas, que se repite con distintas variantes, ilustra claramente la concepción de Heráclito (Frags. 49, 91, 12). El hecho de que en muchas cosas no se aprecie con los sen-

(9) Cf. D’AGOSTINO, 1962; H. R. NEUNSCHWANDER, 1951, y G. FUSCI, 1904.

(10) Cf. los fragmentos 10 y 50. (Para los fragmentos de HERACLITO tenemos presente, aparte de la obra fundamental de DIELS-KRANZ, la edición y comentario de KIRK y diversas traducciones a otras lenguas.) 
tidos ningún tipo de cambio o ninguna mutación, sólo demuestra, en realidad, la necesidad de superar el mundo de las apariencias, puesto que «la naturaleza gusta de esconderse» (Fragm. 123). El fuego, que representa en el pensamiento de Heráclito un papel fundamental (ya sea al hablar del principio constitutivo de los seres, o del orden del universo, o de la doctrina de la ekpyrosis o conflagración universal periódica, etc.) es también, sin duda, un símbolo de este devenir incesante (11), de la inquietud del acontecer universal (como la llama que jamás reposa). Este principio de dinamismo y de mutación no se aplica sólo a la naturaleza, sino al hombre mismo y a todas las creaciones culturales, políticas y sociales. En otro fragmento de Heráclito se dice que el mismo Dios está sometido a esta ley de la transformación universal y que «se cambia como el fuego» (Fragm.67). En Heráclito tenemos, en suma, «la première saisie de l'être en devenir de la totalité» (K. AXELOS, 1962).

El sentido del tránsito, de la finitud, del continuo devenir, del hacerse y deshacerse constante de los seres y de las cosas, es una de las claves de los Soliloquios de Marco Aurelio. En un importante pasaje del libro V, y sirviéndose también de la imagen del río como Heráclito, invita a considerar cómo se van desarrollando los acontecimientos y cómo todo cambia y se transforma, aludiendo al fin «al abismo del pasado y del futuro» en el que todo se desvanece (12). En otro pasaje anterior habia ya hecho referencia a una imagen semejante, combinando la idea del río que fluye y se desliza sin pausa con la del torrente que todo lo arrastra consigo (Soliloquios, IV, 43). Se complace, en particular, refiriéndose a la vida humana, en dejar claro que la duración temporal es sólo un punto, que su sustancia fluye, que el cuerpo se desmorona, que vive en realidad exilado en un país extraño (Soliloquios II, 17). En esta situación, sólo hay una cosa que pueda guiarle, a saber, la filosofía (Soliloquios, II, 17).

Esta forma de entretener la vida revela cómo el estoicismo de la época de los Antoninos, con su mezcla de orgullo y de tristeza, es - como ha señalado Görlitz- un reflejo de la civilización de este período tardío de un Imperio cuya madurez ya había sido superada y para el que comenzaba la decadencia. El orgullo de la grandeza del Imperio se combina así con el sentimiento interior del carácter efímero de toda obra humana. De hecho, ninguna frase se repite tanto en la obra de Marco Aurelio (de formas diferentes) como la de que el hombre y las aspiraciones humanas están llamadas a perecer (W. GÖRLITZ, 1962, 50). Esta convicción de la fragilidad de las cosas humanas está a la base de su visión y comprensión de la historia. En el libro IX, después de referirse a la doctrina de los ciclos y de las transformaciones periódicas del mundo y de volver a repetir que la causa de la universalidad de las cosas es un torrente que todo lo arrastra, increpa con dureza a aquellos hombres mezquinos que juegan a políticos y creen que obran como filósofos (Soliloquios, IX, 29).

B. - Los conceptos de "lucha» y «armonía» son inseparables en Heráclito y en Marco Aurelio. Para el filósofo griego, la realidad es unión de contrarios, tensión y conflicto. Explícitamente afirma que «la guerra es la madre de todas las cosas» (Fragms. 53 y 80). Sin la existencia de contrarios no sería posible el constante devenir, aquel eterno fluir que es el presupuesto esencial de su doctrina cosmológica. Ahora bien, de la tensión universal de todas las fuerzas que se contraponen surge la armonía;

(11) Sobre el tema del «fuego» en HERACLITO, cf. W. CH. KIRK, 1940; a propósito de la dificultad que presenta interpretar sus textos, cf., por ejemplo, R. MONDOLFO, 1966.

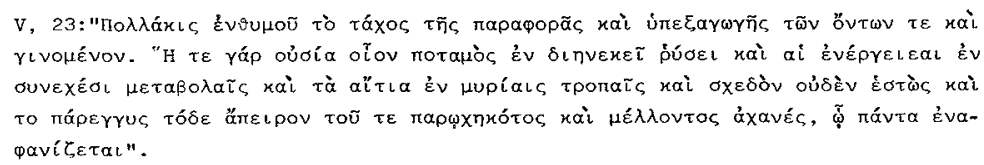


de la oposición y la lucha, el equilibrio. Uno de sus más importantes fragmentos dice: «ellos no comprenden cómo lo que difiere de sí mismo concuerda; armonía en tensión, como la del arco y la lira» (Fragm. 51), y en otro lugar se lee: «de las cosas que difieren entre sí se engendra la armonía más bella» (Fragm. 8). No existe fecundidad posible ni fuerza creadora al margen de esta oposición de los contrarios. Las contradicciones y antítesis aparentes, correspondientes a distintos momentos del desarrollo de la realidad, no son la negación de esta armonía, aunque así lo consideren los hombres que se atienen únicamente al testimonio de los sentidos. Porque «la armonía invisible es superior a la visible» (Fragm. 54).

Heráclito no abandona la idea de unidad hacia la que se orientó ya desde un comienzo la filosofía griega; lo grandioso de su concepción consistió en la idea de que esa unidad no se cierne sobre los contrarios, reconciliándolos y poniendo término a su lucha, sino que vive y se realiza en el propio conflicto. La armonía antagónica o armonía de tensiones es la ley de las cosas y la unidad del mundo, unidad no por encima o por debajo de los contrarios, sino en los contrarios mismos. En esta doctrina hay probablemente una reacción contra el intento de Anaximandro de definir como una injusticia las recíprocas intrusiones de los opuestos entre sí, en virtud de las cuales debían sufrir el correspondiente castigo o «expiación» (13). Sin embargo, ya en este filósofo se habla de la unidad originaria de la oposición, de modo que «il germogliare dell'unità è il comune pensiero di Anassimandro è di Heraclito» (14).

También en Marco Aurelio se encuentra la expresión de que la vida es lucha (Soliloquios, II, 7 y VII, 61) y, de modo singular, la idea y el sentimiento vivo de la unidad y armonía del universo, la mutua dependencia y concatenación de sus partes y elementos (Soliloquios, IV, 40). A fin de animar al hombre a no sustraerse a este concierto universal, le pide que considere la cohesión de todo lo que existe en el mundo y las estrechas relaciones que unen a las cosas entre sí y las hace, en algún modo, sentirse amigas, en perfecto acuerdo y sintonía (Soliloquios, VI , 38). Vivir en armonía con el universo es aceptar el destino, ver en los acontecimientos una ordenación de la naturaleza universal y de la voluntad de los dioses. Lo que acontece al hombre afecta también al «todo» y el universo está como mutilado por poco que sea lo que se sustraiga a la cohesión y al encadenamiento de las causas, no menos que de las partes. Tal encadenamiento de las partes se rompe, en cuanto depende del hombre, cuando se obstina en rebelarse contra los acontecimientos e intenta, en cierto sentido, destruirlos (Soliloquios, V, 8).

C. - La doctrina del Logos es otra de las fuentes en que se inspiran los estoicos y que está presente, en particular, en la filosofía de Marco Aurelio. Casi todos los intérpretes coinciden en señalar que el término logos en Heráclito no tiene un sentido único, siendo en realidad un vocablo intraducible. En los distintos fragmentos su significado varía notablemente, según los contextos en que se usa. Algunas de las acepciones más importantes son, por ejemplo, verdad, palabra, orden, medida, proporción, idea, razón, ley, destino. Pese a la innegable polisemia e imprecisión de este concepto, las diferentes significaciones que va asumiendo no son, sin embargo, independientes unas de otras, sino que existen entre ellas unas conexiones más o menos íntimas que dan al sistema filosófico heracliteo una estructura unitaria.

(13) DIELS-KRANZ traducen así el fragmento 1 de ANAXIMANDRO: «En donde está el nacimiento para las cosas que existen, allí dentro se cumple también su disolución obligatoriamente; porque pagan recíprocamente justo castigo y expiación por su injusticia (12B1).

(14) E. SEVERINO, 1963, 162, después de observar que, pese a lo que se dice ordinariamente, el horizonte de los primeros pensadores griegos no es físico sino metafísico, intenta buscar el significado filosófico de las palabras dikè y adikía en Anaximandro, teniendo presente el modo en que tales palabras resuenan en Heráclito y Parménides. 
En el fragmento I se afirma claramente que «todas las cosas suceden según este logos», el cual -según nos dice Aecio interpretando a Heráclito- «penetra por la esencia del universo» (15). Es, en otras palabras, la ley universal a la que todo obedece y que el sabio debe descubir detrás del acontecer cósmico, del flujo incesante de los fenómenos. La mayoría de los hombres se atiene sólo a las apariencias y «se engañan en el conocimiento de las cosas visibles» (Fragm. 56). En su hablar y en su decir se comportan como los «durmientes» (Fragm. 73), «no conocen las cosas después de haberlas aprehendido, aunque a ellos les parezca que sí» (Fragm. 17). Y pese a que el logos es común para todos los hombres, muchos viven como si tuvieran una sabiduría propia (Fragm. 2).

Por el Logos, que permanece inmutable a través de los cambios, existe un orden racional en el universo y todo se hace «según medida». Es la razón ordenadora que preside el devenir de la naturaleza, la ley inmanente del universo. En este sentido, el logos se aproxima a la Necesidad o Heimarmene y se identifica prácticamente con ella. De hecho, y sirviéndose de su lenguaje figurado, Heráclito llama al orden cósmico de diferentes formas, entre ellas «Necesidad» y «Logos». Por otra parte, esta Heimarmene no es una realidad personal ni se identifica con Dios (entendido de acuerdo con nuestros esquemas culturales); es la ley suprema que todo lo rige: el mundo, los hombres y los dioses. Todo está bajo el imperio de esta fuerza misteriosa de la Heimarmene, todo sucede según ella (16).

Esta razón ordenadora, Logos divino o ley universal, puede ser conocida por el hombre, cuando es capaz de servirse de su razón y salir del mundo de las meras «opiniones» (las cuales son para él meros «juegos de niños» o formas inferiores de conocimiento) (Fragm. 70); la sabiduría consiste justamente en conocer la razón que gobierna todas las cosas a través de todas las cosas (Fragm. 41) y la esencia y fin moral del hombre no son otra cosa que la sumisión voluntaria a ella, esto es, el obrar conforme a la naturaleza (Fragm. 112).

Evidentemente, en tales afirmaciones hay una serie de ideas y de palabras que revelan inmediatamente una casi identidad de doctrinas con el estoicismo. Si el hombre es para Heráclito el «oyente del Logos» o «Hörer des Logos» (J. B. LOTZ, 1953, 543 ss.) y debe conformar su vida a las exigencias de la naturaleza e imperativos de la razón, en Marco Aurelio encontramos expresadas de diferentes modos esta concepción antropológica y ética. En las exigencias de la naturaleza y en los preceptos de la razón se hace presente al hombre el criterio moral auténtico, más allá de los cambios, de la multiplicidad de los fenómenos y del enredo y contradicción de las opiniones, intereses o sentimientos particulares (Soliloquios, IV, 39).

Para una comprensión más amplia de la doctrina de Marco Aurelio hay que tener en cuenta que en él están presentes todos los grandes temas estoicos, en los que la influencia de Heráclito, entre otras varias, constituye un hecho cierto. Dejando a un lado otros aspectos que se alejan de la problemática aquí abordada, conviene tener presentes algunos datos importantes que se contienen en la tradición estoica antigua y media.

Según los maestros de la Estoa, en cada hombre en particular hay una participación del Logos eterno y divino, que es una Ley o Razón universal, el Principio rector y gobernador de todo el universo y que se identifica con el Destino (Heimarmene) o Providencia(Pronoia) a que se debe la armonía y unidad del universo, a través de los ciclos periódicos y rítmicos de su desarrollo. El hombre debe reconocer este orden universal en el que todo está dirigido y determinado por el Logos y la Pronoia y del que se deduce la perfecta racionalidad del Cosmos. Finalidad y determinismo se reconcilian en una unidad superior, ya que «ex omni aeternitate fluens veritas sempiterna» (CICERON, De

(15) Cf. este y otros testimonios de Aecio y de Sexto Empírico en D. MAYOR, 1960, 311.

(16) A esta ley necesaria se han referido los filósofos griegos de las diferentes épocas con otras palabras (Moira, Anankè, Dikè). 
Divinatione, I, 55). Marco Aurelio podrá decir, haciéndose eco de este orden providencial, que lo que llega a punto para el Cosmos no puede llegarle a él ni demasiado tarde ni demasiado pronto (Soliloquios, IV, 23).

La moral estoica, según esto, consistirá en insertarse voluntariamente en este orden universal adaptando su conducta a él. Este es el significado esencial del principio que establece que la virtud consiste en vivir «conforme a la Naturaleza». Y puesto que la razón individual de cada hombre es una participación del principio divino universal inmanente en el Cosmos, vivir «conforme a la razón» es ajustarse al orden del Universo regido por el Logos o Razón divina. La vida racional y libre no tiene, según los estoicos, otro sentido (17).

En Marco Aurelio es constante la invitación a pensar según el Logos, a vivir y comportarse conforme a las exigencias de la naturaleza. En este sentido, es un prototipo del hombre estoico, aunque encontramos en él una serie de matices y de acentos nuevos (18). El fundamento mismo de la filosofía radica en vivir como quiere la naturaleza (que para los estoicos es digna de reverencia religiosa, como si fuera la persona misma de Dios). Es inútil buscar la dicha en otra parte: en la riqueza, en el placer, en la gloria e incluso en el estudio de la lógica y de la física (19). Se trata de ir más allá y descubrir los principios que regulan los instintos y las acciones; viviendo según ellos, conforme a las exigencias de la naturaleza racional, el hombre será justo, independiente, virtuoso, libre. Un pasaje del libro VIII resume admirablemente estas ideas esenciales. En otro lugar precisa que la filosofía sólo quiere lo que quiere la naturaleza y que nada hay más atrayente que seguirla porque en ella se encuentra la auténtica grandeza del alma, la rectitud, la libertad, la benevolencia, la piedad, la sabiduría.

Descendiendo de la naturaleza universal, según la cual todo acontece, a la naturaleza racional del hombre o physis logiké, Marco Aurelio se detiene a explicar algunos criterios concretos para juzgar si realmente sigue o no su camino; en el orden de las ideas, se trata de no asentir a lo falso o dudoso; en el orden de los instintos, de preocuparse principalmente por llevar a cabo aquellas acciones que son útiles a la comunidad; en el orden de las cosas que hay que buscar o evitar, de adherirse únicamente a lo que a cada cual corresponde según la naturaleza universal, de la cual ella es sólo una parte (como la hoja lo es de la planta) (Soliloquios, VIII, 7). Viviendo según la recta razón (orthos logos) y manteniendo siempre puro el daimon interior, ocupándose en todo momento de que cada una de las acciones se haga kata physin, no es posible que nada ni nadie impida ser feliz (Soliloquios, III, 12).

En este contexto de reflexión -y siempre en relación con los conceptos de naturaleza, razón, destino, divinidad y providencia o «pronoia»- encuentra su sentido último la doctrina de Marco Aurelio sobre la muerte. Nada de cuanto acontece carece de sentido ni es ajeno, de algún modo, al bien general del universo (Soliloquios, II, 3). El acto por el cual morimos es sólo uno de tantos actos de que se compone la vida y ningún

(17) Evidentemente, en este resumen esquemático quedan fuera una serie de cuestiones difíciles y cuyo tratamiento no es de este lugar. Para la relación entre el tema de la libertad humana y la doctrina del logos y la heimarmene, cf. E. ELORDUY, 1972, 139 ss.; más adelante explica el autor cómo se enlazan los problemas del conocimiento y de la libertad. En el vol. II de esta obra se estudian ampliamente el sistema moral estoico y todos los problemas conexos.

(18) A. PUECH, 1964, VIII-IX, observa a este propósito que los pensamientos más altos de MARCO AURELIO «tiennent au tréfonds du stoïcisme» y que él ha encontrado, de una vez para siempre, la regla de su conducta y la fuente de su energía en las máximas del Pórtico.

(19) De las tres grandes partes en que se dividía la doctrina estoica (física, lógica y moral), siempre se consideró la última la más importante, a la que las demás se encontraban subordinadas; MARCO AURELIO agradece a los dioses el que cuando comenzó a gustar de la filosofía no fue a caer en manos de un sofista, ni se limitó al análisis de autores o silogismos, ni perdió su tiempo en el estudio de la física celeste (Soliloquios, I, 17). 
hombre consciente puede rebelarse contra ella o mostrarse contrariado, siendo en realidad algo tan natural como la aparición de los dientes o del cabello, o como la fecundación y el alumbramiento (Soliloquios, IX, 3). Nacimiento y muerte constituyen uno de los misterios de la naturaleza, siendo idénticos los elementos que se combinan, se interpenetran y, por último, se disuelven (Soliloquios, IV, 5).

El pensamiento de la muerte está presente a lo largo de los libros de los Soliloquios, como una obsesión, como una permanente invitación a familiarizarse con ella, a reconciliarse con el propio límite (20). En muchos casos se trata sólo de una breve pincelada, una simple insinuación: «la vida es breve» (Soliloquios, VI, 30), «hay que aprovechar el presente» (Soliloquios, IV, 26), «la perfección moral exige que se viva cada día como si fuera el último» (Soliloquios, VII, 69). Otras veces se extiende a reflexionar sobre una serie de hechos, personajes y acontecimientos para poner de manifiesto la inconsistencia y la caducidad de todo, la obra implacable del tiempo, la igualdad esencial ante la muerte (Soliloquios, IV, 48). Aunque de esta vivencia profunda de la finitud y temporalidad no deduce Marco Aurelio una invitación a desertar de las tareas humanas, a abandonarse ciegamente a los acontecimientos o descuidar los propios deberes como hombre racional y como ciudadano de la Polis, es indudable que deja entrever un espíritu penetrado de melancolía y da una sensación casi morbosa de tristeza y de vacío. Como veremos más adelante, esta forma de entender la vida humana y la historia iba a reflejarse necesariamente en una concepción estática de la vida social y en una visión conservadora de la política y del derecho.

\section{III}

El Logos no es sólo la ley que rige el acontecer cósmico y gobierna la vida racional y moral del individuo. En uno de sus más importantes fragmentos, Heráclito decía: «Es preciso que los que hablan de acuerdo con la razón se apoyen en lo que es común a todos, como la ciudad en la ley, e incluso mucho más; porque todas las leyes humanas se alimentan de esta única ley divina» (Fragm. 114). Esta ley divina subyacente a las leyes humanas ha sido interpretada como una ley natural eterna que se dirige a la razón del hombre, en la medida en que éste participa del Logos eterno. Tal idea de un derecho natural no queda excluida por la diversidad de las leyes humanas, que no serían sino una encarnación de la ley divina y un medio para que el pensamiento racional reconozca la verdad de la misma. Esta doctrina vendría a ser un precedente remoto de la teoría cristiana de la ley eterna (21). Sea cual sea el sentido que Heráclito atribuía a este texto, parece cierto que, por primera vez en la historia del pensamiento, aparece en él la idea de un fundamento absoluto de las leyes positivas, esto es, de lo que luego se llamará «ley natural». Para Heráclito esta ley divina - que es la primera y verdadera ley-no puede ser más que el Logos, la Razón universal, sustancia y principio (Arché) de toda la realidad, a la cual llega el hombre gracias a la filosofía, pasando del sueño a la vigilia (G. FASSO, 1966, 25).

Esta doctrina, prolongada más tarde en el estoicismo, había sido reelaborada por Cicerón, especialmente en su tratado De Legibus. En diversos lugares hacía referencia a aquella ley, anterior a toda ley escrita, la cual «orta est simul cum mente divina» (22).

(20) «Metaphor after metaphor, simile after simile, are brought in as the emperor struggles to reconcile himself with the prospect that his life was nearing its end» (J. BIRLEY, 1966, 299).

(21) Cf., por ejemplo, E. ROMMEN, 1950: Derecho Natural. Historia-Doctrina; A. TRUYOL Y SERRA, 1961: Historia de la Filosofía del Derecho y del Estado I; más ampliamente A. MENZEL, «Heraklits Rechtsphilosophie», Zör, 12, 177 ss.

(22) De Leg. II, 4, 10; el texto sigue: «Quam ob rem lex vera atque princeps apta ad iubendum et ad vetandum ratio est recta summi Iovis» (cf. también De natura deorum, I, 14, 37). 
En un pasaje importante, y tras ponderar la importancia de conocer el valor de aquella razón por la cual hemos de definir los derechos (qua nobis iura definienda sint), había recordado que la opinión común de los más sabios parece ser la de que la ley no es una invención de la inteligencia de los hombres ni una decisión de los pueblos, sino algo eterno que regiría el mundo entero con una sabiduría que impera y prohíbe. Por eso decían que el espíritu de Dios es la primera y definitiva ley, que todo lo manda o prohíbe con la razón. De ella procede aquella que recibe el nombre de ley, dada por los dioses al género humano, pues la razón espiritual del sabio es idónea para ordenar el bien y desterrar el mal (23). Establecido el carácter divino de la ley natural, es evidente que las leyes humanas están en todo caso subordinadas a ella. Las leyes que hace cada pueblo, varias y temporales, tienen el nombre de «leyes» más por aceptación que por serlo realmente (favore magis quam re); fueron inventadas para salvación de los ciudadanos (ad salutem civitatum), seguridad de las ciudades y pacífico bienestar de la vida humana (vitamque hominum quietam et beatam); por lo tanto, los que dieron a los pueblos órdenes perversas e injustas, no dieron leyes sino otra cosa muy distinta; en el mismo sentido, pues, de la palabra «ley» está ínsito en substancia el concepto del saber seleccionar lo justo y lo verdadero (De Legibus, V, 11-12).

Bajo la influencia de Heráclito, e inserto en la tradición estoica y ciceroniana, Marco Aurelio establece una vinculación profunda entre los conceptos de naturaleza, razón, ley y justicia. A la base está siempre presente su convicción de que todo proviene de la naturaleza universal (Soliloquios, VI, 9); que la mente del universo lleva siempre la iniciativa y se ocupa de cada cosa (Soliloquios, IX, 28). Ser sabio es conocer el Logos que rige todo a través de los ciclos cósmicos, la «razón» según la cual se suceden los acontecimienos y a cuyos designios se ajusta el devenir (Soliloquios, V, 32 y VI, 1). En un pasaje importante (VII, 9) Marco Aurelio habla de la unión sagrada que conexiona y vincula entre sí a las cosas, de modo que ninguna es extraña a las otras, y que explica el orden y la armonía del cosmos: el mundo es uno, uno es también el Dios presente en todas partes; una la sustancia, una la ley, una la razón común a todos los seres inteligentes; por último, una es la verdad, puesto que también es una perfección para los seres que participan de la misma razón. Esta idea de la unidad es la base última de su metafísica y de su doctrina moral, de su filosofía jurídica y de su concepción de la política (E. JARRA, 1932, 503).

Supuesto que al Logos, identificado por Marco Aurelio con la naturaleza universal, está sometido todo, cualquier intento de apartarse de esta ley soberana es entendida lógicamente como una deserción (24). El hombre participa de él por la razón; y puesto que ésta es quien prescribe lo que debe hacerse o evitarse, puede hablarse realmente de una ley común(ó vouos xoı vós). Admitida esta conclusión, es evidente que formamos

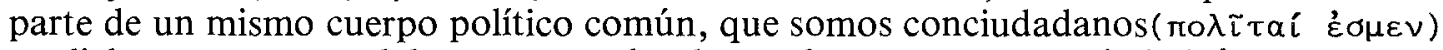
o, dicho con otras palabras, que todo el mundo es como una ciudad (ó xóouos...

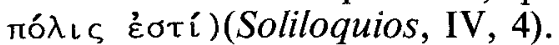

Esta «ley común», a través de la cual se expresan las exigencias de la razón y, por consiguiente, los imperativos de la naturaleza, constituye la forma suprema de ley. Ajustando las leyes positivas y la política a este nomos superior, los que gobiernan contribuyen eficazmente a realizar, en su sentido más profundo, la unidad última del universo.

(23) «Hanc igitur video sapientissimorum fuisse sententiam, legem neque hominum ingeniis excogita tam, nec scitum aliquod esse populorum, sed aeternum quiddam, quod universum mundum regeret..." (De Leg. II, 4, 8).

(24) El razonamiento de MARCO AURELIO es el siguiente: «el que abandona a su señor es un desertor. Por tanto, quien se aparta de la ley, que es nuestro señor, deserta» (Soliloquios, X, 25). 
Esta doctrina explica por qué Marco Aurelio concibe la justicia como conformidad con la ley. Fundada en la naturaleza y en la razón, la justicia está en el origen de todas las demás virtudes (Soliloquios, XI, 10). Al enumerar los bienes supremos de la vida humana, sitúa en primer lugar la justicia, seguida de la verdad, de la templanza y del valor. Vivir según ellos es ser fieles a las exigencias de la vida racional y a la finalidad esencial de la Polis; deben ser preferidos, en cualquier caso, a las riquezas, al poder, a los placeres, a la fama (Soliloquios, III, 6). En otro momento de sus reflexiones, y deseando explicar los principios por los que deben dirigirse las acciones humanas, aconseja, ante todo, obrar como lo haría la Justicia misma (Soliloquios, XII, 24).

Marco Aurelio entiende que la verdadera salvación de la vida individual y de la comunidad consiste en practicar con toda el alma la justicia y en decir la verdad (Soliloquios, XII, 29). Junto con el espíritu religioso y la piedad, la justicia constituye la exigencia suprema de la naturaleza racional de los hombres. Al estudiar, en efecto, los caracteres propios de ésta (capacidad de pensarse a sí misma, de proponerse unos fines, de ver todo el pasado y el futuro en la identidad del presente), concluye subrayando que el amor de los demás es una de sus̀ características esenciales y que no existe verdaderamente diferencia entre la recta razón y la razón de la justicia (Soliloquios, XI, 1).

Por último, el mismo impulso que mueve al hombre a obrar conforme a la naturaleza y a la razón, fundamentos de la justicia, le lleva a acomodar su conducta también con las leyes positivas de la Polis (25). Recurriendo a una expresión poética, Marco Aurelio decía que lo que es bello en sí mismo no necesita de nada más. Ni la ley, ni la verdad, ni la benevolencia aumentan su belleza esencial por ser alabados, ni se disminuyen en absoluto porque se las desprecie o se las someta a críticas; la esmeralda - diceno pierde su encanto por falta de alabanzas, ni la hermosura de la flor, ni el color de la púrpura, ni el brillo del oro, ni el sonido de la lira (Soliloquios, IV, 20). En la obediencia a la ley está el secreto del bien del Estado. La íntima relación existente entre el derecho y la Polis queda claramente subrayada en un pasaje importante del libro X, según el cual nada daña a un ciudadano si no daña a la comunidad, y nada atenta contra ésta si no atenta contra la ley. Por lo cual -concluye- aquello que no va contra el nomos tampoco afecta negativamente a la Polis o al ciudadano (Soliloquios, X, 33).

Marco Aurelio ha sabido apreciar como pocos la importancia del derecho, pero destacando, ante todo, sus valores morales. Por otra parte, es clara la influencia de la concepción socrática, puesto que equipara el obrar según la justicia con el obrar conforme a la ley; esto significa, en otras palabras, «ridurre il diritto positivo ai fondamenti della giustizia» (E. JARRA, 1932, 500). El diálogo Critón, que intenta establecer los principios esenciales para mantener el orden jurídico en un pueblo, había afrontado el problema de la autoridad del Estado sobre los ciudadanos y de la obediencia absoluta a las leyes. Sócrates, al que es ofrecida la posibilidad de huir de la cárcel y salvarse, prefiere morir porque así lo quieren las leyes. El primero de los principios en que justifica su actitud es el que U. E. Paoli llama «principio de la justicia absoluta» (26), el cual le llevará a concluir que aunque la Polis ha sido injusta condenándolo, él no puede ser injusto con la Polis violando sus leyes. A él se añade también el «principio de autoridad» que se concreta en la absoluta subordinación del ciudadano a la Polis o, dicho de otro modo, en la autoridad absoluta de la Polis sobre el ciudadano. En cierto modo, Sócrates opta por la afirmación de la omnipotencia del Estado. La inviolabilidad de la ley, pues,

(25) Al final del II, 16, dice literalmente que «el fin de los seres racionales es obedecer a la razón y a la ley de la ciudad».

(26) Cf. U. E. PAOLI, 1932: «Problemi di diritto publico nel Critone platonico», RIFD, 12, 611; el autor expone con claridad el sentido de este principio, observando que es necesario tener presente, para entender su alcance, los postulados de la conciencia jurídica griega, no aislando el diálogo de las circunstancias dramáticas en que se desenvuelve. 
y la necesidad de obedecerla, se basa en su «santidad», no en su contenido; sea cual sea éste, el ciudadano le debe respeto y obediencia, porque es ley: debe permanecer en la esfera de la voluntad de quien lo domina, encontrando en ella su norma (no sólo un abstracto criterio de equidad, que sólo tiene valor entre iguales) (27).

La influencia de esta doctrina en Marco Aurelio y el hecho de que aluda con tanta frecuencia a la precariedad y fragilidad de todas las cosas, en especial del hombre, se ha interpretado algunas veces como un intento de sobrevalorar el Estado, presentándolo al individuo particular como un remedio a su debilidad e impotencia. En la identificación con él y con sus leyes podría encontrar una vía para huir de su soledad y encontrar amparo, protección y seguridad; en este sentido, era lógico que considerara como verdadero mal sólo lo que amenazaba a la Polis, o se oponía a sus leyes, o minaba los cimientos de su seguridad (Soliloquios, X, 33 y V, 22).

G. Drago piensa que en realidad la estatolatría no presenta en estos textos «un effettivo agguato ideologico» (DRAGO, 1957, 255). Tales alusiones, escasas y breves, se refieren más bien a la sociedad de todos los hombres que a un verdadero y propio organismo político; en su pasaje importante del libro IX, 23, hace esta reflexión: puesto que cada individuo es un miembro del cuerpo social, cada una de sus acciones debe contribuir a perfeccionar la vida social. Todo lo que en cada uno de los miembros no se ordene, de algún modo, al bien social es disgregador de la vida del todo, debe considerarse como una «sedición», lo mismo que si en una república alguien pretendiera mantenerse al margen de este concierto.

Ya se trate de solidaridad cósmica o política, el estoicismo intentó fundamentar y organizar, en un universo tan complejo, el civismo imperial. Esta filosofía, vacía de contenido político, pero rica en imperativos generales (sacrificio ante el interés colectivo, sentido de la unidad del mundo civilizado, aceptación de una moral común), fue «el crisol donde se elaboró, al menos para las clases privilegiadas, una nueva idea de Imperio» (J. TOUCHARD, 1972, 82).

\section{IV}

Marco Aurelio, que era sin duda «una figura excepcional de hombre político y al mismo tiempo de hombre culto» (A. GUARINO, 1975, 335), subrayó con especial vigor el carácer social del hombre, siendo esta idea una de las claves de su concepciòn de la vida política. En un pasaje del libro V razona del modo siguiente: todos los seres son movidos y dirigidos por el fin para el que han sido constituidos; donde está su fin, allí se encuentra también para cada uno su interés y su felicidad; ahora bien, el fin de un ser racional es la sociedad: para vivir en sociedad hemos sido hechos los hombres; porque si los seres inferiores están destinados a servir a los superiores, estos últimos deben vivir unos para otros (Soliloquios, V, 16). La sociabilidad es la primera característica de la condición del hombre (VII, 55). Es un ser naturalmente sociable, en cuanto ser dotado de razón (IV, 24). Vivir al margen del cuerpo social sería atentar contra la vida del «todo», constituirse en factor de desequilibrio y desorden (IX, 23).

(27) Ib., 116 ss.; observa PAOLI también que aunque más tarde PLATON, en la República, desenvolverá sistemáticamente su doctrina del principio asociativo que preside la formación de la Polis, ya en el

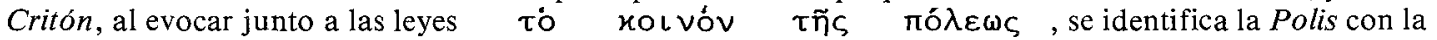
colectividad que la constituye y su voluntad con la voluntad de los consociados, a la cual el individuo debe someterse. 
A fin de expresar de forma inteligible esta doctrina, Marco Aurelio recurre a imágenes y metáforas que ilustran con claridad su pensamiento. El hombre separado de la sociedad vendría a ser algo tan monstruoso como una mano o un pie que quisieran desprenderse del cuerpo y vivir independientes, rompiendo con la unión natural (Soliloquios, VIII, 34). Pensando en sí mismo, expresa su deseo de mantenerse en sociedad y, con el pensamiento de Dios siempre presente, actuar y vivir dentro de ella (Soliloquios, VI, 7). Esta presencia activa exige, por otra parte, una serie de disposiciones interiores: el desinterés, la sensibilidad para percibir el auténtico bien de la comunidad, la voluntad de servicio y la decisión de hacer lo que es útil a la sociedad (Soliloquios, V, 6).

La doctrina de Marco Aurelio no está, pues, presidida únicamente por la idea de la felicidad personal, por un ideal moral individualista. Las acciones humanas deben orde-

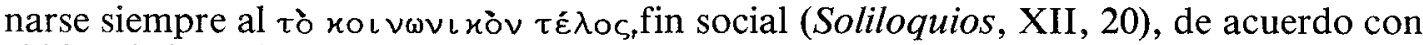
el bien de la Polis. Aconseja que cuando uno encuentre fuerzas para abandonar el reposo y salir de la inacción recuerde que su constitución racial y su naturaleza le destinan a obrar por la utilidad de la sociedad en que vive; mostrándose en su vida de acuerdo con esta exigencia interior, encontrará la fuente del gozo y el secreto de su felicidad como hombre (Soliloquios, VIII, 12). Haciendo así se mostrará como un verdadero sacerdote y ministro de los dioses (Soliloquios, III, 14).

Mientras que los demás seres son mantenidos en unión por diversas fuerzas, la Inteligencia (dianoia), por un privilegio singular, tiende a establecer vínculos entre los hombres y a satisfacer así la necesidad de comunicación, más allá de todos los obstáculos (Soliloquios, X, 30). En un pasaje importante del libro XI, 18, tras afirmar explícitamente que «estamos hechos los unos para los otros», hace un análisis de los peligros que amenazan la sociabilidad: la ignorancia y los prejuicios, la hipocresía, el egoísmo, los odios, la ira; termina con esta reflexión: no admitir que los malvados cometen desmanes y ofensas sería una locura, equivaldría a exigir lo imposible; pero permitir que obren así con los demás hombres preocupándose sólo de que a uno mismo le respeten. sería una falta de cordura y, a la vez, una manifestación de tiranía.

Este profundo sentimiento de la solidaridad universal encuentra su expresión última en el amor al género humano, al cual invita explícitamente Marco Aurelio de diferentes maneras. Unas veces recuerda que los hombres son partes de una totalidad superior a cuyo bien deben contribuir las acciones de los individuos particulares, poniendo el interés común por encima de toda ambición o apetencia personales (Soliloquios, X, 6); otras veces desarrolla ampliamente las consecuencias que se derivan del principio de que «hemos sido hechos unos para los otros» (Soliloquios, XI, 18); en algunos momentos, renunciando a toda digresión ulterior, establece el principio del amor al género humano de forma imperativa y directa (28). En una ocasión afirma que si en cuanto Antonino es un miembro de Roma, su patria, en cuanto hombre su patria es el mundo (29).

La concepción del universo como un todo unitario y orgánico manifiesta claramente hasta qué punto había influido en Marco Aurelio la doctrina de Posidonio (30). Un

(28) Soliloquios VII, 31; el principio del amor universal, que había sido proclamado por las grandes religiones de la antigüedad anteriores al cristianismo, encontró en el estoicismo una formulación que no había sido suficientemente puesta de relieve todavía por los griegos, más interesados por la idea de la justicia que por el ideal de la benevolencia (cf. A. C. GARNETT, 1956: «Charity and Natural Law», Ethics, 66, 177 ss.).

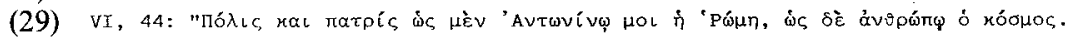

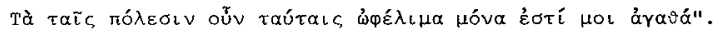

(30) Este filósofo, representante máximo del llamado «estoicismo medio», tuvo un influjo muy notable en una serie de pensadores romanos anteriores a MARCO AURELIO. Particularmente debe recordarse su estimación por parte de CICERON, SENECA, LUCRECIO, VARRON y PLINIO. Una breve caracterización de su filosofia puede verse en R. REIZENSTEIN, 1930: «Die Charakteristik der Philosophie bei Poseidonios», Hermes, 81 ss. 
eco claro de esta influencia puede verse en el célebre pasaje del libro VI donde se habla de la "cohesión de todo lo que existe en el mundo», del «encadenamiento de unas cosas con otras», de la «unión de la substancia»y del «perfecto concierto» que existe en el universo (31). Si es cierto que la idea de la «totalidad orgánica» es una de las tesis que caracterizan desde el principio al estoicismo (V. GOLDSCHMIDT, 1972, 283), POSIDONIO introduce nuevos elementos y elabora de forma original la doctrina de la $s y$ mpatheia, concibiéndola como originada del Fuego, que en su sistema es al mismo tiempo principio primordial de los seres y Razón ordenadora (E. ELORDUY, 1972, I, 89).

Mientras que todas las cosas en el universo, desde las inferiores a las superiores, siguen espontáneamente el impulso que las lleva a buscar a sus semejantes y a fundirse con ellos, el hombre es el único ser que, olvidando su condición razonable y social, puede marginarse de la sociedad y aislarse, rompiendo los lazos que le unen a los demás hombres. Pero es un intento vano, puesto que la naturaleza «es siempre la más fuerte» (Soliloquios, IX, 9). En realidad, todos aquellos obstáculos que se oponen a la convivencia (el egoísmo, el odio, la envidia, la insolencia, la mentira) y que enfrentan a los hombres entre sí, cuando no se les opone resistencia, hacen que el hombre obre y se comporte contrariamente a la naturaleza (Soliloquios, II, 1) y, por tanto, contra la razón, puesto que el bien de un ser razonable es la sociedad (Soliloquios, V, 16).

Por otra parte, como observa Jarra, Marco Aurelio no se ocupa de la división jurídica de la sociedad humana. Partiendo del principio según el cual los seres inferiores han nacido para los superiores y éstos deben vivir unos para los otros, como ya expusimos, establece la división de los hombres en subordinados y coordinados. Su razonamiento es el siguiente: la inteligencia universal es sociable; ahora bien, ella ha subordinado y coordinado los seres, asignando a cada uno su parte, $\mathrm{y}$ ha dispuesto que los seres superiores vivan entre ellos armoniosamente. No interesa tanto la superioridad o inferioridad de origen, puesto que el estoicismo había ya repetidamente enseñado la igualdad natural de todos los hombres (32), como la igualdad social. Expresamente dice que debe a Claudio Severo el haber adquirido la clara noción de un Estado democrático, con un gobierno fundado en la igualdad del derecho para todos (Soliloquios, I, 14).

Esta última consideración obliga a plantear el tema de la esclavitud en Marco Aurelio. Aunque se preocupó por aliviar la situación de los esclavos (33), su propia filosofía cerraba el paso a cualquier intento que significara romper con el orden establecido y el sistema de clases que estaba a su base. La unidad y armonía del cosmos, presidida por el logos universal, encontraba un reflejo inmediato en la estructuración jerárquica de la propia civitas, en la organización social del Imperio. La doctrina de la armonía, de la coordinación y subordinación, combinada con la constante apelación a la pronoia, imponía a cada hombre el permanecer fiel a los deberes que le impone su propio estado, à la situación concreta que señala a cada uno la naturaleza universal (Soliloquios, V, 55).

Por lo demás, sean cuales fueren los méritos del estoicismo en orden a invalidar las anteriores ideas griegas sobre la esclavitud (34), lo cierto es que la Estoa no se atrevió a

(31) Soliloquios, VI, 8; esta idea de la armonía universal en Posidonio ha sido ampliamente estudiada por K. REINHARDT, 1926: Kosmos und Sympathie.

(32) Particularmente importante es la insistencia de SENECA en esta idea. En De Beneficiis, 3, 28, escribía: «eadem omnibus principia, eademque origo; nemo altero nobilior, nisi cui rectius ingenium, et artibus bonis aptius est... Unus omnium parens mundus est: sive per sordidos gradus, sive per splendidos, ad hunc prima cujusque origo perducitur». Cf. el estudio de P. AUBENQUE, I, 1960: «Sénéque et l'unité du genre humain», Actas del Congreso Internacional de Filosofía, Córdoba, 77 ss.

(33) Algunas leyes promulgadas por MARCO AURELIO limitaban las ventas de los esclavos para hacer de ellos gladiadores, obligando al comprador de un esclavo a darle la libertad si se había acordado así (D. $40,2,20,1)$.

(34) Cf., por ejemplo, P. A. MILANI, 1972: La schiavitù nel pensiero politico: I. Dei Greci al Basso Medioevo, Milán. 
proclamar la libertad total de los esclavos (E. ELORDUY, 1972, 270), aunque contribuyó eficazmente a mejorar su situación y a humanizar las leyes. En este sentido debe destacarse la decisiva influencia de Séneca (35). Al comienzo de la República los esclavos vivían con los hombres libres en una estrecha comunidad de vida y de trabajo; posteriormente, a consecuencia de las grandes explotaciones agrícolas e industriales, terminaron convirtiéndose en un mero instrumento de trabajo, pasando a la categoría de res (36). El esclavo no es sujeto de derecho; no tiene derechos personales ni patrimoniales y viene a ser, en suma, «une sorte d'animal domestique» (GAUDEMET, 1967, 146). Más adelante, en especial por influencia de las doctrinas estoicas (y por la sensibilidad a las mismas de los juristas), fueron atenuándose estas condiciones, aunque no se les concede personalidad jurídica. Incluso bajo los emperadores cristianos no se llega a suprimir la esclavitud en el ordenamiento jurídico romano. Sólo en el derecho de las Novellae aflora el principio de que los hombres nacen naturalmente libres y que la condición del esclavo no es inherente a la persona. En el caso de Marco Aurelio, como ya apuntamos, las bases ideológicas en que se apoya su visión del Imperio y de la vida política no ofrecían, en éste como en otros campos, ninguna base para cualquier innovación sustancial en los planteamientos.

Como aparece claramente de la exposición anterior, Marco Aurelio no ofrece en su obra una doctrina política en sentido estricto. Al resumir el contenido doctrinal de sus Soliloquios «se diría que se agota por entero en la práctica de la justicia, virtud general, o en ese deber de actividad social que para cada uno predica. La moral ha absorbido completamente a la reflexión política» (J. TOUCHARD, 1972, 85). El estoicismo, tras haber llegado a ser el regulador de un Imperio unificado y bien establecido, asegurando el ejercicio moderado del poder monárquico e imponiendo a todos la participación en los negocios públicos como un deber categórico, se había ido desgastando paulatinamente; de este modo, «el tono que adopta Marco Aurelio se ha detenido y la política no es sino conservación» (J. TOUCHARD, 1972, 86).

Más recientemente, al estudiar el pensamiento estoico en la época imperial y su peculiaridad ideológica, G. Puente Ojea (1974, 212 ss.) ha destacado cómo al acentuar tan fuertemente la resignación a la voluntad divina y el retorno a la intimidad de la conciencia, el estoicismo, impregnado por los ideales de la civitas, se vuelve manifiestamente ambiguo y se resuelve últimamente en un claro conformismo político (37). En concreto, las meditaciones de Marco Aurelio, menos obsesionado por la huida del mundo que Epicteto (38), trasluce la específica función ideológica del estoicismo al servicio del Imperio (PUENTE OJEA, 1974, 229). La insistencia en la pronoia, en la justicia inmanente que rige el orden cósmico, en la fugacidad de la existencia personal, en la mutación de todas las cosas y en la armonía del mundo, «expresa el sentido conservador y estático de la filosofía social del Imperio» (PUENTE OJEA, 1974, 230), el intento de liberar al sabio de comprometerse en la reforma de la sociedad y de conseguir de todos el respeto al

(35) Es clásica, por ejemplo, la obra de J. LICHY, 1927: De servorum condicione quid senserit L. $A$. Seneca, Münster; cf. también E. ELORDUY, 1972, 268 ss.

(36) Cf. J. IGLESIAS, 1972: Derecho Romano, 117; acerca del tiempo de esplendor de la economía de los esclavos en la República romana cf. STAERMAN, 1969: Die Blütezeit der Sklaven wirtschaft in der römischen Republik, Wiesbaden.

(37) G. PUENTE OJEA, 1974, 212 ss. En los capítulos anteriores, el autor estudia la ideología estoica en la crisis de los reinos helenísticos y en el apogeo romano, intentando descubrir sus fundamentos filosóficos y su peculiaridad ideológica en cada uno de estos momentos de su historia.

(38) En la Historia de la Filosofía publicada por la Academia de Ciencias de la URSS (Ed. Grijalbo, México, 1960, I, 141-142) se señala que «en la doctrina estoica del liberto Epicteto se expresaba cierta protesta de las masas oprimidas contra el régimen de la esclavitud, cuando se apagaba la luz de la razón y la ciencia, y la filosofía idealista se hundía en las tinieblas del misticismo fundida por completo con la religión». 
poder político, garantía de una convivencia que preserva contra la disgregación y el caos.

El problema de las relaciones del Estado romano con la Iglesia cristiana adquiere una relevancia singular en la época de Marco Aurelio. Curiosamente, sólo en un pasaje de sus Soliloquios se hace una mención explícita de los «cristianos», juzgando su prontitud para afrontar la muerte y su disponibilidad para el martirio como muy poco inspirada en la razón, excesivamente fanáticas y teñidas de «pose teatral» (Soliloquios, XI, 3). Esta valoración coincide con la convicción expresada por Epicteto, para quien la aparente intrepidez cristiana es más bien un ejemplo de obstinación absurda; sacrificio irracional, más que voluntad reflexiva; instinto ciego, más que inteligencia clara y conducta dictada por el «logos» (39).

Según algunos autores, debe considerarse también como una alusión a los cristianos el pasaje del libro III en que se habla de las diferentes formas de tomar la inteligencia por guía sólo en apariencia (Soliloquios, III, 16), así como otros textos a propósito de la actividad ante la muerte (Soliloquios, VII, 68), o la irracionalidad de la conducta (Soliloquios, VIII, 51). En cualquier caso, según veremos, consideró que la fidelidad a la religión tradicional de Roma le obligaba a oponerse con energía a la expansión y consolidación de la nueva religión en el Imperio.

La religión, aparte de sus aspectos mítico y natural, había tenido, sobre todo a finales de la República, una función eminentemente política. En ella residía uno de los instrumentos esenciales para el gobierno del Estado. Cicerón tuvo una conciencia clara de este hecho. Una de las consignas que da en su De Legibus es el mantener los dioses públicamente admitidos, rechazando los nuevos y extraños (40), puesto que estos últimos introducirían la confusión en la Civitas (41). Manteniéndose los ciudadanos fieles a los cultos establecidos y sometiéndose al consejo y autoridad de los hombres de más prestigio, en especial los sacerdotes y augures, no dejarán de formarse opiniones útiles y verdaderas sobre el auténtico bien de la República (42).

Los motivos políticos y patrióticos fueron también, sin duda, los que determinaron a Marco Aurelio a preocuparse con gran diligencia del culto de los dioses tradicionales. Pese a que, siguiendo el ejemplo de los emperadores anteriores, su Pantheon estaba abierto a todos los dioses y él mismo se inició en el conocimiento de diversos cultos, la razón de estado y el respeto por la antigüedad prevalecieron (L. PARETI, 1966, 352). Por otra parte, en su época, una serie de escritores, apoyándose en las antiguas acusa-

(39) Para EPICTETO el ethos no es nada sin el logos; por eso «no concede ningún valor a un sacrificio irracional, dictado por una fe obtusa o por el contagio ejemplar» (P. DE LABRIOLLE, 1942, «Tiempos de seguridad y de desdén», Escorial, 9, 49-50).

(40) «Separatim nemo habessit deos neve novos neve advenas nisi publici adscitos; privatim colunto quos rite a patribus cultos acceperint» (De Legibus II, 8, 19).

(41) CICERON considera que los dioses y los hombres viven dentro de la misma comunidad como miembros de ella. Entiende que hicieron muy bien los griegos y los antepasados de Roma al concebir de este modo las cosas, pues de ahí se sigue un aumento de la piedad para con los dioses y, al mismo tiempo, la religión se muestra como útil para la Civitas (De Legibus, II, 11, 26).

(42) «Quod sequitur vero, non solum ad religionem pertinet sed etiam ad civitatis statum, ut sine iis qui sacris publice praesint, religioni privatae satis facere non possint. Continet enim rem publicam, consilio et auctoritate optimatium semper populum indigere.... (De Legibus, II, 12, 31); casi inmediatamente señala CICERON que dentro de la República el orden jurídico principal y más relevante se apoya en la autoridad de los augures, a quienes corresponde disolver los comicios o concilios convocados por los más altos poderes, o anular los que ya se celebraron. 
ciones populares, se oponían abiertamente al cristianismo. Baste pensar en su maestro Frontón, en Apuleyo y en Celso (J. DAZA, 1975, 37). En el Digesto se hace alusión a un rescripto de Marco Aurelio en el que se toman medidas contra quienes intentan aterrorizar a los espíritus más débiles con supersticiones (literalmente, «por la superstición de un Numen»); tal disposición se completa con otro texto similar que refiere Paulo (Sentent. 5, 21, 2: D. 48, 19, 30). Observa Pareti que este rescripto se refiere a los cristianos, o, al menos, los comprende. En cualquier caso, «siamo così tornati indietro, nella prassi coi cristiani, ai sistemi suggeriti da Traiano a Plinio Secondo: e colpa sufficiente per procedere è, ch'essi facciano propaganda della loro fede» (L. PARETI, 1966, 354).

En torno al año 177, tres años antes de la muerte de Marco Aurelio, se opera un endurecimiento brusco del Estado romano contra el cristianismo (43). Los nuevos decretos del Emperador no alteraban oficialmente la legislación referente a los cristianos (M. SORDI, 1961, 365), pero reflejaban la tendencia de la legislación imperial a centralizar toda la administración de la justicia, aun cuando se otorgaba una mayor libertad de iniciativa a los gobernadores de provincia. En cualquier caso, demuestran la voluntad personal del emperador de oponerse al cristianismo; de hecho, la persecución que tuvo lugar poco antes del año 177 fue decretada ciertamente por él (M. SORDI, 1962, 2).

No es fácil explicar por qué Marco Aurelio, por primera vez después de Nerón y Domiciano, llegaba a la conclusión de que los cristianos representaban una seria amenza para el Imperio y que, por tanto, debían ser combatidos (J. DAZA, 1975, 37 ss.). De acuerdo con las investigaciones recientes, especialmente los estudios de M. Sordi, debe decirse que lo que en realidad provocó la alarma de las clases dirigentes romanas no fue la intransigencia de los mártires, sino más bien la actitud provocativa adoptada por el movimiento montanista, tan peligroso para la sociedad romana como para la propia Iglesia. Aparte de su pretendida inspiración religiosa, debe reconocerse el núcleo de verdad que encierra la interpretación del Montanismo dada por Kovaliov y otros autores marxistas, según los cuales este movimiento apareció como una doctrina que se oponía a la universalidad del Cristianismo, era contraria a cualquier intento de entendimiento con el Estado y denunciaba el compromiso de los sectores más pudientes de la comunidad cristiana con la sociedad dominante romana (S. I. KOVALIOV, 1973, 256).

En esta situación confusa, no es extraño que entre los años 172 y 177 fueran dirigidas a Marco Aurelio diversas «Apologías» cuya finalidad común consistía en intentar aclarar el equívoco que había hecho surgir el Montanismo entre el Imperio y el Cristianismo, a causa de su carácter intransigente frente a la sociedad pagana. Así Milciades es autor, además de una obra antimontanista y otra contra los valentinianos (J. QUASTEN, I, 1961, 219), de tres apologías que comprendían (aparte de otros libros) una obra en defensa de la doctrina cristiana dirigida a los «príncipes de la tierra», esto es, a Marco Aurelio y Lucio Vero. Apolinar es autor de otro discurso dirigido a Marco Aurelio en el año 172 (EUSEBIO, IV, 27), casi en la misma fecha en que el obispo de Sardes, Melitón, dirige al Emperador otra apología en la que se manifiesta quizá, por primera vez, el pensamiento de que un régimen de relaciones amistosas entre el Estado y la Iglesia debería ser cosa normal (B. ALTANER, 1952, 126). Por último, Atenágoras, a quien J. Quasten $(1961,220)$ califica como el más elocuente de los apologistas cristianos primitivos, escribe en el año 177 su conocida «súplica en favor de los cristianos», en cuya introdución queda expresado con toda claridad el propósito de la obra: «Por nuestro discurso habéis de comprender que sufrimos sin causa y contra toda ley y razón; os suplicamos que también sobre nosotros pongáis alguna atención para que cese, finalmente, el degüello a que nos someten los calumniadores» (M. PELLEGRINO, 1947, 65).

(43) Este mismo año, según el testimonio de EUSEBIO, hubo una gran cantidad de mártires (Historia Eclesiástica, V, prólogo). 
Esto supuesto, el hecho de que al año siguiente apareciera la obra de Celso «Alethès Logos» (44), se interpreta como una respuesta a tales Apologías. En efecto, este filósofo estaba íntimamente vinculado con la clase dirigente romana y, según ha subrayado Harnack, su obra está presidida por una clara preocupación política. La valoración negativa del Cristianismo que se hace en ella obedece a su intento de defender la supremacía de la tradición cultural griega y las bases ideológicas en que se asienta el Imperio (45). En diversas ocasiones pide que los cristianos salgan de su aislamiento político y que colaboren con el Emperador en un momento en que se precisa su ayuda para luchar contra los pueblos bárbaros (46). Pero era consciente de la amenaza real que representaba el Cristianismo para los ideales vigentes en el Imperio.

En efecto, Celso, que participaba de la convicción de que las leyes de la CIUDAD, establecidas desde el origen, son como el eco y la presencia inmanente de un orden inmutable dado por los dioses (ORIGENES, $C$. Celsum, IV, 69), comprendió inmediatamente el peligro de subversión que llevaba consigo la doctrina monoteísta cristiana y el carácter universalista de la nueva fe. Para él resultaba claro el nexo entre ambas cosas: supuesto que el «Dios Supremo» en que él se apoya tolera las religiones tradicionales de los diversos pueblos, no puede en modo alguno aceptar como válido un ideal de vida que no impone la obediencia a una tradición y que subvierte los cultos nacionales, poniendo en peligro uno de los fundamentos del mismo Imperio Romano. Así se explica el dilema que formula el mismo Celso a los cristianos, en el sentido de que si ellos se obstinaban en ponerse al margen de la comunidad política, el Emperador no podía tolerar su presencia (C. Celsum, VIII, 78). Reconoce incluso que podría discutirse la posibilidad de admitir la fe monoteísta cristiana en el caso de que las particularidades nacionales fueran superadas alguna vez; pero esto le parece a él imposible ( $C$. Celsum, VIII, 72). En suma, Celso retiene como verdaderamente inaceptable la ruptura con el antiguo principio de la vinculación política y nacional de lo religioso que lleva consigo implícita la fe cristiana.

Pese a que el monoteísmo que profesaban los cristianos era una doctrina heredada del judaísmo, el hecho de que la religión judía acentuara el carácter nacional, mientras que el cristianismo insistía más bien en el ideal universalista, la hacía más aceptable para la mentalidad dominante en el Imperio. C. Lepelley da la explicación siguiente de este hecho: si los judíos fueron más tolerados, se debe a que constituían una etnia particular y bien definida que podía ser aceptada de acuerdo con las exigencias de la organización jurídica romana; en cambio, el universalismo cristiano y su apertura a todas las razas y pueblos tenía que juzgarse intolerable (C. LEPPELLEY, 1969, 17). Ya los apologetas habían insistido en el carácter de novedad del mensaje cristiano, subrayando que la Iglesia es el Nuevo Israel, sujeto de la elección divina, el tertium genus predestinado a ser el ámbito privilegiado de la Oikonomía. Orígenes insistirá más tarde en esta universalidad, subrayando su condición de «Ecclesia ex gentibus». La mayor benignidad de la política imperial respecto a los judíos se explicaría por su fidelidad a un pasado, a unas tradiciones, costumbres y creencias, mientras que la intransigencia con el cristianismo estaría justificada por su carácter innovador, interpretado como una amenaza por el poder establecido (47).

(44) No hay unanimidad sobre la fecha exacta de su aparición, cf. H. CHADWICK, 1965, IX ss.

(45) Este aspecto ha sido estudiado en profundidad por C. ANDRESSEN, 1955; cf. también J. DAZA, 1975,37 ss.

(46) He aquí las palabras de CELSO recogidas por ORIGENES: «...nam si te omnes imitarentur, nec mora, solus rex relinqueretur et desertus et quaecumque in terra sunt in impiorum et agrestissimorum barbarorum dictionem venirent, cultusque tui veraeque sapientiae gloria ex hominibus evanesceret) $(C . C e l$ sum, VIII, 78).

(47) Cf. M. SIMON, 1964: Verus Israel, 125 ss. (todo el capítulo IV está dedicado al tema «Roma, Judaísmo y Cristianismo»). En p. 138 insinúa que el judaísmo, tolerado y protegido por el Estado romano, pudo ser muy bien un instrumento apto para hacer frente al cristianismo. 
No puede pasarse por alto que ya en esta época, muy próxima a la gran crisis del siglo III, al naufragar los antiguos valores y creencias, al afirmarse nuevas fuerzas disgregadoras, al mostrarse claramente incapaces de nuevas creaciones las filosofías vigentes, aparecían claramente insatisfechas las aspiraciones de los hombres del Imperio. Era normal que, aparte de otras razones de tipo político, se intentara absorber al mensaje cristiano dentro del sistema social dominante, a fin de neutralizar así —como ocurrió con otras religiones - su fuerza subversiva en relación con la cultura tradicional de Roma (48). De modo particular, debe tenerse en cuenta que el cristianismo, como ya expusimos en otro lugar (J. DAZA, 1975, 53 ss.), se oponía abiertamente al culto imperial, que, más que una simple apoteosis litúrgica, era una forma sutil de explotación política de la religión romana y un medio de mantener vivo el espíritu romano en las provincias del Imperio (49).

M. Sordi, tras aludir a una disposición que, según el testimonio de Tertuliano, habría promulgado Marco Aurelio, y en el cual el Estado asumía la iniciativa de perseguir ex officio a los cristianos, al mismo tiempo que ponía límites a las acusaciones privadas contra ellos, señala que así se buscaba cumplir dos objetivos: de una parte, mantener el derecho de intervenir directamente en el caso de que la difusión del Cristianismo constituyera un peligro político; por otro lado, hacer posible a los cristianos la participación en la vida pública a la cual les invitaba Celso, según vimos. De este modo, entiende que Marco Aurelio abría una nueva página en la historia de las relaciones entre el Cristianismo y el Imperio (50). Sin embargo, las raíces profundas del conflicto permanecían intactas y la oposición de fondo iba a seguir viva - ya sea de forma latente o manifiestadurante mucho tiempo.

(48) Cf. E. R. DODDS, 1968: Pagan and christian in age of anxiety, Cambridge, 107.

(49) El culto al emperador, observa H. LECLERQ («Eglise et Etat», Dic. Archeol., IV, 2249), significa fundamentalmente que éste quedaba constituido como un ser sagrado precisamente en cuanto representante del Estado romano; su autoridad no se apoyaba sobre la religión: era ella misma una religión; el emperador no representaba a una divinidad, sino que él mismo era un dios. Consiguientemente, este culto era de hecho una manifestación pública de lealtad poíitica.

(50) M. SORDI, 1965, 197; la autora amplía esta idea diciendo que con MARCO AURELIO «lo stato usciva dall'indifferenza e dalla neutralità che fino allora aveva mantenuto, salvo che con Nerone e Domiziano, nei confronti della nuova religione, e cominciava a considerare il cristianesimo come un problema político che doveva essere risolto o con una lotta aperta, senza quartiere, o con un tentativo di conciliazione». Si en un primer momento MARCO AURELIO, a causa de la agitación montanista, siguió el primer camino de la dureza e intransigencia, posteriormente el emperador se habría convencido de que la colaboración era posible.

Una exposición amplia de la política religiosa de los Antoninos puede verse en J. BEAUJEU, 1955, 96 ss.; interesantes observaciones y tomas de posición se encuentran también en J. BIRLEY, 1966, 328-331. 


\section{BIBLIOGRAFIA}

ALFONSI, L.: "Contributo allo studio delle fonti del pensiero di Marco Aurelio», Aevum, 28, 101 ss. ALSINA, J. 1971: Tragedia, religión y mito entre los griegos, Barcelona.

ALTANER, B. 1952: Patrología, Barcelona.

ANDRESSEN, C. 1955: Logos und Nomos. Die Polemik des Kelsos wider Christentum, Berlín.

AXELOS, K.: 1962: Héraclite et la Philosophie, la première saisie de l'être en devenir de la totalité, avec' une orientation bibliographique, París.

ARNOLD, E. V. 1958: Roman Stoicism, Londres.

BEAUJEU, J. 1955: La religion romaine à l'apogée de l'Empire, I, París.

BIRLEY, A. 1966: Marcus Aurelius, Londres.

BODSON, A. 1967: La morale sociale des derniers stö̈ciens. Sénèque, Epictète et Marc-Aurèle, París.

CARRATA, F. 1955: Per la critica di Marco Aurelio, Turín.

CHADWICK, H. 1965: C. Celsum, Cambridge.

D'AGostino, V. 1962: Studi sul neostoicismo. Seneca, Plinio il Giovane, Epitteto, Marco Aurelio, Turin.

DAZA, J. 1975: Imperio Romano y Cristianismo. Ideología y política en la polémica de Origenes contra Celso, Cuenca.

DE PROYAT, P. 1962: Marc-Aurèle, un empereur citoyen du monde. París.

DILL, S. 1904: Roman Society from Nero to Marcus Aurelius, Londres.

DRAGO, G. 1957: «Marco Aurelio Antonino», Novissimo Digesto Italiano, Turín.

ELORDUY, E. 1972: El estoicismo, Madrid.

FARQUHARSON, A. S. 1944: The Meditations of Marcus Antoninus, Oxford.

FASSO, G. 1966: Storia della Filosofia del diritto, I, Bolonia.

FUSCI, G. G. 1904: La Filosofia di Ant. in rapporto con la filosofia di Seneca, Musonio ed Epitteto, Modica.

GAUDEMET, J. 1967: Institutions de l'Antiquité, París.

GOLDSCHMIDT, V. 1953: Le système stö̈cien et l'idée de temps, París.

GÖRLITZ, W. 1962: Marc-Aurèle empereur et philosophe, París.

GUARINO, A. 1975: Storia del Diritto Roman, Nápoles.

HAINES, C. R. 1955: The correspondence of Marcus C. Fronto, Londres.

JARRA, E. 1932: «Marco Aurelio filosofo del diritto», RIFD, 12, 499 ss.

JONES, A. 1966: Decline of Ancient World, Londres.

KILB, G. 1939: Ethische Grundbegriffe der alten Stoa..., Friburgo.

KIRK, W. CH. 1940: Fire in the cosmological speculations of Heraclitus, Minneápolis.

KOVALIOV, 1973: Historia de Roma, II, Madrid.

LEPPELLEY, C. 1969: L'Empire Romain et le Christianisme, París.

LOTZ, J. B. 1953: «Hörer des Logos. Der Mensch bei Heraklit von Ephesus», Scholastik, 28, 543-570.

MANCINI, G. 1940: L'Etica stoica da Zenone a Crissipo, Padua.

MAYOR, D. 1960: «Heráclito «el sombrío», Humanidades, XII, 311 ss.

MIGNUCCI, M. 1965: Il significato della logica stoica, Bolonia.

MONDOLFO, R. 1966: Heráclito. Textos y problemas de su interpretación, México.

NEUNSCHWANDER, H. R. 1951: Mark Aurels Beziehungen zu Seneca und Poseidonios, Berna.

PARETI, L. 1960: Storia di Roma e del mondo romano, V, Turín.

PELLEGRINO, M. 1947: Studi sull'antica apologetica, Roma.

PUECH, A. 1964: en el «Preface» a la edición bilingüe de los Pensamientos de Marco Aurelio, París.

PUENTE OJEA, G. 1974: Ideología e historia. El fenómeno estoico en la sociedad antigua, Madrid.

QUASTEN, J. 1961: Patrología, I, Madrid.

RENAN, E. 1881: Marc-Aurèle et la fin du monde antique, París.

REMONDON, R. 1967: La crisis del Imperio Romano, Barcelona.

ROSTOVTZEFF, M. 1973: Historia social y económica del Imperio Romano, II, Madrid.

SEVERINO, E. 1963: «La parola di Anaximandro», Ruv. di Fil Neo-Scol., LV, 162 ss.

SIRAGO, V. A. 1974: Involuzione politica e spirituale nell'Impero del II secolo, Roma.

SORDI, M. 1961: «I nuovi decreti di M. Aurelio contro i cristiani», Studi Romani, IX, 365 ss.

- 1962: «Le polemiche intorno al cristianesimo nel II secolo e la loro influenza sugli sviluppi della politica imperiale verso la Chiesa, Rivista di Storia della Chiesa in Italia, XVI, 2 ss.

1965: Il Cristianesimo e Roma, Bolonia.

STARR, C. G. 1954: Civilization and the Caesars, N. Rork.

TOYNBEE, A. J. 1959: «Hellenism». The History of a civilization, Londres.

TOUCHARD, J. 1972: Historia de las ideas políticas, Madrid.

WALSER G.-PEKARY, T. 1962: Die Krise des römischen Reiches, Berlín.

VAN DEN HOUT, M. 1950: «Reminiscences of Fronto in Marcus Aurelius Book of Meditations», Mnemosyne, 4, 33 ss.

WENLEY, R. M. 1948: El estoicismo y su influencia, Buenos Aires. 


\title{
EL PRESTAMO Y LA USURA EN EL MEDITERRANEO ANTIGUO
}

\author{
JOSE MARIA GARCIA GONZALEZ \\ Universidad de Alicante
}

\begin{abstract}
La regulación de préstamo con intereses en los distintos pueblos del antiguo Mediterráneo está condicionada no sólo por concepciones teóricas sobre la riqueza, el dinero y su tráfico, concepciones que, a veces, como en el caso de Grecia y Roma, son muy similares, sino también por las ideas políticas y por las particulares condiciones de vida en que cada uno de aquellos pueblos se desenvuelve. De ahí las diferencias de tratamiento que recibe el asunto en los derechos romano, griego, egipcio e israelita. Estos derechos serán, durante la expansión de Roma y por efecto de ella, relativamente homogeneizados en el seno del propio derecho romano. Finalmente se superpondrá, tomando como vehículo a la propia Roma, la idea cristiana de la caridad y la hermandad universales.
\end{abstract}

The regulation of loan with interest rates in the various populations of the ancient Mediterranean is conditioned not only by commerce (which are sometimes very similar, as is the case of Greece and Rome), but also by political ideas and by the charateristic conditions of existence developed in each of the populations. This is the reason for the different treatment given to this matter in Roman, Greek, Egyptian and Israelite law. These laws were, during the expansion of Rome and by its effects, relatively homogeneous within Roman Law itself. The Christian ideas of universal charity and brotherhood will be superimposed on it, taking Rome itself as their vehicle.

El tema de la usura y su discontinua, espectacular y accidentada suerte histórica se proyecta en áreas muy variadas de la vida social que, desde siempre, se han visto colonizadas por abundante y minuciosísima literatura. No hay para qué ponderar la acumulada en los campos de la ética y la teología moral, de la economía, del derecho... Aun la literatura de recreo, desde Aristóteles o Plauto hasta Moliere o Balzac, ha extraído de las multifariae calliditates de los usureros inagotable pábulo para la hilaridad de las generaciones; o para su estremecimiento dramático, en que el sombrío horror de un Shylock es casi literal resonancia del apóstrofe senequiano contra las sanguinolentae centesimae. Y, a su vez, como cerrando un círculo, estas criaturas de la ficción parecen retribuir a las ciencias de la conducta humana parte del préstamo que, al remedarla, toman de dicha conducta: los estudiosos, por ejemplo, de la antropología criminal, han obtenido en los estereotipos de la escena un repertorio riquísimo, y de no mala calidad, para la confección de tipos criminológicos, tan interesantes a la ciencia penal.

Entre los variadísimos problemas suscitados por la usura, uno de los datos que más inmediatamente se observan es el de la permanente tensión que mantiene en todo tiempo conectados dos órdenes de desarrollos: el normativo, dominado por el recelo hacia la usura y la obsesión por cohibir o, al menos, controlar su ejercicio; y el de la vida práctica que, con no menor tenacidad y con recurrente y, a veces, llamativo éxito, trata de burlar a aquél. Supuesta la sensatez del horaciano leges sine moribus vanae, el contraste 
entre las valoraciones de legisladores o juristas y las realidades vitales puede servir como un ilustrativo incidente de la más general y perpetua cuestión sobre las relaciones entre derecho y moral. Y aun, quizás, particularmente ilustrativo, pues versa sobre un material tan implacable, tan mal avenido con la ambigüedad de matices, como es el dinero.

El préstamo a interés no es la única, pero sí la más frecuente y significativa fuente de usuras (1); la que pudiéramos llamar su figura rectora y más agudamente problemática ya en el mundo antiguo y que, hasta nuestros días, ha conservado sensiblemente el centro de la palestra. Por eso, las páginas que siguen se concentran sobre el préstamo a interés.

Esta concentración pretende conjugarse con lo que, a primera vista, parece una simplificación que a cualquier historiador resultaría intolerable: la referencia al Mediterráneo antiguo, como si se tratara de algo homogéneo. En adelante se verá que no pretendo sugerir tal cosa, sino aludir a un ámbito cultural, político, económico, comercial... que Roma encuentra cuando accede a las riberas de Nuestro Mar. Pues Roma no sólo encuentra tal ámbito y lo incorpora a su dominio, sino que asimila los elementos del mismo, los integra con sus propios hábitos y con el sistema de vida que ella misma había desarrollado, los metaboliza y los transmite. Sólo a este efecto de unificación final, en cuanto la concepción y disciplina del préstamo que Roma nos lega lleva aglutinados materiales muy diversos, unos autóctonos, otros oriundos de las sociedades anteriores y coetáneas, aludo cuando me refiero al Mediterráneo antiguo como algo indiferenciado.

Los factores económicos que intervienen en el asunto son, sin duda, importantísimos e insoslayables, y ello requiere una advertencia: no he creído que tal importancia obligase a orientar su estudio en términos, precisamente, de ciencia económica. Para empezar, ello excedería de mis aptitudes: la economía es labor de economistas, en cuya competencia la figura del «outsider» carece de legitimidad y de interés. Además, y por fortuna, cuando los propios antiguos describieron fenómenos económicos (y lo hicieron con cierta frecuencia y con notable exactitud) no sintieron que estuvieran «haciendo economía» ni, al parecer, necesidad de hacerla. La «Ley de Gresham» podría muy bien llamarse Ley de Aristófanes, pues el comediógrafo griego la había enunciado en Las Ranas, tan secularmente antes y en no peores términos que el político inglés (aunque sólo como parábola, para explicar el aparente predominio numérico, en la Atenas de su tiempo, de los ciudadanos malos sobre los buenos). También Aristóteles describió, en La Política, los efectos de la devaluación monetaria (y también emplea, para explicarlo, una parábola, la fábula del Rey Midas). Y la llamada «Ley de Bodin», sobre el alza secular de los precios determinada por el aumento del metal precioso en circulación, pudo inspirarse en Plinio y quizás se hallaba ya en Varron. Por mucho que estos ejemplos, y otros innumerables, puedan tildarse, incluso, probablemente, no sean más, de lo que Schumpeter llama intuiciones «precientíficas», de las que «sería absurdo que las subrayásemos como si fuesen descubrimientos», son, indiscutiblemente, un dato y como tal

(1) Empleo el término usura en sentido clásico: el que tuvieron, en latín, la voz usurae (p. ej. VARRON, De Lingua latina, $5 \mathrm{~V} .{ }^{\circ}$ usura; o Digesto, 50, 16, 121), en griego tókos (p. ej. ATISTOTELES, Política, 1, 7), en hebreo neshék (p. ej. Deuteronomio, XXIII, 19, 20); es decir, como sinónimo de interés debido por razón de préstamo, de todo suplemento que el prestatario se obligue a pagar al prestamista además de la restitución del capital prestado. No en el sentido moderno de interés abusivo o excesivo, ni con el color peyorativo que originariamente no tuvo, pero con que lo dejó definitivamente teñido la omnímoda proscripción cristiana. Y por lo cual acabaron utilizándose las palabras «interés», para designar ciertos suplementos legítimos, y «usura», para los excesivos, indebidos o ilícitos. En sendas glosas de AZON y ACURSIO se justifica como legítimo el id quod interest... quia loco interesse praestatur et fructuum (Glosa a la Ley Usuras emptor) y porque non usurare, sed ut interesse petuntur (Glosa a la Ley Cunctos populos, C. I. 1, 1. De Summa Trinitate, en las palabras Petrum Apostolum). 
lo alego (2). En fin, en la literatura moderna existen también vigorosas corrientes de reacción (3) contra la que podríamos llamar superstición economicista como vía exclusiva o principal para la interpretación de la historia antigua, que tan extendida está, aún, entre autores de uno u otro signo.

Escapando, pues, de ese prejuicio, podemos partir de una sencilla hipótesis negativa. D. Hume $(1903,415)$, minucioso lector y conocedor de los clásicos, hizo, a propósito de la economía de las civilizaciones antiguas, esta interesante observación: «No recuerdo un pasaje de ningún autor antiguo en que el crecimiento de una ciudad sea atribuido al establecimiento de una manufactura. El comercio, del que se dice que floreció, es principalmente el intercambio de aquellos artículos que se dan en distintos suelos y climas». Esta constatación y su inmediato corolario, de que las economías de las ciudades antiguas son economías de consumo, suponen que en ellas y, eminentemente, en las metrópolis, la riqueza circula en sentido fijo: entran, se importan mercancías, no para su transformación sino para su consumo; y sale el dinero con que se paga. Es decir: la parte del capital no gastada, que es la hipotéticamente susceptible de préstamo, responde, a falta de otras solicitudes, al concepto exclusivo de «ahorro reservado». Respecto del cual es coherente el juicio de estéril que los pensadores, como veremos, formulan. Y, a su vez, como el destino natural de este dinero, una vez prestado, sería, en esta mecánica económica, la adquisición de bienes para el consumo, son también comprensibles los eventuales recelos sobre la legitimidad de los intereses y la conveniencia de someterlos a límite.

Con esto queda anticipado cuáles son las dos cuestiones fundamentales que en la antigüedad se plantean acerca del préstamo con interés: la primera, su posibilidad; la segunda, su medida. Preferentemente ontológica y objetiva, la primera; típicamente ética y especularmente jurídica, la segunda. Y jerárquicamente escalonadas: sólo si la primera es contestada afirmativamente, tiene interés plantear la segunda (4).

(2) No sabría explicar, ni, afortunadamente, interesa a mi propósito, por qué los griegos no racionalizaron estas intuiciones ni, como escribo líneas arriba, parecieron sentir la necesidad de un análisis económico; ni siquiera la de «razonar por cifras sobre las cosas relacionadas con el gobierno», como definía DAVENANT, lo que él llamaba «aritmética política», nosotros, «estadística» (WESTERGAARD, 1932, 40). La falta de interés por tal labor parece la única explicación, pues si a la estirpe de los Pitágoras, Euclides, Apolonio..., sobraba algo, era, precisamente, «números» y capacidad de análisis. El hecho de la falta de estadística, y aun de cómputos fiables con los que confeccionarlas, es uno de los obstáculos constantemente señalados para la reconstrucción de las antiguas economías. Un solo ejemplo: para un mismo período, el de la Atenas clásica, y trabajando sobre las mismas fuentes, el cálculo, por los autores modernos, de la cifra total de esclavos, fluctúa escandalosamente entre 20.000 (cifra a que llega JONES, 1957, 76 ss.) y los 400.000 (que aparece en Athenaeus, VI, 272, c; vid. crítica de WESTERMANN, 1941, 451 ss.).

(3) Como ejemplo entre los más brillantes y prolíficos de tal orientación merece mencionarse el encabezado por FINLEY, que aborda el estudio de temas como la esclavitud, el capitalismo, las relaciones de trabajo, el comercio... de los pueblos antiguos, con criterios extraídos de los documentos de todo tipo, reliquias arqueológicas, cualquier vestigio de los modos de vida de aquéllos; es decir, como desde el seno de las propias sociedades analizadas, con un método que podríamos llamar etonómico, más que económico.

(4) Actualmente los datos del problema son distintos: concausas complejas, que se inician en el siglo $\mathrm{XV}$ con la afluencia del oro americano y la primera inflación de los tiempos modernos y se consolidan con la revolución maquinista e industrial del siglo XVII, dan origen a una nueva concepción del capital y a que, junto al ahorro reservado, aparezca una segunda categoría de capital ahorrado: el ahorro «creador» o para inversión productiva. De éste ya no se discute - ni, por definición, puede hacerse-su capacidad «natural» para producir más dinero. Y subsiste sólo la cuestión de los límites del interés. Cambia, incluso, el concepto del dinero: de res primo usu fungibilis según la fórmula tradicional, en el sentido impropio de consumible, pasa a considerarse «peculiarmente» fungible: desaparece para quien compra un objeto, pero reaparece en quien lo vende e, incluso, permanece en el comprador en la estimación financiera de la cosa. De donde el interés aparece como remuneración específica del elemento productivo que es el capital. Más aún: algunos economistas dudan que el dinero sea adecuado al objeto del contrato de préstamo y piensan en el interés como remuneración del «alquiler» del capital. 
Situándonos, empero, en el mundo «precapitalista» del antiguo Mediterráneo, se nos aparece un mosaico de pueblos, un sistema de culturas, cuyo lugar común son las aguas de Nuestro Mar; ámbito de relación en unos aspectos, barrera de separación en otros. Es la impresión que Platón (Fedón, 109) nos da del mundo de su tiempo: «habitamos una pequeña porción de tierra, desde Fasis hasta las Columnas de Hércules, alrededor del mar, como hormigas y ranas en torno a una charca».

Es hipótesis verosímil que las economías de todos los inquilinos del estanque mediterráneo se comportarían originariamente de un modo muy semejante. En lo que atañe a los préstamos, éstos se concertarían primero en especies y como un recurso para cubrir las necesidades de consumo o cultivo (SEGRE, 1922, 38-43 y 112-115; 1924, 119-121). Paulatinamente aparece y se generaliza el uso de la moneda, lo cual es un factor decisivo: de un lado, al proporcionar un módulo estable de valor que dota de agilidad y seguridad a las transacciones; de otro, por su típica aptitud para ahorrarse, almacenada, en cantidades y por tiempo teóricamente indefinidos (5).

La economía monetaria es, además, de implantación típicamente urbana. Estrabón sumaría el acceso de los pueblos a la cultura en los consabidos escalones: vida nómada -caza y pastoreo-; vida sedentaria, mediante la agricultura; y «civilización» en el sentido de construcción de ciudades. Lo que no es sino insistir en un tópico de la tradición griega y romana - y que en tiempos modernos volvería a suscitar Spengler $(1926,129$ ss.) - muy significativos: el medio excelente de vida es, por antonomasia, la agricultura -no el comercio ni la manufactura-, pero la civilización requiere la ciudad. El com-

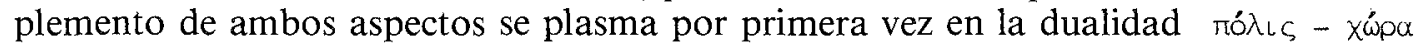

de los estados griegos. La polis es el centro organizativo y de convivencia; la jóra es la encargada de abastecerle. La perfección ideal del modelo fue diseñada por Platón (República, 370) y Aristóteles (Política, 25-31) a base de la autosuficiencia. Ahora bien: la polis (y todas las ciudades antiguas, como advertí) es, básicamente, y Max Weber (1924, 1-288) hace de esta afirmación una especie de dogma, un centro de consumo. Y es muy difícil de imaginar e imposible de encontrar en la historia un caso de autosuficiencia completa (DE SANCTIS, 1939, II, 154), lo que, históricamente y en concreto, quiere decir que la estabilidad del modelo dependerá de los medios con que cada pueblo cuente para suplementar esas insuficiencias. Medios que se derivan de las circunstancias geográficas, demográficas, históricas, de carácter..., de dicho pueblo. Son las que Toynbee llama «incitaciones» (TOYNBEE, 1977, Introducción) y Marchal (1963, 565-597) «fuerzas motrices», que imprimen a cada entidad política o nacional una fisonomía, unos hábitos de vida y, a la postre, una ética social y cívica peculiares.

(5) Ambas funciones de la moneda, como facilitadora de los canjes, al nivelar los valores subjetivos de las mercancías que se canjean y como «garantía» de futuros y eventuales canjes, en ARISTOTELES (Et. $a N .5,5,10-14)$. En la mayoría de los manuales de teoría monetaria sigue proponiéndose como suficiente y satisfactoria esta doctrina de la función dual del dinero, que incluso es pasada sin discusión en la vigente polémica que keynesianos y monetaristas mantienen acerca de la interrelación entre las variables reales y monetarias de la economía. En realidad, para las economías antiguas y aun hasta los primeros compases del capitalismo moderno, apenas tiene interés plantear cuestiones como la de la función del dinero como capital, a partir del uso diferencial que del mismo hacen los diversos factores económicos. Cuestión que, en cambio, se hace insoslayable hoy, a causa del protagonismo adquirido, en las actuales economías de mercado capitalista, por las grandes sociedades corporativas, en que aparecen disociadas la titularidad del capital y la adopción de decisiones sobre su utilización. Este nuevo planteamiento sí supone modificar y complicar el esquema dual aristotélico. Vid. desarrolladas estas ideas en DUARTE CARBALLO (1983, 22-24).

Por otro lado, líneas arriba acepto la hipótesis de una economía precapitalista. La aparición del dinero, a expensas, sobre todo, de su aptitud para el ahorro y la acumulación, determina, sin embargo, un cierto capitalismo, que parece deteriorar la hipótesis inicial. En realidad, para los efectos de este trabajo, el deterioro sería muy leve, por lo que más adelante diré sobre las limitadas funciones de los bancos antiguos y sobre la persistente concepción real del dinero, como cosa valiosa por sí misma. 
De esta manera, pueden distinguirse en el mundo mediterráneo los siguientes sistemas de regulación del préstamo, según la licitud y la extensión de los intereses: incondicionalmente permisivo, el de Grecia; limitadamente permisivos, los de Egipto y Roma; selectivamente permisivo, el de Israel; absolutamente prohibitivo, el cristiano (6).

1. En Grecia, las incitaciones de la vida económica pueden resumirse: en su feliz posición geográfica, el fácil acceso a las florecientes colonias del levante asiático, de Campania, de Sicilia, la especial aptitud de sus costas para la instalación de puertos, en que fue asentándose un numeroso contingente de marinos, comerciantes, pequeños empresarios, cambistas y argentarios... (GIACCHERO, 1966, 160), entre quienes era normal el préstamo a interés, aprendido de los fenicios. A importar la riqueza desde el mar incitaba, por otro lado, la escasez de terreno cultivable de la quebrada península helénica, en su inmensa mayoría apta, a lo más, para pastos y no de los más rentables. A este modo de vida obligaban, además, la presión de los belicosos vecinos del norte y la competencia entre los minúsculos estados, que hacen más natural la expansión marítima que la terrestre. Lo que no quiere decir que la autarquía agrícola no fuera un desideratum (PLATON, República, 4, 2 ss.). Plutarco alaba, en este sentido, el sistema de vida de Pericles (PLUTARCO, Pericles, 1, 3-5). Pero, en contraste, cuando las musas del Helicón se acercan a inspirar al pastor Hesiodo, no pueden dedicarle nada mejor que el

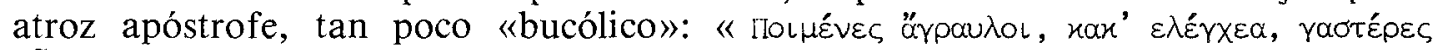
oĩov...» (HESIODO, Teogonía, 25).

El hábito social engendrado, a la larga, es la ausencia de reservas acerca del présta-

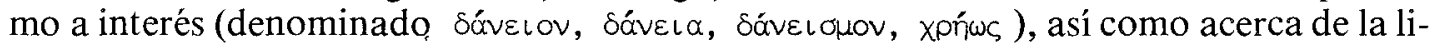

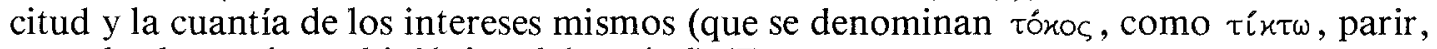
a modo de producto biológico del capital) (7).

Es la situación del mercado la que, en una especie de fisiocracia espontánea, va fijando la cifra de los intereses. Que son, naturalmente, más altos en el ordinario y el comercial que en el hipotecario (en que el riesgo de insolvencia se cubre con la eventual ejecución de la garantía). Y aún superiores, en el vautıxóv sáveıov (8) (en razón de la expectativa de lucro y del suplemento de riesgo) (9).

Un gran volumen de estos préstamos era controlado por las bancas públicas y por los santuarios (10). Ahora bien, de la documentación de éstos y de otras fuentes epigráficas y literarias, bastante abundantes, podemos extraer las siguientes consecuencias:

Para las ciudades griegas y para todas las de la antigüedad, hablar de bancos no debe inducir la idea de establecimientos de crédito en sentido moderno; el dinero es exclusivamente dinero «real», no puede hablarse de dinero legal ni bancario, ni concebirse como normales operaciones, tan sencillas hoy, como la apertura de crédito en cuenta

(6) Egipto, país mediterráneo en términos estrictamente geográficos, culturalmente subsidiario de Grecia a partir de la fundación de Naucratis -640 a. C. - y, definitivamente, por la conquista macedonia y la fundación de Alejandría -332 a. C.-, e Israel, culturalmente incorporado al área mediterránea, a partir de la conquista helenizante de Ptolomeo - 331 a. C.- y en razón de los ulteriores y muy influyentes asentamientos judíos en Alejandría y en otras plazas mediterráneas. La referencia al cristianismo es también obligada, como cultura que nace y se incuba en el ambiente mediterráneo, y en él fragua la primera gran revisión moral sobre el préstamo a interés.

(7) Sobre las formas y disciplinas del préstamo griego, cfr. v. c. PAOLI, 1930, 73 ss.; BEAUCHET, 1897, IV, 227-325.

(8) Sobre préstamo marítimo griego y romano y sus regímenes comparados, vid. últimamente CASTRESANA, 1983.

(9) Sobre las cifras de interés en general, cfr. CICOTTI, 1905, I, 2. a , 516-518. Sobre el préstamo marítimo griego, cfr. BISCARDI, 1936, 345 ss.; DE MARTINO, 1936, 433 ss.; JONES, 1956, 216 ss.

(10) Sobre la banca griega y sus funciones, cfr. la fundamental bibliografía moderna de BOGAERT (1956, 140-156). Y, entre los «clásicos», sigue siendo fundamental BILLETER (1898, 9-10 y 58-61). 
corriente o incorporado a instrumentos negociables. Su actividad se centra en el almacenamiento de monedas en sótanos o bóvedas, en forma de depósitos sin intereses.

Como corolarios: los particulares, como los propios establecimientos, tienen rígidamente limitada su posibilidad de conceder préstamos por la cantidad real de efectivo existente, sin capacidad para crear dinero, aumentando el circulante, o sea, para operar con dinero fiduciario.

Los tesoros de estos establecimientos, que, en ocasiones, fueron enormes, constituyeron, por un lado, una importantísima arma política (11). Por otro, fueron, seguramente, el fondo de reserva amortiguador de las oscilaciones del mercado (12). Lo que explica que los tipos medios de interés se mantuvieran bastante estables a través del tiempo (BILLETER, 1898, 20-29, préstamo ordinario; 30-41, préstamo marítimo).

Sobre todo: el dinero sigue teniendo en esta época el concepto de cosa. Jurídicamente, en nada se diferencia de la cabeza de ganado que se da como precio, ni del lingote de metal que, en igual concepto, se corta y se pesa; económicamente, sólo en su relativa función de referencia de valor. Relativa, puesto que la conocida pasión de los griegos por las monedas variadas y artísticas - como expresión de patriotismo, propaganda (KEYNES, 1930, I, 12) o identidad local- producía algún entorpecimiento y el lucro de los omnipresentes cambistas que, paralelamente, ejercían también la usura. La unificación, bajo Pericles, de todas las monedas locales y el monopolio a favor de la ateniense es un episodio más bien excepcional, por lo aislado y por su clara intención política de mostración de la supremacía de Atenas (ERXLEBEN, 1969, 91-139; 1970, 66-132; 1971, 145-162).

Sí parecen haber conservado todos los estados antiguos el monopolio de la fe pública del cuño. Pero no complementaron dicha prerrogativa con el compromiso de mantener circulando un abasto suficiente de monedas, que dependió siempre de los aportes del exterior, principalmente del botín de las guerras y del laboreo de las minas (REINACH, 1896, 531-533 y notas).

Por fin, y en el terreno de los conceptos, del dinero, considerado como módulo de valor, es estrictamente cierto lo que es estrictamente falso a propósito del dinero como símbolo de valor: que es incapaz de multiplicarse. Por ello es perfectamente justo el famoso reproche aristotélico (13): ...con toda razón se repudia el préstamo a interés, pues

(11) El traslado a Atenas, por Pericles, del tesoro de Delos en que se guardaba la tesoreria de la Liga (454 a. C.) es el ejemplo más claro de esta utilización política. Sobre el tema, p. ej. DE SANCTIS, $1939,192$.

(12) Como toda simplificación, la que vengo haciendo sobre el papel bancario de los tesores silencia aspectos interesantes; vid., p. ej., BODEI GIGLIONI, 1974, razona a base de las fuentes epigráficas, literarias, históricas y arqueológicas cómo los grandes trabajos fueron realizados en función de disponibilidades financieras «fortuitas» (utilización de tesoros de los templos y también el botín, impuestos, mecenazgo privado o público) que, como contrapeso a la conocida tendencia a la tesaurización satisficieron la función social de crear empleo (libro interesante por la amplitud de períodos históricos que estudia: mundo griego desde las tiranías arcaicas y épocas republicanas e imperial de Roma; y por la importante bibliografía que incluye).

(13) Además de ser perfectamente coherente con la concepción del dinero del propio ARISTOTELES, que, a mi juicio (aunque la discusión sobre este punto es intemporal y lícita), es convencional en cuanto a la materia, pero claramente metalista en cuanto al valor, cf., Et. a N., 5, 5, 11: «... un medio de inter-

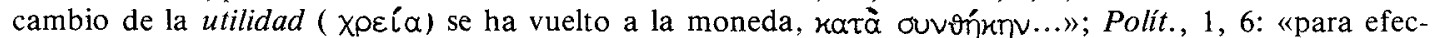
tuar los canjes los hombres convinieron entre sí, para dar y tomar, una materia que, siendo útil por sí misma, fuese de fácil manejo... por ejemplo, el hierro o la plata..., en un comienzo, sólo por dimensión o peso, pero luego con el agregado de una impresión particular, para evitar la continua medición".

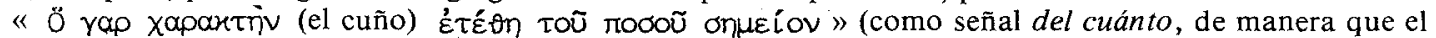
convenio es acerca de la materia, pero con la condición de que ésta sea valiosa ya por sí; y, en cuanto al significado del cuño, por mucha tentación que se tenga de atribuir a ARISTOTELES ideas nominalistas, no veo la menor posibilidad de traducción en otro sentido que el dicho: el cuño es certificado auténtico de la cantidad de sustancia valiosa que contiene la pieza. 
por él el dinero mismo pretende la calidad de productivo, desviándose de su fin, que es mediar en los cambios. Pues porque el interés multiplica el dinero, se le llama tóxos (=hijo); y así como los hijos son de la misma naturaleza que sus padres, el interés es

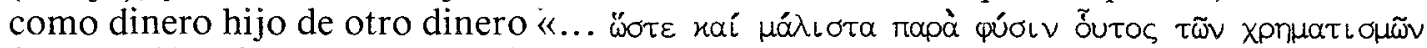
Éotív ». (ARISTOTELES, Política, 1, 7). Lo que ya no resulta tan inocuo es trasladar lo que en Aristóteles es, por una parte, una consideración ontológica - derivada de la naturaleza inerte del dinero-y, por otra, una advertencia metódica - la crematística, una de cuyas fuentes es el préstamo a interés, es materia ajena a la verdadera economía-, al plano de la ética, donde tienen preponderante papel los móviles. Por eso, entre los romanos que, en líneas generales, suscriben el concepto aristotélico acerca del dinero, no se reedita el recelo aristotélico acerca del interés (ARISTOTELES, Políti$c a, 1,6)$. Los verdaderos óbices morales que Aristóteles enuncia con ocasión de la usura

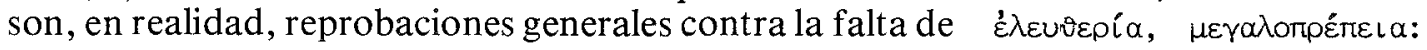
«los que prestan a interés no aprecian a sus deudores» (ARISTOTELES, Etica a Nicómaco, 9, 7); o con la codicia: entre los oficios indignos del hombre libre encontra-

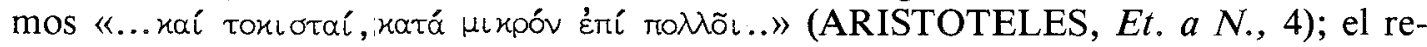
proche, por tanto, va dirigido, más bien que contra la usura, contra la avaricia de su exceso (14).

El promedio de los intereses en Grecia es, comparativamente, elevado y, en números relativos, escasos los préstamos hipotecarios. La explicación, aunque algo laboriosa, parece ser ésta: en todos los estados griegos, en la época clásica, la división entre ciudadanos y no ciudadanos es rígida y, con ella, las barreras entre la tierra y el capital mobiliario -proceso contrario al que Roma coronará en el $212 \mathrm{~d}$. C. con la constitución Antoniniana-. Las reformas de SOLON en el 594 y PERICLES en el 450 a. C. restringen la ciudadanía a sólo los hijos de padre y madre atenienses y se clasifica en cuatro categorías cerradas a los ciudadanos, según sus propiedades inmuebles. A su vez, la propiedad de la tierra es privativa de los ciudadanos, con alguna, contadísima y siempre in-

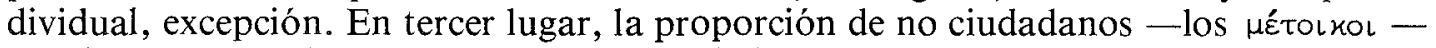
fue siempre muy alta: en Atenas se ha calculado entre seis y dos y medio ciudadanos varones por cada meteco de igual sexo (FINLEY, 1953, 249-268; 1981, 61-64) (15). Además, la mayoría de estos metecos se dedicaban al comercio, a la manufactura y, con frecuencia, al préstamo a interés. Como consecuencia, ni podían ofrecer garantía hipotecaria al pedir un préstamo, ni podían aceptarla cuando lo concedían - puesto que no tenían derecho a juicio hipotecario-. Y, por evidentes razones, el dinero sin garantía es más caro que con ella (SEGRE, 1922, 95-97). Y se admite también, sin reservas, el ávatokıони́́c o préstamo a interés compuesto.

2. En Egipto, la «incitación» que determina fundamentalmente la particular fisonomía del préstamo a interés reside en la monopendencia del Nilo, cuyo complejo sistema de riegos y explotación en general exige un rígida intervención estatal. Como efecto, y desde antiguo, la hipertrofiada y omnipresente burocracia faraónica lo controla todo: también el interés de los préstamos, que sujeta a tasa. Los testimonios papiriáceos, bastante abundantes - también era prolija y meticulosa la contabilidad de las oficinas faraónicas- ofrecen extraordinario interés, no sólo porque permiten entender la fisonomía del préstamo retribuido en Egipto en la época tolemaica y en la romana imperial,

(14) El paralelo de estos dos reproches sí lo encontramos en la literatura latina: al primero, por ejemplo, en SENECA, De benef., 7, 10; al segundo, casi literalmente en la tacha de illiberalis formulada por CICERON, en De off., 1, 150, contra el fenus.

(15) Sobre el estatuto jurídico de los metecos cfr. también MAFFI, A., 1972, 177 ss.; MOSSE, C., $1973,179-185$. 
sino porque, indirectamente, sirven para profundizar en el conocimiento del mundo económico y social greco-romano, en su conjunto. Segre (SEGRE, 1924, 130-133; BINGEN, 1973, 215-219; BIEZUNSKA-MALOWIST, 1973, 253-265) señala cómo, aún en la época imperial, Egipto mantiene su condición de mercado privilegiado de capitales, gracias a lo elevado del interés — que inicialmente era del $24 \%$, hasta que, probablemente Augusto, lo rebajó al 12\%, de manera que competía ventajosamente con Grecia en la atracción de dinero romano (ROSTOVTZEV, 1966, 425-427). Ahora bien: una alta tasa de interés puede mantenerse sólo mientras hay escasez de capital privado, bajando aquélla a medida que el mercado se satisface y cesando, cuando se satura. $\mathrm{Si}$, pues, durante siglos la retribución de los capitales se mantiene constantemente alta, a pesar de su creciente afluencia, ello viene a confirmar la anterior suposición de que las arcas del Estado atesorarían parte del dinero, manteniendo constante el circulante: o sea, artificialmente bajo el nivel de dinero privado. Que es otro modo de conjugar la dialéctica consumo-reserva, característica, según dije, de las economías antiguas.

Ya hemos advertido que el préstamo de dinero tiene su asentamiento primero en las

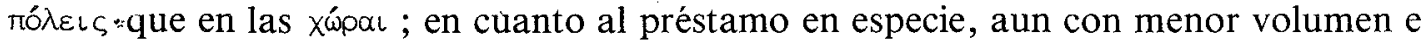
importancia, perdura tenazmente en las zonas rurales egipcias alejadas de las ciudades, aun después de la introducción de la moneda, marcando un curioso contraste con los contratos de sóveı a alejandrinos, casi exclusivamente en dinero y por términos más largos. En cambio, los de especies, importados de Grecia, duraban generalmente los meses transcurridos entre la siembra y la recolección; su retribución consiste en el hemiolion, equivalente ( $\dot{\eta}_{\mu} \iota \mathrm{\lambda} i \boldsymbol{\alpha} \alpha$ ?) a la mitad del capital, a pagar al vencimiento y conjuntamente con aquél (16).

3. En Roma, el fondo general puede resumirse en la base vigorosamente rural y campesina que sostiene la cultura romana de todas las épocas. Sobre este fondo se fijan, y quedan peculiarmente condicionados por los factores autóctonos, los que Roma importa del ámbito mediterráneo.

El cuadro general de la economía romana se nos presenta específicamente basado en la autosuficiencia agrícola, no como una aspiración utópica o*añorante, sino como una finalidad natural posible e inmediata. Es instructivo observar cómo en Grecia, desde mediados del siglo IV, al menos, con los Poroi, de Jenofonte, y poco después con el pseudo-aristotélico Económico, nace una, aún balbuciente, literatura económica. No ocurre lo mismo en Roma, cuyos legados de literatura técnica más antiguos, datados a partir del siglo III, versan sobre agronomía práctica (17). Más en concreto, ya he advertido que la aspiración a la autosuficiencia es un lugar común en todas las literaturas primitivas. La romana, y ello se percibe llamativamente por contraste con la griega, lo es de modo especialmente intenso.

El diseño platoniano de autarquía puede tener, quizás, como referencia ideal, el delirio de una antigua Grecia feraz y silvana, cuyo profundo suelo «fertilizaban las aguas que cada año llovía Zeus; no como hoy, que corren sobre rocas peladas rumbo al mar» (PLATON, Critias, 4). Pero la propuesta de medidas específicas para el logro actual de la autosuficiencia toma como datos los mismos míseros recursos naturales de la Hélade

(16) Contra el hemiolion - y ello da fe de su tenacidad-todavía predicaron los padres occidentales: S. Jerónimo, Comm. in Ezech., VI, 18 (P. L. 25, 176-177); S. Agustín, Enarrat. in Psalm. XXXVI, Sermo III, 6 (P. L. 36, 386-387).

(17) El De agri cultura, de CATON, inaugura la serie, en que van incluyéndose los de VARRON, los SASERNA, SCROFA, COLUMELA, PLINIO... Es de obligada cita en este lugar el libro de MARTIN, 1971, Recherches sur les agronomes latins et leurs conceptions économiques et sociales, París. 
que menudean aludidos en las comedias de Aristófanes. Ni La República, ni Las Leyes, consideran siquiera la posibilidad de dilatar la producción agrícola; al contrario, parecen dar por irremediable su cortedad. Y se aplican al estudio de la mejor ubicación de la ciudad con vistas a los suministros; $y$, sobre todo, a la obsesiva fijación del número máximo de sus habitantes (PLATON, República, 4 y 5); y al pormenor de las restricciones a la nupcialidad y la natalidad, para mantener estable ese número (PLATON, Rep., 2, 2; Leyes, 5, 10-11) (18).

El contraste con Roma no puede ser más diametral: los agronomistas romanos escriben en confortables términos de actualidad, detallando las técnicas que, comprobadamente, iban permitiendo extraer cada vez mayor fruto de la tierra (MARTIN, 1971, 387 ss.); aunque no indefinidamente. La parcimonia, el hábito de vida frugal, le viene inducido al romano por su propia experiencia de que la tierra da sustento relativamente seguro, pero limitado, en último término, por la capacidad de reproducción de las especies biológicas. En contraste, el comerciante puede aspirar a un lucro teóricamente ilimitado, a cambio de una menor seguridad.

El acceso de Roma al mundo del comercio y del mercado monetario es llamativamente tardío. Atenas tenía, desde el s. V, por iniciativa de Temístocles, su gran puerto en El Pireo. Cartago, nada menos que dos siglos antes de convertirse en la gran rival, había festoneado, a bordo de las naves de Hannón, las costas atlánticas de Africa hasta la línea ecuatorial. En cambio, Roma no se orienta decididamente hacia el mar hasta el siglo III. Mientras, aunque ya es grande y populosa y ha impuesto su hegemonía en toda la Península (desde el año 265), sigue solventando el equilibrio producción-consumo a expensas de la periferia agrícola, el botín de las guerras, los tributos y el aporte de algunas mercancías en pequeños barcos que, desde la bahía de Nápoles, costeaban hasta la boca del Tíber y remontaban luego hacia la Ciudad. (Este me parece un importantísimo dato diferencial que contribuye a hacer de Roma una ciudad atípica entre las de su tiempo). Ostia no fue sino un punto de paso, hasta que en el siglo IV se fortificó, por necesidades de defensa.

Cuando la confrontación con Cartago exige el control del mar, Roma se ve obligada a improvisar; no había en ella (POLIBIO, 1, 20-21) quien supiera algo sobre la guerra naval, ni sobre remos, ni sobre velas; no había un solo navío de combate ni conocimientos acerca de su construcción o manejo. La improvisación fue rápida y eficaz, comenzando por el establecimiento en Ostia (el punto más adecuado y cercano de la costa) de un puerto militar, siguiendo con la construcción y organización de una armada y concluyendo, a fines del siglo III, con la victoria sobre Cartago (THIEL, 1954). Sólo entonces comienza a desarrollarse Ostia (MEIGGS, 1969, cap. 3) como ciudad portuaria comercial y a partir de ahí arranca el protagonismo mediterráneo de Roma, con su incorporación al tráfico ambiente basado en una utilización generalizada y relativamente homogénea del dinero (19).

La propia realidad del dinero es concebida en Roma de un modo peculiar: los textos romanos carecen de un equivalente de la formulación aristotélica del vómı ou $\alpha$

(18) Curiosa similitud con MALTHUS, 1951, 91-92, acerca de un país, el Tibet, de condiciones naturales también severas. Preocupaciones del mismo estilo, aunque más atenuadas en ARISTOTELES, Pol., $2,6,4$.

(19) De todos modos, siempre quedó un residuo de la tendencia a la autosufíciencia alimenticia (aunque ampliado el primitivo ámbito de suministro a toda la Península). Pues, si bien las grandes importaciones de grano de Sicilia, Cerdeña y Africa valieron a estas regiones la designación tópica de graneros de Italia, las posibilidades de interrupción de los suministros por la piratería y las guerras hacen sospechar que una gran parte del grano repartido en Roma debía de provenir de la propia Italia; de lo contrario, y en concreto, gran parte de la población no habría sobrevivido en los años 43 a 36, en que estuvo casi continuamente interrumpido el suministro de ultramar; así argumenta BRUNT, 1981, 105. 
(ARISTOTELES, Et. a N., 5, 5, 11); por el contrario, la denominación pecunia perpetúa, en su etimología, su origen: la cabeza de ganado; y las formulaciones de los jurisconsultos perseveran en abarcar, junto a las especies monetarias, las naturales:

appellatione autem pecuniae omnes res in ea lege significantur; itaque (et) si vinum vel frumentum aut si fundum vel hominen stipulemur, haec lex observanda est. (GAYO, Instituciones, 3, 124) (20).

La propia fórmula con que el jurista Paulo describe la «invención» del dinero, que suele citarse, y con razón, como un ejemplo de la homogeneización del concepto con el griego aristotélico, manifiesta significativas diferencias:

Origo emendi vendendique a permutationibus coepit. Olim enim non ita erat nummus, neque aliud merx aliud pretium vocabatur, sed unusquisque secundum necessitatem temporum ac rerum utilibus inutilia permutabat, quando plerumque evenit, ut quod alteri superest alteri desit. Sed quod non semper nec facile concurrebat ut haberes quod ego desiderarem, invicem haberem quod tu accipere velles, electa materia est, cuius publica ac perpetua aestimatio difficultatibus permutationum aequalitate quantitatis subveniret, eaque materia forma publica percussa usum dominiumque non tam ex substantia praebet quam ex quantitate, nec ultra merx utrumque, sed alterum pretium vocatur (D. 18, 1, pr.).

La inspiración de Paulo en el capítulo primero de La Política de Aristóteles puede tenerse por indudable, siendo también común a ambos pasajes la finalidad de manifestar la función de la moneda como igualadora de utilidades en los cambios, superando la injusticia de la permuta. (En el texto de Paulo se observa, para empezar, una aparente mayor economía expresiva, que quizás pueda atribuirse a un puro efecto estilístico). En lo sustantivo se advierte también que es la cantidad, más que la materia, la conformadora del precio. Pero lo que sobre todo me interesa destacar es la falta, en el texto romano, del rigor terminológico y de la univocidad que se observan en la enunciación aristotélica. En efecto: ...electa materia ...eaque materia forma publica percussa... son expresiones que conjugan un equívoco genial en cuanto a su fecundidad jurídica porque, mediante las dos traducciones que dichas expresiones admiten, ambas de igual legitimidad literal, quedan definidas todas las operaciones, tanto no formales como rituales, en las que interviene la pecunia (aunque el texto de Paulo se refiere a la compraventa, la función del dinero que describe es universal, también aplicable al préstamo): electa materia puede traducirse como el bronce, oro o plata monetarios, pero también como el bronce ritual que golpea sobre la libra; y a su vez, forma publica percussa puede traducirse, tanto por «troquelada en la forma oficial» (acuñada) como «golpeada en la forma solemne» (el rito aere et libra) (21).

La actitud de tal pueblo hacia el préstamo puede sintetizarse muy esquemáticamente en estas notas: su propia denominación, mutui datio, delata el lugar preciso que se le

(20) Entre las otras muchas, recogidas en el Digesto, merece citarse, como más representativa, por razón de su sedes, la de HERMOGENIANO: pecuniae nomine non solum numerata pecunia, sed omnes res tam soli quam mobiles et tam corpora quam iura continentur $(D .50,16,222)$.

(21) Se trata de la forma solemne, constitutiva, de ciertos negocios pertenecientes al más antiguo derecho de Roma. Consistía en la percusión con un trozo de bronce sobre uno de los platillos de una balanza (per aes et libram) en presencia de un pesador, que sujetaba la balanza, y de cinco testigos, a la vez que se profería la fórmula oral adecuada al negocio concreto. Es el residuo estilizado del trámite del pesaje real del metal que se daba como precio antes de aparecer el dinero acuñado. 
asigna, entre las actividades de cooperaciỏn recíproca, mutua (22). El repudio hacia los intereses radica, no ya en su condición de antinaturales, sino en la de indecentes: la tacha aristotélica de rapà yúoı no reaparece en los autores latinos sino de modo más bien ocasional, muy retorizado, casi como simple galanura de estilo (23). Es natural que sea así, pues Roma conoce el tráfico monetario ya en acto y, en él, la generación de intereses por el dinero es un dato; para el talento utilitario de los romanos no es un problema a plantear, sino una práctica a valorar. Que dicha valoración es negativa, y con qué intensidad, queda más que patente en el elenco de adjetivos que Catón, Cicerón, Séneca... dedican al fenus: inhonestum, sordidum, illiberale, sanguinolentum... (24); y, en lo jurídi$\mathrm{co}$, por la formal y esencial exclusión del devengo de intereses de la mutui datio como tal, debiendo acudirse para exigirlos al subsidio de un negocio verbal separado, la stipulatio (25). Habría que añadir que el propio ductilísimo idioma latino se ve comprometido en el trance: las palabras fenus, feneratio... (con que se designa la operación compleja de mutui datio y stipulatio usurarum), se confeccionan a base de la adaptación de una raíz, la misma de fecundidad, y sus emparentados, de tan innegable resonancia agrícola (26). La voz usura es, igualmente, utilizada en sentido metafórico en el campo del mutuo: $a b$ usu venit, dice Varrón, siendo así que en la mutui datio no se transmite el uso, sino el dominio; y éste, no aquél, es el que retribuyen las usurae (27).

La sumisión a tasa de las usurae es un nuevo dato omnipresente en el Derecho Romano y que falta en Grecia. Los historiadores romanos remiten expresamente la razón de esta tasa a los abusos cometidos por los feneratores (28). No es éste el lugar de detallar la evolución de este límite, sino de insinuar la razón de esta diferencia de regímenes,

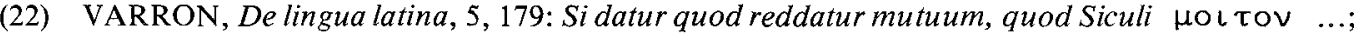
probablemente derivado de la raíz indo-germánica «moi» o «mei», que indica intercambio. Vid. MEILLET-ERNOUT, 1951, Dictionnarie étymologique de la langue latine, PAEZ y POKORNY, 1949, Indogermanisches etymologisches Wörterbuch, Berna. El mismo VARRON, en el pasaje citado, emparenta mutuum con uno de los sentidos de munus: quod mutuo animos qui sunt dant, officii causa, lo que refuerza la idea de intercambio a impulsos de un sentimiento de buena voluntad y cooperación (así CICERON, ad fam, 5, 2: pro mutuo ... animo ... hoc arbitror, quum par voluntas accipitur et redditur). Puede verse también GARCIA GONZALEZ, J. M., 1984, cap. II.

(23) Por ejemplo, en SENECA, De benef., 7, 10,3: ...quid enim ista sunt, quid fenus et kalendarium et usura, nisi humanae cupiditatis extra naturam quaesita nomina?

(24) CATON, De agri cult. Proem. Est interdum... fenerari, si tam honestum siet. CICERON, De officiis, 1, 150: Iam de artificiis et quaestibus, qui liberales habendi, qui sordidi sint, haec fere accepimus. Primum improbantur ii quaestus qui in odia hominum incurrunt ut portitorum, ut feneratorum... SENECA, De benef., 7, 10, 1-4: Quid agis, avritia? quot rerum caritate aurum tuum victum est!... Video istic diplomata, et syngrafas et cautiones: vacua habendi simulacra, umbram avaritiae quaedam laborantis, per quae decipiat animum inanium... quid sunt itae tabellae quid computationes et venale tempus et sanguinolentae centesimae?

(25) Existe otra probable forma arcaica de préstamo, el nexum, que, al menos teóricamente, sería apto para generar intereses. Omito aquí su tratamiento por lo dudoso de su fisonomía y funciones, por ser, seguramente, connatural a una fase pre o incipientemente monetaria y porque me he ocupado con cierta extensión de él en mi trabajo citado en nota 23.

(26) En griego, en cambio, róxos, designa indistintamente, y de ahí el dicterio de ARISTOTELES, el parto de los seres vivos y el de las monedas.

(27) La utilización de la voz usura es propia y exacta en referencia a los iudicia bonae fidei como compensación, previamente convenida, o acordada officio iudicis, de ciertos «usos». CERVENCA, C., $1969,1-11$.

(28) TACITO, Ann. 6, 16, ... primo Duodecim Tabulis... cum antea ex libidine locupletum agitaretur; y líneas más abajo, $6,22, \ldots$ vetus urbi fenebre malum et seditionum creberrima causa...; causa frecuentísima, pero no única. Leemos, por ejemplo, en TITO LIVIO, 4, 12, 13: causa seditionum quaesita, etc., cómo la causa resulta ser, en esa ocasión, una reivindicación agraria. En efecto, la lucha contra la usura, por el reparto de tierras y por el acceso a las magistraturas aparecen constantemente acumuladas, reforzándose como motor de las revueltas de la plebe urbana contra el patriciado. 
siendo así que la valoración moral de la usura coincide sustancialmente en Grecia y en Roma. Posiblemente, entre estas causas hayan de conjugarse las comparativamente mucho menores dimensiones de las ró̉ $\varepsilon\llcorner\varsigma$ griegas que harían correlativamente menor el número y el peso social y político de las masas de inopes, que más habrían de sufrir los abusos de los usureros. Que esto sea así se conecta con el hecho de que la implantación del límite máximo del unciarium fenus (29) es una conquista de la plebe urbana. De todos modos, y cualquiera que sea el juicio acerca de la narración tradicional de la confección de las XII Tablas y de su inspiración en la reforma de Solón (vid. DE MARTI-

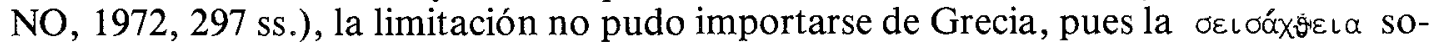
loniana no significó abolición, ni limitación temporal, ni sumisión a tasa, de los intereses, sino sólo la eliminación de la prisión por deudas.

$\mathrm{Al}$ menos en cuanto al límite máximo (centessimae usurae, supra sortis summam, ultra alterum tantum) hay una corriente doctrinal que la sugiere importada de Egipto a fines de la época republicana, siguiendo un texto de Plutarco que atribuye a Lúculo, durante su gobernación, el límite del $12 \%$ al año (que sería el precedente de la centésima), y que, de Asia, habría sido traído luego a Roma (PLUTARCO, Lúculo, 20). Diodoro Sículo también postula el origen egipcio de la tasa máxima, pero remitiéndolo al derecho antiguo, autóctono, de aquella región, durante el siglo VIII a. C. (30).

Mención aparte merece la especial forma de préstamo llamada "̌pavos que, con razón, Paoli declara fuori di questioni (PAOLI, 1930, 73). Platón se manifiesta favorable a este préstamo, en cuya virtud quien lo necesita puede acudir en busca de socorro a los parientes y amigos y éstos deben prestarlo sin que por ello adquieran derecho a pedir ni siquiera la restitución del capital (PLATON, Leyes, 11, 2, 915). Digo que debe mencionarse aparte, en primer lugar, porque no afecta a nuestro tema. Se trata de un deber de piedad reconocido en todas las latitudes y singularmente en Roma, donde de la pietas familiar se había hecho una especie de virtud nacional (sobre "̌pavol en Roma, DE ROBERTIS, 1971, II, 20-23); en segundo lugar, la idea platónica del "̌pavos se funda en presupuestos filosófico-ideales: Platón escribe acerca de «su» República, donde están proscritos el oro, la plata y todo tipo de dinero (Leyes, 5, 742). En Platón el problema moral supera y trasciende el momento económico-jurídico; y se tiñe, incluso, de recelos de exclusivismo nacionalista, ante el vivo peligro que para su patria pueda suponer el cosmopolitismo financiero. (Sobre la moneda usada como símbolo, República, II, 12, 371; contra el interés en los préstamos, Rep., VIII, 555; Leyes, 5, 743).

La mención del हैpovos es, sin embargo, necesaria, porque, con cierta insistencia se ha conectado con las ideas humanitarias del estoicismo romano e, incluso, como incidente del exagerado «platonismo» que al cristianismo se atribuye, se ha hecho de este Épavos un precedente de la limosna evangélica. Muy poco tiene que ver con ésta, pues mientras aquél es un deber de solidaridad cívica, familiar o corporativa (31), la limosna

(29) El establecimiento del límite unciario se atribuye por TACITO a las XII Tablas (Ann. 6, 16) y por LIVIO a una Lex Duilia Menenia, (a. U. c. $7,16,1$ ). La cuestión de preferencia, planteada ya por MONTESQUIEU (El espíritu de las leyes, XXII, 22), suele resolverse hoy entendiéndose la ley citada por TITO LIVIO como confirmatoria de la disposición decenviral, quizás poco observada o caída en desuso.

(30) CERVENCA, C., 1971, 299, notas 2 y 3, en que selecciona de la nómina de los autores integrantes de la corriente doctrinal aludida a WINDSCHEID y GLUCK, entre los pandectistas, y MITTEIS y SEGRE, entre los modernos.

(31) Los significados de los términos griegos son netamente diferentes y bastante fijos a lo largo

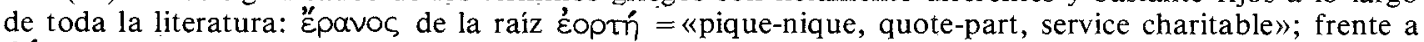
Sóvelov de la raíz dō = «créance -dette», en BOISACQ, Dictionn. ethymol. langue grecque, París, 1923. Compruébese la fijeza de estos significados en los lexica, tanto el de ASTIUS, F., 1835, Lexicon Platonicum, sive vocum platonicarum, Lipsiae, como el de BETANT, E. A., 1961, Lexicon Thucydideum, Hildesheim, como el de NAUCK, A. 1892, Tragica dictionis index spectans ad tragicorum graecorum fragmenta, Petersburg, como el de WYTTENBACH, D., 1830, Lexicon Plutarcheum, I, Oxford. 
tiene su principal característica en ser un deber desinteresado, despersonalizado y de misericordia. Séneca, de quien con igual legitimidad puede decirse que es un óptimo enunciador de los ideales del Pórtico medio (DOBSON, A., 1957, 207; ELORDUY, E., 1972), como que converge en muchos puntos con las ideas cristianas (32) y, en concreto, con la predicación del propio SAN PABLO (BENOIT, P., 1946, 7-36), diferencia, en términos bien claros y sin margen para el equívoco, la laudable clemencia estoica, de su corrupción, la despreciable misericordia:

...per speciem enim severitatis in crudelitatem incidimus, per speciem clementiae in misericordiam. In hoc leviore periculo erratur, sed par error est a vero recedentium.

Ergo quemadmodum religio deos colit, superstitio violat, ita clementiam mansuetudinemque omnes boni viri praestabunt, misericordiam autem vitabunt; est enim vitium pusilli animi ad speciem alienorum malorum succidentis. Itaque, pessimo cuique familiarissima est; anus et mulierculae sunt quae lacrimis nocentissimorum moventur, quae, si liceret, carcerem effringerent. Misericordia non causam, sed fortunam spectat; clementia rationi accedit.

Misericordia vicina est miseriae; habet enim aliquid trahitque ex ea. Imbecillos oculos esse scias qui ad alienam lippitudinem et ipsi suffunduntur... misericordia vitium est animorum nimis miseria parentium, quam si quis a sapiente exigit, prope est, ut lamentationem exigat et alienis funeribus gemitus. (SENECA, De clementia, 2, 3, 3 y 2, 4, 4).

Circula en estas líneas no una clemencia inspirada por la pura calidad de hombre del necesitado, sino la convivial y utilitaria causam spectans, rationi accedens, de vigorosa progenie estoica, cuyo límite es un «desapego» aristocrático, no menos utilitario y también genuinamente estoico, mediante el cual el clemente evita el propio sufrimiento. Es el mismo utilitarismo que dictó la frase de Epicteto (Disertaciones, 3, 24, 85-88): «...si besáis a un hijo... nunca os dejéis llevar sin freno por el sentimiento o por vuestras emociones... Realmente no está mal musitar al niño, mientras se le besa: mañana morirás». Desapego como medio para evitar el dolor que, en palabras de Toynbee (TOYNBEE, A. J., 1977, II, 242), si como logro intelectual es imponente, como logro moral es abrumador. No es de esta estirpe el «Bienaventurados los misericordiosos», ni es casual, ni permite continuidad ninguna con este ambiente moral, el que el cristianismo prefiriera la palabra limosna ( $\varepsilon \lambda \varepsilon \varepsilon \mu o \sigma u ́ \nu \eta, d e \varepsilon \lambda \varepsilon \varepsilon \tilde{u} \omega)$ que conecta con el sentimiento de lástima, de compasión, precisamente con la estéril, la denostada misericordia, que hace sufrir a quien la experimenta. Por el contrario, sólo a partir de una revolucionaria concepción antropológica logrará el cristianismo superar esta aporía del pensamiento estoico (33).

(32) Así, la idea de fraternidad universal: ... membra sumus corporis magni. Natura nos cognatos edidit... Haec nobis amorem indidit mutuum... (Ep. 95, 52).

La mención, precisamente de SENECA, es por razón del contraste con el fragmento de De clementia cuya cita sigue. Pero la idea de cognación entre todos los hombres no es, ni mucho menos exclusiva, ni especialmente intensa en este autor. Al contrario, su perfusión entre los pensadores romanos es vastísima; por ejemplo - y sigue siendo sólo un ejemplo-, CICERON, De finibus, 5, 23, 5; De officiis, 1, 17, 56. Y aun entre los juristas: por ejemplo, FLORENTINO, en $D .1,1,3:$... et cum inter nos cognationem quamdam natura constituit...

(33) A diferencia de otras filosofías y concepciones antiguas, que tendían a anegar al hombre en el exterior (ya sea en el universo, o en la especie, o en el grupo social), la conciencia antropológica del hombre cristiano es autoconciencia del hombre como ser primordialmente personal, fin en sí mismo; sólo a partir de esta idea se puede entender la mutua, y ya para siempre perdurable, imbibición entre la cultura romana y la cristiana; ver sobre este asunto, el reciente e interesantísimo trabajo de DAZA, J., 1982, 97. 
4. No intentaré siquiera una síntesis de esa revolución antropológica, pues la erección del hombre nuevo cristiano en protagonista de los, también nuevos, tiempos supone un cambio cualitativo, cuyo examen requeriría una ruptura del método que vengo siguiendo (34). Y también requeriría un exceso de formato.

No obstante, la doctrina cristiana sobre el préstamo y la usura, en cuanto producto histórico, ofrece evidentes nexos con las concepciones de las sociedades en que surge y en las que se integra. Jesús, en efecto, predica en Palestina y tiene como auditorio inmediato al pueblo de Israel. Por ello, deberá contarse con la doctrina del Antiguo Testamento, tanto más cuando la Nueva Ley no venía a derogar, sino a dar plenitud a la Vieja. En segundo lugar, se trata de una Palestina fuertemente impregnada de helenismo y romanismo, de manera que debe contarse también con esos dos factores (35). Cualificadamente con el segundo, el romano, porque la difusión del cristianismo tuvo como foco la propia ciudad de Roma.

La explicación de cómo, a partir de los sistemas anteriores, se pase al cristianismo de omnímoda (y duradera, salvo matices, desde los Santos Padres hasta 1745, con la Encíclica Vix pervenit) prohibición de todo interés en los préstamos, es asunto sumamente complejo. Aquí me limitaré a enunciar, a modo de síntomas, los principios y los textos fundamentales en que, a mi parecer, esa mutación se manifiesta (36).. Procediendo desde lo más sencillo, hay ciertas claves léxicas muy evocadoras. La riqueza, para griegos y romanos, es algo bueno y deseable: rilovoíos y locuples, respectivamente, expresan, en sus raíces, la idea de plenitud (y dives, emparentado con diu; con divus,

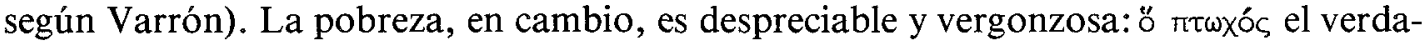
dero pobre (37), comparte raíz con rтíoow, encogerse de miedo o de vergüenza. Otro tanto pasa en latín con pauper y paveo. El pobre es indigno y no hay ninguna obligación de ayuda hacia él. Existen la filantropía y la generosidad, pero no tienen que ver con el tema (38). Falta por completo la noción de caridad como deber (39).

Pues bien, la doctrina de Jesús subvierte por entero esta jerarquía de estimaciones. La riqueza es un óbice para entrar en su Reino, comparable a la corpulencia del camello

(34) También aquí se precisa un utillaje especializado, el de la teología, acerca del cual debo hacer una confesión de limitaciones simétrica a la que, acerca de la economía, escribí en los primeros párrafos.

(35) Me parece superfluo indicar textos concretos. La propia predicación de Jesús, ambulante y mediante parábolas, recuerda muy claramente a la de ciertos filósofos griegos. En los relatos evangélicos se razona por talentos, minas, dracmas, óbolos, denarios; comparecen centuriones y publicanos; y esclavos (Israel desconocía esa institución, incluso carecía de vocablo para designarla). En la parábola de los talentos (o minas, según se lea en S. Lucas o en S. Mateo) hay algo semejante a una constitución de peculio y una referencia final a nummularii y usura.

(36) Una buena explicación de cómo el Nuevo Testamento y, en particular, los Evangelios sinópticos y los Hechos de los Apóstoles, constituyen una fuente necesaria para reconstruir la historia jurídica de las provincias a partir del siglo I, puede verse en SERWIN-WHITE, A. N., 1963, 204 y ss. La riqueza liberadora; para dedicarse a las actividades «nobles», vinculadas a la idea de ocio: VEBLEN, T., Teoría de la clase ociosa, Méjico, p. 19. Como situación del que no depende económicamente de otro, ARISTOTELES, $1367,32$.

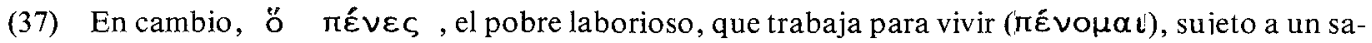
lario, no tiene equivalente latino; se aproxima a la condición de los mercenarii, de quienes CICERON, en De off., 1, 150, cit., dice que no son libres porque merces ipsa est auctoramentum servitutis.

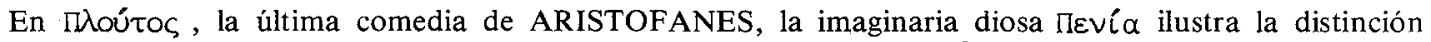

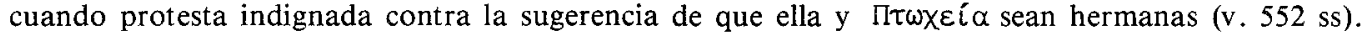

(38) Filantropía es, originariamente, una cualidad divina, o el beneficio concedido por un dios. Luego se usó analógicamente para designar los favores concedidos generosamente por personas de posición elevada. Vid. HUNGER, 1963, p. 20.

(39) «Al que no da, no le deis», escribe HESIODO, T. y D., v. 355, cuyo sentido abarca al que no puede dar; el testimonio no viene, como con frecuencia, de un miembro de la aristocracia o de las clases económicamente acomodadas. 
para enhebrarse en una aguja. (Sólo por eso dejaría ya de ser legítima la especulación usuraria, como cualquier otro medio de conseguir riqueza). Por otro lado, la hermandad entre todos los hombres se impone, no en el sentido ideal y metafísico de la comunidad de naturaleza, sino en el concreto y personal de la filiación común con el Padre Celestial. Esta condición personal (40) de ser hijos de Dios es el nuevo timbre de aristocracia que el cristianismo opone a los modelos anteriores. A base de él, los pobres aparecen liberados en un sentido distinto del clásico: no para el ocio, sino para el servicio de Dios; cuyo servicio es incompatible con el de las riquezas. Se les declara bienaventurados. El amor, como consecuencia de la hermandad es, cabalmente, el mandamiento nuevo. He ahí la caridad hacia todo prójimo, aun hacia el enemigo, instalada como distintivo del humanismo cristiano. Los dos signos que Jesús declara como específicamente distintivos de su doctrina son: El Evangelio se predica a los pobres, y los hombres conocerán que sois mis discípulos en esto: en que os amáis los unos a los otros.

5. El pueblo de Israel había observado, en cuanto al préstamo a interés, un sistema particular, que podríamos llamar permisivo selectivo, que tiene su razón de ser en las propias necesidades de cohesión interna de una nación errante, a menudo en condiciones de subsistencia precarias, rodeada de enemigos y con clara conciencia de su exclusividad como pueblo de Dios. A la finalidad «política», de evitar tensiones disgregadoras en el seno de la comunidad y, complementariamente, preservarla de la confusión con los otros pueblos con los que ocasionalmente entraba en contacto, obedece la regla fundamental en la materia:

Non fenerabis fratri tuo ad usuram pecuniam, nec fruges, nec quamlibet aliam rem: Sed alieno. Fratri tuo absque usura id quod indiget commodabis (41).

Fenerabis cunctos populos (42).

Con ello se prohíbe, pues, cualquier exigencia de un plus en la restitución de los préstamos a los compatriotas (43), pero se permite, y aun se ofrece como un privilegio divino, la explotación usuraria sobre los extranjeros, infieles (44). Pero la predicha proclamación cristiana de la hermandad de todos deja sin sentido la diferencia entre frater y alienus, entre compatriota y extranjero, produce la generalización automática, a todos los hombres, de las prohibiciones feneraticias contenidas en el Antiguo Testamento. Prohibición que, de modo directo, se contiene también en los Evangelios:

(40) Las relaciones del hombre con Dios adquieren categoría de cuestión personal (el pecado, concepto también nuevo, es uno de los episodios de ella); también, a través de la caridad, las relaciones entre aquél y los demás hombres. Vid. sobre la novedad de esta concepción, DEMPF, 1952, cap. II y III.

(41) Deut., XXII, 19-20.

(42) Regla reiterada y complementada en: Ex., XXII, 25; Lev. XXV, 35, 36, 37; Psalm., XIV, 5; Ez., XVIII, 8, 13; XXII, 12; LIV, 12 . Véase en todos ellos la restricción de la prohibición sólo al frater. También la falta de fijeza en el modo de designar las usuras: amplius quam dedisti, superabundantia, amplius accipere... Esta generalidad se reproduce en los predicadores cristianos, que perseveran en la condena de cualquier plus accipere quam datum, quodcumque sorti accedit, supplementum, superabundantiam... y por cualquier título, etiamsi sub contractus speci aut transactionis hos fortasse factum sit: S. AMBROSIO (Libro de Tobías, con la llamada excepción ambrosiana, ubi ius belli ibi ius usurae); S. JERONIMO (Ezequiel, XVIII, 6).

(43) Compatriota o connacional es el significado del hebreo $a h$, que el frater latino traduce sólo aproximadamente.

(44) En hebreo nokri=extranjero, alienus. Y fenerari, usura, son neshék, que literalmente significa mordisco de serpiente. Como mera curiosidad, señalo la convergencia con el angloamericano «loanshark», en que sólo varía el animal que metafóricamente muerde, que aquí es un tiburón. 
Et si mutuum dederitis iis a quibus speratis recipere quae gratia est vobis, nam et peccatores peccatoribus fenerantur ut recipiant aequalia (45). Verumtamem diligite inimicos vestros... et mutuum date, nihil inde sperantes (46).

Los judíos que no aceptaron el Evangelio quedaron, de esta manera, convertidos en monopolistas del comercio usurario (47), pues mientras los judíos y comunidades judías que vivían incrustados en otras de cristianos seguían considerando a éstos como infieles y alieni, los cristianos, en cambio, tenían vedada toda posibilidad de actuar recíprocamente. He aquí cómo un punto de interpretación jurídica y no una predisposición racial de los judíos a la codicia ha facilitado, a modo de incitación histórica, su tradicional dedicación a los negocios y a la Banca. Y ha cooperado a modelar el estereotipo popular que identifica al judío con el prestamista ávido, despiadado y acumulador de riquezas; estigma que tanta malquerencia, sangre y diáspora adicionales han costado, a lo largo de la historia, al pueblo de la Diáspora.

(45) Fenerari, ut recipiant aequalia. Sin embargo, en términos jurídicos, prestar para recibir otro tanto es mutuo dare (p. ej. D. 2,14,17). Fenerari es prestar a interés, con usurae. De manera que en este pasaje de S. LUCAS parece haber una utilización figurada de fenus como contrapuesto, no a simple préstamo gratuito, sino a dación desinteresada. Al modo que SENECA, De benef., 1, 1, 9: demus beneficia, non feneremus: ibid. 3, 15, 4: qui dat deos imitatur, qui repetit feneratores. O CICERON, De finibus, 2, 35, 117: nec enim cum tua causa cui commodes beneficium illud habendum est, sed feneratio.

(46) S. LUCAS, VI, 34, 35. Parece confirmar lo dicho en la nota anterior en texto griego de la parte

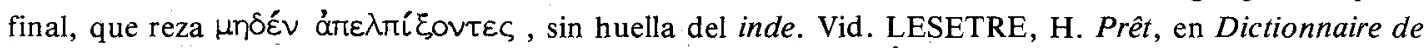
la Bible, T. V., col. 620. La interpretación rigurosa tanto de $\mu \eta \delta \varepsilon ́ v$ como de aequalia es, en opinión dominante de los exegetas, no de precepto, sino consejo de perfección.

(47) Ya desde el principio: vid. LEON, 1960, y MALONEY, 1971, p. 79 ss 


\section{BIBLIOGRAFIA}

BEAUCHET, L. 1897, Le droit privé de la République Athénienne, IV, París.

BENOIT, P. 1946, «Sénèque et St. Paul», Revue Biblique, 23, 7-36.

BIEZUNSKA-MALOVIST, I. 1973, La propriété foncière dans l'Egipte romain et le rôle de l'élèment romain, París.

BILLETER, G. 1898, Geschichte des Zinsfusses im griechisch-römichen Alterum bis auf Justinian, Leipzig.

BINGEN, J. 1973, «Présence grecque et milieu rural ptolemaïque», París.

BISCARDI, A. 1936, La struttura classica del «fenus nauticum», Studi in onore Albertoni, Padua, 345 ss. BODEI GIGLIONI, G. 1974, Lavori pubblici e occupazione nell'Antichità classica, Bolonia.

BOGAERT, B. 1965, «Banquiers, courtiers et prêts maritimes à Aléxandrie», Chronique d'Egipte, 40, 140156.

- 1966, Les origines antiques de la banque de dépôt, Leiden.

- 1968, Banques et banquiers dans les cités grecques, Leiden.

BRUNT, P. A. 1981, «La plebe romana», Estudios sobre historia antigua, Madrid, 87-117.

CASTRESANA, A. 1983, El préstamo marítimo griego y la pecunia traiecticia romana, Salamanca.

CERVENCA, G. 1969, Contributo allo studio delle usurae considette legali nel diritto romano, Milán.

- 1971, «Sul divieto delle cosi dette usurae supra duplum», Index, 2.

CICOTTI, E. 1905, L'interesse del dennaro nell'antiquità classica, Roma.

DAZA MARTINEZ, J. 1982, «Aequitatis ratio», Anales de la Facultad de Derecho de la Universidad de Alicante, 1,97 ss.

DEMPF, A. 1952, Christliche Philosophie. Der Mensch zwischen Gott und Welt, Bonn.

DOBSON, A. 1957, La morale sociale des derniers stö̈ciens, París.

DUARTE CARBALLO, A. 1983, «QQué es el dinero?» Campus, Revista de la Universidad de Alicante, $22-$ 24.

ELORDUY, E. 1972, El estoicismo, Madrid.

ERXLEBEN, E. 1969, 1970, 1971, «Das Münzgesetz des delisch-attischen Seebundes», Archiv Für Papyrusforschung, 19, 91-139; 20, 66-132; 21, 145-162.

FINLEY, M. I. 1953, «Land, Debt and the Man of Property in Athens», Political Science quarterly, 68, 249-268.

1981 «Demagogos atenienses». Estudios sobre historia antigua, Madrid, 11-85.

GARCIA GONZALEZ, J. M. 1984, Creditum-fides, Alicante.

GIACCHERO, J. 1966, «L'influsso di Plutarco sulla condanna basiliana del prestito ad interesse», Tetraonyma, $160 \mathrm{ss}$.

HUME, D. 1903, Of the Populousness of Ancient Nations, en Essays, Londres, World's Classics.

HUNGER, H. 1963, " $\Phi \iota \lambda \alpha v \vartheta p \omega r i \alpha$; eine griechische Wortprägung auf ihren Wege von Aischilos bis Theodoros Metochites》. Anzeiger des Ostenrreichischen Akademie d. Wiss. Phil. hist. Klass., 20 ss.

JONES, A. H. M. 1957, Athenian Democracy, Oxford.

JONES, J. W. 1956, The Law and legal Theory of the Greeks, Oxford.

KEYNES, J. M. 1930, A Treatise of Money, Londres.

LEON, H. 1960, «The Jews of Ancient Rome», The Jewish Publication Society of America (The Morris Loch Series). Filadelfia.

MAFFI, A. 1972, «La capacità di diritto privato dei meteci nel mondo greco classico», Studi in onore di G. Scherillo, I, Milán, 177 ss.

MALONEY, R. P. 1971, «Usury in Greek, Roman and Rabbinic Thought», Traditio, 27, $79-109$.

MALTHUS, R. 1951, Ensayos sobre el principio de población, México.

MARCHAL, A. 1973, Systèmes et structures économiques, París.

MARTIN, R. 1971, Recherches sur les agronomes latins et leurs conceptions économiques et sociales, París.

MARTINO, F. DE, 1936, Ancora sul «fenus nauticum», Rivista di diritto della navigazione, II, 443 ss. 1972, Storia della Constituzione Romana, Nápoles.

MEIGSS, R. 1969, Roman Ostia, Oxford.

MOSSE, C. 1973, «Le statut des paysans en Attique au IV siècle», Problèmes de la terre en Grèce ancienne, París, 179-185.

PAOLI, V. E. 1930, Studi di Diritto Attico, Florencia.

PERNAUT ARDANAZ, 1958, Economía Política, II, Madrid.

REINACH, TH. 1896, «Une crise monétaire au III siècle de l'ère chrétienne», Bull. Corr. Hell. $X X, 531$ ss. ROBERTIS, F. M. DE, 1971, Storia delle corporazioni e del regime associativo nel mondo romano, Bari. ROSTOVTZEV, M. 1966, Storia economica e sociale del mondo ellenistico, Florencia.

SANCTIS, G. DE, 1939, Storia dei Greci. Florencia. 
SEGRE, A. 1922, Circolazione monetaria e prezzi nel mondo antico, Roma.

1924, «Il mutuo e il tasso d'interesse nell'Egitto greco-romano», Atene e Roma, N. S ${ }^{\mathrm{c}}, \mathrm{V}, 119 \mathrm{ss}$.

SERWIN-WHITE, A. N. 1963, «Roman Society and Roman Law in the New Testament», The Sarum Lectures, 1960-61, 204 ss.

THIEL, J. H. 1954, A History of Roman Sea-Power before the Second Punic War. Amsterdam.

TOYNBEE, A. 1977, Estudio de la Historia. Compendio, Madrid.

VEBLEN, T. Teoría de la clase ociosa, Méjico (s. f.).

WEBER, M. 1924, «Agrarverhältnisse im Altertum», Gesammte Aufsätze zur Sozial und Wirtschaftsgeschichte, Tubinga, 1-288.

WESTERGAARD, H. 1932, Contribution to the History of Statistics, Londres.

WESTERMANN, W. L. 1941, «Athenaeus and the Slaves of Athens», Harvard Studies in Classical Phito$\log y, 451$ ss. 


\section{NORMAS PARA LA REDACCION DE ORIGINALES}

1. Los originales deberán estar mecanografiados a doble espacio, en folios de 30 líneas de 70 espacios cada una. Deberán venir acompañados de un resumen en la propia lengua del trabajo y, si es posible, otro en lengua internacional (inglés, francẻs, italiano o alemán). Los resúmenes tenđrán una extensión máxima de 15 líneas de 70 espacios cada una.

2. La extensión máxima de los trabajos se establece en 40 páginas de texto y 20 de láminas (dibujos y fotografías). Los dibujos deben venir realizados en papel vegetal con tinta china y ya en láminas compuestas. Cada una de éstas deberá traer su escala gráfica.

3. Se acompañará una hoja aparte con los piés de las figuras. Si éstas están tomadas de otras publicaciones, se citará la fuente.

4. En el encabezamiento del trabajo se indicará el nombre del autor o de los autores y el centro o los centros en que trabajan.

5. Las citas bibliográficas se harán de la siguiente manera:

5.1. Si son notas cortas, en las que sólo aparece el nombre del autor, la obra y la página, se pondrá el nombre del autor en letras mayúsculas, seguido del año de edición de la obra, página o páginas y figura o figuras, todo ello separado por comas. Estas citas figurarán en el interior del texto del artículo y no irán a pié de página ni al final.

5.2. Si son notas largas, deberán ir al final del texto, encabezadas por la referencia bibliográfica, que será igual que 5.1 .

6. La lista bibliográfica vendrá al final del artículo, dispuesta por orden alfabético del primer apellido de los autores. En caso de que un mismo autor tenga varias obras, la ordenación se hará por la fecha de publicación, de más antigua o más moderna. Si en el mismo año coinciden dos obras de un solo autor, se distinguirán con letras minúsculas (a, b, c, etc.), que también se incluirán en las referencias de 5.1. y 5.2 .

6.1. En caso de que se trate de un libro, se citará por este orden: nombre del autor, fecha de edición, título de la obra y lugar de edición.

6.2. Si es un artículo de revista: autor, año, título del trabajo, título de la revista, tomo y páginas.

6.3. El nombre de los autores deberá venir en letras mayúsculas; el título de los libros y de las revistas, subrayado, y el de los artículos de revistas, entre comillas.

6.4. En el caso de que los títulos de las revistas vengan abreviados, deberá utilizarse el sistema de siglas de las revistas Archàologische Bibliographie y Jahrbuch des Deutschen Archàologischen Instituts.

7. Las tablas de valores vendrán escritas a máquina - a ser posible electrónica - y sin erratas, para que puedan ser reproducidas como una figura.

8. El Consejo de Redacción se reserva el derecho a devolver los originales que no se correspondan con la línea de la revista o no cumplan las normas de publicación.

\section{EJEMPLOS DE CITAS:}

5.1. (BENDALA y NEGUERUELA, 1980, 384, f. 15)

5.2. BENDALA y NEGUERUELA $(1980,384)$ opinan que...

6.1. CAGNAT, T. 1976: Cours d'épigraphie latine, Roma, $4 .^{\mathrm{a}} \mathrm{ed}$.

6.2. BENDALA, M. y NEGUERUELA, I. 1980: «Baptisterio paleocristiano y visigodo en los Reales Alcázares de Sevilla», Noticiario Arqueológico Hispánico, 10, 335-380. 



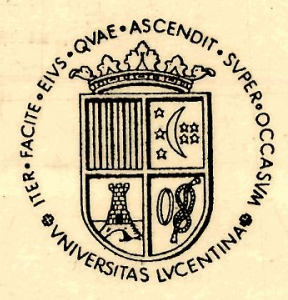

